NIST GCR 19-021

\title{
Characterization of Residential Air Distribution System Performance for Thermal Comfort
}

\author{
Hyojin Kim, Ph.D. \\ Khiem Nguyen \\ Anne McGuinness \\ Toan Vo Dai \\ The Catholic University of America
}

This publication is available free of charge from:

https://doi.org/10.6028/NIST.GCR.19-021

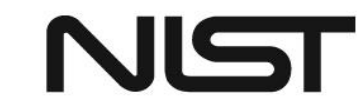

National Institute of Standards and Technology U.S. Department of Commerce 


\title{
Characterization of Residential Air Distribution System Performance for Thermal Comfort
}

\author{
Prepared for \\ U.S. Department of Commerce \\ Engineering Laboratory \\ National Institute of Standards and Technology \\ Gaithersburg, MD 20899-8600
}

By

Hyojin Kim, Ph.D.

Khiem Nguyen

Anne McGuinness

Toan Vo Dai

The Catholic University of America

This publication is available free of charge from:

https://doi.org/10.6028/NIST.GCR.19-021

December 2019

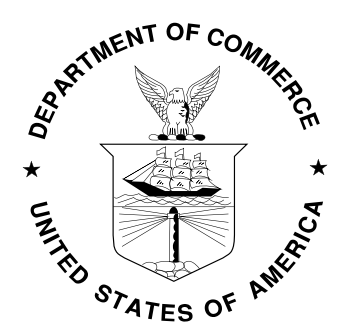

U.S. Department of Commerce Wilbur L. Ross, Jr., Secretary

National Institute of Standards and Technology Walter Copan, NIST Director and Undersecretary of Commerce for Standards and Technology 


\section{DISCLAIMER}

This publication was produced as part of contract 60NANB18D202 with the National Institute of Standards and Technology. The contents of this publication do not necessarily reflect the views or policies of the National Institute of Standards and Technology or the US

Government. 


\section{ACKNOWLEDGMENTS}

The authors gratefully acknowledge the NIST Net-Zero Energy Residential Test Facility (NZERTF) team for their assistance and support with data collection used in this study. Special thanks goes to Lisa Ng, Ph.D., Brian P. Dougherty, Vance (Wm.) Payne, Ph.D., William M. Healy, Ph.D., and Andrew K. Persily, Ph.D. for their valuable input to this Report. 


\section{LIST OF ACRONYMS}

ACCA Air Conditioning Contractors Association

$\mathrm{ACH} \quad$ Air Changes per Hour

ASHRAE American Society of Heating, Refrigerating, and Air-Conditioning Engineers

BA Bathroom

BR Bedroom

BSMT Basement

CDHP Conventionally-Ducted Heat Pump

DAS Data Acquisition System

DOE Department of Energy

DR Dining Room

DST Daylight Saving Time

EH Entry Hallway

FPM Feet Per Minute

FPS Frames Per Second

FSEC Florida Solar Energy Center

IAQ Indoor Air Quality

IBACOS Integrated Building and Construction Solutions

IEQ Indoor Environmental Quality

IQR Interquartile Range

HP Heat Pump

HRV Heat Recovery Ventilator

HVAC Heating, Ventilating and Air Conditioning

KIT Kitchen

LR Living Room

MBA Master Bathroom

MBR Master Bedroom

MHL Manufactured Housing Laboratory

MRT Mean Radiant Temperature

NIST National Institute of Standards and Technology

NOAA National Oceanic and Atmospheric Administration

NZERTF Net-Zero Energy Residential Test Facility

OA Outdoor Air

PD Percent Dissatisfied

PMV Predicted Mean Vote

PPD Predicted Percentage Dissatisfied

PV Photovoltaic

$\mathrm{RH} \quad$ Relative Humidity

RP Research Project

SDHV Small Duct High Velocity

Ta Air Temperature

Tg Globe Temperature 
TCPI Thermal Comfort Performance Index

$\mathrm{Va} \quad$ Air Velocity

WD Washer and Dryer 


\section{EXECUTIVE SUMMARY}

Despite broad recognition that air distribution plays an important role in comfort for residential buildings, previous efforts to evaluate and characterize the performance of residential air distribution systems have largely focused on their impact on the heating and cooling energy consumption. However, fewer studies addressed the effectiveness of the tested residential air distribution systems to provide and maintain comfort in the conditioned space by delivering the designed air temperature to individual rooms throughout the house. Therefore, the purpose of this research is to develop an improved understanding of the impact of residential air distribution systems on whole-house thermal comfort and to propose analytical methods for evaluating this impact.

To accomplish this, this research reviewed the literature to identify relevant work and explored several new methods to properly characterize whole-house thermal comfort performance of residential air distribution systems using one-year of detailed building and system data collected from the Net-Zero Energy Residential Test Facility (NZERTF) on the campus of the NIST. During the analysis period from September 2016 to August 2017, two different heat pumps that utilize different air distribution systems such as a ConventionallyDucted Heat Pump (CDHP) and a Small Duct High Velocity (SDHV) system were operated alternately every other week.

The collected thermal comfort performance data were analyzed to characterize and evaluate the whole-house thermal comfort performance, including the temperature deviation from the set-point temperature (i.e., room-to-thermostat temperature difference), room-to-room temperature difference to evaluate spatial thermal uniformity, cyclic discomfort to evaluate temporal thermal uniformity, and latent performance, as well as the potential horizontal and vertical thermal stratification within a single room for the two air distribution systems (i.e., CDHP and SDHV) as installed at NZERTF. The analysis also included a comparison of the measurements at NZERTF against the relevant benchmarks such as the ACCA Manual RS and the ASHRAE Standard 55-2017.

Besides, to fully understand the continuously-measured long-term thermal comfort data, this study performed a statistical characterization of the one-year granular thermal comfort data not only for the primary rooms but also for the attic and the basement that are thermally important due to possible heat transfer from/to the primary rooms. The data were properly decomposed by system type and on/off cycle as well as by season (i.e., cooling season, heating season, and transitional season) to extract meaningful information from large datasets. For an accurate characterization, this study proposed to use a graphical index by displaying multiple percentiles based on $\pm 1.5 \%, \pm 2.5 \%, \pm 5 \%$, and $\pm 10 \%$ deviation, including the recommended criteria for acceptable deviations (i.e., $3 \%$ and $5 \%$ ) provided in the Annex G of the European standard, DIN EN 15251.

To better understand the observed temporal variations of the long-term thermal comfort data, which was revealed from a statistical characterization, this study also performed an advanced characterization of the measured thermal comfort data related to the outdoor climate and the time of the day. It was found that the characterization of temporal variations related to outdoor temperature allowed a weather-normalized characterization and comparison of the impact of the two tested systems on thermal comfort. The time-of-day characterization was useful to understand the dynamic interactions between uneven internal 
heat gains from occupants, lighting, appliances, and miscellaneous electronic devices and the measured thermal conditions.

Furthermore, this study explored a graphical analysis of thermal comfort data using the psychrometric chart and trend animation, which allowed a quick characterization and analysis of granular thermal comfort data. The proposed graphical analysis was one of the ways of visualizing the voluminous data efficiently in a condensed form to maximize the information contained in the data in addition to the statistical and advanced characterization of the results.

Lastly, to gain more general insights on the thermal comfort performance of residential air distribution systems in terms of their fundamental ability to produce and deliver a setpoint temperature to multiple rooms in a house, the results from the NZERTF were compared with four field studies that also measured the performance of a SDHV with a focus on thermal uniformity as well as one study collected relatively large field data from the 36 highperformance occupied houses.

In the report, the results are presented in the context of benchmarks to which other houses and air distribution systems can be compared. Recommendations for future research were discussed based on findings from this research. The findings from this study will contribute to the existing knowledge and measurement and benchmarking of the whole-house, long-term performance of residential air distribution systems for thermal comfort. 


\section{TABLE OF CONTENTS}

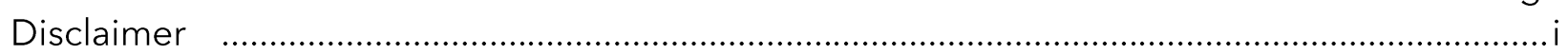

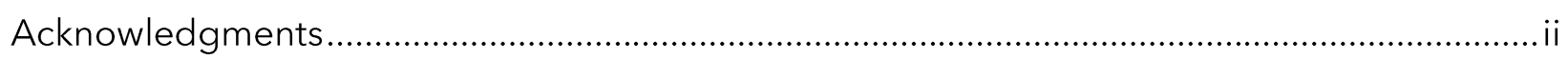

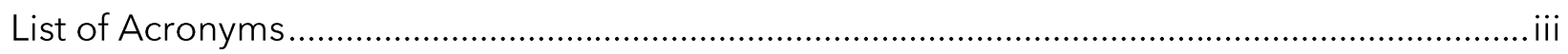

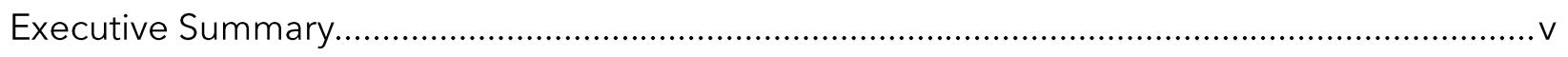

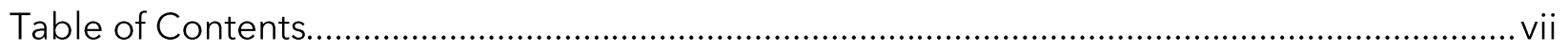

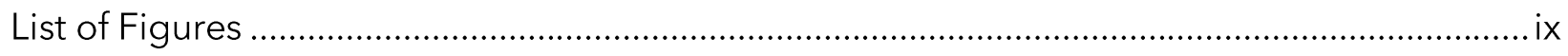

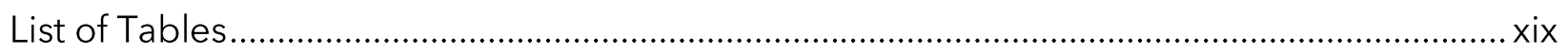

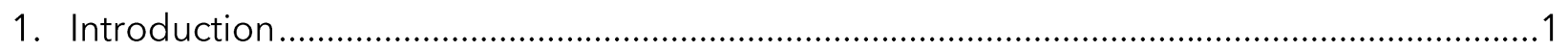

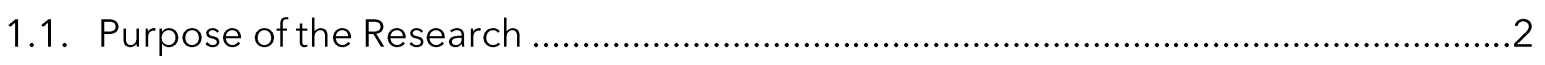

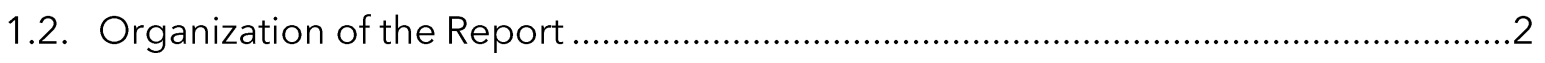

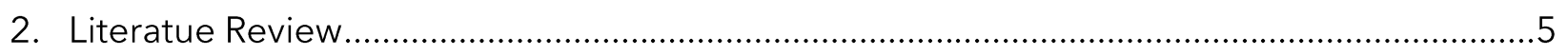

2.1. Previous Studies on the Whole-House Thermal Comfort Performance of

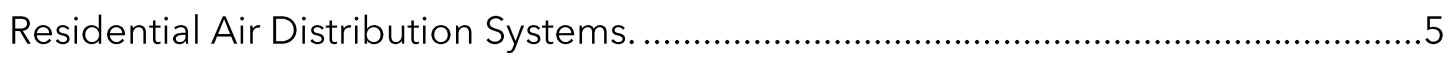

2.2. Thermal Comfort Performance Measurement Protocols and Benchmarks ........... 12

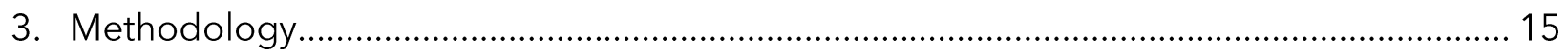

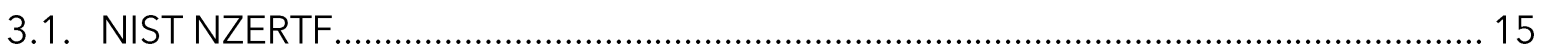

3.2. Thermal Comfort and System Performance Data ................................................. 18

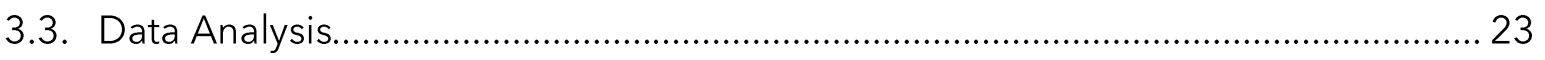

4. Whole-House Thermal Comfort Analysis............................................................................ 27

4.1. Temperature Deviation from the Setpoint Temperature ....................................... 27

4.2. Room-To-Room Temperature Difference .............................................................. 37

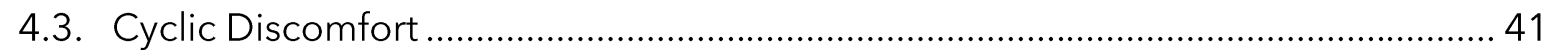

4.4. Statistical Characterization of Long-Term Room Temperature .............................. 44

4.5. Advanced Characterization of Temporal Variations Related to Outdoor

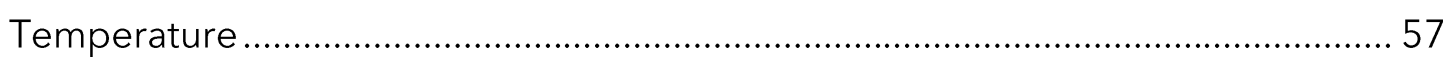

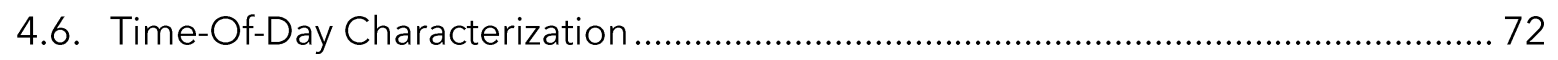

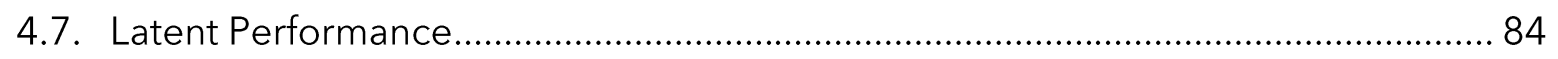

4.8. Graphical Analysis Using the Psychrometric Chart .......................................... 102

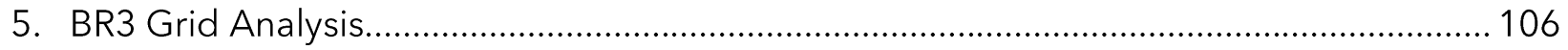

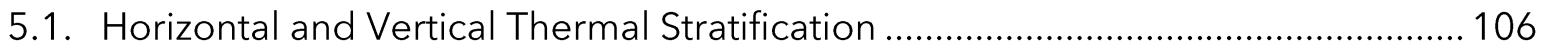

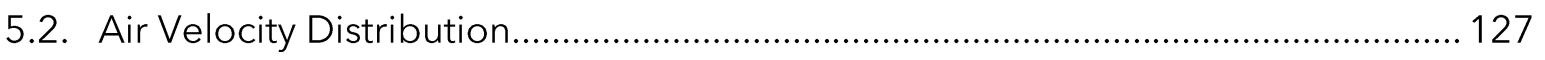




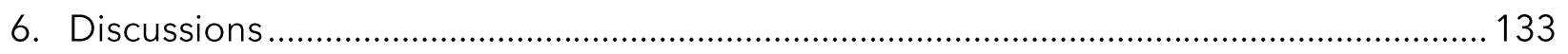

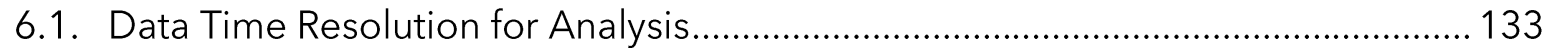

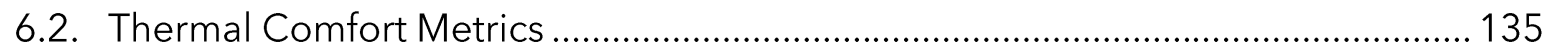

6.3. Graphical Index for Long-Term Thermal comfort Data ........................................... 141

6.4. Long-Term Thermal comfort Data Decomposition.................................................. 143

6.5. Trend Animation for Granular Analysis ............................................................... 146

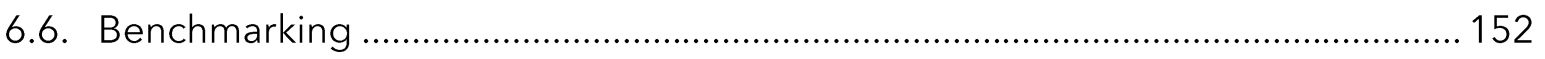

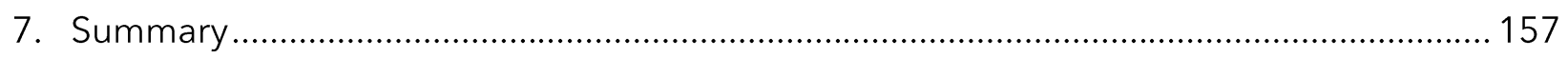

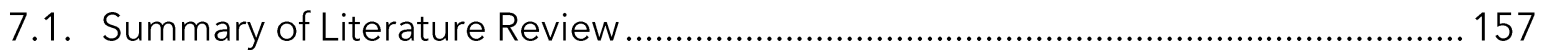

7.2. Summary of Whole-House Thermal Comfort Analysis ............................................. 158

7.3. Summary of BR3 Grid Analysis ........................................................................... 164

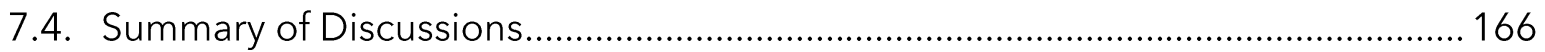

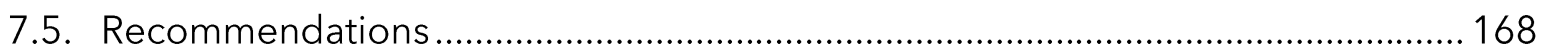

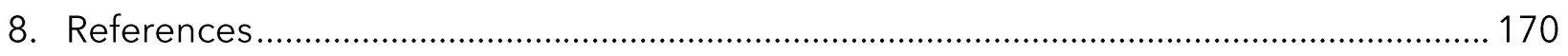

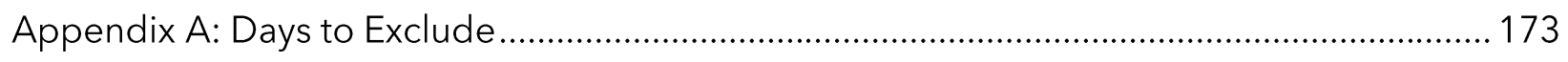

Appendix B: Whole-House Temperature Data Correction........................................................ 174

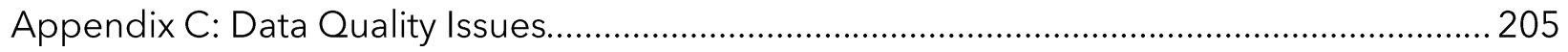

Appendix D: Binned Room Air Temperatures Against Outdoor Temperatures (Other Rooms)

Appendix E: Hourly Room Temperature Profiles (KIT, BR2, and BR3)................................... 216

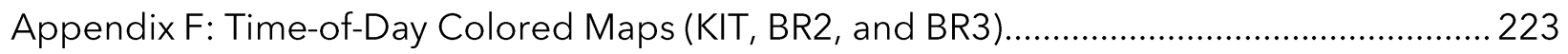

Appendix G: Graphical Analysis Using the Psychrometric Chart (KIT, BR2, BR3, Attic, BSMT,

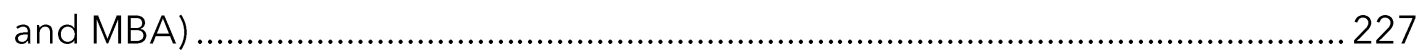

Appendix H: Statistical Characterization of the BR3 Grid Measurements ............................... 234

Appendix I: Temperature Data Visualization/Animation using MATLAB 2017b ..................... 255

Appendix J: Directories of Trend Animation Files Attached .......................................................265 


\section{LIST OF FIGURES}

Figure 1: Front View of the NIST NZERTF (South Façade)......................................................... 16

Figure 2: Sensors Mounted on the Metal Stand in the Center of the Room (Davis et al.)........ 19

Figure 3: Rooms Selected for Whole-House Thermal Comfort Data Monitoring...................... 19

Figure 4: Sensors Mounted on the Metal Stands in BR3......................................................... 21

Figure 5: Specific Thermal Comfort Variables Monitored at Each Measurement Points based on $3 \times 3 \times 3$ Grid of Measurement System in BR3 (September 12016 to August 9, 2017).

Figure 6: Graphical Summaries of the 5-Min Average Room-To-Thermostat Temperature Differences for the Cooling Mode.

Figure 7: Graphical Summaries of the 5-Min Average Room-To-Thermostat Temperature Differences for the Heating Mode.

Figure 8: Graphical Summaries of the 5-Min Average Room-To-Thermostat Temperature Differences for the Cooling Season.

Figure 9: Graphical Summaries of the 5-Min Average Room-To-Thermostat Temperature Differences for the Heating Season.

Figure 10: Graphical Summaries of the 5-Min Average Room-To-Thermostat Temperature Differences for the Transitional Season.

Figure 11: Graphical Summaries of the 5-Min Average Room-To-Thermostat Temperature Differences by HP System Seasonal Operation Mode.

Figure 12: Graphical Summaries of the 5-Min Average Room-To-Thermostat Temperature Differences by Season.

Figure 13: Graphical Index to Display Continuously-Measured 5-Min Average Thermal Comfort Data for CDHP (Left Figure) and SDHV (Right Figure).

Figure 14: Graphical Summaries of the 5-Min Average Room Temperatures When the System Was On Cycle (Left Figure) and Off Cycle (Right Figure) for the Cooling Season.

Figure 15: Graphical Summaries of the 5-Min Average Room Temperatures When the System Was On Cycle (Left Figure) and Off Cycle (Right Figure) for the Heating Season.

Figure 16: Graphical Summaries of the 5-Min Average Room Temperatures When the System Was On Cycle (Left Figure) and Off Cycle (Right Figure) for the Transitional Season. 56

Figure 17: Binned LR Room Air Temperatures Against Outdoor Temperatures....................... 61

Figure 18: Binned KIT Room Air Temperatures Against Outdoor Temperatures. 62 
Figure 19: Binned MBR Room Air Temperatures Against Outdoor Temperatures................. 63

Figure 20: Binned BR2 Room Air Temperatures Against Outdoor Temperatures.................. 64

Figure 21: Binned BR3 Room Air Temperatures Against Outdoor Temperatures.................. 65

Figure 22: Binned Attic Room Air Temperatures Against Outdoor Temperatures................. 66

Figure 23: Binned BSMT Room Air Temperatures Against Outdoor Temperatures............... 67

Figure 24: Comparison of Median Values of Binned Room Temperatures of the Seven Rooms Against Outdoor Temperatures.......................................................................... 69

Figure 25: Comparison of Median Values of Binned Room Temperatures Averaged by Floor

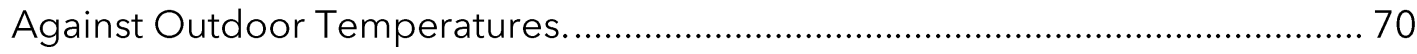

Figure 26: Binned Room-To-Room Temperature Differences Against Outdoor Temperatures

Figure 27: Hourly LR Temperature Profiles by Different System Types and On/Off Cycle during the Cooling Season.

Figure 28: Hourly LR Temperature Profiles by Different System Types and On/Off Cycle

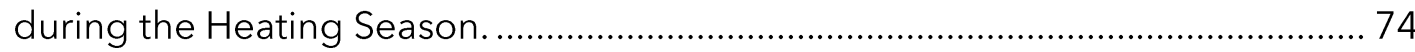

Figure 29: Hourly LR Temperature Profiles by Different System Types and On/Off Cycle during the Transitional Season.

Figure 30: Hourly MBR Temperature Profiles by Different System Types and On/Off Cycle during the Cooling Season

Figure 31: Hourly MBR Temperature Profiles by Different System Types and On/Off Cycle during the Heating Season.

Figure 32: Hourly MBR Temperature Profiles by Different System Types and On/Off Cycle during the Transitional Season......

Figure 33: Time-of-Day Colored Map of LR Temperature ................................................... 81

Figure 34: Time-of-Day Colored Map of MBR Temperature ................................................... 82

Figure 35: Time-of-Day Colored Map of Room-To-Room Temperature Difference. ............... 83

Figure 36: Graphical Summaries of the 5-Min Average Room Humidity When the System Was On Cycle (Left Figure) and Off Cycle (Right Figure) for the Cooling Season. ..... 88

Figure 37: Graphical Summaries of the 5-Min Average Room Humidity When the System Was On Cycle (Left Figure) and Off Cycle (Right Figure) for the Heating Season....... 89

Figure 38: Graphical Summaries of the 5-Min Average Room Humidity When the System Was On Cycle (Left Figure) and Off Cycle (Right Figure) for the Transitional Season. 90

Figure 39: Binned LR Room Air Humidity Ratios Against Outdoor Dew Point Temperatures. 93 Figure 40: Binned KIT Room Air Humidity Ratios Against Outdoor Dew Point Temperatures. 
Figure 41: Binned MBR Room Air Humidity Ratios Against Outdoor Dew Point Temperatures.

Figure 42: Binned BR2 Room Air Humidity Ratios Against Outdoor Dew Point Temperatures. 96

Figure 43: Binned BR3 Room Air Humidity Ratios Against Outdoor Dew Point Temperatures.

Figure 44: Binned Attic Room Air Humidity Ratios Against Outdoor Dew Point Temperatures.

Figure 45: Binned BSMT Room Air Humidity Ratios Against Outdoor Dew Point

Temperatures.

Figure 46: Comparison of Median Values of Binned Room Air Humidity Ratios of the Seven Rooms Against Outdoor Dew Point Temperatures. 100

Figure 47: Comparison of Median Values of Binned Room Air Humidity Ratios Averaged By Floor Against Outdoor Dew Point Temperatures............................................... 101

Figure 48: Hourly LR Operative Temperature and Humidity Data Plotted on the ASHRAE 552017 Comfort Zones. 104

Figure 49: Hourly MBR Operative Temperature and Humidity Data Plotted on the ASHRAE 55-2017 Comfort Zones. 105

Figure 50: Comparison of Median Values of the 5-Min Average Temperatures at the Three Measurement Heights When the System Was On Cycle (Left Figure) and Off Cycle (Right Figure) for the Cooling Season Before August 10, 2019. 109

Figure 51: Graphical Summaries of the 5-Min Average Stand-to-Stand Temperature Difference at the Three Measurement Heights When the System Was On Cycle (Left Figure) and Off Cycle (Right Figure) for the Cooling Season Before August $10,2019$.

Figure 52: Graphical Summaries of the 5-Min Average Vertical Temperature Difference Between $1.7 \mathrm{~m}$ and $0.6 \mathrm{~m}$ When the System Was On Cycle (Left Figure) and Off Cycle (Right Figure) for the Cooling Season Before August 10, 2019. 111

Figure 53: Graphical Summaries of the 5-Min Average Vertical Temperature Difference Between $1.1 \mathrm{~m}$ and $0.6 \mathrm{~m}$ When the System Was On Cycle (Left Figure) and Off Cycle (Right Figure) for the Cooling Season Before August 10, $2019 .$. 112

Figure 54: Comparison of Median Values of the 5-Min Average Temperatures at the Three Measurement Heights When the System Was On Cycle (Left Figure) and Off Cycle (Right Figure) for the Cooling Season After August 10, 2019.

Figure 55: Graphical Summaries of the 5-Min Average Stand-to-Stand Temperature Difference at the Three Measurement Heights When the System Was On Cycle (Left Figure) and Off Cycle (Right Figure) for the Cooling Season After August 10, 2019. 
Figure 56: Graphical Summaries of the 5-Min Average Vertical Temperature Difference Between $1.7 \mathrm{~m}$ and $0.6 \mathrm{~m}$ When the System Was On Cycle (Left Figure) and Off Cycle (Right Figure) for the Cooling Season After August 10, 2019. 115

Figure 57: Graphical Summaries of the 5-Min Average Vertical Temperature Difference Between $1.1 \mathrm{~m}$ and $0.6 \mathrm{~m}$ When the System Was On Cycle (Left Figure) and Off Cycle (Right Figure) for the Cooling Season After August 10, 2019 .................. 116

Figure 58: Comparison of Median Values of the 5-Min Average Temperatures at the Three Measurement Heights When the System Was On Cycle (Left Figure) and Off Cycle (Right Figure) for the Heating Season

Figure 59: Graphical Summaries of the 5-Min Average Stand-to-Stand Temperature Difference at the Three Measurement Heights When the System Was On Cycle (Left Figure) and Off Cycle (Right Figure) for the Heating Season...................... 119

Figure 60: Graphical Summaries of the 5-Min Average Vertical Temperature Difference Between $1.7 \mathrm{~m}$ and $0.6 \mathrm{~m}$ When the System Was On Cycle (Left Figure) and Off Cycle (Right Figure) for the Heating Season. 120

Figure 61: Graphical Summaries of the 5-Min Average Vertical Temperature Difference Between $1.1 \mathrm{~m}$ and $0.6 \mathrm{~m}$ When the System Was On Cycle (Left Figure) and Off Cycle (Right Figure) for the Heating Season.

Figure 62: Comparison of Median Values of the 5-Min Average Temperatures at the Three Measurement Heights When the System Was On Cycle (Left Figure) and Off Cycle (Right Figure) for the Transitional Season.

Figure 63: Graphical Summaries of the 5-Min Average Stand-to-Stand Temperature Difference at the Three Measurement Heights When the System Was On Cycle (Left Figure) and Off Cycle (Right Figure) for the Transitional Season. 124

Figure 64: Graphical Summaries of the 5-Min Average Vertical Temperature Difference Between $1.7 \mathrm{~m}$ and $0.6 \mathrm{~m}$ When the System Was On Cycle (Left Figure) and Off Cycle (Right Figure) for the Transitional Season. 125

Figure 65: Graphical Summaries of the 5-Min Average Vertical Temperature Difference Between $1.1 \mathrm{~m}$ and $0.6 \mathrm{~m}$ When the System Was On Cycle (Left Figure) and Off Cycle (Right Figure) for the Transitional Season. 126

Figure 66: Graphical Summaries of the 5-Min Average Air Velocity When the System Was On Cycle (Left Figure) and Off Cycle (Right Figure) for the Cooling Season Before August 10, 2019. 129

Figure 67: Graphical Summaries of the 5-Min Average Air Velocity When the System Was On Cycle (Left Figure) and Off Cycle (Right Figure) for the Cooling Season After August 10, 2019. 130

Figure 68: Graphical Summaries of the 5-Min Average Air Velocity When the System Was On Cycle (Left Figure) and Off Cycle (Right Figure) for the Heating Season. 131 
Figure 69: Graphical Summaries of the 5-Min Average Air Velocity When the System Was On Cycle (Left Figure) and Off Cycle (Right Figure) for the Transitional Season..... 132

Figure 70: Comparison of the BR3 Temperatures with Different Time Resolutions, Including 1Min, 5-Min Average, and Hourly Average (January 1 to 31, 2017). 134

Figure 71: Graphical Summaries of the 5-Min Average Globe-To-Air Temperature Differences When the System Was On Cycle (Left Figure) and Off Cycle (Right Figure) for the Cooling Season. 137

Figure 72: Graphical Summaries of the 5-Min Average Globe-To-Air Temperature Differences When the System Was On Cycle (Left Figure) and Off Cycle (Right Figure) for the Heating Season. 138

Figure 73: Graphical Summaries of the 5-Min Average Globe-To-Air Temperature Differences When the System Was On Cycle (Left Figure) and Off Cycle (Right Figure) for the Transitional Season. 139

Figure 74: Graphical Summaries of the 5-Min Average Globe-To-Air Temperature Differences When the System Was On Cycle for the Cooling Season Before July 14 (Left Figure) and After July 14 (Right Figure).

Figure 75: Traditional Box-and-Whisker Plot (Left Figure) versus the Proposed Graphical Index (Right Figure) to Display Continuously-Measured Thermal Performance Data.

Figure 76: Comparison of an Application of the Traditional Box-and-Whisker Plot (Left Figures) versus the Proposed Graphical Index (Right Figures) to Display the Binned LR Temperatures against Outdoor Temperatures.

Figure 77: Binned LR Temperatures against Outdoor Temperatures for the CDHP Combined Data, Including Both On and Off Cycles. 144

Figure 78: Binned LR Temperatures against Outdoor Temperatures, Separately for (a) CDHP On Cycle and (b) CDHP Off Cycle. 144

Figure 79: Classification of the Heating, Transitional, and Cooling Seasons Based on Daily Average Outdoor Air Temperature.

Figure 80: Daily HP Electricity Use Against the Daily Outdoor Air Temperature with a FiveParameter (5-P) Change-Point Linear Model, Including the Heating Change-Point Temperature ( $T_{\text {HC }}$ ) and the Cooling Change-Point Temperature $\left(T_{C C}\right) \ldots \ldots \ldots \ldots \ldots . . . .145$

Figure 81: Animated Whole-House 5-Min Average Temperature Data Analysis Mapped on the NZERTF Floor Plans. 148

Figure 82: Animated 5-Min Average BR3 Temperature Data Analysis Mapped on the Vertical (Upper) and Horizontal (Lower) Measurement Planes..

Figure 83: Animated 5-Min Average Entry Hallway Temperature Data Analysis Mapped on the Vertical Measurement Plane. 150 
Figure 84: Animated Psychrometric Analysis Using Hourly Average Thermal Comfort Data of Living Room (Upper) and Bedroom 2 (Lower) Plotted on the Psychrometric Chart with a Super-Imposed ASHRAE Standard 55-2017 Comfort Zone. 151

Figure 85: A Graphical Comparison of the Room-To-Room Temperature Differences Measured in the NZERTF versus the 36 High-Performance Occupied Houses in a Hot-Humid Climate Reported by Poerschke and Beach (2016)......................... 156

Figure B-1: Recorded and Corrected 1-Min LR Temperature................................................ 175

Figure B-2: Recorded and Corrected 1-Min KIT Temperature.................................................. 176

Figure B-3: Recorded and Corrected 1-Min DR Temperature................................................. 177

Figure B-4: Recorded and Corrected 1-Min BR4 Temperature............................................... 178

Figure B-5: Recorded and Corrected 1-Min BA1 Temperature.............................................. 179

Figure B-6: Recorded and Corrected 1-Min WD Temperature............................................... 180

Figure B-7: Recorded and Corrected 1-Min MBR Temperature................................................ 181

Figure B-8: Recorded and Corrected 1-Min BR2 Temperature............................................... 182

Figure B-9: Recorded and Corrected 1-Min BR3 Temperature................................................. 183

Figure B-10: Recorded and Corrected 1-Min MBA Temperature. .......................................... 184

Figure B-11: Recorded and Corrected 1-Min BA2 Temperature............................................. 185

Figure B-12: Recorded and Corrected 1-Min Attic Northwest Temperature........................... 186

Figure B-13: Recorded and Corrected 1-Min Attic Northeast Temperature............................ 187

Figure B-14: Recorded and Corrected 1-Min Attic Southeast Temperature............................ 188

Figure B-15: Recorded and Corrected 1-Min Attic Southwest Temperature........................... 189

Figure B-16: Recorded and Corrected 1-Min BSMT Northwest Temperature.......................... 190

Figure B-17: Recorded and Corrected 1-Min BSMT Northeast Temperature.......................... 191

Figure B-18: Recorded and Corrected 1-Min BSMT Southeast Temperature.......................... 192

Figure B-19: Recorded and Corrected 1-Min BSMT Southwest Temperature......................... 193

Figure B-20: Recorded and Corrected 1-Min EH Lowest Temperature.................................... 194

Figure B-21: Recorded and Corrected 1-Min EH Lower Middle Temperature......................... 195

Figure B-22: Recorded and Corrected 1-Min EH Middle Temperature................................... 196

Figure B-23: Recorded and Corrected 1-Min EH Upper Middle Temperature........................ 197

Figure B-24: Recorded and Corrected 1-Min EH Upper Temperature.................................... 198

Figure B-25: Recorded and Corrected 1-Min LR Globe Temperature....................................... 199

Figure B-26: Recorded and Corrected 1-Min KIT Globe Temperature..................................... 200 
Figure B-27: Recorded and Corrected 1-Min MBR Globe Temperature.............................. 201

Figure B-28: Recorded and Corrected 1-Min BR2 Globe Temperature............................... 202

Figure B-29: Recorded and Corrected 1-Min BR3 Globe Temperature................................. 203

Figure B-30: Recorded and Corrected 1-Min Outdoor Air (OA) Temperature..................... 204

Figure C-1: Comparison of Hourly Electricity Use of CDHP Outdoor and Indoor Unit (Upper

Figure) and SDHV Indoor Unit (Lower Figure) between Different Data Files.... 206

Figure C-2: Temperature Differences between the Temperatures Logged at Every 00 Second Timestamps and the Temperature Logged at Every 30 Second of the Same Minute for the Outdoor Air Temperature (Left Figures) and Dew Point Temperature (Right Figures) Collected from the East Side of the House near the Heat Pump Outdoor Unit.

Figure C-3: Comparison of Outdoor Air Temperature Collected from the Roof of the House ( $\left.T d b \_R o o f\right)$ versus from the East Side of the House near the Heat Pump Outdoor Unit (Tdb_HP (East)). 207

Figure C-4: Comparison of Outdoor Air Temperature Collected from the Roof of the House (NIST_Tdb_Roof) versus from the NOAA Weather Station at Washington/Dulles International Airport (NOAA_IAD), VA. 208

Figure D-1: Binned DR Room Air Temperatures Against Outdoor Temperatures................ 210

Figure D-2: Binned BR4 Room Air Temperatures Against Outdoor Temperatures.............. 211

Figure D-3: Binned WD Room Air Temperatures Against Outdoor Temperatures................ 212

Figure D-4: Binned MBA Room Air Temperatures Against Outdoor Temperatures............. 213

Figure D-5: Binned BA1 Room Air Temperatures Against Outdoor Temperatures.............. 214

Figure D-6: Binned BA2 Room Air Temperatures Against Outdoor Temperatures.............. 215

Figure E-1: Hourly KIT Temperature Profiles by Different System Types and On/Off Cycle

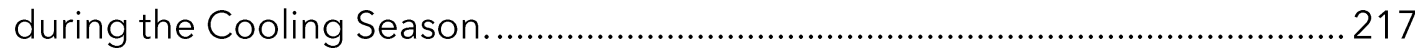

Figure E-2: Hourly KIT Temperature Profiles by Different System Types and On/Off Cycle

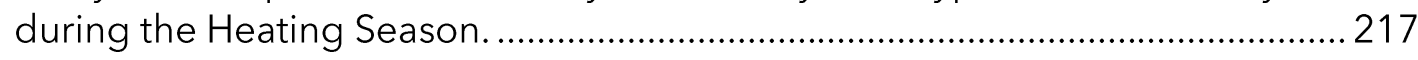

Figure E-3: Hourly KIT Temperature Profiles by Different System Types and On/Off Cycle during the Transitional Season.

Figure E-4: Hourly BR2 Temperature Profiles by Different System Types and On/Off Cycle

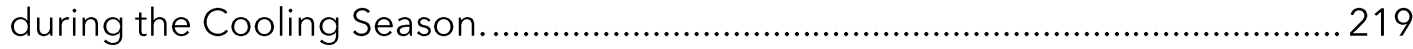

Figure E-5: Hourly BR2 Temperature Profiles by Different System Types and On/Off Cycle during the Heating Season............................................................................... 219

Figure E-6: Hourly BR2 Temperature Profiles by Different System Types and On/Off Cycle during the Transitional Season... 
Figure E-7: Hourly BR3 Temperature Profiles by Different System Types and On/Off Cycle during the Cooling Season.

Figure E-8: Hourly BR3 Temperature Profiles by Different System Types and On/Off Cycle during the Heating Season.

Figure E-9: Hourly BR3 Temperature Profiles by Different System Types and On/Off Cycle during the Transitional Season...

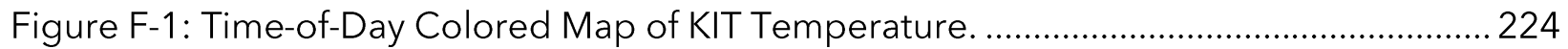

Figure F-2: Time-of-Day Colored Map of BR2 Temperature....................................................225

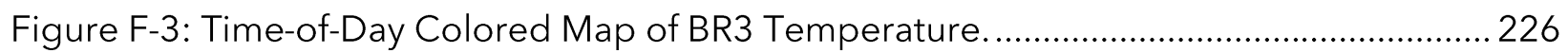

Figure G-1: Hourly KIT Operative Temperature and Humidity Data Plotted on the ASHRAE 55-

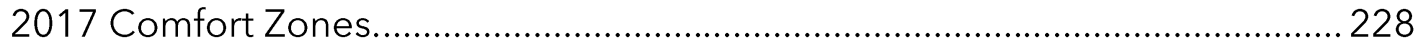

Figure G-2: Hourly BR2 Operative Temperature and Humidity Data Plotted on the ASHRAE 55-2017 Comfort Zones.

Figure G-3: Hourly BR3 Operative Temperature and Humidity Data Plotted on the ASHRAE 55-2017 Comfort Zones.

Figure G-4: Hourly Attic Air Temperature and Humidity Data Plotted on the ASHRAE 55-2017 Comfort Zones.

Figure G-5: Hourly BSMT Air Temperature and Humidity Data Plotted on the ASHRAE 552017 Comfort Zones.

Figure G-6: Hourly MBA Air Temperature and Humidity Data Plotted on the ASHRAE 55-2017 Comfort Zones.

Figure H-1: Graphical Summaries of the 5-Min Average BR3 Stand Temperatures at $1.7 \mathrm{~m}$ When the System Was On Cycle (Left Figure) and Off Cycle (Right Figure) for the Cooling Season Before August 10, 2019.

Figure H-2: Graphical Summaries of the 5-Min Average BR3 Stand Temperatures at $1.1 \mathrm{~m}$ When the System Was On Cycle (Left Figure) and Off Cycle (Right Figure) for the Cooling Season Before August 10, 2019.

Figure H-3: Graphical Summaries of the 5-Min Average BR3 Stand Temperatures at $0.6 \mathrm{~m}$ When the System Was On Cycle (Left Figure) and Off Cycle (Right Figure) for the Cooling Season Before August 10, 2019.

Figure H-4: Graphical Summaries of the 5-Min Average BR3 Stand Globe Temperatures at 1.1 $m$ When the System Was On Cycle (Left Figure) and Off Cycle (Right Figure) for the Cooling Season Before August 10, 2019.

Figure H-5: Graphical Summaries of the 5-Min Average BR3 Stand RH at $1.1 \mathrm{~m}$ When the System Was On Cycle (Left Figure) and Off Cycle (Right Figure) for the Cooling Season Before August 10, 2019. 
Figure H-6: Graphical Summaries of the 5-Min Average BR3 Stand Temperatures at $1.7 \mathrm{~m}$ When the System Was On Cycle (Left Figure) and Off Cycle (Right Figure) for the Cooling Season After August 10, 2019.

Figure H-7: Graphical Summaries of the 5-Min Average BR3 Stand Temperatures at $1.1 \mathrm{~m}$ When the System Was On Cycle (Left Figure) and Off Cycle (Right Figure) for the Cooling Season After August 10, 2019.....

Figure H-8: Graphical Summaries of the 5-Min Average BR3 Stand Temperatures at $0.6 \mathrm{~m}$ When the System Was On Cycle (Left Figure) and Off Cycle (Right Figure) for the Cooling Season After August 10, 2019. 242

Figure H-9: Graphical Summaries of the 5-Min Average BR3 Stand Globe Temperatures at 1.1 $\mathrm{m}$ When the System Was On Cycle (Left Figure) and Off Cycle (Right Figure) for the Cooling Season After August 10, 2019.

Figure H-10: Graphical Summaries of the 5-Min Average BR3 Stand RH at $1.1 \mathrm{~m}$ When the System Was On Cycle (Left Figure) and Off Cycle (Right Figure) for the Cooling Season After August 10, 2019.

Figure H-11: Graphical Summaries of the 5-Min Average BR3 Stand Temperatures at $1.7 \mathrm{~m}$ When the System Was On Cycle (Left Figure) and Off Cycle (Right Figure) for the Heating Season.

Figure H-12: Graphical Summaries of the 5-Min Average BR3 Stand Temperatures at $1.1 \mathrm{~m}$ When the System Was On Cycle (Left Figure) and Off Cycle (Right Figure) for the Heating Season. 246

Figure H-13: Graphical Summaries of the 5-Min Average BR3 Stand Temperatures at $0.6 \mathrm{~m}$ When the System Was On Cycle (Left Figure) and Off Cycle (Right Figure) for the Heating Season.

Figure H-14: Graphical Summaries of the 5-Min Average BR3 Stand Globe Temperatures at $1.1 \mathrm{~m}$ When the System Was On Cycle (Left Figure) and Off Cycle (Right Figure) for the Heating Season.

Figure H-15: Graphical Summaries of the 5-Min Average BR3 Stand RH at $1.1 \mathrm{~m}$ When the System Was On Cycle (Left Figure) and Off Cycle (Right Figure) for the Heating Season.

Figure H-16: Graphical Summaries of the 5-Min Average BR3 Stand Temperatures at $1.7 \mathrm{~m}$ When the System Was On Cycle (Left Figure) and Off Cycle (Right Figure) for the Transitional Season. 250

Figure H-17: Graphical Summaries of the 5-Min Average BR3 Stand Temperatures at $1.1 \mathrm{~m}$ When the System Was On Cycle (Left Figure) and Off Cycle (Right Figure) for the Transitional Season. 251

Figure H-18: Graphical Summaries of the 5-Min Average BR3 Stand Temperatures at $0.6 \mathrm{~m}$ When the System Was On Cycle (Left Figure) and Off Cycle (Right Figure) for the Transitional Season. 252 
Figure H-19: Graphical Summaries of the 5-Min Average BR3 Stand Globe Temperatures at $1.1 \mathrm{~m}$ When the System Was On Cycle (Left Figure) and Off Cycle (Right Figure) for the Transitional Season.

Figure H-20: Graphical Summaries of the 5-Min Average BR3 Stand RH at $1.1 \mathrm{~m}$ When the System Was On Cycle (Left Figure) and Off Cycle (Right Figure) for the Transitional Season. 254

Figure I-1: NZERTF 3D Model Imported from Sketchup into MATLAB ....................................256

Figure I-2: Flowchart Showing Steps to Import 3D Model from Sketchup to MATLAB. ........ 256

Figure I-3: Panels Created for the Animation of the Whole-House Thermal Comfort Analysis.

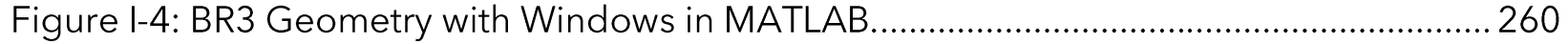

Figure I-5: Panels Created for the Animation of the BR3 Grid Analysis................................... 260

Figure I-6: Entry Hallway Geometry with Windows in MATLAB............................................. 262

Figure 1-7: Panels Created for the Animation of the Entry Hallway Analysis.............................. 262

Figure I-8: Panels Created for the Animation of the Psychrometric Analysis...........................264 


\section{LIST OF TABLES}

Table 1: Summary of the Six Field Studies.

Table 2: ACCA Manual RS Minimum Performance Standards for Thermal Comfort (Residential Single-Zone Systems).

Table 3: Summary of the Characteristics of the Two HVAC Systems at NZERTF. ...................... 17

Table 4: Whole-House Thermal Comfort Measurement Parameters and Instrumentation..... 18

Table 5: BR3 Thermal Comfort Measurement Parameters and Instrumentation....................... 20

Table 6: Summary of the 5-Min Average Room-To-Thermostat Temperature Differences for

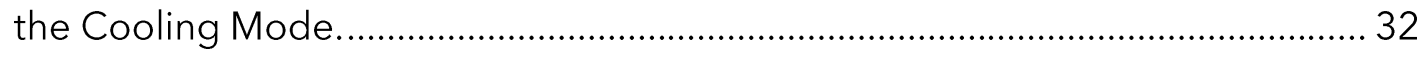

Table 7: Summary of the 5-Min Average Room-To-Thermostat Temperature Differences for the Heating Mode.

Table 8: Summary of the 5-Min Average Room-To-Thermostat Temperature Differences for the Cooling Season............................................................................................. 34

Table 9: Summary of Room-To-Thermostat Temperature Differences for the Heating Season.

Table 10: Summary of Room-To-Thermostat Temperature Differences for the Transitional Season.

Table 11: Summary of the 5-Min Average Room-To-Room Temperature Differences by HP System Seasonal Operation Mode.

Table 12: Summary of the 5-Min Average Room-To-Room Temperature Differences by Season.

Table 13: Percentage of Failures in Cyclic and Drift Temperature Variations Per ASHRAE Standard 55-2017 for the Cooling Mode.

Table 14: Percentage of Failures in Cyclic and Drift Temperature Variations Per ASHRAE Standard 55-2017 for the Heating Mode.

Table 15: Mean (Standard Deviation) of the 5-Min Average Room Air Temperature by the HP System Modes and Seasons.

Table 16: Mean (Standard Deviation) of the 5-Min Average Room Relative Humidity by the HP System Modes and Seasons.

Table 17: A Comparison of the Average Room-to-Room Temperature Differences Between Studies for the Cooling Season.

Table 18: A Comparison of the Percentage of Failures in Room-to-Room Temperature Differences Per ACCA Manual RS Between Studies for the Cooling Season.... 154

Table 19: A Comparison of the Percentage of Failures in Room-to-Thermostat Temperature Differences Per ACCA Manual RS Between Studies for the SDHV.. 
Table 20: A Comparison of the Average Vertical Temperature Differences Between Studies

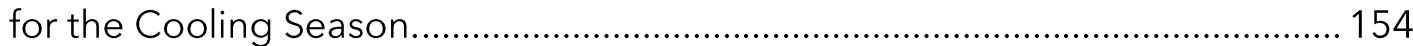

Table 21: A Comparison of the Percentage of Failures in Cyclic and Drift Temperature Variations Per ASHRAE Standard 55-2017 Between Studies for the SDHV....... 155

Table J-1: Directory of the Example Trend Animation Video Files..............................................265 


\section{INTRODUCTION}

Efforts continue to develop low energy technologies and control strategies for buildings that also provide comfortable and healthy indoor environments. However, many performance claims cannot be verified without measurements, characterization, and benchmarking of their actual, long-term energy and Indoor Environmental Quality (IEQ) performance. Field evaluations, especially those conducted by reputable and independent third parties, are essential for a wider acceptance of the low energy technologies in the market and their adoption in the relevant building energy codes and policies. One platform for conducting comprehensive, accurate measurements and evaluations of various residential building technologies is the Net-Zero Energy Residential Test Facility (NZERTF) on the campus of the NIST (Fanney et al. 2015).

The NZERTF is a single-family house that serves as a laboratory where a typical family's occupancy and internal loads can be simulated. At the NZERTF, measurements from nearly 400 sensors are continuously collected and stored, typically in increments of one-minute (Davis et al. 2014; NIST 2019). These data are valuable resources for researchers who aim to improve the performance and ease the means for cost-effectively obtaining low energy homes. The house is also flexible enough to be operated with multiple HVAC systems, including two heat pumps that utilize different air distribution systems:

- Conventionally-Ducted Heat Pump (CDHP) system with a two-stage compressor and a variable speed indoor blower.

- Small Duct High Velocity (SDHV) system with a variable speed compressor and variable speed indoor blower; and

SDHV systems have been recognized as a potential retrofit solution for older residential or historic buildings that were not originally designed for central, conventionally-ducted air distribution systems. These systems offer space savings from using small round ducts, 2 " and 4 " in diameter, as well as easier modular installation requiring less demolition. Other potential benefits compared to conventional "big duct" systems include improved thermal comfort due to enhanced air mixing and dehumidification due to a lower sensible heat ratio; and improved energy efficiency due to reduced leakage and thermal losses, which is partly due to its capability to fit into smaller spaces allowing ideal layout of the ductwork.

Despite broad recognition that air distribution plays an important role in comfort for residential buildings, previous efforts to evaluate and characterize the performance of residential air distribution systems have largely focused on their impact on the heating and cooling energy consumption such as thermal distribution system efficiency affected by duct air leakage and conduction losses (Guyton 1993; Modera 1993; Jump et al. 1996; Siegel et al. 1997; Vineyard et al. 2003; Francisco et al. 2006; Stephens et al. 2011; Poerschke and Rudd 2016). As a result, the ASHRAE Standard 152-2004 (ASHRAE 2004b) and 2014 (ASHRAE 2014) provide the standardized method for testing the design and seasonal efficiencies of residential thermal distribution systems. However, this standard does not address the effectiveness of the tested system to provide and maintain comfort in the conditioned space by delivering the designed or required airflow or air temperature to individual rooms throughout the house. There is no standardized method to quantify the extent of such comfort at the whole-house level and to compare different air distribution systems for whole-house comfort, including appropriate benchmarks, especially for low-load houses. 
Fewer studies have measured whole-house thermal comfort performance of residential air distribution systems as installed within a house (Baskin and Vineyard 2003; Rittelmann 2006; Rittelmann 2008; Poerschke et al. 2016; Poerschke 2017; Martin et al. 2018). These studies evaluated the effectiveness of the tested residential forced-air heating and cooling systems to provide thermal uniformity across the house mostly based on short-term measurements in an unoccupied test house without considering the dynamic internal heat gains from occupants, lighting, and appliances. A detailed review of these studies, as provided in Section 2.1, revealed there is a need for more field studies based on long-term measurements in the same test house (i.e., series approach) with simulated/controlled occupancy and internal loads. This review also found a need to explore and develop more standardized data intervals, metrics, and advanced analytical methods to accurately quantify and report the extent of whole-house thermal comfort (e.g., in terms of thermal uniformity, local discomfort, cyclic discomfort, or latent performance), which will allow a comparison of the results between different field tests in the context of benchmarks.

Therefore, this study explores several new performance metrics and methods to properly characterize, evaluate and document whole-house thermal comfort performance of residential air distribution systems using one-year of detailed building and system data collected from the NIST's NZERTF. During the analysis period, two different heat pumps that utilize different air distribution systems (i.e., CDHP and SDHV) were operated alternately every other week, which provides a unique opportunity for a comparison of the systematic performance of the two systems using the same test house under similar weather conditions. The collected thermal comfort performance data are presented in the context of benchmarks to which other houses and air distribution systems can be compared. The findings from this study will contribute to the existing knowledge and measurement and benchmarking of the whole-house, long-term performance of residential air distribution systems for thermal comfort.

\subsection{PURPOSE OF THE RESEARCH}

The purpose of this research is to develop an improved understanding of the impact of residential air distribution systems on whole-house thermal comfort and to propose analytical methods for evaluating this impact. To accomplish this, this study reviewed the literature to identify relevant work and explored several new methods to properly characterize wholehouse thermal comfort performance of residential air distribution systems using one-year of detailed building and system data collected from NIST's NZERTF from September 2016 to August 2017 (i.e., Year 3 NZERTF Data).

\subsection{ORGANIZATION OF THE REPORT}

This report is organized into six sections.

Section 1 introduces the background of the study, including the purpose of the research.

Section 2 reviews the literature related to this research, including: previous studies on the whole-house thermal comfort performance of residential forced-air heating and cooling systems with a focus on different air distribution systems; and a review of current performance measurement protocols, standards, and benchmarks related to this subject. 
Section 3 describes the methodology used to conduct this research, including a description of NIST NZERTF and the tested HVAC systems; thermal comfort and system performance data collection, processing, and inspection; and data analysis methods.

Section 4 presents a detailed analysis of the whole-house thermal comfort data to characterize and evaluate the whole-house thermal comfort performance of the two air distribution systems as installed at NZERTF.

Section 5 presents a detailed analysis of the BR3 thermal comfort data based on a $3 \times 3 \times 3$ grid of measurement system to characterize and evaluate potential horizontal and vertical thermal stratification within a single room, which was affected by the two air distribution systems as installed at NZERTF.

Section 6 presents discussions on several topics that appeared challenging or important to characterize residential air distribution system performance for thermal comfort, including data time resolution for analysis; suitable thermal comfort metrics; a graphical index for longterm thermal comfort data analysis; long-term thermal comfort data decomposition; trend animation for granular analysis; and benchmarking.

Section 7 summarizes this research and discusses the recommendations for future research, which will contribute to improved design, operation, and measurements of residential air distribution systems for energy efficiency and thermal comfort.

Appendix A provides a list of the 42 days that were excluded from the analysis with the reasons for exclusion.

Appendix B presents graphical summaries of the recorded (i.e., before correction) and the corrected 1-min whole-house temperature data for the 30 temperature data channels.

Appendix $\mathrm{C}$ describes the data quality issues observed with the collected HP electricity and outdoor air and dew point temperature data.

Appendix D presents the binned room air temperatures against outdoor temperatures for the other rooms such as DR, BR4, WD, MBA1, BA1, and BA2 as supplementary materials to Section 4.5.1.

Appendix E presents graphical summaries of the hourly room temperature profiles by different system types and on/off cycle and for the other three primary rooms such as KIT, BR2, and BR3 as supplementary materials to Section 4.6.1.

Appendix F presents time-of-day colored maps applied to the hourly average room temperatures over the entire measurement period for the other three primary rooms such as KIT, BR2, and BR3 as supplementary materials to Section 4.6.2.

Appendix $G$ presents a graphical analysis of the hourly average thermal comfort data using the psychrometric chart with a super-imposed ASHRAE Standard 55-2017 comfort zone for the rooms such as KIT, BR2, BR3, attic, BSMT, and MBA as supplementary materials to Section 4.8 . 
Appendix $\mathrm{H}$ provides the detailed statistical characterization of measurements by individual stands at each measurement height.

Appendix I presents the detailed steps on temperature data visualizing and animation using MATLAB 2017b.

Appendix $\mathrm{J}$ presents the directories of example trend animation files, which accompany this report. 


\section{LITERATUE REVIEW}

This section provides a detailed review of the literature related to this research.

Section 2.1 reviews the previous studies on the whole-house thermal comfort performance of residential forced-air heating and cooling systems with a focus on different air distribution systems.

Section 2.2 provides a review of current performance measurement protocols, standards, and benchmarks related to this subject.

\subsection{PREVIOUS STUDIES ON THE WHOLE-HOUSE THERMAL COMFORT PERFORMANCE OF RESIDENTIAL AIR DISTRIBUTION SYSTEMS.}

Previous studies on the thermal comfort performance of residential HVAC systems as installed within a house were primarily performed or commissioned by national laboratories through the U.S. Department of Energy (DOE) Building America Program (Werling 2015). Several studies have focused on the whole-house performance of forced-air heating and cooling systems that have conventional or unconventional air distribution systems, including a SDHV system (Baskin and Vineyard 2003; Rittelmann 2006; Rittelmann 2008; Poerschke et al. 2016; Poerschke 2017; Martin et al. 2018).

\subsubsection{BASKIN AND VINEYARD (2003)}

Baskin and Vineyard (2003) measured and compared the thermal comfort performance of the two different air distribution systems (i.e., CDHP and SDHV) that are connected to two different heat pump systems installed in the same unoccupied test house, which was a singlestory house in Lenoir City, TN. Using the data collected from a series of short-term field tests performed over three days in the cooling season, this study calculated and used the Predicted Mean Vote (PMV) and Predicted Percentage Dissatisfied (PPD) index to evaluate the level of thermal comfort maintained with the two different systems at the whole-house level. As a result, this study found a higher percentage of comfort (i.e., $8.6 \%$ higher on average based on \pm 0.5 PMV criteria; and $17.1 \%$ higher on average based on $<10 \%$ PPD criteria) with the SDHV system compared to the CDHP system.

However, the reported higher level of comfort was based on the PMV/PPD at a constant clothing level (i.e., $1 \mathrm{clo}^{1}$ ) and metabolic rate (i.e., $1 \mathrm{met}^{2}$ ) assumed in this unoccupied house without information of the HVAC thermostat and the cooling setpoint temperature during the tests. Unless the HVAC system installed in the house was configured to control the thermal conditions of the house/rooms to maintain neutral comfort conditions (i.e., \pm 0.5 PMV criteria) with the assumed personal variables (i.e., 1 clo and 1 met), which is atypical for residential systems, the use of PMV/PPD to evaluate the ability for the tested systems to provide comfort should be supplemental. In addition, a noticeably low percentage of comfort was observed in the living room with the SDHV system. Based on \pm 0.5 PMV criteria, the estimated percentage of comfort was $51.6 \%$ for the living room, while it was above $93.8 \%$ for other bedrooms. The

\footnotetext{
1 The clothing ensembles of trousers, a long-sleeve shirt, and a long-sleeve sweater have approximately 1.0 clo of insulation (ASHRAE 2017), which is the insulation level of clothing typically worn in winter rather than in summer.

${ }^{2}$ A seated person is expected to have a metabolic rate of 1.0 met for reading/writing (ASHRAE 2017).
} 
observed room-to-room thermal nonuniformity should be an important factor to assess the thermal comfort performance of different residential systems at the whole-house level, which was not discussed in this literature.

\subsubsection{RITTELMANN (2006)}

Rittelmann (2006) proposed a short-term field test protocol to evaluate the thermal comfort performance of a residential HVAC system ${ }^{3}$ at the whole-house level. The proposed method was demonstrated using 1-min temperature data collected from an unoccupied test house equipped with forced-air systems in Pittsburgh, PA during the heating season. The PMV index was chosen with a clothing value that was adjusted to achieve a neutral PMV (i.e., 0 PMV) at the heating setpoint temperature (i.e., $21.1^{\circ} \mathrm{C}\left(70.0^{\circ} \mathrm{F}\right)$ ) with a fixed $40 \% \mathrm{RH}$. The collected $1-$ min temperature data during a test period of 48 hours were averaged over one hour, which was used to calculate hourly PMV with assumed $\mathrm{RH}$, mean radiant temperature, and air velocity. The proposed method also included local thermal discomfort caused by draft, vertical air temperature difference, and floor surface temperature using the Percent Dissatisfied (PD) index, which was added to the PMV calculated for each room.

The proposed method appears to be contradictory in the presented demonstration because the provisions on local thermal discomfort in the ASHRAE Standard 55-2004 (ASHRAE $2004 a)^{4}$ can be applied only to a lightly clothed person (i.e., lower than 0.7 clo) engaged in sedentary activities below 1.3 met. However, the assumed clothing level in the presented demonstration was a heavily clothed person (i.e.,1.5 clo) that will make people less thermally sensitive to local discomfort factors. In addition, to calculate PMV, all required parameters except air temperature were not measured but rather assumed, which does not provide accurate assessments of the system. Lastly, the use of hourly average temperature is not likely to capture cyclic discomfort.

\subsubsection{RITTELMANN (2008)}

Rittelmann (2008) evaluated the thermal comfort performance of two forced-air systems equipped with different placement of supply air outlets (i.e., high sidewall diffusers vs. floor registers) at the whole-house level using two unoccupied side-by-side test houses in Fort Wayne, IN. The evaluation was based on the 1) whole-house thermal comfort performance index (TCPI), which is the percentage of time in which the measured thermal conditions satisfy comfort criteria based on ASHRAE Standard 55-2004 (i.e., \pm 0.5 PMV criteria) and was calculated using long-term monitored data, as well as 2 ) head-to-toe and floor-to-floor temperature stratification based on average hourly temperature.

Among the studies reviewed in this report, this was one of the two studies based on longterm monitoring under various outdoor air conditions, which allowed a weather-normalized comparison by analyzing the measured room temperatures and the calculated indices against the outdoor air (OA) temperatures. As a result, this study found that the measured head-to-toe and floor-to-floor temperature stratification were affected by OA temperature, although the levels of impact varied by the type and the mode of the tested system. This

\footnotetext{
3 The proposed protocol aimed to be universally applicable to residential HVAC systems, including a forced-air system and a radiant floor system.

4 Per Section 5.2.4 Local Thermal Discomfort of the ASHRAE Standard 55-2004. The latest edition of the ASHRAE Standard 55-2017 presents the same applicability criteria in Section 5.3.4.1.
} 
study primarily focused on the metrics and did not provide advanced analytical techniques to decompose and convert the collected large data set into useful information.

\subsubsection{POERSCHKE ET AL. (2016)}

Poerschke et al. (2016) measured and compared the cooling season performance of three different types of residential forced air systems (i.e., CDHP, SDHV, and ductless mini-split heat pump system) as installed in occupied two triplex townhomes in Denver, CO. Based on nine days of data selected for the analysis during the cooling season, this study found that the tested SDHV provided better room-to-room temperature uniformity than the standard air distribution system (i.e., CDHP), of which trends were further analyzed by the system on and off cycles as well as OA temperature ${ }^{5}$. In terms of cyclic temperature variations, both the tested CDHP and SDHV met the ASHRAE Standard 55-2013 (ASHRAE 2013a).

Among the studies reviewed in this report, this was the only study performed in occupied houses, which has an inherent limitation in this type of a comparison study due to different occupant behaviors that may introduce uncertainties in the presented comparison results. Some efforts were made to graphically represent and analyze the results of continuously measured performance metrics. For example, the psychrometric chart was used, which provided a graphically rich description of the data, although the analysis mainly focused on a comparison of measured thermal comfort data against the benchmarks such as the ASHRAE Standard 55-2013 comfort zones.

\subsubsection{POERSCHKE (2017)}

Poerschke (2017) tested the whole-house performance of a SDHV system with three constant airflow rates connected to a variable-capacity heat pump using an unoccupied test house, which was a two-story new construction in Pittsburgh, PA. Based on an analysis of six representative days (i.e., three days for the heating season; and three days for the cooling season), this study reported a high incidence of room-to-thermostat ${ }^{6}$ temperature nonuniformity not conforming the Air Conditioning Contractors of America (ACCA) Manual RS guidelines ${ }^{7}$ (ACCA 1997) in the second-floor bedrooms, which was primarily due to insufficient air flows or overheating due to solar heat gains through the windows. The study also reported occasional failures in cyclic and drift temperature variations per ASHRAE Standard 55-2010 (ASHRAE 2010) only with the high-speed fan operation during the heating season, which was caused by condenser coil defrost cycles.

The conclusions derived in this study was primarily based on air temperature, although there are other thermal comfort variables that are identified to be important for human comfort (e.g., humidity, mean radiant temperature, and air velocity) and can also vary depending on

\footnotetext{
5 The authors state that the observed lower room-to-room temperature differences were affected by SDHV's capability to fit into smaller spaces (i.e., second-floor cavity) allowing an ideal layout of the ductwork.

6 The test house had a single-zone HVAC system controlled using a single thermostat centrally located in the living room on the first floor of the house.

${ }^{7} \pm 1.7^{\circ} \mathrm{C}\left( \pm 3.0^{\circ} \mathrm{F}\right)$ in Cooling Mode; and $\pm 1.1^{\circ} \mathrm{C}\left( \pm 2.0^{\circ} \mathrm{F}\right)$ in Heating Mode

8 The ASHRAE Standard 55-2017 (ASHRAE 2017) specifies a peak-to-peak variation in operative temperature for any 15 -minute period shall not exceed $1.1^{\circ} \mathrm{C}\left(2.0^{\circ} \mathrm{F}\right)$ to evaluate cyclic variations. The criteria for drift variations are based on maximum operative temperature change allowed: $1.1^{\circ} \mathrm{C}\left(2.0^{\circ} \mathrm{F}\right)$ for any 15 -minute period; $1.7^{\circ} \mathrm{C}\left(3.0^{\circ} \mathrm{F}\right)$ for any 30 -minute period; $2.2^{\circ} \mathrm{C}\left(4.0^{\circ} \mathrm{F}\right)$ for any 1 -hour period; $2.8^{\circ} \mathrm{C}\left(5.0^{\circ} \mathrm{F}\right)$ for any 2 -hour period; and $3.3^{\circ} \mathrm{C}$ $\left(6.0^{\circ} \mathrm{F}\right)$ for any 4 -hour period.
} 
the type of the system installed at the house. For example, the observed possible discomfort due to solar heat gains could be better understood and evaluated with the measurement of mean radiant temperature, which is often influenced by the type and placement of windows at the tested house. In addition, this study focused solely on SDHV performance assessment rather than a performance comparison between the tested SDHV and any reference system (e.g., a conventional big duct system). However, the reported issues with thermal comfort can be also influenced by the physical characteristics of the test house, which was not fully addressed in this literature.

\subsubsection{MARTIN ET AL. (2018)}

Martin et al. (2018) evaluated the whole-house energy and comfort performance of three different residential HVAC systems that use variable-capacity heat pumps, including a SDHV, with a primary focus on their moisture control capability (i.e., latent performance) in a hot and humid climate. The long-term energy and thermal comfort (i.e., room temperature and humidity) data were collected from the Florida Solar Energy Center's (FSEC) Manufactured Housing Laboratory (MHL), which is a one-story house with simulated occupancy and internal loads located in Cocoa, FL. As a result, the study found that the tested SDHV system provided good thermal uniformity based on hourly room-to-temperature differences conforming to the ACCA Manual RS guidelines. In addition, the SDHV system maintained indoor humidity below $60 \%$ relative humidity $(\mathrm{RH})$ across the house except for the utility room?

Among the studies reviewed in this report, this was the only study performed in a house with simulated occupancy and internal loads. This was also one of the two studies based on longterm monitored data ${ }^{10}$. However, the hourly average ${ }^{11}$ temperature and humidity data were selected for the analysis, which is not likely to capture cyclic discomfort. In addition, the analysis is based on basic analytical methods such as a descriptive analysis (e.g., average, \% of hours in a certain condition) or a time-series plot with appropriate benchmarks. Few efforts were made to decompose and convert the collected large data set into useful information.

\subsubsection{SUMMARY}

In summary, these studies evaluated the effectiveness of the tested residential forced-air heating and cooling systems to provide thermal comfort to individual rooms across the house mostly in an unoccupied test house. Table 1 provides a summary of the six field studies reviewed in this report. Out of the six studies, four studies (Baskin and Vineyard 2003; Poerschke et al. 2016; Poerschke 2017; Martin et al. 2018) tested the installed performance of a SDHV system. The major findings from the literature review include:

1) Test house occupancy: The use of an unoccupied test house has an inherent limitation such that the dynamic interactions between uneven internal heat gains from occupants, lighting, appliances, and miscellaneous electronic devices and the measured thermal conditions tend to be ignored, although they can have significant localized impacts on indoor climates even in low-load houses (Stecher et al. 2012).

There was one study performed in occupied houses (Poerschke et al. 2016), which has another type of limitation due to different occupant behaviors that may introduce

\footnotetext{
9 The utility room had high $\mathrm{RH}$ levels due to the outdoor air mechanical ventilation supplied to the utility room.

1026 days for the heating mode; 153 days for the standard cooling mode; and 133 days for the dry cooling mode.

11 The temperature and relative humidity data were scanned every ten seconds and averaged into 15-minute data.
} 
uncertainties in the presented comparison results. Only one study by Martin et al. (2018) was performed in a house with simulated occupancy and internal loads, which is unique. Therefore, more field studies in a house with controlled occupancy and internal loads that may have different physical characteristics (e.g., a single-story house vs. a two-story house) or be located in different climates are needed for an improved understanding of this subject.

2) Type of testing for a performance comparison: Of the six studies, four studies compared the measured performance of a certain system against another type of system based on side-by-side tests using different houses (i.e., parallel approach) (Rittelmann 2008; Poerschke et al. 2016) or before-and-after tests (or test-in and testout) (i.e., series approach) using the same test house (Baskin and Vineyard 2003; Martin et al. 2018). The use of the same test house for comparison is likely to reduce uncertainties in the reported system performance caused by the physical characteristics of the test house (e.g., solar heat gains from relatively large windows in one room) rather than the tested system itself. Therefore, more field studies using the same test house to compare a systematic performance of the tested HVAC system are needed for an improved understanding of this subject.

3) Short-term vs. long-term field studies: In terms of a data analysis period, four studies (Baskin and Vineyard 2003; Rittelmann 2006; Poerschke et al. 2016; Poerschke 2017) were based on a series of short-term field tests between 1 and 9 days. Because outdoor conditions can have a large influence on the measured thermal comfort performance of the systems, it is important to properly normalize weather conditions in such an analysis to allow a direct comparison between different system modes/types of an interest, which is harder to accomplish with short-term field tests. The other two studies (Rittelmann 2008; Martin et al. 2018) were based on long-term field tests, which was helpful to fully understand different behaviors of the tested residential HVAC systems under different outdoor climate conditions, including both extreme and typical heating and cooling days as well as a transitional season. Therefore, more field studies based on long-term measurements are needed for an improved understanding of this subject.

4) Different intervals for data scanning, logging, and analysis: Information on the data scanning or logging intervals were not always available from the studies. For data analysis, either one-minute or hourly average data was commonly used. The two studies with long-term monitored data (Rittelmann 2008; Martin et al. 2018) used hourly average data, which might be affected by the easiness of data management of this large volume of data. However, the use of hourly average data is not likely to capture cyclic fluctuations or discomfort. Therefore, there is a need to explore appropriate data intervals that can accurately capture and evaluate the impact of residential HVAC systems on whole-house comfort.

5) Different performance metrics to assess thermal uniformity: All studies performed a thermal uniformity analysis to assess whole-house thermal comfort performance in terms of providing uniform space temperatures across the house. However, disagreement appeared between the studies in the selected performance metrics to evaluate thermal uniformity. Half of the studies (Baskin and Vineyard 2003; Rittelmann 
2006; Rittelmann 2008 ${ }^{12}$ ) used the PMV/PPD indices calculated with assumed personal variables (i.e., clothing level and metabolic rate) as a primary metric in the analysis. The other half of the studies (Poerschke et al. 2016; Poerschke 2017; Martin et al. 2018) used room air temperature as a primary metric in the analysis. For example, these studies calculated floor-to-floor or room-to-room temperature differences and compared the results against an acceptable level of stratification per ACCA Manual RS (ARCC 1997). Therefore, there is a need to explore a more standardized method to quantify and report the extent of thermal uniformity at the whole-house level, which will allow a comparison of the results between different field tests in the context of benchmarks.

6) Other performance metrics for whole-house thermal comfort assessment: Previous field studies have largely focused on an analysis of thermal uniformity across the floors or rooms to determine whole-house thermal comfort. However, some efforts were also made to assess local or cyclic discomfort. Rittelmann (2006 and 2008) analyzed local discomfort caused by several factors such as radiant temperature asymmetry, vertical air temperature difference (i.e., head-to-ankle temperature stratification), floor surface temperature, and drafts per ASHRAE Standard 55-2004 (ASHRAE 2004). Two studies (Poerschke et al. 2016; Poerschke 2017) analyzed cyclic discomfort using 1min temperature data based on short-term measurements, which was based on peakto-peak temperature variations for the given time periods. Only one study by Martin et al. (2018) provided a detailed analysis of indoor relative humidity data collected from different rooms across the house, which is important to evaluate the system's ability to control humidity, especially in low-load houses due to their lower sensible cooling demand. Therefore, there is a need to explore other performance metrics that may be useful to quantify the extent of whole-house thermal comfort that may vary between different residential HVAC systems.

7) Lack of an in-depth analysis of dynamic thermal comfort data: No studies discussed advanced analytical techniques to characterize dynamic thermal comfort data beyond a traditional time-series or frequency analysis. For example, Kim and Haberl (2014) found the use of the psychrometric chart for different occupancy modes provided a graphically rich description of the continuously measured dynamic thermal comfort data while allowing a quick determination of how space is conditioned between different occupancy modes. The use of the time-of-day colored maps was also useful to track the measurement space over the course of a day to figure out possible reasons for different distribution patterns of the measured IEQ variables. Therefore, there is a need to explore more advanced analytical techniques, including trend animations of thermal comfort data, which may be useful to quantify the extent of whole-house thermal comfort that may vary between different residential HVAC systems.

Therefore, this literature review revealed a need for more field studies based on long-term measurements in the same test house with simulated/controlled occupancy and internal loads in order to develop an improved understanding of the impact of residential forced-air heating and cooling systems with a focus on different air distribution systems on thermal comfort at the whole-house level. This review also found there is a need to explore and

\footnotetext{
12 In addition to PMV analysis, Rittelmann (2008) analyzed floor-to-floor temperature differences in the test houses.
} 
develop more standardized data intervals, metrics, and advanced analytical methods to accurately quantify and report the extent of whole-house thermal comfort (e.g., in terms of thermal uniformity, local discomfort, cyclic discomfort, and latent performance), which will allow a comparison of the results between different field tests in the context of benchmarks.

Table 1: Summary of the Six Field Studies.

\begin{tabular}{|c|c|c|c|c|c|c|}
\hline & $\begin{array}{l}\text { Baskin and } \\
\text { Vineyard } \\
(2003)\end{array}$ & $\begin{array}{l}\text { Rittelmann } \\
\text { (2006) }\end{array}$ & $\begin{array}{l}\text { Rittelmann } \\
\text { (2008) }\end{array}$ & $\begin{array}{l}\text { Poerschke et al. } \\
\qquad(2016)\end{array}$ & $\begin{array}{l}\text { Poerschke } \\
\text { (2017) }\end{array}$ & $\begin{array}{l}\text { Martin et al. } \\
\quad(2018)\end{array}$ \\
\hline \multicolumn{7}{|l|}{ Test House Details } \\
\hline Location & Lenoir City, TN & Pittsburgh, PA & Fort Wayne, IN & Denver, CO & Pittsburgh, PA & Cocoa, FL \\
\hline $\begin{array}{l}\text { Test House } \\
\text { Occupancy }\end{array}$ & Unoccupied & Unoccupied & Unoccupied & Occupied & Unoccupied & $\begin{array}{l}\text { Simulated } \\
\text { Occupancy }\end{array}$ \\
\hline \multicolumn{7}{|c|}{ Details on the Tested HVAC Systems } \\
\hline SDHV Tested & Yes & No & No & Yes & Yes & Yes \\
\hline $\begin{array}{l}\text { System } \\
\text { Comparison }\end{array}$ & $\begin{array}{c}\text { Yes } \\
\text { (test-in and test-out } \\
\text { comparison) }\end{array}$ & No & $\begin{array}{c}\text { Yes } \\
\text { (side-by-side } \\
\text { comparison) }\end{array}$ & $\begin{array}{c}\text { Yes } \\
\text { (side-by-side } \\
\text { comparison) }\end{array}$ & No & $\begin{array}{c}\text { Yes } \\
\text { (before-and-after } \\
\text { comparison) }\end{array}$ \\
\hline \multicolumn{7}{|c|}{ Details on Data Collected and Analyzed } \\
\hline $\begin{array}{l}\text { Data Analysis } \\
\text { Period }\end{array}$ & $3 d$ & $1-2 d$ & $240 d^{1)}$ & $9 \mathrm{~d}$ & $6 \mathrm{~d}$ & $312 \mathrm{~d}$ \\
\hline $\begin{array}{l}\text { Data Scanning } \\
\text { Interval }\end{array}$ & $N A^{2)}$ & $15-s$ & NA & NA & NA & $10-\mathrm{s}$ \\
\hline $\begin{array}{l}\text { Data Logging } \\
\text { Interval }\end{array}$ & $N A$ & 1-h avg. & $N A$ & $N A$ & NA & 15-m avg. \\
\hline $\begin{array}{l}\text { Data Analysis } \\
\text { Interval }\end{array}$ & avg. per location & 1-h avg. & 1-h avg. & $1-m$ & $1-\mathrm{m}$ & 1-h avg. \\
\hline \multicolumn{7}{|c|}{ Metrics Used in the Studies } \\
\hline PMV & Yes & Yes & Yes & No & No & No \\
\hline $\begin{array}{l}\text { Thermal } \\
\text { Uniformity }\end{array}$ & $\begin{array}{c}\text { Partially } \\
\text { (table comparing } \\
\text { avg. values) }\end{array}$ & $\begin{array}{c}\text { Partially } \\
\text { (graphically using } \\
\text { PMV) }\end{array}$ & Yes & Yes & Yes & Yes \\
\hline Local Discomfort ${ }^{4)}$ & No & Yes & $\begin{array}{c}\text { Partially } \\
\text { (only head-to-toe } \\
\text { stratification) }\end{array}$ & No & No & No \\
\hline Cyclic Discomfort ${ }^{5)}$ & No & No & No & Yes & Yes & No \\
\hline $\begin{array}{l}\text { Latent } \\
\text { Performance }\end{array}$ & No & No & No & $\begin{array}{c}\text { Partially } \\
\text { (graphically using } \\
\text { psychrometric } \\
\text { chart) }\end{array}$ & No & Yes \\
\hline $\begin{array}{l}\text { Advanced Data } \\
\text { Analytics }\end{array}$ & No & No & No & $\begin{array}{c}\text { Partially } \\
\text { (data } \\
\text { decomposition by } \\
\text { HVAC on/off cycle) }\end{array}$ & No & No \\
\hline
\end{tabular}

Note:

1) Estimated from Figure 4-6.

2) $N A$ : Not Available.

3) Thermal uniformity analysis primarily consists of an analysis of floor-to-floor or room-to-room temperature stratification (ARCC 1997).

4) Local discomfort analysis includes discomfort caused by radiant temperature asymmetry, vertical air temperature difference (i.e., head-toankle temperature stratification), floor surface temperature, and drafts (ASHRAE 2017).

5) Cyclic discomfort analysis is based on peak-to-peak temperature variations for the given time periods: $1.1^{\circ} \mathrm{C}$ for $0.25 \mathrm{~h} ; 1.7^{\circ} \mathrm{C}$ for $0.50 \mathrm{~h}$; $2.2^{\circ} \mathrm{C}$ for $1.0 \mathrm{~h} ; 2.8^{\circ} \mathrm{C}$ for $2.0 \mathrm{~h}$; and $3.3^{\circ} \mathrm{C}$ for $4.0 \mathrm{~h}$ (ASHRAE 2017). 


\subsection{THERMAL COMFORT PERFORMANCE MEASUREMENT PROTOCOLS AND BENCHMARKS}

Most of today's field studies on the whole-house thermal comfort performance of residential forced-air heating and cooling systems follow the methodology in one of the following two documents:

- ASHRAE Standard 55 Thermal Environmental Conditions for Human Occupancy (ASHRAE 2017); and

- ACCA Manual RS - Comfort, Air Quality, and Efficiency by Design, Section 1 Comfort (ACCA 1997).

Both documents provide guidelines in terms of the parameters and metrics that should be measured to assess thermal comfort in occupied spaces with comparable benchmarks. The two documents agree with each other in terms of primary comfort parameters, including air temperature, humidity, thermal radiation (e.g., mean radiant temperature (MRT) in the ASHRAE Standard 55; surface temperatures of interior walls in the ACCA Manual RS), and air speed in balance with clothing and metabolic rate, although they were developed for quite different purposes.

The ASHRAE Standard 55 aims to define the conditions that will produce acceptable thermal environmental conditions for a majority of the occupants within the space. As a result, to evaluate thermal comfort in occupied buildings, the ASHRAE Standard 55 method focuses on whether the occupants of the building are comfortable ${ }^{13}$, which can be demonstrated using an occupant survey or a comparison of the combinations of measured indoor thermal environmental factors (i.e., air temperature, humidity, thermal radiation, and air speed) and the two personal factors (i.e., clothing and activity) against the PMV-based comfort zone as defined in Section 5.3.1 of the standard ${ }^{14}$.

On the other hand, the ACCA Manual RS aims to provide guidelines about how to characterize the performance of residential heating and cooling systems in terms of maintaining comfort in occupied zones ${ }^{15}$ of a house. As a result, the ACCA Manual RS focuses on the HVAC system's ability to produce and deliver comfort to multiple occupied spaces as installed in the house, which is primarily based on a temperature deviation from the thermostat setpoint (i.e., room-to-thermostat temperature difference) in any conditioned room of a house and the resultant room-to-room (or floor-to-floor) temperature differences.

Another noticeable difference between the two documents is that the ASHRAE Standard 55 provides explicit measurement and evaluation methods of the defined thermal comfort parameters and metrics, while the ACCA Manual RS does not. For example, Section 7.3 of the ASHRAE Standard 55 provides methods for measurement of the comfort parameters in terms of measurement periods, intervals, and locations, and Section 7.4 of the standard provides methods to evaluate the measured or calculated thermal comfort metrics, including the

\footnotetext{
13 The ASHRAE Standard 55-2017 defines thermal comfort as "that condition of mind that expresses satisfaction with the thermal environment and is assessed by subjective evaluation."

${ }^{14}$ In addition to the graphic method using the PMV-based comfort zone in Section 5.3.1, the ASHRAE Standard 55-2017 provides other compliance methods, including an analytical method based on the calculation of the PMV; and a method that uses elevated air speed to provide comfort. The standard also provides a separate method for occupant-controlled naturally conditioned space.

$152 \mathrm{ft}$. inward from each of the room's walls and ceilings.
} 
calculation of exceedance hours, which is the number of hours in which environmental conditions are outside the PMV-based comfort zone.

For benchmarking, both documents provide desired thermal comfort benchmarks. The ASHRAE Standard 55 provides the PMV-based benchmarks (i.e., $-0.5<$ PMV $<+0.5$ ), which is defined as the comfort zone on the psychrometric chart for occupants with clothing insulation between 0.5 and 1.0 clo and metabolic rates of between 1.0 and 1.3 met. This method is applicable only for the spaces of which average air speeds are equal to or lower than 0.20 $\mathrm{m} / \mathrm{s}$ (40 fpm). In addition, the ASHRAE Standard 55 provides comparable benchmarks for:

- Local thermal discomfort caused by radiant temperature asymmetry, vertical air temperature difference, and floor surface temperature, which is applicable only for occupants with clothing insulation less than 0.7 clo and metabolic rates below 1.3 met; and

- Temperature variations with time (i.e., cyclic and drift temperature variations).

On the other hand, the ACCA Manual RS provides the minimum performance standards for comfort for two different residential applications (i.e., single-zone systems and multi-zone systems), which is based on air temperature and relative humidity, as summarized in Table 2. The ACCA Manual RS's primary focus on air temperature provides reasonable benchmarks for the studies aiming to assess and compare the installed HVAC system's fundamental ability to maintain a certain and uniform temperature throughout the house since most residential HVAC systems are single-zone systems that are configured to control the thermal conditions of the house solely based on air temperature at the thermostat. However, the provided benchmarks developed in 1997 are based on relatively old HVAC systems and houses built 20 years ago, which may not be applicable for today's low-load houses.

In addition to the criteria in Table 2, the ACCA Manual RS provides a discussion with comparable benchmarks in the following areas:

- Thermostat throttling range will be about $\pm 0.6^{\circ} \mathrm{C}\left( \pm 1^{\circ} \mathrm{F}\right)$ for an electronic thermostat and $\pm 1.1^{\circ} \mathrm{C}\left( \pm 2^{\circ} \mathrm{F}\right)$ for a mechanical thermostat.

- Temperature drift near the thermostat due to the largest possible load during extreme weather conditions can occur for about 55 hours during the heating season and 75 hours during the cooling season.

- Ideal air velocity in an occupied zone is about $0.13 \mathrm{~m} / \mathrm{s}$ (25 feet per minute (fpm)), while the minimum air velocity to prevent stagnant air is equal to or greater than 0.08 $\mathrm{m} / \mathrm{s}(15 \mathrm{fpm})$.

- The comfort zones for the neck and ankles to prevent local discomfort due to drafts are defined in terms of air temperature and air velocity.

The manual also provides a discussion on radiant temperature asymmetry and cold floor surface temperature with no explicit benchmarks. However, there is no discussion on cyclic or drift temperature variations. 
Table 2: ACCA Manual RS Minimum Performance Standards for Thermal Comfort (Residential Single-Zone Systems).

\begin{tabular}{|c|c|c|}
\hline Thermal Comfort Item & Heating Season & Cooling Season \\
\hline \multicolumn{3}{|l|}{ Air Temperature } \\
\hline Thermostat setpoint ${ }^{11}$ & $21.1^{\circ} \mathrm{C}\left(70^{\circ} \mathrm{F}\right)$ & $23.9^{\circ} \mathrm{C}\left(75^{\circ} \mathrm{F}\right)$ \\
\hline $\begin{array}{l}\text { Dry-bulb temperature at the thermostat; } \\
\text { or in any conditioned room }\end{array}$ & Thermostat setpoint $\pm 1.1^{\circ} \mathrm{C}\left( \pm 2^{\circ} \mathrm{F}\right)$ & Thermostat setpoint $\pm 1.7^{\circ} \mathrm{C}\left( \pm 3^{\circ} \mathrm{F}\right)$ \\
\hline $\begin{array}{l}\text { Room-to-room or floor-to-floor } \\
\text { temperature difference }\end{array}$ & $\begin{array}{l}\text { Average } 1.1^{\circ} \mathrm{C}\left( \pm 2^{\circ} \mathrm{F}\right) \\
\text { Maximum } 2.2^{\circ} \mathrm{C}\left( \pm 4^{\circ} \mathrm{F}\right)\end{array}$ & $\begin{array}{l}\text { Average } 1.7^{\circ} \mathrm{C}\left( \pm 3^{\circ} \mathrm{F}\right) \\
\text { Maximum } 3.3^{\circ} \mathrm{C}\left( \pm 6^{\circ} \mathrm{F}\right)\end{array}$ \\
\hline Vertical air temperature difference ${ }^{2)}$ & $\begin{array}{l}0.6^{\circ} \mathrm{C}\left(1^{\circ} \mathrm{F}\right) \text { for each } 8.3^{\circ} \mathrm{C}\left(15^{\circ} \mathrm{F}\right) \\
\text { of indoor-outdoor temperature } \\
\text { difference }\end{array}$ & $\begin{array}{l}1.7^{\circ} \mathrm{C}\left(3^{\circ} \mathrm{F}\right) \text { for each } 5.6^{\circ} \mathrm{C}\left(10^{\circ} \mathrm{F}\right) \\
\text { of indoor-outdoor temperature } \\
\text { difference }\end{array}$ \\
\hline \multicolumn{3}{|l|}{ Relative Humidity $(\mathrm{RH})^{3)}$} \\
\hline Maximum RH & $30 \% \mathrm{RH}$ & $55 \% \mathrm{RH}$ at $23.9^{\circ} \mathrm{C}\left(75^{\circ} \mathrm{F}\right)^{4)}$ \\
\hline Minimum $\mathrm{RH}$ & $25 \%$ to $30 \% \mathrm{RH}$ & $25 \%$ to $55 \% \mathrm{RH}$ at $23.9^{\circ} \mathrm{C}\left(75^{\circ} \mathrm{F}\right)^{4)}$ \\
\hline
\end{tabular}

Note:

1) ACCA Manual $\mathrm{J}$ design conditions: $70^{\circ} \mathrm{F}$ with $30 \% \mathrm{RH}$ for the heating season; $75^{\circ} \mathrm{F}$ with $50 \% \mathrm{RH}$ for the cooling season.

2) Temperature variation from 4 inches above the floor to 72 inches above the floor.

3) Humidification is optional for the heating season.

4) ACCA Manual J design conditions. 


\section{METHODOLOGY}

This section describes the methodology used to conduct this research. This research collected one-year of high resolution (i.e., 10-sec or 1-min) data throughout the NIST NZERTF in Gaithersburg, MD from September 2016 to August 2017 along with coincident outdoor weather data. During the analysis period, two different heat pumps that utilize different air distribution systems such as a Conventionally-Ducted Heat Pump (CDHP) and a Small Duct High Velocity (SDHV) system were operated alternately every other week, which provides a unique opportunity for a comparison of systematic performance of the two systems using the same test house under similar weather conditions.

Although the primary interest of this study is the impact of different residential air distribution systems on whole-house thermal comfort, it should be noted that the results may be affected by the differences of the two heat pumps serving different air distribution systems of interest rather than the differences of the two air distribution systems themselves. However, the differences found between the two heat pumps as well as their locations and operations ${ }^{16}$ well represent real-world applications of the two different residential air distribution systems compared in this study.

Section 3.1 presents a description of the NIST NZERTF, including the two heat pump systems that utilize different air distribution systems.

Section 3.2 presents an overview of the thermal comfort and system performance data collection, processing and inspection.

Section 3.3 describes the data analysis methods.

\subsection{NIST NZERTF}

\subsubsection{HOUSE DESCRIPTION}

The NZERTF is a two-story house shown in Figure 1 that has a basement and attic and is similar in size and aesthetics to homes in the surrounding communities. The occupiable floor area consisting of the first floor $(1 \mathrm{~F})$ and the second floor $(2 \mathrm{~F})$ is $242 \mathrm{~m}^{2}\left(2,605 \mathrm{ft}^{2}\right)$. The total floor area of the house, including basement, $1 F, 2 F$, and attic, is $485 \mathrm{~m}^{2}\left(5,221 \mathrm{ft}^{2}\right)$. The house is unoccupied and unfurnished other than permanently installed cabinetry. Despite it being unoccupied, the activities of a family of four (i.e., two adults and two children) were simulated in terms of electrical use (i.e., appliances and lighting), hot water use, and metabolic heat and moisture generation. Details of these control schedules can be found in Omar and Bushby (2013) and Kneifel (2012).

One of the ways the NZERTF achieved its net-zero energy goals was by minimizing heating and cooling loads by installing a well-insulated and tight building envelope. The exterior walls were constructed of wood studs, a fully-adhered membrane applied to plywood sheathing, two layers of polyisocyanurate foam board, fiber cement lap siding, and blow-in

\footnotetext{
16 The main differences between the two heat pumps and their locations and operations are summarized in Section 3.1.2 and Table 3. In addition, the SDHV is operated with a lower supply air temperature for improved dehumidification at low flow rates.
} 
cellulose insulation. The calculated U-factor of the exterior above-grade walls, including framing members, is $0.13 \mathrm{~W} / \mathrm{m}^{2}{ }^{\circ} \mathrm{C}$. The windows are double-hung units with a rated U-factor of $1.14 \mathrm{~W} / \mathrm{m}^{2}{ }^{\circ} \mathrm{C}$. A continuous air barrier system was installed to minimize infiltration, and ventilation was provided by a Heat Recovery Ventilator (HRV). Upon completion of the NZERTF, Pettit et al. (2014) reported the results of the airtightness test, which was 0.55 Air Changes per Hour $(\mathrm{ACH})$ at $50 \mathrm{~Pa}$ with kitchen and dryer vents sealed; and $0.63 \mathrm{ACH}$ at $50 \mathrm{~Pa}$ with kitchen and dryer vents unsealed.

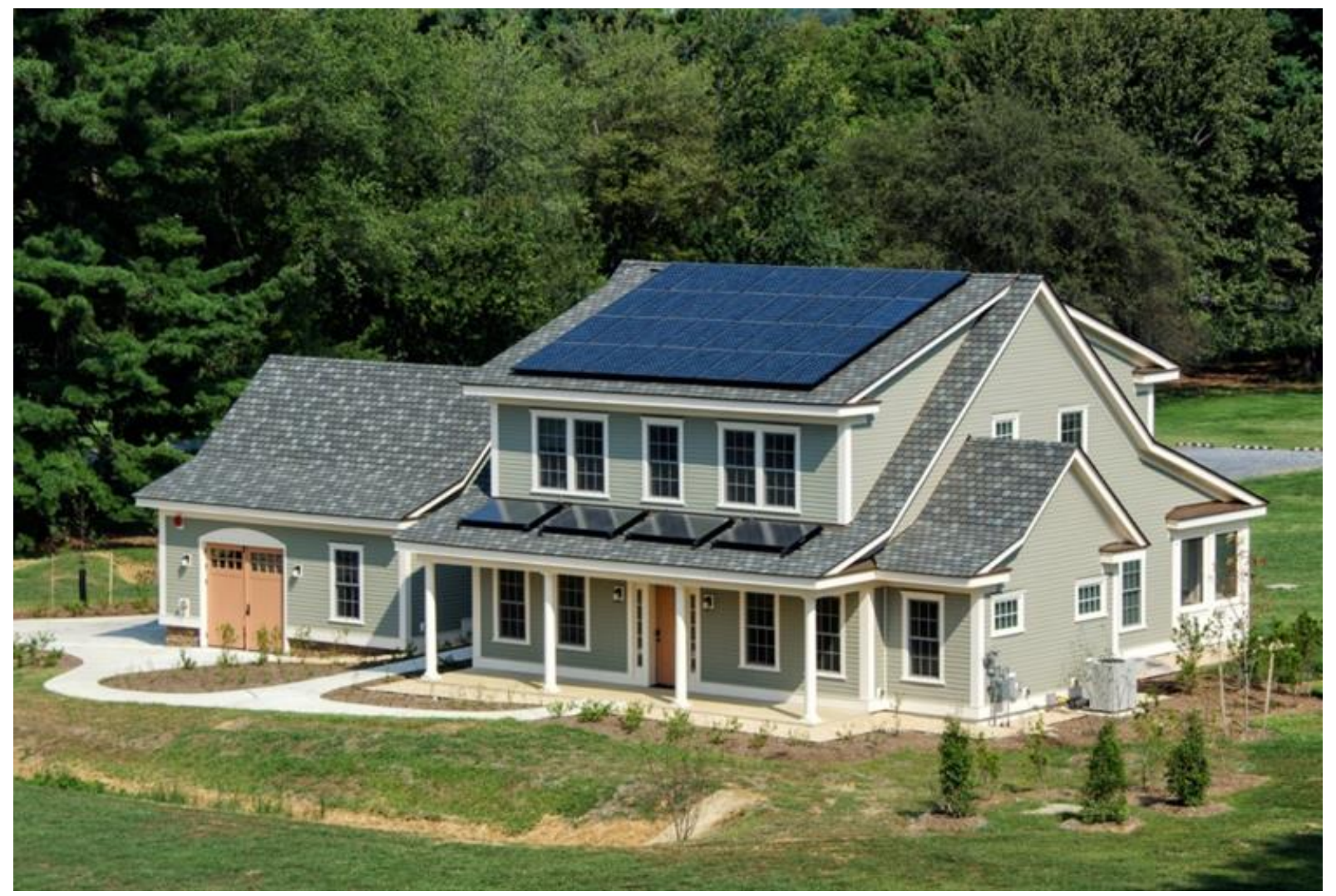

Figure 1: Front View of the NIST NZERTF (South Façade).

\subsubsection{HVAC SYSTEMS}

Other ways that the NZERTF achieved its net-zero energy goals were through the $10.2 \mathrm{~kW}$ photovoltaic (PV) system, high-efficiency air-to-air heat pumps, and a solar hot water system. Both central heat pump systems provide supply air to all floors except the attic. The CDHP has a two-stage compressor and a variable speed indoor blower. The SDHV has a variable speed compressor and variable speed indoor blower.

During the analysis period, the cooling setpoint temperature was $23.8^{\circ} \mathrm{C}\left(75^{\circ} \mathrm{F}\right)$, and the heating setpoint temperature was $21.1^{\circ} \mathrm{C}\left(70^{\circ} \mathrm{F}\right)$ with no setback schedules. The two heat pumps were operated in the heating mode between November 16, 2016 and April 4, 2017, while they were in the cooling mode for any other analysis period. Table 3 summarizes the characteristics of the CDHP and the SDHV installed at NZERTF. During the analysis period, the typical air flow rates delivered by two heat pumps were around $660 \mathrm{cfm}$ for the CDHP and between 150 and $300 \mathrm{cfm}$ for the SDHV. 
Both the CDHP and SDHV ducts are insulated with about R-6 insulation ${ }^{17}$. All ductworks are located within the conditioned space since the fully-adhered membrane air and moisture barrier was applied from the roof down to the foundation. During the analysis period, neither the dedicated dehumidification capability in the CDHP nor the stand-alone whole-house dehumidifier was activated. Passive air transfer grilles connect the basement to the first floor and the attic to the second floor of the house. Air is returned to the heat pump via three return air grilles (i.e., one on the first floor and two on the second floor), which is common for both systems.

A balanced, ducted HRV ${ }^{18}$ system supplies outdoor air to the first-floor living area and three second-floor bedrooms. It draws return air for heat recovery from one bathroom on the first floor and two bathrooms on the second floor. During the analysis period, the HRV was operated on an intermittent schedule (i.e., approximately 40 minutes on and 20 minutes off with an extra on-time in order to account for the start-up time of the supply fan to reach maximum speed) to provide $137 \mathrm{~m}^{3} / \mathrm{h}$ of outdoor air (i.e., $0.09 \mathrm{ACH}$ based on the entire volume of the house, including basement, $1 \mathrm{~F}, 2 \mathrm{~F}$, and attic), which is the minimum ventilation requirements of the ASHRAE Standard 62.2-2010 (ASHRAE 2010) without including any infiltration credit $^{19}$.

Table 3: Summary of the Characteristics of the Two HVAC Systems at NZERTF.

\begin{tabular}{lcc} 
& $\begin{array}{c}\text { CDHP } \\
\text { Two-stage compressor and } \\
\text { variable-speed indoor blower }\end{array}$ & $\begin{array}{c}\text { SDHV } \\
\text { Cooling Capacity }\end{array}$ \\
\hline Heating Capacity & $7.6 \mathrm{~kW}$ & $\begin{array}{c}\text { Variable-speed compressor and } \\
\text { variable-speed indoor blower }\end{array}$ \\
\hline Efficiency & $7.8 \mathrm{~kW}$ at $8.3^{\circ} \mathrm{C}$ & $8.6 \mathrm{~kW}$ \\
\hline Electric resistance heater & $\mathrm{SEER} 4.63 \mathrm{~W} / \mathrm{W}$ & $\mathrm{SEER} 4.10 \mathrm{WW} / \mathrm{W}$ \\
\hline External Static Pressure & $\mathrm{HSPF} 2.65 \mathrm{~W} / \mathrm{W}$ & $\mathrm{HSPF} 2.45 \mathrm{~W} / \mathrm{W}$ \\
\hline Throttling range & $5 \mathrm{~kW}$ & None \\
\hline
\end{tabular}

\footnotetext{
${ }^{17}$ The CDHP ducts are insulated with either $5 \mathrm{~cm}$ (2 inches) of rigid glass fiberboard or flexible glass fiber blanket. ${ }^{18}$ The installed HRV has a maximum airflow delivery rate of $205 \mathrm{~m}^{3} / \mathrm{h}$.

${ }^{19}$ The intermittent schedule for the HRV allowed to reduce the delivered ventilation rate from $205 \mathrm{~m}^{3} / \mathrm{h}$ down to $137 \mathrm{~m}^{3} / \mathrm{h}$ (i.e., a $33 \%$ reduction in delivered airflow), which is the minimum ventilation requirements of the ASHRAE Standard 62.2-2010.
} 


\subsection{THERMAL COMFORT AND SYSTEM PERFORMANCE DATA}

At the NZERTF, sensors were installed throughout the house to monitor the ambient conditions as well as the performance of each particular subsystem in the house. The instrumentation, data acquisition system, and measurement uncertainty associated with the heat pump system, as well as all other electrical/mechanical subsystems within the NZERTF are described in Davis et al. (2014). The measurements from nearly 400 sensors are continuously collected and stored, typically in increments of one minute, and publicly available (NIST 2019).

\subsubsection{DATA COLLECTION}

This study collected detailed building and system performance data and controlled HVAC schedules of NZERTF during the analysis period from September 2016 to August 2017 (i.e., Year 3 NZERTF data). The specific Year 3 NZERTF thermal comfort data collected in this study include:

- 1-min whole-house thermal comfort data; and

- 10 -sec bedroom (BR) 3 thermal comfort data.

The 1-min whole-house thermal comfort data include air temperature (Ta), relative humidity $(\mathrm{RH})$, and globe temperature $(\mathrm{Tg})$ in the center of the selected rooms at approximately $1.4 \mathrm{~m}$ (55 in.) above the floor, as shown in Figure 2. Table 4 lists the measurement parameters and instrumentation used for the whole-house thermal comfort measurements.

Figure 3 shows the rooms selected for whole-house thermal comfort data monitoring with specific variables monitored. All three variables were monitored in primary rooms such as living room (LR), kitchen (KIT), master bedroom (MBR), BR2, and BR3. In the rooms that are not primary habitable but either produce or are near moisture sources such as master bathroom (MBA), attic, and basement (BSMT), two variables (i.e., Ta and $\mathrm{RH}$ ) were monitored ${ }^{20}$. Lastly, only air temperature was monitored in other rooms, including bathroom (BA) 1, BA2, washer and dryer (WD), dining room (DR), BR4, and entry hallway (EH) ${ }^{21}$.

Table 4: Whole-House Thermal Comfort Measurement Parameters and Instrumentation.

\begin{tabular}{|c|c|c|c|c|}
\hline Parameter & Instrumentation & Sensor Type & Range & Accuracy \\
\hline \multicolumn{5}{|c|}{ Whole-House Thermal Comfort Measurements } \\
\hline Air Temperature ( $\mathrm{Ta})$ & Omega & Type T thermocouple & $13^{\circ} \mathrm{C}$ to $30^{\circ} \mathrm{C}$ & $\pm 0.2^{\circ} \mathrm{C}$ \\
\hline Relative Humidity $(\mathrm{RH})$ & $\begin{array}{l}\text { Michell Instruments } \\
\text { WM32-3-XX-HX }\end{array}$ & Capacitive polymer & $\begin{array}{l}0 \% \mathrm{RH} \text { to } \\
100 \% \mathrm{RH}\end{array}$ & $\pm 3 \% \mathrm{RH}$ \\
\hline Globe Temperature (Tg) & Omega & $\begin{array}{l}\text { Type T thermocouple } \\
\text { inside grey ping pong ball }\end{array}$ & $13^{\circ} \mathrm{C}$ to $30^{\circ} \mathrm{C}$ & $\pm 0.2^{\circ} \mathrm{C}$ \\
\hline
\end{tabular}

\footnotetext{
20 The attic and basement air temperatures were monitored at four different locations (i.e., in the middle of each quadrant of the room such as northeast, northwest, southeast, and southwest), while room relative humidity was monitored at one location.

21 The entry hallway air temperature were monitored at the five different levels: the lowest level at a height of 0.6 $\mathrm{m}$ (24 in.); the lower middle level at a height of $1.8 \mathrm{~m}$ (71 in.); the middle level at a height of $3.0 \mathrm{~m}$ (118 in.); the upper middle level at a height of $4.3 \mathrm{~m}$ (169 in.); and the upper level at a height of $5.5 \mathrm{~m}(217 \mathrm{in}$.).
} 


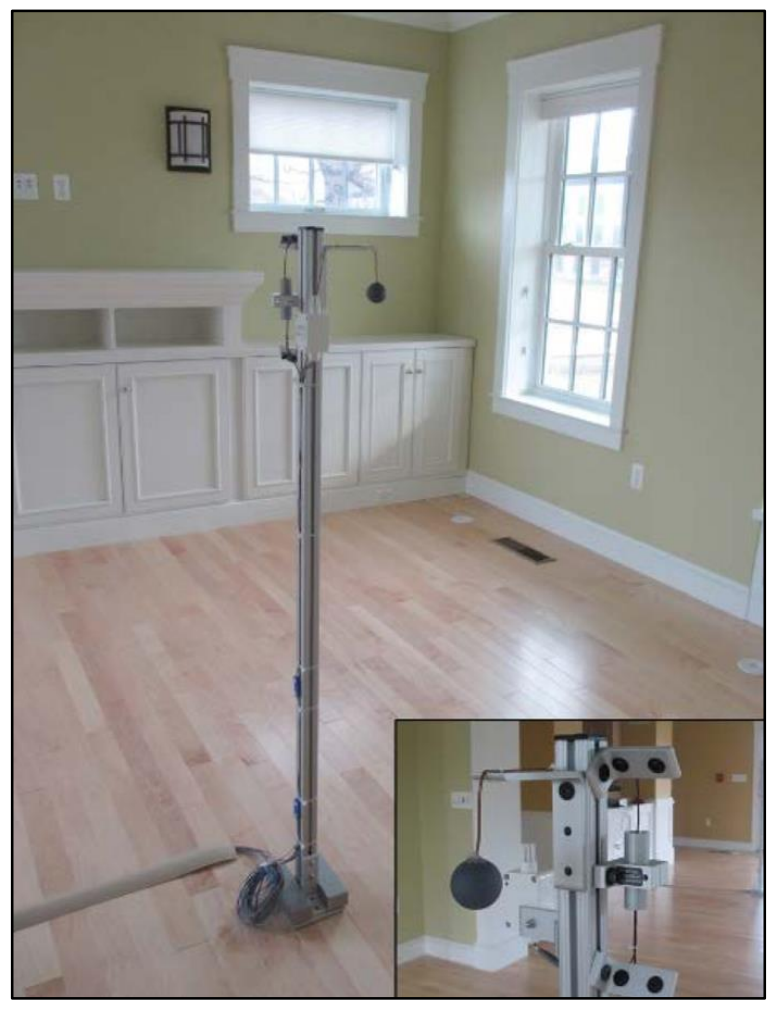

Figure 2: Sensors Mounted on the Metal Stand in the Center of the Room (Davis et al.).

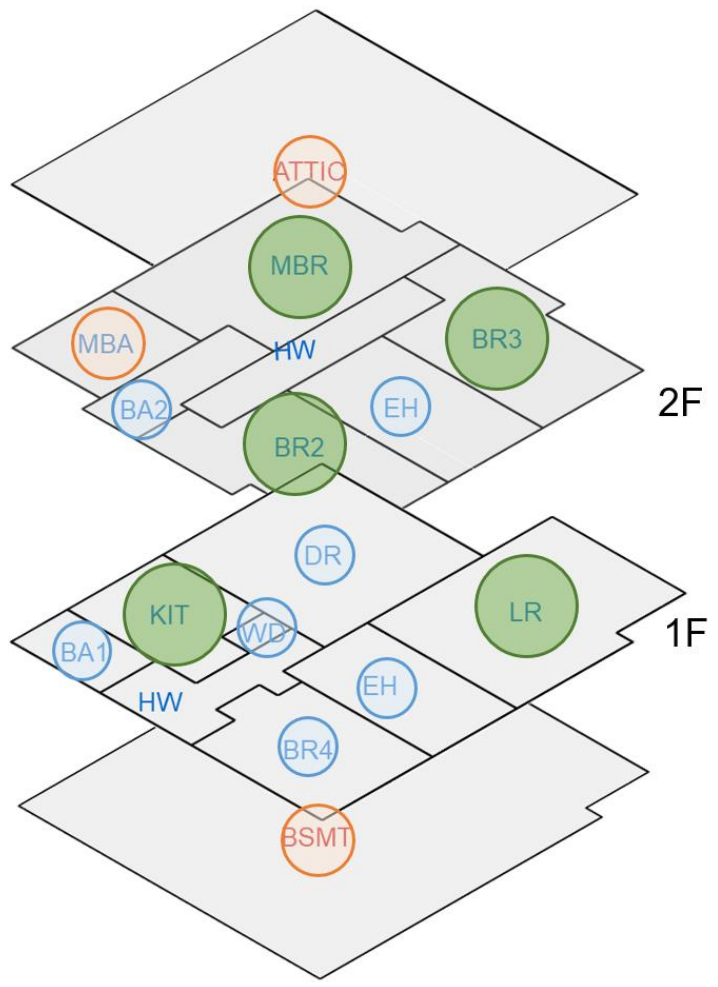

$\bigcirc \mathrm{Ta} / \mathrm{RH} / \mathrm{Tg}$

$\mathrm{Ta} / \mathrm{RH}$

$\mathrm{Ta}$

Figure 3: Rooms Selected for Whole-House Thermal Comfort Data Monitoring. 
The 10-sec BR3 thermal comfort data include the three variables monitored for whole-house thermal comfort (i.e., $\mathrm{Ta}, \mathrm{RH}$, and $\mathrm{Tg}$ ) and air velocity $(\mathrm{Va})$ at the selected measurement points in BR3 based on a $3 \times 3 \times 3$ grid of measurement system (i.e., three different heights at nine locations of the room) as shown in Figures 4 and 5 . The sensor stands were located at the selected nine measurement points as shown in Figures 4 (a) and 5 during the analysis period from September 1, 2016, to August 9, 2017. On August 10, 2017, the sensor stands except the stand 5 were spread out to be closer to the walls, as shown in Figure 4 (b).

Table 5 lists the measurement parameters and instrumentation used for the BR3 thermal comfort measurements. The approximate heights of the sensors were $0.6,1.1$ and $1.7 \mathrm{~m}$ (24, 43 , and $67 \mathrm{in.}$.) above the floor which are the approximate heights of seated and standing adults according to ASHRAE Standard 55-2017 (ASHRAE 2017) ${ }^{22}$ and ASHRAE Standard 1132013 (ASHRAE 2013b) ${ }^{23}$.

In addition to the thermal comfort data, this study collected:

- 3-sec or 10-sec electric power for the indoor and outdoor units of the CDHP and SDHV24;

- 1-min OA temperature and 10-sec OA dew point temperature; and

- Basic building and system characteristics, including as-built architectural and mechanical drawings; and HVAC system operation and event logs.

The collected HP power was used to determine each system's on and off cycling and the season classification as described in Section 6.4. The coincident weather data from nearby National Oceanic and Atmospheric Administration (NOAA) weather stations (NOAA 2019), including Gaithersburg, MD and Washington/Dulles International Airport, VA, were also collected and compared against $O A$ temperature and dew point temperature data collected from NZERTF.

Table 5: BR3 Thermal Comfort Measurement Parameters and Instrumentation.

\begin{tabular}{llllc}
\hline \multicolumn{1}{c}{ Parameter } & \multicolumn{1}{c}{ Instrumentation } & \multicolumn{1}{c}{ Sensor Type } & Range & Accuracy \\
\hline BR3 Thermal Comfort Measurements & & & \\
Air Temperature (Ta) & Omega & Type T thermocouple & $13^{\circ} \mathrm{C}$ to $30^{\circ} \mathrm{C}$ & $\pm 0.2^{\circ} \mathrm{C}$ \\
\hline Relative Humidity (RH) & Michell Instruments & Capacitive polymer & $0 \% \mathrm{RH}$ to & $\pm 2 \% \mathrm{RH}$ \\
\hline Globe Temperature (Tg) & Omega & $100 \% \mathrm{RH}$ & $\pm 2-\mathrm{HX}$ \\
\hline Air velocity (Va) & TSI 8475 & $\begin{array}{l}\text { Type T thermocouple } \\
\text { inside a } 40 \mathrm{~mm} \text { grey ping }\end{array}$ & $13^{\circ} \mathrm{C}$ to $30^{\circ} \mathrm{C}$ & $\pm 0.2^{\circ} \mathrm{C}$ \\
\hline
\end{tabular}

22 The ASHRAE Standard 55-2017 requires to measure air temperature at the 0.1, 0.6, and 1.1 $\mathrm{m}(4,24$, and $43 \mathrm{in}$.)

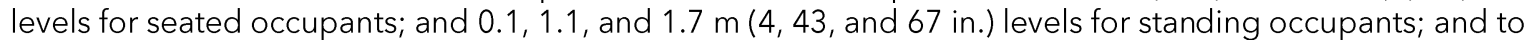
measure or calculate operative temperature or PMV at the $0.6 \mathrm{~m} \mathrm{(24} \mathrm{in.)} \mathrm{level} \mathrm{for} \mathrm{seated} \mathrm{occupants} \mathrm{and} \mathrm{the} 1.1 \mathrm{~m}$ (43 in.) level for standing occupants.

${ }^{23}$ Based on the ASHRAE Standard 113-2013, each measurement position should include temperature measurements at the $0.1,0.6,1.1$, and $1.7 \mathrm{~m}(4,24,43$, and $67 \mathrm{in}$.) levels above the floor.

24 Power for the indoor and outdoor units of the CDHP and SDHV were recorded every three seconds when the unit was in standby and every 10 seconds when the unit was on. 


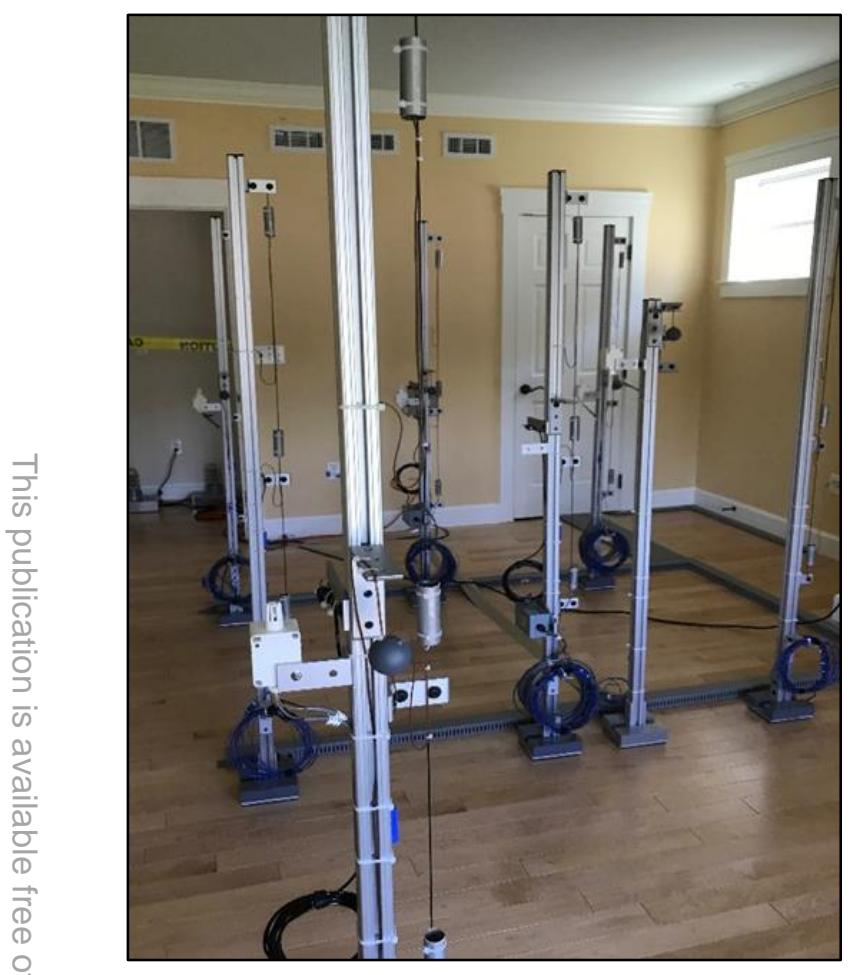

(a) Before August 10, 2017

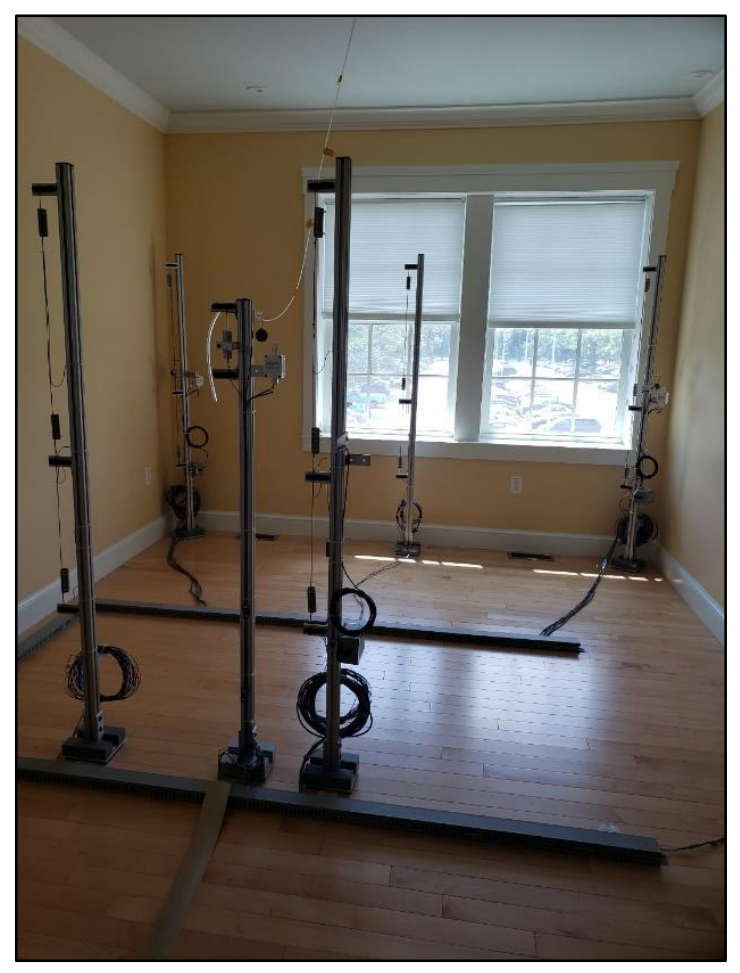

(b) After August 10, 2017

Figure 4: Sensors Mounted on the Metal Stands in BR3.

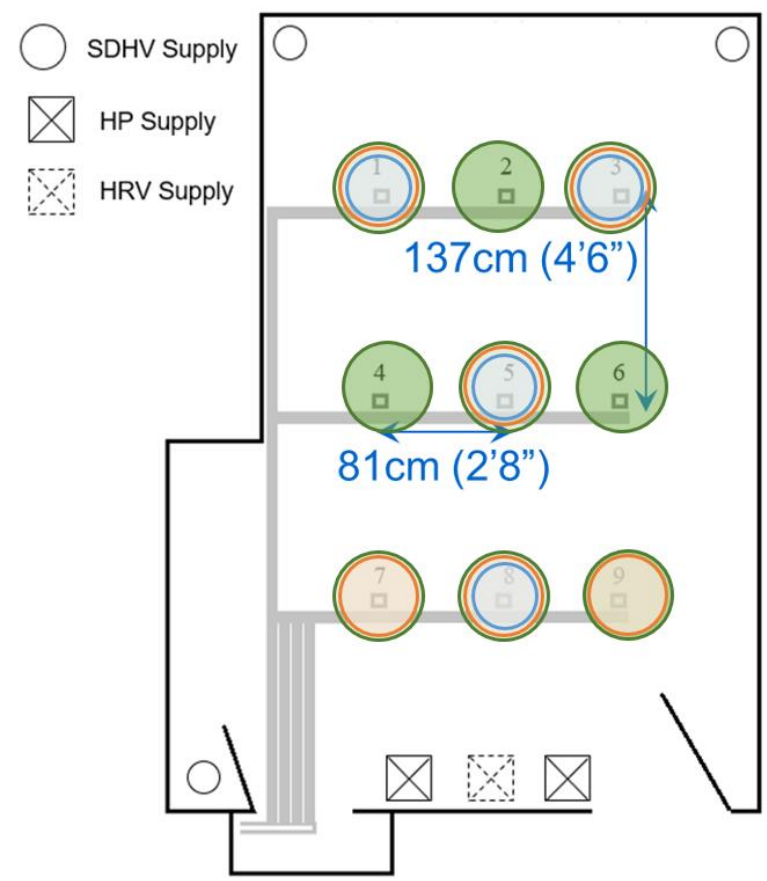

Ta $(0.6 \mathrm{~m}, 1.1 \mathrm{~m}$, and $1.7 \mathrm{~m})$

Added RH/Tg (1.1 m)

Added Va (1.1 m)

Figure 5: Specific Thermal Comfort Variables Monitored at Each Measurement Points based on $3 \times 3 \times 3$ Grid of Measurement System in BR3 (September 12016 to August 9, 2017). 


\subsubsection{DATA PROCESSING AND INSPECTION}

The collected raw data were processed and inspected using a set of data processing templates that were developed to ensure accuracy and consistency in the collected raw data. The data processing templates are capable of filling in short periods of missing data, replacing bad data with -99 , and producing $1-\mathrm{min}, 5$-min average, and hourly average data based on consistent Daylight Saving Time (DST) timestamp.

The processed data were then inspected along with the collected HVAC system operation and event log in order to identify and document any long-term missing data or abnormal/invalid data that must be excluded from the analysis. As a result, this study identified 42 days that should be excluded from the analysis due to operational anomalies of the heat pump system, activities at NZERTF that might affect the collected thermal comfort data, or the Indoor Air Quality (IAQ) testing ${ }^{25}$. Appendix A provides a list of the 42 days with the reasons for exclusion.

The study also identified several data quality issues. For example, disagreement appeared in the collected BR3 room temperature between different data sources (i.e., whole-house vs. BR3 grid measurements). After consultation with the NIST NZERTF team, the 30 temperature data channels were corrected by following the thermocouple correction procedures provided by NIST. Appendix B presents graphical summaries of the recorded (i.e., before correction) and the corrected 1-min whole-house temperature data for the following 30 temperature data channels:

- 24 room air temperatures

- 5 room globe temperatures; and

- 1 outdoor air temperature.

Another data quality issue observed in this study was unexpected data patterns in the collected BR3 air and globe temperature data. After consultation with the NIST NZERTF team, the mislabeled data channels for 27 air temperatures were identified and corrected with proper labels. In addition, the 6 globe temperatures for the measurement locations of stands $1,3,5,7,8$, and 9 in BR3 were corrected with proper calibration factors provided by NIST.

Lastly, the study revealed issues with data accuracy and reliability of the heat pump electricity use data collected from in-house data acquisition system (DAS) and the outdoor air and dew point temperatures collected from the east side of the house near the heat pump outdoor unit, as summarized in Appendix C of this report. After consultation with the NIST NZERTF team, this study decided to use the heat pump electricity use data collected from different data loggers ${ }^{26}$ and the outdoor air temperature data collected from the roof of the house, which reasonable agreed with the outdoor air temperature collected from the NOAA weather station at Washington/Dulles International Airport, VA, along with the outdoor humidity data collected from the same NOAA weather station at Washington/Dulles International Airport, VA.

\footnotetext{
25 The 20 days from October 27, 2016 to November 15, 2016 when Indoor Air Quality (IAQ) testing was taking place were excluded from the analysis.

${ }^{26}$ Each heat pump has a dedicated data logger that collects more variables at the finer sampling interval.
} 


\subsection{DATA ANALYSIS}

The processed 1-min, 5-min average, and hourly average data based on consistent DST timestamp were analyzed to characterize and evaluate the whole-house thermal comfort performance and the potential horizontal and vertical thermal stratification within a single room for the two air distribution systems (i.e., CDHP and SDHV) as installed at NZERTF.

\subsubsection{WHOLE-HOUSE THERMAL COMFORT ANALYSIS}

The whole-house thermal comfort performance was evaluated in terms of:

- Temperature deviation from the set-point temperature (i.e., room-to-thermostat temperature difference);

- Room-to-room temperature difference to evaluate spatial thermal uniformity;

- Cyclic discomfort to evaluate temporal thermal uniformity; and

- Latent performance.

The room temperature deviation from the thermostat setpoint temperature was calculated as room-to-thermostat temperature difference (i.e., $\Delta \mathrm{T}\left({ }^{\circ} \mathrm{C}\right)=$ Troom - Tsetpoint) using the 5-min average room temperature data collected from the five primary rooms (i.e., LR, KIT, MBR, BR2, and BR3) and two additional rooms on the first floor (i.e., DR, and BR4). The percentage distribution of the room-to-thermostat temperature difference was then compared against the ACCA Manual RS benchmarks:

- Thermostat setpoint $\pm 1.67^{\circ} \mathrm{C}\left( \pm 3^{\circ} \mathrm{F}\right)$ for a cooling season; and

- Thermostat setpoint $\pm 1.11^{\circ} \mathrm{C}\left( \pm 2^{\circ} \mathrm{F}\right)$ for a heating season.

To evaluate the spatial thermal uniformity of the two HP systems across the house, the roomto-room temperature difference was calculated using the 5-min average room temperature data collected from the five primary rooms (i.e., LR, KIT, MBR, BR2, and BR3) and two additional rooms on the first floor (i.e., DR, and BR4): $\Delta T\left({ }^{\circ} \mathrm{C}\right)=\operatorname{MAX}($ Troom1, Troom2, ... ) MIN(Troom1, Troom2, ...). The percentage distribution of the room-to-room temperature difference was then compared against the ACCA Manual RS benchmarks:

- $1.67^{\circ} \mathrm{C}\left(3^{\circ} \mathrm{F}\right)$ average and $3.33^{\circ} \mathrm{C}\left(6^{\circ} \mathrm{F}\right)$ maximum for a cooling season; and

- $1.11^{\circ} \mathrm{C}\left(2^{\circ} \mathrm{F}\right)$ average and $2.22^{\circ} \mathrm{C}\left(4^{\circ} \mathrm{F}\right)$ maximum for a heating season.

To evaluate the temporal thermal uniformity of the two HP systems, the cyclic and drift temperature variations with time were calculated using the 1-min operative temperature for the five primary rooms (i.e., LR, KIT, MBR, BR2, and BR3) and the 1-min room air temperature for the two additional rooms on the first floor (i.e., DR, and BR4). The 1-min operative temperature was calculated in accordance with Appendix A of the ASHRAE Standard 552017 to be used in this analysis per Section 5.3.5 of the ASHRAE Standard 55-2017. However, for the DR and BR4 where globe temperature was not measured, the 1-min room air temperature was directly used in this analysis. The percentage of failures in cyclic and drift temperature variations was then calculated based on the ASHRAE Standard 55-2017 benchmarks (ASHRAE 2017):

- $1.1^{\circ} \mathrm{C}\left(2.0^{\circ} \mathrm{F}\right)$ maximum for any 15 -minute period;

- $1.7^{\circ} \mathrm{C}\left(3.0^{\circ} \mathrm{F}\right)$ maximum for any 30 -minute period;

- $2.2^{\circ} \mathrm{C}\left(4.0^{\circ} \mathrm{F}\right)$ maximum for any 1 -hour period;

- $2.8^{\circ} \mathrm{C}\left(5.0^{\circ} \mathrm{F}\right)$ maximum for any 2 -hour period; and 
- $3.3^{\circ} \mathrm{C}\left(6.0^{\circ} \mathrm{F}\right)$ maximum for any 4 -hour period.

To evaluate the latent performance of the two HP systems, a statistical characterization of the continuously-measured humidity data was performed, as described below in Section 3.3.3, in addition to an advanced characterization of the observed temporal variation related to outdoor humidity, as described in Section 3.3.4.

\subsection{2. $\quad$ BR3 GRID ANALYSIS}

The potential horizontal and vertical thermal stratification within a single room was evaluated using the BR3 thermal comfort data based on a $3 \times 3 \times 3$ grid of measurement system (i.e., three different heights at nine locations of the room). To evaluate horizontal thermal stratification, the stand-to-stand temperature difference was calculated using the 5-min average temperature data collected from the nine measurement stands: $\triangle \mathrm{T}\left({ }^{\circ} \mathrm{C}\right)=$ MAX(Tstand1, Tstand2, ...) - MIN(Tstand1, Tstand2, ...).

To evaluate vertical thermal stratification within a single room, the temperature differences between $1.7 \mathrm{~m}$ and $0.6 \mathrm{~m}$ (i.e., $\Delta \mathrm{T}_{\text {standing }}\left({ }^{\circ} \mathrm{C}\right)=\mathrm{T} 1.7 \mathrm{~m}-\mathrm{T} 0.6 \mathrm{~m}$ ) and between $1.1 \mathrm{~m}$ and $0.6 \mathrm{~m}$ (i.e., $\Delta T_{\text {seated }}\left({ }^{\circ} \mathrm{C}\right)=\mathrm{T} 1.1 \mathrm{~m}-\mathrm{T} 0.6 \mathrm{~m}$ ) were calculated using the 5 -min average temperature data collected from each measurement location (i.e., stand). The results were then compared against the ASHRAE Standard 55-2017 benchmarks for the vertical air temperature difference:

- $\quad 3^{\circ} \mathrm{C}\left(5.4^{\circ} \mathrm{F}\right)$ for seated occupants (i.e., $1.1 \mathrm{~m}$ head level); and

- $\quad 4^{\circ} \mathrm{C}\left(7.2^{\circ} \mathrm{F}\right)$ for standing occupants (i.e., $1.7 \mathrm{~m}$ head level).

However, it should be noted that the exclusion of an ankle-level height (i.e., $0.1 \mathrm{~m}$ ) in this study was not enough to evaluate the vertical thermal stratification based on the ASHRAE Standard 55-2017. The vertical air temperature difference benchmarks provided in Section 5.3.4.3 of the ASHRAE Standard 55 are intended for the air temperature difference between head level (i.e., $1.1 \mathrm{~m}$ for seated occupants and $1.7 \mathrm{~m}$ for standing occupants) and ankle level (i.e., $0.1 \mathrm{~m}$ ).

Lastly, the air velocity distribution in the occupied zone ${ }^{27}$ was analyzed using the 5-min average air velocity data measured at the height of $1.1 \mathrm{~m}$ of the four different locations in the BR3: stands 1, 3, 5, and 8. The results were then compared against the ideal and minimum air velocity of the ACCA Manual RS, which is $0.13 \mathrm{~m} / \mathrm{s}(25 \mathrm{fpm})$ and $0.08 \mathrm{~m} / \mathrm{s}$ (15 fpm), respectively; and the maximum air velocity limit of the ASHRAE Standard 55-2017 to use the PMV-based comfort zone method, which is $0.20 \mathrm{~m} / \mathrm{s}$ ( $40 \mathrm{fpm}$ ).

\subsubsection{STATISTICAL CHARACTERIZATION}

In addition, this study performed a statistical characterization of the continuously-measured long-term thermal comfort data not only for the primary rooms but also for the attic and the basement that are thermally important due to possible heat transfer from/to the primary

\footnotetext{
27 The occupied zone is defined to be $2 \mathrm{ft}$. inward from each of the room's walls and ceilings based on the ACCA Manual RS (ACCA 1997); or between the floor and $6 \mathrm{ft}$. above the floor and more than $3.3 \mathrm{ft}$. from outside walls/windows or fixed HVAC equipment, and $1 \mathrm{ft}$. from internal walls based on the ASHRAE Standard 55-2017 (ASHRAE 2017).
} 
rooms. To accurately characterize and report the extent of thermal comfort performance of the tested HP systems under different outdoor climate conditions, the one-year granular thermal comfort data were divided into the subgroups as follows ${ }^{28}$ :

- By system type and on/off cycle:

- CDHP on cycle

- CDHP off cycle

- SDHV on cycle

- SDHV off cycle

- By seasonal operation mode and actual response under given weather conditions:

- Cooling season

- Heating season

- Transitional season

The descriptive statistics of the thermal comfort data were then calculated for each subgroup, which was also graphically displayed using the graphical index proposed to display longterm thermal comfort data and compared against relevant benchmarks. In the proposed graphical index, multiple percentile ranks were selected to characterize extreme variations based on $\pm 1.5 \%, \pm 2.5 \%, \pm 5 \%$ and $\pm 10 \%$ deviations ${ }^{29}$. For example, the $1.5^{\text {th }}$ and $98.5^{\text {th }}$ percentiles were chosen to characterize data based on $\pm 1.5 \%$ deviation, which corresponds to $3 \%$ of the period in total. In the same way, the $2.5^{\text {th }}$ and $97.5^{\text {th }}$ percentiles were chosen based on $\pm 2.5 \%$ deviation (i.e., $5 \%$ of the period in total), the $5^{\text {th }}$ and $95^{\text {th }}$ percentiles were chosen based on $\pm 5 \%$ deviation (i.e., $10 \%$ of the period in total), and the $10^{\text {th }}$ and $90^{\text {th }}$ percentiles were chosen based on $\pm 10 \%$ deviation (i.e., $20 \%$ of the period in total).

\subsubsection{ADVANCED CHARACTERIZATION}

To better understand the observed temporal variations of the long-term thermal comfort data, which was revealed from a statistical analysis, this study performed an advanced characterization of the measured thermal comfort data related to the outdoor climate and the time of the day.

First, this study characterized variations of the measured thermal comfort data related to outdoor climate using a $5^{\circ} \mathrm{C}\left(9^{\circ} \mathrm{F}\right)$ binned quartile analysis, which also allowed a weathernormalized characterization and comparison of the impact of the two tested systems on thermal comfort. To accomplish this, the 5-min average air temperatures measured in each room were characterized using the modified binned box-and-whisker plots, as further discussed in Section 6.3, for four different HVAC system modes (i.e., CDHP on, CDHP off, SDHV on, and SDHV off), where the $1.5^{\text {th }}, 2.5^{\text {th }}, 5^{\text {th }}, 10^{\text {th }}, 25^{\text {th }}, 50^{\text {th }}, 75^{\text {th }}, 90^{\text {th }}, 95^{\text {th }}, 97.5^{\text {th }}$, and $98.5^{\text {th }}$ percentiles, as well as minimum, mean, and maximum values, were arranged against outdoor temperatures binned into $5^{\circ} \mathrm{C}\left(9^{\circ} \mathrm{F}\right)$ bins.

Another characterization performed in this study was a time-of-day analysis of the hourly average room temperature data, which was performed based on the ASHRAE Research Project 1093 Diversity Factor procedure (Abushakra et al. 2001) as well as a time-of-day colored map (i.e., heat map). In the first method using the ASHRAE Diversity Factor procedure, the $10^{\text {th }}, 25^{\text {th }}, 50^{\text {th }}, 75^{\text {th }}$, and $90^{\text {th }}$ percentiles, as well as minimum, mean, and

\footnotetext{
${ }^{28}$ A detailed explanation of the proposed data decomposition is provided in Section 6.4.

${ }^{29}$ An additional discussion on the proposed graphical index is provided in Section 6.3.
} 
maximum values, were reported for each hour of the day, which was also graphically displayed.

Lastly, this study also explored a graphical analysis of thermal comfort data using the psychrometric chart and trend animation, which allowed a quick characterization and analysis of granular thermal comfort data.

\subsubsection{BENCHMARKING}

To gain more general insights on the thermal comfort performance of residential air distribution systems in terms of their fundamental ability to produce and deliver a setpoint temperature to multiple rooms in a house, the results from the NZERTF were compared with four field studies that also measured the performance of a SDHV with a focus on thermal uniformity, including Baskin and Vineyard (2003), Poerschke et al. (2016), Poerschke (2017) and Martin et al. (2018) ${ }^{30}$, as well as one study by Poerschke and Beach (2016) collected relatively large field data from the 36 high-performance occupied houses.

The benchmarking efforts performed in this study include:

- Spatial thermal uniformity analysis

- Average room-to-room temperature difference with two benchmarks by Baskin and Vineyard (2003) and Poerschke et al. (2016)

- Percentage of failures in room-to-room temperature difference with one benchmark by Poerschke et al. (2016)

- Percentage of failures in room-to-thermostat temperature difference with two benchmarks by Poerschke (2017) and Martin et al. (2018)

- Average vertical temperature difference with one benchmark by Baskin and Vineyard (2003)

- Temporal thermal uniformity analysis

- Percentage of failures in cyclic and drift temperature variations with one benchmark by Poerschke (2017)

- Graphical comparison

- Room-to-room temperature difference graphically using cumulative percentage with one benchmark by Poerschke and Beach (2016)

30 Detailed reviews of each study are provided in Section 2.1, including Table 1 summarizing details on the test house and data. 


\section{WHOLE-HOUSE THERMAL COMFORT ANALYSIS}

This section presents a detailed analysis of the whole-house thermal comfort data to characterize and evaluate the whole-house thermal comfort performance of the two air distribution systems as installed at NZERTF.

Section 4.1 presents the results of a room temperature deviation analysis from the set-point temperature based on the room-to-thermostat temperature difference.

Section 4.2 presents the results of a room-to-room temperature difference analysis performed to evaluate the spatial thermal uniformity of the two HP systems.

Section 4.3 presents the results of a cyclic discomfort analysis performed to evaluate the temporal thermal uniformity of the two HP systems.

Section 4.4 presents a statistical characterization of the continuously-measured long-term room temperature data.

Section 4.5 presents an advanced characterization of the continuously-measured long-term room temperature data related to the outdoor temperature.

Section 4.6 presents the time-of-day characterization of the continuously-measured longterm room temperature data based on the ASHRAE Research Project 1093 Diversity Factor procedure (Abushakra et al. 2001) and a time-of-day colored map (i.e., heat map).

Section 4.7 presents a statistical and advanced characterization of the continuously-measured long-term room humidity data related to outdoor humidity to evaluate the latent performance of the two HP systems.

Section 4.8 presents a graphical analysis of the thermal comfort data using the psychrometric chart.

\subsection{TEMPERATURE DEVIATION FROM THE SETPOINT TEMPERATURE}

Tables 6 (cooling mode) and 7 (heating mode) present the percentage distributions of the 5min average room-to-thermostat temperature difference with the number of data points $(n)$ that were grouped based on a degree of temperature difference $(\Delta T)$ as follows:

- $\quad \Delta \mathrm{T}$ above $1.67^{\circ} \mathrm{C}\left(3^{\circ} \mathrm{F}\right)$;

- $\Delta \mathrm{T}$ from $1.11^{\circ} \mathrm{C}$ to $1.67^{\circ} \mathrm{C}\left(2^{\circ} \mathrm{F}\right.$ to $\left.3^{\circ} \mathrm{F}\right)$;

- $\Delta \mathrm{T}$ from $0.56^{\circ} \mathrm{C}$ to $1.11^{\circ} \mathrm{C}\left(1^{\circ} \mathrm{F}\right.$ to $\left.2^{\circ} \mathrm{F}\right)$;

- $\quad \Delta \mathrm{T}$ from $0^{\circ} \mathrm{C}$ to $0.56^{\circ} \mathrm{C}\left(0^{\circ} \mathrm{F}\right.$ to $\left.1^{\circ} \mathrm{F}\right)$;

- $\Delta \mathrm{T}$ from $-0.56^{\circ} \mathrm{C}$ to $0^{\circ} \mathrm{C}\left(-1^{\circ} \mathrm{F}\right.$ to $\left.0^{\circ} \mathrm{F}\right)$;

- $\quad \Delta \mathrm{T}$ from $-1.11^{\circ} \mathrm{C}$ to $-0.56^{\circ} \mathrm{C}\left(-2^{\circ} \mathrm{F}\right.$ to $\left.-1^{\circ} \mathrm{F}\right)$;

- $\quad \Delta \mathrm{T}$ from $-1.67^{\circ} \mathrm{C}$ to $-1.11^{\circ} \mathrm{C}\left(-3^{\circ} \mathrm{F}\right.$ to $\left.-2^{\circ} \mathrm{F}\right)$; and

- $\Delta \mathrm{T}$ below $-1.67^{\circ} \mathrm{C}\left(-3^{\circ} \mathrm{F}\right)$.

In these tables, the relevant ACCA Manual RS benchmarks (i.e., thermostat setpoint $\pm 1.67^{\circ} \mathrm{C}$ $\left( \pm 3^{\circ} \mathrm{F}\right)$ for a cooling season; and thermostat setpoint $\pm 1.11^{\circ} \mathrm{C}\left( \pm 2^{\circ} \mathrm{F}\right)$ for a heating season) are also presented for comparison. The groups meeting the ACCA benchmarks were highlighted 
in green, while the groups unfavorably exceeding the ACCA benchmarks (i.e., $\triangle T$ above $1.67^{\circ} \mathrm{C}$ in the cooling mode and $\Delta \mathrm{T}$ below $-1.11^{\circ} \mathrm{C}$ in the heating mode) were highlighted in red. The same results are also graphically presented in Figures 6 (cooling mode) and 7 (heating mode), which are comprised of color-coded bars: dark blue bars for the CDHP and orange bars for the SDHV.

\subsubsection{COOLING MODE RESULTS}

Important observations on the room-to-thermostat temperature difference during the cooling mode (Table 6 and Figure 6) are:

- Rooms on the first floor (i.e., LR, KIT, DR, and BR4)

- The compliance percentages of the CDHP for the rooms on the first floor varied from $88.9 \%$ (KIT) to $93.7 \%$ (BR4) of the period, which was higher than the compliance percentages of the SDHV from $81.8 \%$ (KIT) to $87.3 \%$ (BR4) of the period.

- The first-floor room-to-thermostat temperature differences were mostly on the low side (i.e., $\triangle \mathrm{T}$ below $0^{\circ} \mathrm{C}$ ), which is clearer in Figure 6. There were no occasions when the room-to-thermostat temperature difference unfavorably exceeded the ACCA cooling benchmarks (i.e., $\triangle T$ above $1.67^{\circ} \mathrm{C}$ ) in the first-floor rooms.

- However, the non-compliance percentages of the first-floor rooms on the low side (i.e., $\triangle \mathrm{T}$ below $-1.67^{\circ} \mathrm{C}$ ) varied from $6.3 \%$ (BR4) to $11.1 \%(\mathrm{KIT})$ of the period with the CDHP and from $12.7 \%$ (BR4) to $18.2 \%$ (KIT) of the period with the SDHV. A further investigation using the data decomposed by three seasons (i.e., cooling, heating, and transitional seasons) revealed that this low-side deviation mostly occurred during the swing season when the system was off cycle due to favorable weather conditions (i.e., cool OA temperature) except the kitchen, which is discussed in Section 4.1.3.

- In the kitchen, the observed high percentages of low-side deviations were affected by possible evaporative cooling effect from the two humidifiers that were operated to emulate latent heat generation and located near the measurement stand in the kitchen until July 14, 2017. A further investigation comparing the cooling data before versus after July 14, 2017, when the kitchen measurement stand was moved further from the humidifiers ${ }^{31}$ confirmed this evaporative cooling effect causing lower temperature readings in the kitchen. For example, out of 5,544 data points that were categorized as the group with $\Delta \mathrm{T}$ below $-1.67^{\circ} \mathrm{C}$, only 19 data points (i.e., equivalent to 1.6 hours) occurred after July 14, 2017.

- Rooms on the second floor (i.e., MBR, BR2, and BR3)

- For the rooms on the second floor, the compliance percentages in total were comparable between the two systems, which varied from 93.9\% (MBR) to $97.1 \%$ (BR3) of the period with the CDHP and from 96.1\% (BR3) to $97.6 \%$ (BR2) of the period with the SDHV.

- However, the CDHP room-to-thermostat temperature differences tended to be on the high side (i.e., warmer room temperature) compared to the SDHV, which is clearer in Figure 6.

\footnotetext{
31 The kitchen measurement stand was moved from the edge of the kitchen island facing the two humidifiers to the center of the island on July 14, 2019.
} 
- There were also occasions when the room-to-thermostat temperature difference unfavorably exceeded the ACCA cooling benchmarks (i.e., $\triangle T$ above $1.67^{\circ} \mathrm{C}$ ) in the second-floor bedrooms. The maximum deviation occurred in MBR: $3.5 \%$ of the period with the CDHP and $1.8 \%$ of the period with the SDHV. A further investigation revealed that this deviation consistently occurred during the nighttime and between 6 PM to 7 PM, which was affected by heat gains from the simulated internal loads (i.e., occupancy and plug loads) as discussed in Section 4.6.2.

- The lower-side non-compliance percentages (i.e., $\Delta \mathrm{T}$ below $-1.67^{\circ} \mathrm{C}$ ) were much smaller in the second-floor rooms compared to the deviations observed in the first-floor rooms.

\subsubsection{HEATING MODE RESULTS}

Important observations on the room-to-thermostat temperature difference during the heating mode (Table 7 and Figure 7) are:

- Comparison of the cooling mode results

- The compliance percentages during the heating mode were consistently smaller than the deviation observed in the cooling mode with the CDHP. However, when the SDHV was in operation, the compliance percentages were higher in the firstfloor rooms (except the kitchen) but smaller in the second-floor rooms compared to the cooling mode. The kitchen had the lowest compliance percentages for both systems: $76.2 \%$ of the period with the CDHP and $78.4 \%$ of the period with the SDHV.

- Rooms on the first floor (i.e., LR, KIT, DR, and BR4)

- The compliance percentages of the first-floor rooms except the kitchen varied from $87.2 \%$ (BR4) to $91.6 \%$ (LR) of the period with the CDHP and from $94.6 \%$ (BR4) to $97.0 \%(L R)$ of the period with the SDHV.

- Like the cooling mode, the first-floor room-to-thermostat temperature differences tended to be on the low side (i.e., $\Delta \mathrm{T}$ below $0^{\circ} \mathrm{C}$ ) though to a lesser extent during the heating mode. There were also occasions when the room-to-thermostat temperature difference unfavorably exceeded the ACCA heating benchmarks (i.e., $\Delta \mathrm{T}$ below $-1.11^{\circ} \mathrm{C}$ ) in the first-floor rooms especially when the CDHP was in operation: $2.1 \%(\mathrm{LR}), 18.8 \%$ (KIT), $2.8 \%$ (DR) and 3.1\% (BR4). A further investigation, as presented in Section 4.6.2, revealed that this deviation occurred over two days (i.e., mostly on December 16, 2016 32 and February 10, 2017) when the CDHP's electric resistance backup heater stayed off although the LR temperature was below the heating setpoint temperature.

- Similar to the cooling mode results, the kitchen had high non-compliance percentages on the low side regardless of the type of system, which was affected by the evaporative cooling effect from the two humidifiers located near the kitchen measurement stand during the entire heating season.

- The non-compliance percentages of the first-floor rooms on the high side (i.e., $\Delta T$ above $1.67^{\circ} \mathrm{C}$ ) varied from $5.0 \%$ (LR) to $9.7 \%$ (BR4) of the period with the CDHP and from $2.2 \%$ (KIT) to $5.4 \%$ (BR4) of the period with the SDHV. Like the cooling

\footnotetext{
32 December 16, 2016 was the day when the lowest OA temperature of the analysis period occurred, which was $10.4^{\circ} \mathrm{C}$.
} 
mode results, a further investigation using the data decomposed by three seasons (i.e., cooling, heating, and transitional seasons) revealed that this high-side

deviation mostly occurred during the swing season when the system was off cycle due to favorable weather conditions (i.e., warm OA temperature), which is discussed in Section 4.1.3.

- Rooms on the second floor (i.e., MBR, BR2, and BR3)

- For the rooms on the second floor, the compliance percentages of the CDHP varied from $77.1 \%$ (BR2) to $83.6 \%$ (MBR) of the period, which was lower than the compliance percentages of the SDHV from $81.0 \%$ (BR2) to $87.1 \%$ (MBR) of the period.

- Unlike the cooling mode results, the compliance percentage of the second-floor rooms were lower than the compliance percentages of the first-floor rooms along with higher non-compliance percentages on the high side (i.e., $\Delta T$ higher than $1.11^{\circ} \mathrm{C}$ ). This occurred partly due to favorable weather conditions, but the greater high-side non-compliance percentages of the second-floor bedrooms can be explained by natural stratification of warm air in addition to favorable weather conditions.

- There were also occasions when the room-to-thermostat temperature difference unfavorably exceeded the ACCA heating benchmarks (i.e., $\Delta T$ below $-1.11^{\circ} \mathrm{C}$ ) in the second-floor rooms, which were less than $2 \%$ of the period and occurred mostly when the CDHP was in operation. Like the first-floor rooms, a further investigation, as presented in Section 4.6.2, revealed that this deviation occurred mostly on December 16, 2016. December 16, 2016 was the day when the lowest OA temperature of the analysis period occurred, which was $-10.4^{\circ} \mathrm{C}$. However, the CDHP's electric resistance backup heater stayed off although the LR temperature was below the heating setpoint temperature.

\subsubsection{RESULTS BY SEASON}

As discussed in Sections 4.1.1 and 4.1.2., there were occasions when the HP systems did not necessarily provide cooling or heating while maintaining room temperatures way below cooling setpoint temperature during the cooling mode; or above heating setpoint temperature during the heating mode, which naturally occurred due to favorable weather conditions rather than a result of the system's undesirable overcooling or overheating ${ }^{33}$. The inclusion of these periods in the analysis may not allow accurate characterization of room-tothermostat temperature deviation, which resulted in higher non-compliance percentages of low-side deviation in the cooling mode and high-side deviation in the heating mode.

Accordingly, for a more accurate characterization and benchmarking of room-to-thermostat temperature deviation based on long-term measurements, this study defined transitional season based on coincident daily average outdoor air (OA) temperature to reflect the system's actual response under given weather conditions in addition to the HP system's seasonal operation mode set by a user (i.e., cooling mode or heating mode). In this proposed classification, if the tested HPs were operated in the heating mode between November 16, 2016 and April 4, 2017, the days when the daily average $\mathrm{OA}$ temperature was below $11.2^{\circ} \mathrm{C}$

\footnotetext{
33 In actual homes, residents are likely to switch their system from one mode to the other mode as needed under these conditions, which did not happen in this occupancy-simulated house.
} 
$\left(52.2^{\circ} \mathrm{F}\right)$ were considered the heating season, while the days when the daily average OA temperature was above $11.2^{\circ} \mathrm{C}\left(52.2^{\circ} \mathrm{F}\right)$ were considered the transitional season. If the tested HPs were operated in the cooling mode between September 1, 2016 and November 15, 2016 and between April 5, 2017 to August 31, 2017, the days when the daily average OA temperature was above $15.5^{\circ} \mathrm{C}\left(60.0^{\circ} \mathrm{F}\right)$ were considered the cooling season, while the days when the daily average $\mathrm{OA}$ temperature was below $15.5^{\circ} \mathrm{C}\left(60.0^{\circ} \mathrm{F}\right)$ were considered the transitional season. $11.2^{\circ} \mathrm{C}\left(52.2^{\circ} \mathrm{F}\right)$ and $15.5^{\circ} \mathrm{C}\left(60.0^{\circ} \mathrm{F}\right)$ were the actual heating and cooling change-point temperatures of the HP electricity use regression model as presented in Section 6.4 .

Tables 8 to 10 present the percentage distributions of the 5 -min average room-to-thermostat temperature difference recalculated by the season as defined above: cooling season (Table 8), heating season (Table 9), and transitional season (Table 10). The same results are also graphically presented in Figures 8 to 10, which are comprised of color-coded bars: dark blue bars for the CDHP and orange bars for the SDHV.

As a result, it was found that the non-compliance percentages of low-side deviation in the cooling mode and high-side deviation in the heating mode due to mild weather conditions could be separately analyzed as the transitional season with this new proposed data decomposition. For example, the non-compliance percentages of low-side deviation in the living room decreased from $7.5 \%$ (cooling mode) to $1.5 \%$ (cooling season) of the period with the CDHP and from $15.8 \%$ (cooling mode) to $8.2 \%$ (cooling season) of the period with the SDHV. The kitchen still had the highest percentages of low-side deviation, though to a lower extent compared to the cooling mode results: i.e., from $11.1 \%$ (cooling mode) to $5.3 \%$ (cooling season) of the period with the CDHP and from 18.2\% (cooling mode) to $13.5 \%$ of the period (cooling season) with the SDHV. As discussed above, this occurred due to the evaporative cooling effect from the two humidifiers.

The non-compliance percentages of high-side deviation in the heating mode also decreased. For example, in the living room, the percentages decreased from $6.3 \%$ (heating mode) to $1.3 \%$ (heating season) of the period with the CDHP and from $3.0 \%$ (heating mode) to $0.3 \%$ (heating season) of the period with the SDHV. The second-floor bedrooms still had relatively high percentages of high-side deviation, though to a lesser extent compared to the heating mode results. This can be explained mostly by natural stratification of warm air.

Lastly, during the transitional season, as shown in Table 10 and Figure 10, the compliance percentages of the CDHP based on the ACCA Manual RS cooling benchmarks were consistently higher in the first-floor rooms but lower in the second-floor bedrooms compared to the compliance percentages of the SDHV. Although relatively high percentages of both low-side and high-side deviations were observed, a further investigation revealed that the systems were mostly off cycle during the transitional season, which means the observed deviations did not occur due to the system's undesirable overcooling or overheating. Accordingly, the noted room-to-thermostat deviations against the ACCA benchmarks during the transitional season should not be used to evaluate the installed system's ability to produce and deliver a certain temperature to multiple occupied spaces as installed in the house. 
Table 6: Summary of the 5-Min Average Room-To-Thermostat Temperature Differences for the Cooling Mode.

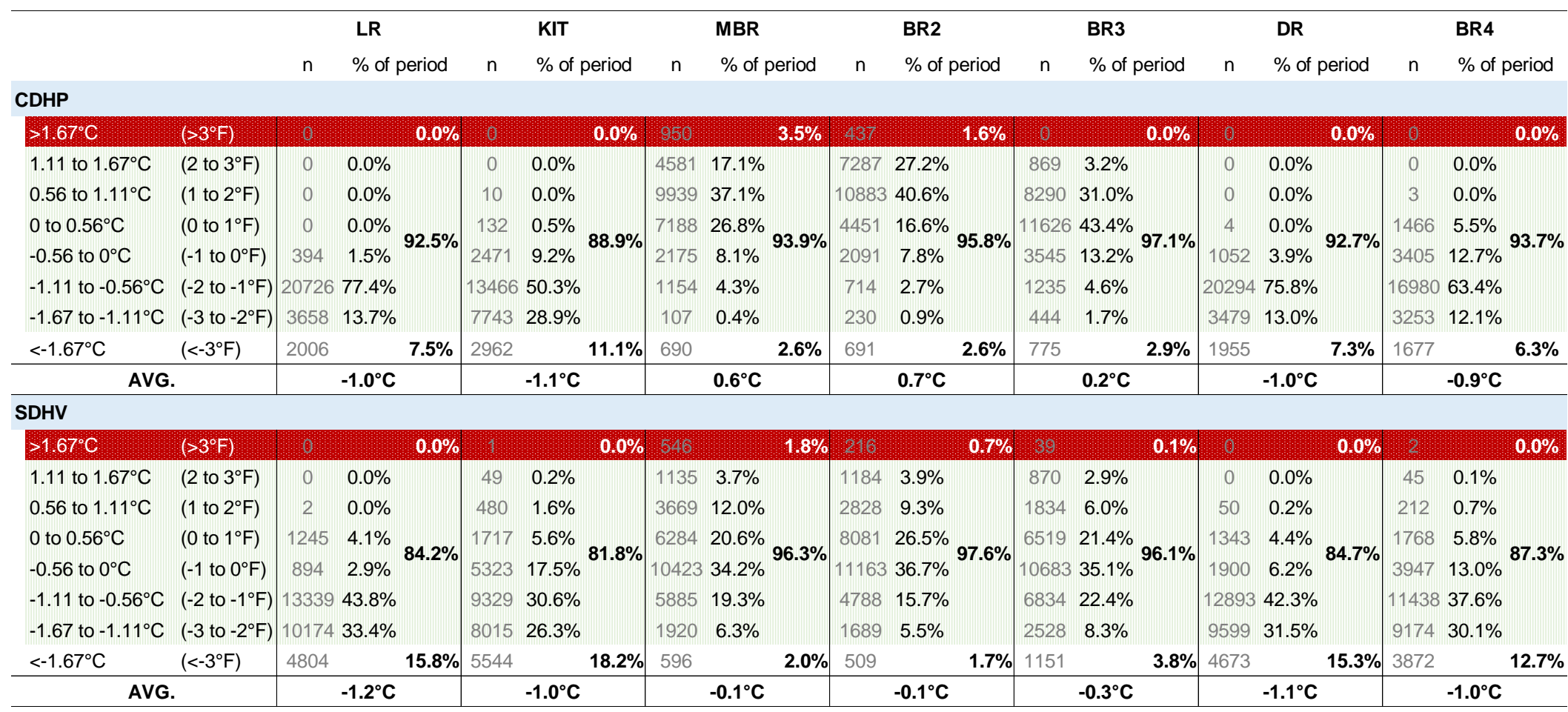

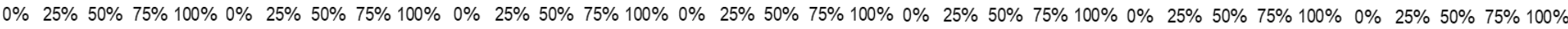
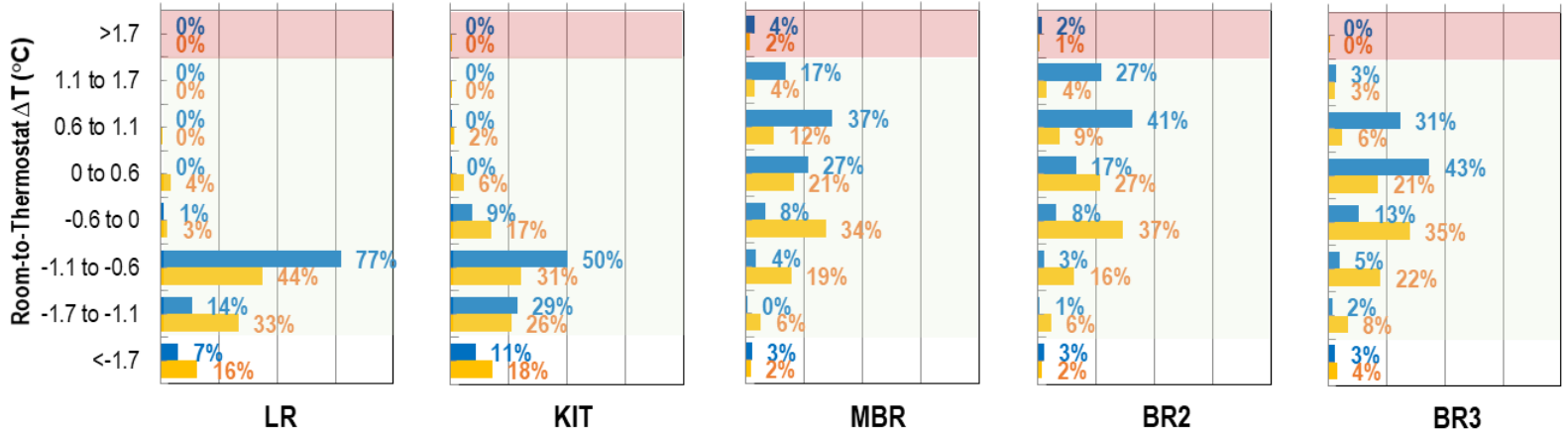

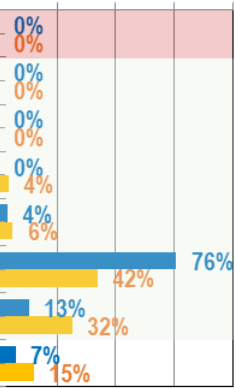

DR

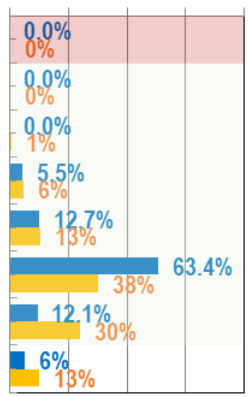

BR4

Figure 6: Graphical Summaries of the 5-Min Average Room-To-Thermostat Temperature Differences for the Cooling Mode. 
Table 7: Summary of the 5-Min Average Room-To-Thermostat Temperature Differences for the Heating Mode.

\begin{tabular}{|c|c|c|c|c|c|c|c|c|c|c|c|c|c|c|c|}
\hline & & \multicolumn{2}{|r|}{ LR } & \multicolumn{2}{|r|}{ KIT } & \multicolumn{2}{|r|}{ MBR } & \multicolumn{2}{|r|}{ BR2 } & \multicolumn{2}{|r|}{ BR3 } & \multicolumn{2}{|r|}{ DR } & \multicolumn{2}{|r|}{ BR4 } \\
\hline & & $\mathrm{n}$ & $\%$ of period & $\mathrm{n}$ & $\%$ of period & $\mathrm{n}$ & $\%$ of period & $\mathrm{n}$ & $\%$ of period & $\mathrm{n}$ & $\%$ of period & $\mathrm{n}$ & $\%$ of period & $\mathrm{n}$ & $\%$ of period \\
\hline \multicolumn{16}{|l|}{ CDHP } \\
\hline$>1.67^{\circ} \mathrm{C}$ & $\left(>3^{\circ} \mathrm{F}\right)$ & 582 & $3.1 \%$ & 510 & $2.7 \% \quad 5.0 \%$ & 1501 & $15.2 \%$ & 2029 & $10.7 \%$ & 1626 & $19.5 \%$ & 604 & $6.5 \%$ & 847 & \\
\hline 1.11 to $1.67^{\circ} \mathrm{C}$ & ( 2 to $\left.3^{\circ} \mathrm{F}\right)$ & 618 & $3.3 \%^{6.3 \%}$ & 441 & $2.3 \%^{5.0 \%}$ & 1393 & $7.3 \%^{15.2 \%}$ & 2145 & $11.3 \%{ }^{22.0 \%}$ & 2079 & $10.9 \%{ }^{19.5 \%}$ & 640 & $3.4 \%{ }^{6.5 \%}$ & 989 & $5.2 \%$ \\
\hline 0.56 to $1.11^{\circ} \mathrm{C}$ & $\left(1\right.$ to $\left.2^{\circ} \mathrm{F}\right)$ & 1416 & \multirow{3}{*}{$91.6 \%$} & 1011 & $5.3 \%$ & 2146 & $11.3 \%$ & 2463 & \multirow{3}{*}{$77.1 \%$} & 2082 & $11.0 \%$ & 1320 & \multirow{3}{*}{$90.7 \%$} & 2020 & $10.6 \%$ \\
\hline 0 to $0.56^{\circ} \mathrm{C}$ & $\left(0\right.$ to $\left.1^{\circ} \mathrm{F}\right)$ & 3527 & & 2454 & $12.9 \%$ & 4144 & $21.8 \%$ & 3972 & & 3936 & $20.7 \%$ & 3456 & & 3470 & $18.3 \%$ \\
\hline-0.56 to $0^{\circ} \mathrm{C}$ & $\left(-1\right.$ to $\left.0^{\circ} \mathrm{F}\right)$ & 4077 & & 4918 & $25.9 \%^{7}$ & 6124 & $32.2 \%^{83.6 \%}$ & 5487 & & 5584 & $29.4 \%^{7}$ & 4623 & & 4305 & $22.6 \%^{8}$ \\
\hline-1.11 to $-0.56^{\circ} \mathrm{C}$ & $\left(-2\right.$ to $\left.-1^{\circ} \mathrm{F}\right)$ & 8389 & $44.1 \%$ & 6107 & $32.1 \%$ & 3480 & $18.3 \%$ & 2741 & $14.4 \%$ & 3321 & $17.5 \%$ & 7835 & $41.2 \%$ & 6780 & $35.7 \%$ \\
\hline-1.67 to $-1.11^{\circ} \mathrm{C}$ & $\left(-3\right.$ to $\left.-2^{\circ} F\right)$ & 384 & & 30011 & $15.8 \%$ & 213: & $1.1 \%, 1.2 \%$ & 17 & & 880 & $2.0 \%$ & 102 & & 164 & $2.4 \%$ \\
\hline$<-1.67^{\circ} \mathrm{C}$ & $\left(<-3^{\circ} \mathrm{F}\right)$ & 65 & $0.3 \% \quad 2.1 \%$ & 566 & $3.0 \%$ & 7 & $0.0 \% \quad 1.2 \%$ & (0) & $0.0 \%$ & 角 & $0.0 \%$ & $12: 8$ & $0.7 \% \quad 2.8 \%$ & 148 & $0.8 \%$ \\
\hline \multicolumn{2}{|l|}{ AVG. } & \multicolumn{2}{|r|}{$-0.2^{\circ} \mathrm{C}$} & \multicolumn{2}{|r|}{$-0.4^{\circ} \mathrm{C}$} & \multicolumn{2}{|r|}{$0.2^{\circ} \mathrm{C}$} & \multicolumn{2}{|r|}{$0.4^{\circ} \mathrm{C}$} & \multicolumn{2}{|r|}{$0.3^{\circ} \mathrm{C}$} & \multicolumn{2}{|r|}{$-0.2^{\circ} \mathrm{C}$} & & $-0.1^{\circ} \mathrm{C}$ \\
\hline SDHV & & & & & & & & & & & & & & & \\
\hline$>1.67^{\circ} \mathrm{C}$ & $\left(>3^{\circ} \mathrm{F}\right)$ & 174 & $1.0 \%$ & 137 & $0.8 \%$ & 853 & $5.1 \%$ & $\mid$\begin{tabular}{|l|}
1468 \\
|
\end{tabular} & $8.8 \%$ & 1125 & $6.7 \%$ & 193 & $1.2 \%$ & 367 & $2.2 \%$ \\
\hline 1.11 to $1.67^{\circ} \mathrm{C}$ & $\left(2\right.$ to $\left.3^{\circ} \mathrm{F}\right)$ & 330 & $2.0 \%$ & 223 & $1.3 \%$ & 1302 & $7.8 \%$ & 1700 & $10.2 \%{ }^{19.0 \%}$ & 1513 & $9.1 \%$ & 338 & $2.0 \%$ & 539 & $3.2 \%$ \\
\hline 0.56 to $1.11^{\circ} \mathrm{C}$ & $\left(1\right.$ to $\left.2^{\circ} \mathrm{F}\right)$ & 862 & $5.2 \%$ & 586 & $3.5 \%$ & 4799 & $28.7 \%$ & 4814 & $28.8 \%$ & 3284 & $19.7 \%$ & 753 & $4.5 \%$ & 1470 & $8.8 \%$ \\
\hline 0 to $0.56^{\circ} \mathrm{C}$ & $\left(0\right.$ to $\left.1^{\circ} \mathrm{F}\right)$ & 2385 & $14.3 \%$ & 2291 & $13.7 \%$ & 6345 & $38.0 \%$ & 6627 & $39.7 \%$ & 6141 & $36.8 \%$ & 3019 & $18.1 \%$ & 3399 & $20.3 \%$ \\
\hline-0.56 to $0^{\circ} \mathrm{C}$ & $\left(-1\right.$ to $\left.0^{\circ} \mathrm{F}\right)$ & 7773 & $46.5 \%^{9}$ & 4597 & $27.5 \%$ & 3208 & $19.2 \%$ & 1993 & $11.9 \%^{8}$ & 3884 & $23.3 \%$ & 7258 & $43.5 \%$ & 7107 & $42.5 \%$ \\
\hline-1.11 to $-0.56^{\circ} \mathrm{C}$ & $\left(-2\right.$ to $\left.-1^{\circ} \mathrm{F}\right)$ & 5180 & $31.0 \%$ & 5615 & $33.6 \%$ & 197 & $1.2 \%$ & 102 & $0.6 \%$ & 742 & $4.4 \%$ & 5097 & $30.5 \%$ & 3821 & $22.9 \%$ \\
\hline-1.67 to $-1.11^{\circ} \mathrm{C}$ & $\left(-3\right.$ to $\left.-2^{\circ} F\right)$ & 0 & $0.0 \%$ & 2717 & $16.3 \%$ & (1) & $0.0 \%$ & (0) & $0.0 \%$ & 115 & $0.1 \%$ & $46:$ & $0.3 \%$ & 1. & $0.0 \%$ \\
\hline$<-1.67^{\circ} \mathrm{C}$ & $\left(<-3^{\circ} \mathrm{F}\right)$ & 0 & $0.0 \%$ & $58:$ & $3.2 \%$ & (0) & $0.0 \%$ & (0) & $0.0 \%$ & (e) & $0.0 \%$ & (0) & $0.0 \%$ & (0. & $0.0 \%$ \\
\hline AVG. & & & $-0.2^{\circ} \mathrm{C}$ & & $-0.5^{\circ} \mathrm{C}$ & & $0.5^{\circ} \mathrm{C}$ & & $0.6^{\circ} \mathrm{C}$ & & $0.4^{\circ} \mathrm{C}$ & & $-0.2^{\circ} \mathrm{C}$ & & $-0.1^{\circ} \mathrm{C}$ \\
\hline
\end{tabular}

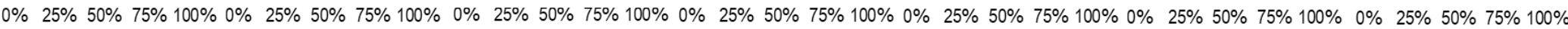
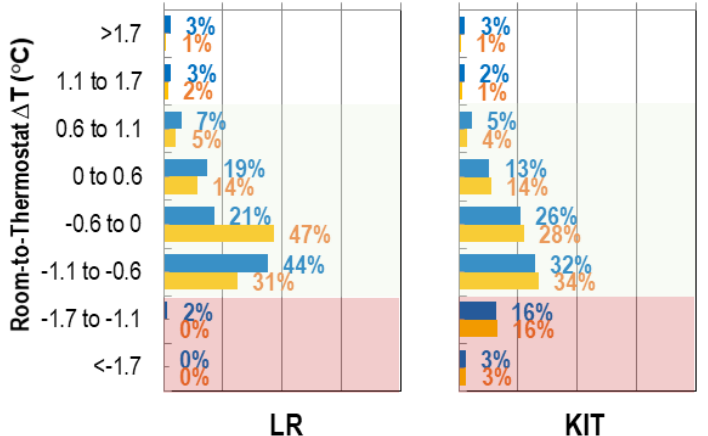

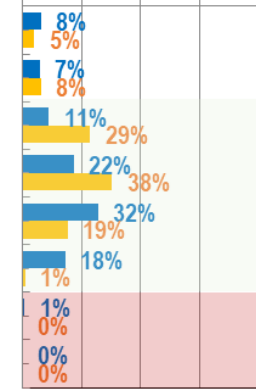

MBR

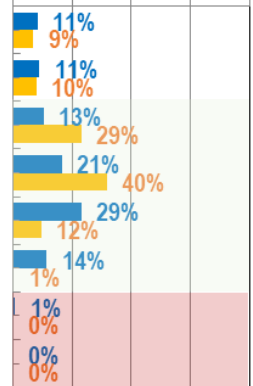

BR2

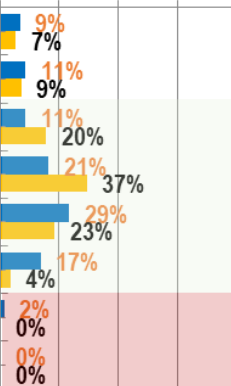

BR3

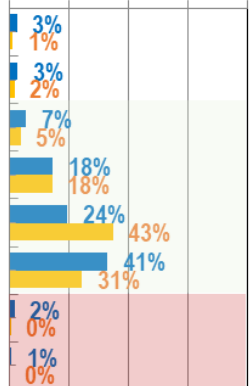

DR

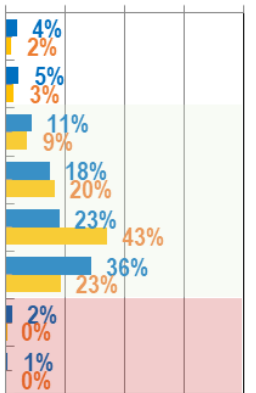

BR4

Figure 7: Graphical Summaries of the 5-Min Average Room-To-Thermostat Temperature Differences for the Heating Mode. 
Table 8: Summary of the 5-Min Average Room-To-Thermostat Temperature Differences for the Cooling Season.

\begin{tabular}{|c|c|c|c|c|c|c|c|c|c|c|c|c|c|c|c|}
\hline & & \multicolumn{2}{|r|}{ LR } & \multicolumn{2}{|r|}{ KIT } & \multicolumn{2}{|r|}{ MBR } & \multicolumn{2}{|r|}{ BR2 } & \multicolumn{2}{|r|}{ BR3 } & \multicolumn{2}{|r|}{ DR } & \multicolumn{2}{|r|}{ BR4 } \\
\hline & & $n$ & $\%$ of period & $\mathrm{n}$ & $\%$ of period & $\mathrm{n}$ & $\%$ of period & $\mathrm{n}$ & $\%$ of period & $\mathrm{n}$ & $\%$ of period & $\mathrm{n}$ & $\%$ of period & $\mathrm{n}$ & $\%$ of period \\
\hline \multicolumn{16}{|l|}{ CDHP } \\
\hline$>1.67^{\circ} \mathrm{O}$ & $\left(>3^{\circ} \mathrm{F}\right)$ & 0 & $0.0 \%$ & 6 & $0.0 \%$ & 99 & $4.2 \%$ & 467 & $1.9 \%$ & (0) & $0.0 \%$ & 6 & $0.0 \%$ & 6! & $0.0 \%$ \\
\hline 1.11 to $1.67^{\circ} \mathrm{C}$ & $\left(2\right.$ to $\left.3^{\circ} \mathrm{F}\right)$ & 0 & \multirow{6}{*}{$98.5 \%$} & 0 & \multirow{6}{*}{$94.7 \%$} & 4562 & $20.1 \%$ & 7287 & $32.0 \%$ & 869 & $3.8 \%$ & 0 & \multirow{6}{*}{$98.4 \%$} & \multirow{6}{*}{\multicolumn{2}{|c|}{\begin{tabular}{c|c}
1361 \\
3099 \\
16080 \\
1957
\end{tabular}}} \\
\hline 0.56 to $1.11^{\circ} \mathrm{C}$ & $\left(1\right.$ to $\left.2^{\circ} \mathrm{F}\right)$ & 0 & & 10 & & 9637 & \multirow{4}{*}{$95.8 \%$} & 10553 & $46.4 \%$ & 8290 & \multirow{4}{*}{$100 \%$} & 0 & & & \\
\hline 0 to $0.56^{\circ} \mathrm{C}$ & $\left(0\right.$ to $\left.1^{\circ} \mathrm{F}\right)$ & 0 & & 132 & & 6278 & & 3341 & $14.7 \%$ & 10857 & & 4 & & & \\
\hline-0.56 to $0^{\circ} \mathrm{C}$ & $\left(-1\right.$ to $\left.0^{\circ} \mathrm{F}\right)$ & 394 & & 2148 & & 1076 & & 932 & $4.1 \%$ & 2249 & & 1050 & & & \\
\hline-1.11 to $-0.56^{\circ} \mathrm{C}$ & $\left(-2\right.$ to $\left.-1^{\circ} \mathrm{F}\right)$ & 19782 & & 12492 & & 250 & & 119 & $0.5 \%$ & 347 & & 19153 & & & \\
\hline-1.67 to $-1.11^{\circ} \mathrm{C}$ & $\left(-3\right.$ to $\left.-2^{\circ} \mathrm{F}\right)$ & 2226 & & 6756 & & 0 & $0.0 \%$ & 83 & $0.4 \%$ & 140 & $0.6 \%$ & 2175 & & & \\
\hline$<-1.67^{\circ} \mathrm{C}$ & $\left(<-3^{\circ} \mathrm{F}\right)$ & 350 & $1.5 \%$ & 1214 & $5.3 \%$ & 0 & $0.0 \%$ & 0 & $0.0 \%$ & 0 & $0.0 \%$ & 370 & $1.6 \%$ & 252 & $1.1 \%$ \\
\hline \multicolumn{2}{|l|}{ AVG. } & \multicolumn{2}{|r|}{$-0.9^{\circ} \mathrm{C}$} & \multicolumn{2}{|r|}{$-1.0^{\circ} \mathrm{C}$} & \multicolumn{2}{|r|}{$0.8^{\circ} \mathrm{C}$} & \multicolumn{2}{|r|}{$0.9^{\circ} \mathrm{C}$} & \multicolumn{2}{|r|}{$0.4^{\circ} \mathrm{C}$} & \multicolumn{2}{|r|}{$-0.9^{\circ} \mathrm{C}$} & \multicolumn{2}{|r|}{$-0.7^{\circ} \mathrm{C}$} \\
\hline \multicolumn{16}{|l|}{ SDHV } \\
\hline$>1.67^{\circ} \mathrm{C}$ & $\left(>3^{\circ} \mathrm{F}\right)$ & (a) & $0.0 \%$ & 1 & $0.0 \%$ & 546 & $2.2 \%$ & \multicolumn{2}{|r|}{$0.9 \%$} & \multicolumn{2}{|r|}{$0.2 \%$} & \multicolumn{2}{|r|}{$0.0 \%$} & \multicolumn{2}{|r|}{$0.0 \%$} \\
\hline 1.11 to $1.67^{\circ} \mathrm{C}$ & (2 to $\left.3^{\circ} \mathrm{F}\right)$ & 0 & \multirow{5}{*}{$91.8 \%$} & 49 & \multirow{6}{*}{$86.5 \%$} & 1131 & $4.6 \%$ & 1184 & $4.8 \%$ & 870 & $3.5 \%$ & 0 & $0.0 \%$ & 45 & $0.2 \%$ \\
\hline 0.56 to $1.11^{\circ} \mathrm{C}$ & $\left(1\right.$ to $\left.2^{\circ} \mathrm{F}\right)$ & 2 & & 480 & & 3605 & $14.6 \%$ & 2615 & $10.6 \%$ & 1833 & $7.4 \%$ & 50 & $0.2 \%$ & 207 & $0.8 \%$ \\
\hline 0 to $0.56^{\circ} \mathrm{C}$ & $\left(0\right.$ to $\left.1^{\circ} \mathrm{F}\right)$ & 1245 & & 1717 & & 5928 & $24.0 \%$ & 7039 & $28.5 \%$ & 6070 & $24.6 \%$ & 1343 & $5.4 \%$ & 1570 & $6.4 \% 93.7 \%$ \\
\hline-0.56 to $0^{\circ} \mathrm{C}$ & $\left(-1\right.$ to $\left.0^{\circ} \mathrm{F}\right)$ & 892 & & 4693 & & 8629 & $34.9 \%$ & 9397 & $38.0 \%$ & 9396 & $38.0 \%$ & 1884 & $7.6 \%$ & 3407 & $13.8 \%{ }^{93.1 \%}$ \\
\hline-1.11 to $-0.56^{\circ} \mathrm{C}$ & $\left(-2\right.$ to $\left.-1^{\circ} \mathrm{F}\right)$ & 11900 & & 7795 & & 3769 & $15.3 \%$ & 3400 & $13.8 \%$ & 5158 & $20.9 \%$ & 11454 & $46.4 \%$ & 10288 & $41.7 \%$ \\
\hline-1.67 to $-1.11^{\circ} \mathrm{C}$ & $\left(-3\right.$ to $\left.-2^{\circ} \mathrm{F}\right)$ & 8624 & $34.9 \%$ & 6626 & & 824 & $3.3 \%$ & 595 & $2.4 \%$ & 922 & $3.7 \%$ & 8028 & $32.5 \%$ & 7622 & $30.9 \%$ \\
\hline$<-1.67^{\circ} \mathrm{C}$ & $\left(<-3^{\circ} \mathrm{F}\right)$ & 2035 & $8.2 \%$ & 3337 & $13.5 \%$ & 266 & $1.1 \%$ & 252 & $1.0 \%$ & 410 & $1.7 \%$ & 1939 & $7.9 \%$ & 1557 & $6.3 \%$ \\
\hline AVG & & & $-1.1^{\circ} \mathrm{C}$ & & $-0.9^{\circ} \mathrm{C}$ & & $0.0^{\circ} \mathrm{C}$ & & $0.0^{\circ} \mathrm{C}$ & & $-0.2^{\circ} \mathrm{C}$ & & $-1.0^{\circ} \mathrm{C}$ & & $-0.9^{\circ} \mathrm{C}$ \\
\hline
\end{tabular}

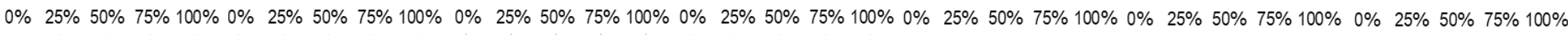
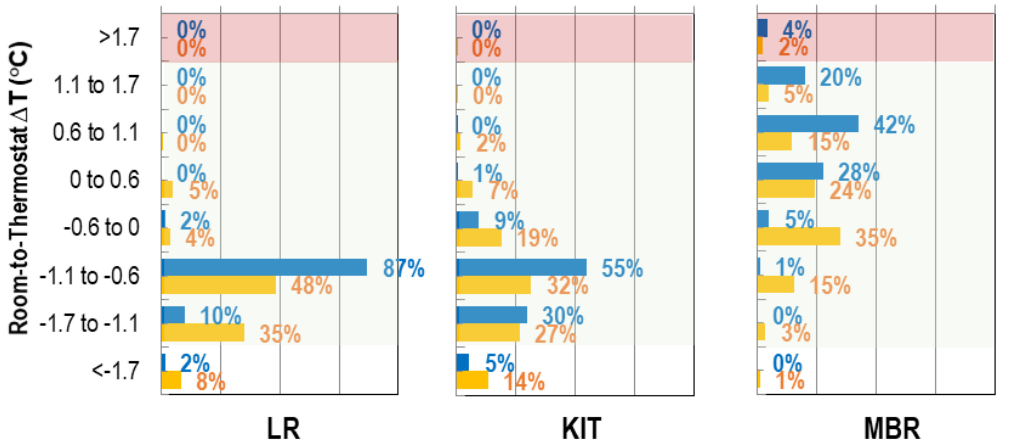

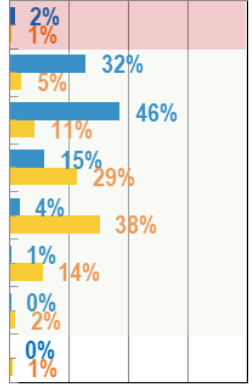

BR2

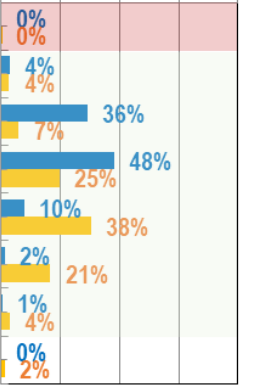

BR3

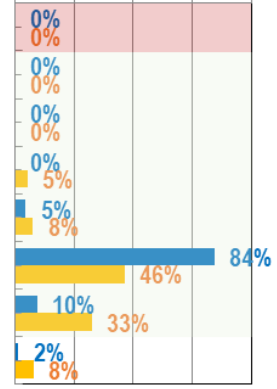

DR

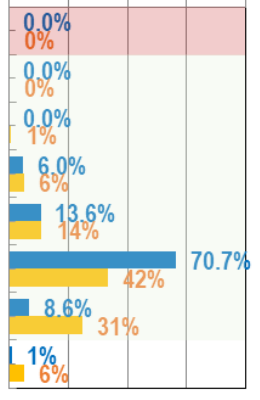

BR4

Figure 8: Graphical Summaries of the 5-Min Average Room-To-Thermostat Temperature Differences for the Cooling Season. 
Table 9: Summary of Room-To-Thermostat Temperature Differences for the Heating Season.

\begin{tabular}{|c|c|c|c|c|c|c|c|c|c|c|c|c|c|c|c|}
\hline & & & LR & & KIT & & MBR & & BR2 & & BR3 & & DR & & BR4 \\
\hline & & $\mathrm{n}$ & $\%$ of period & $\mathrm{n}$ & $\%$ of period & $\mathrm{n}$ & $\%$ of period & $\mathrm{n}$ & $\%$ of period & $\mathrm{n}$ & $\%$ of period & $\mathrm{n}$ & $\%$ of period & $\mathrm{n}$ & $\%$ of period \\
\hline \multicolumn{16}{|l|}{ CDHP } \\
\hline$>1.67^{\circ} \mathrm{C}$ & $\left(>3^{\circ} \mathrm{F}\right)$ & 3 & $0.0 \% \quad 1.3 \%$ & 20 & $0.1 \% \quad 0.7 \%$ & 455 & $3.1 \% \quad 6.5 \%$ & 739 & & 468 & $3.2 \% \quad 10.5 \%$ & 3 & & 63 & $0.4 \% \quad 2.9 \%$ \\
\hline 1.11 to $1.67^{\circ} \mathrm{C}$ & (2 to $\left.3^{\circ} \mathrm{F}\right)$ & 186 & $1.3 \%{ }^{1.3 \%}$ & 82 & $0.6 \%$ & 500 & $3.4 \%{ }^{6.5 \%}$ & 1155 & $7.9 \%{ }^{12.9 \%}$ & 1081 & $7.4 \%$ & 169 & $1.2 \%$ & 363 & $2.5 \% \quad 2.9 \%$ \\
\hline 0.56 to $1.11^{\circ} \mathrm{C}$ & $\left(1\right.$ to $\left.2^{\circ} \mathrm{F}\right)$ & 574 & & 314 & $2.1 \%$ & 1201 & & 1628 & \multirow{3}{*}{$85.9 \%$} & 1354 & $9.2 \%$ & 327 & \multirow{3}{*}{$95.2 \%$} & 1230 & \multirow{3}{*}{$93.0 \%$} \\
\hline 0 to $0.56^{\circ} \mathrm{C}$ & $\left(0\right.$ to $\left.1^{\circ} \mathrm{F}\right)$ & 2241 & $15.3 \%$ & 1478 & $10.1 \%$ & 2997 & $20.4 \%$ & 3050 & & 2951 & $20.1 \%$ & 2255 & & 2533 & \\
\hline-0.56 to $0^{\circ} \mathrm{C}$ & $\left(-1\right.$ to $\left.0^{\circ} \mathrm{F}\right)$ & 3438 & $23.4 \%{ }^{96.0 \%}$ & 3998 & $27.2 \%$ & 5835 & $39.7 \%{ }^{92.0 \%}$ & 5204 & & 5281 & $36.0 \%$ & 4106 & & 3579 & \\
\hline-1.11 to $-0.56^{\circ} \mathrm{C}$ & $\left(-2\right.$ to $\left.-1^{\circ} \mathrm{F}\right)$ & 7847 & $53.4 \%$ & 5546 & $37.8 \%$ & 3480 & $23.7 \%$ & 2741 & $18.7 \%$ & 3191 & $21.7 \%$ & 7298 & $49.7 \%$ & 6323 & $43.0 \%$ \\
\hline-1.67 to $-1.11^{\circ} \mathrm{C}$ & $\left(-3\right.$ to $\left.-2^{\circ} F\right)$ & 884 & & 2746 & $18.7 \%$ & 213 & $1.5 \%, 1.5 \%$ & 17 & & 362 & $2.5 \%, 5 \%$ & 402 & & 454 & \\
\hline$<-1.67^{\circ} \mathrm{C}$ & $\left(<-3^{\circ} \mathrm{F}\right)$ & 65 & $0.4 \% \quad 2.1 \%$ & 507 & $3.5 \%$ & 7 & $0.0 \%$ & 0 & $0.0 \%$ & 0 & $0.0 \% \quad 2.5 \%$ & 128 & $0.9 \%$ & 148 & $1.0 \%$ \\
\hline \multicolumn{2}{|l|}{ AVG. } & \multicolumn{2}{|r|}{$-0.4^{\circ} \mathrm{C}$} & \multicolumn{2}{|r|}{$-0.7^{\circ} \mathrm{C}$} & \multicolumn{2}{|r|}{$-0.1^{\circ} \mathrm{C}$} & \multicolumn{2}{|r|}{$0.1^{\circ} \mathrm{C}$} & \multicolumn{2}{|r|}{$0.0^{\circ} \mathrm{C}$} & \multicolumn{2}{|r|}{$-0.4^{\circ} \mathrm{C}$} & \multicolumn{2}{|r|}{$-0.3^{\circ} \mathrm{C}$} \\
\hline \multicolumn{16}{|l|}{ SDHV } \\
\hline$>1.67^{\circ} \mathrm{C}$ & $\left(>3^{\circ} \mathrm{F}\right)$ & 4 & $0.0 \%$ & 5 & $0.0 \%$ & 313 & $2.1 \% \quad 8.9 \%$ & 744 & $5.1 \%$ & 569 & $3.9 \%$ & 3 & $0.0 \%$ & 48 & $0.3 \%$ \\
\hline 1.11 to $1.67^{\circ} \mathrm{C}$ & (2 to $3^{\circ} \mathrm{F}$ ) & 46 & $0.3 \% \quad 0.3 \%$ & 19 & $0.1 \%$ & 989 & $6.7 \%{ }^{8.9 \%}$ & 1345 & $9.2 \%$ & 1039 & $7.1 \%$ & 36 & $0.2 \%$ & 264 & $1.8 \%$ \\
\hline 0.56 to $1.11^{\circ} \mathrm{C}$ & $\left(1\right.$ to $\left.2^{\circ} \mathrm{F}\right)$ & 549 & $3.7 \%$ & 250 & $1.7 \%$ & 4150 & $28.3 \%$ & 4368 & $29.7 \%$ & 2894 & $19.7 \%$ & 413 & $2.8 \%$ & 1065 & $7.3 \%$ \\
\hline 0 to $0.56^{\circ} \mathrm{C}$ & $\left(0\right.$ to $\left.1^{\circ} \mathrm{F}\right)$ & 1861 & $12.7 \%$ & 1863 & $12.7 \%$ & 5955 & $40.5 \%$ & 6280 & $42.8 \%$ & 5876 & $40.0 \%$ & 2491 & $17.0 \%$ & 3060 & $20.8 \%$ \\
\hline-0.56 to $0^{\circ} \mathrm{C}$ & $\left(-1\right.$ to $\left.0^{\circ} \mathrm{F}\right)$ & 7243 & $49.3 \%^{y}$ & 4160 & $28.3 \%$ & 3084 & $21.0 \%$ & 1849 & $12.6 \%$ & 3572 & $24.3 \%$ & 6777 & $46.1 \%$ & 6600 & $44.9 \%$ \\
\hline-1.11 to $-0.56^{\circ} \mathrm{C}$ & $\left(-2\right.$ to $\left.-1^{\circ} \mathrm{F}\right)$ & 4985 & $33.9 \%$ & 5311 & $36.2 \%$ & 197 & $1.3 \%$ & 102 & $0.7 \%$ & 723 & $4.9 \%$ & 4922 & $33.5 \%$ & 3650 & $24.9 \%$ \\
\hline-1.67 to $-1.11^{\circ} \mathrm{C}$ & $\left(-3\right.$ to $\left.-2^{\circ} F\right)$ & 0 & $0.0 \%$ & 2597 & $17.7 \%$ & (9) & $0.0 \%, 0.0 \%$ & (a) & $0.0 \%$ & 15 & $0.1 \%$ & 46 & $0.3 \%$ & 11. & $0.0 \%$ \\
\hline$<-1.67^{\circ} \mathrm{C}$ & $\left(<-3^{\circ} \mathrm{F}\right)$ & 0 & $0.0 \%$ & 488 & $3.3 \%$ & 6 & $0.0 \%$ & 0 & $0.0 \%$ & 0 & $0.0 \%$ & 0 & $0.0 \%$ & (a) & $0.0 \%$ \\
\hline AVG. & & & $-0.3^{\circ} \mathrm{C}$ & & $-0.6^{\circ} \mathrm{C}$ & & $0.4^{\circ} \mathrm{C}$ & & $0.6^{\circ} \mathrm{C}$ & & $0.3^{\circ} \mathrm{C}$ & & $-0.3^{\circ} \mathrm{C}$ & & $-0.2^{\circ} \mathrm{C}$ \\
\hline
\end{tabular}

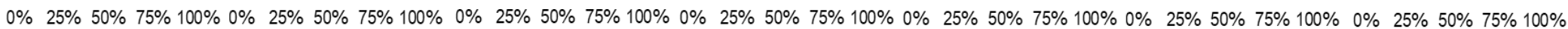
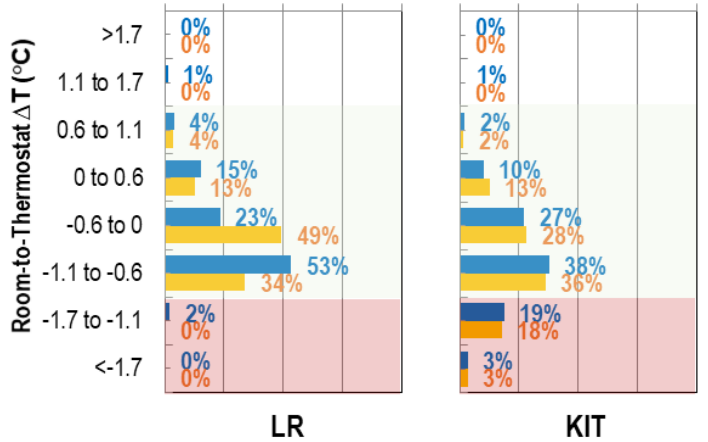

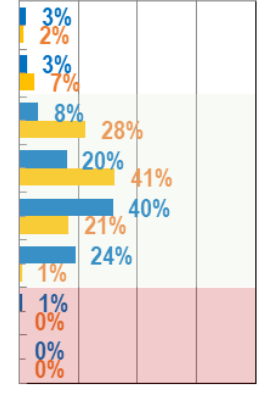

MBR

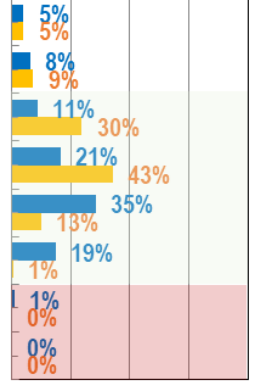

BR2

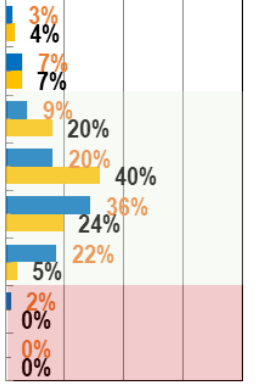

BR3

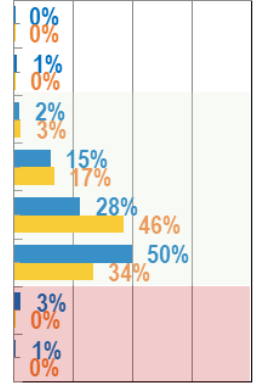

DR

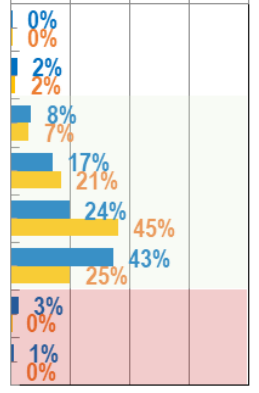

BR4

Figure 9: Graphical Summaries of the 5-Min Average Room-To-Thermostat Temperature Differences for the Heating Season. 
Table 10: Summary of Room-To-Thermostat Temperature Differences for the Transitional Season.

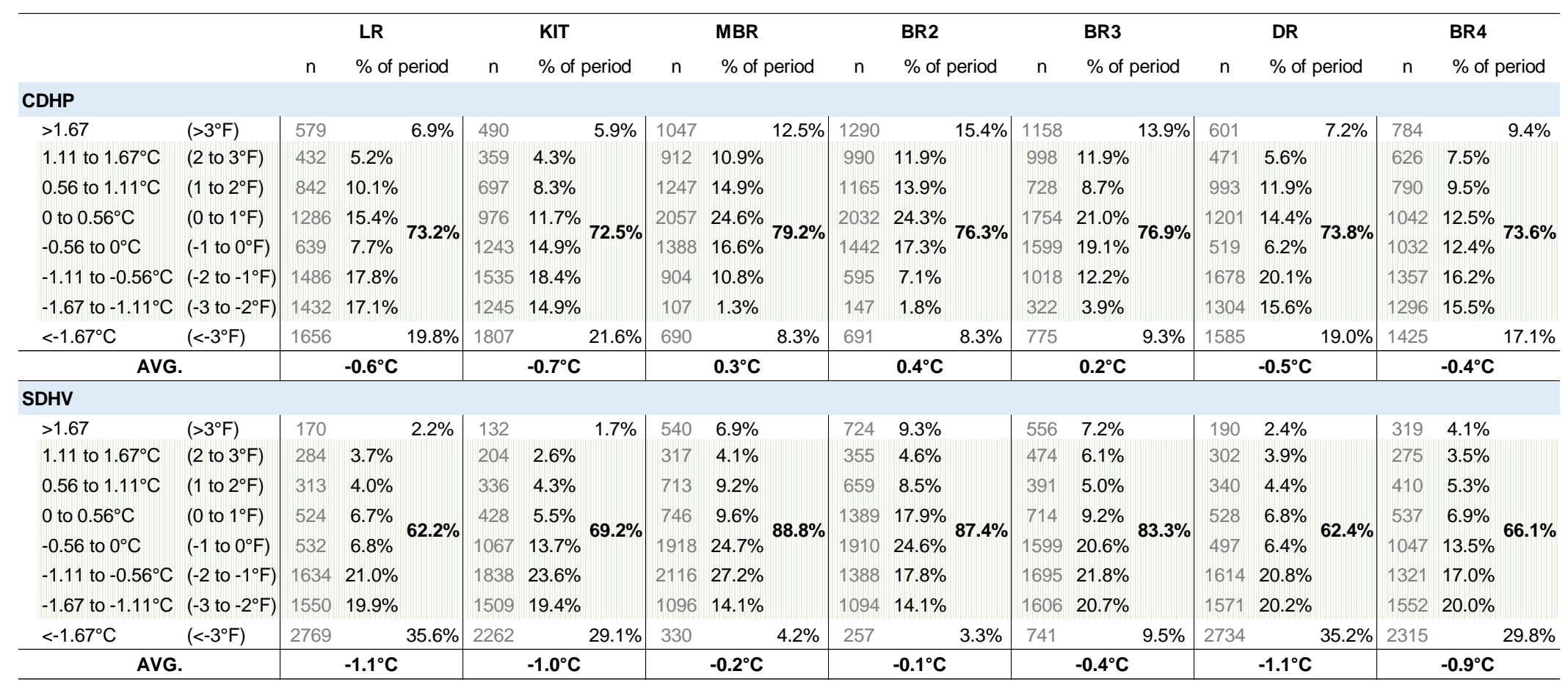

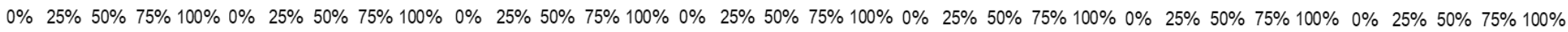

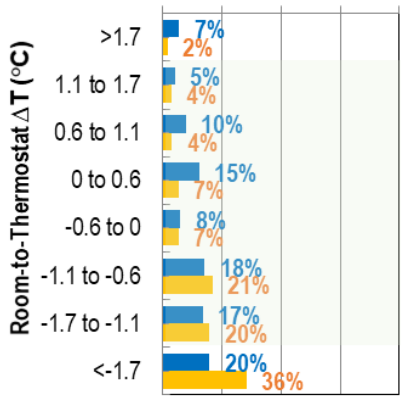

LR

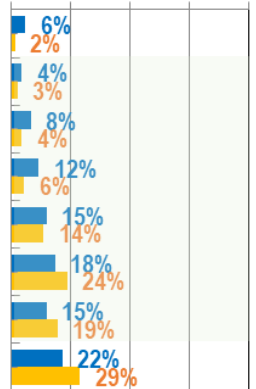

KIT

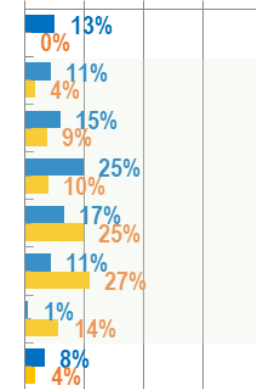

MBR

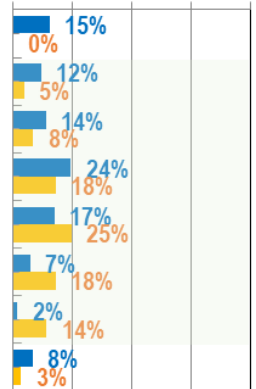

BR2

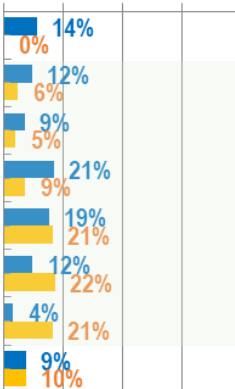

BR3

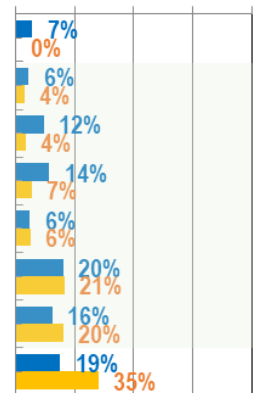

DR

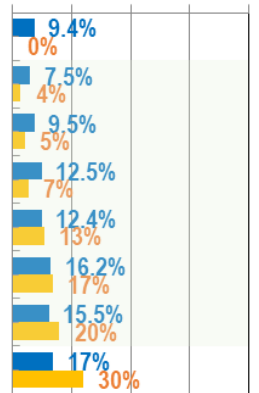

BR4

Figure 10: Graphical Summaries of the 5-Min Average Room-To-Thermostat Temperature Differences for the Transitional Season. 


\subsection{ROOM-TO-ROOM TEMPERATURE DIFFERENCE}

Tables 11 (by HP system seasonal mode) and 12 (by cooling/heating/transitional season) present the percentage distributions of the 5 -min average room-to-room temperature difference with the number of data points $(n)$ that were grouped based on a degree of temperature difference $(\Delta \mathrm{T})$ as follows:

- $\Delta \mathrm{T}$ above $3.33^{\circ} \mathrm{C}\left(6^{\circ} \mathrm{F}\right)$;

- $\Delta \mathrm{T}$ from $2.78^{\circ} \mathrm{C}$ to $3.33^{\circ} \mathrm{C}\left(5^{\circ} \mathrm{F}\right.$ to $\left.6^{\circ} \mathrm{F}\right)$;

- $\Delta \mathrm{T}$ from $2.22^{\circ} \mathrm{C}$ to $2.78^{\circ} \mathrm{C}\left(4^{\circ} \mathrm{F}\right.$ to $\left.5^{\circ} \mathrm{F}\right)$;

- $\Delta$ T from $1.67^{\circ} \mathrm{C}$ to $2.22^{\circ} \mathrm{C}\left(3^{\circ} \mathrm{F}\right.$ to $\left.4^{\circ} \mathrm{F}\right)$;

- $\Delta$ T from $1.11^{\circ} \mathrm{C}$ to $1.67^{\circ} \mathrm{C}\left(2^{\circ} \mathrm{F}\right.$ to $\left.3^{\circ} \mathrm{F}\right)$;

- $\quad \Delta \mathrm{T}$ from $0.56^{\circ} \mathrm{C}$ to $1.11^{\circ} \mathrm{C}\left(1^{\circ} \mathrm{F}\right.$ to $\left.2^{\circ} \mathrm{F}\right) ;$ and

- $\Delta \mathrm{T}$ from $0^{\circ} \mathrm{C}$ to $0.56^{\circ} \mathrm{C}\left(0^{\circ} \mathrm{F}\right.$ to $\left.1^{\circ} \mathrm{F}\right)$.

In these tables, the relevant ACCA Manual RS benchmarks (i.e., $1.67^{\circ} \mathrm{C}\left(3^{\circ} \mathrm{F}\right.$ ) average and $3.33^{\circ} \mathrm{C}\left(6^{\circ} \mathrm{F}\right)$ maximum for cooling; and $1.11^{\circ} \mathrm{C}\left(2^{\circ} \mathrm{F}\right)$ average and $2.22^{\circ} \mathrm{C}\left(4^{\circ} \mathrm{F}\right)$ maximum for heating) are also presented for a comparison. The groups meeting the ACCA average benchmarks (i.e., $\Delta \mathrm{T}$ below $1.67^{\circ} \mathrm{C}$ in the cooling mode and $\Delta \mathrm{T}$ above $1.11^{\circ} \mathrm{C}$ in the heating mode) were highlighted in green, while the groups exceeding the ACCA average benchmarks but still meeting its maximum benchmarks (i.e., $\Delta \mathrm{T}$ above $3.33^{\circ} \mathrm{C}$ in the cooling mode and $\Delta \mathrm{T}$ above $2.22^{\circ} \mathrm{C}$ in the heating mode) were highlighted in orange. Lastly, the groups exceeding even the ACCA maximum benchmarks were highlighted in red. The same results are also graphically presented in Figures 11 (by HP system seasonal mode) and 12 (by cooling/heating/transitional season), which are comprised of color-coded bars: dark blue bars for the CDHP and orange bars for the SDHV.

Important observations on the room-to-room temperature difference are:

- Cooling Mode Results

- The SDHV maintained much smaller room-to-room temperature differences than the CDHP with an average room-to-room temperature difference of $1.3^{\circ} \mathrm{C}$, which was lower than the ACCA average benchmarks (i.e., $1.67^{\circ} \mathrm{C}$ for cooling). About $79.3 \%$ of the period, the calculated room-to-room temperature differences were below the ACCA average benchmarks for cooling when the SDHV was operated.

- However, the CDHP's compliance percentage with the ACCA average benchmarks was only $29.6 \%$ with an average room-to-room temperature difference of $2.0^{\circ} \mathrm{C}$, which exceeded the ACCA average benchmarks for cooling.

- There were occasions when the room-to-room temperature difference exceeded the ACCA maximum benchmarks for cooling, which was about $0.8 \%$ of the period when the CDHP was in operation. A further investigation, as presented in Section 4.6.2, revealed that this deviation mostly occurred when the MBR's room-tothermostat temperature difference exceeded the ACCA cooling benchmarks, which was affected by possible heat gains from the radiator in the MBR emulating sensible heat gains from an iron ${ }^{34}$.

- Heating Mode Results

\footnotetext{
${ }^{34}$ The MBR time-of-day temperature profile, including a spike between 6 PM and 7 PM, is presented in Section 4.6.1.
} 
- During the heating mode, the trend was opposite to the cooling mode. The CDHP maintained a smaller room-to-room temperature difference than the SDHV with an average room-to-room temperature difference of $1.1^{\circ} \mathrm{C}$, which was lower than the ACCA average benchmarks (i.e., $1.11^{\circ} \mathrm{C}$ for heating). About $61.0 \%$ of the period, the calculated room-to-room temperature differences were below the ACCA average benchmarks for heating when the CDHP was operated.

- However, the SDHV's compliance percentage with the ACCA average benchmarks was $36.9 \%$ of the period with an average room-to-room temperature difference of $1.3^{\circ} \mathrm{C}$, which exceeded the ACCA average benchmarks for heating.

- Compared to cooling, there were more occasions when the room-to-room temperature difference exceeded the ACCA maximum benchmarks for heating, which was about $2.2 \%$ of the period with the CDHP and $4.7 \%$ of the period with the SDHV. The observed non-compliance with the ACCA maximum benchmarks mainly occurred due to the low-side deviation of the room-to-thermostat temperature difference in the kitchen. The deviation mostly occurred during the nighttime before the sun rises due to the combined effect of the evaporative cooling effect from the two humidifiers and no presence of the simulated occupancy at night in the kitchen, as confirmed in a time-of-day colored map analysis presented in Section 4.6.2.

- Results by Season

- Like the room-to-thermostat temperature difference analysis by season (i.e., cooling season, heating season, and transitional season) presented in Section 4.1.3, the percentage distributions of the 5-min average room-to-room temperature difference were recalculated by season to separately analyze the swing season when the systems were off cycle due to favorable weather conditions (i.e., cool OA temperature), as shown in Table 12 and Figure 12. This will allow a more accurate characterization and benchmarking of room-to-room temperature deviation based on long-term measurements.

- As a result, it was found that the non-compliance frequency in the heating mode decreased from 427 (heating mode) to 267 (heating season) with the CDHP and from 789 (heating mode) to 681 (heating season) with the SDHV. However, the non-compliance frequency reported in the cooling mode was the same.

- The room-to-room temperature differences during the transitional season were smaller compared to the cooling season but higher compared to the heating season. For example, the room-to-room temperature differences were below the ACCA average cooling limit for about 73.8\% (CDHP) and $82.1 \%$ (SDHV) of the period without any frequency exceeding the ACCA maximum cooling benchmarks. This means the natural stratification of warm air in this two-story house during the system off cycle still provided acceptable spatial thermal uniformity. 
Table 11: Summary of the 5-Min Average Room-To-Room Temperature Differences by HP System Seasonal Operation Mode.

\begin{tabular}{|c|c|c|c|c|c|}
\hline & & \multicolumn{2}{|c|}{ Cooling Mode } & \multicolumn{2}{|c|}{ Heating Mode } \\
\hline & & $\mathrm{n}$ & $\%$ of period & $\mathrm{n}$ & $\%$ of period \\
\hline \multicolumn{6}{|l|}{ CDHP } \\
\hline$>3.33^{\circ} \mathrm{C}$ & $\left(>6^{\circ} \mathrm{F}\right)$ & $218:$ & $0.8 \%$ & 0 & $0.0 \%$ \\
\hline 2.78 to $3.33^{\circ} \mathrm{C}$ & $\left(5\right.$ to $\left.6^{\circ} \mathrm{F}\right)$ & 2029 & $7.6 \%$ & 5 & $0.0 \% \quad 2.2 \%$ \\
\hline 2.22 to $2.78^{\circ} \mathrm{C}$ & $\left(4\right.$ to $\left.5^{\circ} \mathrm{F}\right)$ & 6183 & $23.1 \% 69.5 \%$ & 422 & $2.2 \%$ \\
\hline 1.67 to $2.22^{\circ} \mathrm{C}$ & $\left(3\right.$ to $\left.4^{\circ} \mathrm{F}\right)$ & 10414 & $38.9 \%$ & 2414 & $12.7 \%$ \\
\hline 1.11 to $1.67^{\circ} \mathrm{C}$ & $\left(2\right.$ to $\left.3^{\circ} \mathrm{F}\right)$ & 6238 & $23.3 \%$ & 4570 & $24.0 \%$ \\
\hline 0.56 to $1.11^{\circ} \mathrm{C}$ & $\left(1\right.$ to $\left.2^{\circ} \mathrm{F}\right)$ & 1653 & $6.2 \% \quad 29.6 \%$ & 8520 & $44.8 \%$ \\
\hline 0 to $0.56^{\circ} \mathrm{C}$ & $\left(0\right.$ to $\left.1^{\circ} \mathrm{F}\right)$ & 49 & $0.2 \%$ & 3077 & $16.2 \%$ \\
\hline \multicolumn{2}{|c|}{ AVG. } & & $2.0^{\circ} \mathrm{C}$ & & $1.1^{\circ} \mathrm{C}$ \\
\hline \multicolumn{6}{|l|}{ SDHV } \\
\hline$>3.33^{\circ} \mathrm{C}$ & $\left(>6^{\circ} \mathrm{F}\right)$ & 1 & $0.0 \%$ & 0 & $0.0 \%$ \\
\hline 2.78 to $3.33^{\circ} \mathrm{C}$ & (5 to $6^{\circ} \mathrm{F}$ ) & 150 & $0.5 \%$ & 9: & $0.1 \% \quad 4.7 \%$ \\
\hline 2.22 to $2.78^{\circ} \mathrm{C}$ & (4 to $\left.5^{\circ} \mathrm{F}\right)$ & 916 & $3.0 \% \quad 20.7 \%$ & 780 & $4.7 \%$ \\
\hline 1.67 to $2.22^{\circ} \mathrm{C}$ & (3 to $\left.4^{\circ} \mathrm{F}\right)$ & 5231 & $17.2 \%$ & 3961 & $23.7 \%$ \\
\hline 1.11 to $1.67^{\circ} \mathrm{C}$ & $\left(2\right.$ to $\left.3^{\circ} \mathrm{F}\right)$ & 12042 & $39.5 \%$ & 5796 & $34.7 \%$ \\
\hline 0.56 to $1.11^{\circ} \mathrm{C}$ & $\left(1\right.$ to $\left.2^{\circ} \mathrm{F}\right)$ & 11451 & $37.6 \% 79.3 \%$ & 5233 & $31.3 \%$ \\
\hline 0 to $0.56^{\circ} \mathrm{C}$ & $\left(0\right.$ to $\left.1^{\circ} \mathrm{F}\right)$ & 667 & $2.2 \%$ & 925 & $5.5 \%$ \\
\hline \multicolumn{2}{|c|}{ AVG. } & & $1.3^{\circ} \mathrm{C}$ & & $1.3^{\circ} \mathrm{C}$ \\
\hline
\end{tabular}

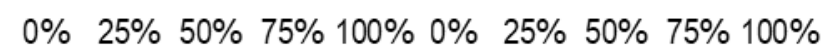
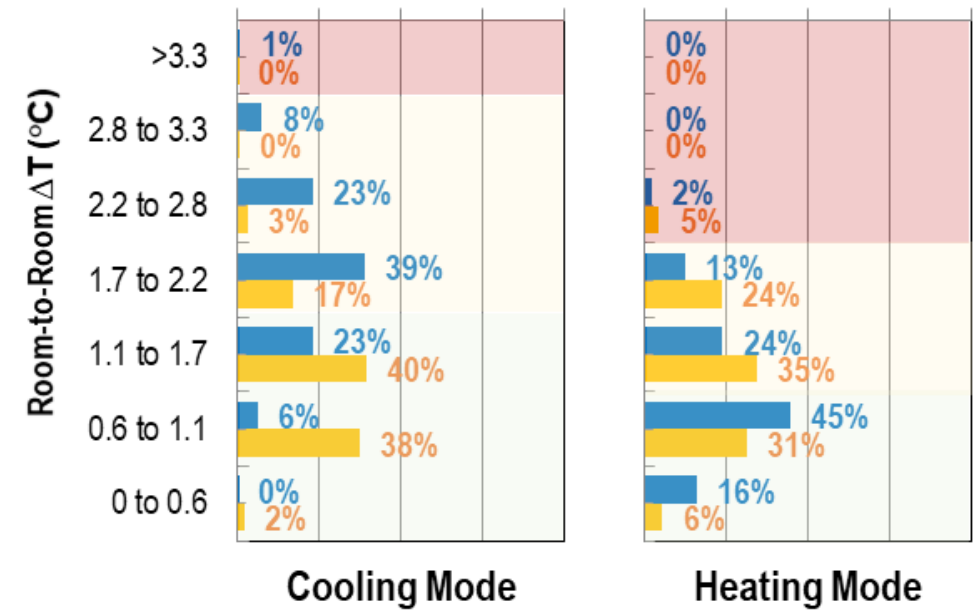

Heating Mode

Figure 11: Graphical Summaries of the 5-Min Average Room-To-Thermostat Temperature Differences by HP System Seasonal Operation Mode. 
Table 12: Summary of the 5-Min Average Room-To-Room Temperature Differences by Season.

\begin{tabular}{|c|c|c|c|c|c|c|c|c|}
\hline & & \multicolumn{3}{|c|}{ Cooling Season } & \multicolumn{2}{|c|}{ Heating Season } & \multicolumn{2}{|c|}{ Transitional Season } \\
\hline & & $\mathrm{n}$ & $\%$ of & period & $\mathrm{n}$ & $\%$ of period & $n$ & $\%$ of period \\
\hline \multicolumn{9}{|l|}{ CDHP } \\
\hline$>3.33^{\circ} \mathrm{C}$ & $\left(>6^{\circ} \mathrm{F}\right)$ & 218 & & $1.0 \%$ & 0 & $0.0 \%$ & (9) & $0.0 \%$ \\
\hline 2.78 to $3.33^{\circ} \mathrm{C}$ & $\left(5\right.$ to $\left.6^{\circ} \mathrm{F}\right)$ & 1952 & $8.6 \%$ & & 5 & $0.0 \% \quad 1.8 \%$ & 77 & $0.9 \%$ \\
\hline 2.22 to $2.78^{\circ} \mathrm{C}$ & $\left(4\right.$ to $\left.5^{\circ} \mathrm{F}\right)$ & 5773 & $25.4 \%$ & $76.3 \%$ & 262 & $1.8 \%$ & 570 & $6.8 \% \quad 26.2 \%$ \\
\hline 1.67 to $2.22^{\circ} \mathrm{C}$ & $\left(3\right.$ to $\left.4^{\circ} \mathrm{F}\right)$ & 9634 & $42.3 \%$ & & 1654 & $11.3 \%$ & 1540 & $18.4 \%$ \\
\hline 1.11 to $1.67^{\circ} \mathrm{C}$ & $\left(2\right.$ to $\left.3^{\circ} \mathrm{F}\right)$ & 4643 & $20.4 \%$ & & 3185 & $21.7 \%$ & 2980 & $35.7 \%$ \\
\hline 0.56 to $1.11^{\circ} \mathrm{C}$ & $\left(1\right.$ to $\left.2^{\circ} \mathrm{F}\right)$ & 514 & $2.3 \%$ & $22.7 \%$ & 6864 & $46.7 \%$ & 2795 & $33.5 \% 73.8 \%$ \\
\hline 0 to $0.56^{\circ} \mathrm{C}$ & $\left(0\right.$ to $\left.1^{\circ} \mathrm{F}\right)$ & 18 & $0.1 \%$ & & 2718 & $18.5 \%$ & 390 & $4.7 \%$ \\
\hline \multicolumn{2}{|c|}{ AVG. } & & $2.1^{\circ} \mathrm{C}$ & & & $1.0^{\circ} \mathrm{C}$ & & $1.3^{\circ} \mathrm{C}$ \\
\hline \multicolumn{9}{|l|}{ SDHV } \\
\hline$>3.33^{\circ} \mathrm{C}$ & $\left(>6^{\circ} \mathrm{F}\right)$ & 11 & & $0.0 \%$ & (9) & $0.0 \%$ & (0) & $0.0 \%$ \\
\hline 2.78 to $3.33^{\circ} \mathrm{C}$ & $\left(5\right.$ to $\left.6^{\circ} \mathrm{F}\right)$ & 150 & $0.6 \%$ & & 9 & $0.1 \% \quad 4.6 \%$ & 0 & $0.0 \%$ \\
\hline 2.22 to $2.78^{\circ} \mathrm{C}$ & $\left(4\right.$ to $\left.5^{\circ} \mathrm{F}\right)$ & 761 & $3.1 \%$ & $22.1 \%$ & 672 & $4.6 \%$ & 263 & $3.4 \% \quad 17.9 \%$ \\
\hline 1.67 to $2.22^{\circ} \mathrm{C}$ & $\left(3\right.$ to $\left.4^{\circ} \mathrm{F}\right)$ & 4540 & $18.4 \%$ & & 3526 & $24.0 \%$ & 1126 & $14.5 \%$ \\
\hline 1.11 to $1.67^{\circ} \mathrm{C}$ & $\left(2\right.$ to $\left.3^{\circ} \mathrm{F}\right)$ & 9479 & $38.4 \%$ & & 5089 & $34.6 \%$ & 3270 & $42.1 \%$ \\
\hline 0.56 to $1.11^{\circ} \mathrm{C}$ & $\left(1\right.$ to $\left.2^{\circ} \mathrm{F}\right)$ & 9278 & $37.6 \%$ & $77.9 \%$ & 4613 & $31.4 \%$ & 2793 & $35.9 \% 82.1 \%$ \\
\hline 0 to $0.56^{\circ} \mathrm{C}$ & $\left(0\right.$ to $\left.1^{\circ} \mathrm{F}\right)$ & 489 & $2.0 \%$ & & 779 & $5.3 \%$ & 324 & $4.2 \%$ \\
\hline \multicolumn{2}{|c|}{ AVG. } & & $1.3^{\circ} \mathrm{C}$ & & & $1.3^{\circ} \mathrm{C}$ & & $1.3^{\circ} \mathrm{C}$ \\
\hline
\end{tabular}

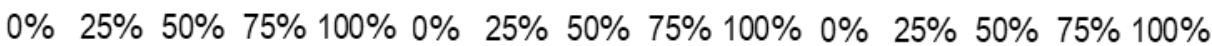

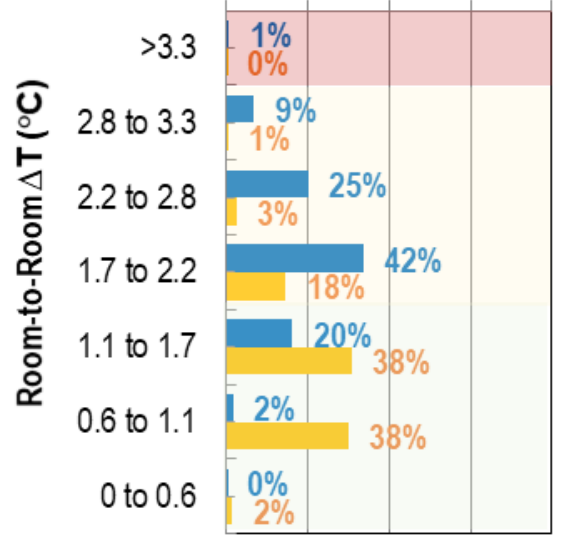

Cooling Season

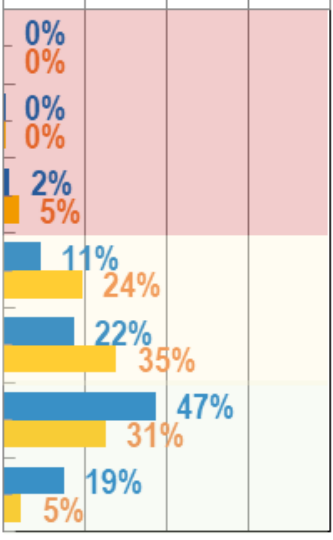

Heating Season

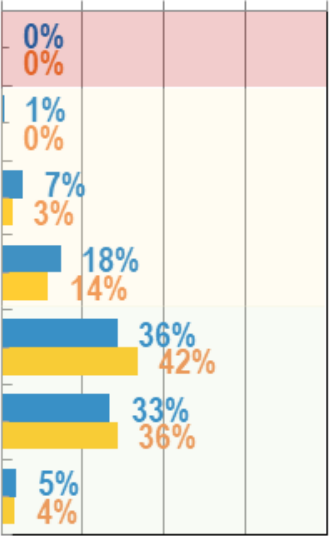

Transitional Season

Figure 12: Graphical Summaries of the 5-Min Average Room-To-Thermostat Temperature Differences by Season. 


\subsection{CYCLIC DISCOMFORT}

Tables 13 (cooling mode) and 14 (heating mode) report the percentage of failures in cyclic and drift temperature variations based on the ASHRAE Standard 55-2017 (ASHRAE 2017) with the number of data points (i.e., minutes) for the following time periods:

- $0.25 \mathrm{~h}$ (15 minutes);

- $0.50 \mathrm{~h}$ (30 minutes);

- $1 \mathrm{~h}$ (60 minutes);

- $2 \mathrm{~h}$ (120 minutes); and

- $4 \mathrm{~h}$ (240 minutes).

The ASHRAE Standard 55-2017 specifies a peak-to-peak variation in operative temperature for any 15 -minute period shall not exceed $1.1^{\circ} \mathrm{C}\left(2.0^{\circ} \mathrm{F}\right)$ to evaluate cyclic variations. The criteria for drift variations are based on maximum operative temperature change allowed: $1.1^{\circ} \mathrm{C}\left(2.0^{\circ} \mathrm{F}\right)$ for any 15 -minute period; $1.7^{\circ} \mathrm{C}\left(3.0^{\circ} \mathrm{F}\right)$ for any 30 -minute period; $2.2^{\circ} \mathrm{C}\left(4.0^{\circ} \mathrm{F}\right)$ for any 1 -hour period; $2.8^{\circ} \mathrm{C}\left(5.0^{\circ} \mathrm{F}\right)$ for any 2 -hour period; and $3.3^{\circ} \mathrm{C}\left(6.0^{\circ} \mathrm{F}\right)$ for any 4 -hour period.

In general, the percentage of failures was negligible, which was less than $0.1 \%$ of the period except for the kitchen and the MBR. No obvious difference was observed between the systems and between the system's seasonal operation modes. The kitchen and the MBR still had quite low percentages of failures below $1 \%$ of the period, and higher failure rates were observed for the shorter time periods such as $0.25 \mathrm{~h}$ and $0.5 \mathrm{~h}$ period.

A further investigation revealed that the shorter-term failures observed in the kitchen occurred at a specific time of the day when the radiator near the kitchen measurement stand was turned on to emulate one of the kitchen appliances (i.e., toaster oven) from 9:20 AM to 9:30 AM. During this time, a sharp increase in the measured air and globe temperatures was observed, which occurred to a greater extent with globe temperature. This confirms the observed cyclic failure occurred due to radiant heat gains from the radiator. Similarly, the shorter-term failures observed in the MBR also occurred at a specific time of the day when the radiator near the MBR measurement stand was turned on to emulate an iron from 6:00 PM to $6: 45 \mathrm{PM}^{35}$.

\footnotetext{
35 The MBR time-of-day temperature profile, including a spike between 6 PM and 7 PM, is presented in Section
} 4.6.1. 
Table 13: Percentage of Failures in Cyclic and Drift Temperature Variations Per ASHRAE Standard 55-2017 for the Cooling Mode.

$$
\text { LR }
$$

KIT

MBR

BR2

BR3

DR

BR4

mins $\%$ of period mins $\%$ of period mins $\%$ of period mins $\%$ of period mins $\%$ of period $\operatorname{mins} \%$ of period $\operatorname{mins} \%$ of period

\section{CDHP}

\begin{tabular}{|c|c|c|c|c|c|c|c|c|c|c|c|c|c|c|c|}
\hline $0.25 \mathrm{~h}$ & $1.1^{\circ} \mathrm{C}\left(2.0^{\circ} \mathrm{F}\right)$ & 106 & $0.08 \%$ & 754 & $0.56 \%$ & 871 & $0.65 \%$ & 0 & $0.00 \%$ & 0 & $0.00 \%$ & 0 & $0.00 \%$ & 0 & $0.00 \%$ \\
\hline $0.50 \mathrm{~h}$ & $1.7^{\circ} \mathrm{C}\left(3.0^{\circ} \mathrm{F}\right)$ & 53 & $0.04 \%$ & 381 & $0.28 \%$ & 1093 & $0.82 \%$ & 0 & $0.00 \%$ & 0 & $0.00 \%$ & 0 & $0.00 \%$ & 0 & $0.00 \%$ \\
\hline $1 \mathrm{~h}$ & $2.2^{\circ} \mathrm{C}\left(4.0^{\circ} \mathrm{F}\right)$ & 0 & $0.00 \%$ & 30 & $0.02 \%$ & 108 & $0.08 \%$ & 0 & $0.00 \%$ & 0 & $0.00 \%$ & 0 & $0.00 \%$ & 0 & $0.00 \%$ \\
\hline $2 \mathrm{~h}$ & $2.8^{\circ} \mathrm{C}\left(5.0^{\circ} \mathrm{F}\right)$ & 0 & $0.00 \%$ & 0 & $0.00 \%$ & 0 & $0.00 \%$ & 0 & $0.00 \%$ & 0 & $0.00 \%$ & 0 & $0.00 \%$ & 0 & 0.00 \\
\hline $4 \mathrm{~h}$ & $3.3^{\circ} \mathrm{C}\left(6.0^{\circ} \mathrm{F}\right)$ & 0 & $0.00 \%$ & 0 & $0.00 \%$ & & $0.00 \%$ & 0 & $0.00 \%$ & 0 & $0.00 \%$ & 0 & $0.00 \%$ & 0 & 0.0 \\
\hline \multicolumn{16}{|l|}{ SDHV } \\
\hline $0.25 h$ & $1.1^{\circ} \mathrm{C}\left(2.0^{\circ} \mathrm{F}\right)$ & 44 & $0.03 \%$ & 542 & $0.36 \%$ & 700 & $0.46 \%$ & 28 & $0.02 \%$ & 0 & $0.00 \%$ & 0 & $0.00 \%$ & 16 & $0.01 \%$ \\
\hline $0.50 \mathrm{~h}$ & $1.7^{\circ} \mathrm{C}\left(3.0^{\circ} \mathrm{F}\right)$ & 14 & $0.01 \%$ & 70 & $0.05 \%$ & 847 & $0.55 \%$ & 0 & $0.00^{\circ}$ & 0 & $0.00 \%$ & 0 & $0.00 \%$ & 0 & 0.00 \\
\hline $1 \mathrm{~h}$ & $2.2^{\circ} \mathrm{C}\left(4.0^{\circ} \mathrm{F}\right)$ & 0 & $0.00 \%$ & 0 & $0.00 \%$ & 229 & $0.15 \%$ & 0 & $0.00 \%$ & 0 & $0.00 \%$ & 0 & $0.00 \%$ & 0 & 0.00 \\
\hline $2 \mathrm{~h}$ & $2.8^{\circ} \mathrm{C}\left(5.0^{\circ} \mathrm{F}\right)$ & 0 & $0.00 \%$ & 0 & $0.00 \%$ & 115 & $0.08 \%$ & 0 & $0.00 \%$ & 0 & $0.00 \%$ & 0 & $0.00 \%$ & 0 & $0.00 \%$ \\
\hline $4 \mathrm{~h}$ & $3.3^{\circ} \mathrm{C}\left(6.0^{\circ} \mathrm{F}\right)$ & 0 & $0.00 \%$ & 0 & $0.00 \%$ & 0 & $0.00 \%$ & 0 & $0.00 \%$ & 0 & $0.00 \%$ & 0 & $0.00 \%$ & 0 & \\
\hline
\end{tabular}


Table 14: Percentage of Failures in Cyclic and Drift Temperature Variations Per ASHRAE Standard 55-2017 for the Heating Mode.

$$
\text { LR }
$$

KIT

MBR

BR2

BR3

DR

BR4

mins $\%$ of period mins $\%$ of period mins $\%$ of period mins $\%$ of period mins $\%$ of period $\operatorname{mins} \%$ of period $\operatorname{mins} \%$ of period

\section{CDHP}

\begin{tabular}{|c|c|c|c|c|c|c|c|c|c|c|c|c|c|c|c|}
\hline $0.25 \mathrm{~h}$ & $1.1^{\circ} \mathrm{C}\left(2.0^{\circ} \mathrm{F}\right)$ & 0 & $0.00 \%$ & 532 & $0.56 \%$ & 679 & $0.71 \%$ & 12 & $0.01 \%$ & 0 & $0.00 \%$ & 0 & $0.00 \%$ & & $0.00 \%$ \\
\hline $0.50 \mathrm{~h}$ & $1.7^{\circ} \mathrm{C}\left(3.0^{\circ} \mathrm{F}\right)$ & 0 & $0.00 \%$ & 164 & $0.17 \%$ & 760 & $0.80 \%$ & 0 & $0.00 \%$ & 0 & $0.00 \%$ & 0 & $0.00 \%$ & 0 & $0.00 \%$ \\
\hline $1 \mathrm{~h}$ & $2.2^{\circ} \mathrm{C}\left(4.0^{\circ} \mathrm{F}\right)$ & 0 & $0.00 \%$ & 11 & $0.01 \%$ & 0 & $0.00 \%$ & & $0.00 \%$ & 0 & $0.00 \%$ & 0 & $0.00 \%$ & & $0.00 \%$ \\
\hline $2 \mathrm{~h}$ & $2.8^{\circ} \mathrm{C}\left(5.0^{\circ} \mathrm{F}\right)$ & 0 & $0.00 \%$ & 34 & $0.04 \%$ & 0 & $0.00 \%$ & 0 & $0.00 \%$ & 0 & $0.00 \%$ & 0 & $0.00 \%$ & 0 & $0.00 \%$ \\
\hline $4 \mathrm{~h}$ & $3.3^{\circ} \mathrm{C}\left(6.0^{\circ} \mathrm{F}\right)$ & 0 & $0.00 \%$ & 0 & $0.00 \%$ & 0 & $0.00 \%$ & 0 & $0.00 \%$ & 0 & $0.00 \%$ & 0 & $0.00 \%$ & & $0.00 \%$ \\
\hline \multicolumn{16}{|l|}{ SDHV } \\
\hline $0.25 \mathrm{~h}$ & $1.1^{\circ} \mathrm{C}\left(2.0^{\circ} \mathrm{F}\right)$ & 0 & $0.00 \%$ & 539 & $0.65 \%$ & 615 & $0.74 \%$ & 0 & $0.00 \%$ & 0 & 0.00 & 0 & $0.00 \%$ & & 0.00 \\
\hline $0.50 \mathrm{~h}$ & $1.7^{\circ} \mathrm{C}\left(3.0^{\circ} \mathrm{F}\right)$ & 0 & $0.00 \%$ & 230 & $0.28 \%$ & 734 & $0.88 \%$ & 0 & $0.00 \%$ & 0 & $0.00 \%$ & 0 & $0.00 \%$ & 0 & 0.00 \\
\hline $1 \mathrm{~h}$ & $2.2^{\circ} \mathrm{C}\left(4.0^{\circ} \mathrm{F}\right)$ & 0 & $0.00 \%$ & 27 & $0.03 \%$ & 74 & $0.09 \%$ & 0 & $0.00 \%$ & 0 & 0.00 & 0 & $0.00 \%$ & & 0.00 \\
\hline $2 \mathrm{~h}$ & $2.8^{\circ} \mathrm{C}\left(5.0^{\circ} \mathrm{F}\right)$ & 0 & $0.00 \%$ & 0 & $0.00 \%$ & 73 & $0.09 \%$ & 0 & $0.00 \%$ & 0 & $0.00 \%$ & 0 & $0.00 \%$ & 0 & 0.00 \\
\hline $4 \mathrm{~h}$ & $3.3^{\circ} \mathrm{C}\left(6.0^{\circ} \mathrm{F}\right)$ & 0 & $0.00 \%$ & 61 & $0.07 \%$ & 0 & $0.00 \%$ & 0 & $0.00 \%$ & 0 & $0.00^{\circ}$ & 0 & $0.00 \%$ & 0 & 0.00 \\
\hline
\end{tabular}




\subsection{STATISTICAL CHARACTERIZATION OF LONG-TERM ROOM TEMPERATURE}

The analysis of the room-to-thermostat and room-to-room temperature difference per ACCA Manual RS benchmarks and cyclic discomfort per the ASHRAE Standard 55-2017 in primary (habitable) rooms revealed different thermal comfort performance between the two systems. However, to fully understand the reasons causing this difference in thermal comfort performance between the two systems, this study performed a statistical characterization of the continuously-measured long-term temperature data not only for the primary rooms but also for the attic and the basement that are thermally important due to possible heat transfer from/to the primary rooms.

Table 15 presents a summary of the 5-min average room temperature data collected from the five primary rooms (i.e., LR, KIT, MBR, BR2, and BR3) as well as the attic and the basement of the NZERTF for different system type and on/off cycle (i.e., CDHP on, CDHP off, SDHV on, and SDHV off) and seasons (i.e., cooling season, heating season, and transitional season). The one-year granular temperature data were divided by the system being on or off in addition to by season to understand how the tested systems responded to different thermal needs. A detailed explanation of the proposed data decomposition is provided in Section 6.4. Only the mean values and standard deviation were included in the table for simplicity.

To characterize the distribution more accurately, the same results were graphically presented using the graphical index proposed to display long-term thermal comfort data using a statistical analysis, as shown in Figure 13 and further discussed in Section 6.3. Multiple percentile ranks were selected to characterize extreme variations based on $\pm 1.5 \%, \pm 2.5 \%$, $\pm 5 \%$ and $\pm 10 \%$ deviations ${ }^{36}$. Data were color-coded by system types: blue for CDHP and orange for SDHV with a superimposed ACCA Manual RS benchmarks (i.e., thermostat setpoint $\pm 1.7^{\circ} \mathrm{C}\left( \pm 3^{\circ} \mathrm{F}\right)$ for a cooling season; and thermostat setpoint $\pm 1.1^{\circ} \mathrm{C}\left( \pm 2^{\circ} \mathrm{F}\right)$ for a heating season). As a result, Figures 14 to 16 graphically present the results, including the $10^{\text {th }}$ percentile for the lower whisker and the $90^{\text {th }}$ percentile for the upper whisker in addition to $1.5^{\text {th }}, 2.5^{\text {th }}, 5^{\text {th }}, 25^{\text {th }}, 50^{\text {th }}, 75^{\text {th }}, 95^{\text {th }}, 97.5^{\text {th }}$, and $98.5^{\text {th }}$ percentiles as well as minimum, mean, and maximum values for air temperature by season: cooling season in Figure 14, heating season in Figure 15, and transitional season in Figure 16.

\footnotetext{
${ }^{36}$ For example, the $1.5^{\text {th }}$ and $98.5^{\text {th }}$ percentiles were chosen to characterize data based on $\pm 1.5 \%$ deviation, which corresponds to $3 \%$ of the period in total. In the same way, the $2.5^{\text {th }}$ and $97.5^{\text {th }}$ percentiles were chosen based on $\pm 2.5 \%$ deviation (i.e., $5 \%$ of the period in total), the $5^{\text {th }}$ and $95^{\text {th }}$ percentiles were chosen based on $\pm 5 \%$ deviation (i.e., $10 \%$ of the period in total), and the $10^{\text {th }}$ and $90^{\text {th }}$ percentiles were chosen based on $\pm 10 \%$ deviation (i.e., $20 \%$ of the period in total).
} 

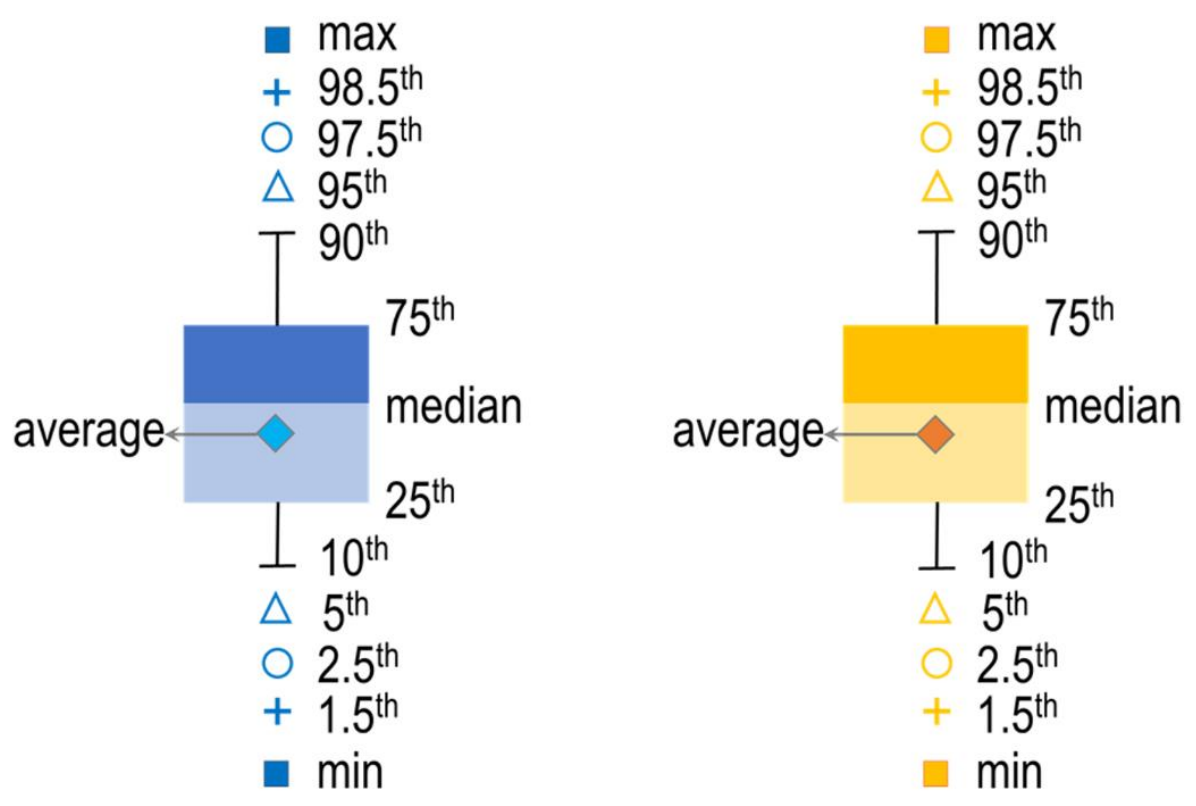

Figure 13: Graphical Index to Display Continuously-Measured 5-Min Average Thermal Comfort Data for CDHP (Left Figure) and SDHV (Right Figure).

\subsubsection{COOLING SEASON}

Important observations on the room temperature during the cooling season (Table 15 and Figure 14) are:

- Outdoor air (OA) temperature

- There was a noticeable difference in the OA temperature when the systems were on cycle versus off cycle. When the system was on, the OA temperature was higher by $5.0^{\circ} \mathrm{C}$ on average (CDHP) and $6.0^{\circ} \mathrm{C}$ on average (SDHV).

- This indicates there was a period when the systems did not necessarily provide cooling because the room temperature was maintained below the cooling setpoint temperature due to favorable weather conditions (i.e., cool OA temperature) during the swing season for a portion of the day (e.g., nighttime).

- Although this study made some efforts to define them as a separate season (i.e., transitional season), the method used in the study was based on daily average OA temperature rather than hourly or sub-hourly classification ${ }^{37}$. As a result, some days were classified as the cooling season although they had a period with low OA temperature as shown on the low side of the OA temperature distributions (i.e., minimum, $1.5^{\text {th }}$ percentile, and $2.5^{\text {th }}$ percentile values).

- Primary rooms on the first floor (i.e., LR and KIT)

- The rooms on the first floor were colder than the rooms on the second floor, of which temperatures tended to be lower than the cooling setpoint temperature (i.e., $23.8^{\circ} \mathrm{C}\left(75^{\circ} \mathrm{F}\right)$ ) for both CDHP and SHDV systems, which needs a further investigation.

- On average, there was no noticeable difference in the first-floor room temperatures between the two systems (i.e., mean values around $23.0^{\circ} \mathrm{C}$ ).

${ }^{37}$ A detailed explanation of the proposed data decomposition is provided in Section 6.4. 
However, the CDHP maintained better temporal variations with noticeably smaller interquartile ranges (i.e., IQR $=75^{\text {th }}$ quartile $-25^{\text {th }}$ quartile) compared to the SDHV.

- Especially the LR where the thermostat was located had tightly-controlled space conditions with very small IQRs and low standard deviations of $0.1^{\circ} \mathrm{C}$ (CDHP on) and $0.3^{\circ} \mathrm{C}$ (CDHP off). On the other hand, when the SDHV was in operation, the standard deviations of the LR temperature were $0.5^{\circ} \mathrm{C}$ (SDHV on) and $0.6^{\circ} \mathrm{C}$ (SDHV off), which were higher than the throttling range of the SDHV (i.e., $\pm 0.14^{\circ} \mathrm{C}$ ).

- Primary rooms on the second floor (i.e., MBR, BR2, and BR3)

- In the rooms on the second floor, there was a noticeable difference in the measured room temperatures between the two systems. The temperatures in the second-floor bedrooms (i.e., MBR, BR2, and BR3) were colder and nearer to the cooling setpoint temperature when the SDHV was operated by $0.7^{\circ} \mathrm{C}$ to $1.1^{\circ} \mathrm{C}$ on average when the systems were on cycle; and $0.5^{\circ} \mathrm{C}$ to $0.7^{\circ} \mathrm{C}$ on average when the systems were off cycle.

- This resulted in smaller room-to-room temperature differences when the SDHV was in operation, which agrees with the observations in Section 4.2.

- The CDHP tended to have smaller temporal variations (i.e., smaller ranges for the $5^{\text {th }}$ to $95^{\text {th }}, 2.5^{\text {th }}$ to $97.5^{\text {th }}$, and $1.5^{\text {th }}$ to $98.5^{\text {th }}$ distributions) compared to the SDHV.

- There were no meaningful differences in the room temperatures when the systems were on cycle versus off cycle.

- Attic and basement (BSMT)

- Like the rooms on the second floor, there was a noticeable difference in the attic temperatures between the two systems. When the SDHV was in operation, the attic temperature was colder by $1.3^{\circ} \mathrm{C}$ (on cycle) and $1.1^{\circ} \mathrm{C}$ (off cycle) on average.

- The observed favorable attic temperature, which was affected by the location of the SDHV supply ductwork within the attic, resulted in cooler second-floor room temperatures and contributed to smaller room-to-room temperature differences when the SDHV was in operation.

- Unlike other primary rooms, there was a meaningful difference in the attic temperature when the systems were on cycle versus off cycle by $0.7^{\circ} \mathrm{C}$ on average $(\mathrm{CDHP})$ and $0.5^{\circ} \mathrm{C}$ on average (SDHV) (i.e., hotter when the systems were on cycle).

- Not surprisingly, the basement temperatures were consistently colder than other rooms in the house, which might be also affected by the heat pump water heater located in the basement.

- Comparison to the ACCA Manual RS benchmarks for Primary Rooms (Higher Temperature Side):

- There were occasions when the room-to-thermostat temperature differences exceeded the ACCA Manual RS cooling benchmarks on the high side, which is a comfort penalty in the cooling season. However, the occasions were less than $2.5 \%$ of the period based on $97.5^{\text {th }}$ percentiles except for the MBR.

- A further investigation (Section 4.6) revealed that this deviation consistently occurred at a specific time of the days when the resistance heating boxes in the second-floor bedrooms were turned on to simulate internal loads (i.e., occupancy and plug loads) as scheduled. 
- Comparison to the ACCA Manual RS benchmarks for Primary Rooms (Lower Temperature Side):

- There were also occasions when the room-to-thermostat temperature differences exceeded the ACCA Manual RS cooling benchmarks on the low side, which was more frequent with the SDHV especially when it was off cycle. This can be explained by favorable weather conditions (i.e., cool OA temperature) during the system off cycle rather than a result of overcooling.

- For example, the low-side extreme variations of the OA temperature when the $\mathrm{SDHV}$ was off cycle varied from $7.0^{\circ} \mathrm{C}$ (minimum value) to $12.8^{\circ} \mathrm{C}\left(2.5^{\text {th }}\right.$ percentile value). Under these low $O A$ temperature conditions, residents are likely to switch their system from cooling mode to heating mode in actual homes, which did not happen in this occupancy-simulated house.

- However, it should be noted that the kitchen had a relatively long period of lowside deviation, which was affected by the evaporative cooling effect from the two humidifiers (i.e., latent heat gains from people and kitchen appliances) in the kitchen. The low-side deviation in the kitchen was more frequent with the SDHV and worse during the system off cycle. 
Table 15: Mean (Standard Deviation) of the 5-Min Average Room Air Temperature by the HP System Modes and Seasons.

\begin{tabular}{|c|c|c|c|c|c|c|c|c|c|c|c|c|}
\hline & \multicolumn{4}{|c|}{ Cooling Season } & \multicolumn{4}{|c|}{ Heating Season } & \multicolumn{4}{|c|}{ Transitional Season } \\
\hline & \multicolumn{2}{|c|}{ CDHP } & \multicolumn{2}{|c|}{ SDHV } & \multicolumn{2}{|c|}{ CDHP } & \multicolumn{2}{|c|}{ SDHV } & \multicolumn{2}{|c|}{ CDHP } & \multicolumn{2}{|c|}{ SDHV } \\
\hline & On & Off & On & Off & On & Off & On & Off & On & Off & On & Off \\
\hline \multicolumn{13}{|c|}{ Sample Size } \\
\hline $\begin{array}{l}\mathrm{n} \\
\text { (hours) } \\
\text { (days) }\end{array}$ & $\begin{array}{c}11856 \\
988 \\
41\end{array}$ & $\begin{array}{c}10896 \\
908 \\
38\end{array}$ & $\begin{array}{c}12336 \\
1028 \\
43\end{array}$ & $\begin{array}{c}12362 \\
1030 \\
43\end{array}$ & $\begin{array}{c}5172 \\
431 \\
18\end{array}$ & $\begin{array}{c}9516 \\
793 \\
33\end{array}$ & $\begin{array}{c}6274 \\
523 \\
22\end{array}$ & $\begin{array}{c}8414 \\
701 \\
29\end{array}$ & $\begin{array}{c}342 \\
29 \\
1\end{array}$ & $\begin{array}{c}8010 \\
668 \\
28\end{array}$ & $\begin{array}{c}790 \\
66 \\
3\end{array}$ & $\begin{array}{c}6986 \\
582 \\
24\end{array}$ \\
\hline \multicolumn{13}{|c|}{ Air Temperature $\left({ }^{\circ} \mathrm{C}\right)$} \\
\hline$O A$ & $25.1(3.7)$ & $20.1(3.9)$ & $.4(4.2)$ & $3(3.9)$ & (4.4) & $4(4.3)$ & $0.0(4.6)$ & $5.9(4.4)$ & $12.3(4.3)$ & $13.8(4.4)$ & $14.0(4.8)$ & $12.7(3.6)$ \\
\hline LR & $23.1(0.1)$ & $22.9(0.3)$ & $22.9(0.5)$ & $22.7(0.6)$ & $20.3(0.2)$ & $20.9(0.5)$ & $20.6(0.3)$ & $20.9(0.5)$ & $21.8(1.3)$ & $21.9(0.9)$ & $21.6(0.9)$ & $22.1(0.7)$ \\
\hline KIT & $22.9(0.4)$ & $22.8(0.4)$ & $23.1(0.7)$ & $22.8(0.7)$ & $20.1(0.4)$ & $20.6(0.6)$ & $20.3(0.5)$ & $20.6(0.6)$ & $21.8(1.7)$ & $21.7(1.1)$ & $21.5(1.2)$ & $22.2(0.9)$ \\
\hline MBR & $24.7(0.5)$ & $24.6(0.6)$ & $23.8(0.7)$ & $24.0(0.7)$ & $20.7(0.4)$ & $21.2(0.8)$ & $21.7(0.4)$ & $21.4(0.6)$ & $22.6(1.3)$ & $22.8(1.1)$ & $22.5(0.8)$ & $23.0(0.7)$ \\
\hline BR2 & $24.9(0.4)$ & $24.6(0.5)$ & $23.8(0.6)$ & $23.9(0.7)$ & $20.7(0.4)$ & $21.5(0.8)$ & $21.6(0.4)$ & $21.7(0.7)$ & $22.8(1.5)$ & $22.9(1.2)$ & $22.7(0.9)$ & $23.1(0.8)$ \\
\hline BR3 & $24.4(0.3)$ & $24.2(0.5)$ & $23.7(0.6)$ & $23.7(0.7)$ & $20.7(0.4)$ & $21.3(0.8)$ & $21.4(0.4)$ & $21.5(0.7)$ & $22.5(1.5)$ & $22.7(1.1)$ & $22.4(0.8)$ & $22.8(0.8)$ \\
\hline ATTIC & $26.2(0.8)$ & $25.5(0.9)$ & $24.9(0.7)$ & $24.4(0.8)$ & $20.6(0.6)$ & $21.4(0.9)$ & $22.3(0.5)$ & $22.2(0.7)$ & $22.9(1.8)$ & $23.2(1.4)$ & $23.0(0.9)$ & $23.5(0.9)$ \\
\hline BSMT & $20.7(0.3)$ & $20.8(0.4)$ & $20.3(0.6)$ & $20.7(0.7)$ & $20.4(0.5)$ & $20.1(0.5)$ & $20.7(0.5)$ & $20.2(0.6)$ & $20.8(0.8)$ & $20.2(0.6)$ & $20.3(0.8)$ & $20.7(0.8)$ \\
\hline
\end{tabular}



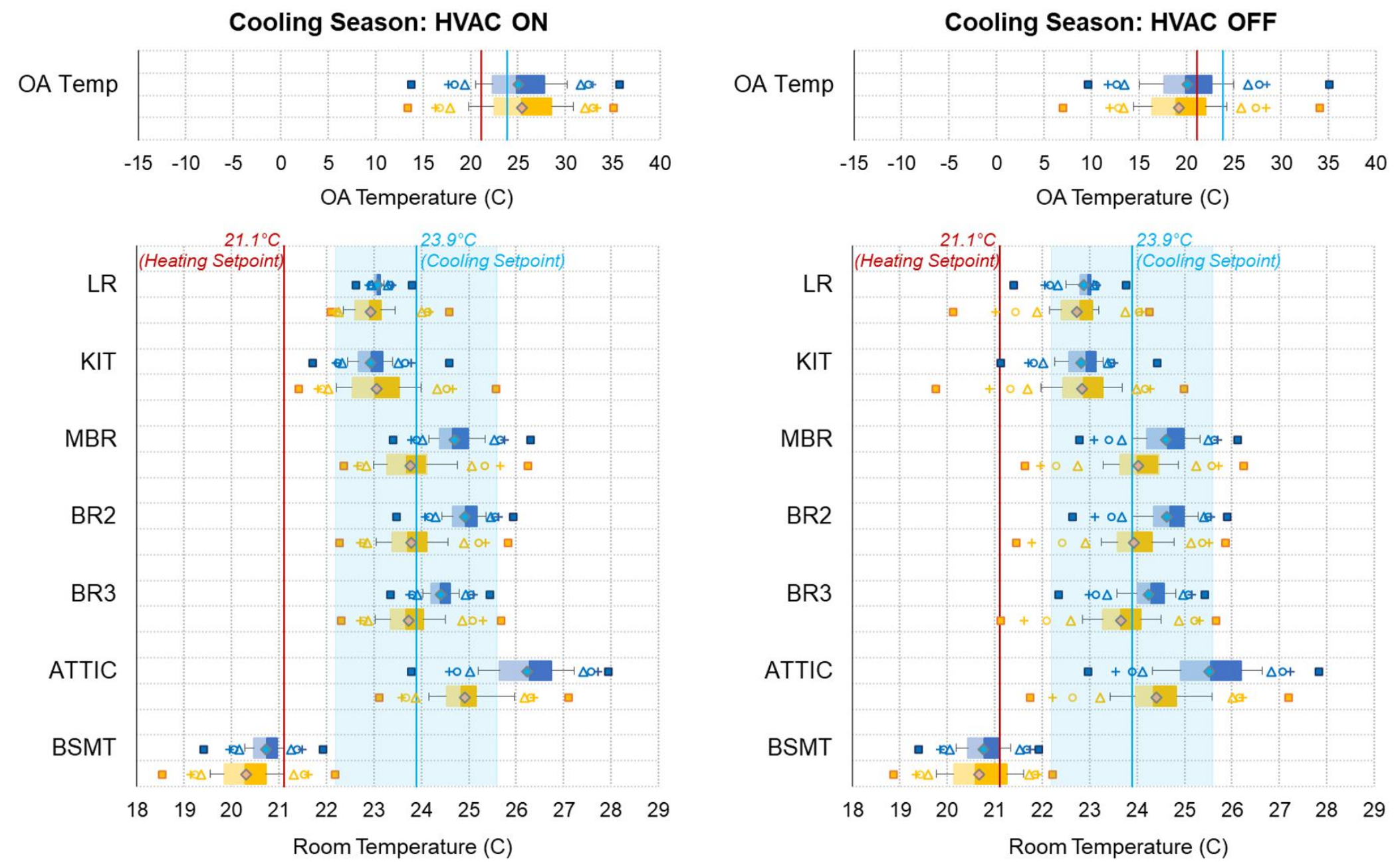

ACCA RS Benchmarks $=$ Cooling Setpoint $\pm 1.7^{\circ} \mathrm{C}\left( \pm 3.0^{\circ} \mathrm{F}\right)$

Figure 14: Graphical Summaries of the 5-Min Average Room Temperatures When the System Was On Cycle (Left Figure) and Off Cycle (Right Figure) for the Cooling Season. 


\subsubsection{HEATING SEASON}

Important observations on the room temperature during the heating season (Table 15 and Figure 15) are:

- Outdoor air (OA) temperature

- There was a noticeable difference in the OA temperature when the systems were on cycle versus off cycle. When the system was off, the OA temperature was higher by $5.4^{\circ} \mathrm{C}$ on average (CDHP) and $5.9^{\circ} \mathrm{C}$ on average (SDHV).

- This indicates there was a period when the systems did not necessarily provide heating because the room temperature was maintained above the heating setpoint temperature due to favorable weather conditions (i.e., warm OA temperature) during the swing season for a portion of the day (e.g., daytime).

- Although this study made some efforts to define them as a separate season (i.e., transitional season), the method used in the study was based on daily average OA temperature rather than hourly or sub-hourly classification. As a result, some days were classified as the heating season although they had a period with high OA temperature as shown on the high side of the OA temperature distributions (i.e., maximum and $98.5^{\text {th }}$ percentile values).

- Primary rooms on the first floor (i.e., LR and KIT)

- Like the cooling season, the rooms on the first floor were colder than the rooms on the second floor, though to a lesser extent.

- Similarly, the room temperatures tended to be lower than the heating setpoint temperature (i.e., $21.1^{\circ} \mathrm{C}\left(70^{\circ} \mathrm{F}\right)$ ) for both CDHP and SHDV systems, though to a lesser extent with the SDHV: $0.5^{\circ} \mathrm{C}$ lower in the heating season but $0.9^{\circ} \mathrm{C}$ lower in the cooling season when the system was on cycle.

- Except for the LR when the CDHP was on cycle, the observed temporal variations between the two systems were comparable.

- The LR where the thermostat was located had tightly-controlled space conditions with a very small IQR and a low standard deviation of $0.2^{\circ} \mathrm{C}$ when the CDHP was on cycle.

- Primary rooms on the second floor (i.e., MBR, BR2, and BR3)

- There was a noticeable difference in the measured room temperatures between the two systems, but the trend was opposite to the cooling season. The temperatures in the second-floor bedrooms were now warmer when the SDHV was operated by $0.7^{\circ} \mathrm{C}$ to $1.0^{\circ} \mathrm{C}$ on average during the system on cycle and $0.2^{\circ} \mathrm{C}$ on average during the system off cycle.

- This resulted in higher room-to-room temperature differences when the SDHV was in operation, which agrees with the observations in Section 4.2.

- Unlike the cooling season, the two systems tended to have comparable temporal variations.

- Unlike the cooling season, there were meaningful differences in the room temperatures when the systems were on cycle versus off cycle, which was to a greater extent with the CDHP. This indicates the system was turned off once it reached the desired temperature, which is expected.

- $\quad$ Attic and basement (BSMT) 
- Like the rooms on the second floor, there was a noticeable difference in the attic temperatures between the two systems. When the SDHV was in operation, the attic temperature was warmer by $1.7^{\circ} \mathrm{C}$ (on cycle) and $0.8^{\circ} \mathrm{C}$ (off cycle) on average.

- The observed favorable attic temperature, which was affected by the location of the SDHV supply ductwork within the attic, resulted in warmer second-floor room temperatures and now contributed to higher room-to-room temperature differences when the SDHV was in operation.

- There was a clear difference in the attic temperature when the CDHP system was on cycle versus off cycle by $0.8^{\circ} \mathrm{C}$ on average (i.e., warmer when the system was off cycle). This difference was not obvious with the SDHV system because of possible heat transfer from the SDHV supply ductwork in the attic when the system was on cycle.

- Not surprisingly, the basement temperatures were lower but to a lesser extent compared to the cooling season.

- Comparison to the ACCA Manual RS benchmarks for Primary Rooms (Higher Temperature Side):

- There were occasions when the room-to-thermostat temperature differences exceeded the ACCA Manual RS heating benchmarks on the high side, which was remarkable in the second-floor bedrooms especially when the systems were off cycle. This can be explained by the natural stratification of warm air during the system off cycle.

- The high-side deviation was less notable in the first-floor rooms, which might be affected by favorable weather conditions (i.e., warm OA temperature) rather than a result of overheating. For example, the high-side extreme variations of the $\mathrm{OA}$ temperature when the systems were off cycle varied from $15.6^{\circ} \mathrm{C}\left(97.5^{\text {th }}\right.$ percentile value) to $20.9^{\circ} \mathrm{C}$ (maximum value) with the $\mathrm{CDHP}$ and from $15.2^{\circ} \mathrm{C}\left(97.5^{\text {th }}\right.$ percentile value) to $21.9^{\circ} \mathrm{C}$ (maximum value) with the SDHV. Under these high OA temperature conditions, residents are likely to switch their system from heating mode to cooling mode in actual homes, which did not happen in this occupancysimulated house.

- Comparison to the ACCA Manual RS benchmarks for Primary Rooms (Lower Temperature Side):

- There were occasions when the room-to-thermostat temperature differences exceeded the ACCA Manual RS heating benchmarks on the low side, which is a comfort penalty in the heating season. The observed low-side deviation was worse with the CDHP. However, the occasions were less than $5.0 \%$ of the period based on $95.0^{\text {th }}$ percentiles for the second-floor bedrooms.

- The LR where the thermostat was located also had a period of low-side deviation when the CDHP was in operation. Although it was less than $10 \%$ of the period, this deviation happened over two days: mostly on December 16, 2016 and February 10, 2017. December 16, 2016 was the day when the lowest OA temperature occurred, which was $-10.4^{\circ} \mathrm{C}$. This was also the day when the low-side deviations of the second-floor bedrooms were observed. A further investigation of the CDHP electricity data revealed that the CDHP's electric resistance backup heater stayed off on both days although the LR temperature was below the heating setpoint temperature. 
- It should be noted that the kitchen had a long period of low-side deviation for both systems over $25 \%$ of the period, which was affected by the evaporative cooling effect from the two humidifiers that were operated to emulate latent heat generation and located near the measurement stand in the kitchen during the heating season. 
Heating Season: HVAC ON
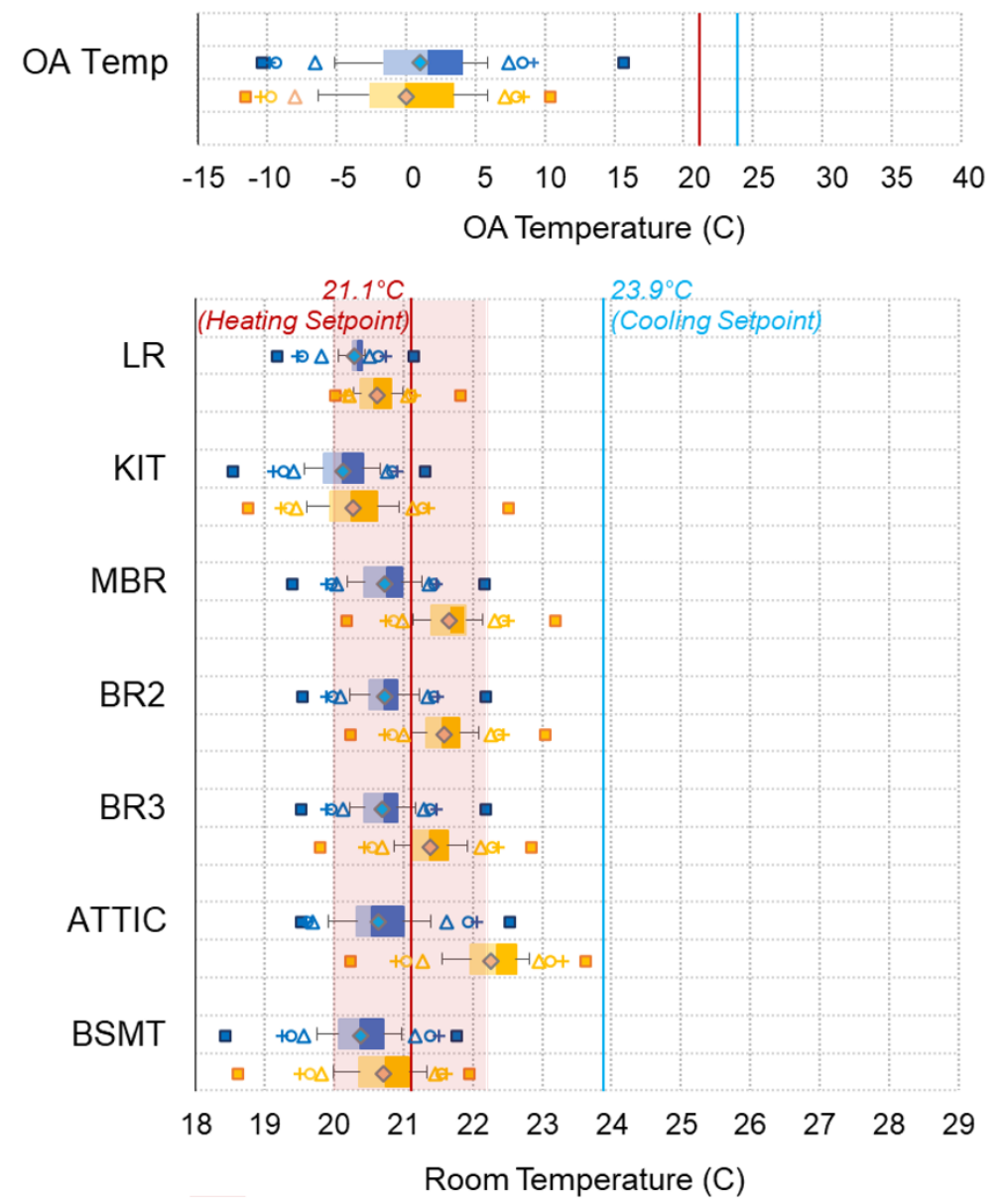

Heating Season: HVAC OFF
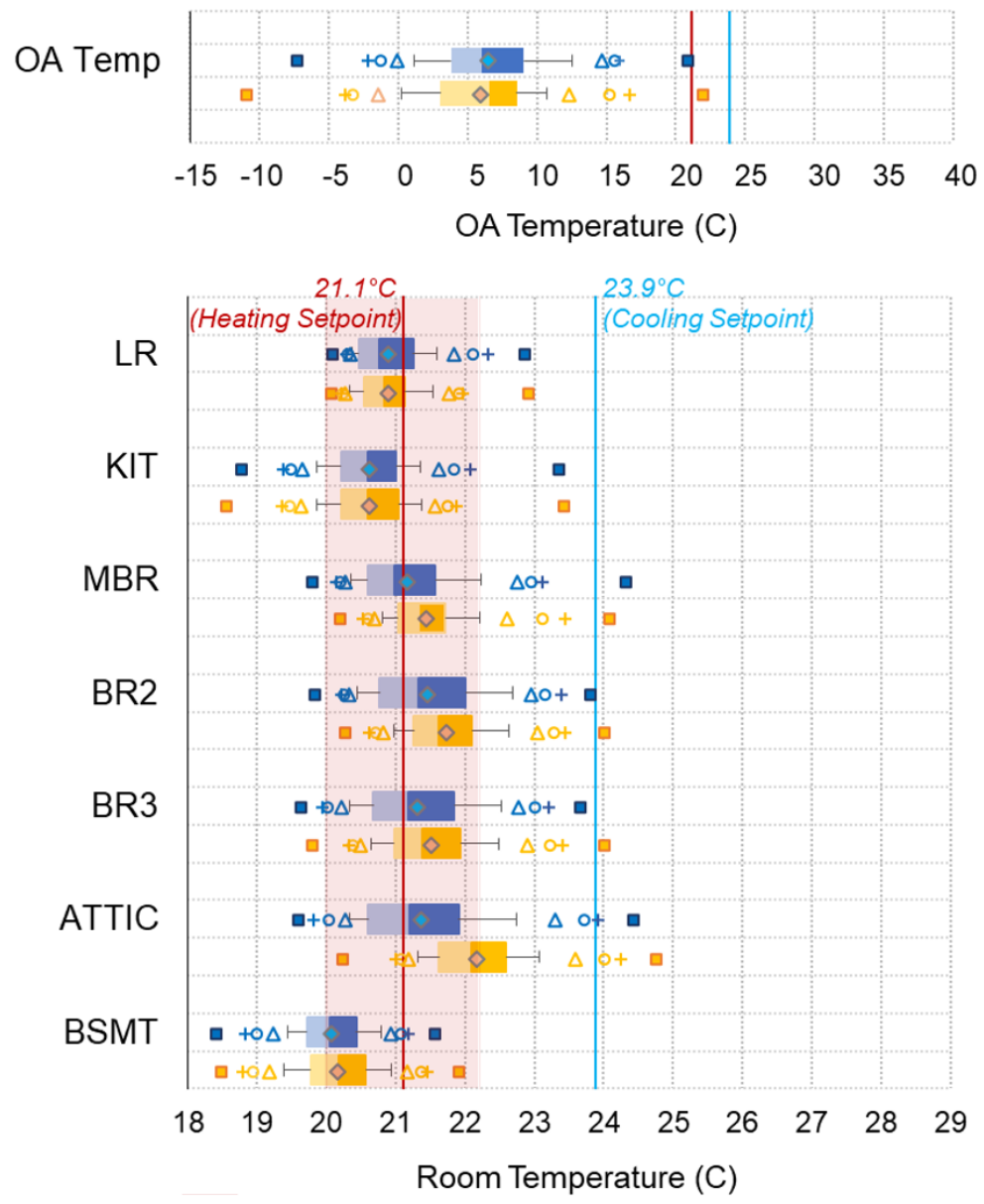

ACCA RS Benchmarks $=$ Heating Setpoint $\pm 1.1^{\circ} \mathrm{C}\left( \pm 2.0^{\circ} \mathrm{F}\right)$

Figure 15: Graphical Summaries of the 5-Min Average Room Temperatures When the System Was On Cycle (Left Figure) and Off Cycle (Right Figure) for the Heating Season. 


\subsubsection{TRANSITIONAL SEASON ${ }^{38}$}

Important observations on the room temperature during the transitional season (Table 15 and Figure 16) are:

- Outdoor air (OA) temperature

- Although the daily average OA temperature during the transitional season was between $11.2^{\circ} \mathrm{C}$ and $15.5^{\circ} \mathrm{C}^{39}$, the 5 -min $\mathrm{OA}$ temperatures had a wide temporal variation: from $1.9^{\circ} \mathrm{C}$ to $25.9^{\circ} \mathrm{C}(\mathrm{CDHP})$ and from $1.6^{\circ} \mathrm{C}$ to $23.5^{\circ} \mathrm{C}$ (SDHV) during the system off cycle. As a result, the systems were occasionally on cycle for about 29 hours (CDHP) and 66 hours (SDHV) in total, as presented in Table 15. Due to the small sample size of the system on cycle, discussion of transitional season data focuses on the data collected during the system off cycle.

- The systems were mostly off: about 668 hours (CDHP) and 582 hours (SDHV) in total. This confirms the proposed data decomposition to separate transitional days from active cooling/heating days using coincident daily OA temperature was performed as intended.

- Primary rooms on the first floor (i.e., LR and KIT)

- Like other seasons, the rooms on the first floor were colder than the rooms on the second floor due to the natural stratification of warm air.

- In general, the room temperatures were between the heating setpoint and the cooling setpoint temperatures for both systems.

- The room temperatures varied a lot more than other seasons (i.e., cooling and heating seasons), including the LR where the thermostat was located. The observed temporal variations were wider with the CDHP. A further investigation revealed that the observed high-side and low-side deviations of the CDHP, which caused wider temporal variations with the CDHP, mostly occurred over the four days of which OA temperatures were relatively higher when the CDHP was in the heating mode (i.e., February 24 and 25, 2017) or lower when the CDHP was in the cooling mode (i.e., April 8 and 9, 2017), which is discussed in Section 4.6.1.

- Primary rooms on the second floor (i.e., MBR, BR2, and BR3)

- Like the first-floor rooms, the room temperatures were between the heating setpoint and the cooling setpoint temperatures for both systems.

- Unlike other seasons, there was not a noticeable difference in the measured room temperatures between the two systems on average, but the observed temporal variations were wider with the CDHP because of the high-side and low-side deviations of the CDHP that mostly occurred over the four specific days, as noted above.

\footnotetext{
${ }^{38}$ As discussed in Section 4.1.3, the transitional season was defined to separately analyze the period when the HP systems did not necessarily provide cooling or heating while maintaining room temperatures below cooling setpoint temperature during the cooling mode; or above heating setpoint temperature during the heating mode, which naturally occurred due to favorable weather conditions rather than a result of the system's undesirable overcooling or overheating due to favorable weather conditions rather than overcooling or overheating. In actual homes, residents are likely to switch their system from one mode to the other mode as needed under these conditions, which did not happen in this occupancy-simulated house.

${ }^{39}$ A detailed explanation of the proposed data decomposition is provided in Section 6.4.
} 
- Attic and basement (BSMT)

- There was not a noticeable difference in the attic temperatures between the two systems on average, but the observed temporal variations were wider with the $\mathrm{CDHP}$, which agrees with the observations made for primary rooms.

- Like other seasons, the basement temperatures were consistently colder than other rooms in the house.

- Comparison to the ACCA Manual RS benchmarks for Primary Rooms (Higher Temperature Side):

- Only for the master bedroom, there were a few occasions when the room-tothermostat temperature differences exceeded the ACCA Manual RS cooling benchmarks on the high side, which was less than $1.5 \%$ of the period.

- Comparison to the ACCA Manual RS benchmarks for Primary Rooms (Lower Temperature Side):

- There were occasions when the room-to-thermostat temperature differences exceeded the ACCA Manual RS heating benchmarks on the low side in the firstfloor bedrooms due to low OA temperature when the system was in the cooling mode. The deviation was more obvious in the kitchen, which might be also affected by the evaporative cooling effect from the two humidifiers that were operated to emulate latent heat generation in the house. 
Transitional Season: HVAC ON
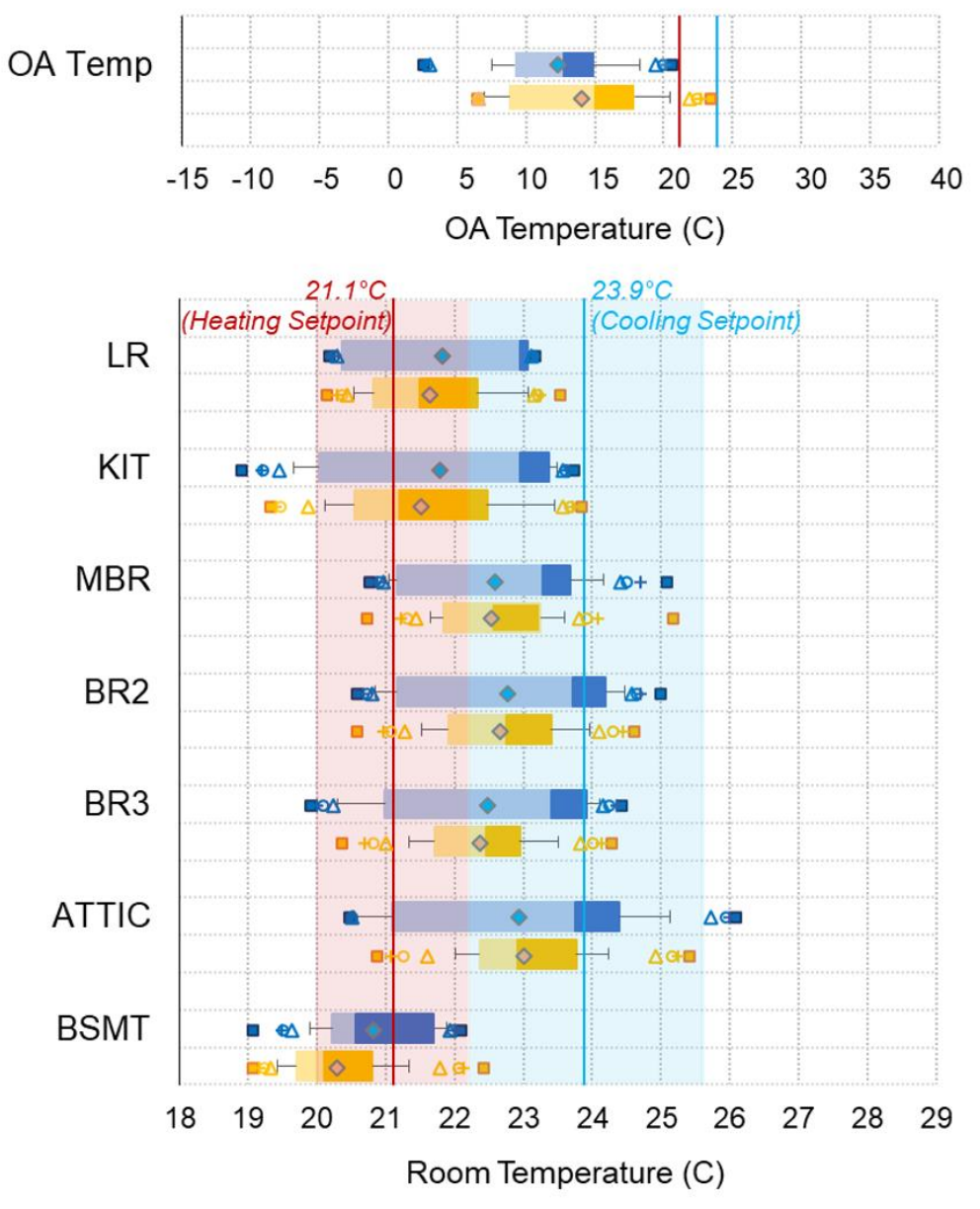

Transitional Season: HVAC OFF
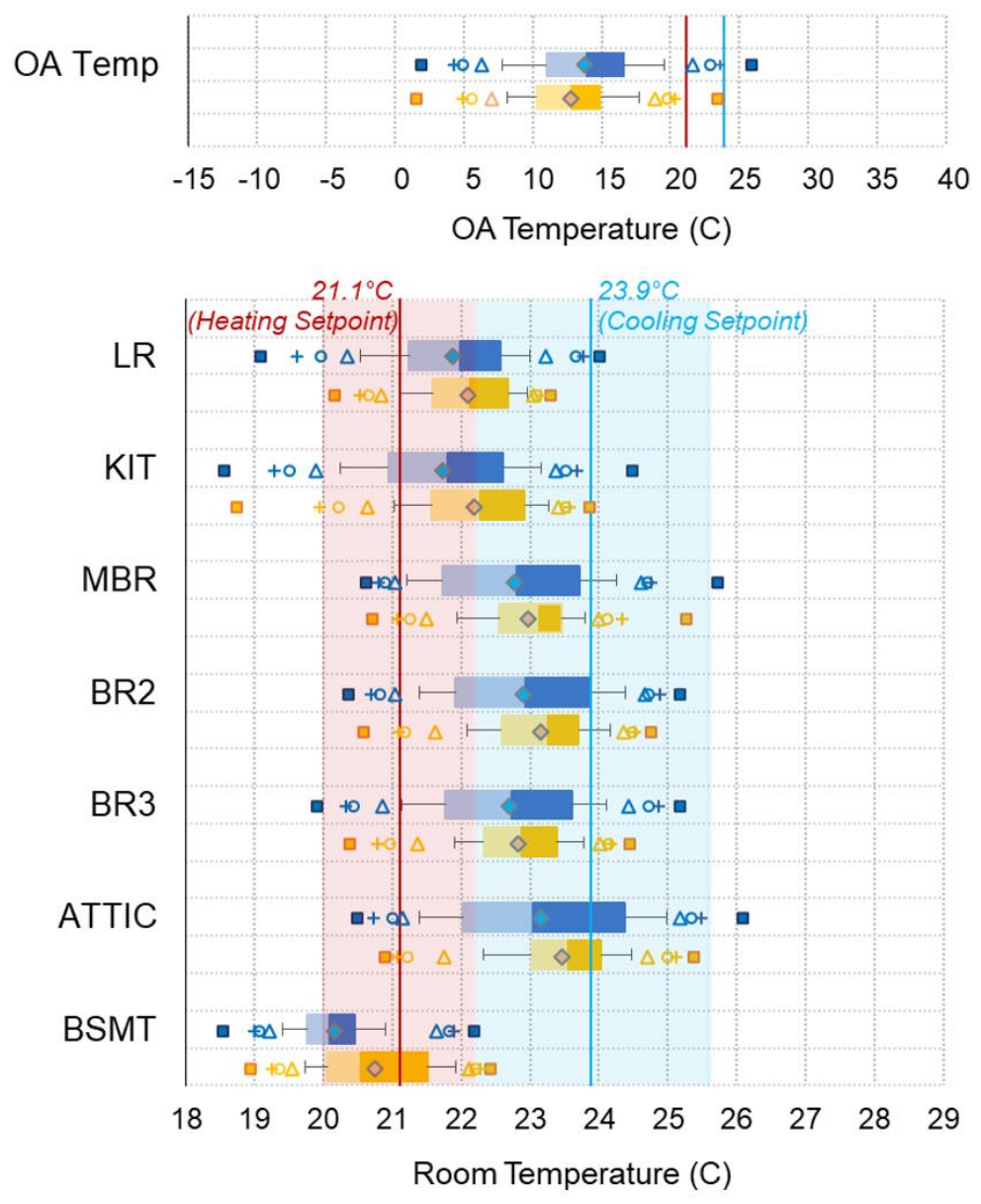

$$
\begin{aligned}
& \text { ACCA RS Benchmarks }=\text { Cooling Setpoint } \pm 1.7^{\circ} \mathrm{C}\left( \pm 3.0^{\circ} \mathrm{F}\right) \\
& \text { ACCA RS Benchmarks }=\text { Heating Setpoint } \pm 1.1^{\circ} \mathrm{C}\left( \pm 2.0^{\circ} \mathrm{F}\right)
\end{aligned}
$$

Figure 16: Graphical Summaries of the 5-Min Average Room Temperatures When the System Was On Cycle (Left Figure) and Off Cycle (Right Figure) for the Transitional Season. 


\subsection{ADVANCED CHARACTERIZATION OF TEMPORAL VARIATIONS RELATED TO OUTDOOR TEMPERATURE}

To better understand the observed temporal variations of the long-term room temperature data, which was revealed from a statistical analysis, this study performed an advanced characterization of the measured room temperature data. First, this study characterized variations of the measured room temperature data related to outdoor climate using a $5^{\circ} \mathrm{C}$ $\left(9^{\circ} \mathrm{F}\right)$ binned quartile analysis, which also allowed a weather-normalized characterization and comparison of the impact of the two tested systems on thermal comfort.

\subsubsection{INDIVIDUAL ROOM RESULTS}

The results of the binned room air temperature against outdoor temperature are presented in Figures 17 to 23 for the five primary rooms (i.e., LR, KIT, MBR, BR2, and BR3) as well as the attic and the basement of the house. Appendix $D$ provides the results for other rooms (i.e., DR, BR4, WD, MBA1, BA1, and BA2) as supplementary materials to avoid redundancy. Each figure consists of the four plots: (a) CDHP on cycle; (b) CDHP off cycle; (c) SDHV on cycle; and (d) SDHV off cycle.

Important observations are:

- LR during the system on cycle (Figure 17 (a) and (c))

- The LR temperature where the thermostat was located was consistently lower than the setpoint temperature regardless of outdoor air temperature, which needs a further investigation considering the proximity of the thermostat to the LR measurement stand.

- The CDHP controlled room temperatures much tighter than the SDHV regardless of outdoor air temperature. This also needs a further investigation considering the comparable throttling range between the two systems: $\pm 0.1^{\circ} \mathrm{C}(\mathrm{CDHP})$ and $\pm 0.14^{\circ} \mathrm{C}(\mathrm{SDHV})$.

- The LR appeared to have lower room temperatures with higher variation (i.e., larger IQR) at the very low $O A$ temperatures (i.e., $-10^{\circ} \mathrm{C}$ and $-5^{\circ} \mathrm{C} O A$ temperature bins) only when the CDHP was operated. This indicates the CDHP's smaller heating capacity $(7.8 \mathrm{~kW})$ could not meet the heating setpoint temperatures at these low OA temperatures ${ }^{40}$, while the SDHV of which heating capacity was 10.3 $\mathrm{kW}$ did not exhibit the same trend.

- On the other hand, at the high OA temperatures, the SDHV appeared to have slightly higher room temperatures with more frequency exceeding the cooling setpoint temperature compared to the CDHP.

- LR during the system off cycle (Figure 17 (b) and (d))

- Not surprisingly, the LR temperatures during the system off cycle had higher temporal variations, which occurred to a greater extent at the mild OA temperatures (i.e., $10^{\circ} \mathrm{C}$ and $15^{\circ} \mathrm{C} \mathrm{OA}$ temperature bins).

- Compared to the conditions during the CDHP on cycle, the room temperatures during the CDHP off cycle were warmer at the low OA temperatures but slightly

\footnotetext{
${ }^{40}$ The CDHP's electric resistance backup heater stayed off although the LR temperature was below the heating setpoint temperature.
} 
lower or almost identical at the high $\mathrm{OA}$ temperature. This might be affected by the very tight throttling range of the $\operatorname{CDHP}\left(\right.$ i.e., $\pm 0.1^{\circ} \mathrm{C}$ ).

- When the SDHV was operated, there was also no obvious difference in the maintained room air temperatures between the system on and off cycle except for the high $\mathrm{OA}$ temperature bins. At the very high $\mathrm{OA}$ temperatures (i.e., $30^{\circ} \mathrm{C}$ and $35^{\circ} \mathrm{C}$ OA temperature bins), the room temperatures during the SDHV off cycle tended to be warmer than the room temperatures during the SDHV on cycle. This is contrary to the expectation.

- $\quad$ KIT during the system on cycle (Figure 18 (a) and (c))

- Not surprisingly, the kitchen had larger temporal variations than the living room.

- Similar to the LR results, the kitchen temperature was consistently lower than the setpoint temperature regardless of outdoor air temperature, and the CDHP tended to have tighter room temperatures than the SDHV, which occurred to a greater extent at high $\mathrm{OA}$ temperatures. The kitchen also appeared to have lower room temperatures at the low $\mathrm{OA}$ temperatures (i.e., $-10^{\circ} \mathrm{C}$ and $-5^{\circ} \mathrm{C} O A$ temperature bins) only with the CDHP of which heating capacity was smaller than the SDHV.

- One interesting trend observed in the kitchen with the CDHP was the kitchen temperatures decreased with increasing outdoor temperatures during the cooling season. This is the opposite of the trends observed in other primary rooms and indicates a possible overcooling issue in the kitchen at the higher OA temperatures with the CDHP, which needs a further investigation.

- KIT during the system off cycle (Figure $18(b)$ and (d))

- Similar to the LR results, the kitchen temperatures during the CDHP off cycle were warmer at the low OA temperatures but slightly lower or almost identical at the high OA temperature except for the very high OA temperature conditions (i.e., $30^{\circ} \mathrm{C}$ and $35^{\circ} \mathrm{C} O A$ temperature bins). At the very high $\mathrm{OA}$ temperature conditions, the kitchen temperatures during the off cycle were warmer than the temperatures during the on cycle. As a result, the observed counter-intuitive trend during the system on cycle occurred to a lesser extent. This also indicates a possible overcooling issue in the kitchen in hot summer days.

- When the SDHV was operated, the same trend as the LR (i.e., warmer kitchen temperature during the system off cycle) was observed, which is contrary to the expectation.

- MBR during the system on cycle (Figure 19 (a) and (c))

- Unlike the first-floor rooms, there was an obvious difference in the maintained MBR room temperatures between the two systems under the same OA temperatures. The SDHV maintained the MBR warmer at the low OA temperatures but cooler at the high OA temperatures than the conditions maintained with the CDHP, which was affected by favorable attic temperatures due to the SDHV supply ductwork within the attic.

- Although similar observations were made based on a statistical characterization of the long-term temperature data by season in Section 4.4, it was not clear whether the observed trend was affected by the outdoor weather conditions. However, this advanced characterization of temperature data related to the OA temperature 
could confirm that the observed trend was not related to outdoor weather conditions.

- Similar to the LR and the kitchen results, the MBR also appeared to have lower room temperatures at the low $\mathrm{OA}$ temperatures (i.e., $-10^{\circ} \mathrm{C}$ and $-5^{\circ} \mathrm{C} \mathrm{OA}$ temperature bins) only with the CDHP of which heating capacity was smaller than the SDHV.

- MBR during the system off cycle (Figure 19 (b) and (d))

- When the CDHP was operated, there was no obvious difference in the room temperatures on average between the system on and off cycle except for the mild OA temperature conditions.

- When the SDHV was operated, the room temperatures during the SDHV off cycle tended to be cooler at the low OA temperatures but warmer at the high OA temperatures than the room temperatures during the SDHV on cycle. This might indicate the reduced heat transfer from the attic that had favorable conditions to the rooms when the SDHV was off cycle.

- $\quad$ BR2 and BR3 during the system on cycle (Figures 20 and 21 (a) and (c))

- The BR2 and the BR3 had very similar trends to that of the MBR.

- BR2 and BR3 during the system off cycle (Figures 20 and 21 (b) and (d))

- When the CDHP was operated, the room temperatures during the CDHP off cycle were slightly warmer at the low OA temperatures but almost identical at the high OA temperature.

- When the SDHV was operated, both bedrooms had trends resembling the MBR.

- Attic during the system on cycle (Figure 22 (a) and (c))

- Like the second-floor bedrooms, there was an obvious difference in the maintained attic temperatures between the two systems under the same OA temperatures. The SDHV maintained the attic warmer at the low OA temperatures but cooler at the high OA temperatures than the conditions maintained with the CDHP, which was caused by the SDHV supply ductwork within the attic.

- At the low OA temperatures, attic temperatures were maintained relatively constant for both systems. However, at the high OA temperatures, attic temperatures continuously increased with increasing $O A$ temperatures with a fairly constant rate of increase.

- Attic during the system off cycle (Figure $22(b)$ and (d))

- When the CDHP was operated, the room temperatures during the CDHP off cycle were warmer at the low OA temperatures but cooler at the high OA temperature.

- When the SDHV was operated, there was no obvious difference in the room temperatures between the system on and off cycle in general, which might result from unexpected interaction between the SDHV supply ductwork and the attic conditions.

- Basement during the system on cycle (Figure 23 (a) and (c))

- The basement temperatures did not show a relationship with outdoor temperatures and had similar room temperatures across the year, which was colder than other rooms in the house. This might be affected by the heat pump 
water heater located in the basement. A further investigation is needed to quantify the possible cooling effect of the heat pump water heater to this outcome.

- The SDHV maintained the basement warmer at the low OA temperatures but cooler at the high OA temperatures than the conditions maintained with the CDHP, which agrees with the observations made for the attic though to a much lesser extent. The SDHV supply ductwork for the first floor is located in the basement.

- Basement during the system off cycle (Figure 23 (b) and (d))

- There was no clear difference in the basement temperatures between the system on and off cycle. 


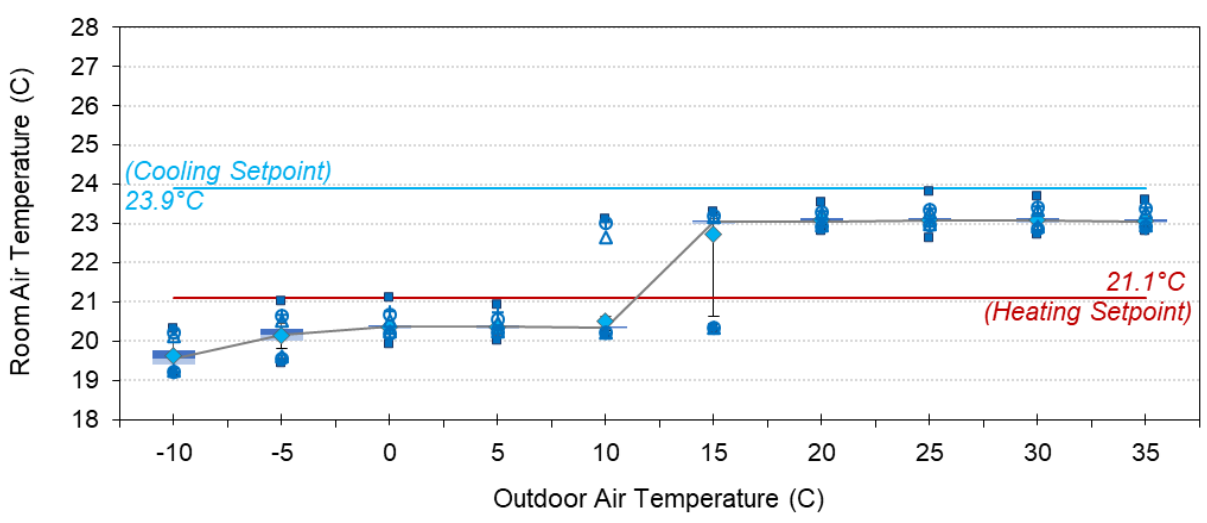

(a) CDHP On

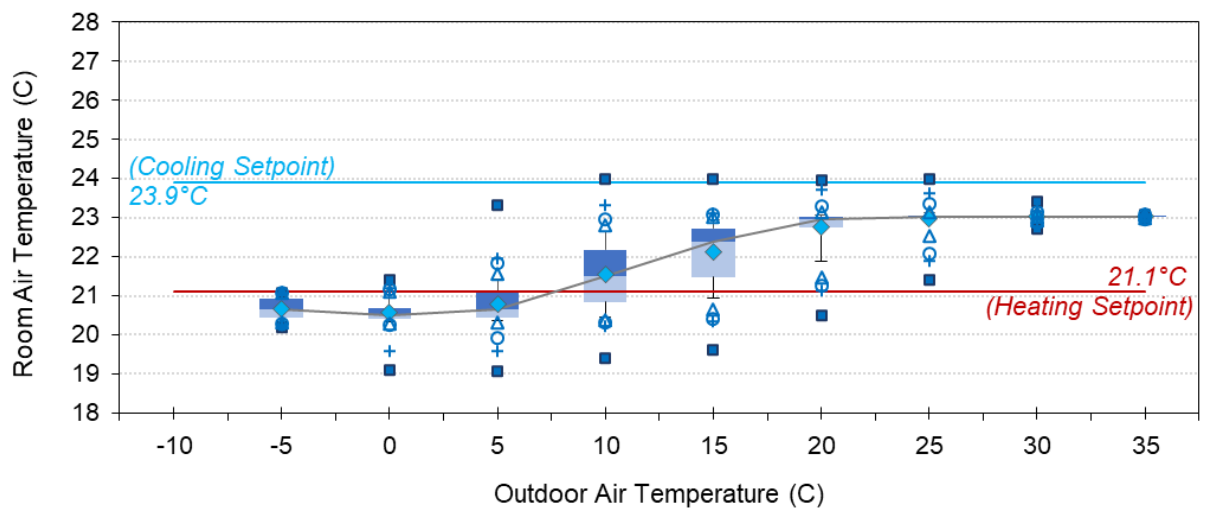

(b) CDHP Off

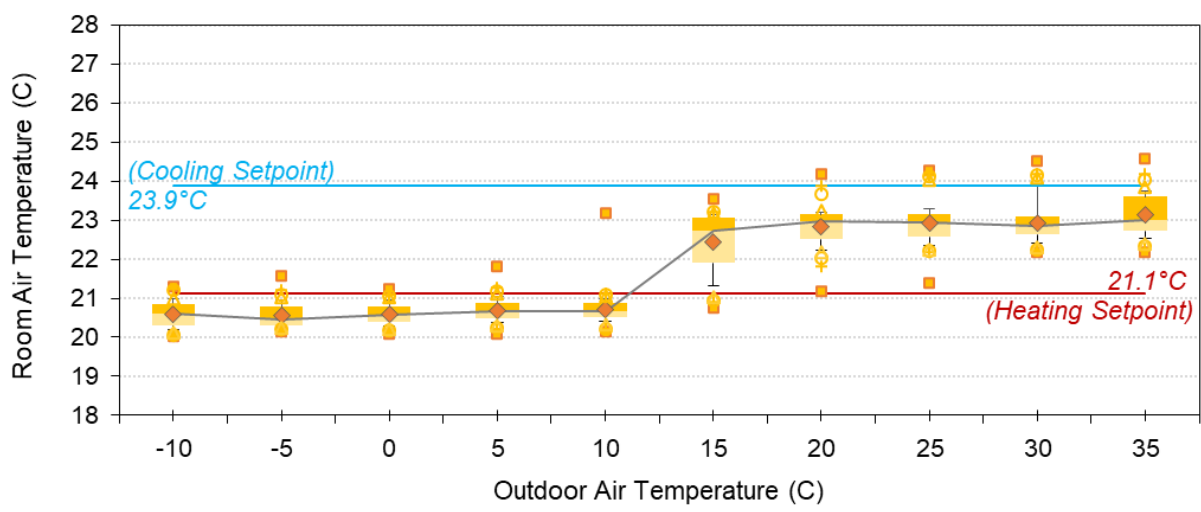

(c) SDHV On

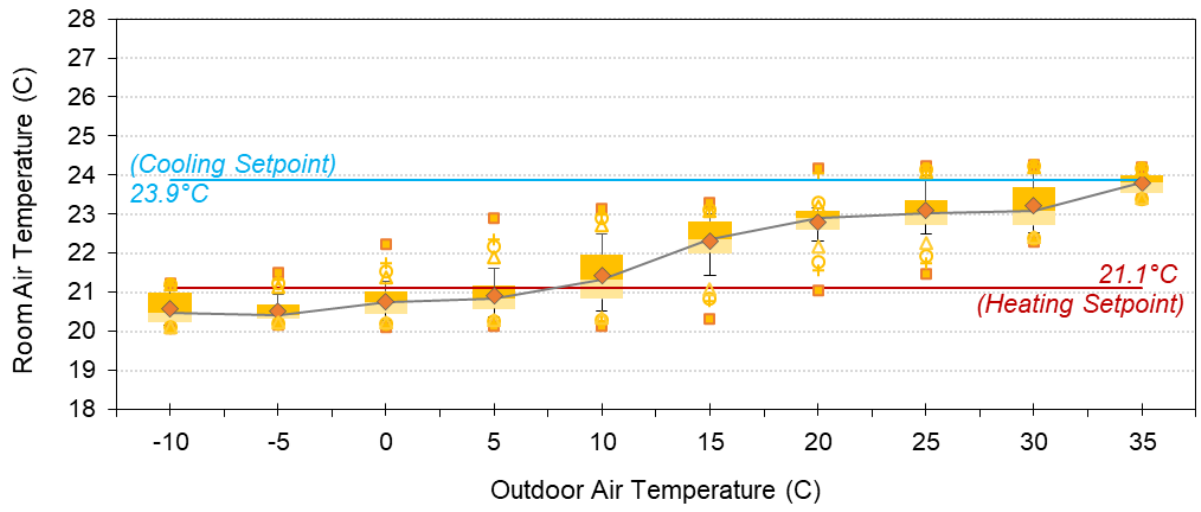

(d) SDHV Off

Figure 17: Binned LR Room Air Temperatures Against Outdoor Temperatures. 


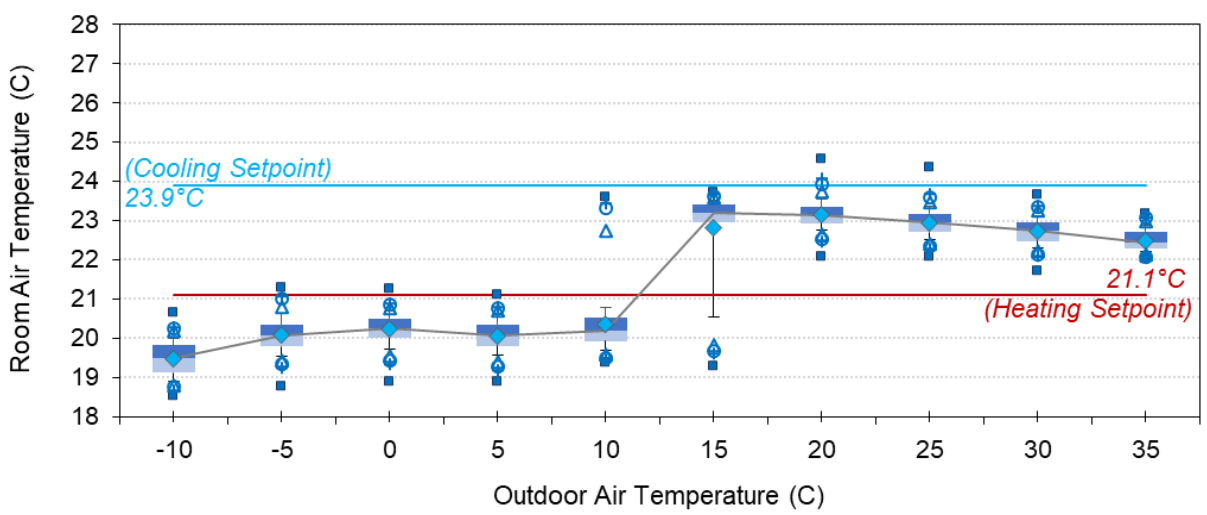

(a) CDHP On

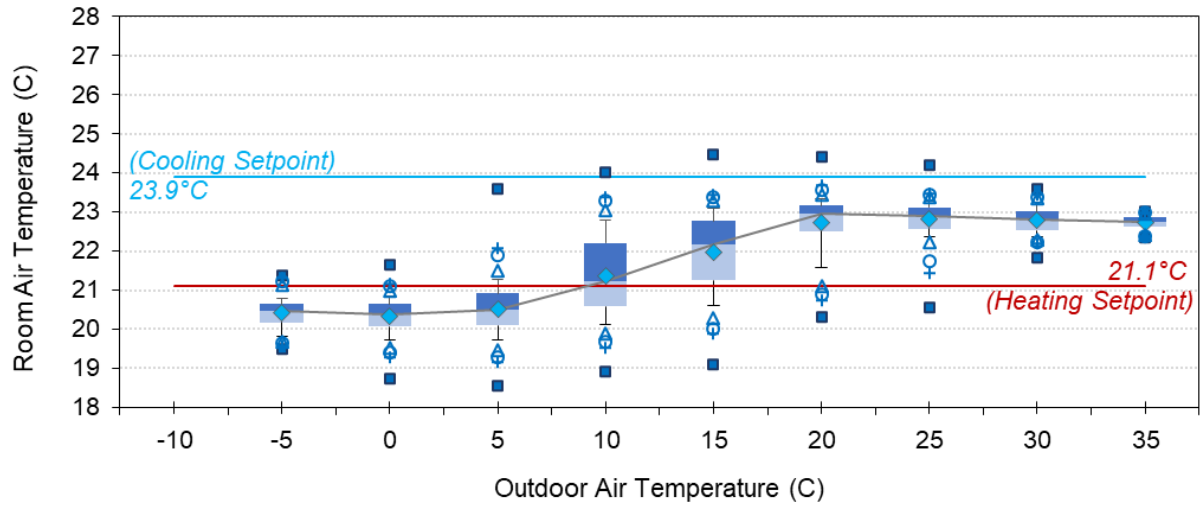

(b) CDHP Off

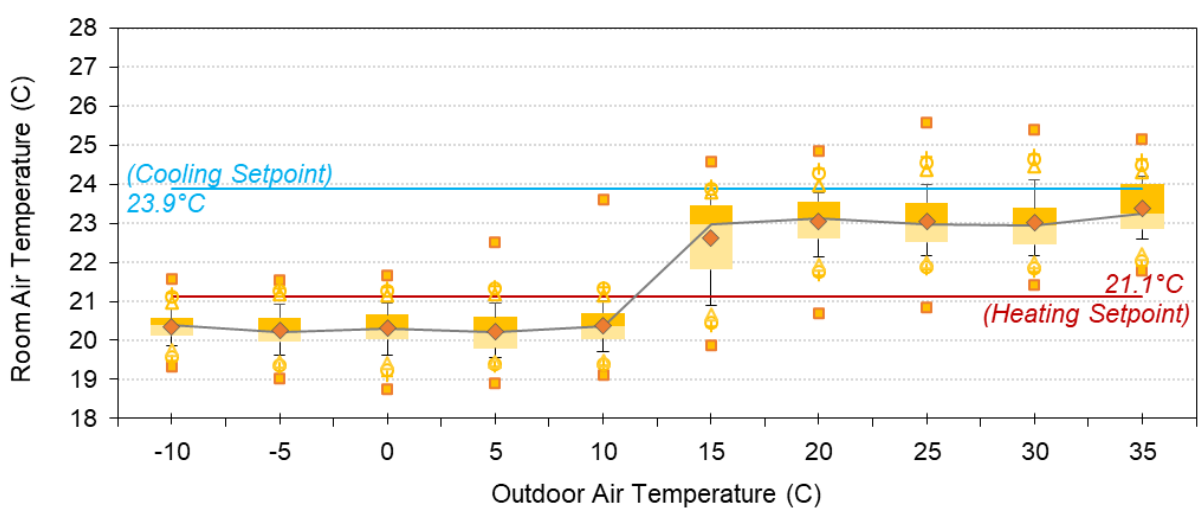

(c) SDHV On

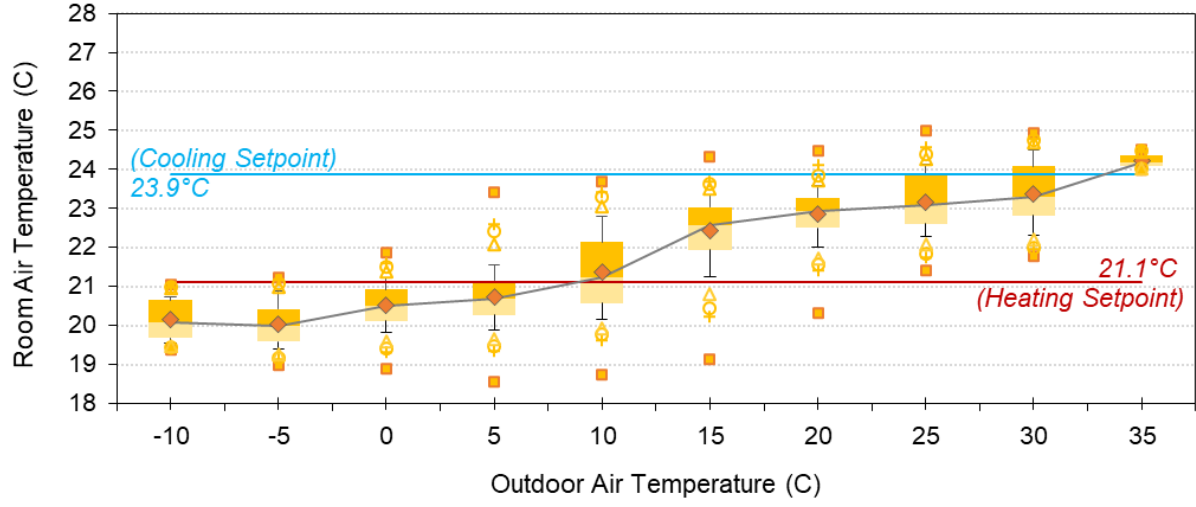

(d) SDHV Off

Figure 18: Binned KIT Room Air Temperatures Against Outdoor Temperatures. 


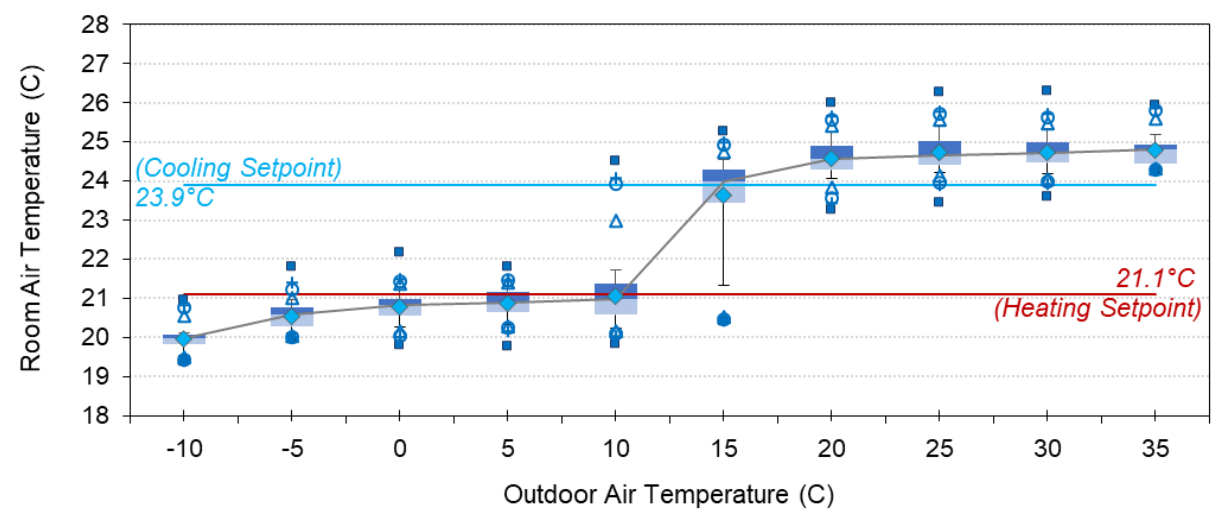

(a) CDHP On

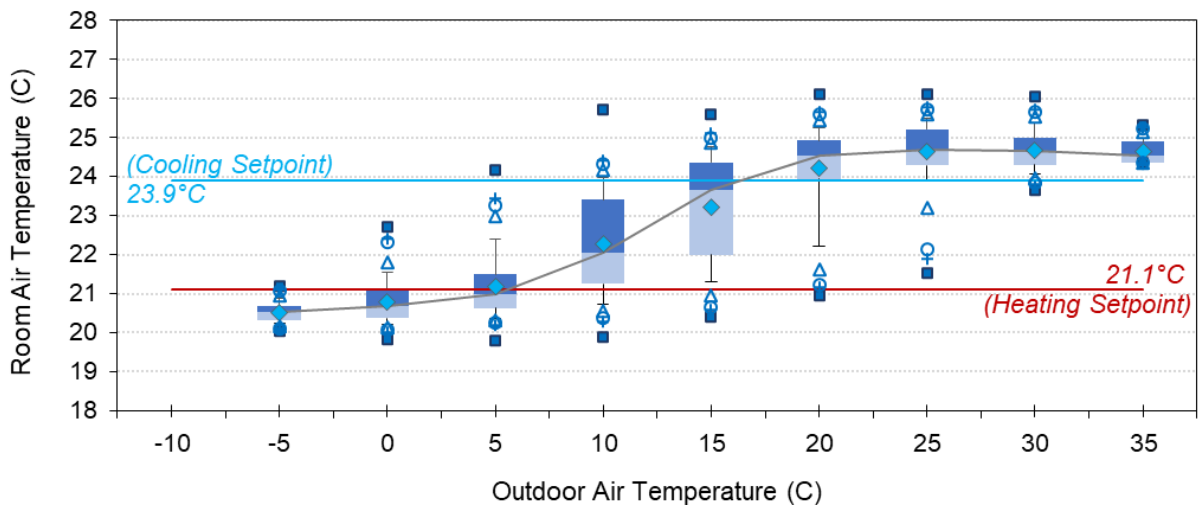

(b) CDHP Off

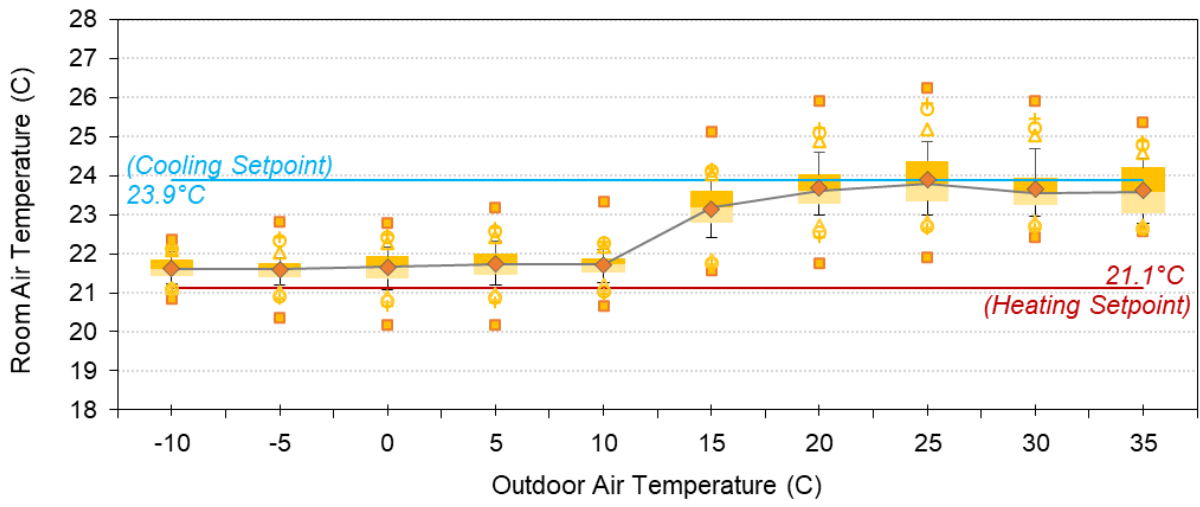

(c) SDHV On

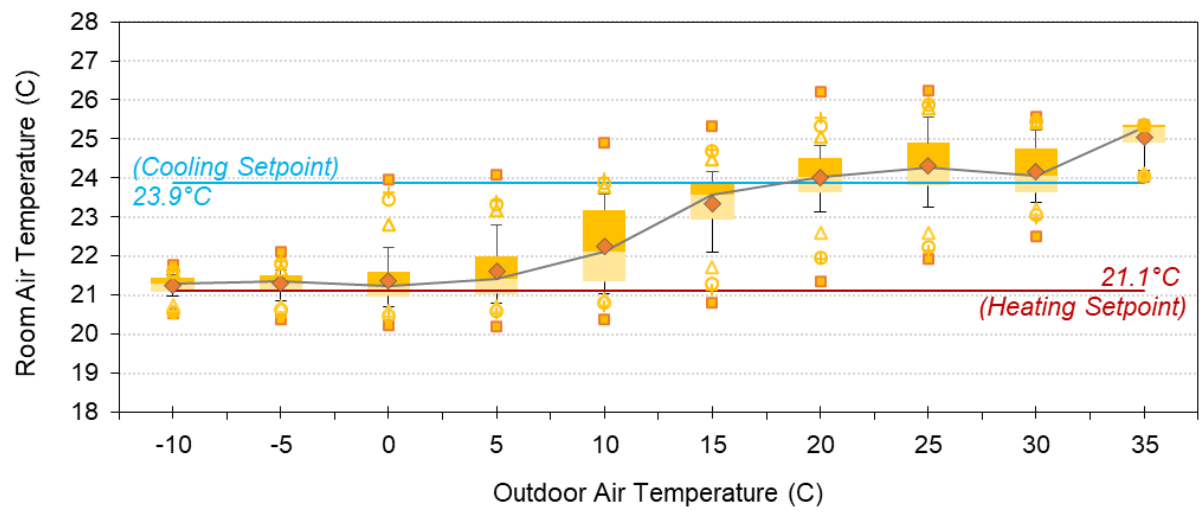

(d) SDHV Off

Figure 19: Binned MBR Room Air Temperatures Against Outdoor Temperatures. 


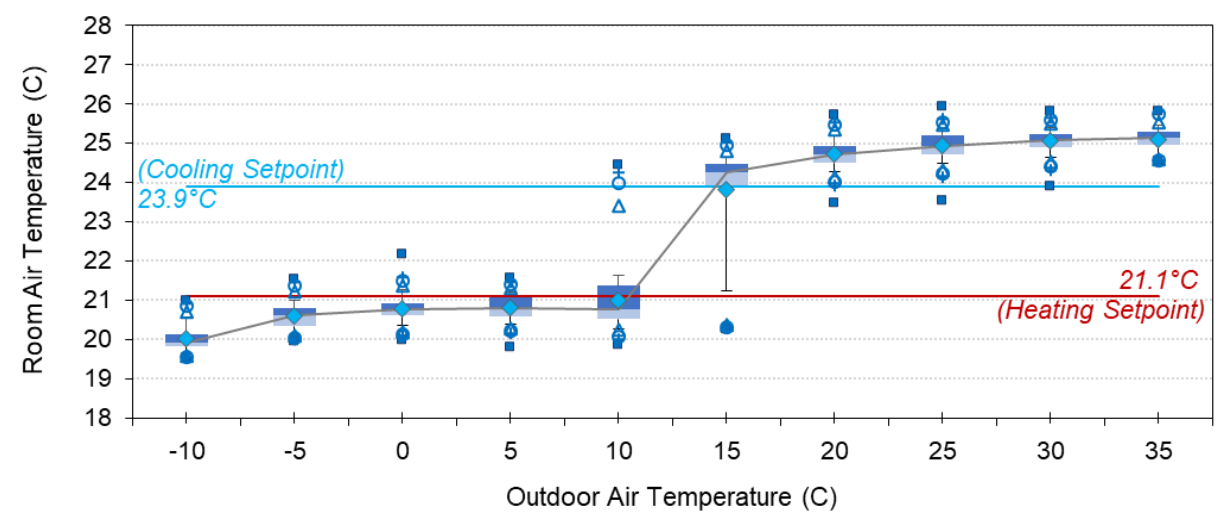

(a) CDHP On

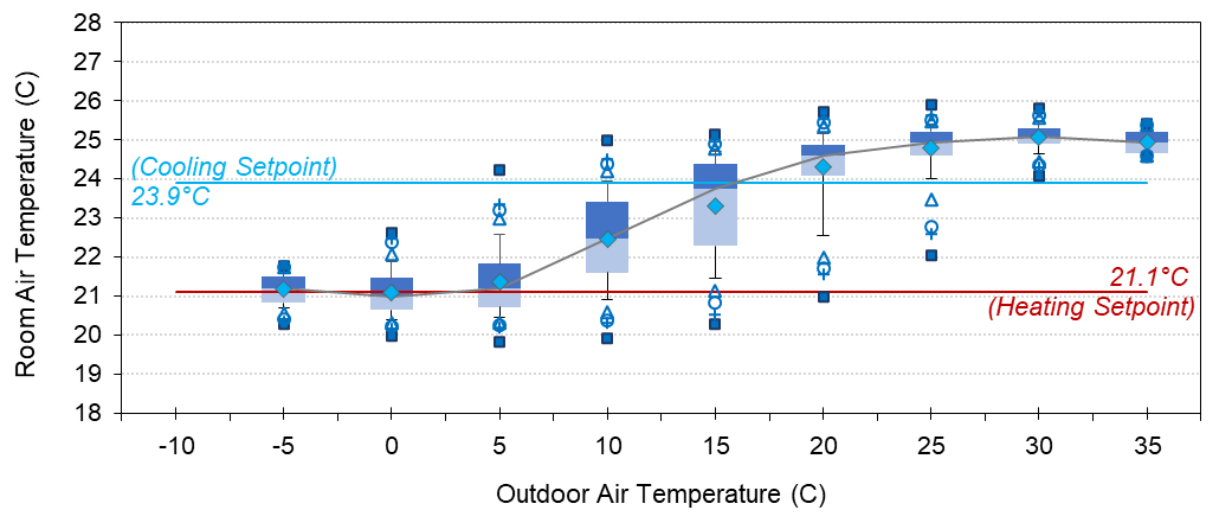

(b) CDHP Off

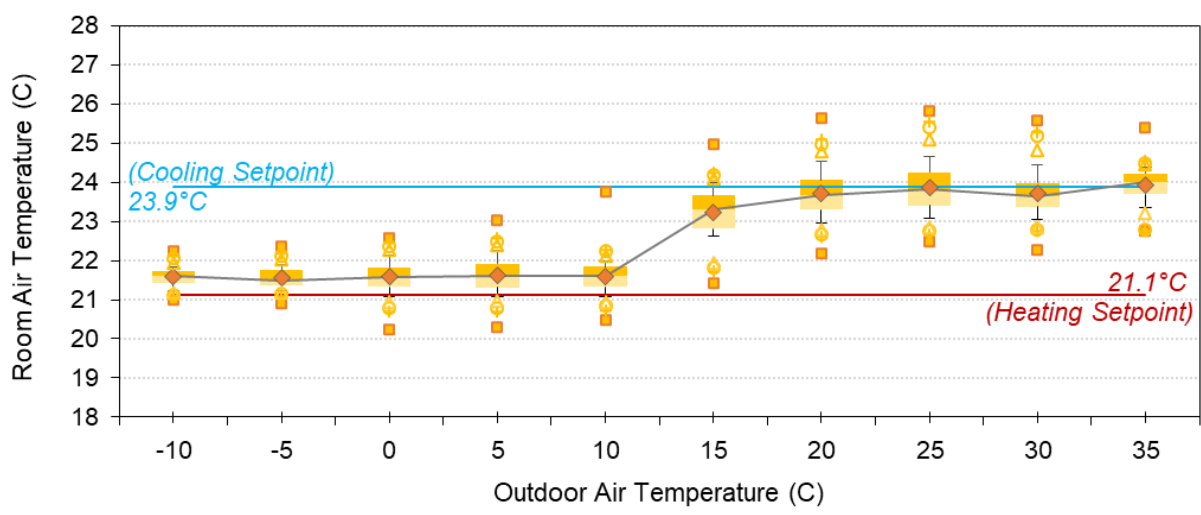

(c) SDHV On

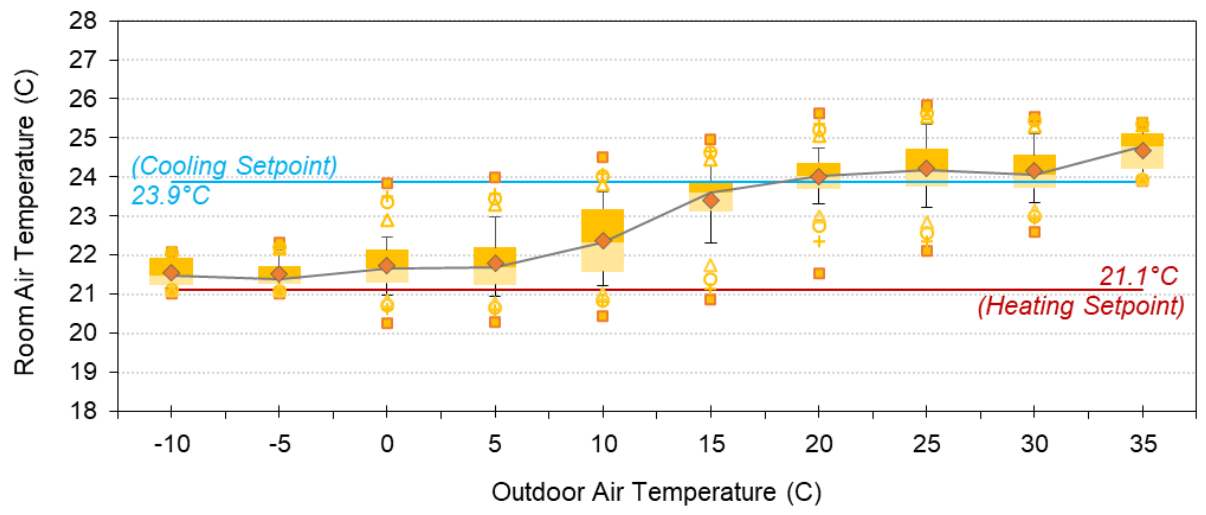

(d) SDHV Off

Figure 20: Binned BR2 Room Air Temperatures Against Outdoor Temperatures. 


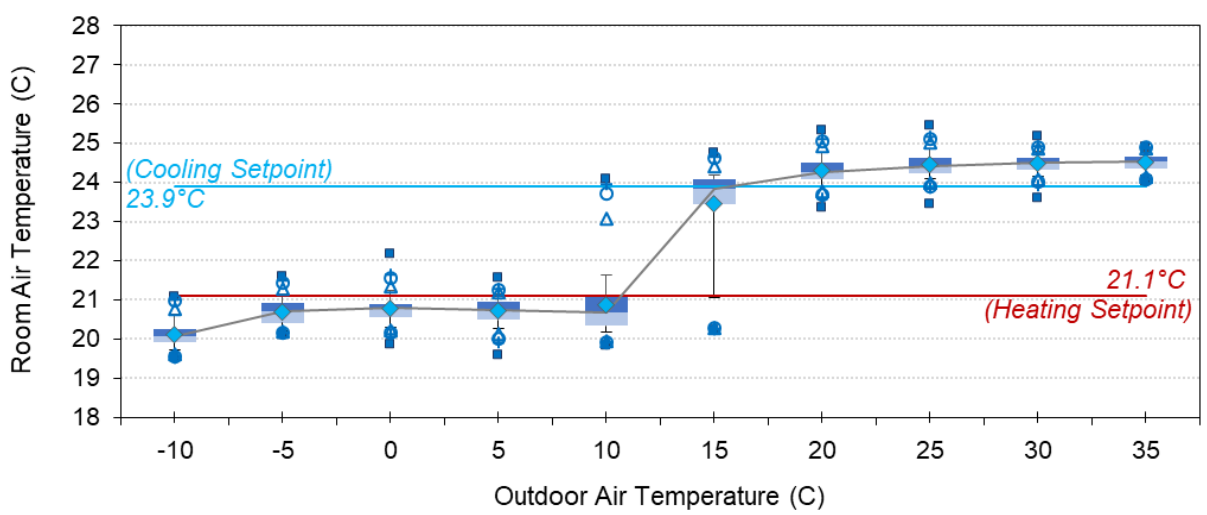

(a) CDHP On

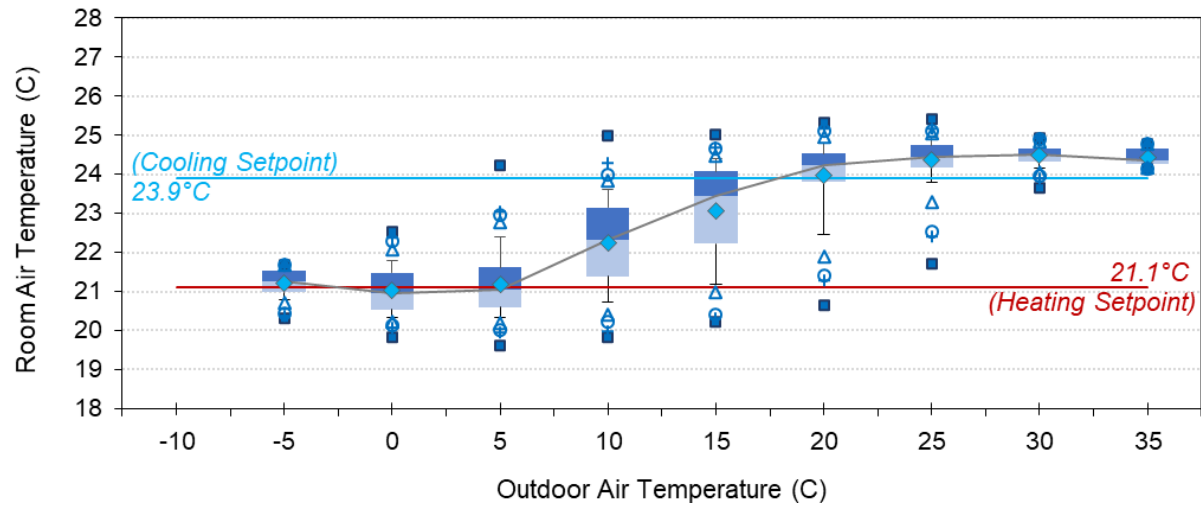

(b) CDHP Off

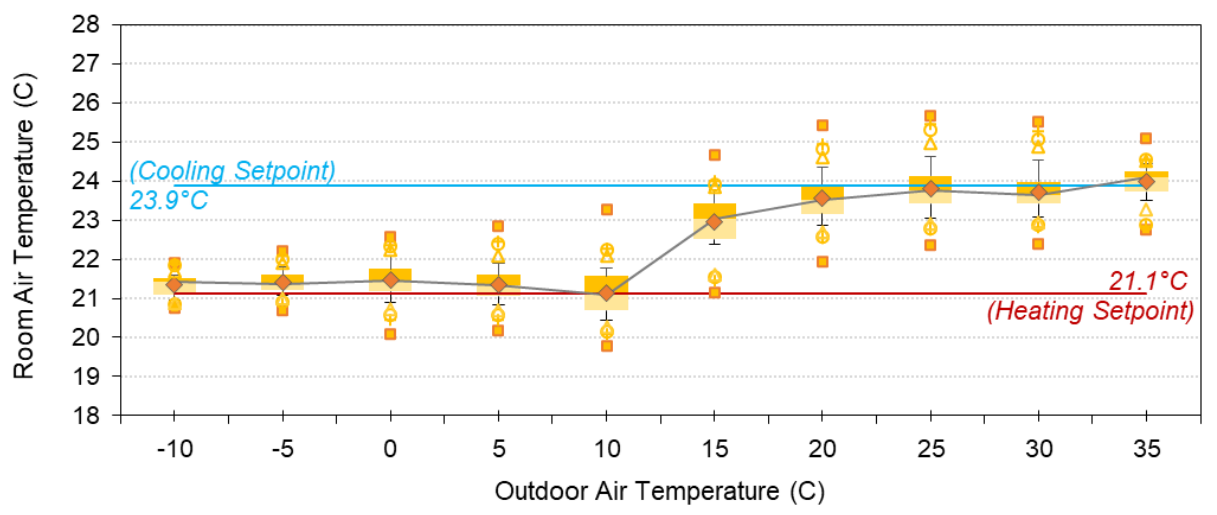

(c) SDHV On

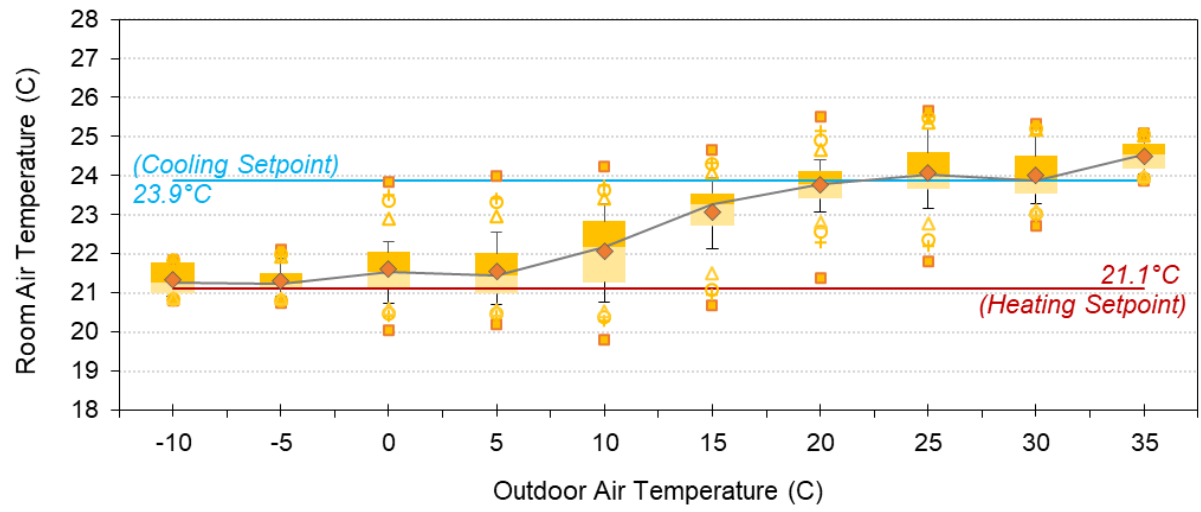

(d) SDHV Off

Figure 21: Binned BR3 Room Air Temperatures Against Outdoor Temperatures. 


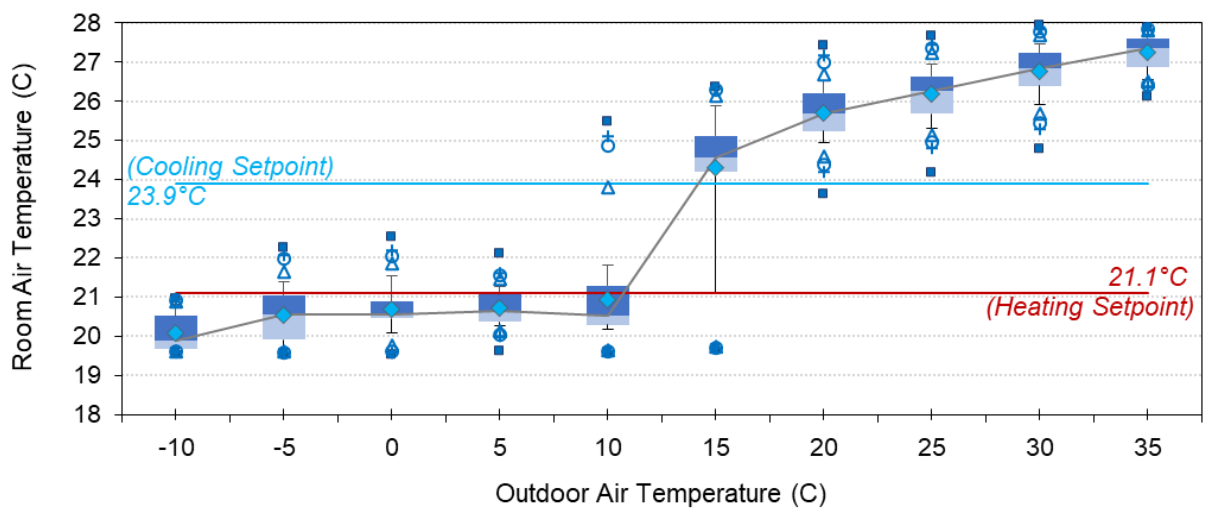

(a) CDHP On

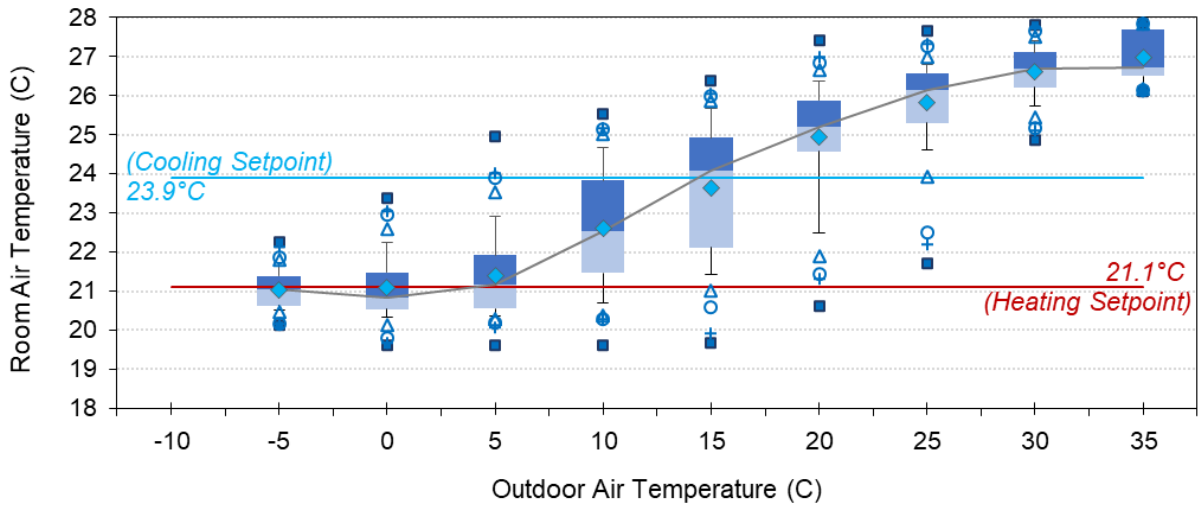

(b) CDHP Off

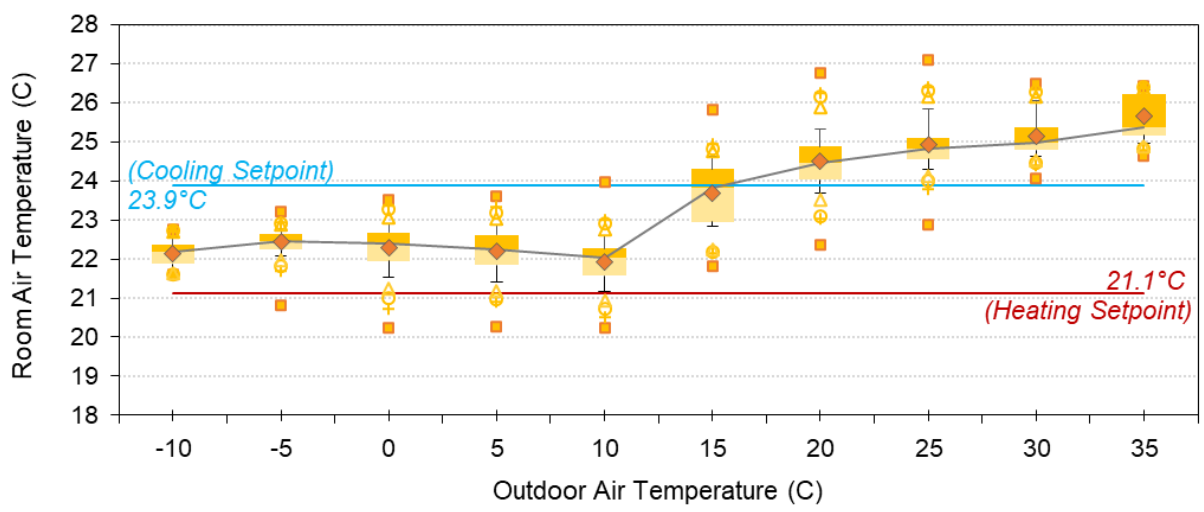

(c) SDHV On

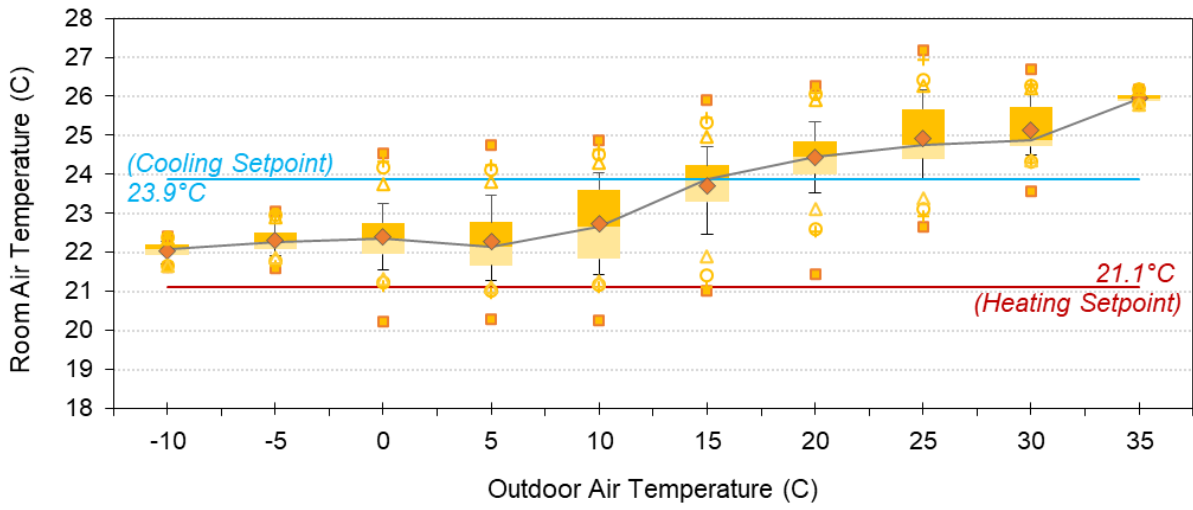

(d) SDHV Off

Figure 22: Binned Attic Room Air Temperatures Against Outdoor Temperatures. 


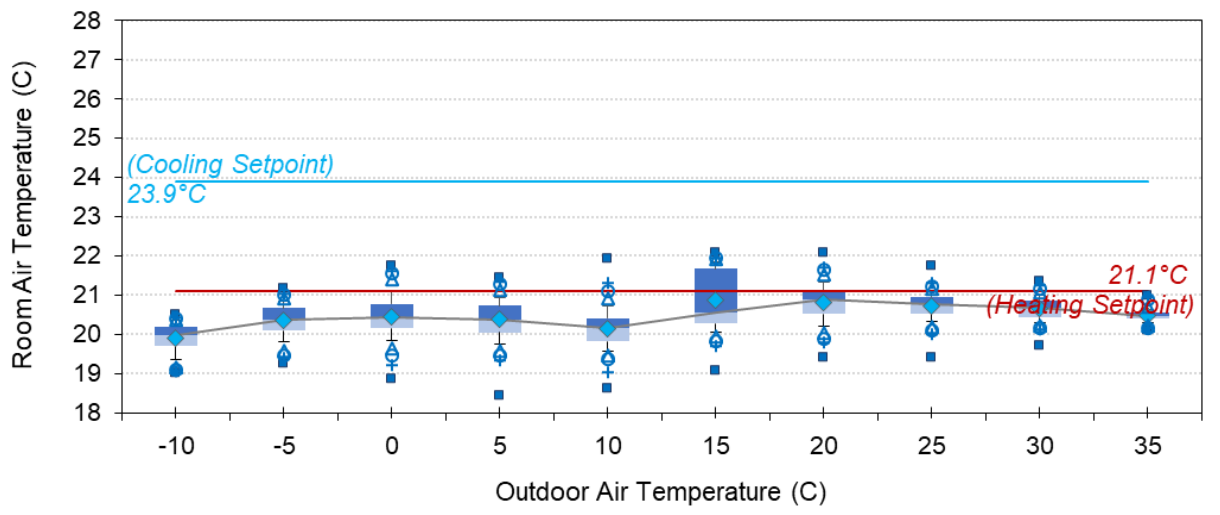

(a) CDHP On

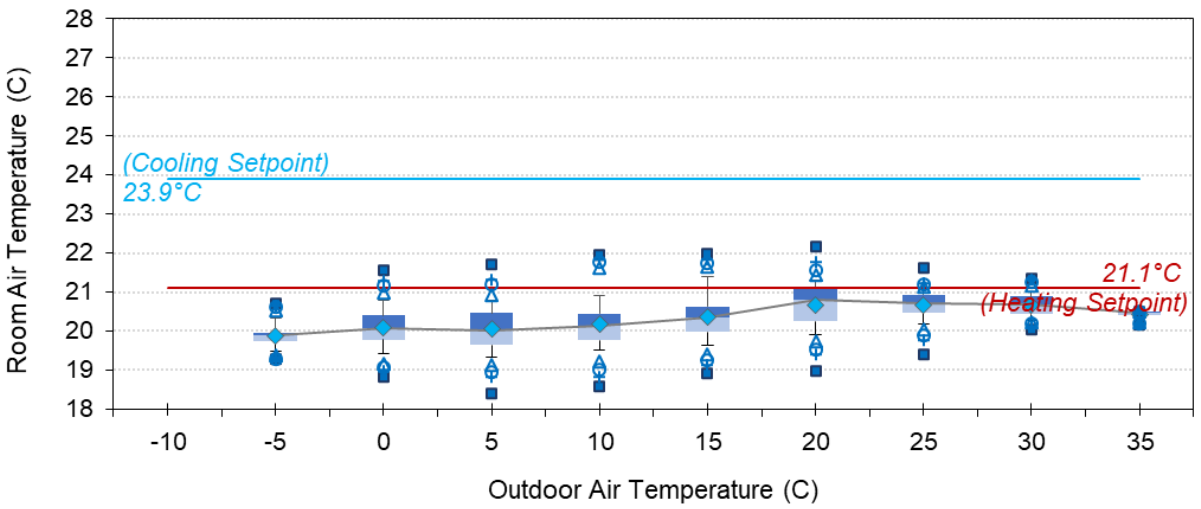

(b) CDHP Off

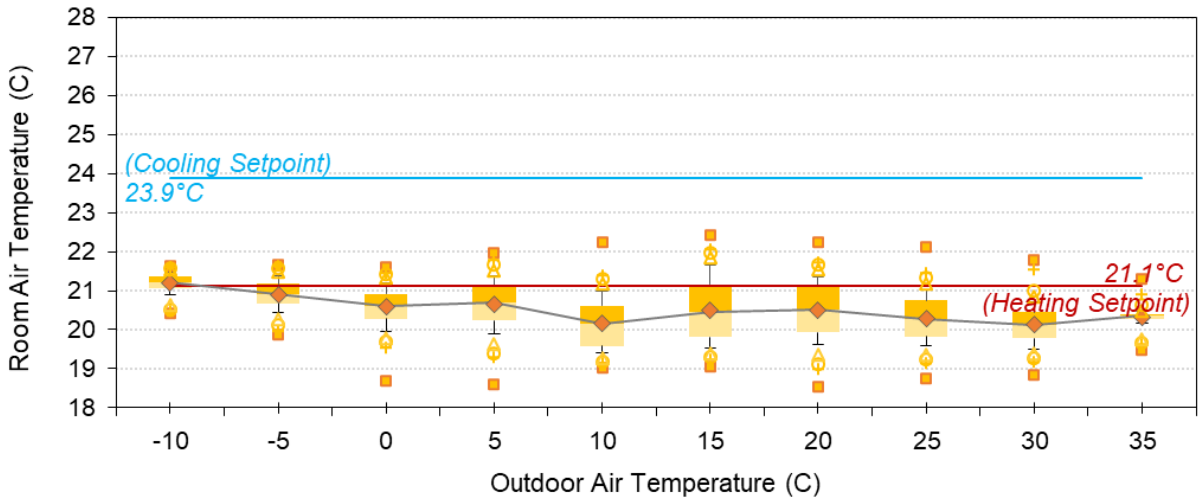

(c) SDHV On

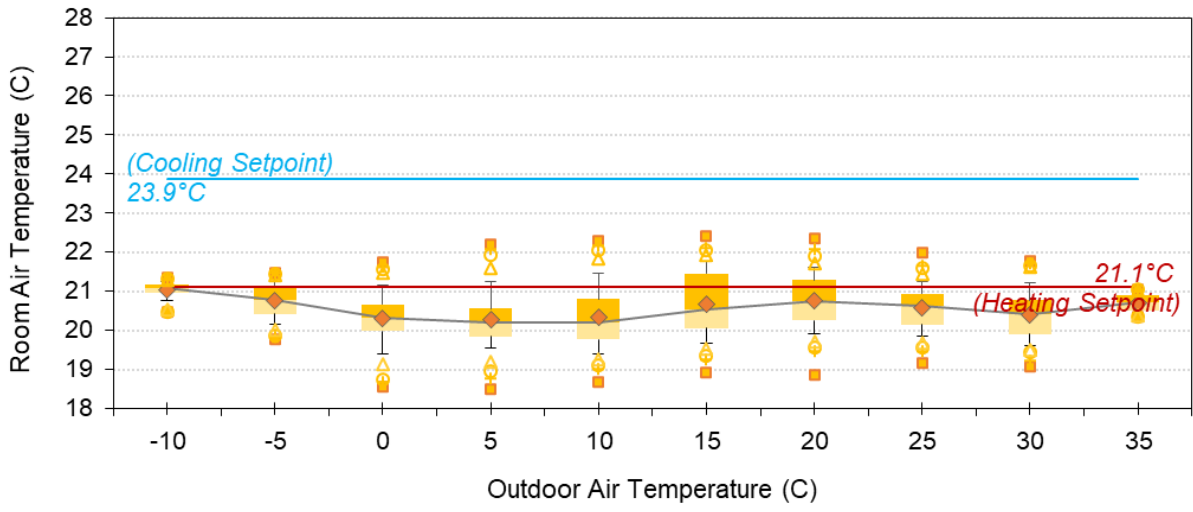

(d) SDHV Off

Figure 23: Binned BSMT Room Air Temperatures Against Outdoor Temperatures. 


\subsubsection{COMPARISON BETWEEN ROOMS}

Figure 24 displays the median values of the binned room temperatures of all seven rooms for a comparison between rooms: (a) CDHP on cycle; (b) CDHP off cycle; (c) SDHV on cycle; and (d) SDHV off cycle. The rooms on the first floor were colder than the rooms on the second floor due to the natural stratification of warm air. The rooms on each floor had similar indooroutdoor temperature relationship to some extent regardless of the type of HP system in operation except for the kitchen. As discussed in Section 4.5.1, the kitchen had decreasing room temperatures with increasing OA temperatures when the CDHP was in operation during the cooling season.

When comparing the three bedrooms on the second floor, the BR3 temperatures were consistently lower than the other two rooms with the CDHP, which might be affected by no presence of simulated occupancy/plug loads in the BR3. The BR2 temperatures were also consistently higher than the other two rooms at the high OA temperatures when the CDHP was in operation. This might be caused by the combined effect of the heat gains from emulated internal loads in the BR2 and higher solar heat gains in this south-facing bedroom. However, when the SDHV was in operation, there was no obvious difference in the room temperatures of the three bedrooms, which might be affected by unexpected interaction between the attic and the second-floor bedrooms.

To compare the thermal conditions between the two systems, the median values of the binned room temperatures were averaged by the floor for simplicity, as shown in Figure 25:

(a) CDHP on vs. SDHV on; and (b) CDHP off vs. SDHV off. As noted in Section 4.5.1, there was an obvious difference in the maintained room temperatures of the second-floor bedrooms and the attic between the two systems under the same OA temperatures. The SDHV maintained the second-floor bedrooms and the attic warmer at the low OA temperatures but cooler at the high OA temperatures than the conditions maintained with the CDHP, which was caused by the SDHV supply ductwork within the attic.

This contributed to smaller room-to-room temperature differences at the higher OA temperatures but larger room-to-room temperature differences at the low OA temperatures when the SDHV was in operation, as shown in Figure 26. In this figure, it is also noteworthy that the CDHP room-to-room temperature difference appeared to have a strong association with the OA temperature during the cooling season (i.e., at the high OA temperature bins). Although this difference observed between the two systems was not directly caused by the tested air distribution system itself but rather affected by the different locations of the two systems' supply ductwork, their different locations in the house represent real-world applications. 

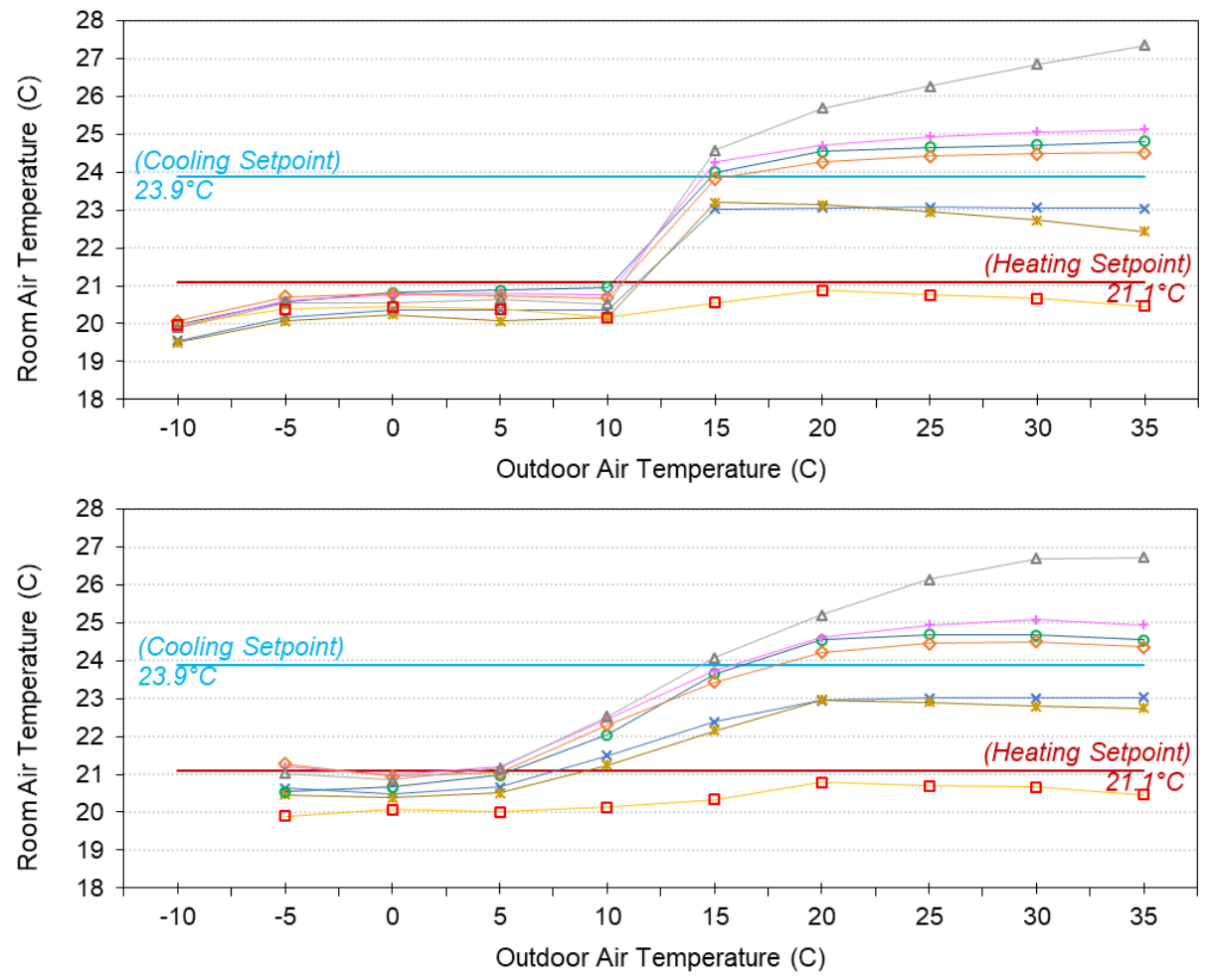

(a) CDHP On

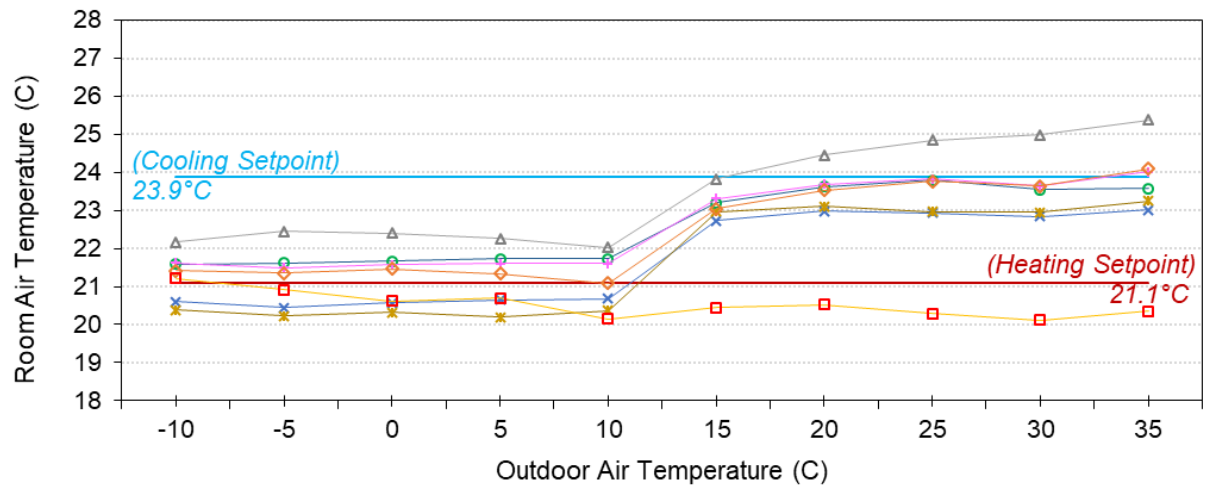

(b) CDHP Off

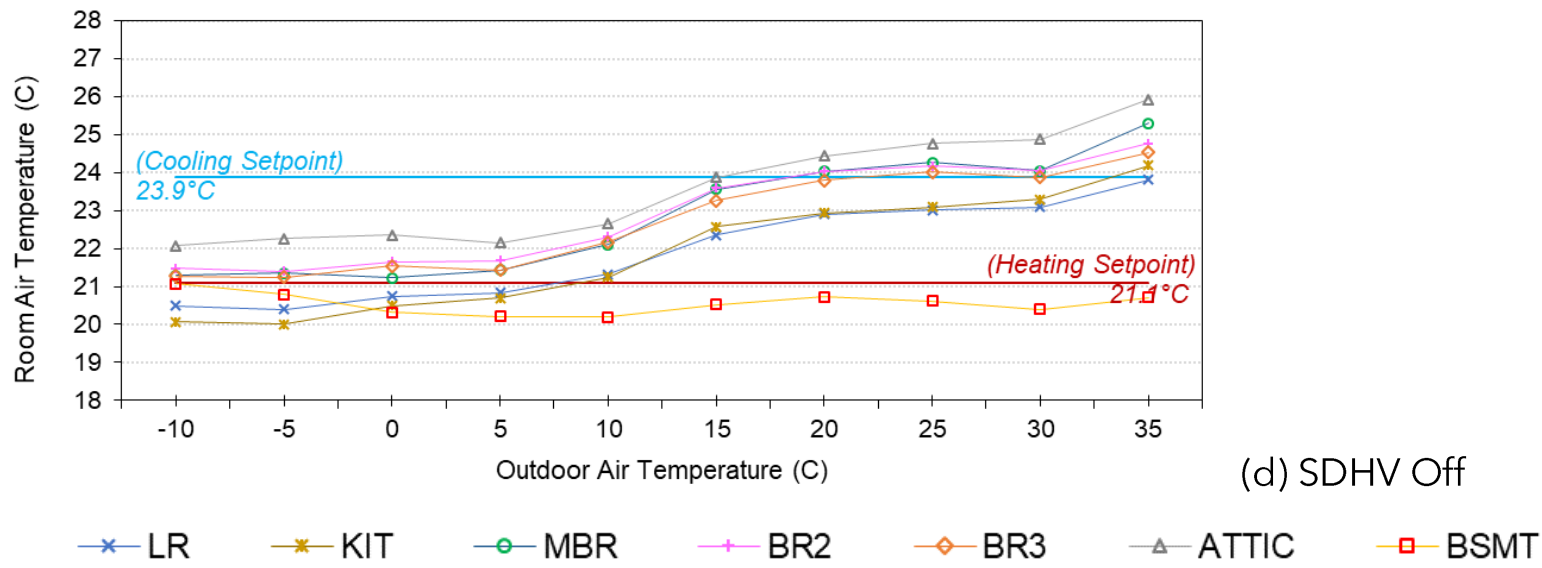

(c) SDHV On

Figure 24: Comparison of Median Values of Binned Room Temperatures of the Seven Rooms Against Outdoor Temperatures. 


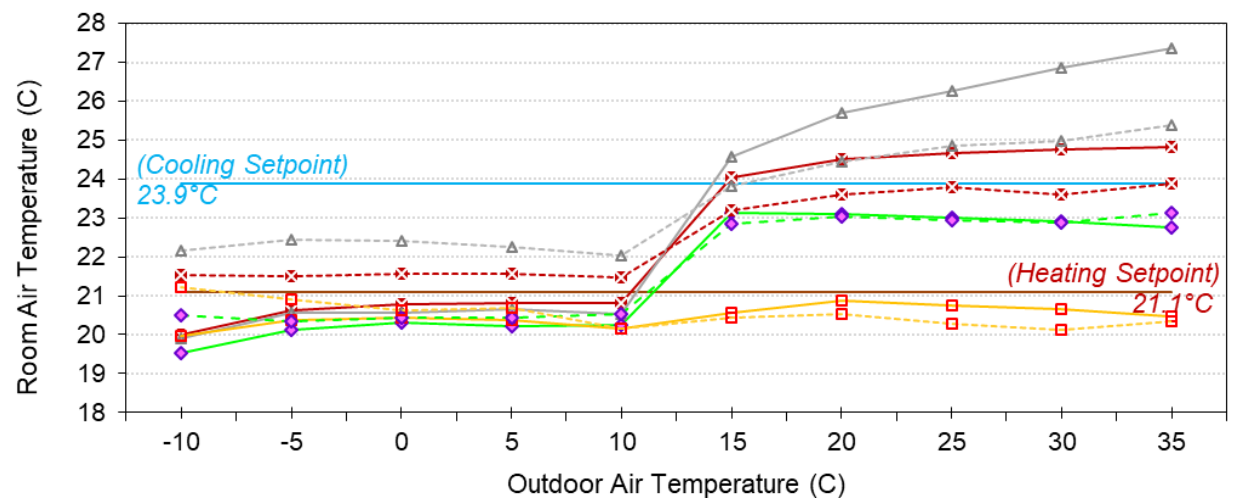

(a) CDHP On vs. SDHV On

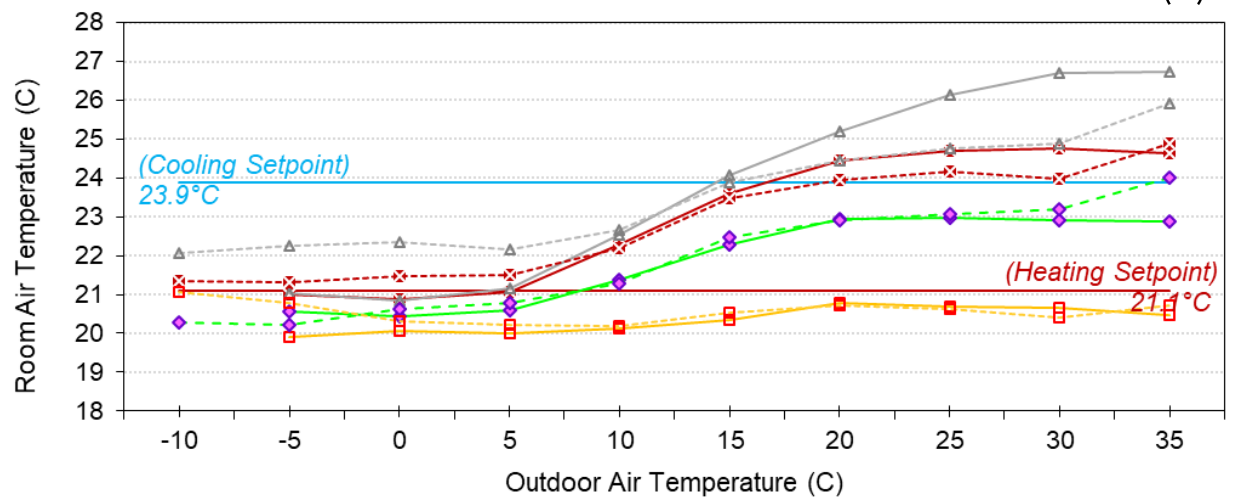

(b) CDHP Off vs. SDHV Off

\begin{tabular}{|c|c|}
\hline$\diamond-\mathrm{CDHP} 1 \mathrm{st}$ & $\rightarrow \longleftarrow$ CDHP 2nd \\
\hline$\diamond-\operatorname{SDHV} 1 \mathrm{st}$ & $--\rightarrow x---$ SDHV 2nd \\
\hline
\end{tabular}

Figure 25: Comparison of Median Values of Binned Room Temperatures Averaged by Floor Against Outdoor Temperatures. 


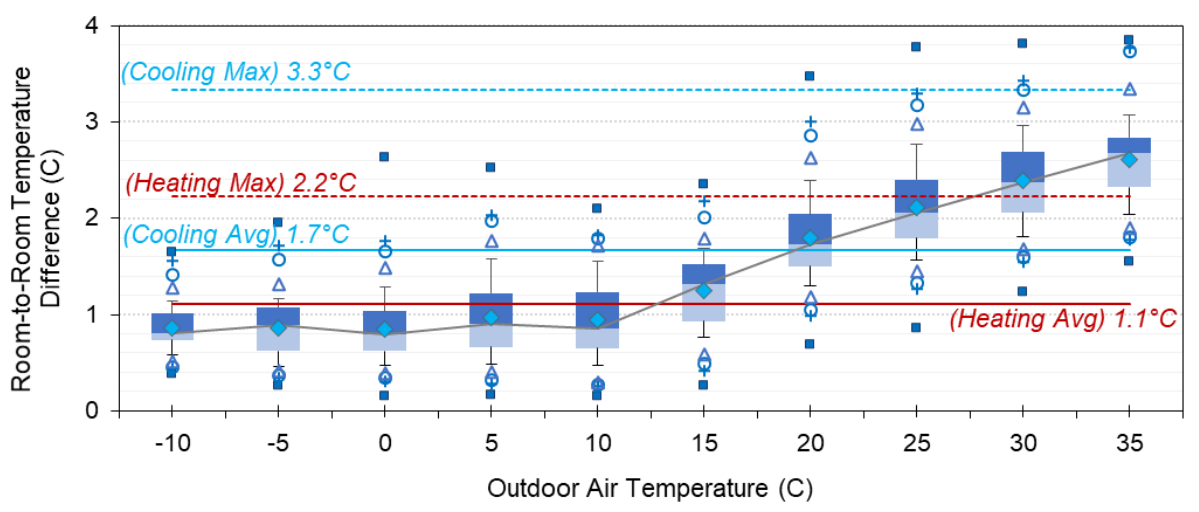

(a) CDHP On

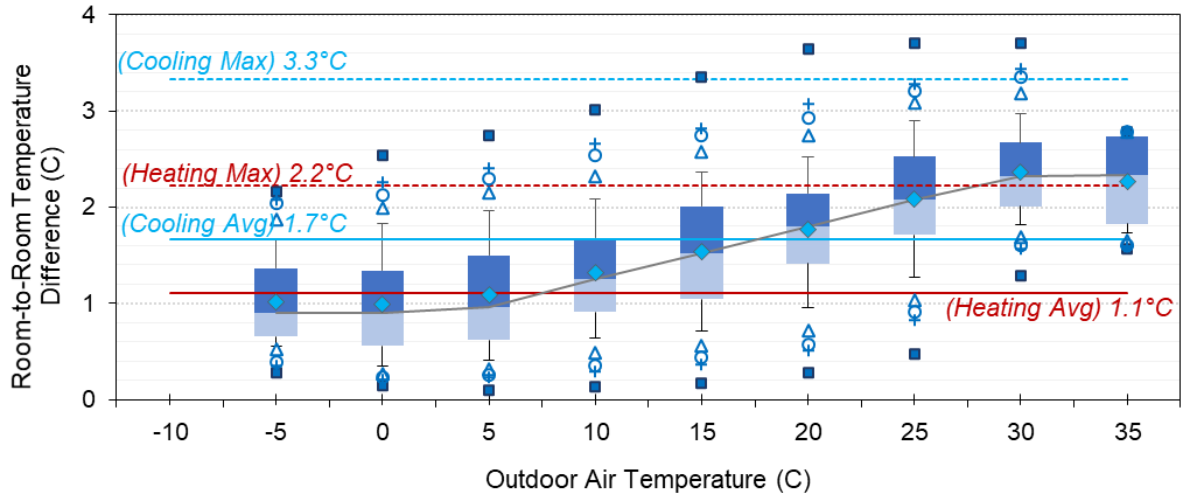

(b) CDHP Off

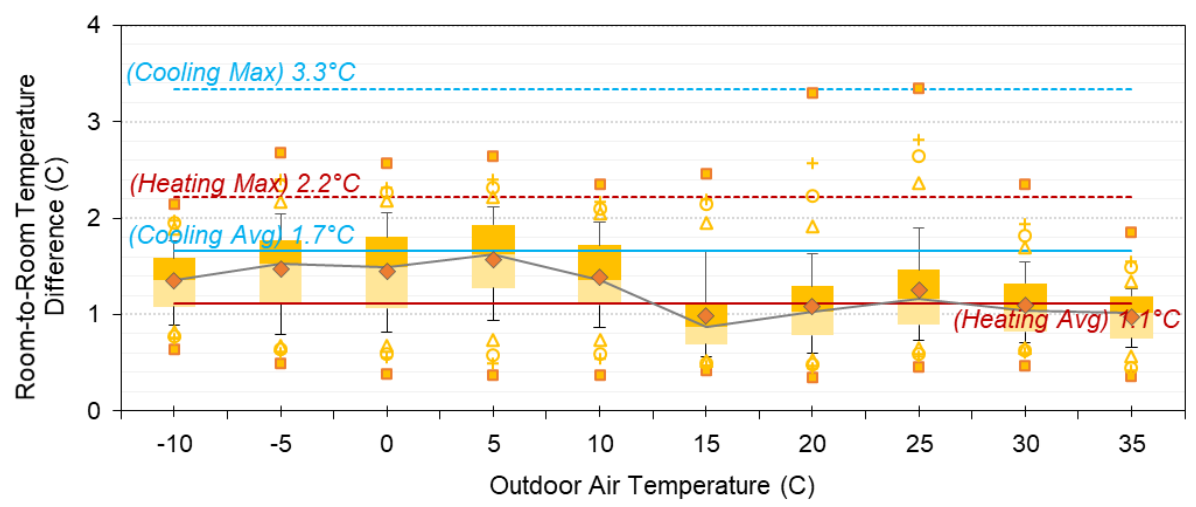

(c) SDHV On

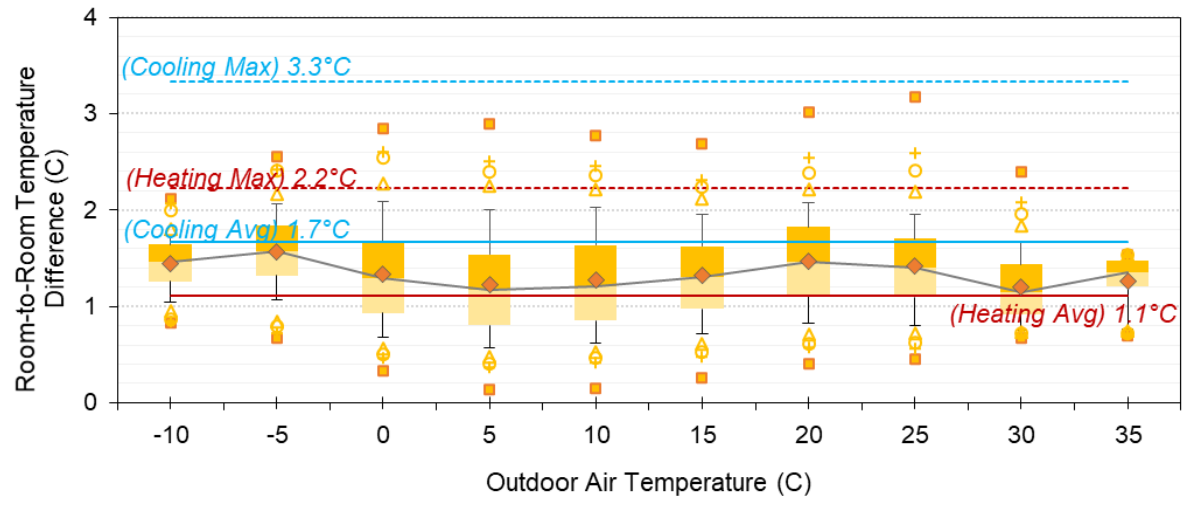

(d) SDHV Off

Figure 26: Binned Room-To-Room Temperature Differences Against Outdoor Temperatures 


\subsection{TIME-OF-DAY CHARACTERIZATION}

Another characterization performed in this study to better understand the observed temporal variations of the long-term temperature data at NZERTF was a time-of-day analysis of hourly average room temperature data. At NZERTF, the activities of a family of four (i.e., two adults and two children) were simulated in terms of electrical use (i.e., appliances and lighting), hot water use, and metabolic heat and moisture generation based on a consistent schedule. This provides a unique opportunity to understand the dynamic interactions between uneven internal heat gains from occupants, lighting, appliances, and miscellaneous electronic devices and the measured thermal conditions since they can have significant localized impacts on indoor climates even in low-load houses (Stecher et al. 2012).

The time-of-day characterization was performed in two different ways: one based on the ASHRAE Research Project 1093 Diversity Factor procedure (Abushakra et al. 2001) and the other using a time-of-day colored map (i.e., heat map).

\subsubsection{HOURLY ROOM TEMPERATURE PROFILES}

First, the time-of-day characterization was performed based on the ASHRAE Research Project 1093 Diversity Factor procedure (Abushakra et al. 2001), which calculates and displays the $10^{\text {th }}, 25^{\text {th }}, 50^{\text {th }}, 75^{\text {th }}$, and $90^{\text {th }}$ percentiles as well as minimum, mean, and maximum values for each hour of the day. For example, Figures 27 to 32 present the results by different system types and on/off cycle (i.e., CDHP on, CDHP off, SDHV on, and SDHV off) and seasons (i.e., cooling season, heating season, and transitional season) for the LR (Figures 27 to 29) and the MBR (Figures 30 to 32) selected to represent the first-floor and the second-floor room, respectively. Appendix $\mathrm{E}$ provides the results for the other three primary rooms (i.e., KIT, BR2, and BR3) as supplementary materials to avoid redundancy.

Important observations are:

- $\quad$ LR (Figures 27 to 29)

- During the cooling season, the hourly LR temperature profile was almost flat with a small peak between 10:00 AM and 12 PM when the CDHP cycled on. The observed small peak was likely to be occurred due to the combined effect of the heat gains from the simulated occupancy and plug loads in the LR and possible solar heat gains through the windows facing east and south.

- When the CDHP cycled off (Figure 27 (b) left figure), there was a period when no profile was presented. This occurred because the CDHP system never stayed off completely through an hour from 8 PM to 11 PM.

- When the SDHV was in operation, there was a continued temperature fluctuation throughout the day with larger day-to-day variations as revealed by a difference between the $10^{\text {th }}$ and the $90^{\text {th }}$ percentiles, which occurred to a greater extent when the SDHV cycled off. Considering the comparable throttling range of the two systems, this needs a further investigation.

- It is also worth pointing out that the maximum LR temperature during the SDHV on cycle had an almost flat profile, which indicates the SDHV maintained the LR temperature not to exceed a certain temperature (i.e., approximately, cooling setpoint $+0.2^{\circ} \mathrm{C}$ ). 
- The heating season profile resembled the cooling season profile when the CDHP cycled on except for the low-side deviation that occurred in the nighttime ${ }^{41}$. The SDHV heating season profiles showed smaller day-to-day variations compared to those observed during the cooling season.

- During the transitional season when the systems mostly cycled off ${ }^{42}$, the time-ofday temperature variations of the two systems followed the expected patterns of temperature drifts when considering the schedule of internal loads simulated in the LR: continued temperature drops before sunrise, increasing temperature in the morning time, and relatively flat profile in the afternoon.

- When the CDHP was in operation, the day-to-day temperature variations were larger than those with the SDHV based on a difference between the minimum and maximum but comparable between the two systems based on a difference between the $10^{\text {th }}$ and the $90^{\text {th }}$ percentiles. A further investigation revealed the high-side deviation of the CDHP mostly occurred over the two days (February 24 and 25,2017 ) of which $O A$ temperatures were high with a maximum hourly $O A$ temperature of $23.2^{\circ} \mathrm{C}$, while the CDHP was in the heating mode. Similarly, the low-side deviation of the CDHP mostly occurred over the two days (April 8 and 9, 2017) of which OA temperatures were low with a minimum hourly OA temperature of $2.1^{\circ} \mathrm{C}$, while the CDHP was in the cooling mode.
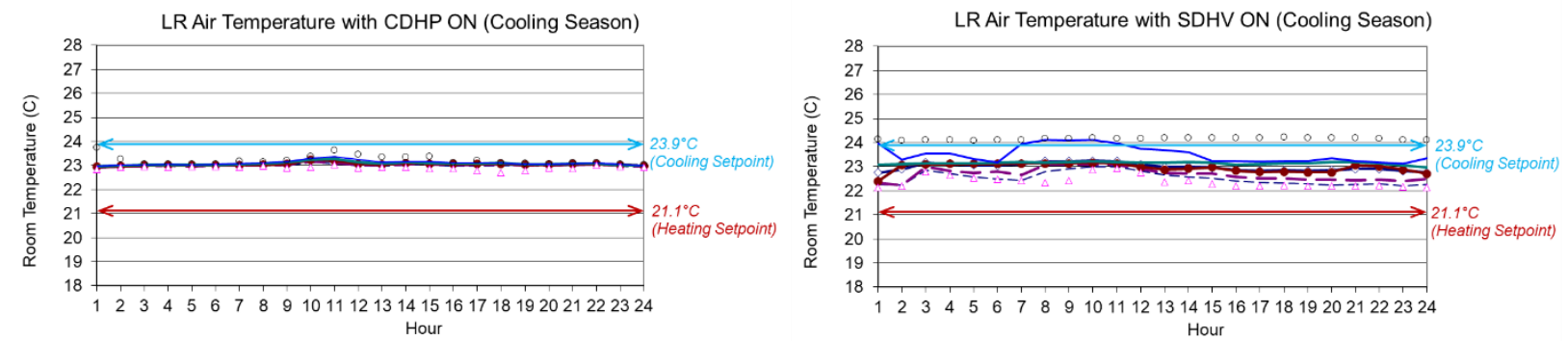

(a) CDHP On vs. SDHV On
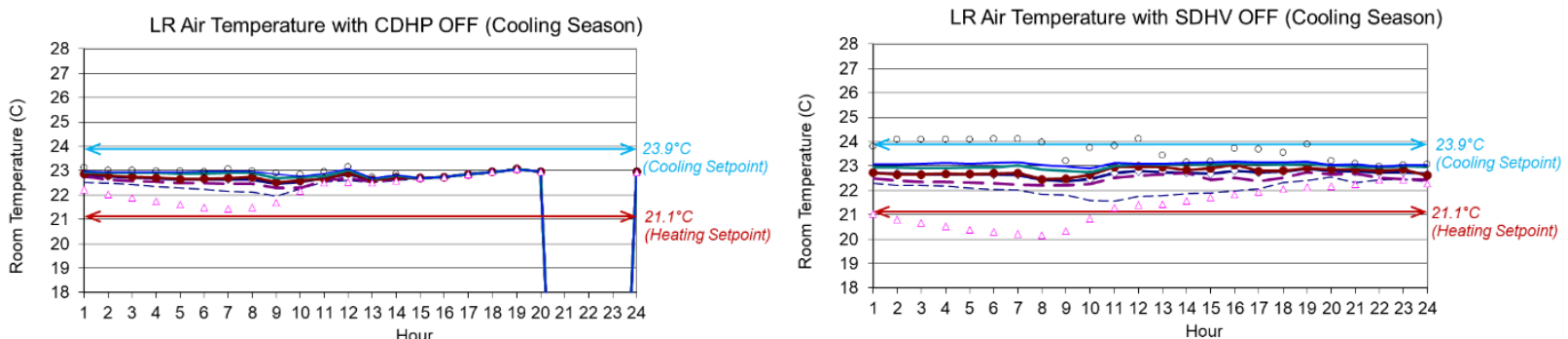

(b) CDHP Off vs. SDHV Off

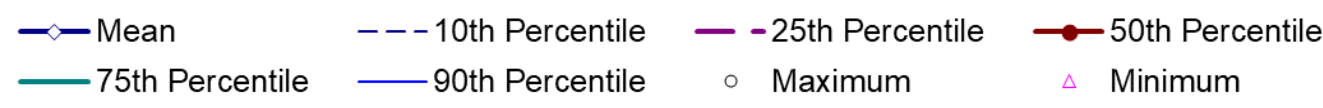

Figure 27: Hourly LR Temperature Profiles by Different System Types and On/Off Cycle during the Cooling Season.

\footnotetext{
${ }^{41}$ As noted in Section 4.5.1, the observed low-side deviation during the nighttime occurred because the CDHP's smaller heating capacity $(7.8 \mathrm{~kW})$ could not meet the heating setpoint temperatures at the very low $\mathrm{OA}$ temperatures.

${ }^{42}$ Due to the small sample size of the system on cycle, discussion of transitional season data focuses on the data collected during the system off cycle.
} 

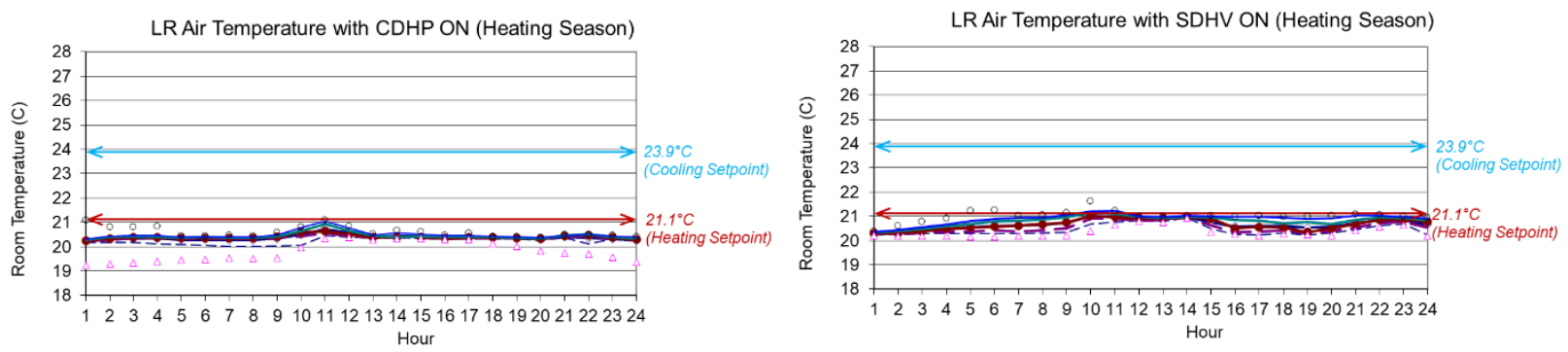

(a) CDHP On vs. SDHV On
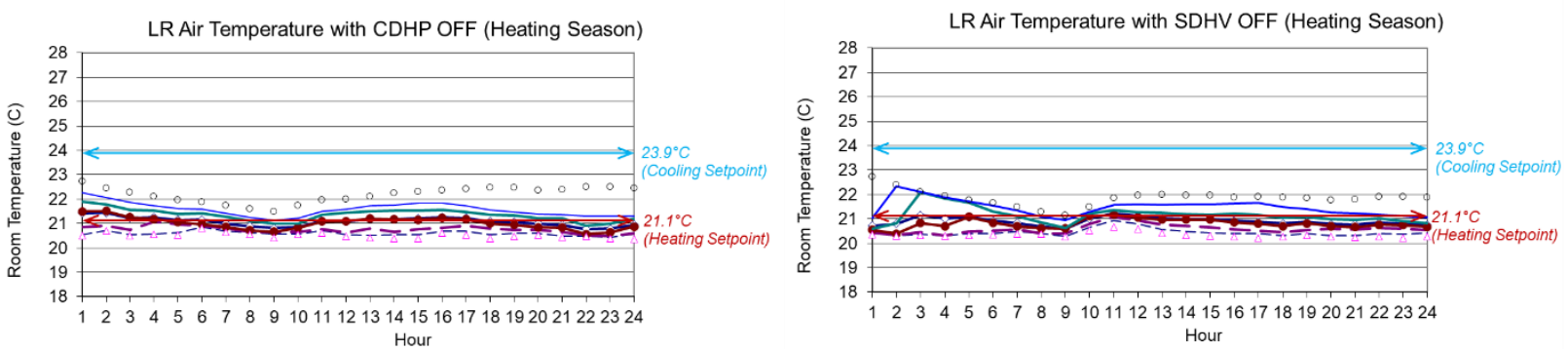

(b) CDHP Off vs. SDHV Off

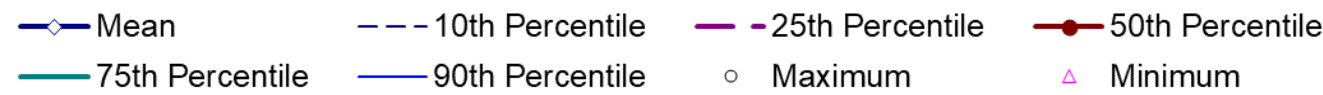

Figure 28: Hourly LR Temperature Profiles by Different System Types and On/Off Cycle during the Heating Season.
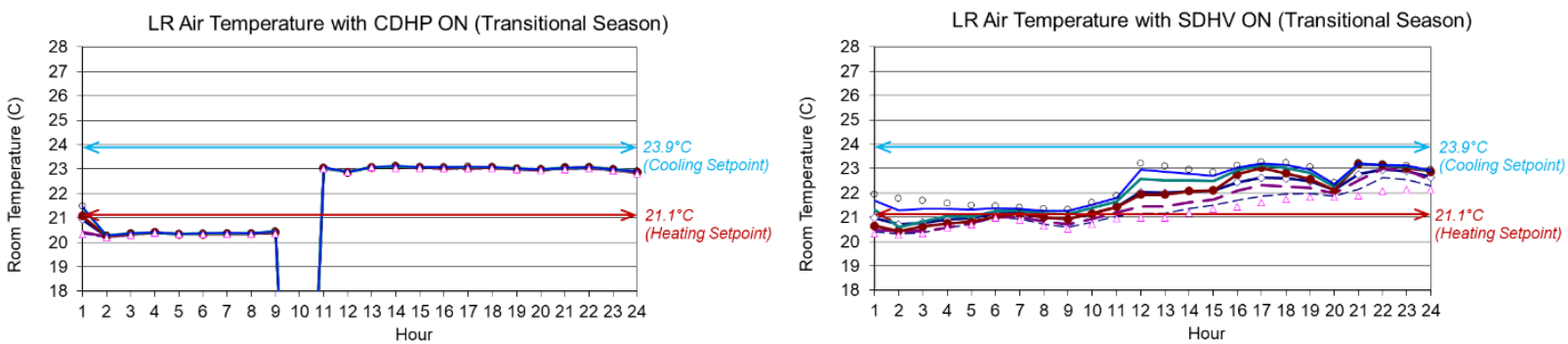

(a) CDHP On vs. SDHV On
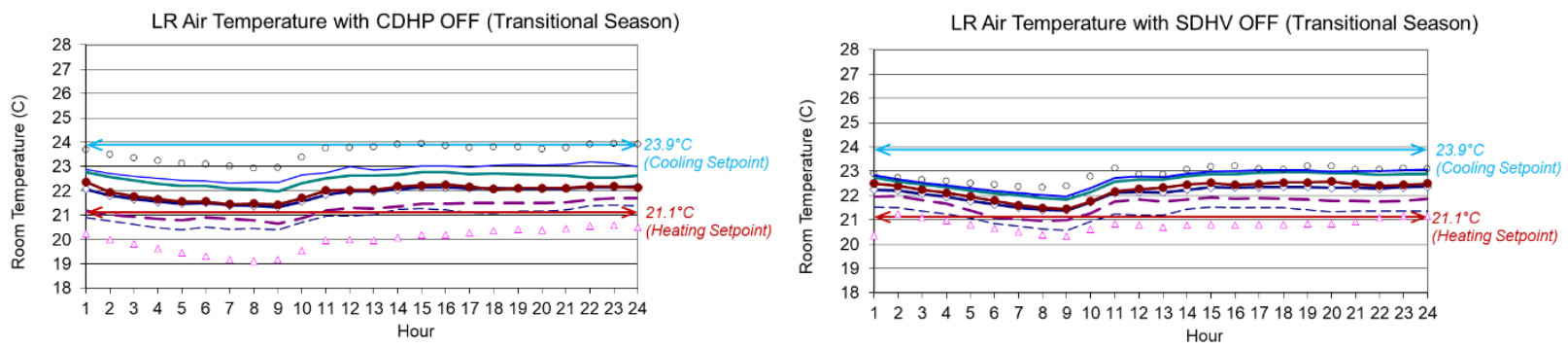

(b) CDHP Off vs. SDHV Off

\begin{tabular}{|c|c|c|c|}
\hline & $\begin{array}{l}--10 \text { th Percentile } \\
\text {-90th Percentile }\end{array}$ & --25 th Percentile & $\rightarrow 5$ \\
\hline
\end{tabular}

Figure 29: Hourly LR Temperature Profiles by Different System Types and On/Off Cycle during the Transitional Season. 
- $\quad$ MBR (Figures 30 to 32)

- The time-of-day temperature variations of the two systems followed the expected patterns of temperature drifts when considering the schedule of internal loads simulated in the MBR (i.e., occupancy and plug loads): gradual temperature increases during the nighttime, decreasing temperature in the morning time, and a spike between 6 PM to 7 PM.

- The spike between 6 PM and 7 PM was consistently observed across the seasons, which was caused by heat gains from the radiator in MBR that was operated to emulate sensible heat gains from an iron and located relatively near the measurement stand in the MBR.

- The observed localized impact of the simulated occupancy and iron on MBR temperature was responsible for the reported compliance failure in a room-toroom temperature difference (Section 4.2) and cyclic and drift temperature variations in MBR (Section 4.3).

- During the cooling season, the day-to-day temperature variations were larger with the SDHV, which was affected by less repeatable LR temperature profiles. The observed low repeatability with the SDHV occurred to a greater extent between 12 $A M$ and $2 A M$, which needs a further investigation when considering an absence of external solar loads during the observed timeframe.

- The SDHV heating season profiles showed smaller day-to-day variations compared to those observed during the cooling season, which agrees with the observations made for the LR.

- Like the LR, the day-to-day temperature variations with the CDHP during the transitional season were larger than those with the SDHV due to the deviations occurred over four specific days. 

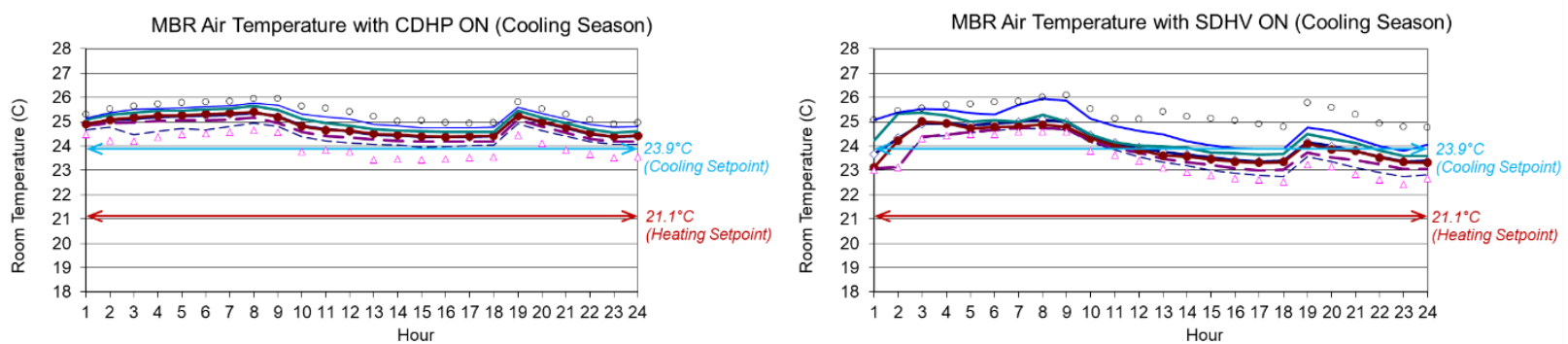

(a) CDHP On vs. SDHV On
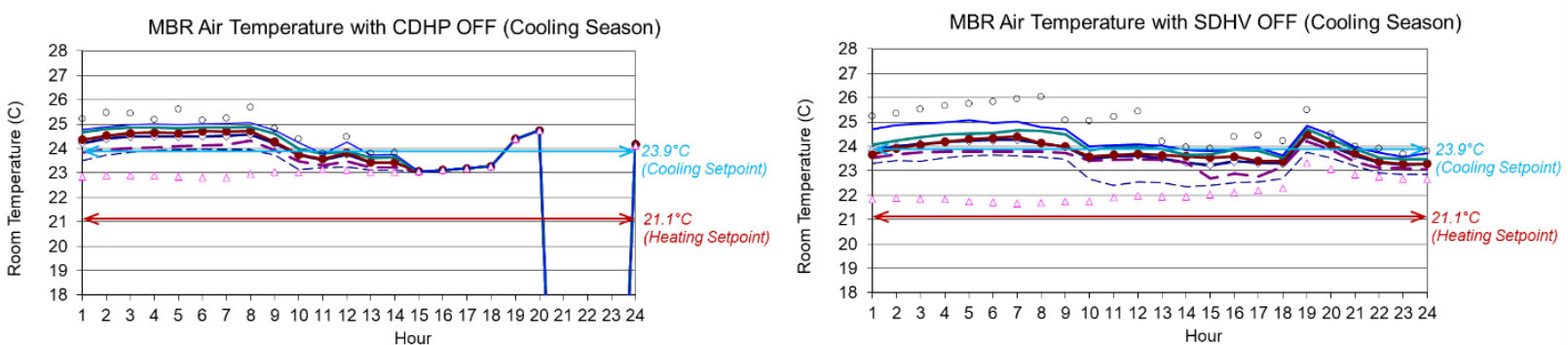

(b) CDHP Off vs. SDHV Off

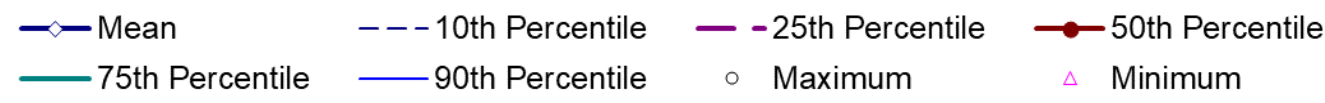

Figure 30: Hourly MBR Temperature Profiles by Different System Types and On/Off Cycle during the Cooling Season.
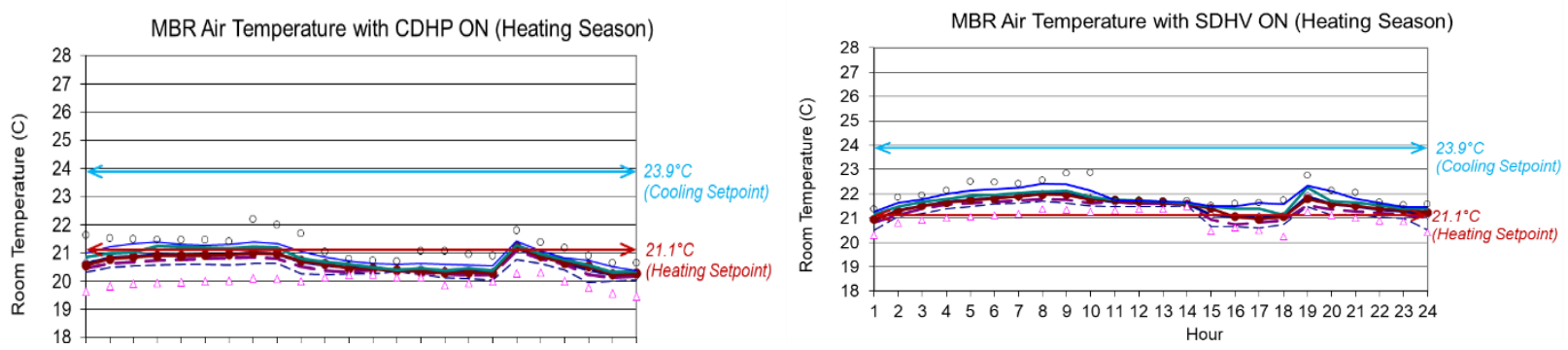

(a) CDHP On vs. SDHV On
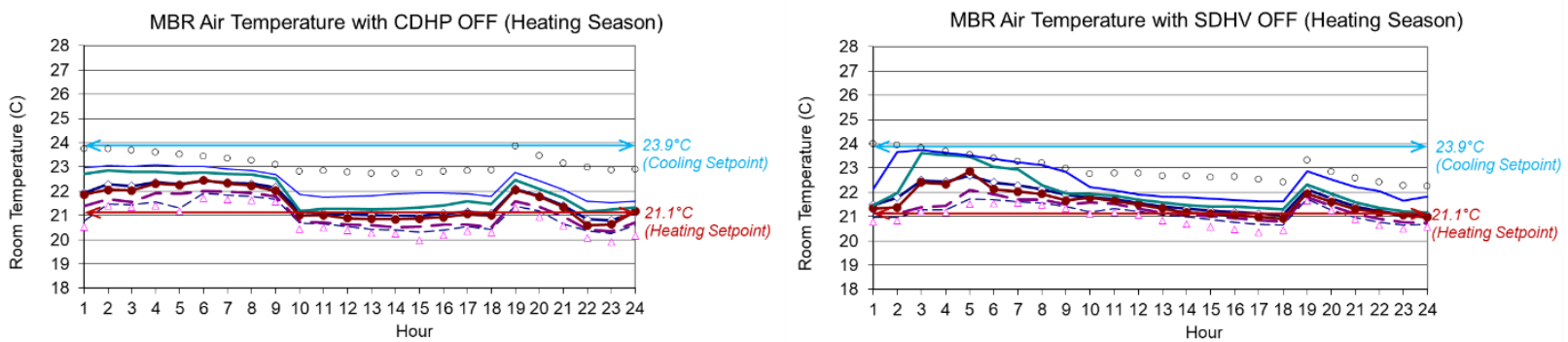

(b) CDHP Off vs. SDHV Off

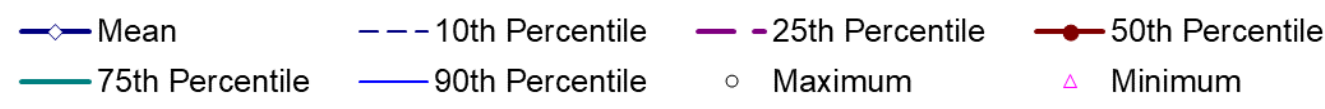

Figure 31: Hourly MBR Temperature Profiles by Different System Types and On/Off Cycle during the Heating Season. 

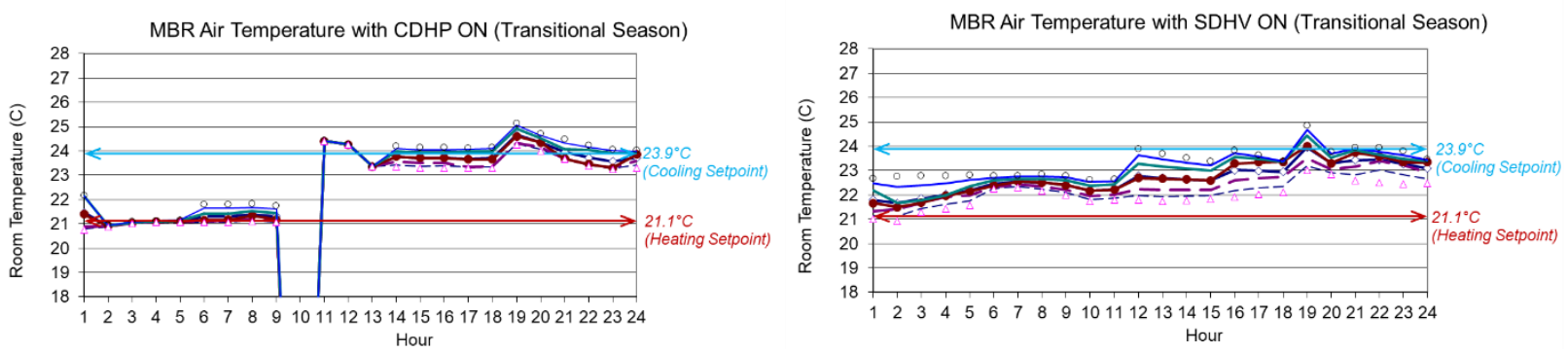

(a) CDHP On vs. SDHV On
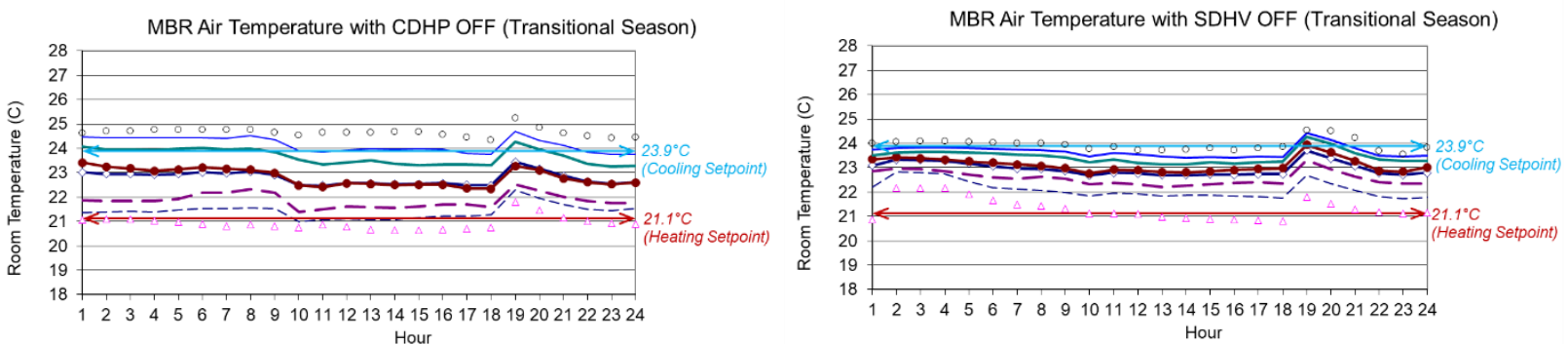

(b) CDHP Off vs. SDHV Off

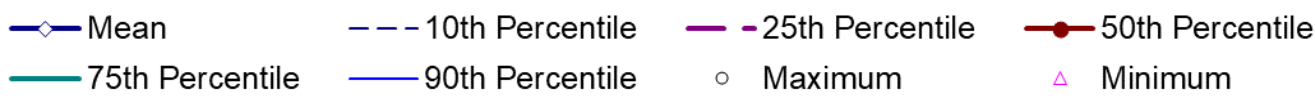

Figure 32: Hourly MBR Temperature Profiles by Different System Types and On/Off Cycle during the Transitional Season. 


\subsubsection{TIME-OF-DAY COLORED MAP}

To better visualize the large volume of room temperature data, a time-of-day colored map (i.e., heat map) was applied to the hourly average room temperatures over the entire measurement period. Figures 33 and 34 present the results for the LR (Figure 33) and the MBR (Figure 34) selected to represent the first-floor and the second-floor room, respectively. Appendix F provides the results for the other three primary rooms (i.e., KIT, BR2, and BR3) as supplementary materials.

In the figures, the HP systems' seasonal operation mode was color-coded (i.e., blue for the cooling mode and dark red for the heating mode) and displayed in the first row named HP Seasonal Mode. The type of the HP system tested for each day was also color-coded (i.e., dark blue for the CDHP and orange for the SDHV) and displayed in the second row named HP Type. The non-colored cells represent the data collected during the 42 days that were excluded from the analysis ${ }^{43}$.

Each room consists of the following three plots with the corresponding color key on the left side of each plot:

- (a) hourly average room temperatures with a continuous scale from $17^{\circ} \mathrm{C}$ to $27^{\circ} \mathrm{C}$;

- (b) hourly average room-to-thermostat temperature difference (i.e., $\Delta \mathrm{T}\left({ }^{\circ} \mathrm{C}\right)=$ Troom Tsetpoint) with a discrete scale to represent the following seven value ranges; and - >1.67: $\Delta \mathrm{T}$ above $1.67^{\circ} \mathrm{C}\left(3^{\circ} \mathrm{F}\right)$

- +1.67: $\quad \Delta \mathrm{T}$ from $1.11^{\circ} \mathrm{C}$ to $1.67^{\circ} \mathrm{C}\left(2^{\circ} \mathrm{F}\right.$ to $\left.3^{\circ} \mathrm{F}\right)$

- +1.11: $\quad \Delta \mathrm{T}$ from $0.56^{\circ} \mathrm{C}$ to $1.11^{\circ} \mathrm{C}\left(1^{\circ} \mathrm{F}\right.$ to $\left.2^{\circ} \mathrm{F}\right)$

- \pm 0.56 : $\quad \Delta \mathrm{T}$ from $-0.56^{\circ} \mathrm{C}$ to $0.56^{\circ} \mathrm{C}\left(-1^{\circ} \mathrm{F}\right.$ to $\left.1^{\circ} \mathrm{F}\right)$

- -1.11: $\quad \Delta \mathrm{T}$ from $-1.11^{\circ} \mathrm{C}$ to $-0.56^{\circ} \mathrm{C}\left(-2^{\circ} \mathrm{F}\right.$ to $\left.-1^{\circ} \mathrm{F}\right)$

- -1.67: $\quad \Delta \mathrm{T}$ from $-1.67^{\circ} \mathrm{C}$ to $-1.11^{\circ} \mathrm{C}\left(-3^{\circ} \mathrm{F}\right.$ to $\left.-2^{\circ} \mathrm{F}\right)$

- <-1.67: $\triangle \mathrm{T}$ below $\left.-1.67^{\circ} \mathrm{C}\left(-3^{\circ} \mathrm{F}\right)\right)$

- (c) ACCA Manual RS compliance based on an hourly average room-to-thermostat temperature difference while the favorable temperature differences (i.e., $\Delta \mathrm{T}$ below $0^{\circ} \mathrm{C}$ in the cooling mode and $\Delta \mathrm{T}$ above $0^{\circ} \mathrm{C}$ in the heating mode) were intentionally color-coded using green.
$-> \pm 1.67$ (red):
$\Delta \mathrm{T}$ above $1.67^{\circ} \mathrm{C}$ (cooling mode) and
- \pm 1.67 (peach):
$\triangle \mathrm{T}$ below $-1.67^{\circ} \mathrm{C}$ (heating mode)
- \pm 1.11 (light green): $\quad \Delta \mathrm{T}$ from $0.56^{\circ} \mathrm{C}$ to $1.11^{\circ} \mathrm{C}$ (cooling mode) and
$\triangle T$ from $1.11^{\circ} \mathrm{C}$ to $1.67^{\circ} \mathrm{C}$ (cooling mode) and
$\Delta T$ from $-1.67^{\circ} \mathrm{C}$ to $-1.11^{\circ} \mathrm{C}$ (heating mode)
- \pm 0.56 (green):
$\triangle T$ below $0.56^{\circ} \mathrm{C}$ (cooling mode) and
$\triangle \mathrm{T}$ above $-0.56^{\circ} \mathrm{C}$ (heating mode)

In this way, the red cells represent only the hours when the room temperatures unfavorably exceeded the ACCA benchmarks (i.e., $\Delta \mathrm{T}$ above $1.67^{\circ} \mathrm{C}$ in the cooling mode and $\triangle T$ below $1.67^{\circ} \mathrm{C}$ in the heating mode). Due to the more stringent ACCA benchmarks for a heating season (i.e., thermostat setpoint $\pm 1.11^{\circ} \mathrm{C}\left( \pm 2^{\circ} \mathrm{F}\right)$ ), the peach cells in the heating mode also represent a non-compliant period.

\footnotetext{
${ }^{43}$ Appendix A provides a list of the 42 days with the reasons for exclusion.
} 
Overall, the use of the proposed time-of-day colored map was useful in tracking how the rooms were conditioned over the course of a day and a year separately for CDHP versus SDHV based on data with an hourly temporal resolution. Different temporal patterns were observed, which was affected by the schedule of internal loads simulated in each room. For example, the LR temperature was always lower during the nighttime before the sun rises, which was affected by no presence of the simulated occupancy/plug loads in the LR at night. However, the opposite pattern (i.e., lower MBR temperatures during the daytime due to no presence of the simulated occupancy) was observed in the MBR.

These maps also allowed the identification of non-compliant periods based on the ACCA Manual RS benchmarks and the resulting thermal discomfort. For example, in the LR, the unfavorable non-compliant period (i.e., red and peach in the heating mode; red in the cooling mode in Figure 33 (c)) occurred mostly on December 16, 2016 and February 10, 2017 because the CDHP's smaller heating capacity $(7.8 \mathrm{~kW})$ could not meet the heating setpoint temperatures at the very low $O A$ temperatures. The level of discomfort was worse on December 16, 2016 when the lowest OA temperature occurred, which was $-10.4^{\circ} \mathrm{C}$.

In the MBR, the heating non-compliance occurred only on December 16, 2016. However, the cooling non-compliance incidences (i.e., red in the cooling mode in Figure 34 (c)) were considerably higher, which mostly occurred during the nighttime until 9 AM when the MBR was occupied by two adults and between 6 PM to 7 PM when the simulated plug loads were turned on. When comparing the two systems, the CDHP had more non-compliance incidences than the SDHV, which was affected by different locations of the supply ductwork of the two systems ${ }^{44}$. When the SDHV was in operation, most non-compliance occurred during one week in July due to higher nighttime OA temperatures.

In addition to the room-to-thermostat temperature compliance with the ACCA Manual RS, the room-to-room temperature differences and the resultant compliance with the ACCA Manual RS were also graphically displayed using a time-of-day colored map, as shown in Figure 35. The hourly average room-to-room temperature difference (i.e., $\triangle \mathrm{T}\left({ }^{\circ} \mathrm{C}\right)=\mathrm{MAX}(\mathrm{Troom} 1$, Troom2, ...) - MIN(Troom1, Troom2, ...)) was color-coded with a discrete scale to represent the following seven value ranges:

- $\Delta \mathrm{T}$ above $3.33^{\circ} \mathrm{C}\left(6^{\circ} \mathrm{F}\right)$;

- $\quad \Delta \mathrm{T}$ from $2.78^{\circ} \mathrm{C}$ to $3.33^{\circ} \mathrm{C}\left(5^{\circ} \mathrm{F}\right.$ to $\left.6^{\circ} \mathrm{F}\right)$;

- $\Delta \mathrm{T}$ from $2.22^{\circ} \mathrm{C}$ to $2.78^{\circ} \mathrm{C}\left(4^{\circ} \mathrm{F}\right.$ to $\left.5^{\circ} \mathrm{F}\right)$;

- $\Delta \mathrm{T}$ from $1.67^{\circ} \mathrm{C}$ to $2.22^{\circ} \mathrm{C}\left(3^{\circ} \mathrm{F}\right.$ to $\left.4^{\circ} \mathrm{F}\right)$;

- $\Delta \mathrm{T}$ from $1.11^{\circ} \mathrm{C}$ to $1.67^{\circ} \mathrm{C}\left(2^{\circ} \mathrm{F}\right.$ to $\left.3^{\circ} \mathrm{F}\right)$;

- $\Delta \mathrm{T}$ from $0.56^{\circ} \mathrm{C}$ to $1.11^{\circ} \mathrm{C}\left(1^{\circ} \mathrm{F}\right.$ to $\left.2^{\circ} \mathrm{F}\right)$; and

- $\quad \Delta \mathrm{T}$ from $0^{\circ} \mathrm{C}$ to $0.56^{\circ} \mathrm{C}\left(0^{\circ} \mathrm{F}\right.$ to $\left.1^{\circ} \mathrm{F}\right)$.

The ACCA Manual RS compliance based on hourly average room-to-room temperature difference was color-coded using three different colors:

- Not compliant (red): $\Delta \mathrm{T}$ above $3.33^{\circ} \mathrm{C}$ (cooling mode) and $\Delta \mathrm{T}$ above $2.22^{\circ} \mathrm{C}$ (heating mode);

- Compliant with the maximum benchmarks (orange): $\Delta \mathrm{T}$ from $1.67^{\circ} \mathrm{C}$ to $3.33^{\circ} \mathrm{C}$ (cooling mode) and $\Delta \mathrm{T}$ from $1.11^{\circ} \mathrm{C}$ to $2.22^{\circ} \mathrm{C}$ (heating mode); and

\footnotetext{
${ }^{44}$ The favorable attic temperature, which was affected by the location of the SDHV supply ductwork within the attic, resulted in cooler second-floor room temperatures when the SDHV was in operation.
} 
- Compliant with the average benchmarks (green): $\Delta T$ below $1.67^{\circ} \mathrm{C}$ (cooling mode) and $\Delta \mathrm{T}$ below $1.11^{\circ} \mathrm{C}$ (heating mode).

As a result, the use of the proposed time-of-day colored map was useful to find out when the non-compliance period reported in Section 4.2 occurred and the level of discomfort. For example, the observed temporal patterns of the room-to-room temperature difference resembled those of the kitchen (Figure G-1 (c)) during the heating mode but to those of the MBR (Figure 34 (c)) during the cooling mode, which were the reasons of the observed noncompliance, as explained in Section 4.2. 


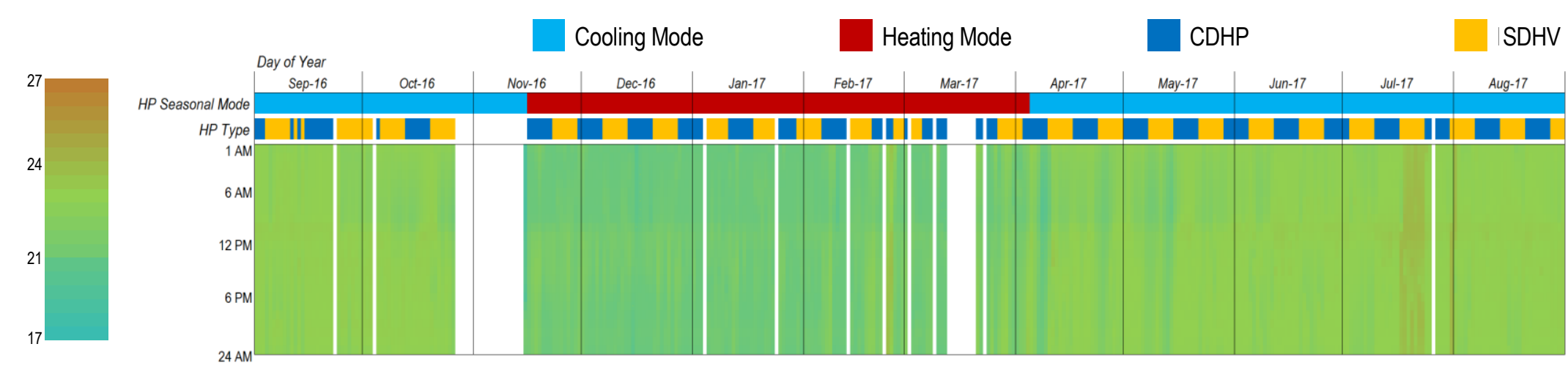

(a) Hourly Average Room Temperatures

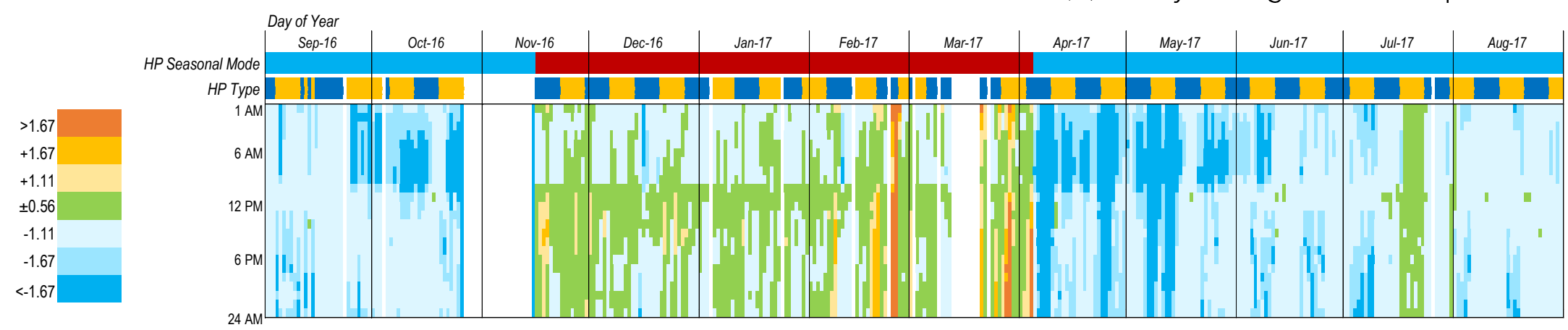

(b) Hourly Average Room-To-Thermostat Temperature Difference

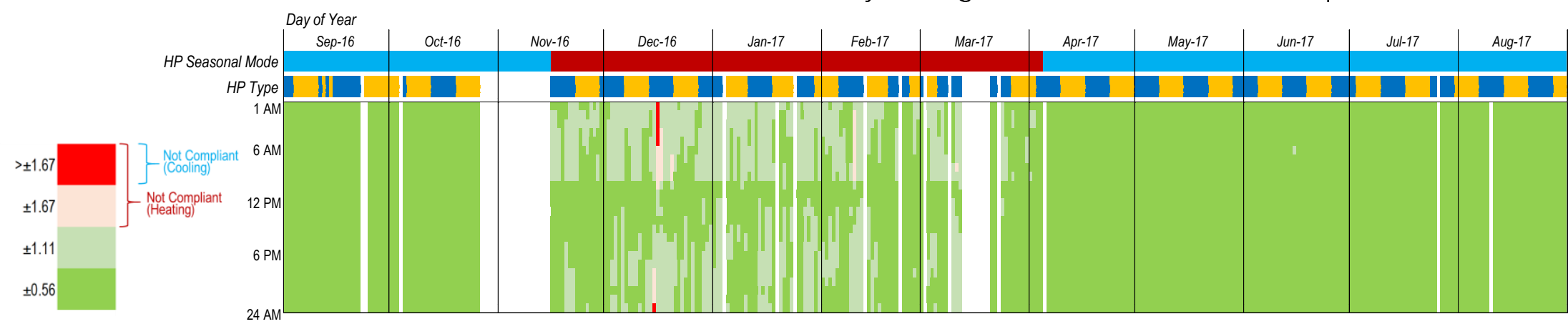

(c) ACCA Compliance Based on Hourly Average Room-To-Thermostat Temperature Difference Figure 33: Time-of-Day Colored Map of LR Temperature. 


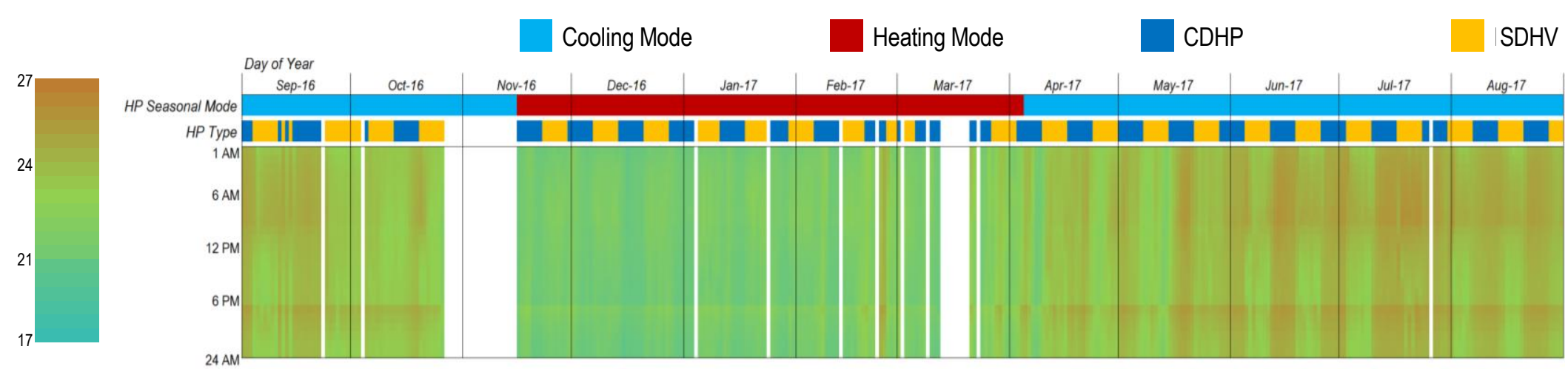

(a) Hourly Average Room Temperatures

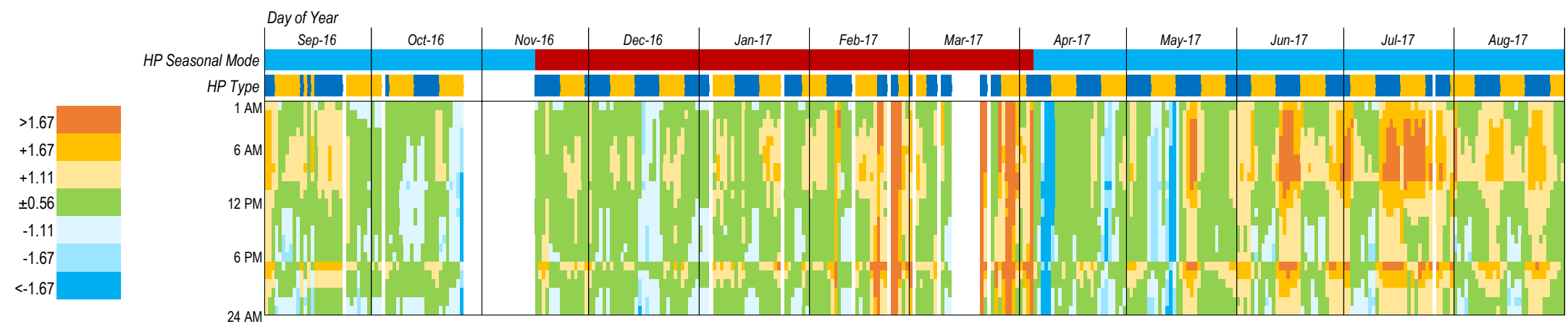

(b) Hourly Average Room-To-Thermostat Temperature Difference

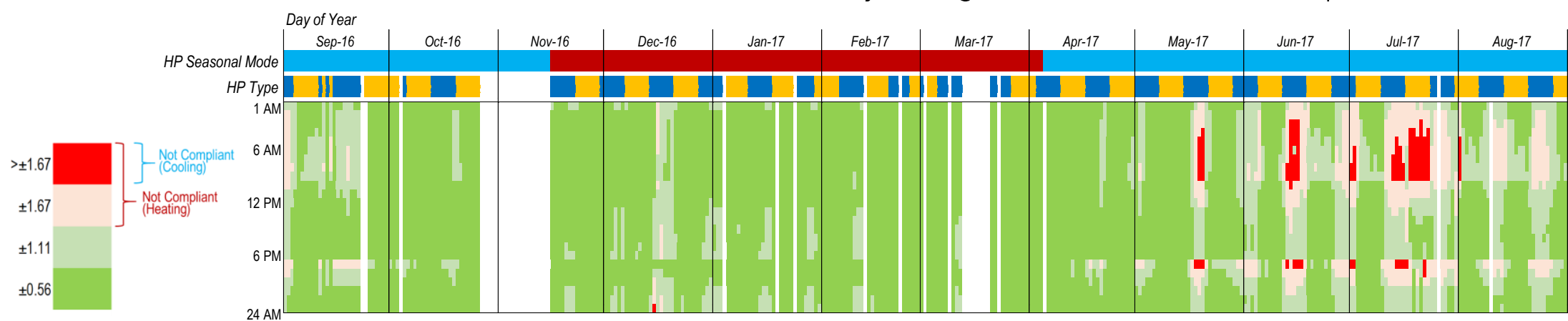

(c) ACCA Compliance Based on Hourly Average Room-To-Thermostat Temperature Difference Figure 34: Time-of-Day Colored Map of MBR Temperature. 


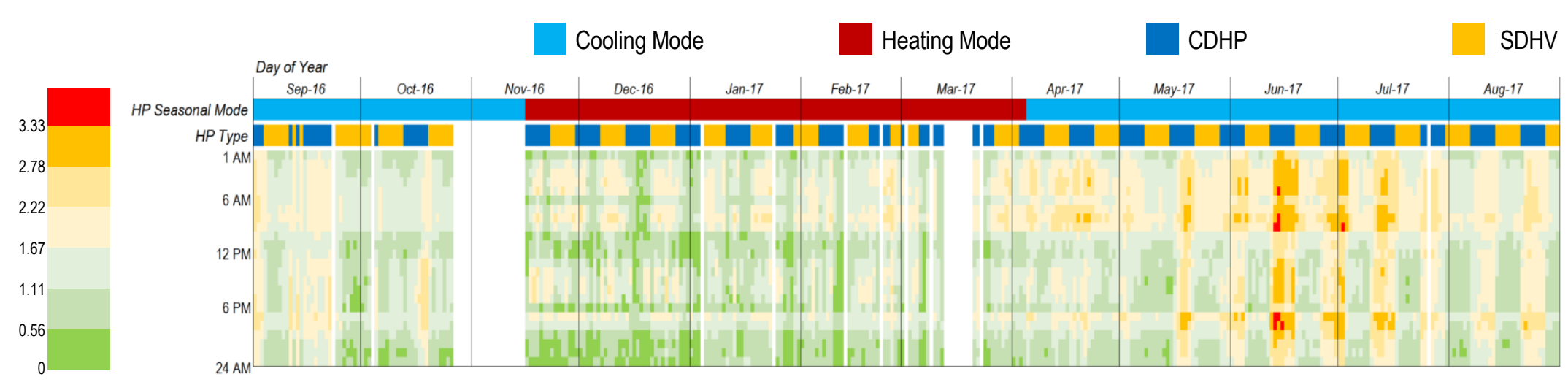

(a) Hourly Average Room-To-Room Temperature Difference

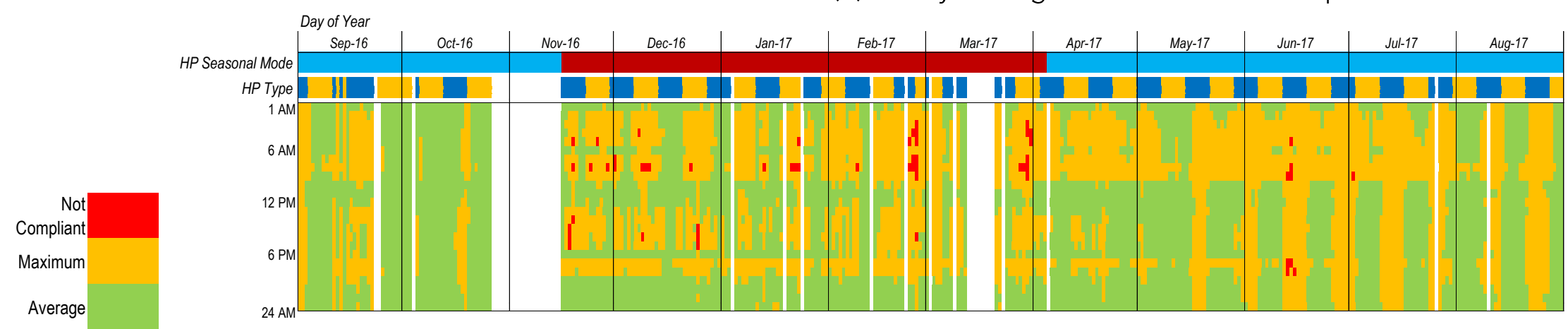

(b) ACCA Compliance Based on Hourly Average Room-To-Room Temperature Difference Figure 35: Time-of-Day Colored Map of Room-To-Room Temperature Difference. 


\subsection{LATENT PERFORMANCE}

Since the tested HP systems were configured to control the thermal conditions of the house solely based on air temperature at the thermostat, there was no humidity setpoint to be used as a reference point in the latent performance evaluation. However, it is important to compare the two systems' latent cooling performance because the SDHV is known to provide improved dehumidification by lowering the supply air temperature.

Therefore, this study first performed a statistical characterization of the continuouslymeasured long-term humidity data for the primary rooms but also for the attic and the basement that are thermally important due to possible moisture transfer from/to the primary rooms. To better understand the observed temporal variations revealed from a statistical analysis, this study also performed an advanced characterization of the measured humidity data by characterizing variations of the measured humidity data related to outdoor climate using a $5^{\circ} \mathrm{C}\left(9^{\circ} \mathrm{F}\right)$ binned quartile analysis.

\subsubsection{STATISTICAL CHARACTERIZATION}

Table 16 presents a summary of the 5 -min average room relative humidity $(\mathrm{RH})$ data collected from the five primary rooms (i.e., LR, KIT, MBR, BR2, and BR3) as well as the attic and the basement of the NZERTF for different system type and on/off cycle (i.e., CDHP on, CDHP off, SDHV on, and SDHV off) and seasons (i.e., cooling season, heating season, and transitional season). Only the mean values and standard deviation were included in the table for simplicity.

Figures 36 to 38 graphically present the results using the graphical index proposed to display long-term thermal comfort data based on a statistical analysis (Figure 13): cooling season in Figure 36, heating season in Figure 37, and transitional season in Figure 38. Data were colorcoded by system types (i.e., blue for CDHP and orange for SDHV) with superimposed RH benchmarks: $30 \%$ to $60 \%$ RH as reported by Sterling et al. (1985) and more recently by Derby and Pasch (2017). The ACCA Manual RS also suggests a $60 \% \mathrm{RH}$ as the upper limit for human comfort during the cooling season. The ASHRAE Standard 62.1-2016 (ASHRAE 2016) limits the relative humidity of occupied spaces to $65 \%$ or less at the dehumidification design conditions.

Important observations on the room RH during the cooling season (Table 16 and Figure 36) are:

- Outdoor air (OA) RH

- There was a noticeable difference in the OA RH levels when the systems were on cycle versus off cycle. When the systems were off, the OA RH was higher by $13.6 \%$ on average (CDHP) and $18.3 \%$ on average (SDHV), which was affected by the temperature-dependent nature of the metric (i.e., relative humidity) ${ }^{45}$ rather than actual OA moisture levels. During the cooling season, the HP systems were off mostly during the nighttime with lower OA temperatures.

\section{- Room RH}

${ }^{45} \mathrm{~A}$ detailed analysis of variations observed in the measured absolute humidity is provided in Section 4.7.2. 
- When the systems cycled on, the room RH levels were well within the optimum $\mathrm{RH}$ range between $30 \%$ and $60 \%$ for most of the measurement period with a deviation of less than $3 \%$ of the period except for the kitchen. The kitchen had a higher percentage of the high-side deviation (i.e., over $60 \% \mathrm{RH}$ ). The kitchen's RH levels were also higher than other rooms in general, which might be biased due to its location near the two humidifiers that were operated to emulate latent heat generation in the house.

- When comparing the two systems during the system on cycle, the SDHV maintained lower RH levels in the rooms on the first floor, while the RH levels measured in the second-floor rooms were comparable between the two systems. This means the SDHV dehumidification performance was slightly better than the CDHP when considering lower room temperatures maintained in the second-floor bedrooms when the SDHV cycled on during the cooling season (Figure 14).

- When the systems cycled off, the room RH levels tended to be higher than those during the system on cycle with higher interquartile ranges regardless of the system type. However, attic and basement that did not directly get the OA ventilation from the HRV maintained similar room $\mathrm{RH}$ levels regardless of the system on and off cycle.

- When comparing the two systems during the system off cycle, the reported RH levels in the second-floor bedrooms were lower when the CDHP was operated, which was due to warmer second-floor room temperatures rather than lower absolute humidity levels.

Important observations on the room RH during the heating season (Table 16 and Figure 37) are:

- OARH

- Compared to the cooling season, a difference in the OA RH levels when the systems were on cycle versus off cycle was less noticeable. On average, the OA RH was slightly lower when the systems were off, which was due to warmer OA temperatures rather than lower OA moisture levels.

- Room RH

- When the systems cycled on, the room RH levels were below the lower limit of the optimum $\mathrm{RH}$ range (i.e., below $30 \% \mathrm{RH}$ ) for most of the measurement period except for the kitchen.

- Although the kitchen $\mathrm{RH}$ levels were well within the optimum $\mathrm{RH}$ range, the kitchen $\mathrm{RH}$ levels might be biased due to its location near the two humidifiers that were operated to emulate latent heat generation in the house.

- The LR had higher RH levels compared to the second-floor bedrooms, which might be also affected by the two humidifiers in the kitchen.

- When comparing the two systems, the reported $\mathrm{RH}$ levels in the second-floor bedrooms tended to be lower when the SDHV was operated, which was due to warmer second-floor room temperatures rather than lower absolute humidity levels.

- When the systems cycled off, the room RH levels tended to be slightly higher than those during the system on cycle with slightly higher interquartile ranges regardless of the system type. However, attic and basement that did not directly get the OA ventilation from the HRV maintained similar room $\mathrm{RH}$ levels regardless of the system on and off cycle. 
Important observations on the room RH during the transitional season (Table 16 and Figure 38) are:

- OARH

- During the transitional season when the systems mostly cycled off ${ }^{6}$, there was no noticeable difference in the measured OA RH levels between the two systems, which tended to be higher than the $\mathrm{OA}$ RH levels during the heating season but lower than the $\mathrm{OA} \mathrm{RH}$ levels during the cooling season.

- Room RH

- Like the OA RH levels, the room RH levels during the transitional season were higher than the room $\mathrm{RH}$ levels during the heating season but lower than the room $\mathrm{RH}$ levels during the cooling season.

- Like other seasons, the room RH levels of the first-floor rooms were higher than the levels of the second-floor rooms.

- When comparing the two systems during the system off cycle, the measured $\mathrm{RH}$ levels were comparable between the two systems.

${ }^{46}$ Due to the small sample size of the system on cycle, discussion of transitional season data focuses on the data collected during the system off cycle. 
Table 16: Mean (Standard Deviation) of the 5-Min Average Room Relative Humidity by the HP System Modes and Seasons.

\begin{tabular}{|c|c|c|c|c|c|c|c|c|c|c|c|c|}
\hline & \multicolumn{4}{|c|}{ Cooling Season } & \multicolumn{4}{|c|}{ Heating Season } & \multicolumn{4}{|c|}{ Transitional Season } \\
\hline & \multicolumn{2}{|c|}{ CDHP } & \multicolumn{2}{|c|}{ SDHV } & \multicolumn{2}{|c|}{ CDHP } & \multicolumn{2}{|c|}{ SDHV } & \multicolumn{2}{|c|}{ CDHP } & \multicolumn{2}{|c|}{ SDHV } \\
\hline & On & Off & On & Off & On & Off & On & Off & On & Off & On & Off \\
\hline \multicolumn{13}{|c|}{ Sample Size } \\
\hline $\begin{array}{l}\mathrm{n} \\
\text { (hours) } \\
\text { (days) }\end{array}$ & $\begin{array}{c}11856 \\
988 \\
41\end{array}$ & $\begin{array}{c}10896 \\
908 \\
38\end{array}$ & $\begin{array}{c}12336 \\
1028 \\
43\end{array}$ & $\begin{array}{c}12362 \\
1030 \\
43\end{array}$ & $\begin{array}{c}5172 \\
431 \\
18\end{array}$ & $\begin{array}{c}9516 \\
793 \\
33\end{array}$ & $\begin{array}{c}6274 \\
523 \\
22\end{array}$ & $\begin{array}{c}8414 \\
701 \\
29\end{array}$ & $\begin{array}{c}342 \\
29 \\
1\end{array}$ & $\begin{array}{c}8010 \\
668 \\
28\end{array}$ & $\begin{array}{c}790 \\
66 \\
3\end{array}$ & $\begin{array}{c}6986 \\
582 \\
24\end{array}$ \\
\hline \multicolumn{13}{|c|}{ Relative Humidity (\%) } \\
\hline OA & & $66.1(18.5)$ & $53.9(19.2)$ & $72.2(17.5)$ & & $51.2(20.8)$ & & & & & & $57.6(22.8)$ \\
\hline LR & $49.2(4.5)$ & $52.8(6.4)$ & $45.6(5.8)$ & $55.8(7.1)$ & $31.8(4.9)$ & $36.0(6.2)$ & $31.1(5.5)$ & $35.6(6.2)$ & $43.2(4.7)$ & $45.8(6.5)$ & $44.8(5.7)$ & $45.9(6.0)$ \\
\hline KIT & $53.0(5.4)$ & $57.5(7.4)$ & $49.7(6.6)$ & $60.2(8.1)$ & $38.1(6.8)$ & $42.4(8.1)$ & $39.9(7.7)$ & $41.8(7.5)$ & $47.7(5.5)$ & $51.0(8.2)$ & $50.4(5.9)$ & $49.2(7.3)$ \\
\hline MBR & $44.3(4.7)$ & $45.6(6.3)$ & $43.8(5.1)$ & $48.9(6.4)$ & $28.6(4.7)$ & $31.8(6.2)$ & $25.5(5.6)$ & $29.8(6.1)$ & $37.8(5.0)$ & $38.1(6.9)$ & $40.2(6.2)$ & $38.0(6.0)$ \\
\hline $\mathrm{BR} 2$ & $43.6(5.2)$ & $45.3(7.0)$ & $44.5(5.5)$ & $49.3(7.5)$ & 27.5 & $29.5(6.8)$ & $25.2(5.7)$ & $27.5(6.6)$ & $36.0(4.9)$ & $36.5(7.4)$ & $38.8(5.8)$ & $36.3(6.3)$ \\
\hline BR3 & $45.9(5.9)$ & $46.9(7.5)$ & $44.3(6.2)$ & $51.0(8.5)$ & $26.6(5.0)$ & $29.0(6.8)$ & $24.6(6.2)$ & $28.1(6.6)$ & $36.7(4.8)$ & $37.4(7.1)$ & $38.8(5.4)$ & $36.2(6.9)$ \\
\hline ATTIC & $53.5(2.2)$ & $53.1(2.3)$ & 44.1 (3.2) & $45.0(3.4)$ & $44.3(2.7)$ & $45.3(3.4)$ & 32.4 (3.6) & $36.1(3.6)$ & 47.5 (3.9) & $47.5(3.0)$ & $37.1(3.5)$ & $40.1(3.4)$ \\
\hline BSMT & $52.0(2.3)$ & $51.3(2.9)$ & 47.4 (2.9) & $49.7(3.6)$ & 36.7 (3.6) & $38.9(4.1)$ & 35.6 (4.3) & $38.3(4.2)$ & 44.7 (5.9) & $44.9(4.9)$ & $45.0(3.9)$ & $47.1(3.9)$ \\
\hline
\end{tabular}



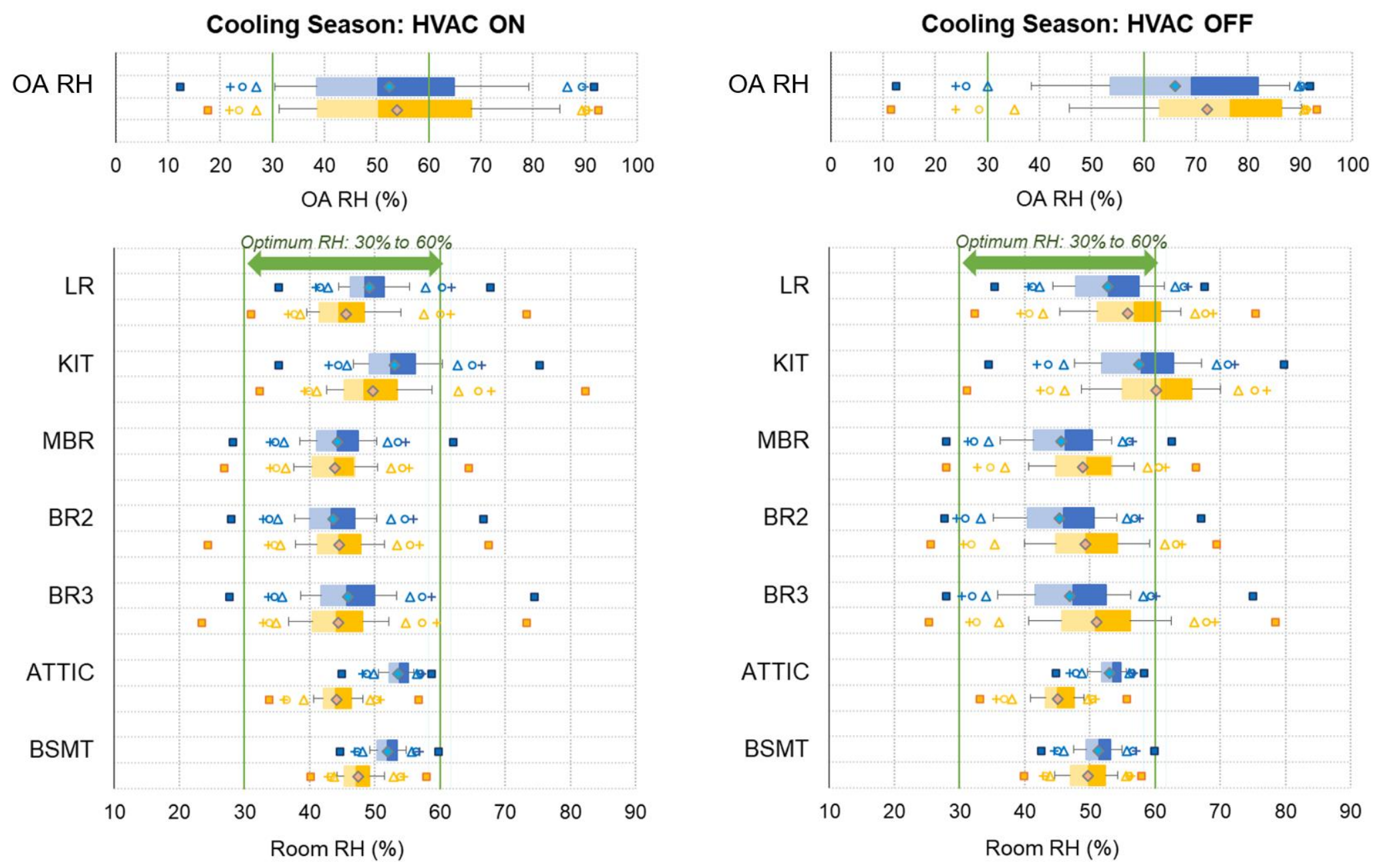

Figure 36: Graphical Summaries of the 5-Min Average Room Humidity When the System Was On Cycle (Left Figure) and Off Cycle (Right Figure) for the Cooling Season. 


\section{Heating Season: HVAC ON}
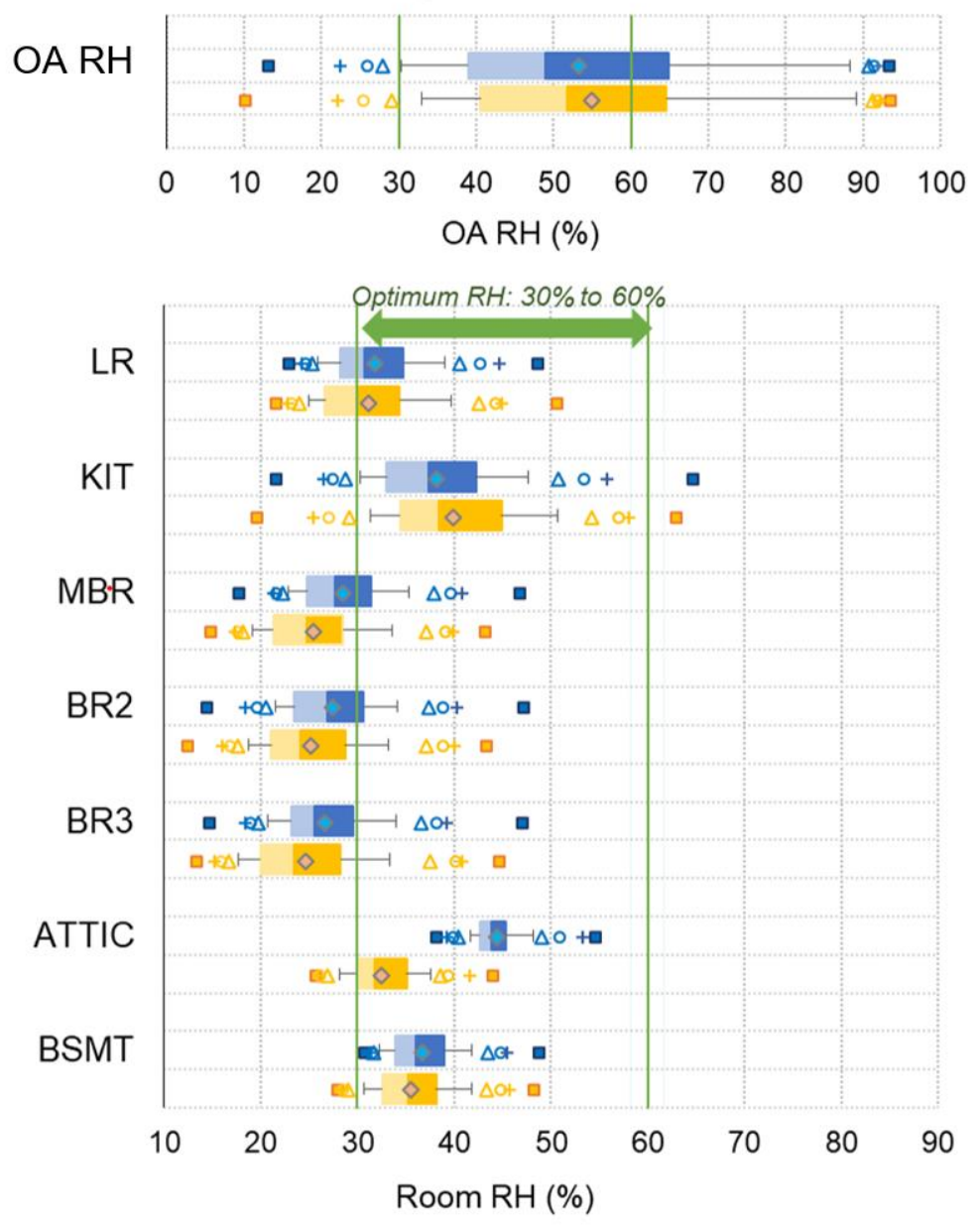

Heating Season: HVAC OFF
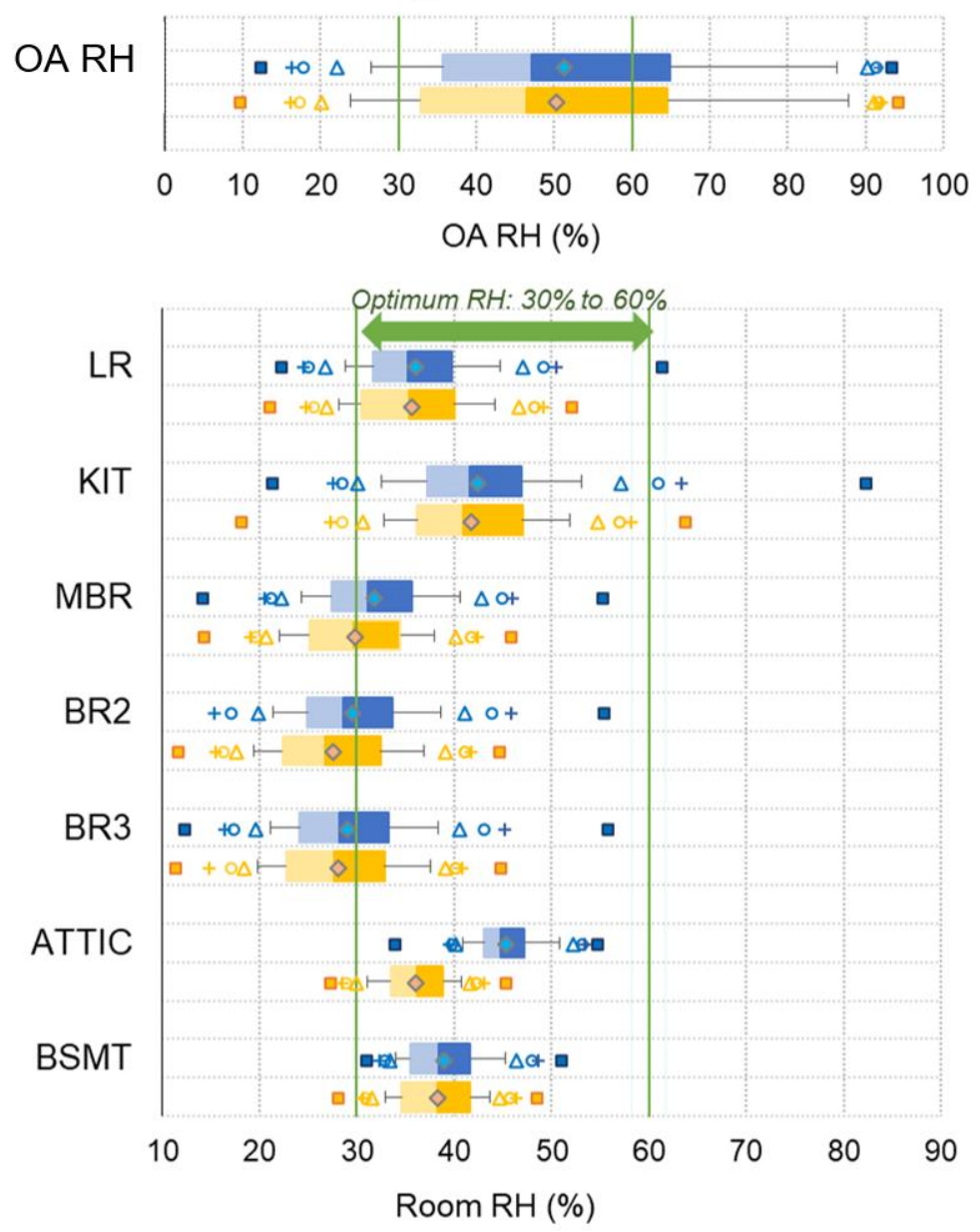

Figure 37: Graphical Summaries of the 5-Min Average Room Humidity When the System Was On Cycle (Left Figure) and Off Cycle (Right Figure) for the Heating Season. 
Transitional Season: HVAC ON
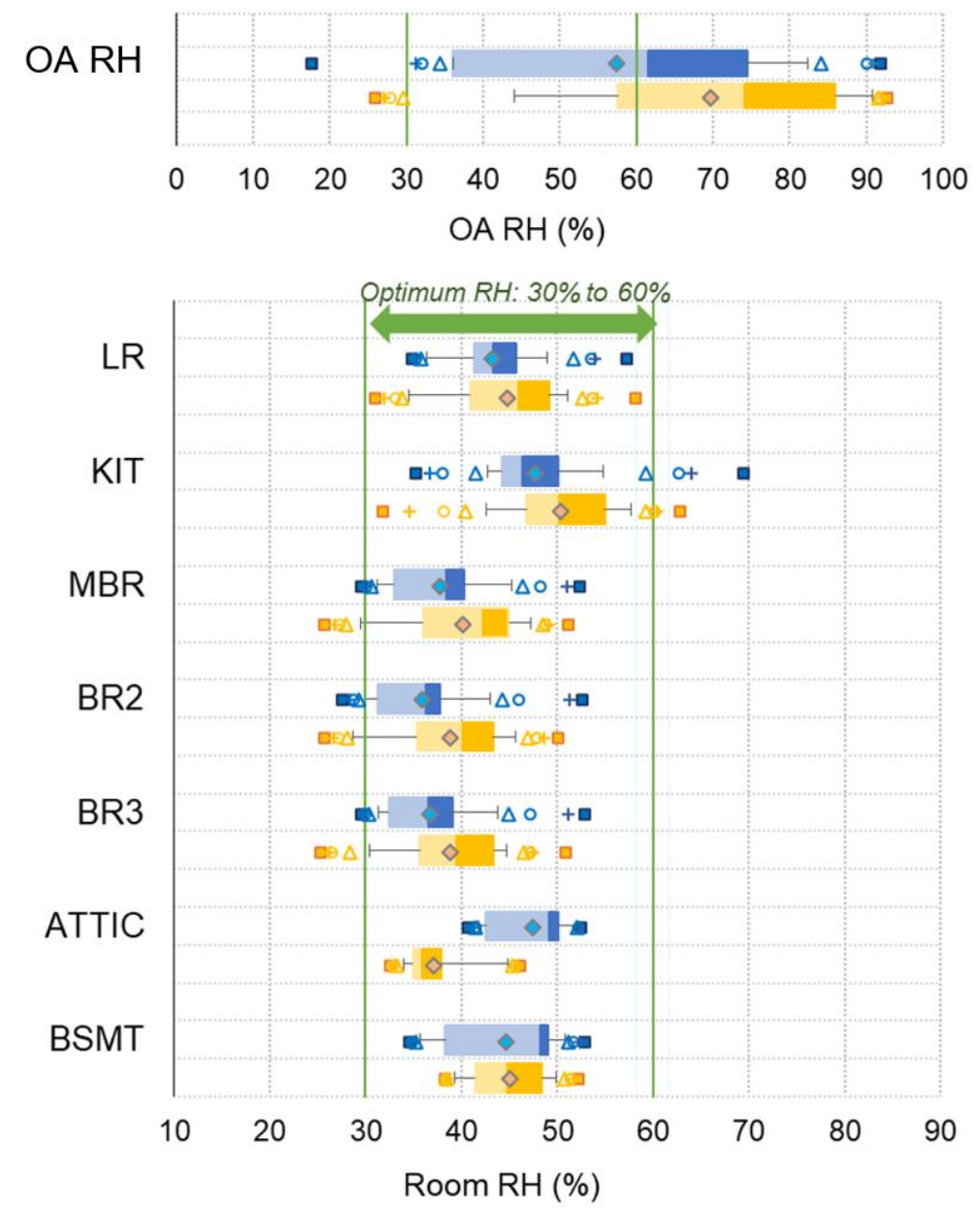

Transitional Season: HVAC OFF
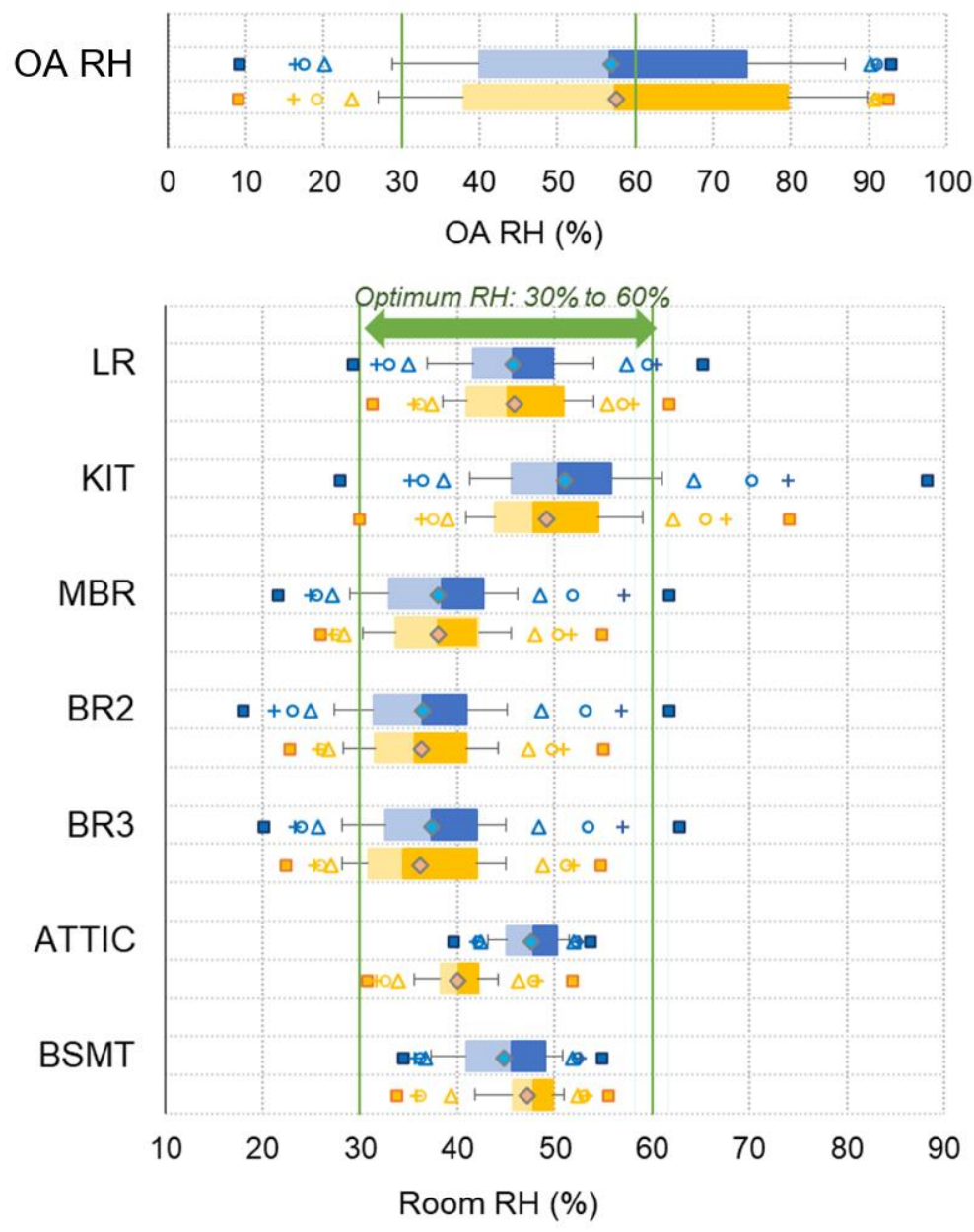

Figure 38: Graphical Summaries of the 5-Min Average Room Humidity When the System Was On Cycle (Left Figure) and Off Cycle (Right Figure) for the Transitional Season. 


\subsubsection{TEMPORAL VARIATIONS RELATED TO OUTDOOR HUMIDITY}

Figures 39 to 45 present the results of the binned room absolute humidity levels (i.e., humidity ratio in $\mathrm{g} \mathrm{H}_{2} \mathrm{O} / \mathrm{kg}$ dry air) against outdoor dew point temperatures for the five primary rooms (i.e., LR, KIT, MBR, BR2, and BR3) as well as the attic and the BSMT of the house. Figure 46 displays the median values of the binned room absolute humidity ratio of all seven rooms for a comparison between rooms. Each figure consists of the four plots: (a) CDHP on cycle; (b) CDHP off cycle; (c) SDHV on cycle; and (d) SDHV off cycle.

All primary rooms appeared to have an association between the outdoor and indoor absolute humidity levels to some extent regardless of the type of HP system in operation (Figures 39 to 43). The observed relationship was not linear and was less clear at the lower or the higher outdoor dew point temperatures. At the high outdoor dew point temperatures (i.e., cooling season), the tested HP systems along with the HRV system effectively removed moisture from the air and maintained humidity ratios in the rooms below the upper recommended humidity limit of the ASHRAE Standard 55-2017 (i.e., $0.012 \mathrm{~kg} / \mathrm{kg}$, which is equivalent to $17.2^{\circ} \mathrm{C}\left(63^{\circ} \mathrm{F}\right)$ dew point temperature $)$ for most of the measurement period with wider temporal variations. There were a few incidences when the maximum humidity ratios exceeded $0.012 \mathrm{~kg} / \mathrm{kg}$, which occurred to a great extent in the kitchen and the BR3 especially when the SDHV was off cycle. The humidity ratios measured in the attic and the basement of the house (Figures 44 and 45 ) that did not directly get the OA ventilation from the HRV appeared to be less sensitive to outdoor dew point temperatures.

When comparing the median values of the rooms (Figure 46), the first-floor rooms (i.e., LR and $\mathrm{KIT}$ ) appeared to have higher humidity ratios than the ratios of the second-floor rooms (i.e., MBR, BR2, and BR3) at the low outdoor dew point temperatures, which might be affected by the two humidifiers in the kitchen. Between the first-floor rooms, the kitchen had higher humidity ratios than those of the living room. However, at the higher outdoor dew point temperatures, the living room had the lowest mean humidity ratio among the primary rooms despite the presence of the two humidifiers on the first floor. The basement, which had the least sensitive profile to outdoor humidity due to an absence of the OA ventilation supply (i.e., dry outdoor air in the heating season and moist outdoor air in the cooling season), had similar mean humidity ratios as those of the kitchen at the low outdoor dew point temperatures but the lowest mean humidity ratios at the high outdoor dew point temperatures, which is noteworthy.

To compare the humidity ratios between the two systems more clearly, the median values of the binned room temperatures were averaged by the floor for simplicity, as shown in Figure 47: (a) CDHP on vs. SDHV on; and (b) CDHP off vs. SDHV off. At the low outdoor dew point temperatures (i.e., heating season), the humidity ratios of the primary rooms were comparable between the two systems regardless of the system on and off cycle, which is expected since heating is all sensible and the same HRV was operated on the same schedule. However, the attic humidity ratio showed an obvious difference between the two systems at both low and high outdoor dew point temperatures. When the CDHP was in operation, the measured humidity ratios were consistently higher than the ratios when the SDHV was in operation. Since the attic did not get the OA ventilation directly from the HRV, the observed higher absolute humidity levels with the CDHP were likely to be introduced from the outside when the negative attic pressure with respect to the outside might pull humid outdoor air, which needs a further investigation. 
At the high outdoor dew point temperatures (i.e., cooling season), the SDHV appeared to maintain the primary rooms drier under the same outdoor dew point temperatures when the systems cycled on, which was more obvious at the outdoor dew point temperature bins between $10^{\circ} \mathrm{C}$ and $20^{\circ} \mathrm{C}$. When considering the same HRV schedule during the analysis period, this difference agrees with the SDHV's improved dehumidification capability at low air flow rates by lowering the supply air temperature. However, when the systems cycled off, the SDHV had higher humidity ratios than those of the CDHP especially at the higher outdoor dew point temperatures between $15^{\circ} \mathrm{C}$ and $20^{\circ} \mathrm{C}$. As a result, there were a number of incidences when the humidity ratios exceeded $0.012 \mathrm{~kg} / \mathrm{kg}$ when the SDHV cycled off, which occurred to a great extent in the kitchen and the BR3. 


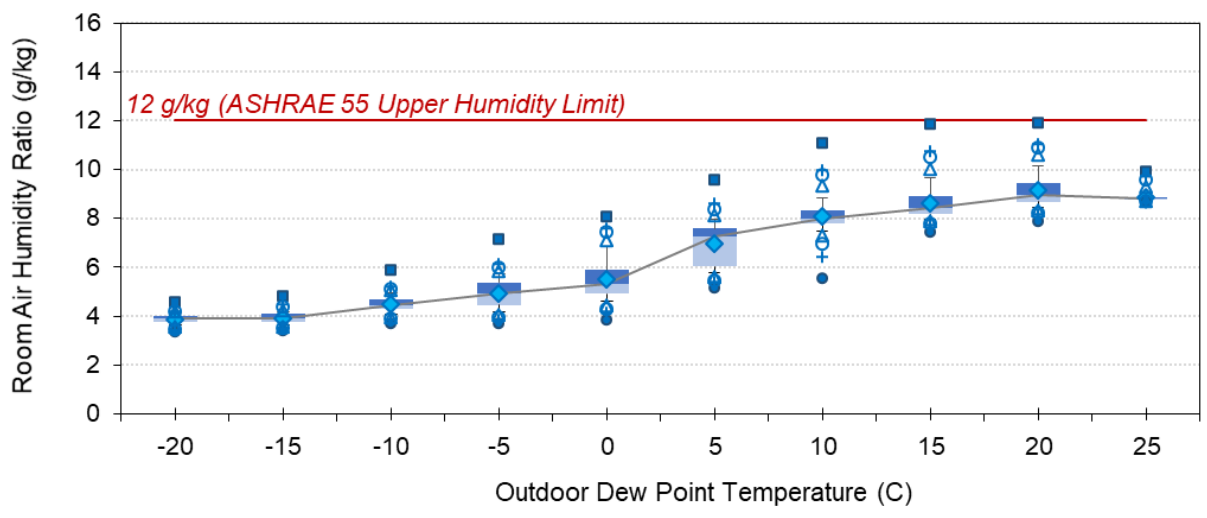

(a) CDHP On

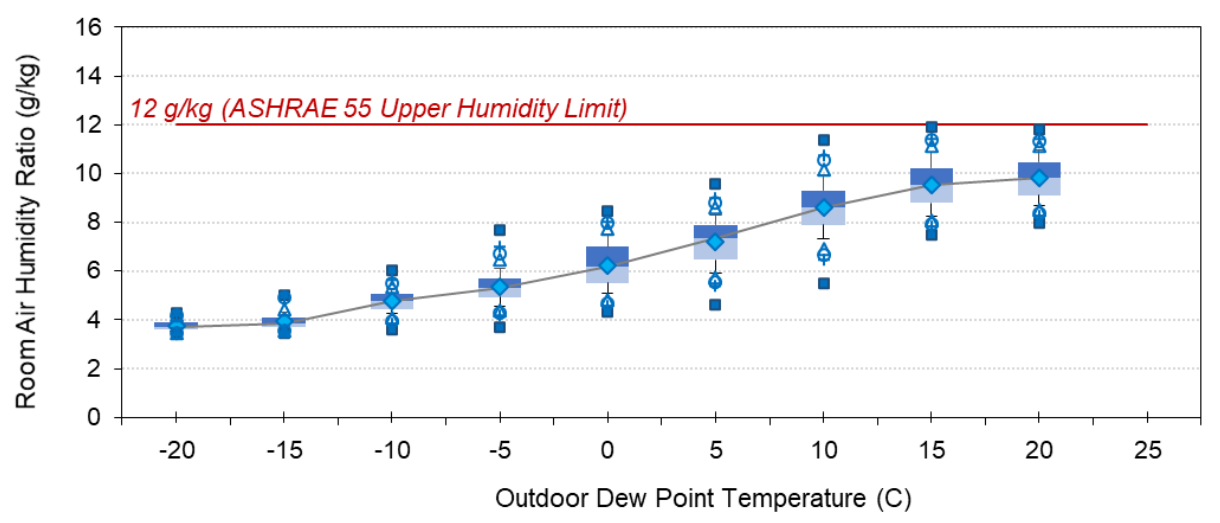

(b) CDHP Off

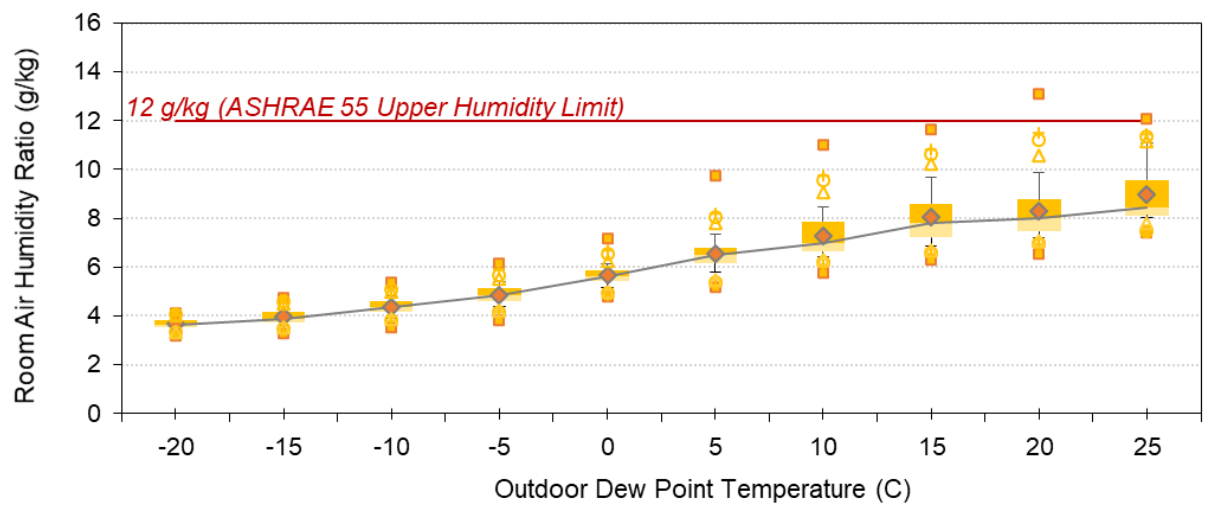

(c) SDHV On

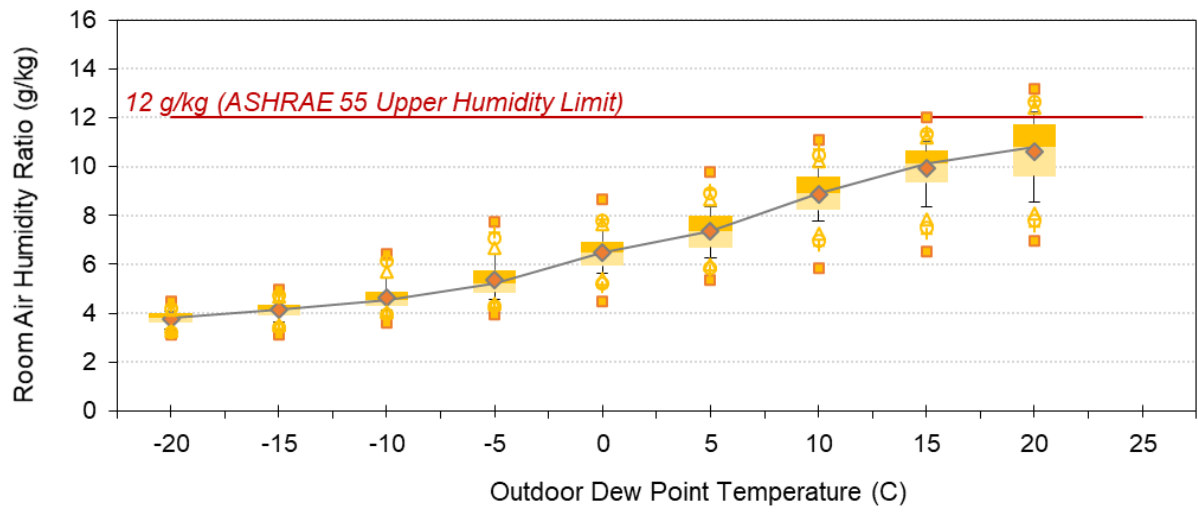

(d) SDHV Off

Figure 39: Binned LR Room Air Humidity Ratios Against Outdoor Dew Point Temperatures. 


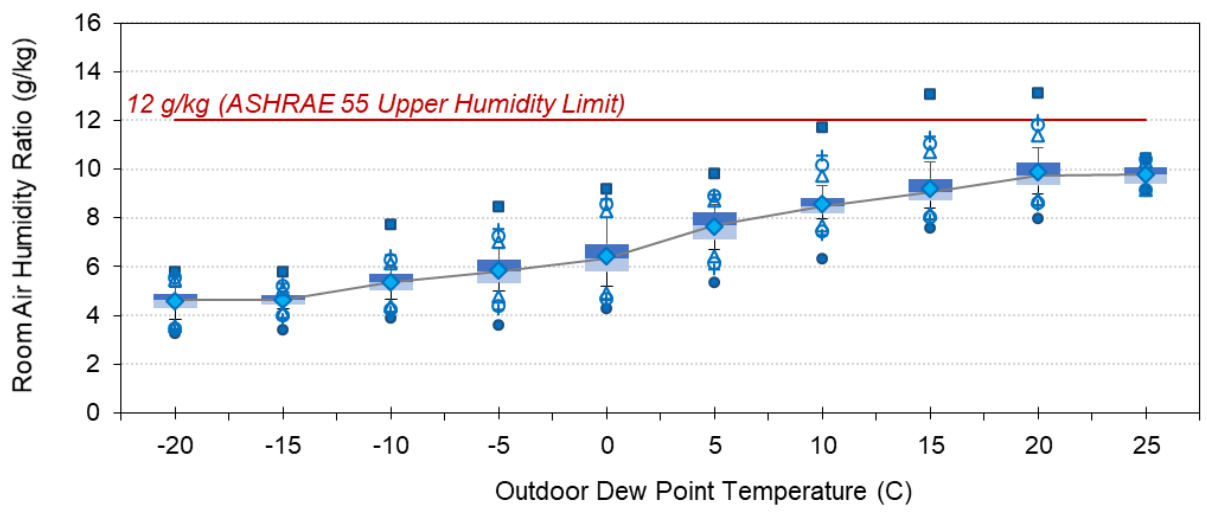

(a) CDHP On

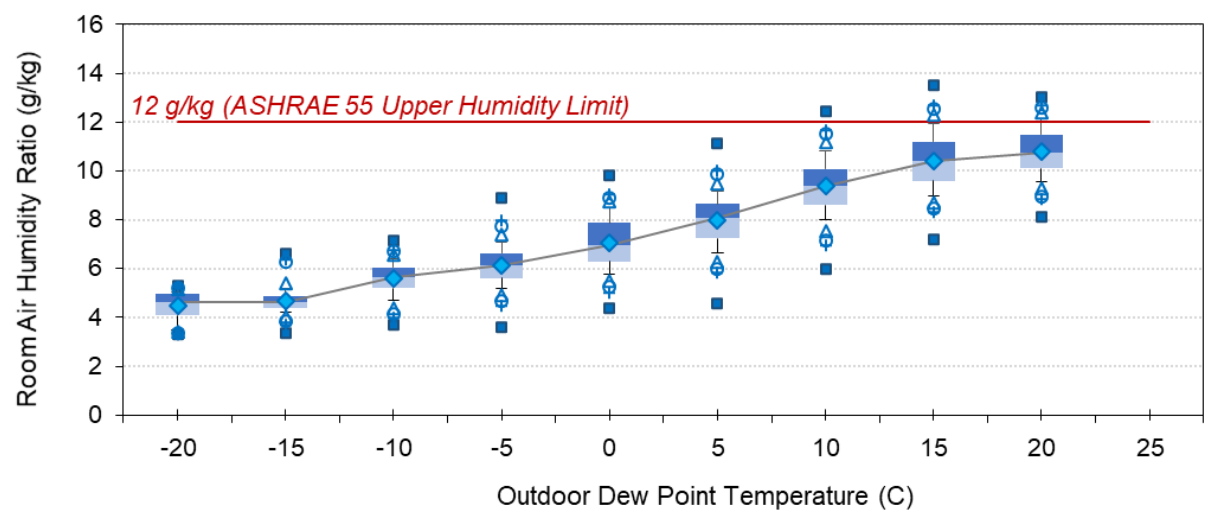

(b) CDHP Off

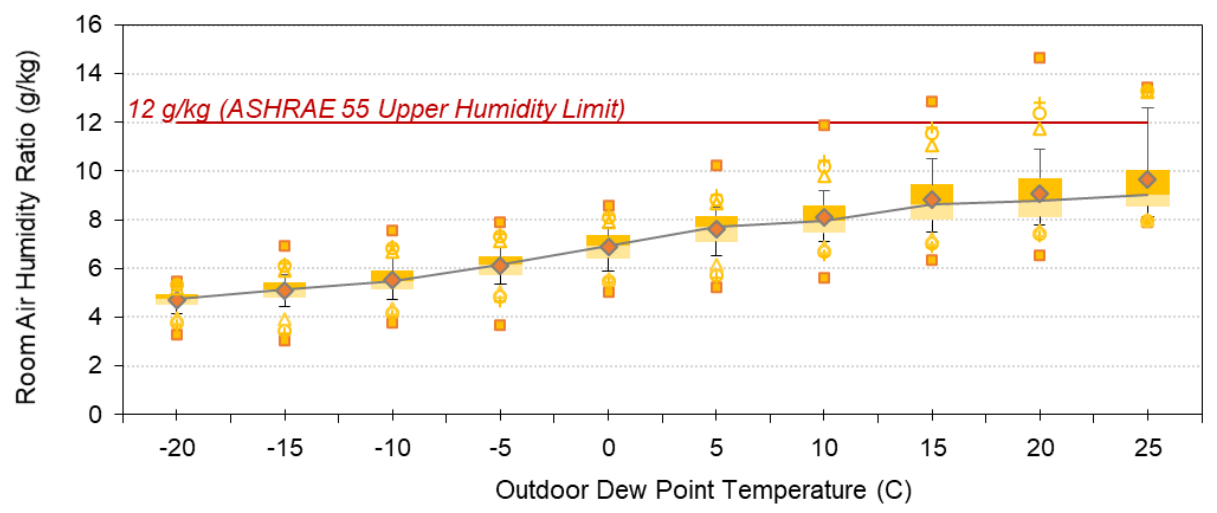

(c) SDHV On

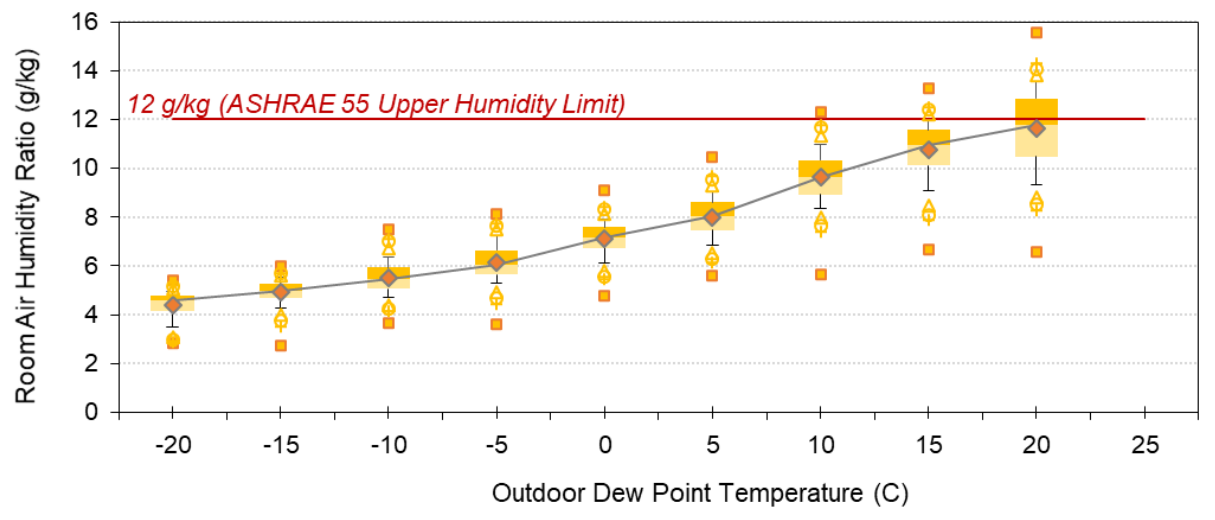

(d) SDHV Off

Figure 40: Binned KIT Room Air Humidity Ratios Against Outdoor Dew Point Temperatures. 


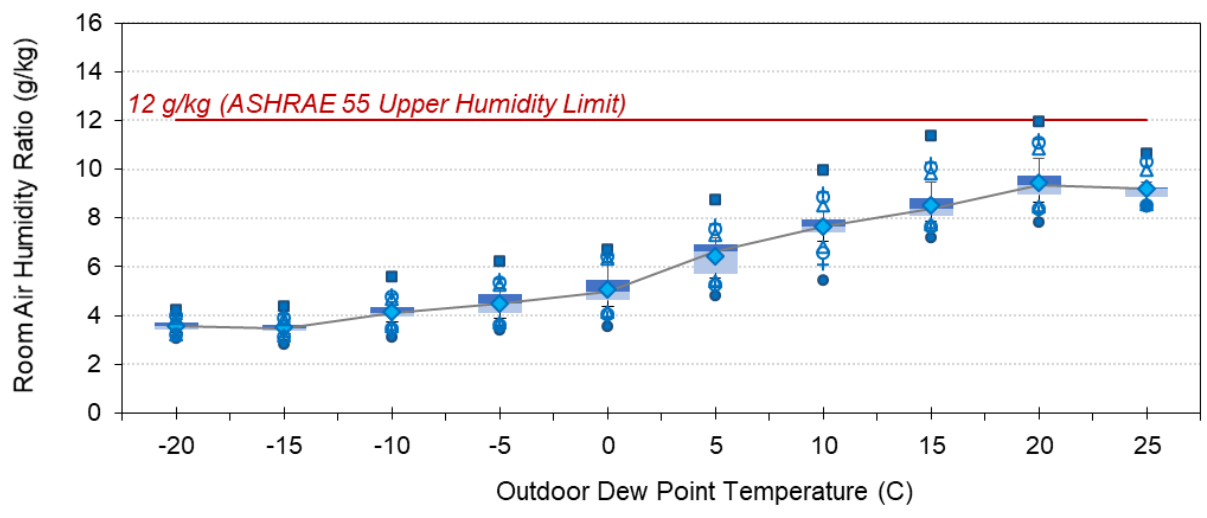

(a) CDHP On

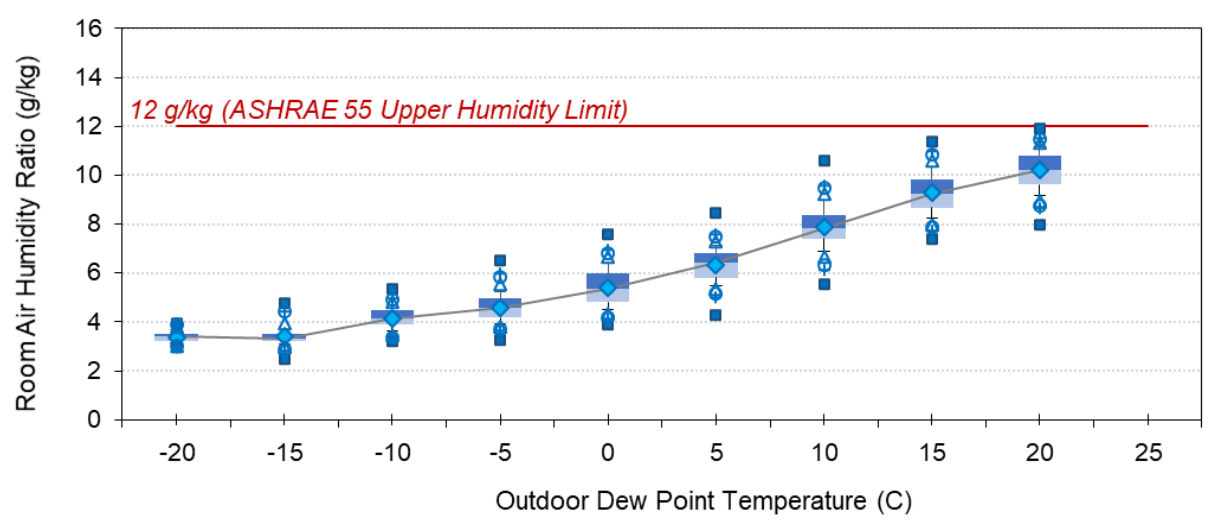

(b) CDHP Off

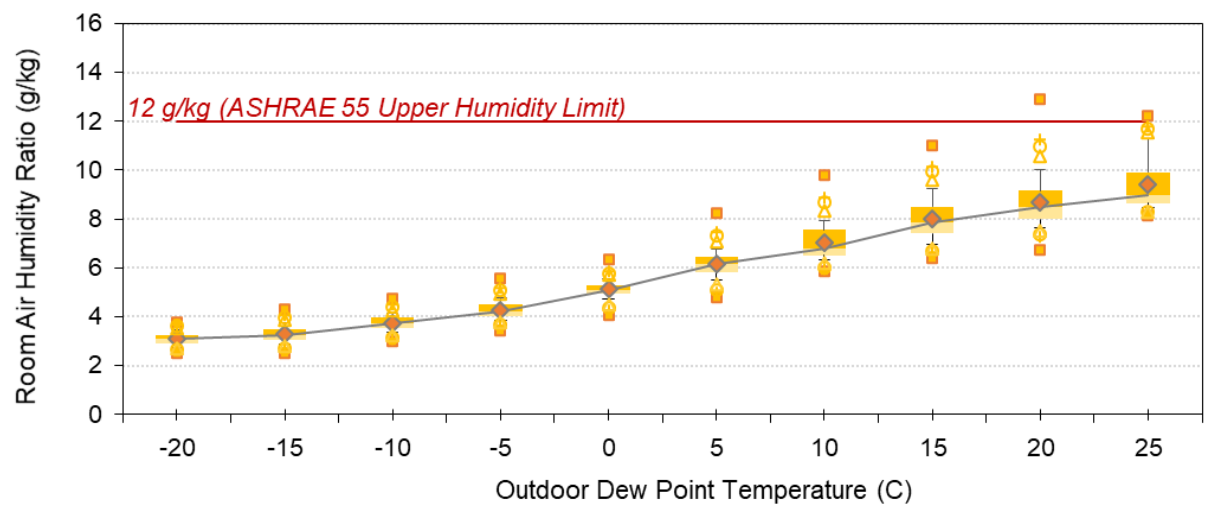

(c) SDHV On

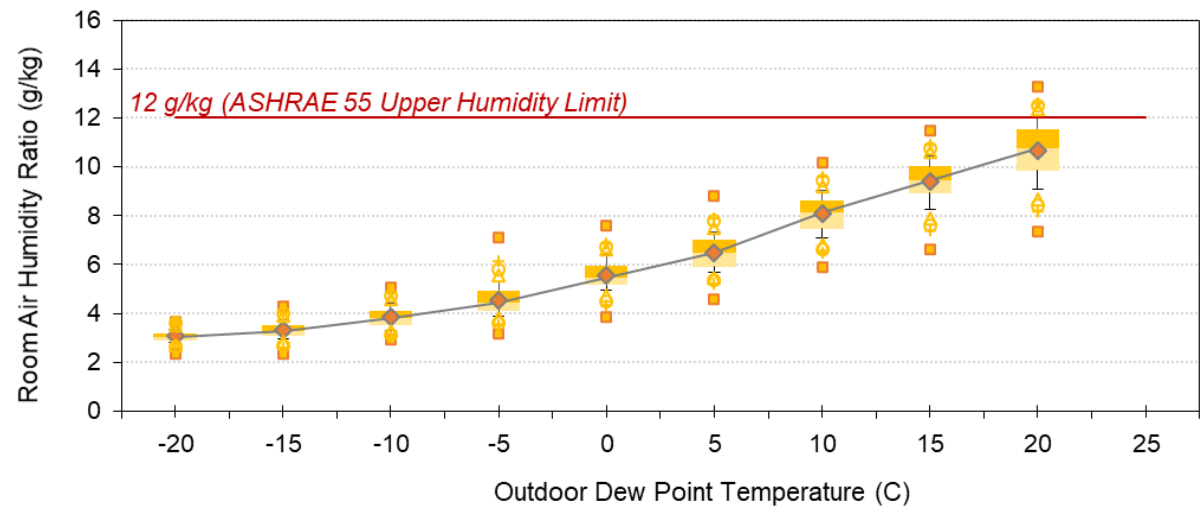

(d) SDHV Off

Figure 41: Binned MBR Room Air Humidity Ratios Against Outdoor Dew Point Temperatures. 


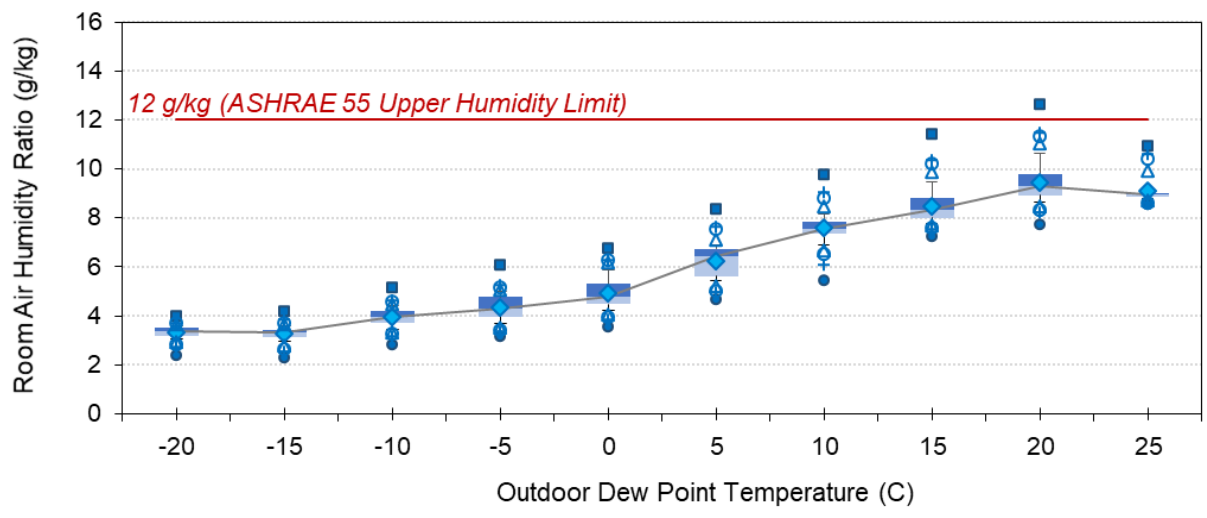

(a) CDHP On

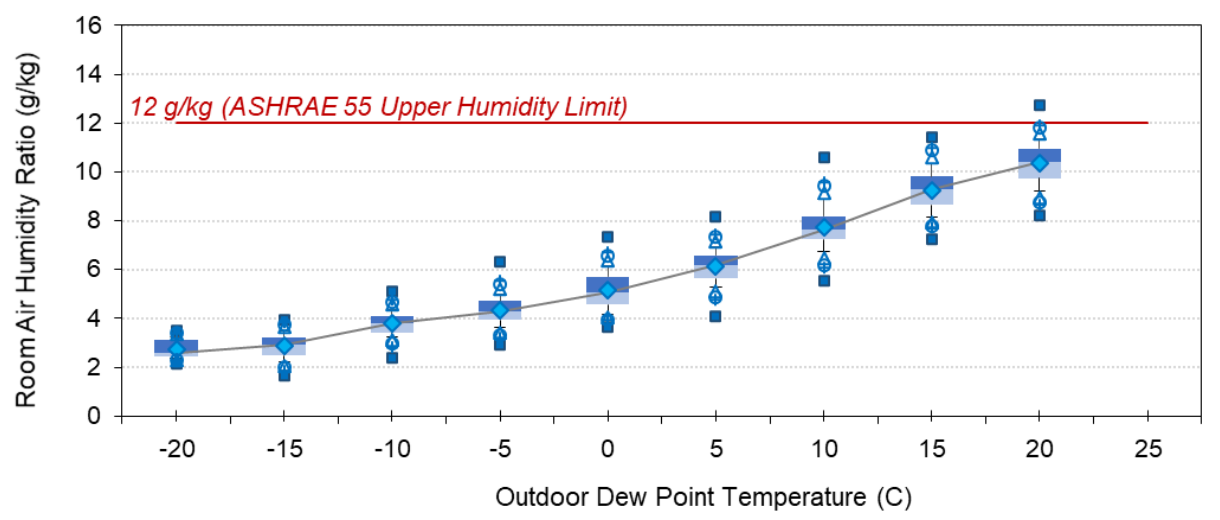

(b) CDHP Off

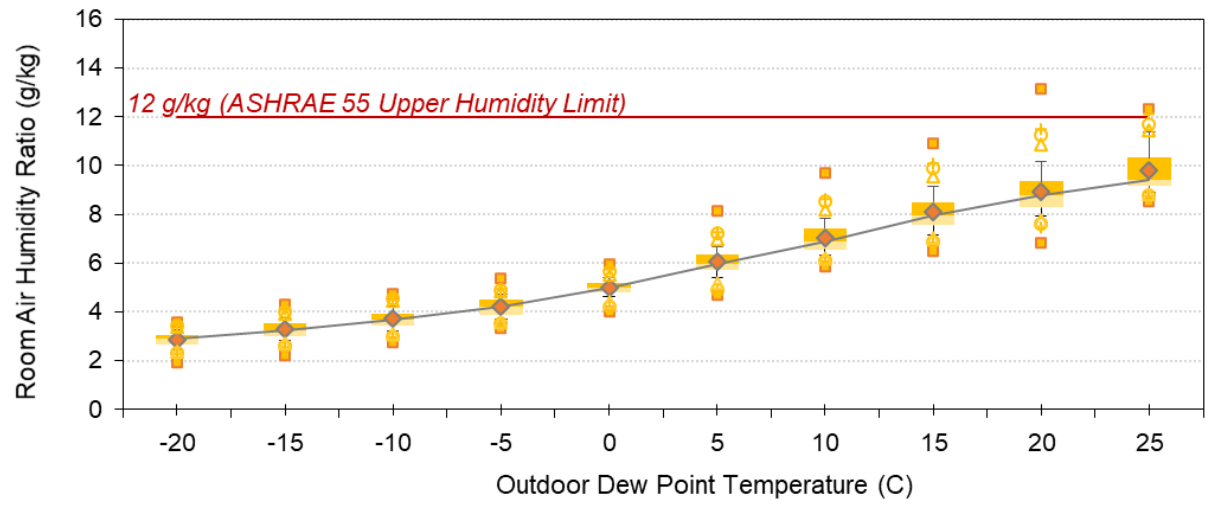

(c) SDHV On

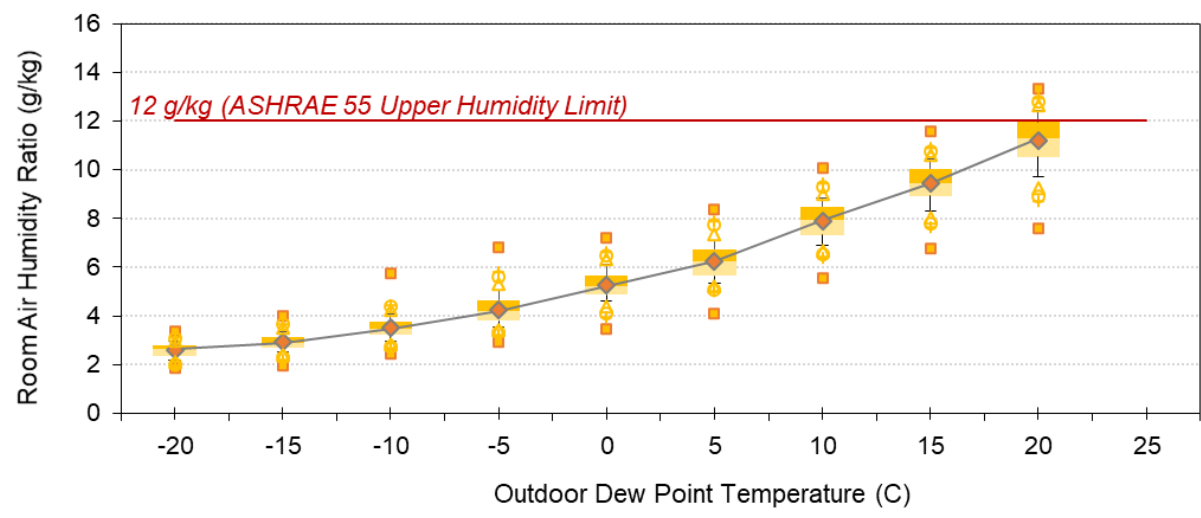

(d) SDHV Off

Figure 42: Binned BR2 Room Air Humidity Ratios Against Outdoor Dew Point Temperatures. 


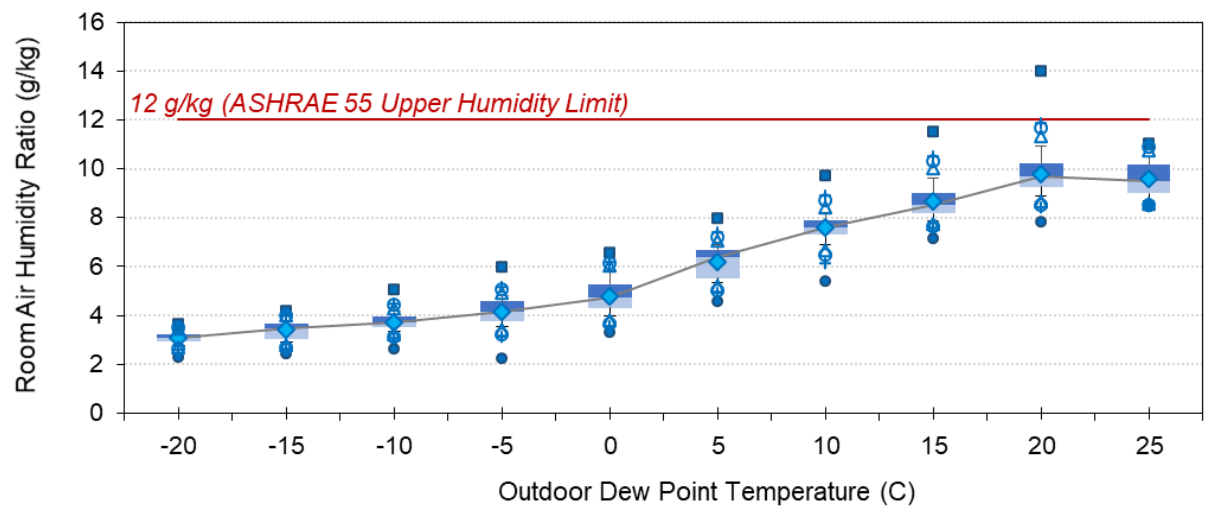

(a) CDHP On

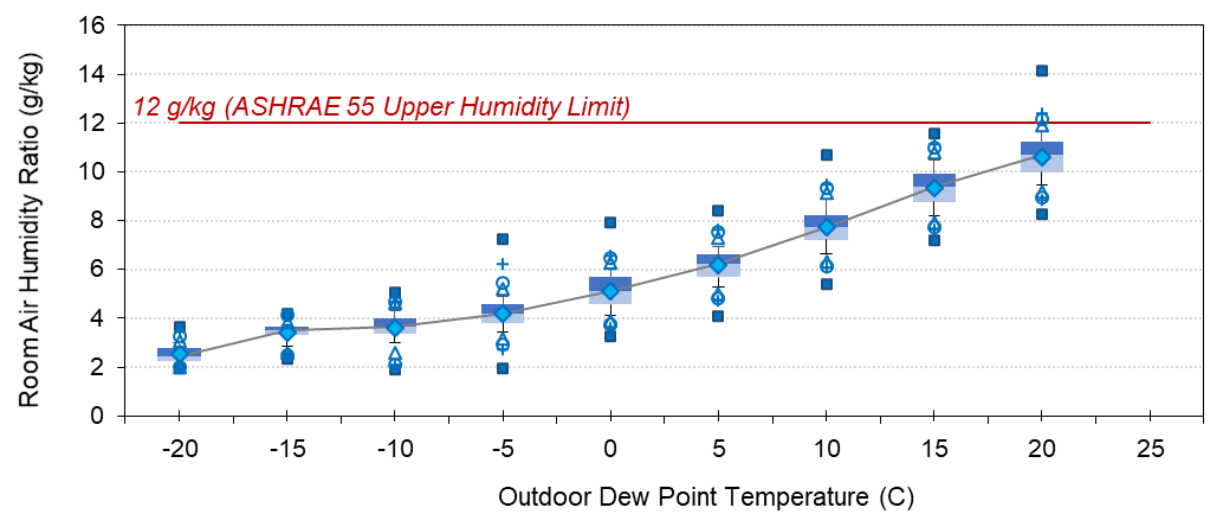

(b) CDHP Off

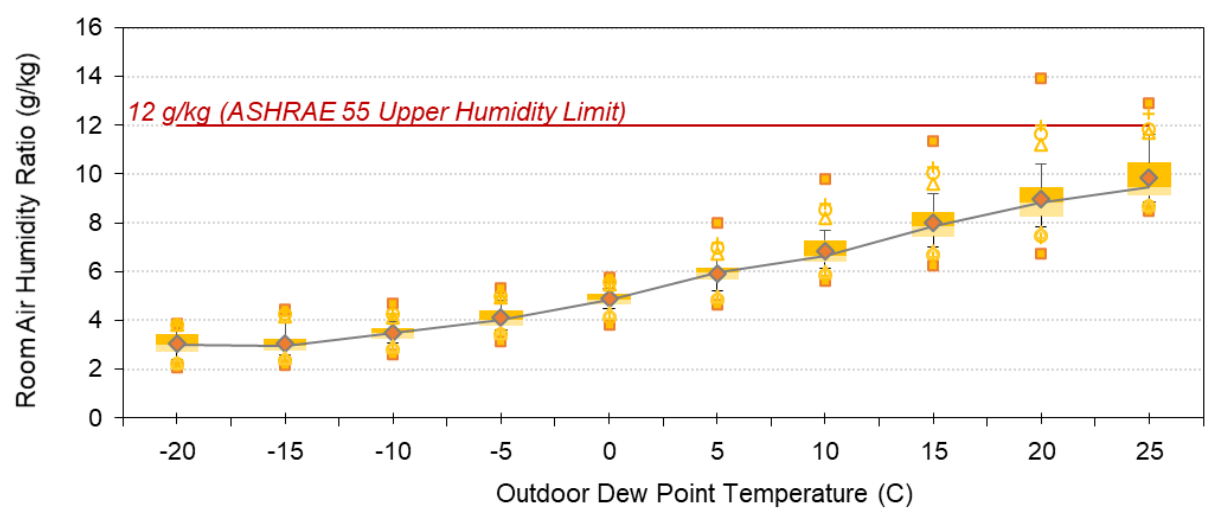

(c) SDHV On

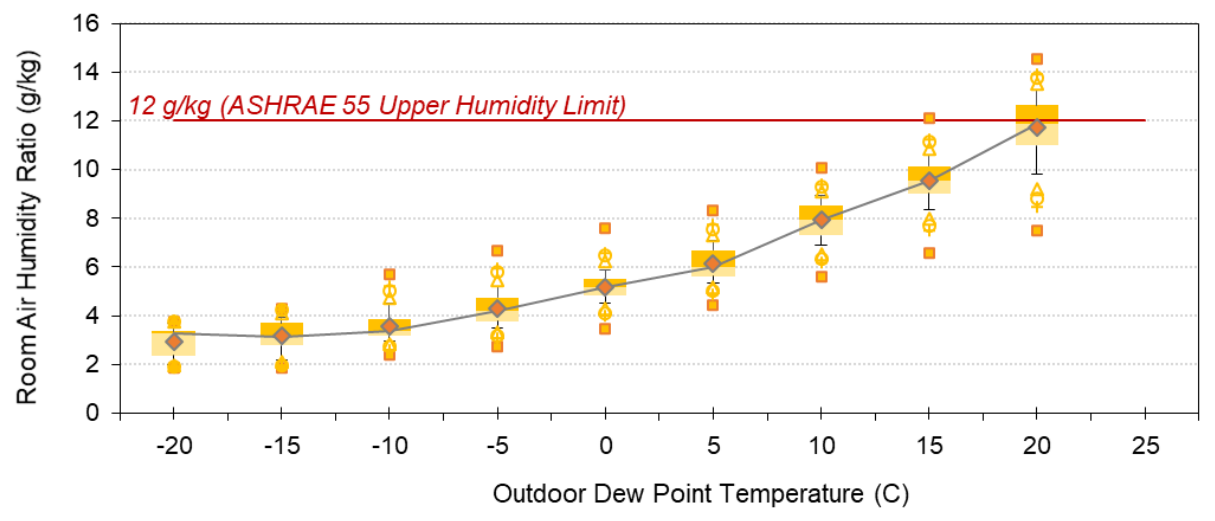

(d) SDHV Off

Figure 43: Binned BR3 Room Air Humidity Ratios Against Outdoor Dew Point Temperatures. 


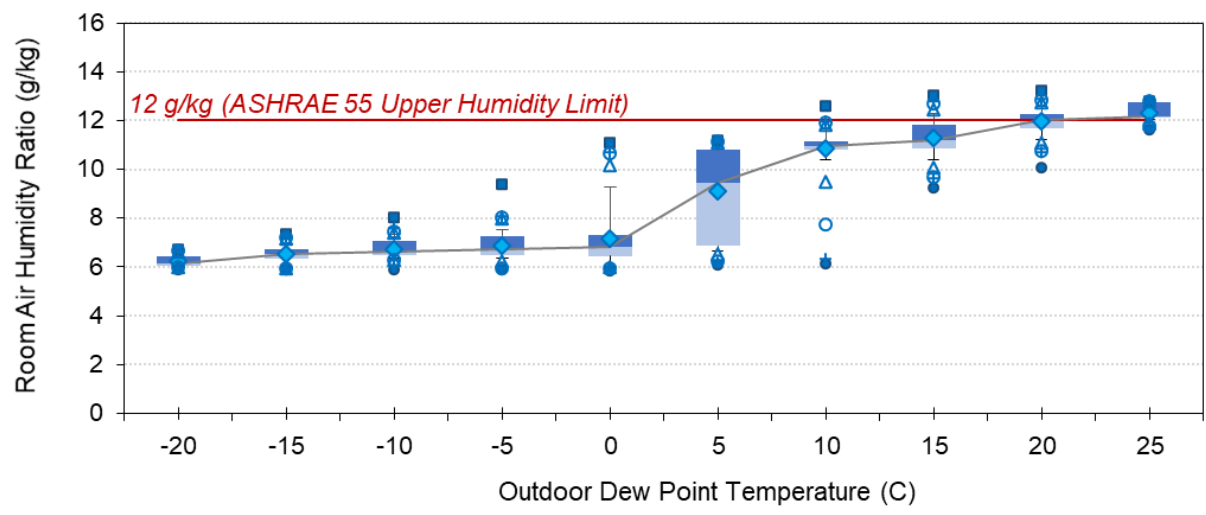

(a) CDHP On

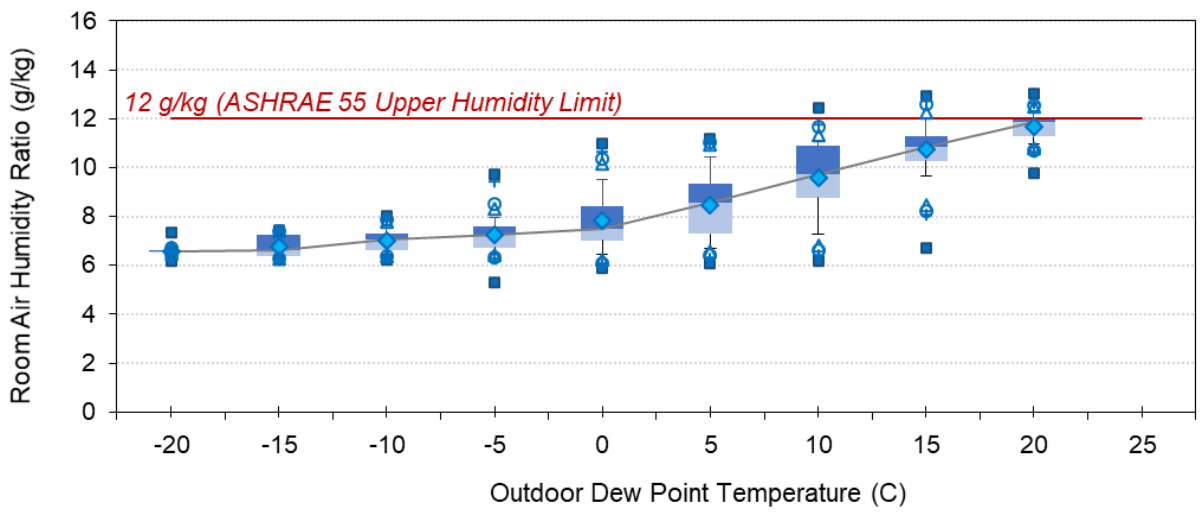

(b) CDHP Off

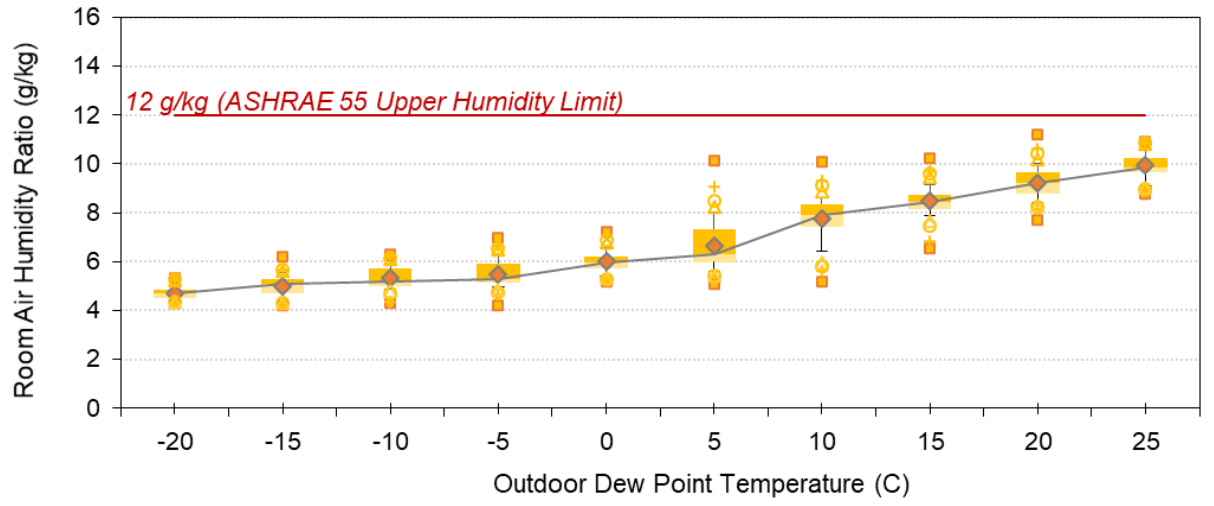

(c) SDHV On

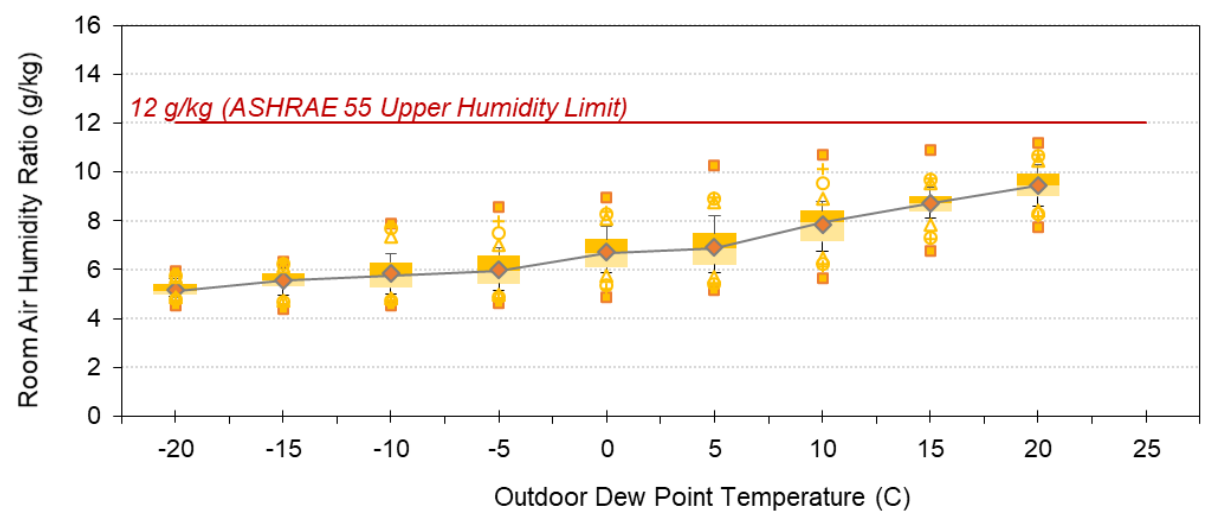

(d) SDHV Off

Figure 44: Binned Attic Room Air Humidity Ratios Against Outdoor Dew Point Temperatures. 

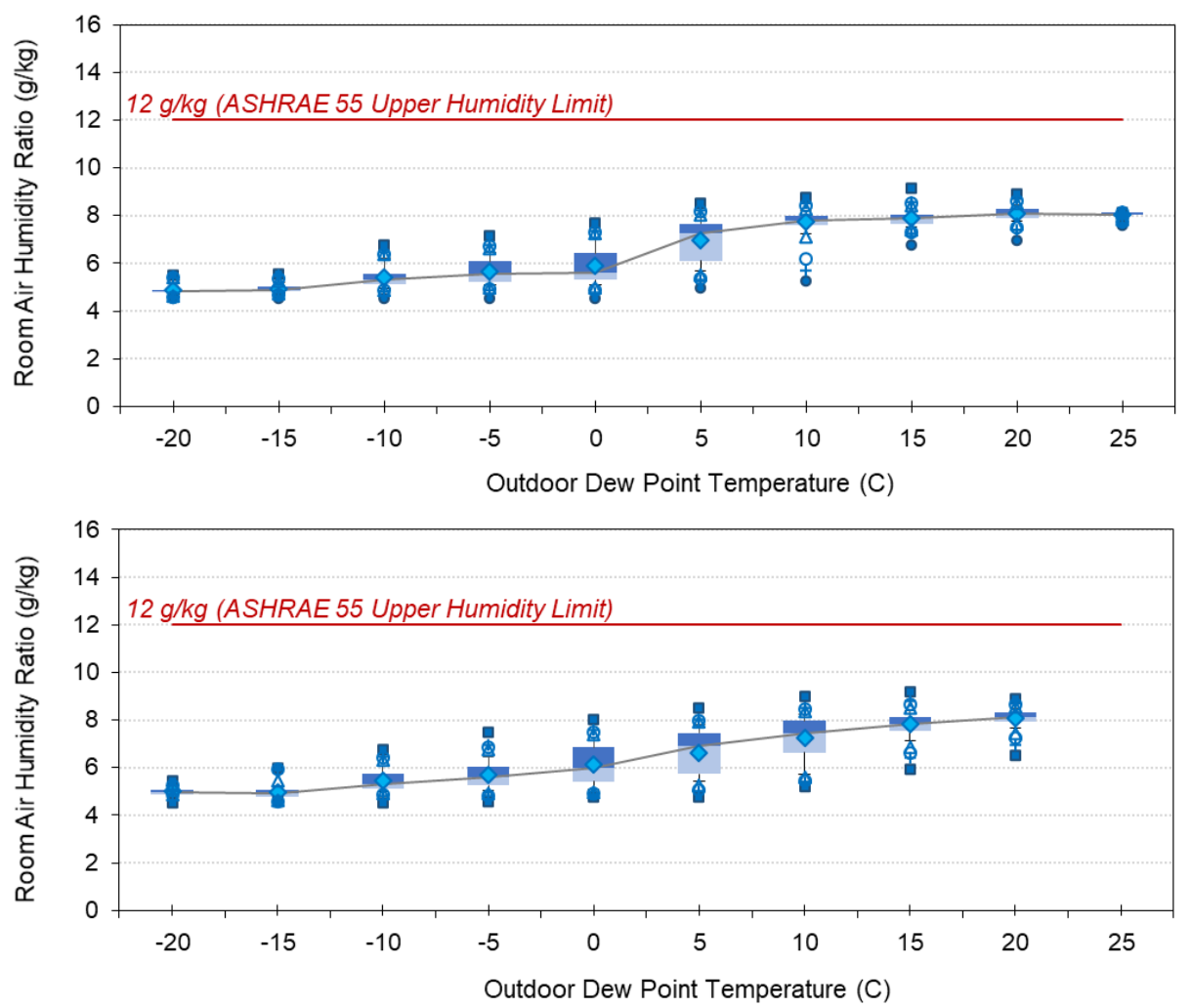

(a) CDHP On

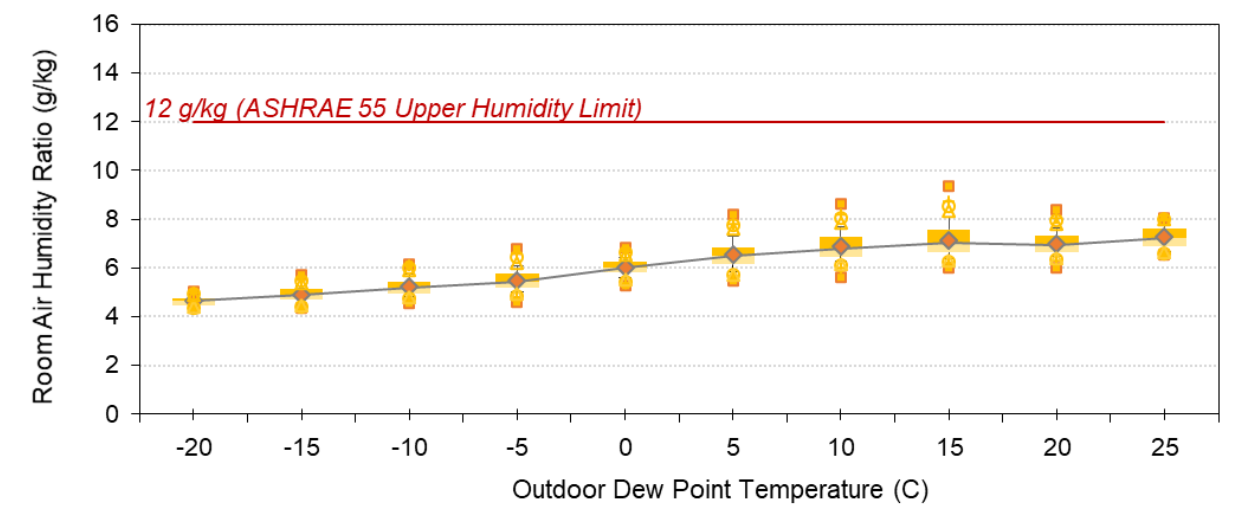

(b) CDHP Off

(c) SDHV On

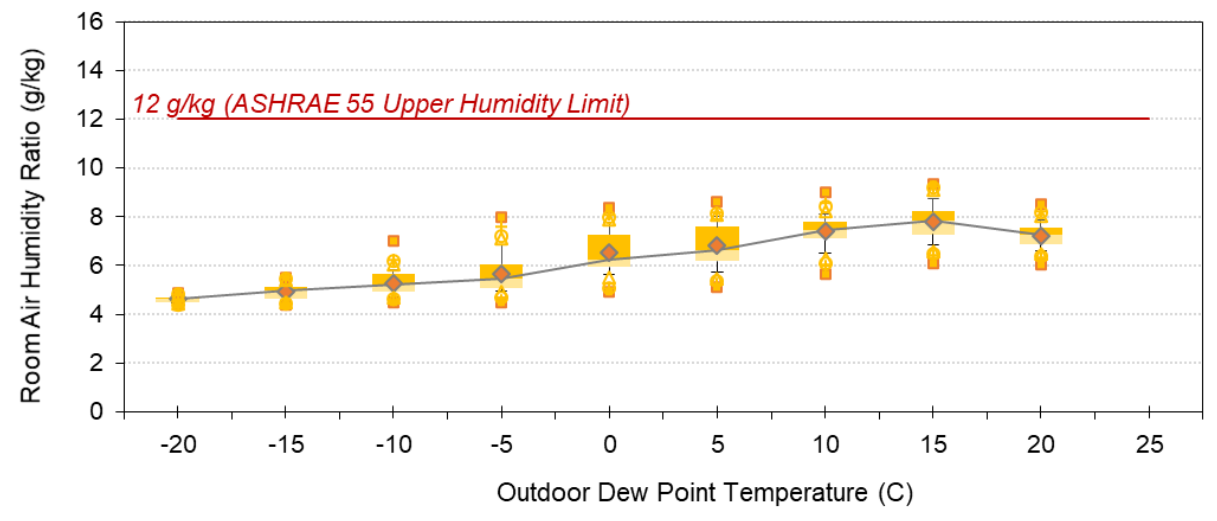

(d) SDHV Off

Figure 45: Binned BSMT Room Air Humidity Ratios Against Outdoor Dew Point Temperatures. 


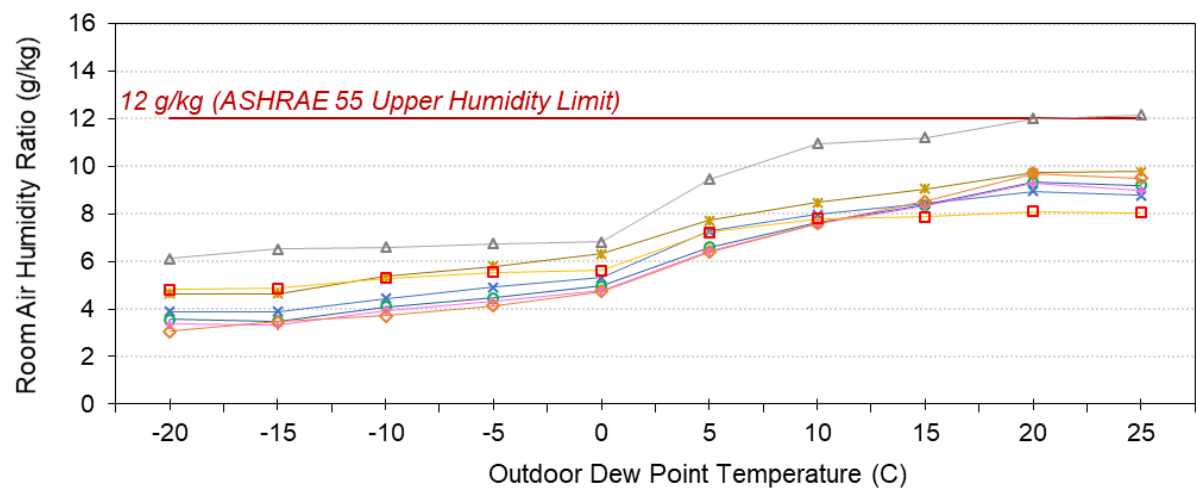

(a) CDHP On

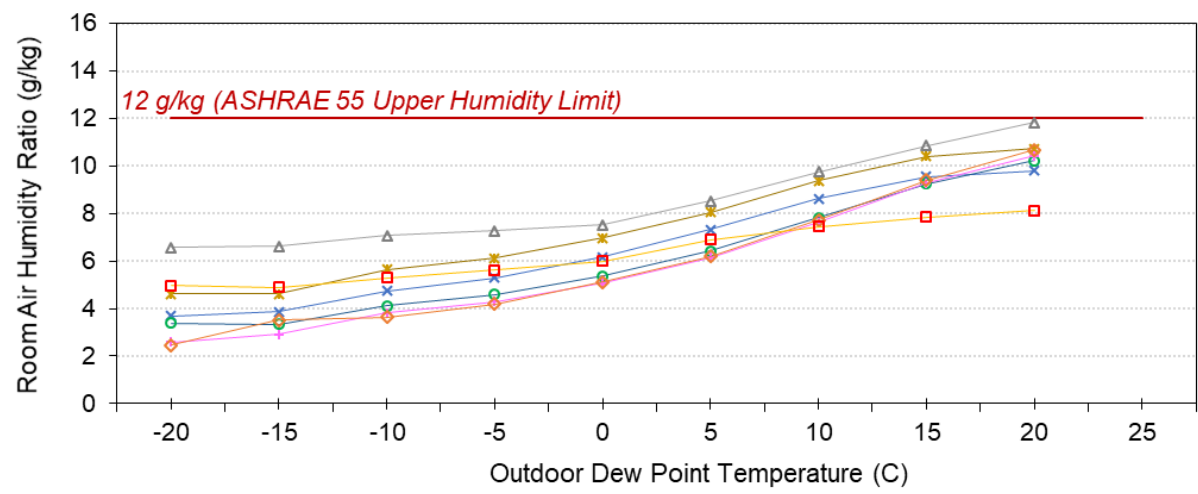

(b) CDHP Off

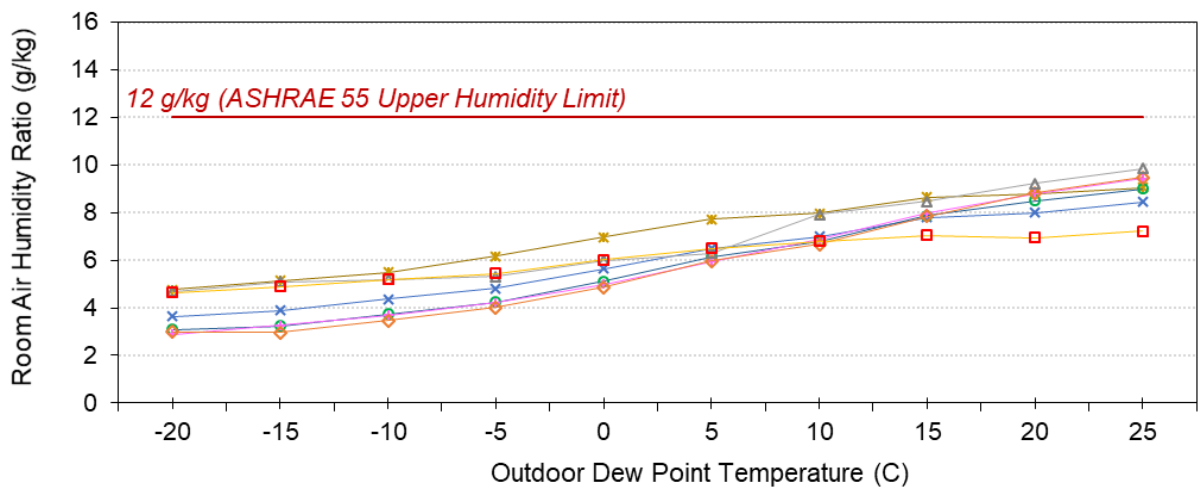

(c) SDHV On

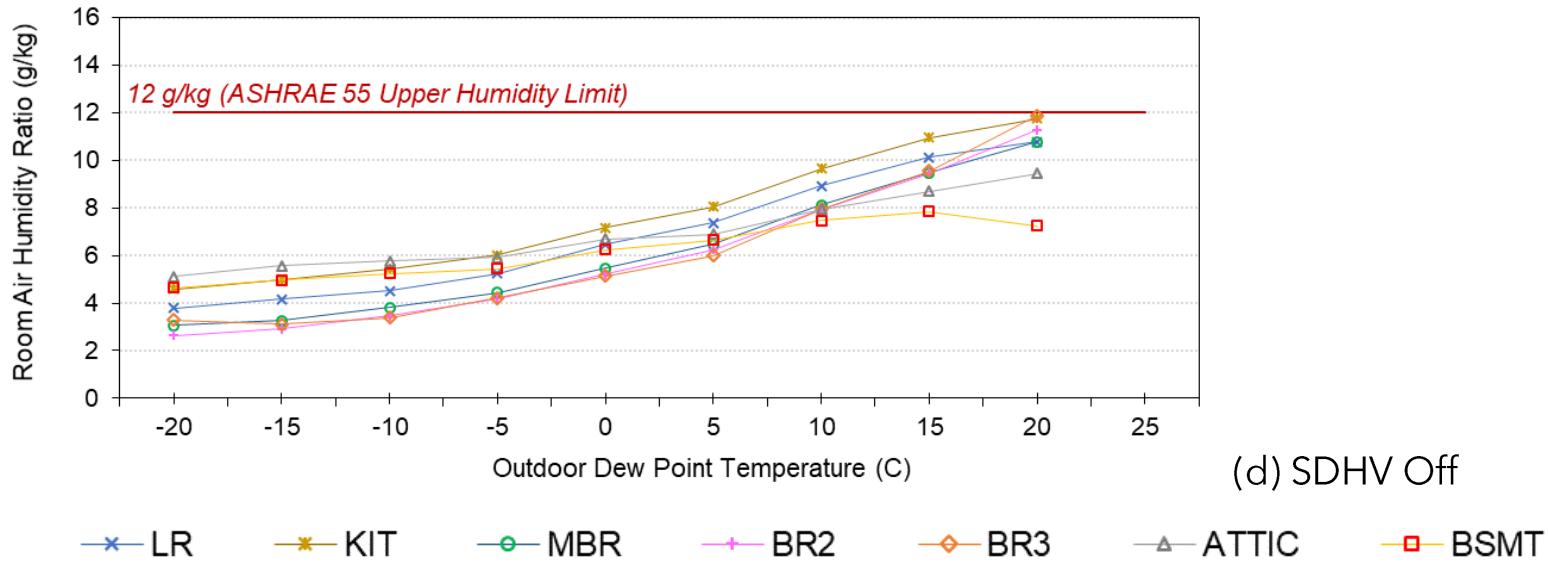

Figure 46: Comparison of Median Values of Binned Room Air Humidity Ratios of the Seven Rooms Against Outdoor Dew Point Temperatures. 


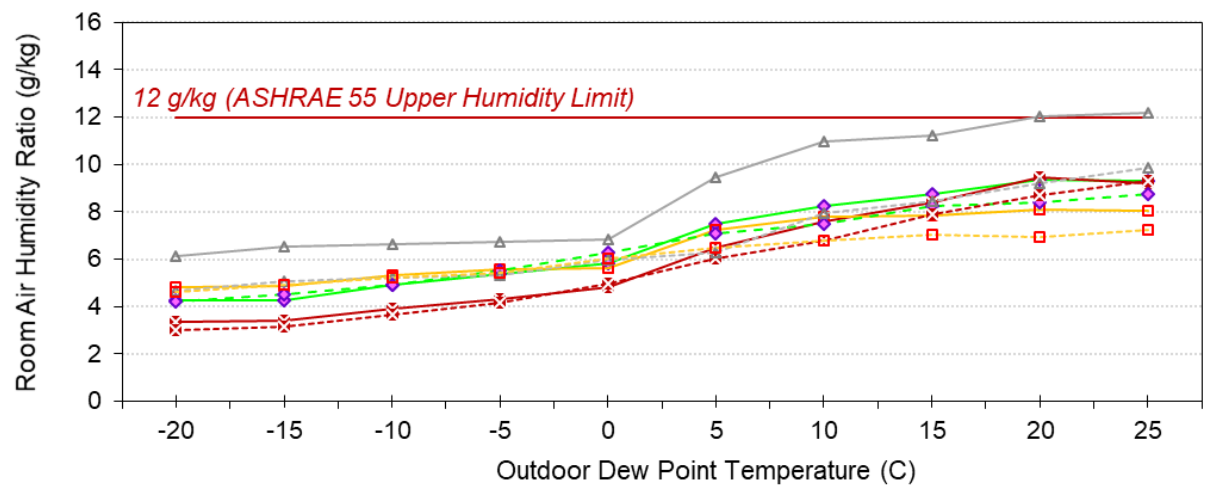

(a) CDHP On vs. SDHV On

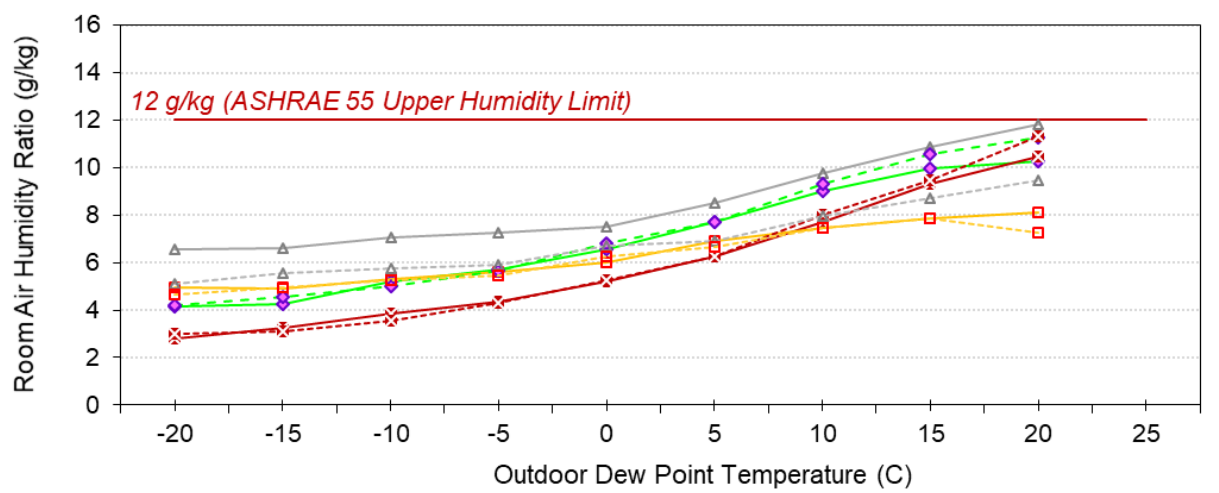

(b) CDHP Off vs. SDHV Off

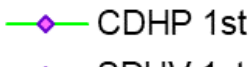

$\rightarrow$ CDHP 2nd

$\triangle$ CDHP ATTIC

$\because-\mathrm{CDHP} B S M T$

$-\diamond-$ SDHV 1st

$--\rightarrow---$ SDHV 2nd

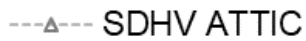

--- SDHV BSMT

Figure 47: Comparison of Median Values of Binned Room Air Humidity Ratios Averaged By Floor Against Outdoor Dew Point Temperatures. 


\subsection{GRAPHICAL ANALYSIS USING THE PSYCHROMETRIC CHART}

To quickly characterize granular thermal comfort data, this study used the psychrometric chart with a super-imposed ASHRAE Standard 55-2017 comfort zone that also integrates the four environmental variables (i.e., dry bulb temperature, humidity, mean radiant temperature (MRT), and air speed). The hourly average operative temperature was calculated in accordance with Normative Appendix A of the ASHRAE Standard 55-2017 and used in the analysis per ASHRAE Standard 55-2017.

Figures 48 and 49 present the results for the LR (Figure 48) and the MBR (Figure 49) selected to represent the first-floor and the second-floor room, respectively. Appendix $G$ provides the results for the other three primary rooms (i.e., KIT, BR2, and BR3) as well as other three rooms that are not primary habitable but either produce or are near moisture sources such as the attic, BSMT, and $\mathrm{MBA}^{47}$ as supplementary materials. In the figures, the data are presented separately using color-coded data points by different system types: dark blue for the CDHP and orange for the SDHV. The upper figures present the results by the system on cycle (upper left figure) versus off cycle (upper right figure), while the lower figures present the same data by the types of HP system in operation: CDHP (lower left figure) versus SDHV (lower right figure).

It should be noted that the house's heating and cooling setpoint temperatures were at the low side of each ASHRAE 55 comfort zone (i.e., a red parallelogram for 1.0 clo representing winter clothing level; a blue parallelogram for 0.5 clo representing summer clothing level), respectively, which was also recognized in the ACCA Manual $\mathrm{RS}^{48}$. For example, the PMV calculated at the heating setpoint temperature (i.e., $21.1^{\circ} \mathrm{C}\left(70.0^{\circ} \mathrm{F}\right)$ ) with a $30 \% \mathrm{RH}, 0.1 \mathrm{~m} / \mathrm{s}$ air velocity, $1.0 \mathrm{clo}$, and 1.1 met is -0.44 between -1 (slightly cool) and 0 (neutral), which is equivalent to $9 \%$ PPD. The PMV calculated at the cooling setpoint temperature (i.e., $23.9^{\circ} \mathrm{C}$ $\left(75.0^{\circ} \mathrm{F}\right)$ ) with a $50 \% \mathrm{RH}, 0.1 \mathrm{~m} / \mathrm{s}$ air velocity, $0.5 \mathrm{clo}$, and 1.1 met is -0.49 , which is equivalent to $10 \%$ PPD.

As a result, a direct comparison of the measurements against the ASHRAE 55 comfort zones does not deem reasonable in this study unless the comfort zone is adjusted to achieve a neutral PMV (i.e., 0 PMV) at the chosen heating and cooling setpoint temperatures. For example, the use of higher clothing levels (i.e., 1.33 clo for the heating and 0.75 clo for the cooling) will yield 0 PMV at the chosen heating and cooling setpoint temperatures in this study. With the adjusted comfort zone, a direct comparison of the measurements against the ASHRAE 55 comfort zones might provide useful insights in terms of evaluating discomfort due to strong external or internal radiation sources if they existed.

Important observations are:

- LR (Figure 48)

- When the systems cycled on, both HP systems were performing appropriately compared to the chosen thermostat setpoint temperatures in general: the left clusters for the heating season and the right clusters for the cooling season.

\footnotetext{
${ }^{47}$ In these rooms, only two variables (i.e., Ta and $\mathrm{RH}$ ) were monitored. As a result, the air temperature was directly used instead of operative temperature.

48 The ACCA Manual RS states: "these conditions provide a reasonable margin of error if the actual operating condition is not coincident with the design point."
} 
- During the system on cycle, the SDHV data points were more scattered compared to the CDHP. The scattered data points during the cooling season might be affected by lower supply air temperatures which resulted in lower humidity ratios (i.e., better dehumidification) as well. The scattered data points during the heating season need a further investigation considering the comparable throttling range between the two systems: $\pm 0.1^{\circ} \mathrm{C}(\mathrm{CDHP})$ and $\pm 0.14^{\circ} \mathrm{C}(\mathrm{SDHV})$.

- During the system on cycle, the SDHV also had a separate small cluster on the right side of its larger cooling cluster, which mostly occurred during one week of July (i.e., July 17 to 24, 2017) due to relatively hotter OA conditions (Figure 33 (a)).

- The CDHP heating cluster during the system on cycle had a few data points extended to the left, which occurred due to the smaller heating capacity of the CDHP (Figure 33 (c)).

- When the systems cycled off, the clusters formed a parallelogram shape connecting the cooling season cluster with the heating season cluster. The CDHP cluster during the system off cycle had a few data points extended to the left, which occurred during the transitional season due to low OA temperature when the system was in the cooling mode.

- When the CDHP was operated, the thermal environments were conditioned differently for the system on cycle versus off cycle. However, no distinct differences were observed in the measured thermal environments between the SDHV on cycle versus off cycle. The observed mixed data points with the SDHV may represent the graphical signatures of the thermal comfort performance of the variable-speed compressor.

- The SDHV had few incidences exceeding the upper humidity limit of the ASHRAE 55 comfort zone when the system cycled on. However, when the system cycled off, there were more incidences when the room humidity ratios exceeded the upper humidity limit of the ASHRAE 55 comfort zone, as also reported in Section 4.7.2.

- $\operatorname{MBR}$ (Figure 49)

- Unlike the LR, when the systems cycled on, there was a clear distinction between the two systems with little overlap. As discussed in Section 4.4, when the SDHV was in operation, the MBR temperatures were cooler and drier in the cooling season but warmer in the heating season, which was caused by favorable attic temperature (in addition, lower absolute humidity levels during the cooling season as discussed in Section 4.7.2) due to the SDHV supply ductwork within the attic.

- There was no longer a clear distinction between the CHDP on cycle versus off cycle with a number of overlaps between the two conditions.

- Like the LR, the CDHP heating cluster during the system on cycle had a few data points extended to the left, and the SDHV had some incidences exceeding the upper humidity limit of the ASHRAE 55 comfort zone when the system cycled off. 

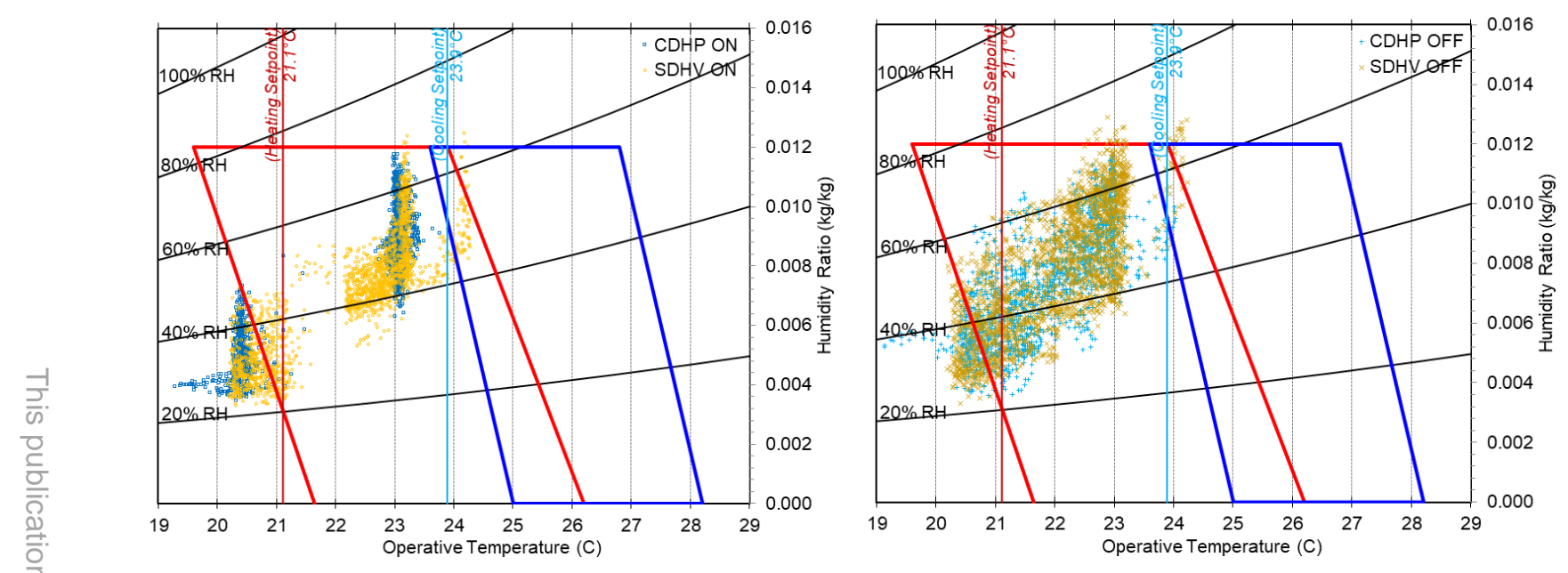

(a) HP On vs. Off
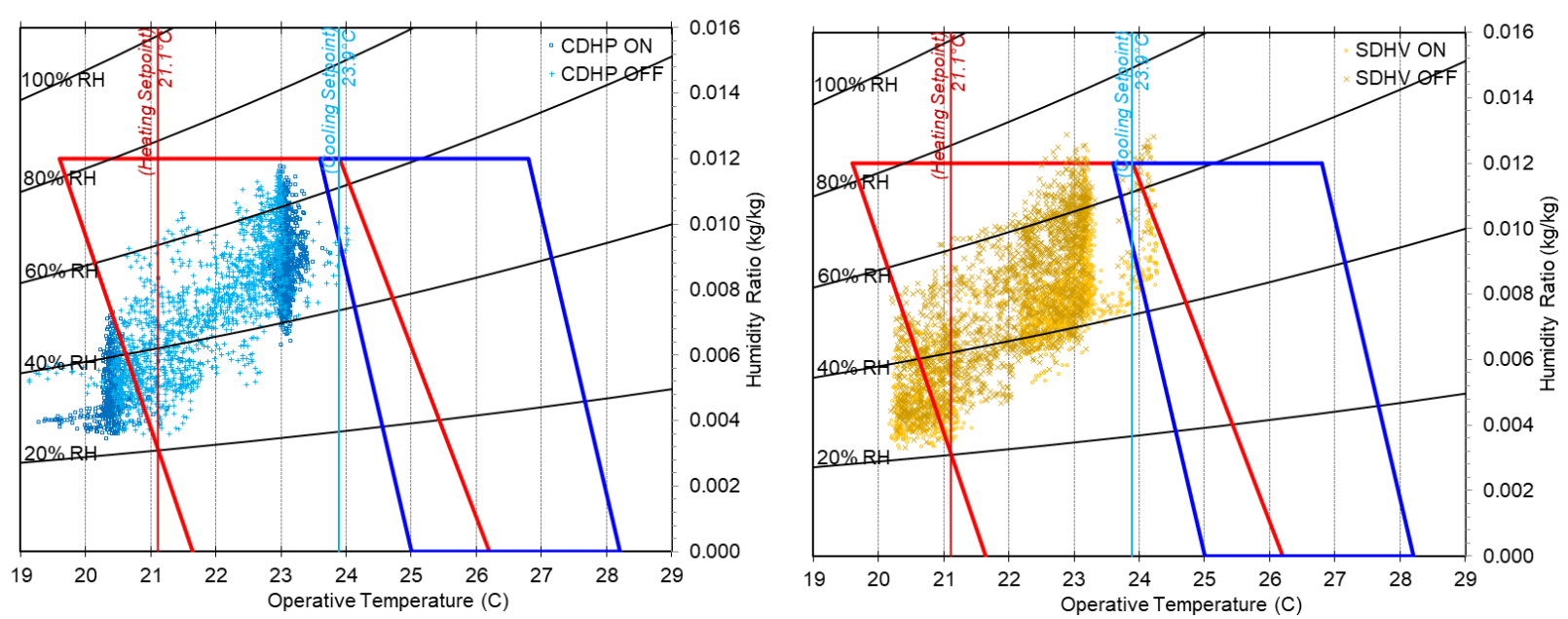

(b) CDHP vs. SDHV

Figure 48: Hourly LR Operative Temperature and Humidity Data Plotted on the ASHRAE 552017 Comfort Zones. 

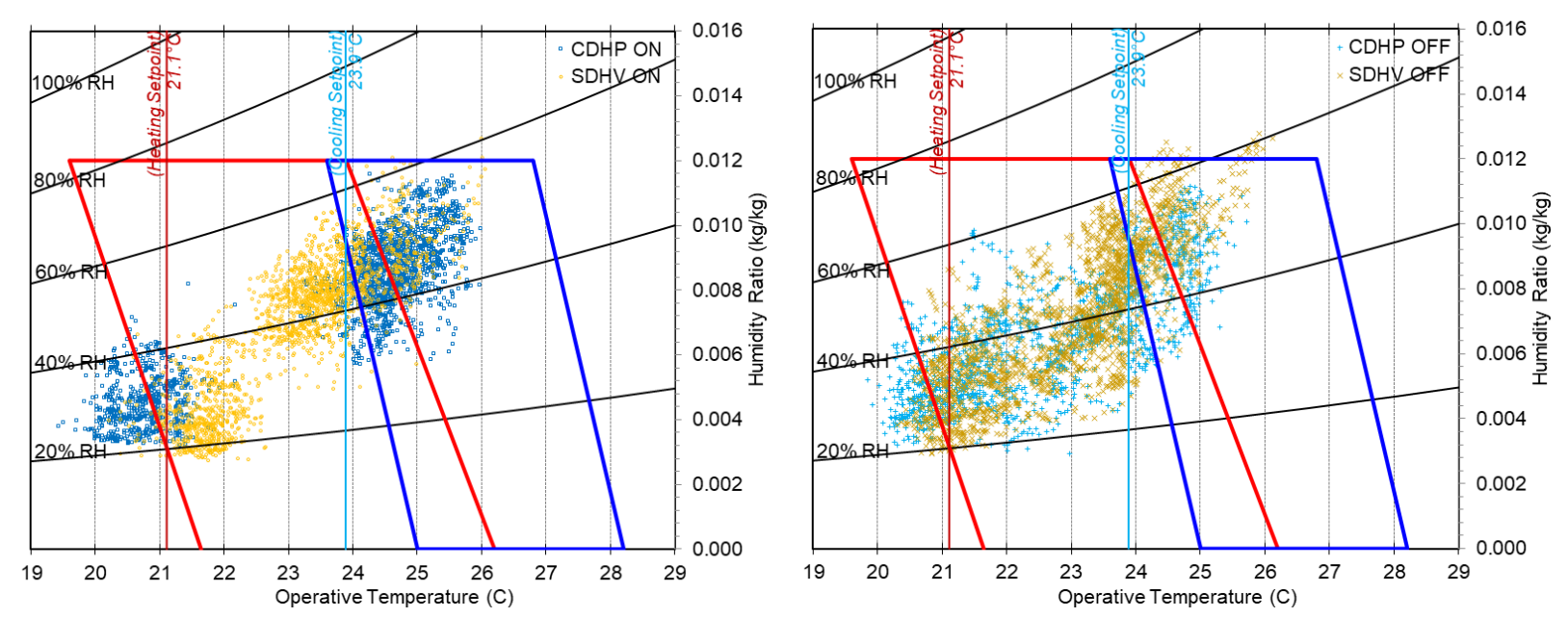

(a) HP On vs. Off
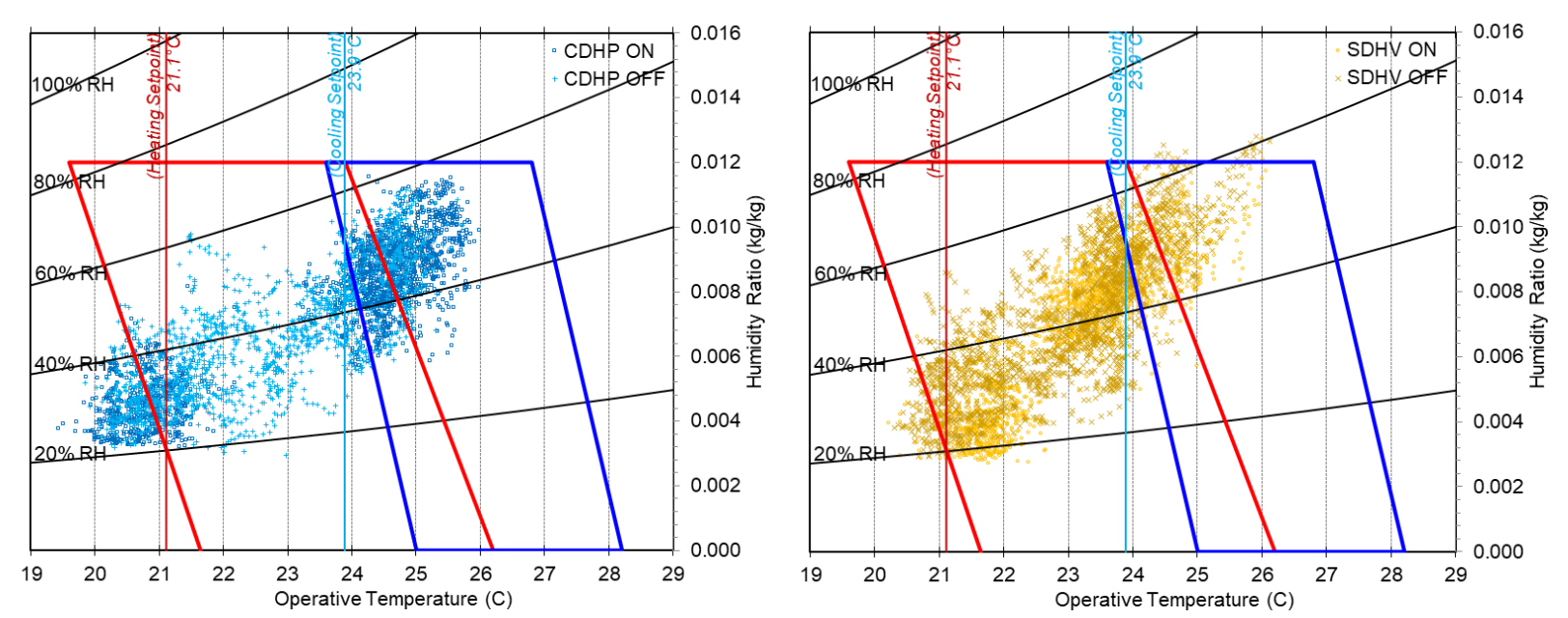

(b) CDHP vs. SDHV

Figure 49: Hourly MBR Operative Temperature and Humidity Data Plotted on the ASHRAE 55-2017 Comfort Zones. 


\section{BR3 GRID ANALYSIS}

This section presents a detailed analysis of the BR3 thermal comfort data based on a $3 \times 3 \times 3$ grid of measurement system (i.e., three different heights at nine locations of the room) to characterize and evaluate potential horizontal and vertical thermal stratification within a single room, which was affected by the two air distribution systems as installed at NZERTF.

Section 5.1 presents the results of an analysis of the BR3 horizontal and vertical thermal stratification.

Section 5.2 presents the results of an analysis of the BR3 air velocity distribution.

\subsection{HORIZONTAL AND VERTICAL THERMAL STRATIFICATION}

The results of an analysis on the BR3 horizontal and vertical thermal stratification are graphically presented by season using the 5-min average temperature data collected from the nine measurement stands: cooling season before August 10, 2017, cooling season after August 10, 2017, heating season, and transitional season. The cooling season results are displayed separately for the period before August 10, 2017 and after August 10, 2017 since the sensor stands except the Stand 5 were spread out to be closer to the walls on August 10, 2017. Each season consists of the following four graphical summaries:

- Mean values of the 5-min average temperatures of the nine BR3 stands at the three measurement heights (i.e., $0.6 \mathrm{~m}, 1.1 \mathrm{~m}$, and $1.7 \mathrm{~m}$ ) for simplicity, which provides information on both horizontal and vertical thermal stratification in the BR3 on average (Figures 50, 54, 58, and 62);

- BR3 stand-to-stand temperature differences at the three measurement heights (Figures 51, 55, 59, and 63);

- BR3 vertical temperature differences for each measurement location (i.e., stand) between $1.7 \mathrm{~m}$ and $0.6 \mathrm{~m}$ (i.e., $\Delta \mathrm{T}_{\text {standing }}\left({ }^{\circ} \mathrm{C}\right)=\mathrm{T} 1.7 \mathrm{~m}-\mathrm{T} 0.6 \mathrm{~m}$ ) (Figures 52, 56, 60, and 64); and

- $\quad$ BR3 vertical temperature differences for each measurement location (i.e., stand) between $1.1 \mathrm{~m}$ and $0.6 \mathrm{~m}$ (i.e., $\Delta \mathrm{T}$ seated $\left({ }^{\circ} \mathrm{C}\right)=\mathrm{T} 1.1 \mathrm{~m}-\mathrm{T} 0.6 \mathrm{~m}$ ) (Figures 53, 57, 61, and 65).

Except for the analysis with the mean values, the results were displayed using the graphical index proposed to display long-term thermal comfort data (Figure 13) and color-coded by system types: blue for CDHP and orange for SDHV. As supplementary materials, Appendix H provides the detailed statistical characterization of measurements by individual stands at each measurement height.

\subsubsection{COOLING SEASON}

Important observations on the BR3 horizontal and vertical thermal stratification during the cooling season (Figures 50 to 57) are:

- Cooling Season Before August 10, 2017 (Figures 50 to 53)

- No significant amounts of horizontal and vertical stratification were observed for both systems with the $98.5^{\text {th }}$ stand-to-stand temperature differences below $0.8^{\circ} \mathrm{C}$ at all three heights and the vertical temperature differences way below the 
ASHRAE Standard 55 limits (i.e., $3^{\circ} \mathrm{C}$ for $1.1 \mathrm{~m}$ head level and $4^{\circ} \mathrm{C}$ for $1.7 \mathrm{~m}$ head level) $)^{49}$.

- In terms of horizontal stratification, the SDHV maintained smaller stand-to-stand temperature differences at $1.7 \mathrm{~m}: 0.35^{\circ} \mathrm{C}$ with the CDHP on average and $0.15^{\circ} \mathrm{C}$ with the SDHV on average. However, the larger stand-to-stand temperature difference observed with the CDHP was caused by the stand 8 near the two CDHP supply air outlets. When excluding the stand 8 , the average stand-to-stand temperature difference at $1.7 \mathrm{~m}$ with the $\mathrm{CDHP}$ decreased from $0.35^{\circ} \mathrm{C}$ to $0.14^{\circ} \mathrm{C}$. As a result, on average, the stand-to-stand temperature differences at all three heights were comparable between the two systems.

- In terms of temporal variations of horizontal stratification, the CDHP showed larger IQRs in Figure 51, which was caused by the stand 8. When excluding the stand 8, the IQRs between the two systems became comparable.

- The three stands near the supply air outlets exhibited unique profiles. The stand 8 near the CDHP supply air outlets on the upper wall had lower air temperatures at $1.1 \mathrm{~m}$ and $1.7 \mathrm{~m}$ only when the CDHP was on cycle. When the SDHV was on cycle, the profiles of the stands 1 and 3, which were near the SDHV supply air outlets on the ceiling, did not follow the typical vertical temperature gradient related to the room height. For example, the stand 1 temperature at $1.7 \mathrm{~m}$ was lower than the temperature at $1.1 \mathrm{~m}$, while the stand 3 temperature at $1.1 \mathrm{~m}$ was lower than the temperature at $0.6 \mathrm{~m}$.

- In terms of vertical stratification, $\Delta T$ standing was slightly larger than $\Delta T$ seated, which is an expected gradient related to the room height. The two systems exhibited

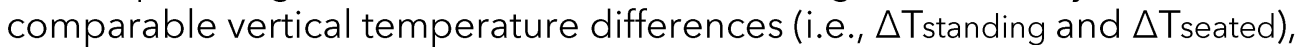
although the CDHP tended to have slightly larger $\triangle T$ standing at some measurement locations (e.g., stands 1, 3, 4, 6, and 7). The observed outliers of the stands 8 and 9 were likely to be affected by their locations near to the HRV supply air outlet.

- Not surprisingly, the observed horizontal and vertical stratification was lower when the systems were off cycle, which created well-mixed air distribution patterns in the BR3.

- Cooling Season After August 10, 2017 (Figures 54 to 57)

- The stand-to-stand temperature differences were larger when the sensor stands were spread out to be closer to the walls or windows except for the stand 5 remained in the center of the BR3. The observed larger temperature difference was affected by a few stands that showed changed profiles as they moved to the outside of occupied zones ${ }^{50}$.

- For example, when the CDHP was on cycle, the stand 1 moved to the southeast corner of the BR3 exhibited a strong vertical temperature stratification. The stand 2 moved near to the large south-facing window exhibited a strong stratification between $0.6 \mathrm{~m}$ and $1.1 \mathrm{~m}$ but no stratification between $1.1 \mathrm{~m}$ and $1.7 \mathrm{~m}$. As a result,

\footnotetext{
${ }^{49}$ It should be noted that the exclusion of an ankle-level height (i.e., $0.1 \mathrm{~m}$ ) in this study was not enough to evaluate the vertical thermal stratification based on the ASHRAE Standard 55-2017. The vertical air temperature difference benchmarks provided in Section 5.3.4.3 of the ASHRAE Standard 55 are intended for the air temperature difference between head level (i.e., $1.1 \mathrm{~m}$ for seated occupants and $1.7 \mathrm{~m}$ for standing occupants) and ankle level (i.e., $0.1 \mathrm{~m}$ ).

50 The occupied zone is defined to be $2 \mathrm{ft}$. inward from each of the room's walls and ceilings based on the ACCA Manual RS (ACCA 1997); or between the floor and $6 \mathrm{ft}$. above the floor and more than $3.3 \mathrm{ft}$. from outside walls/windows or fixed HVAC equipment, and $1 \mathrm{ft}$. from internal walls based on the ASHRAE Standard 55-2017 (ASHRAE 2017).
} 
both stands contributed to larger stand-to-stand temperature differences at the heights of $0.6 \mathrm{~m}$ and $1.1 \mathrm{~m}$ when the CDHP was on cycle.

- When the SDHV was on cycle, the stand 3 moved to right below one of the SDHV supply air outlets had consistently lower temperatures at all three heights, which caused larger stand-to-stand temperature differences when the SDHV was on cycle. However, the stand 3 itself maintained a well-mixed air distribution without a significant amount of vertical temperature stratification.

- Although the vertical temperature differences (i.e., $\Delta T$ standing and $\Delta T$ seated) tended to increase at some measurement locations (e.g., stands 1 and 2) when the CDHP was in operation, they were still way below the ASHRAE Standard 55 limits.

- When the systems were off cycle, the stand 9 moved to the doorway of the BR3 as well as the stand 2 moved near to the window exhibited changed profiles, which mainly contributed to larger stand-to-stand temperature differences. 

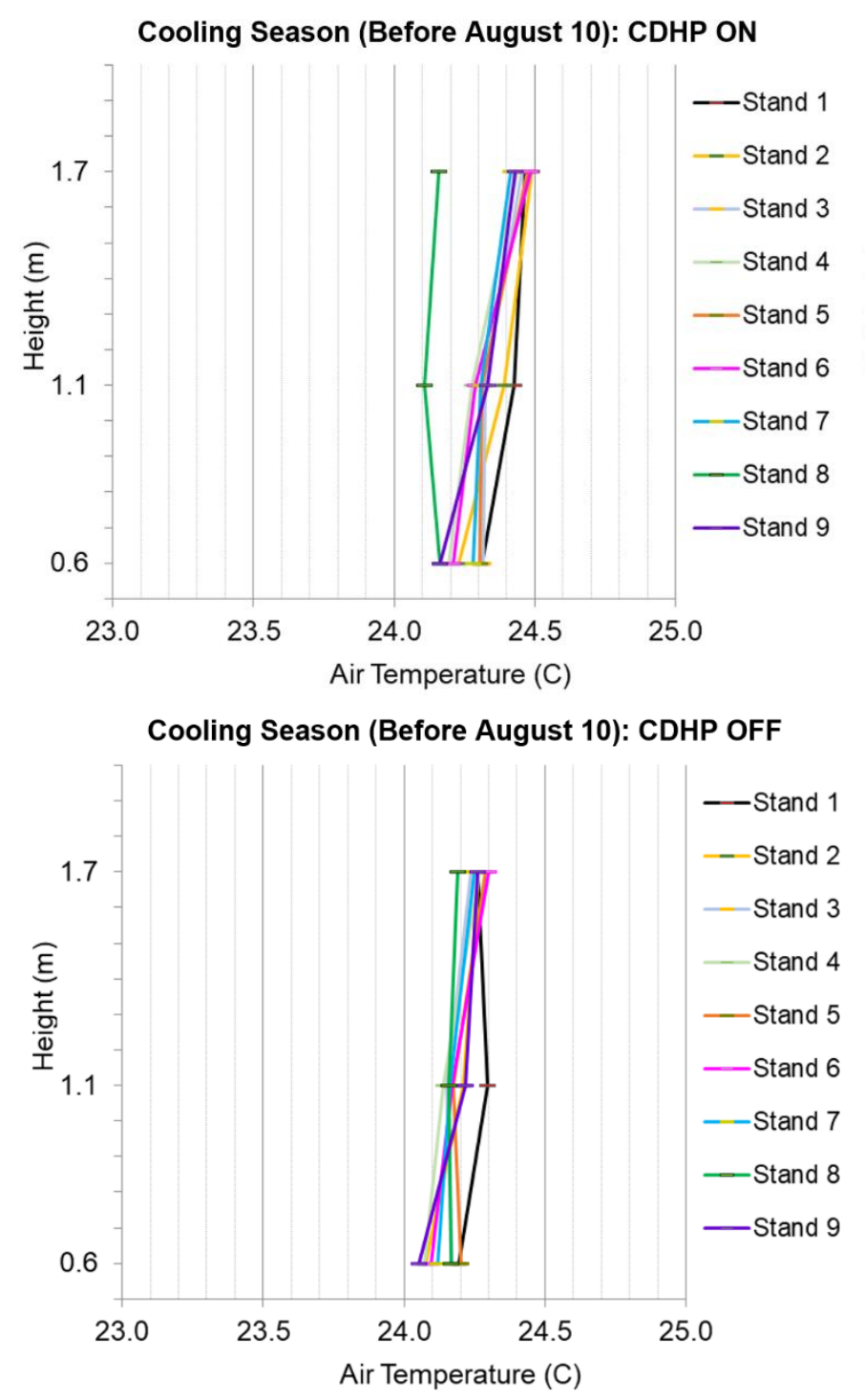

Cooling Season (Before August 10): SDHV ON

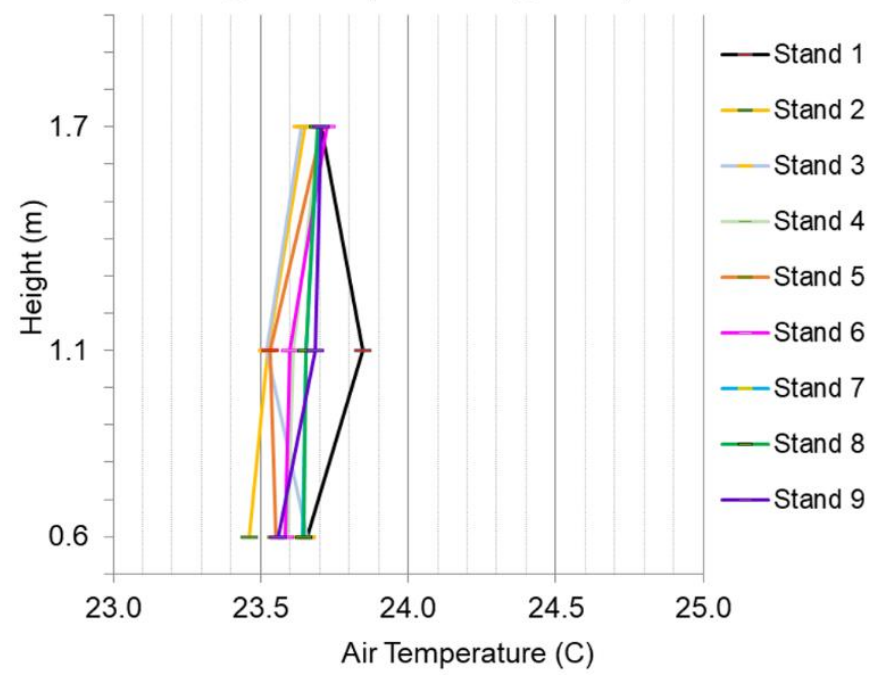

(a) CDHP On vs. SDHV On

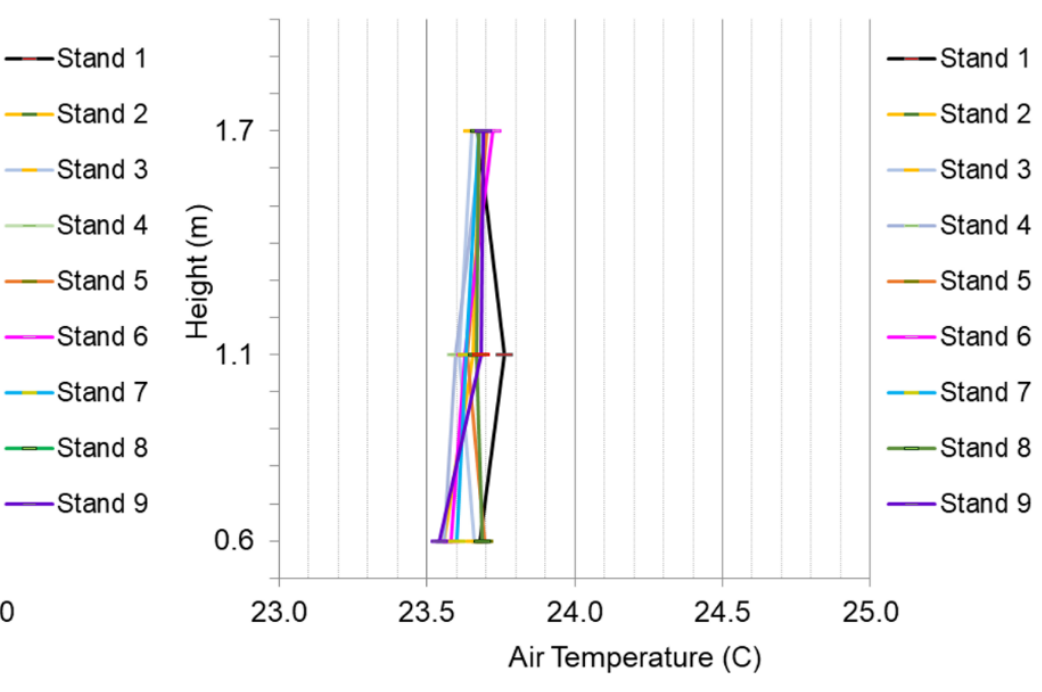

(b) CDHP Off vs. SDHV Off

Figure 50: Comparison of Median Values of the 5-Min Average Temperatures at the Three Measurement Heights When the System Was On Cycle (Left Figure) and Off Cycle (Right Figure) for the Cooling Season Before August 10, 2019. 
Cooling Season (Before August 10): HVAC ON
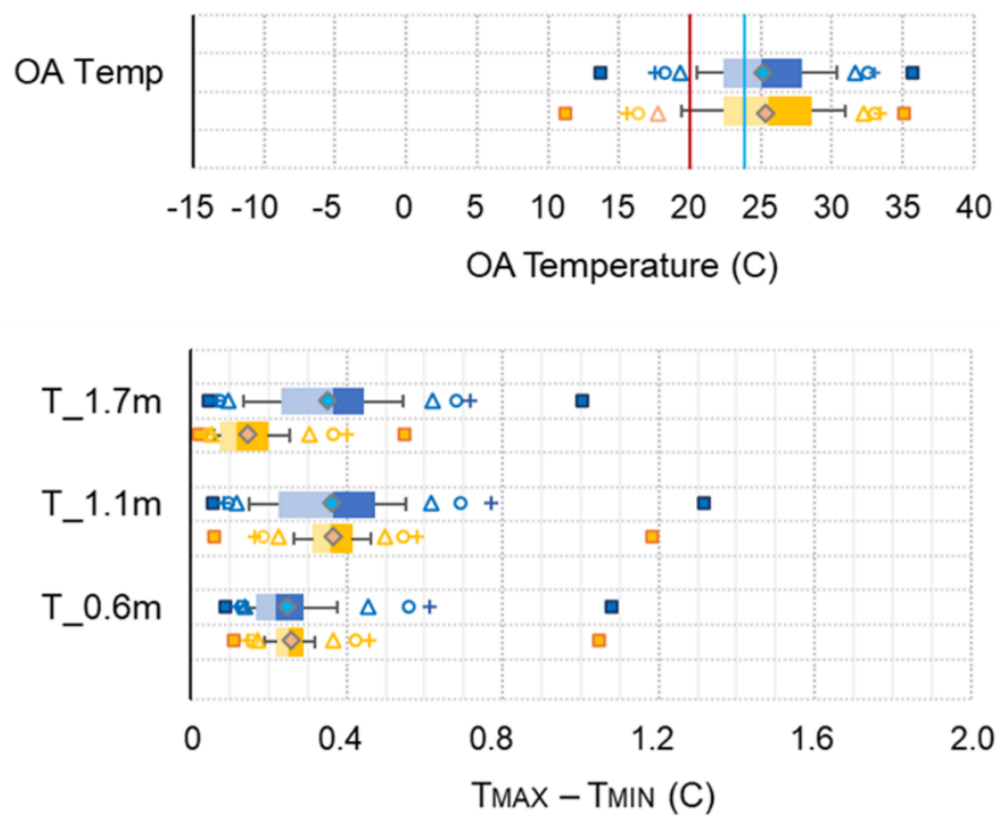

Cooling Season (Before August 10): HVAC OFF
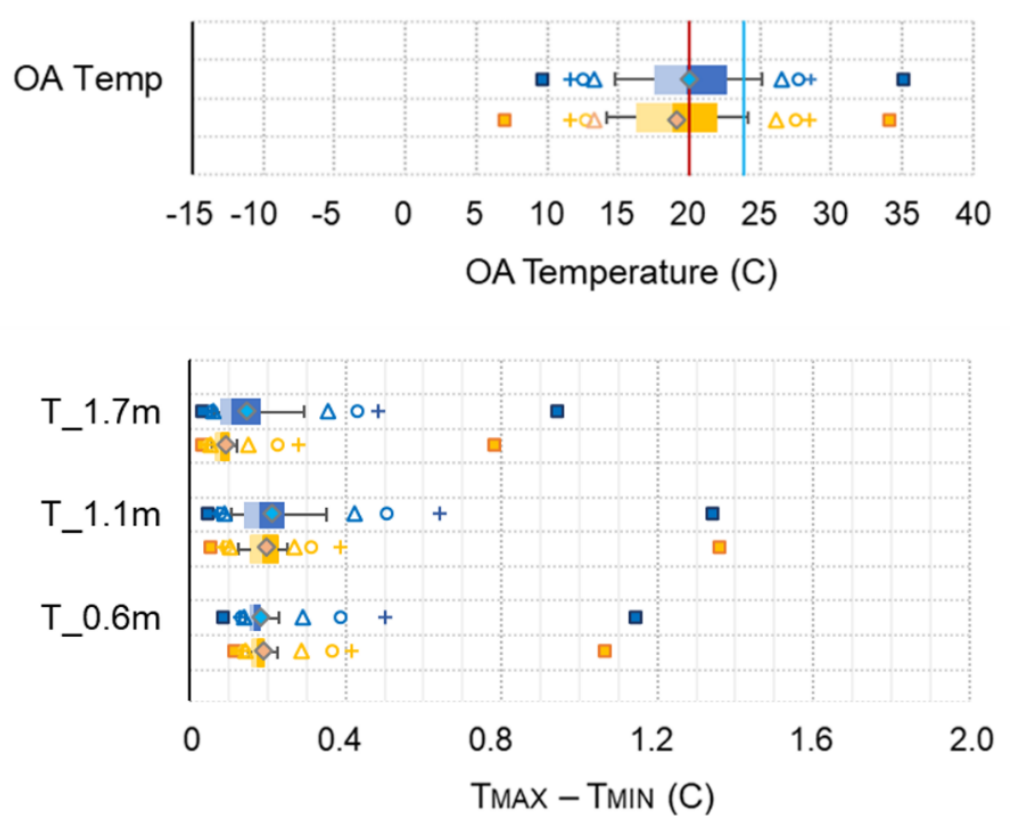

Figure 51: Graphical Summaries of the 5-Min Average Stand-to-Stand Temperature Difference at the Three Measurement Heights When the System Was On Cycle (Left Figure) and Off Cycle (Right Figure) for the Cooling Season Before August 10, 2019. 


\section{Cooling Season (Before August 10):} HVAC ON

\section{Cooling Season (Before August 10):} HVAC OFF
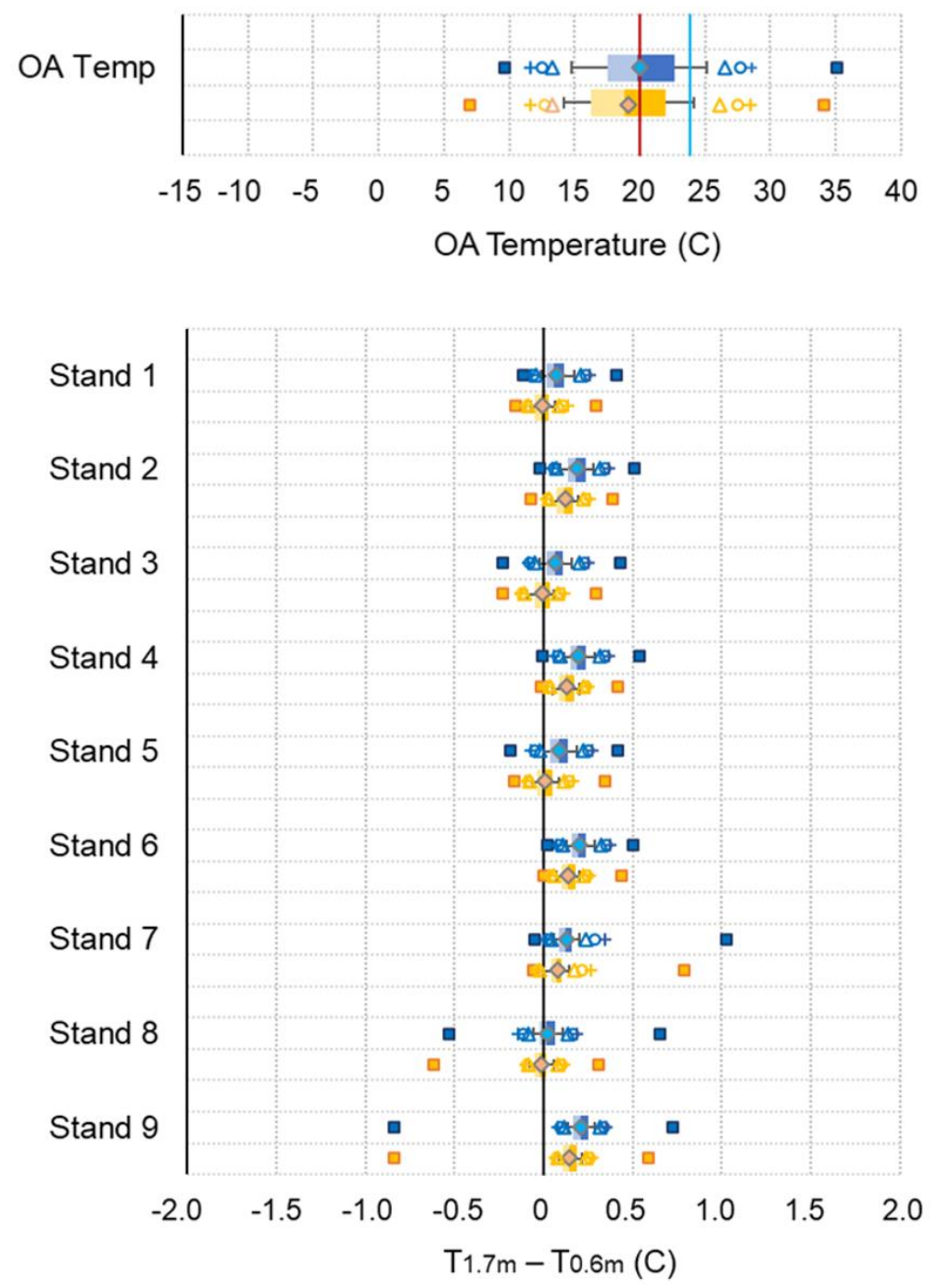

Figure 52: Graphical Summaries of the 5-Min Average Vertical Temperature Difference Between $1.7 \mathrm{~m}$ and $0.6 \mathrm{~m}$ When the System Was On Cycle (Left Figure) and Off Cycle (Right Figure) for the Cooling Season Before August 10, 2019. 
Cooling Season (Before August 10): HVAC ON
Cooling Season (Before August 10): HVAC OFF
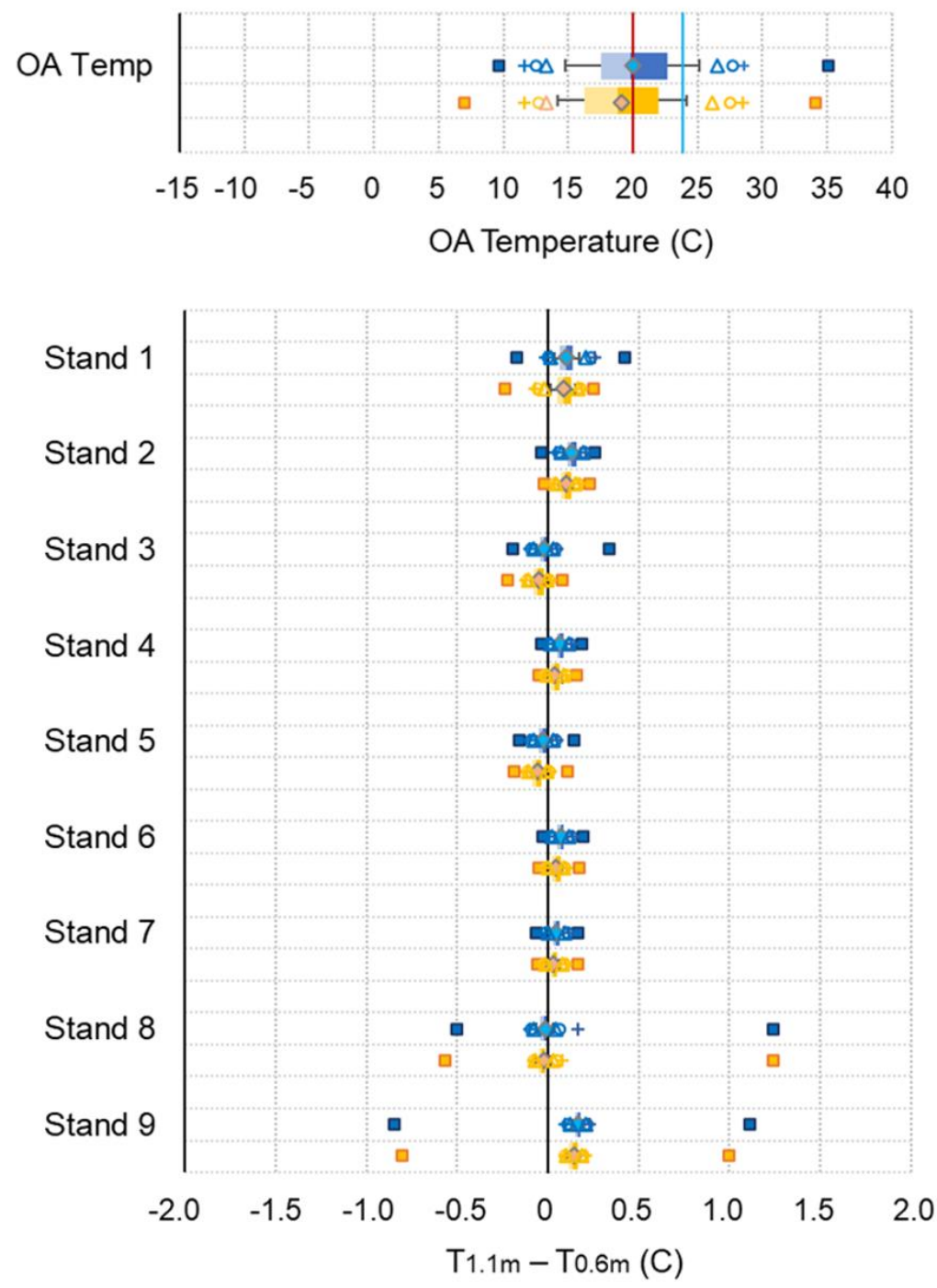

Figure 53: Graphical Summaries of the 5-Min Average Vertical Temperature Difference Between $1.1 \mathrm{~m}$ and $0.6 \mathrm{~m}$ When the System Was On Cycle (Left Figure) and Off Cycle (Right Figure) for the Cooling Season Before August 10, 2019. 


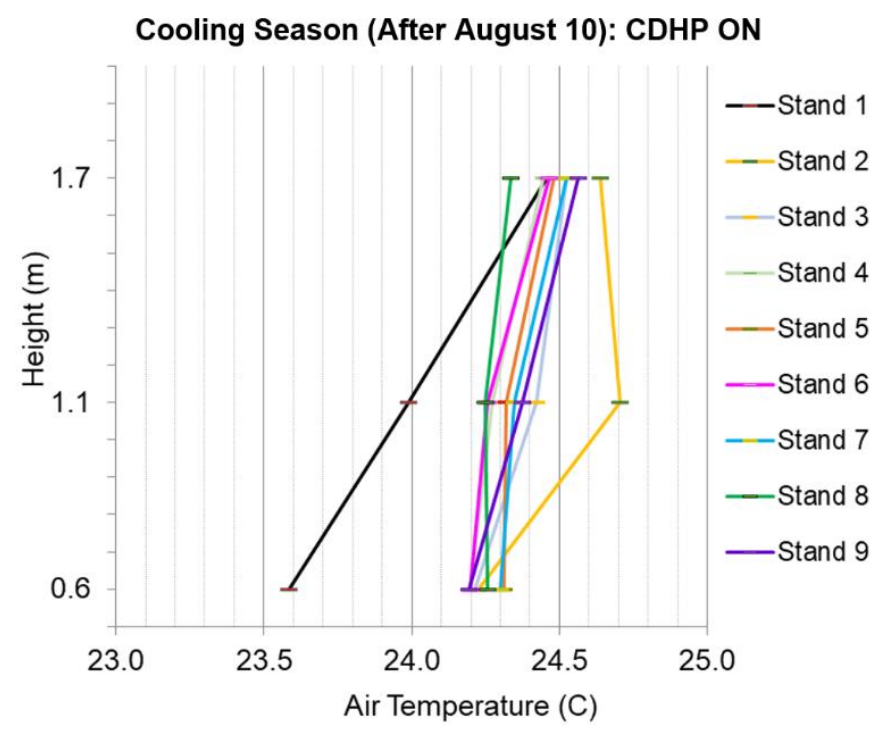

Cooling Season (After August 10): CDHP OFF

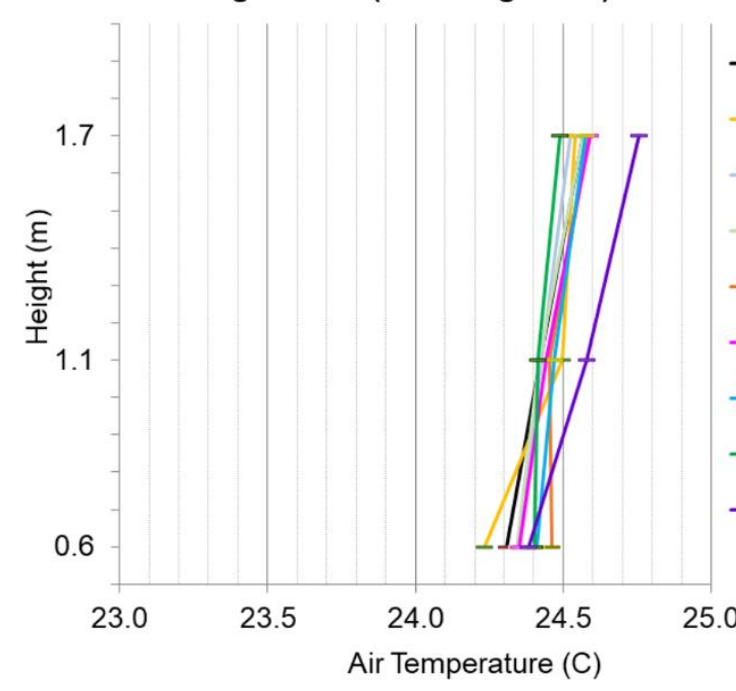

Cooling Season (After August 10): SDHV ON

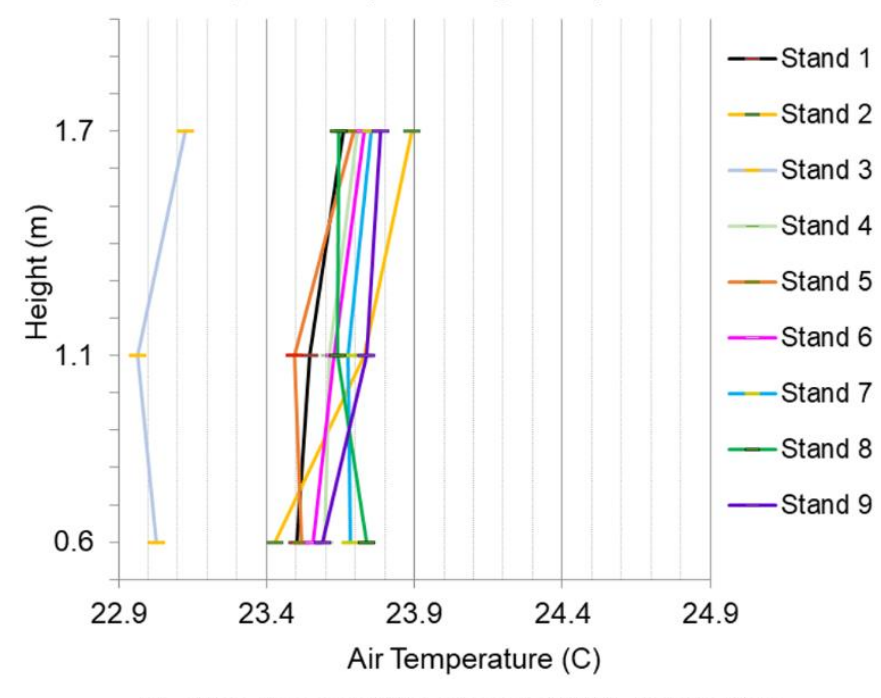

(a) CDHP On vs. SDHV On

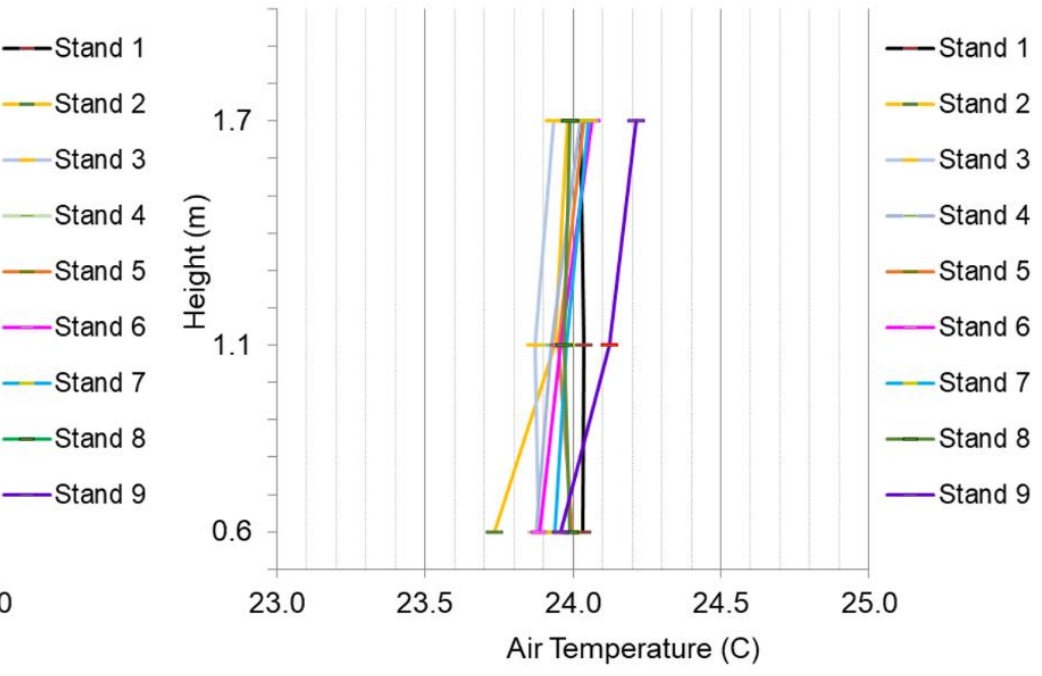

(b) CDHP Off vs. SDHV Off

Figure 54: Comparison of Median Values of the 5-Min Average Temperatures at the Three Measurement Heights When the System Was On Cycle (Left Figure) and Off Cycle (Right Figure) for the Cooling Season After August 10, 2019. 
Cooling Season (After August 10): HVAC ON
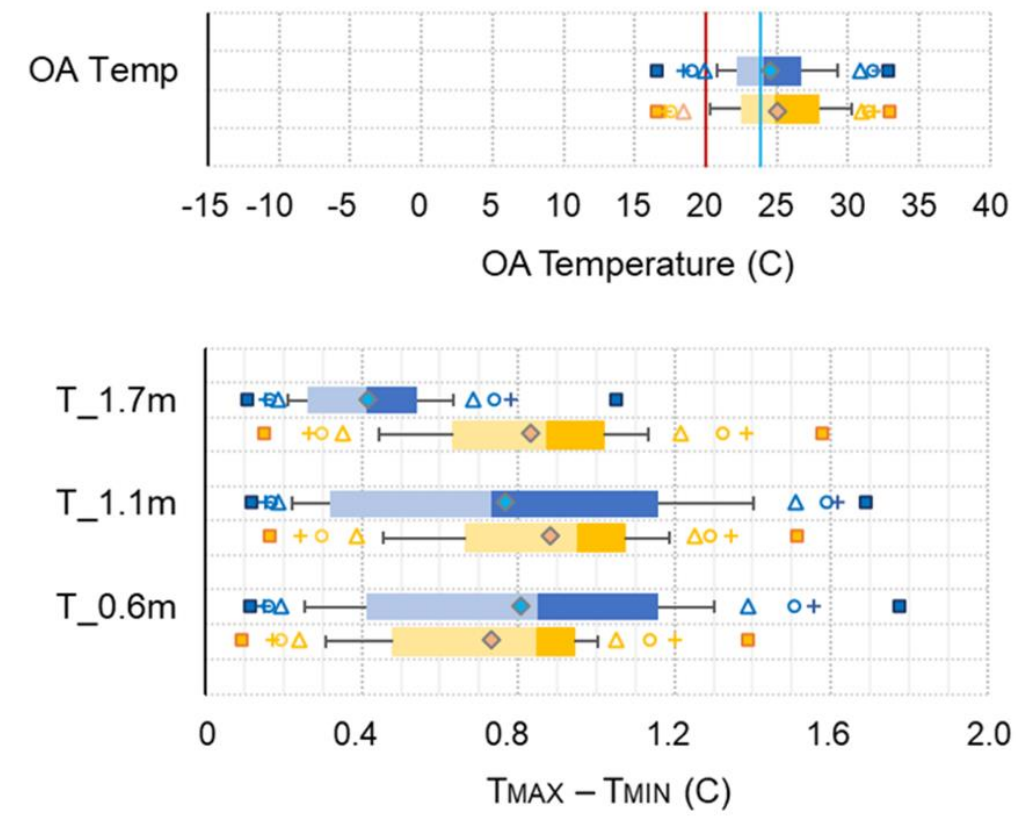

Cooling Season (After August 10): HVAC OFF
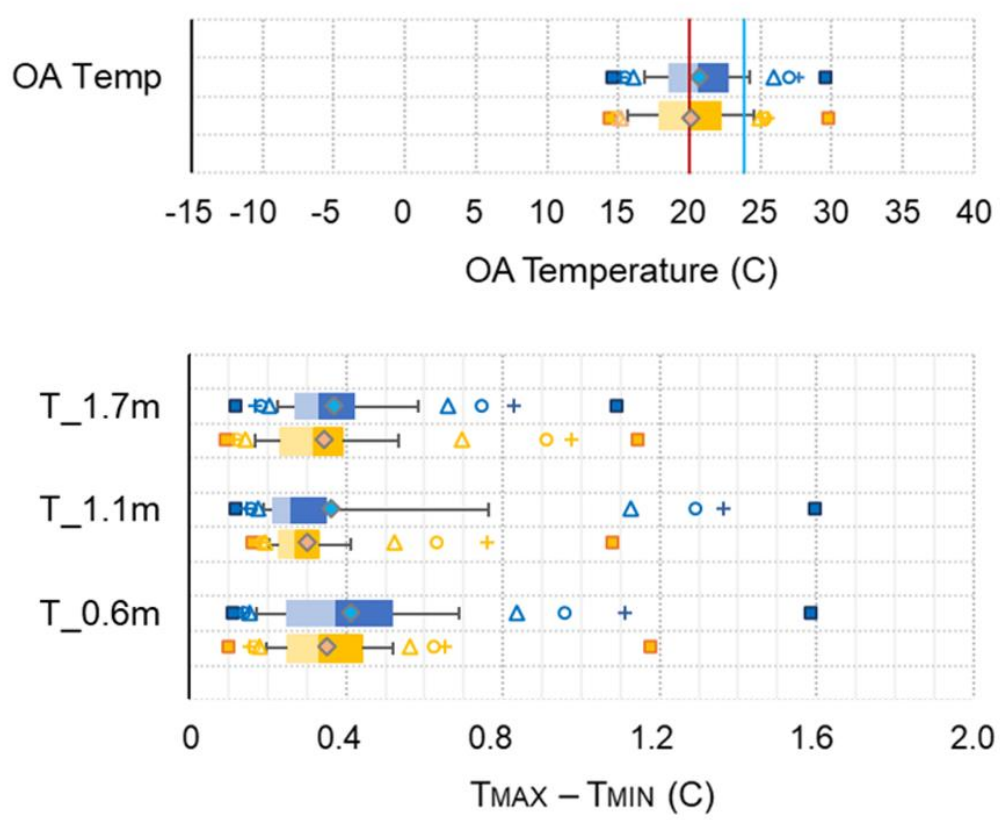

Figure 55: Graphical Summaries of the 5-Min Average Stand-to-Stand Temperature Difference at the Three Measurement Heights When the System Was On Cycle (Left Figure) and Off Cycle (Right Figure) for the Cooling Season After August 10, 2019. 
Cooling Season (After August 10): HVAC ON
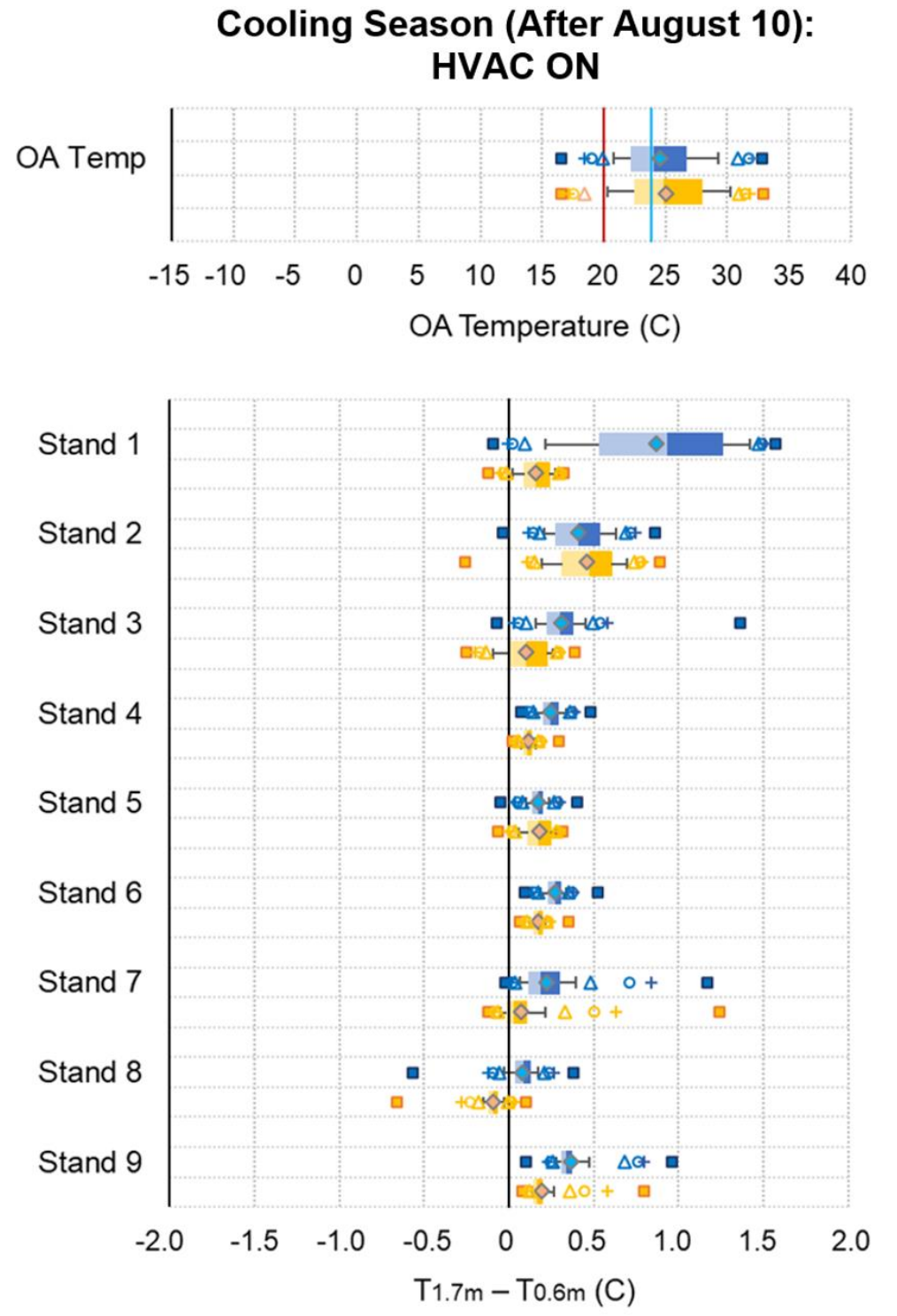

Cooling Season (After August 10): HVAC OFF
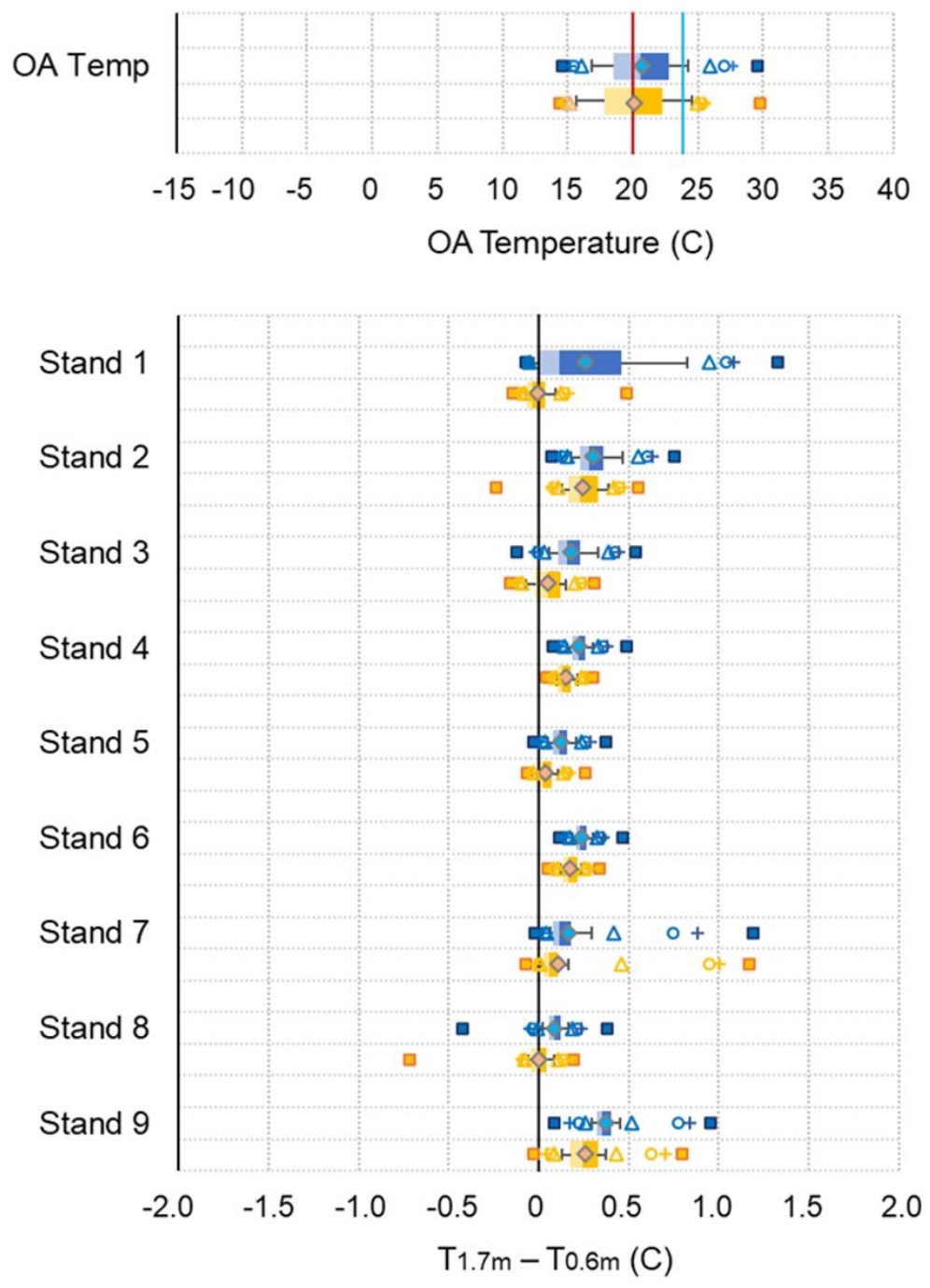

Figure 56: Graphical Summaries of the 5-Min Average Vertical Temperature Difference Between $1.7 \mathrm{~m}$ and $0.6 \mathrm{~m}$ When the System Was On Cycle (Left Figure) and Off Cycle (Right Figure) for the Cooling Season After August 10, 2019. 
Cooling Season (After August 10): HVAC ON
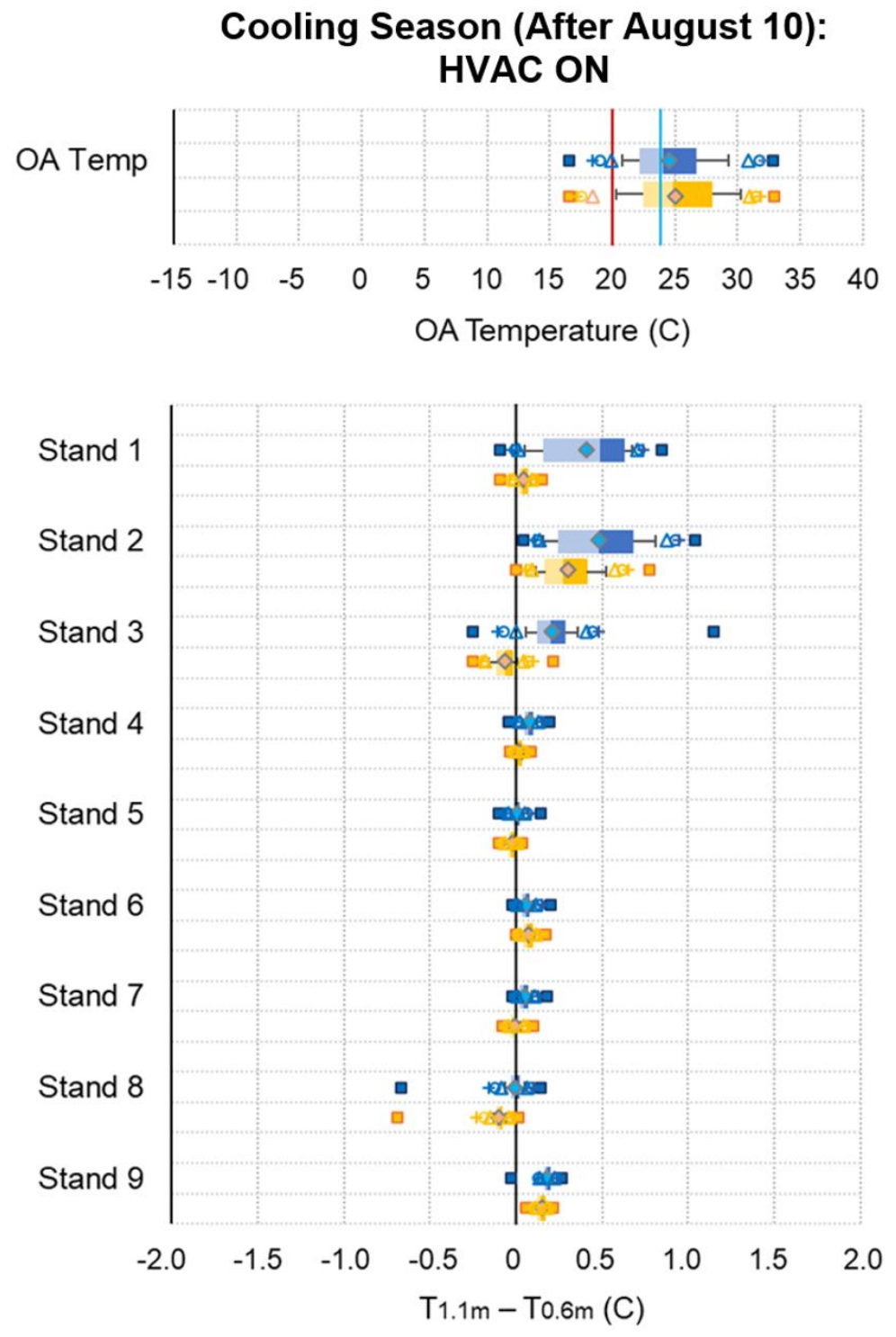

Cooling Season (After August 10): HVAC OFF
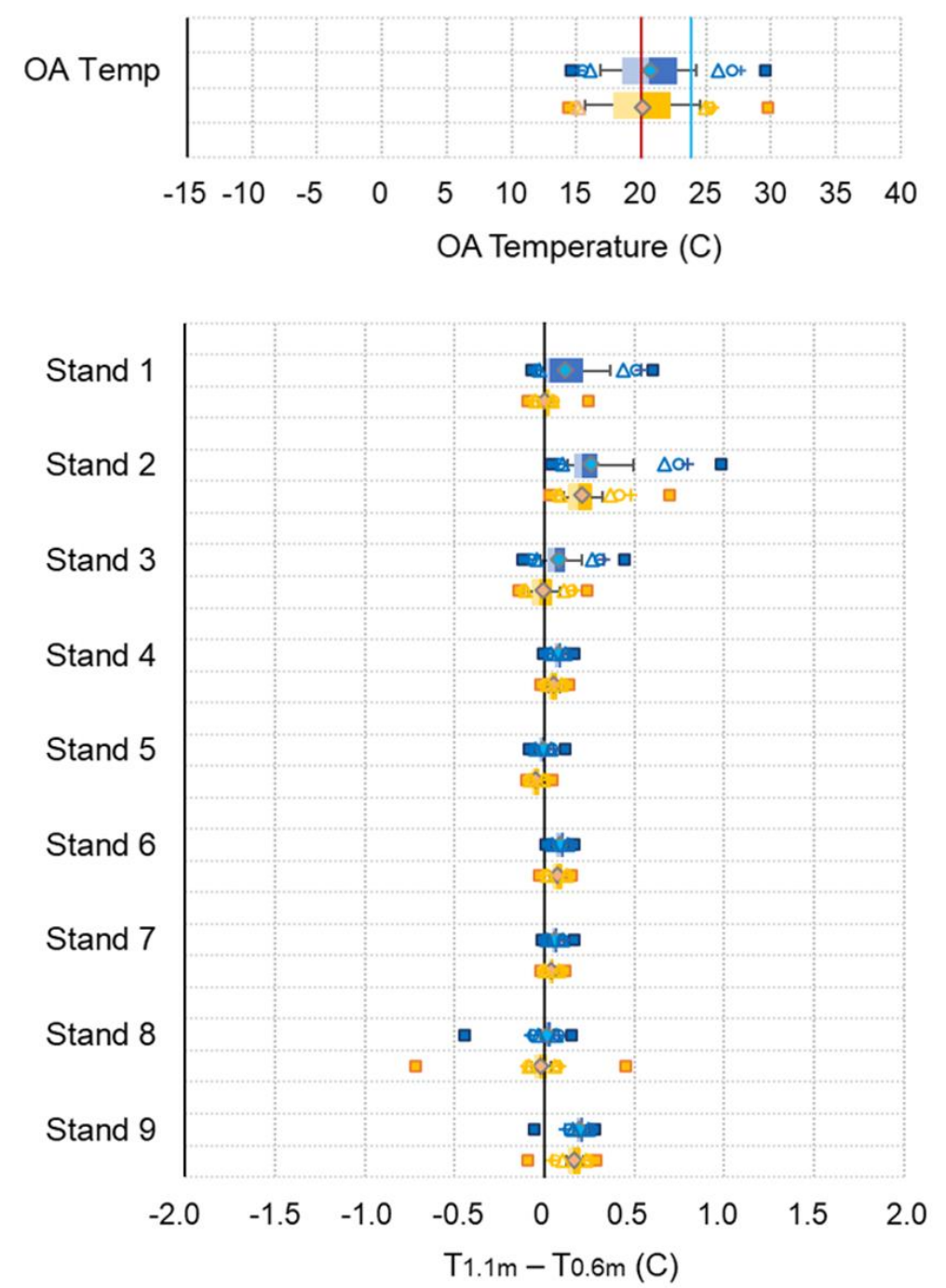

Figure 57: Graphical Summaries of the 5-Min Average Vertical Temperature Difference Between $1.1 \mathrm{~m}$ and $0.6 \mathrm{~m}$ When the System Was On Cycle (Left Figure) and Off Cycle (Right Figure) for the Cooling Season After August 10, 2019 


\subsubsection{HEATING SEASON}

Important observations on the BR3 horizontal and vertical thermal stratification during the heating season (Figures 58 to 61) are:

- Unlike the cooling season, the on-cycle profile with the SDHV exhibited vertical stratification, while the CDHP had a similar on-cycle profile as the cooling season except for the stand 8 . The off-cycle profiles of the heating season were similar to those of the cooling season before August 10, 2017 when the stands were arranged in the same way.

- The on-cycle vertical stratification with the SDHV was consistently observed across the nine stands with IQRs larger than the CDHP, which indicates insufficient air circulation. However, both $\triangle T$ standing and $\triangle T$ seated were way below the ASHRAE Standard 55 limits, of which maximum vertical temperature differences were below $1.5^{\circ} \mathrm{C}$.

- The observed lower temperature gradient with the CDHP regardless of the season might be affected by the two perimeter floor supplies in the BR3, although an attempt was made to make them inactive by closing both their in-duct mechanical dampers and the face dampers of their in-room supply registers. The air flows from the two perimeter supplies were about $43 \%$ to $53 \%$ of those at the two high-wall supplies ${ }^{51}$.

- The on-cycle stand-to-stand temperature differences with the CDHP were comparable to those of the cooling season when excluding the stand 8 that had a distinct profile during the cooling season. However, the SDHV had higher on-cycle stand-to-stand temperature differences compared to the cooling season, which was affected by the stand 1 . The stand 1 located below one of the SDHV supply air outlets had a dissimilar profile of which average temperature at $1.1 \mathrm{~m}$ was lower than those of other stands by about $0.3^{\circ} \mathrm{C}$.

- The off-cycle stand-to-stand temperature differences tended to be larger than those of the cooling season, which was also affected by the stand 1 . The stand 1 did not follow the typical vertical temperature gradient related to the room height, of which temperature at $1.7 \mathrm{~m}$ was lower than the temperature at $1.1 \mathrm{~m}$. The same observations were made for the cooling season.

\footnotetext{
51 Each of the perimeter supplies provided approximately $9 \mathrm{cfm}$, while each of the interior supplies provided approximately $19 \mathrm{cfm}$.
} 

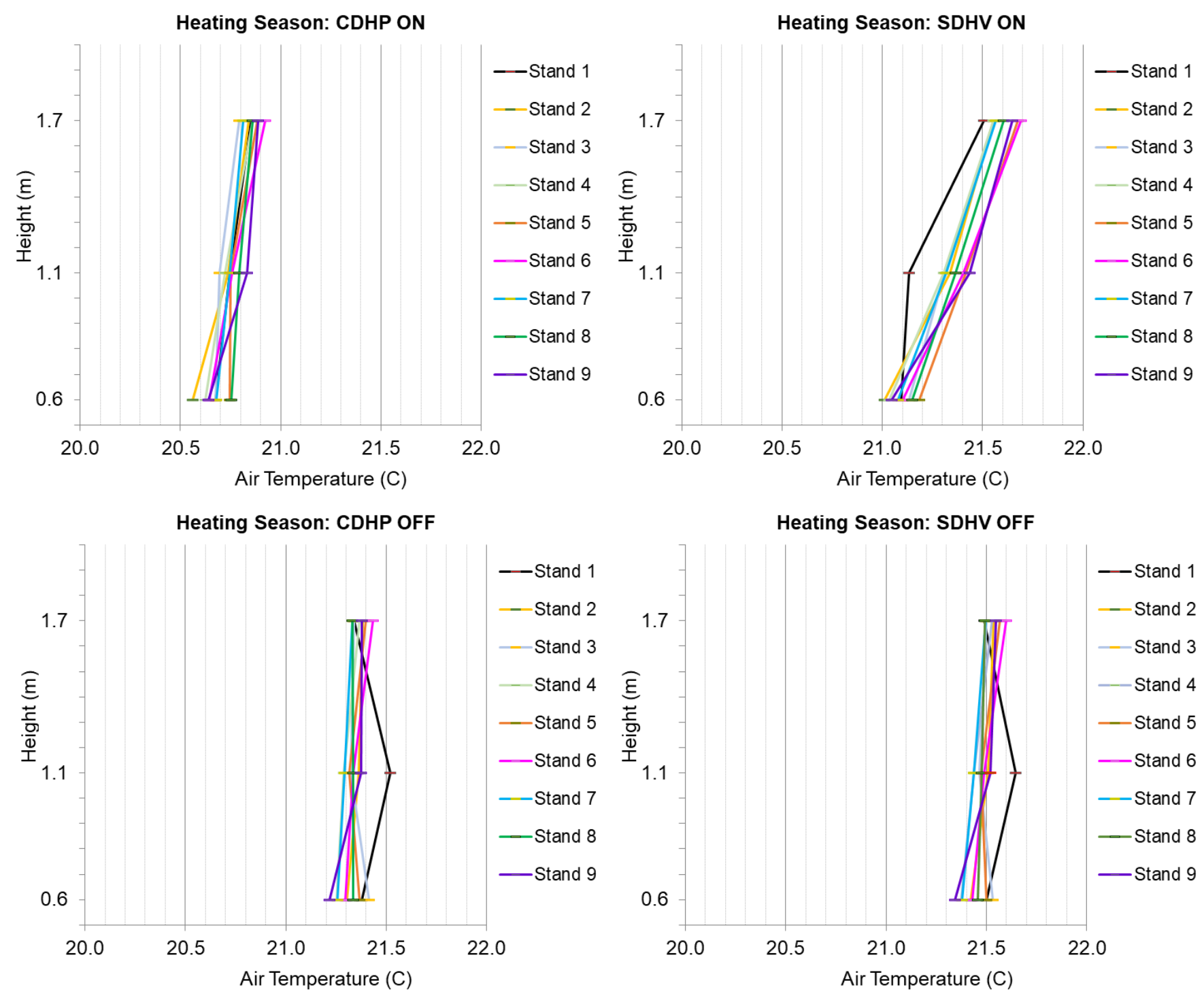

(a) CDHP On vs. SDHV On

Figure 58: Comparison of Median Values of the 5-Min Average Temperatures at the Three Measurement Heights When the System Was On Cycle (Left Figure) and Off Cycle (Right Figure) for the Heating Season. 
Heating Season: HVAC ON
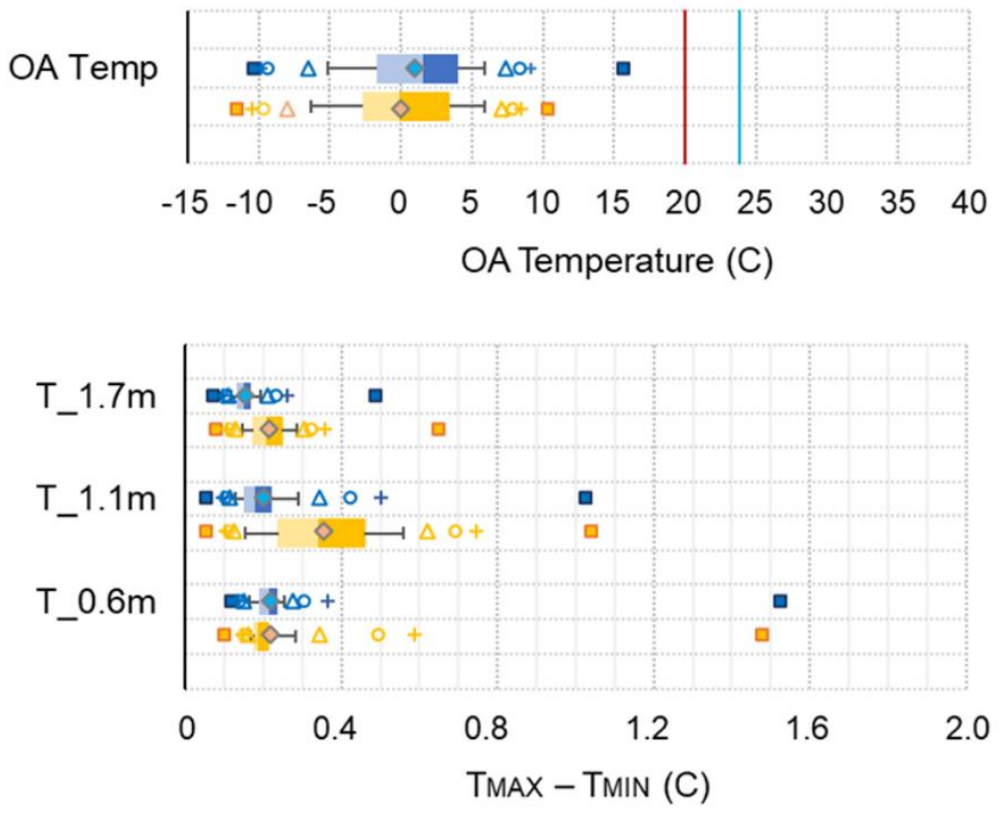

Heating Season: HVAC OFF
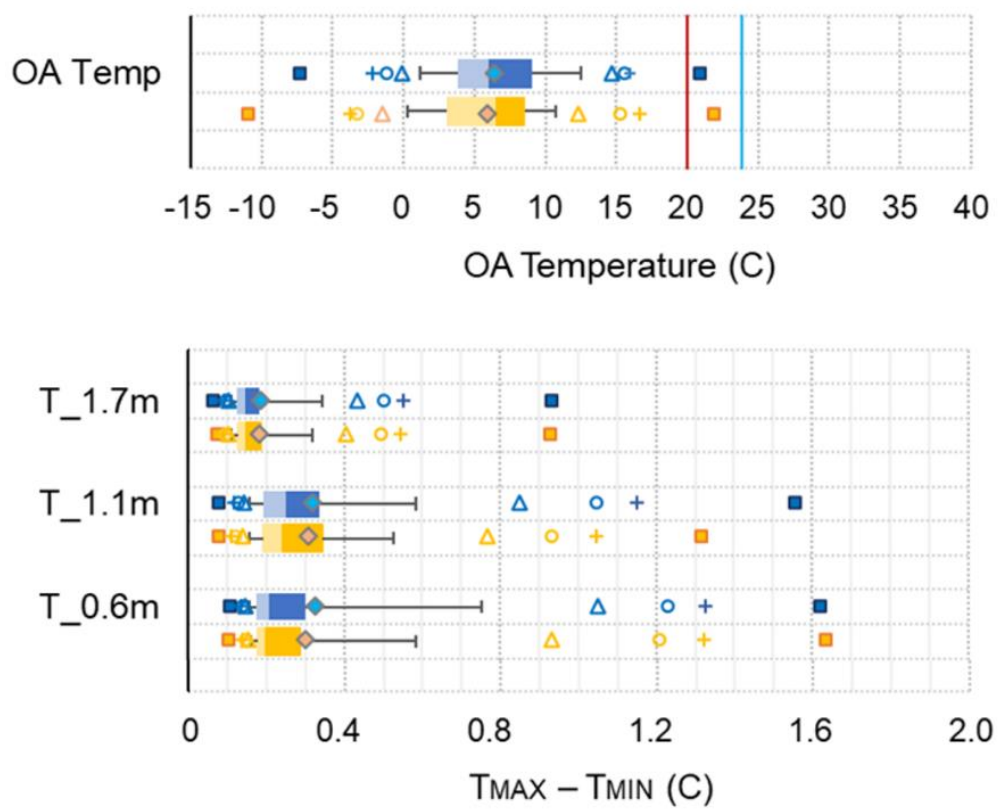

Figure 59: Graphical Summaries of the 5-Min Average Stand-to-Stand Temperature Difference at the Three Measurement Heights When the System Was On Cycle (Left Figure) and Off Cycle (Right Figure) for the Heating Season. 


\section{Heating Season: HVAC ON}
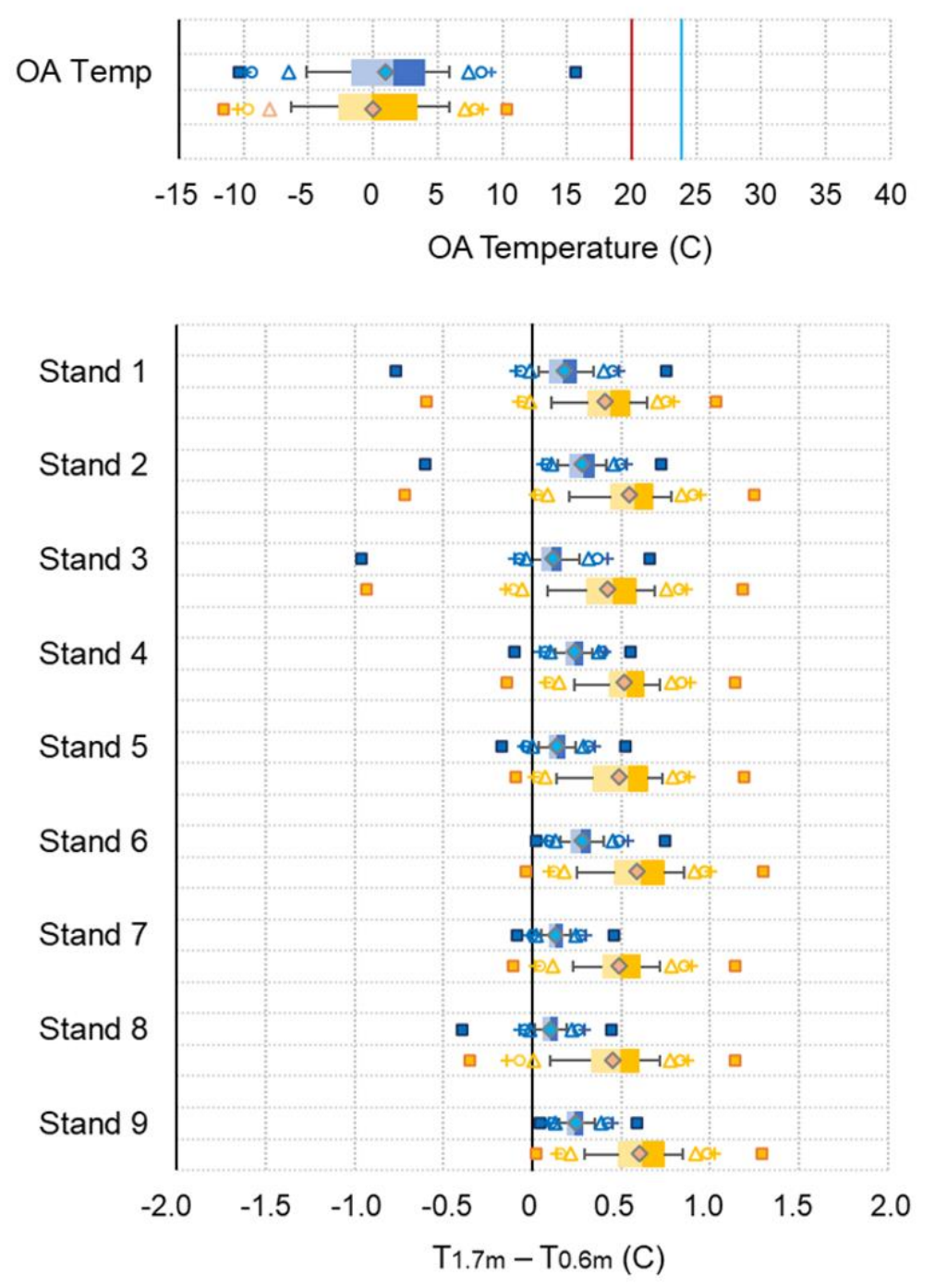

Heating Season: HVAC OFF
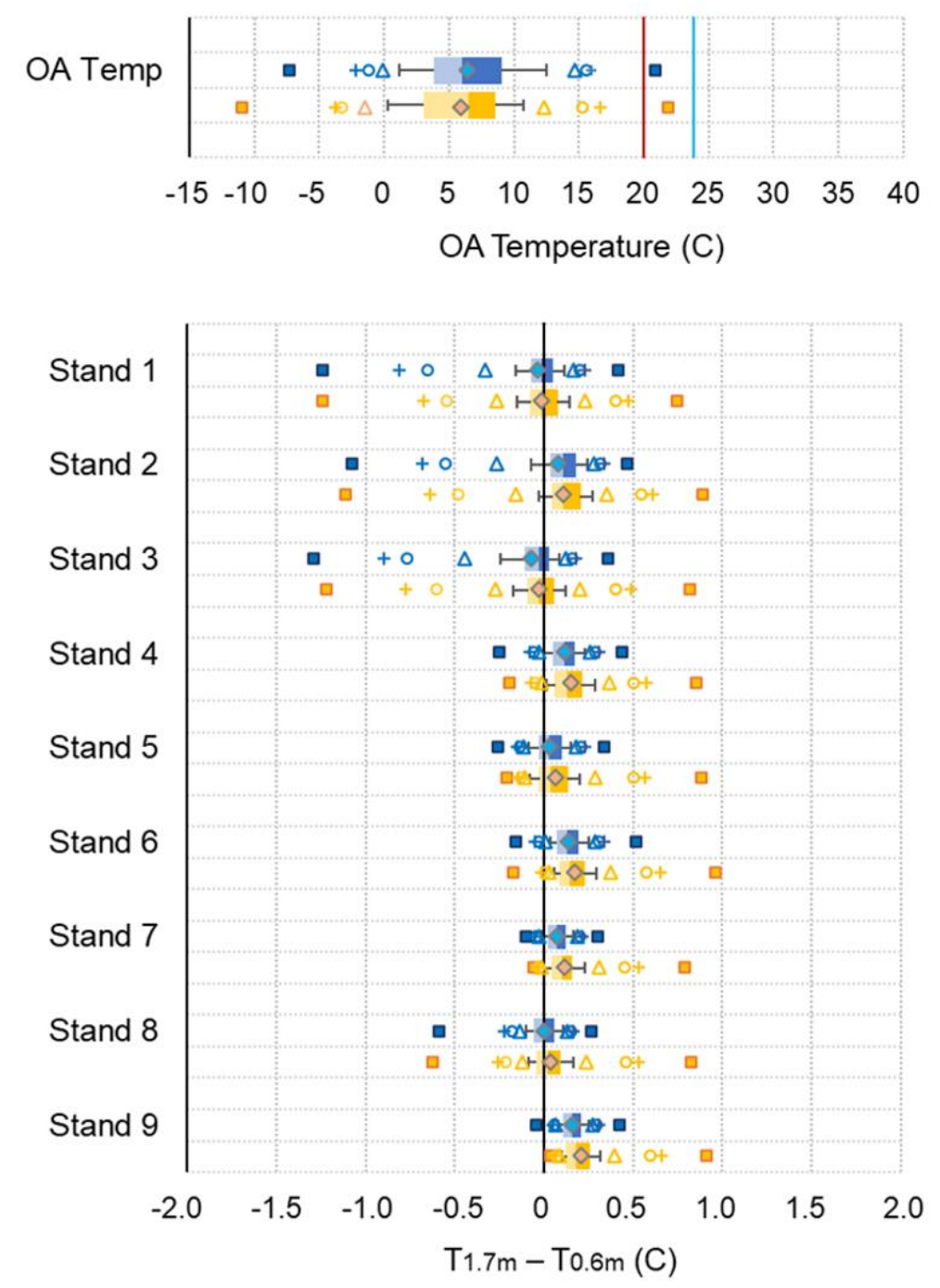

Figure 60: Graphical Summaries of the 5-Min Average Vertical Temperature Difference Between $1.7 \mathrm{~m}$ and $0.6 \mathrm{~m}$ When the System Was On Cycle (Left Figure) and Off Cycle (Right Figure) for the Heating Season. 


\section{Heating Season: HVAC ON}
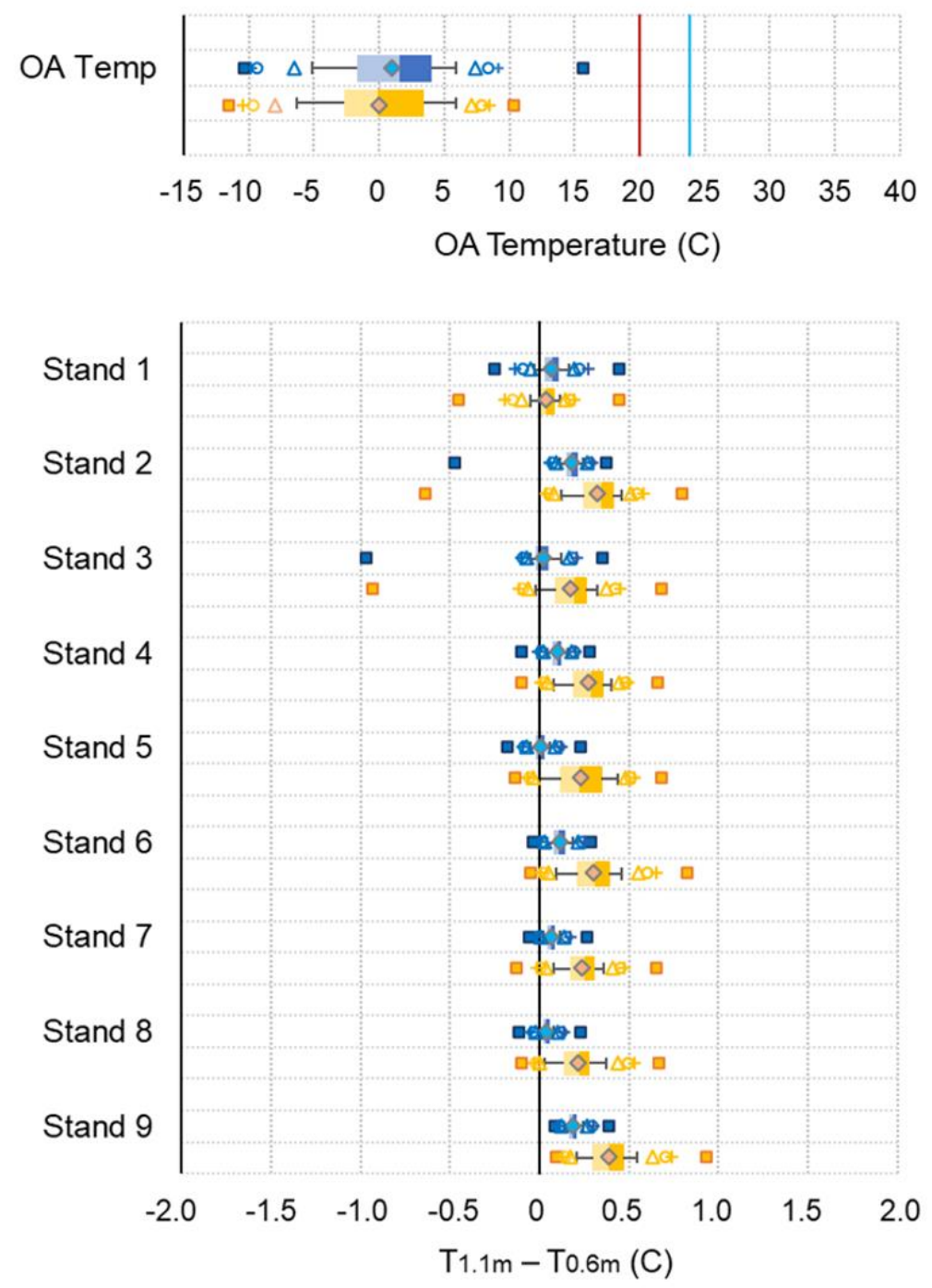

Heating Season: HVAC OFF
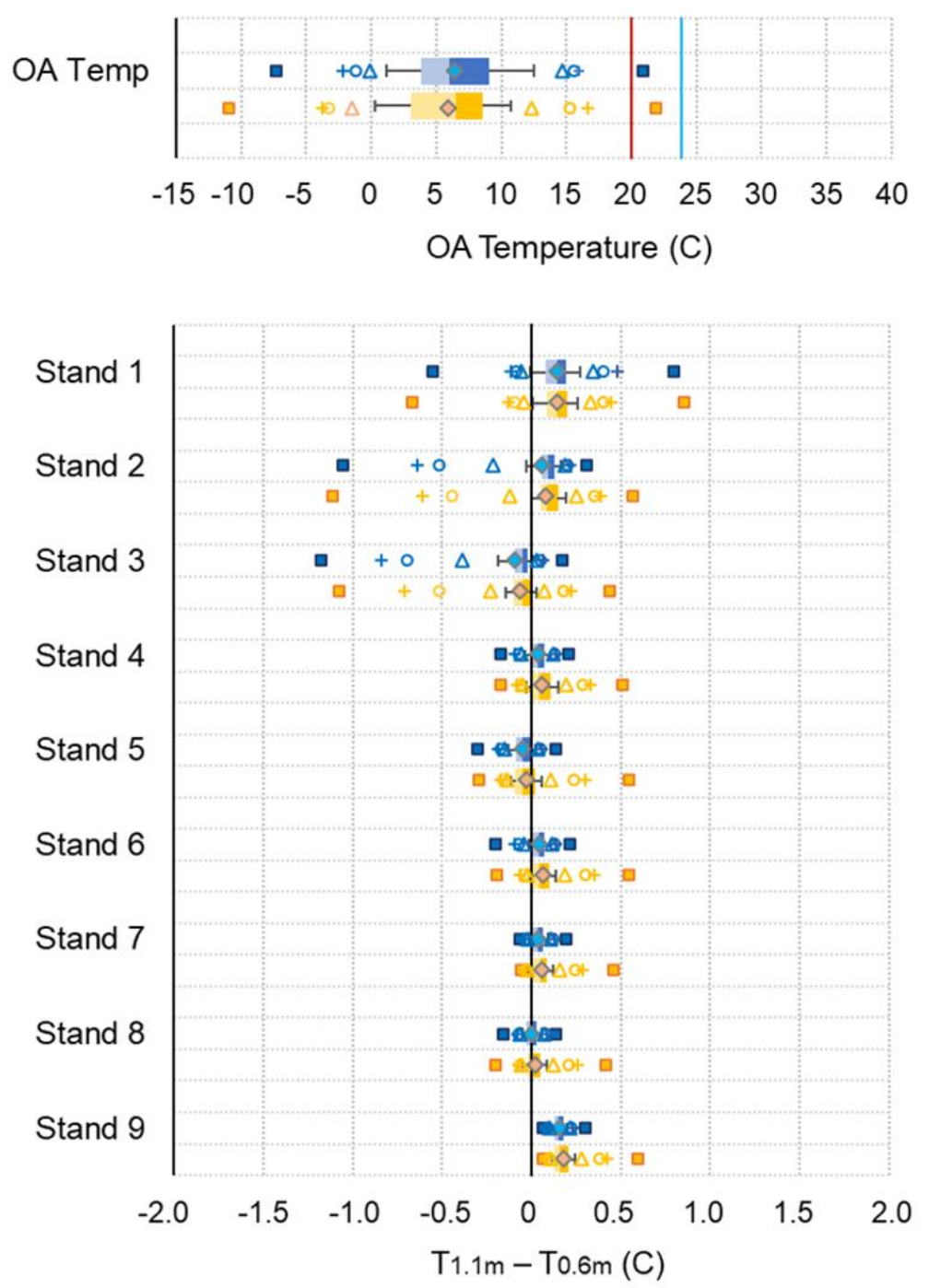

Figure 61: Graphical Summaries of the 5-Min Average Vertical Temperature Difference Between $1.1 \mathrm{~m}$ and $0.6 \mathrm{~m}$ When the System Was On Cycle (Left Figure) and Off Cycle (Right Figure) for the Heating Season. 


\subsubsection{TRANSITIONAL SEASON}

Important observations on the BR3 horizontal and vertical thermal stratification during the transitional season ${ }^{52}$ (Figures 62 to 65 ) are:

- Not surprisingly, both horizontal and vertical stratification during the transitional season were comparable to other seasons or better without any significant amounts of stratification. Both $\Delta T$ standing and $\triangle T$ seated were way below the ASHRAE Standard 55 limits.

- The off-cycle profiles of the transitional season were very similar to those of the cooling season before August 10 and the heating season with temperatures lower than the cooling season but higher than the cooling season.

- Like other seasons, the stand 1 did not follow the typical vertical temperature gradient related to the room height, of which temperature at $1.7 \mathrm{~m}$ was lower than the temperature at $1.1 \mathrm{~m}$.

52 Due to the small sample size of the system on cycle, discussion of transitional season data focuses on the data collected during the system off cycle. The systems were occasionally on cycle for about 29 hours (CDHP) and 66 hours (SDHV) in total. 

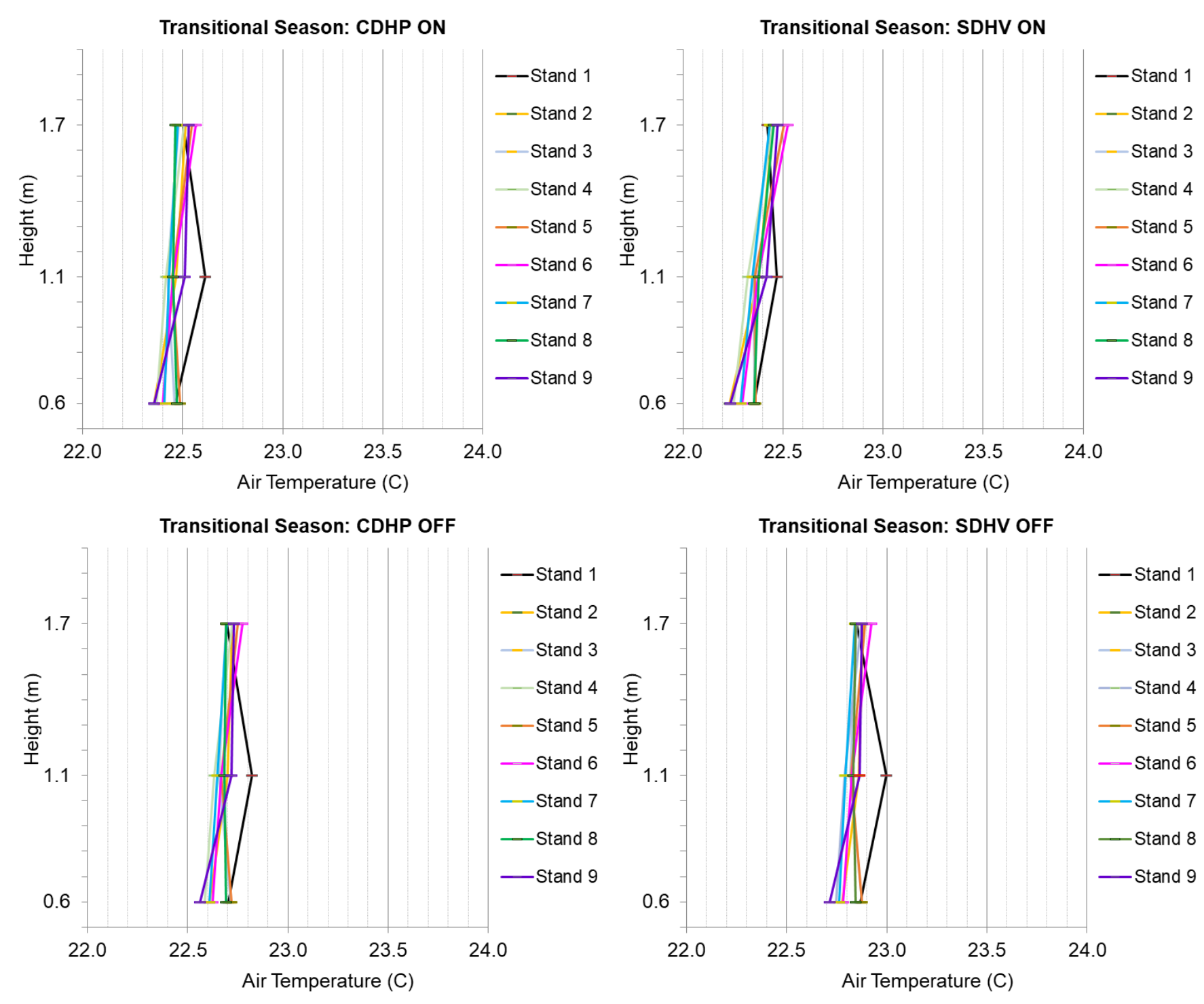

(a) CDHP On vs. SDHV On

Figure 62: Comparison of Median Values of the 5-Min Average Temperatures at the Three Measurement Heights When the System Was On Cycle (Left Figure) and Off Cycle (Right Figure) for the Transitional Season. 
Transitional Season: HVAC ON
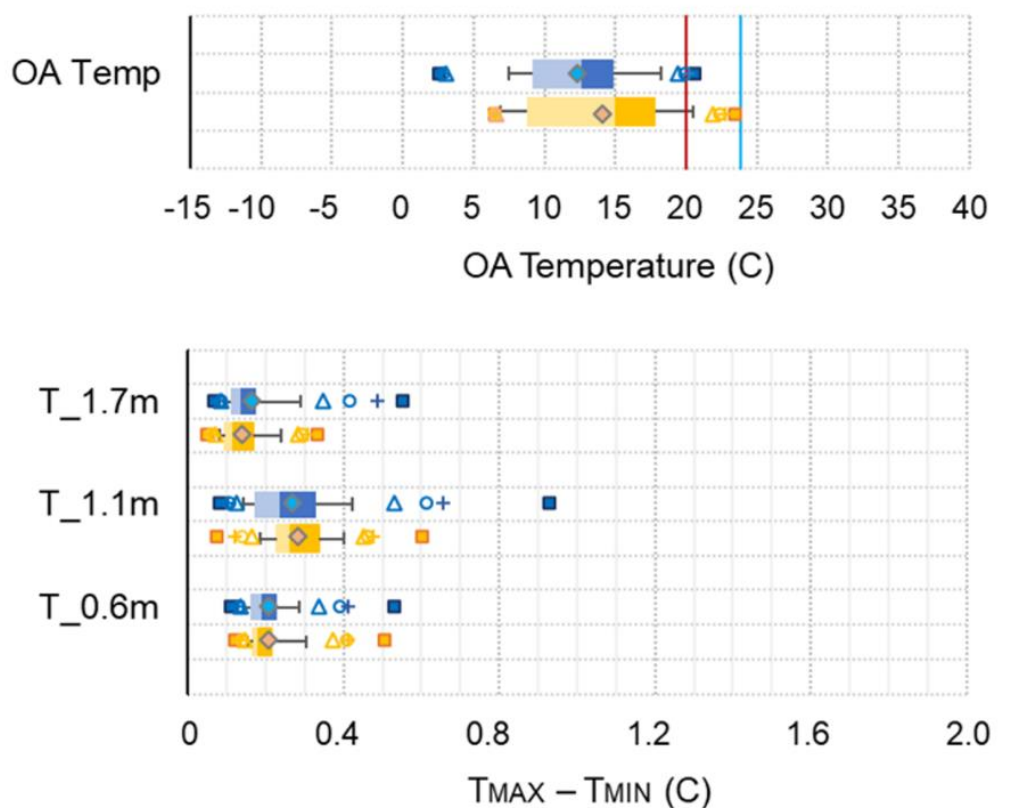

Transitional Season: HVAC OFF
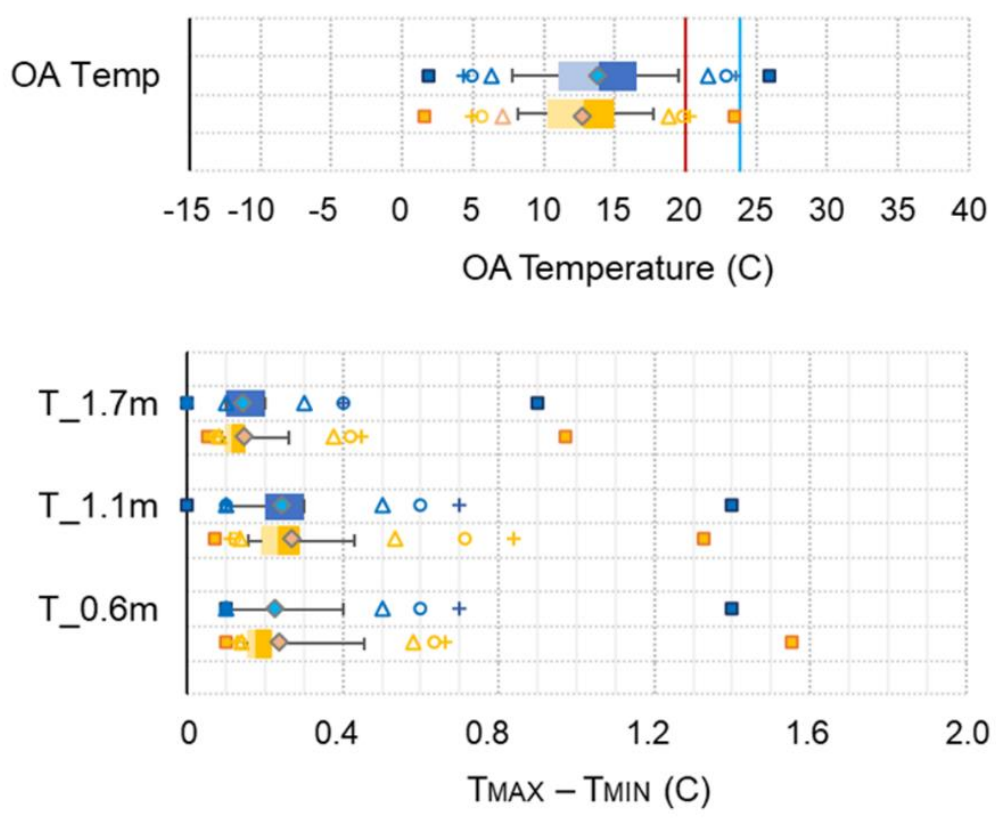

Figure 63: Graphical Summaries of the 5-Min Average Stand-to-Stand Temperature Difference at the Three Measurement Heights When the System Was On Cycle (Left Figure) and Off Cycle (Right Figure) for the Transitional Season. 
Transitional Season: HVAC ON
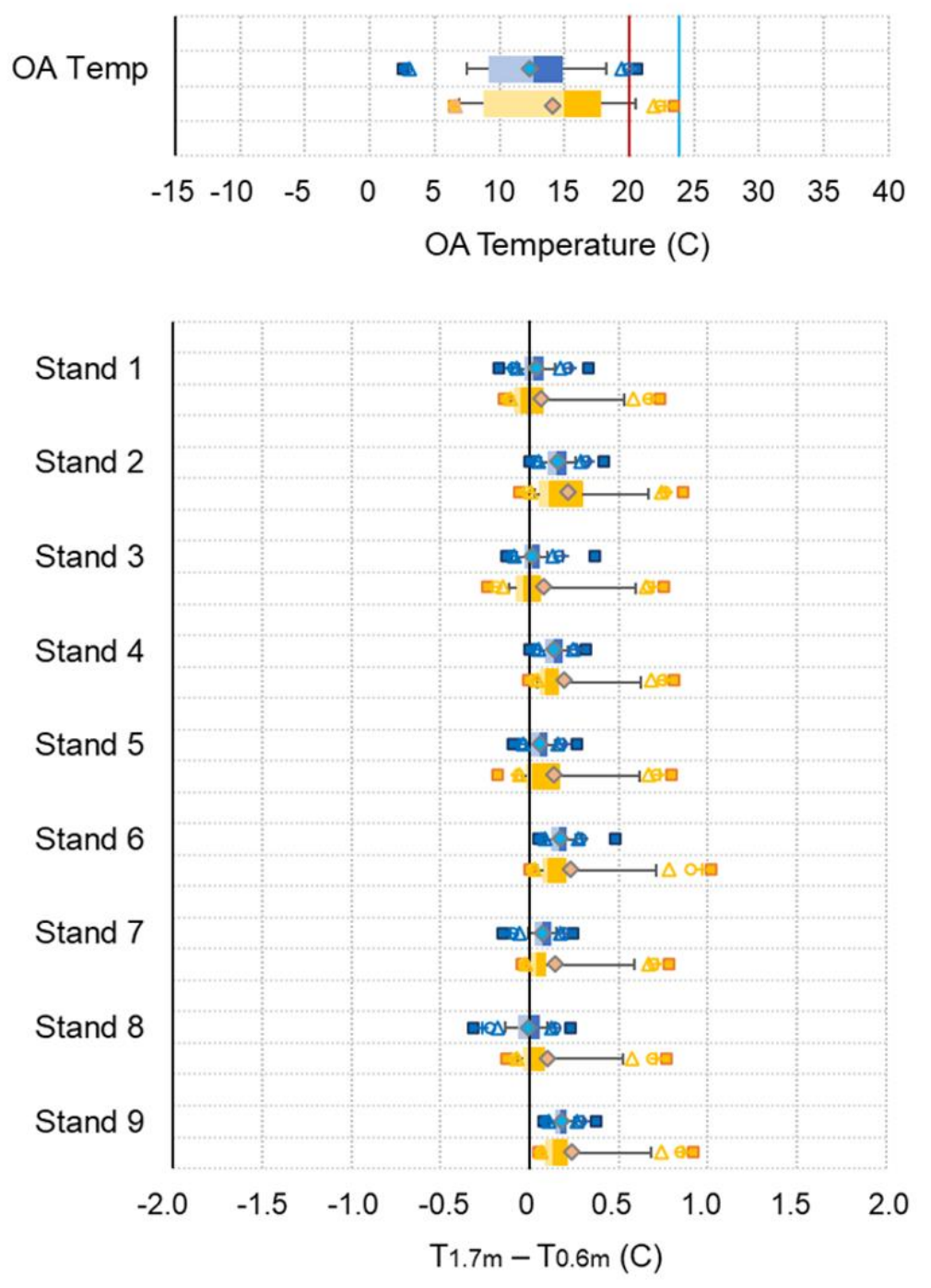

Transitional Season: HVAC OFF
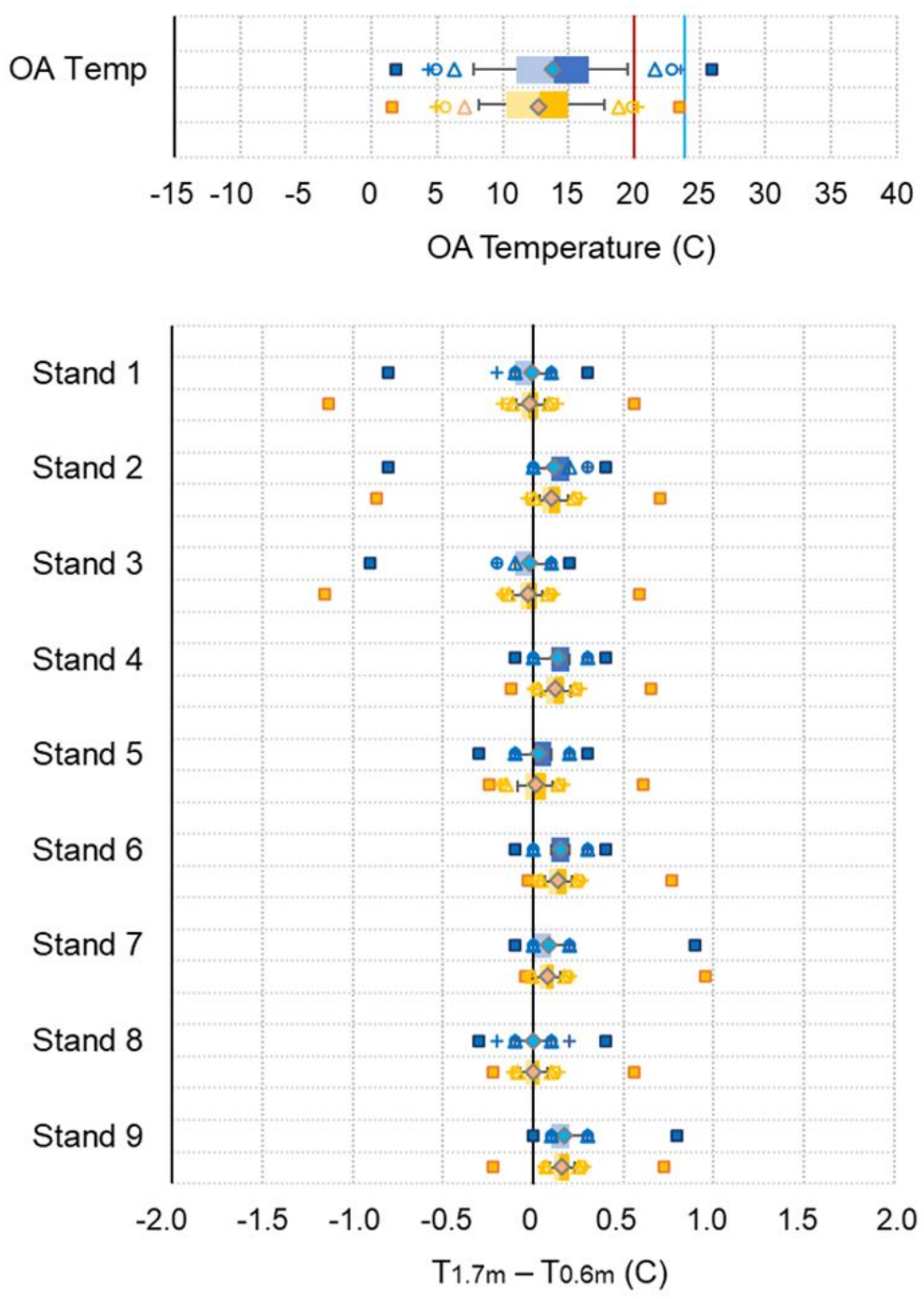

Figure 64: Graphical Summaries of the 5-Min Average Vertical Temperature Difference Between $1.7 \mathrm{~m}$ and $0.6 \mathrm{~m}$ When the System Was On Cycle (Left Figure) and Off Cycle (Right Figure) for the Transitional Season. 
Transitional Season: HVAC ON
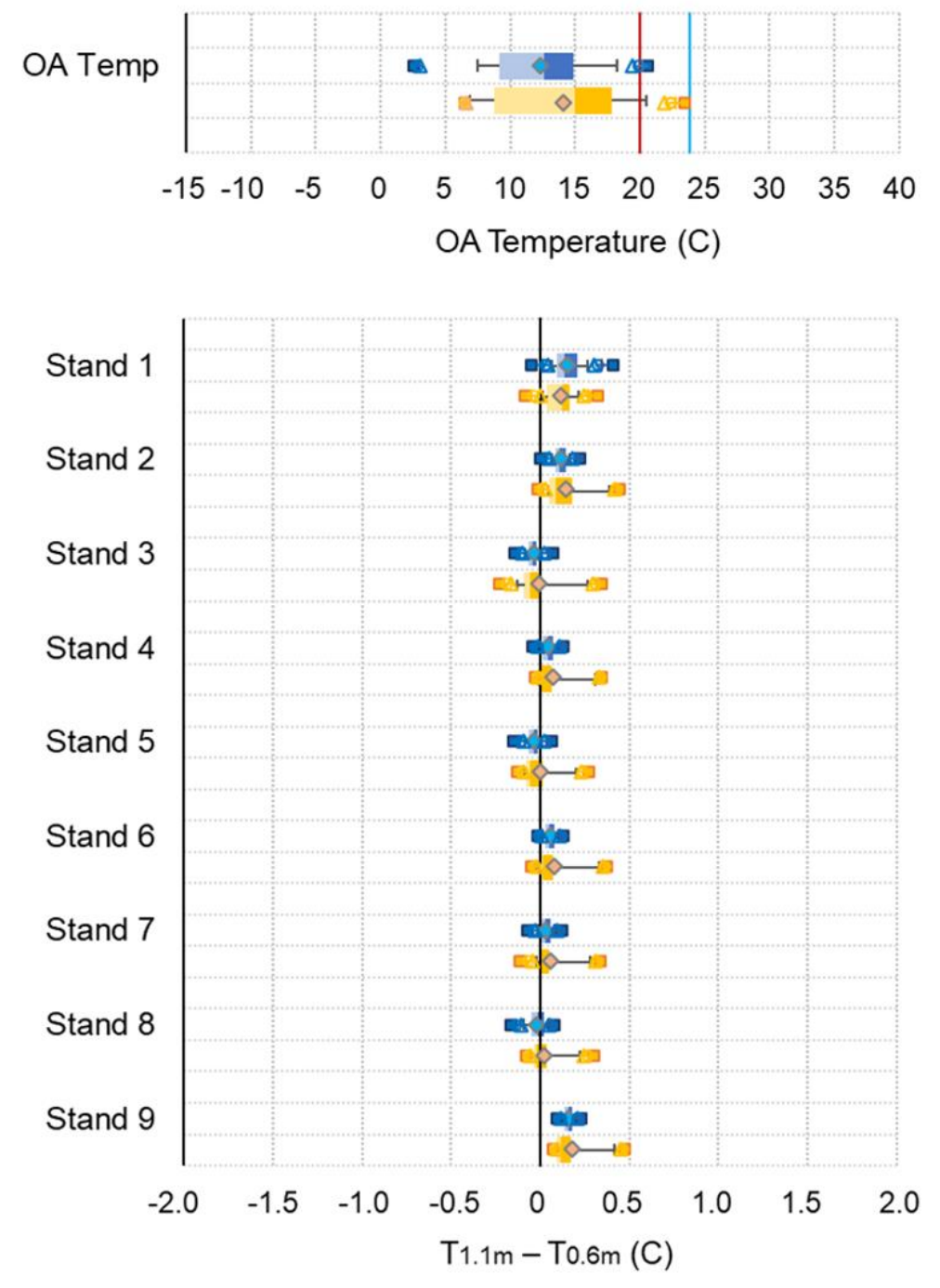

Transitional Season: HVAC OFF
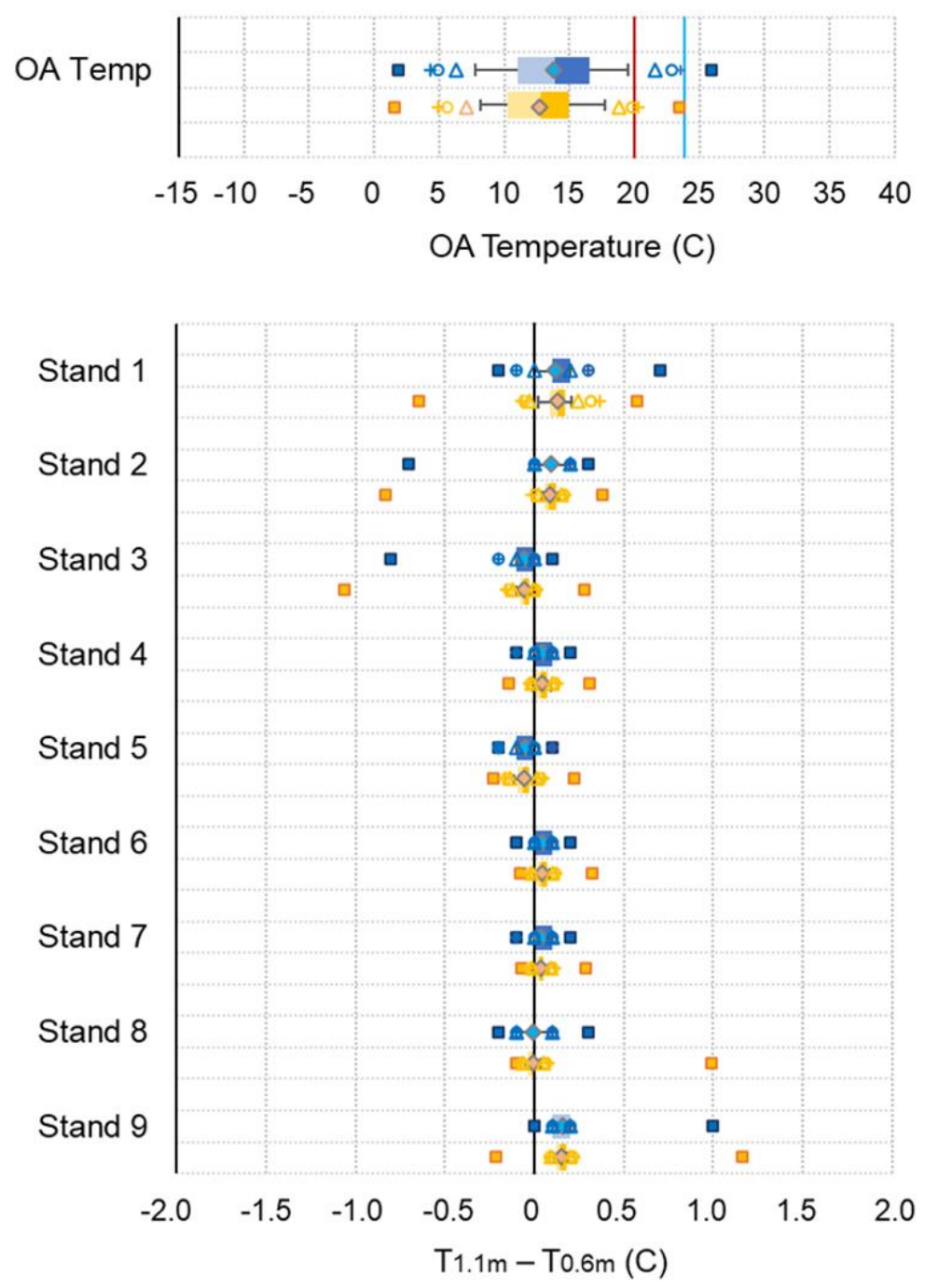

Figure 65: Graphical Summaries of the 5-Min Average Vertical Temperature Difference Between $1.1 \mathrm{~m}$ and $0.6 \mathrm{~m}$ When the System Was On Cycle (Left Figure) and Off Cycle (Right Figure) for the Transitional Season. 


\subsection{AIR VELOCITY DISTRIBUTION}

Figures 66 and 69 present graphical summaries of the 5-min average air velocity distributions measured at the height of $1.1 \mathrm{~m}$ of the four different locations in the BR3 (i.e., stands 1, 3, 5, and 8) using the graphical index proposed to display long-term thermal comfort data (Figure 13) by season. The results were displayed using the graphical index proposed to display long-term thermal comfort data (Figure 13) and color-coded by system types (i.e., blue for CDHP and orange for SDHV) with a superimposed air velocity benchmarks: the ACCA minimum air velocity $(0.08 \mathrm{~m} / \mathrm{s})$, the ACCA ideal air velocity $(0.13 \mathrm{~m} / \mathrm{s})$, and the ASHRAE 55 maximum limit for the PMV-based comfort zone method $(0.20 \mathrm{~m} / \mathrm{s})$.

Important observations on the BR3 air velocity distribution are:

- Cooling Season Before August 10, 2017 (Figure 66)

- Except for the stand 8 during the CDHP on cycle, the air velocities were generally lower than the ideal air velocity (i.e., $0.13 \mathrm{~m} / \mathrm{s}$ ) of the ACCA Manual RS for most of the measurement period.

- The stand 8 located near the CDHP supply air outlets on the upper wall had air velocities that often exceeded the ACCA ideal air velocity when the CDHP was on cycle, which indicates possible local discomfort due to drafts around the stand 8. The stand 8 also had occasions exceeding the maximum air velocity limit of the ASHRAE Standard 55 (i.e., $0.20 \mathrm{~m} / \mathrm{s}$ ), which was more than $10 \%$ of the period.

- When comparing the two systems, the SDHV had higher air velocities with larger IQRs at the locations of the stands 1 and 3, which were near the SDHV supply air outlets, although the occasions exceeding the ACCA ideal air velocity were less than $10 \%$ of the period. As a result, the SDHV had fewer occasions when the measured air velocities were below the ACCA minimum air velocity (i.e., $0.08 \mathrm{~m} / \mathrm{s}$ ) to prevent stagnant air at the locations of stands 1 and 3 compared to the CDHP. However, the CDHP had a substantial amount of time when the air velocities were below the ACCA minimum limit.

- In the center of the room at the location of the stand 5, the CDHP tended to have higher air velocities with a larger IQR, while the SDHV had a substantial amount of time when the air velocities were below the ACCA minimum limit, which indicates potential issues due to stagnant air.

- When the systems were off cycle, the measured air velocities were comparable between the two systems with more than $50 \%$ of the occasions when the air velocities were lower than the ACCA minimum limit except for the stand 8 . The stand 8 tended to have slightly higher air velocities compared to other locations, which was affected by its proximity to the HRV supply air outlet.

- Cooling Season After August 10, 2017 (Figure 67)

- When the sensor stands were spread out to be closer to the walls or windows, the stand 3 moved to right below one of the SDHV supply air outlets had extremely increased air velocities. The occasions exceeding the maximum air velocity limit of the ASHRAE Standard 55 at the stand 3 was more than $90 \%$ of the period.

- On the other hand, the stand 8 moved nearer to the wall had decreased air velocities since the air injected from the CDHP supply air outlets located on the upper wall did not directly reach the stand at the height of $1.1 \mathrm{~m}$.

- When the systems were off cycle, the stands 1 and 3 had decreased air velocities, which is expected as these stands were moved to the room corners. 
- Heating Season (Figure 68)

- Compared to the cooling season before August 10, 2017, both systems maintained lower air velocities during the heating season, which resulted in more incidences when the air velocities were lower than the ACCA minimum air velocity (i.e., $0.08 \mathrm{~m} / \mathrm{s}$ ).

- Unlike the cooling season, the SDHV had lower or similar air velocities at the locations of the stands 1 and 3 compared to the CDHP, although the two stands were located near the SDHV supply air outlets. The stand 8 located near the CDHP supply air outlets also had similar air velocities as the SDHV, of which trend differed from the cooling season. This means both systems with variable-speed indoor blowers delivered lower supply airflow rates in this low-load house during the heating season, which resulted in poorer air mixing compared to the cooling season.

- In the center of the room at the location of the stand 5, the SDHV tended to have higher air velocities with a larger IQR, which was opposite to the cooling season. The CDHP had more than $90 \%$ of the time when the air velocities were below the ACCA minimum limit, which indicates potential issues due to stagnant air.

- When the systems were off cycle, the measured air velocities tended to be higher than those during the systems on cycle, which seemed counter-intuitive. This occurred due to the unexpected interaction with the other conditioning mechanisms in the BR3: HRV.

- Transitional Season (Figure 69)

- The two systems maintained comparable air velocities during the transitional season. Not surprisingly, the off-cycle air velocities except for several outliers were very similar to those of the cooling season before August 10 and the heating season. 
Cooling Season (Before August 10): HVAC ON

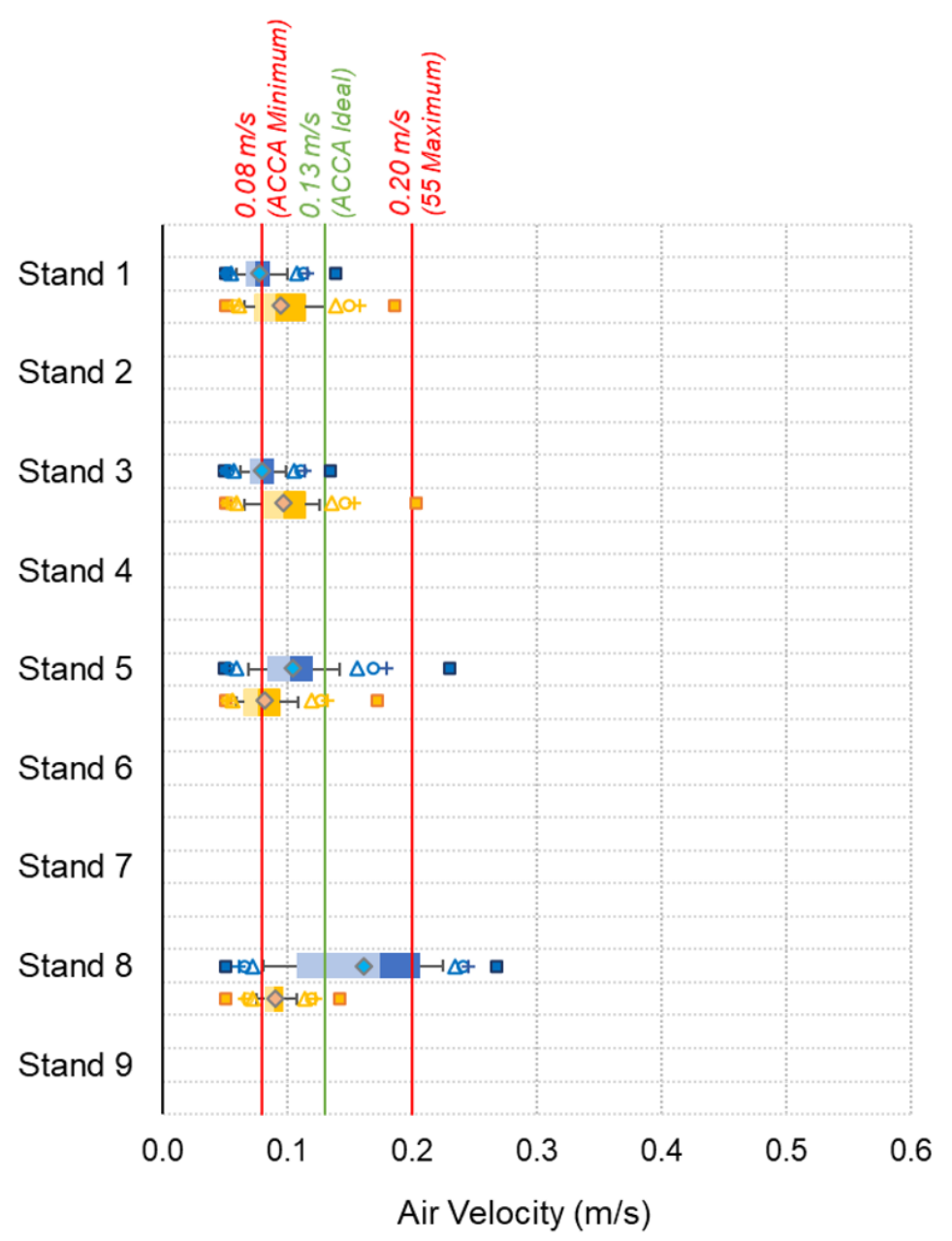

\section{Cooling Season (Before August 10):} HVAC OFF

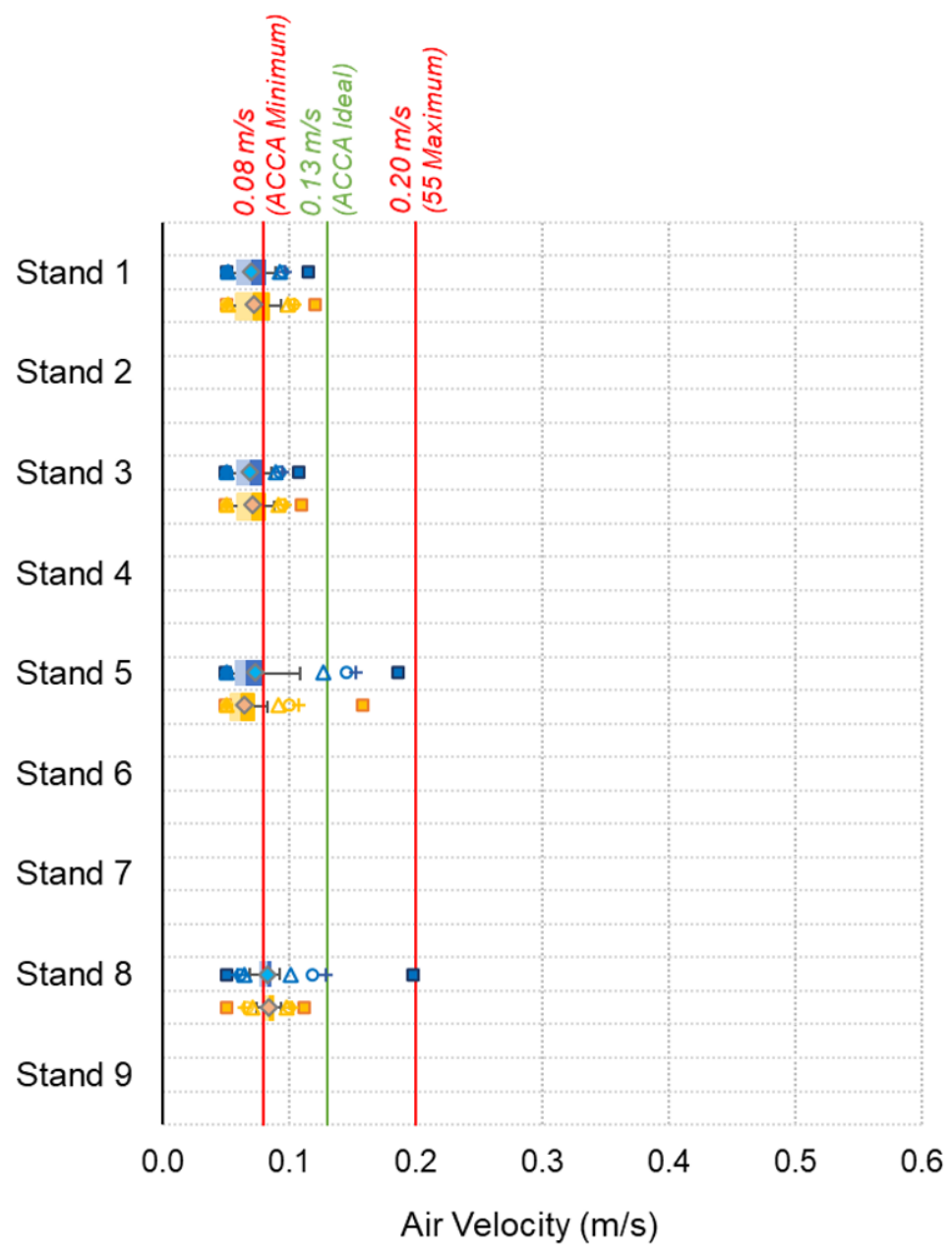

Figure 66: Graphical Summaries of the 5-Min Average Air Velocity When the System Was On Cycle (Left Figure) and Off Cycle

(Right Figure) for the Cooling Season Before August 10, 2019. 


\section{Cooling Season (After August 10):} HVAC ON

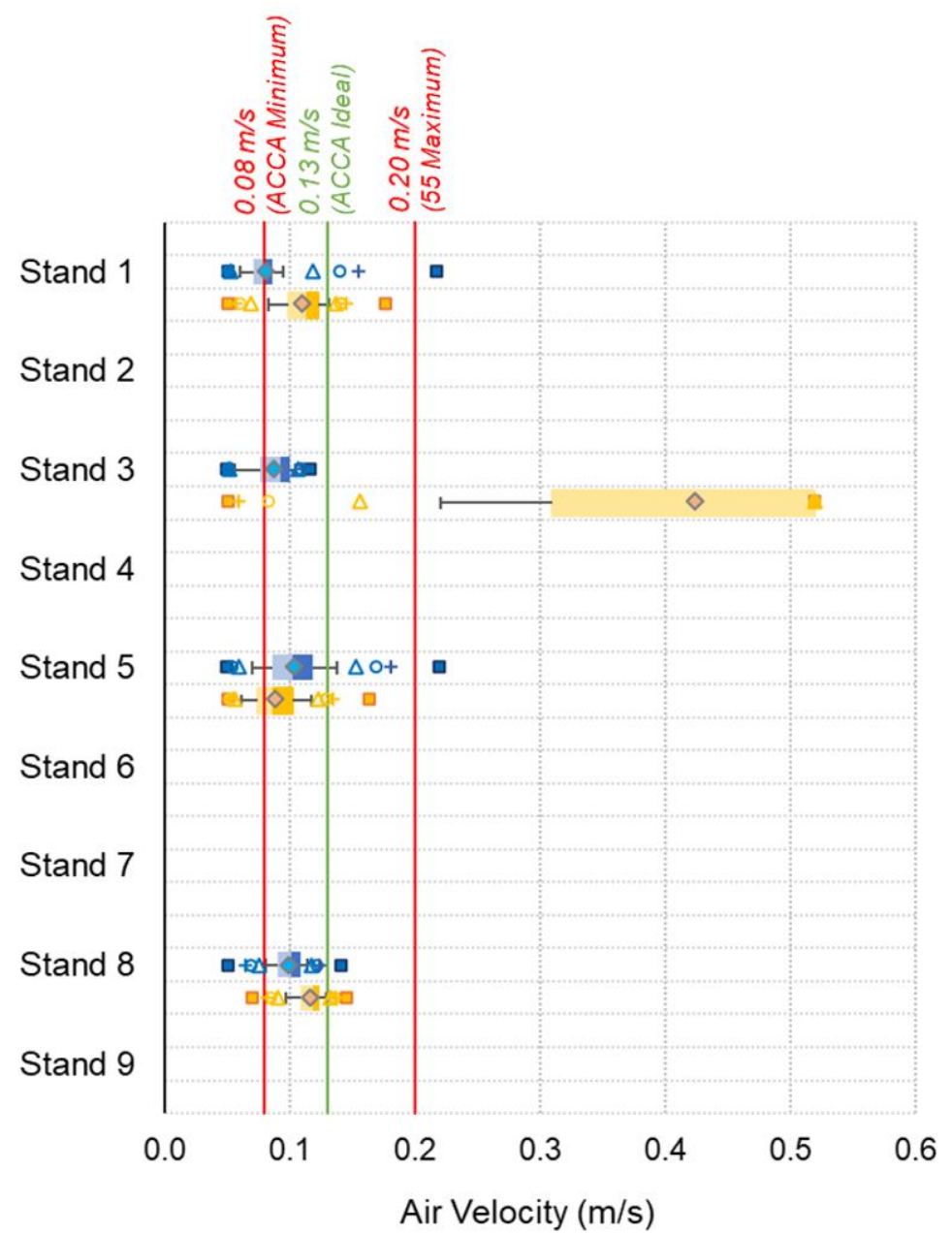

Cooling Season (After August 10):

HVAC OFF

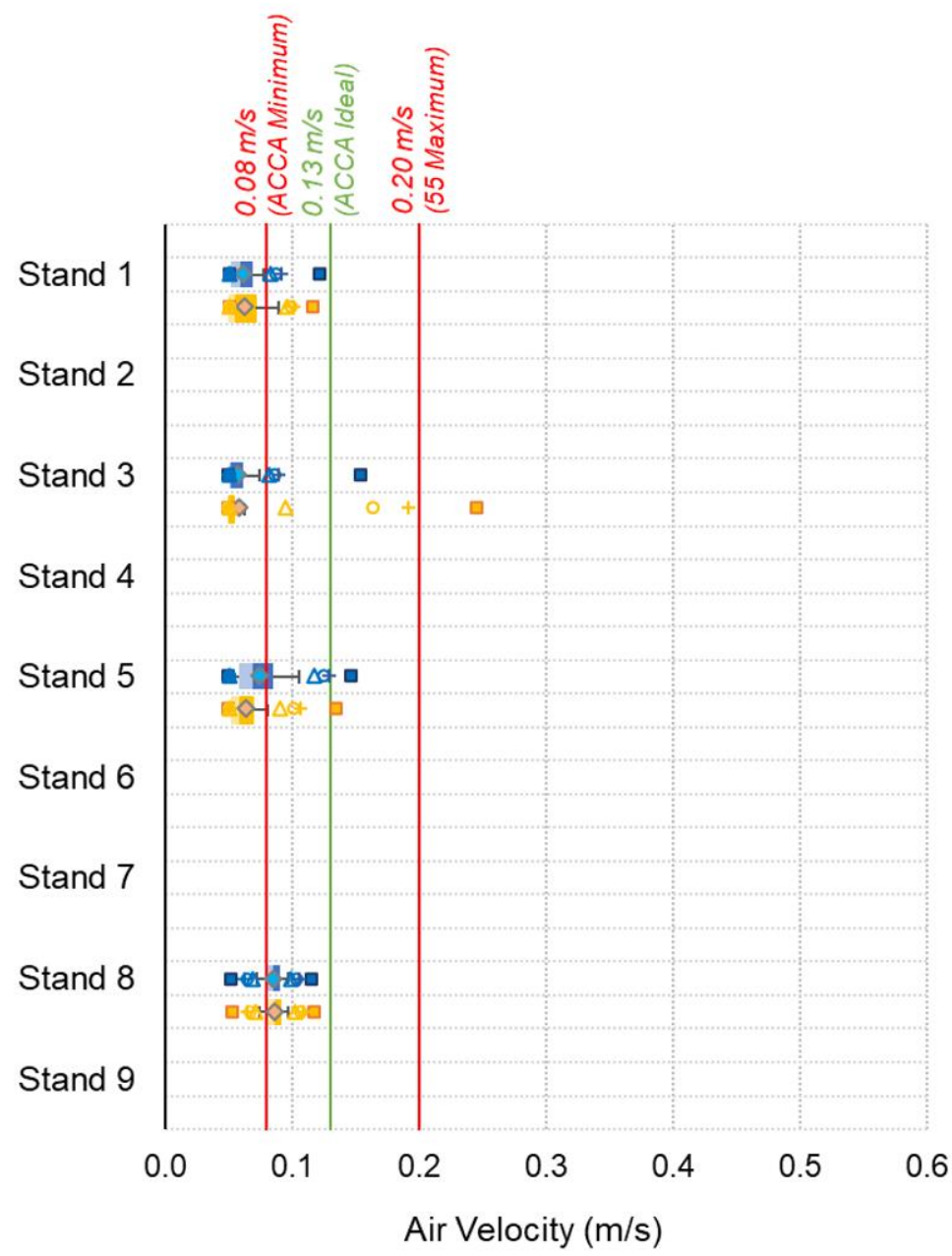

Figure 67: Graphical Summaries of the 5-Min Average Air Velocity When the System Was On Cycle (Left Figure) and Off Cycle (Right Figure) for the Cooling Season After August 10, 2019. 
Heating Season: HVAC ON

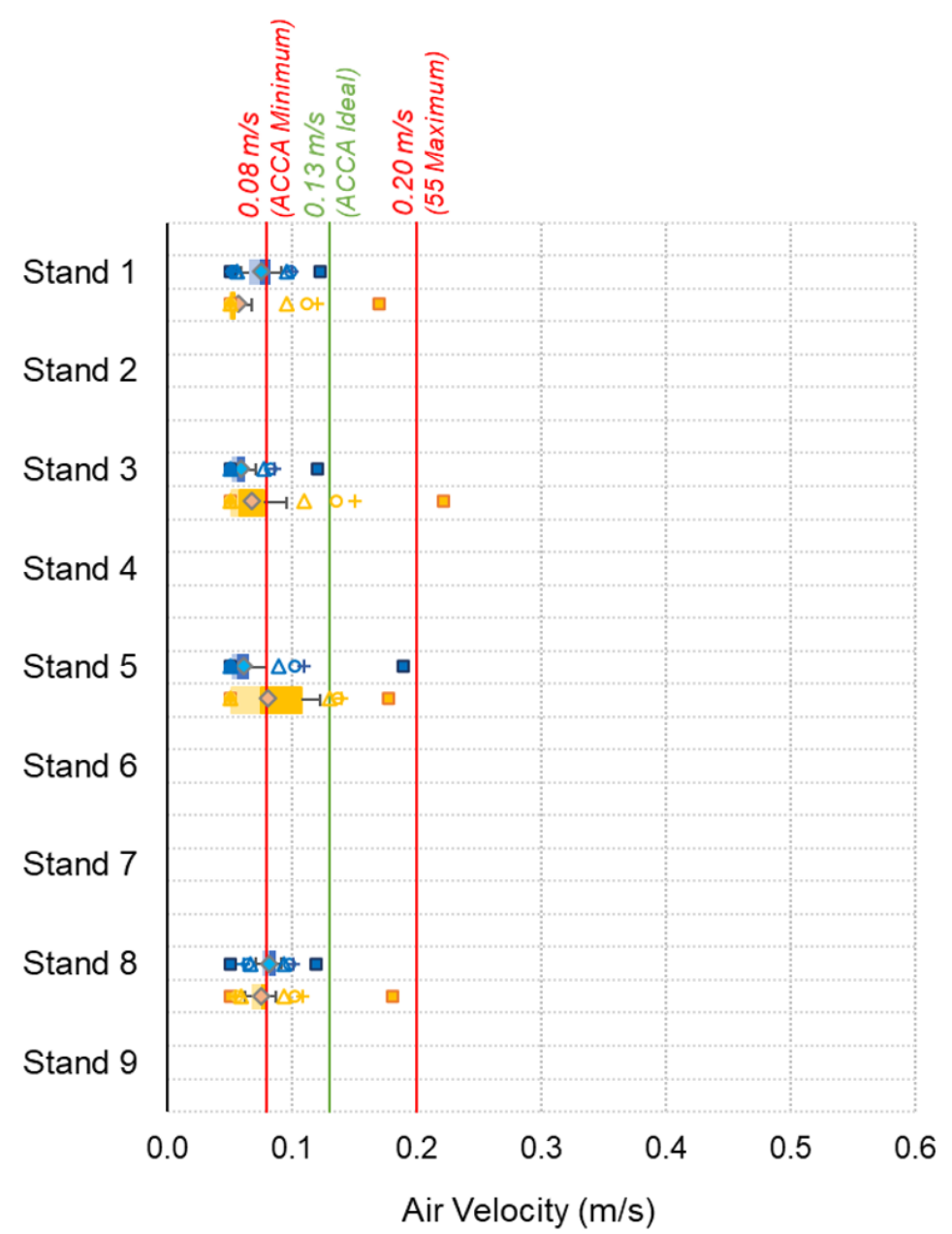

Heating Season: HVAC OFF

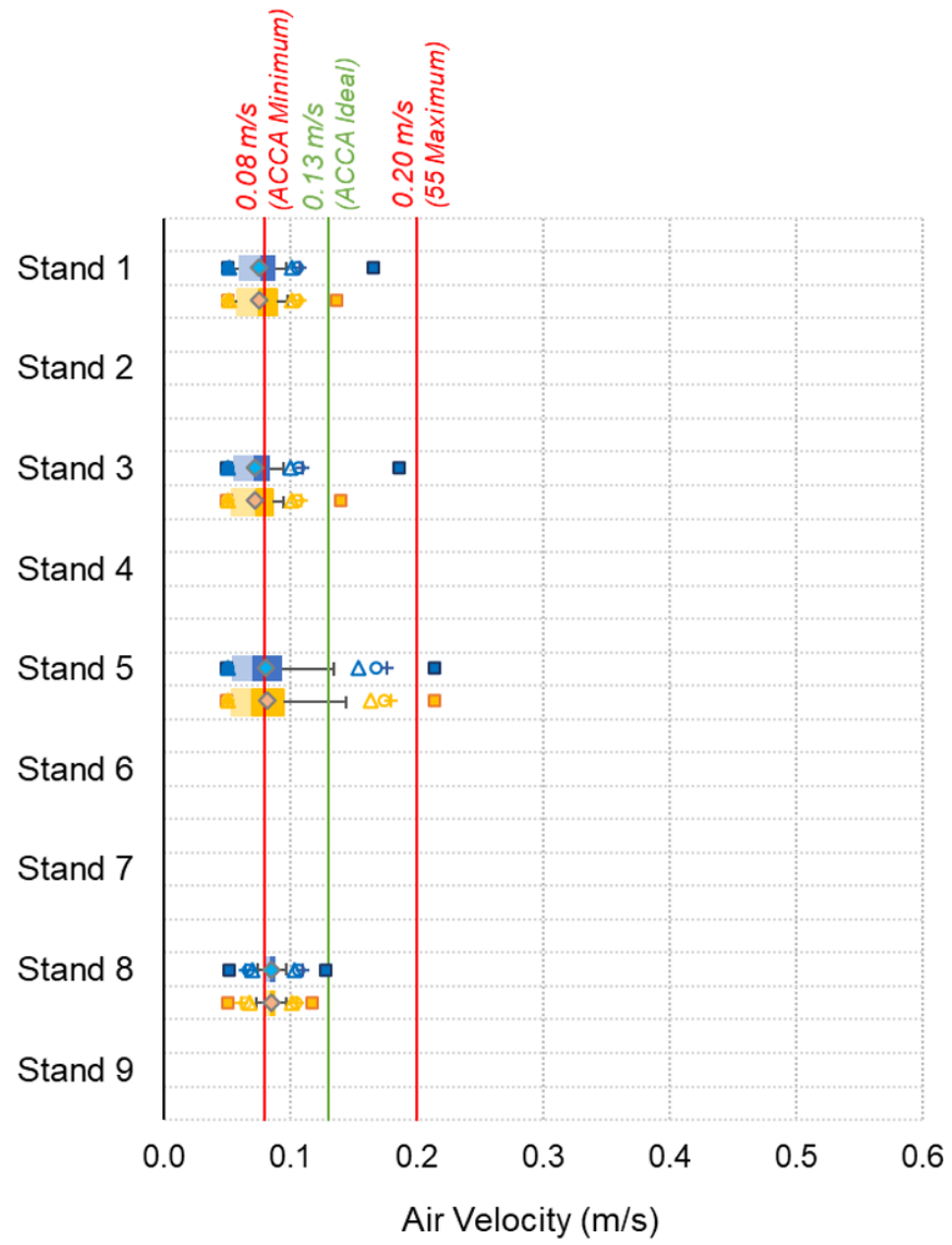

Figure 68: Graphical Summaries of the 5-Min Average Air Velocity When the System Was On Cycle (Left Figure) and Off Cycle (Right Figure) for the Heating Season. 


\section{Transitional Season: HVAC ON}

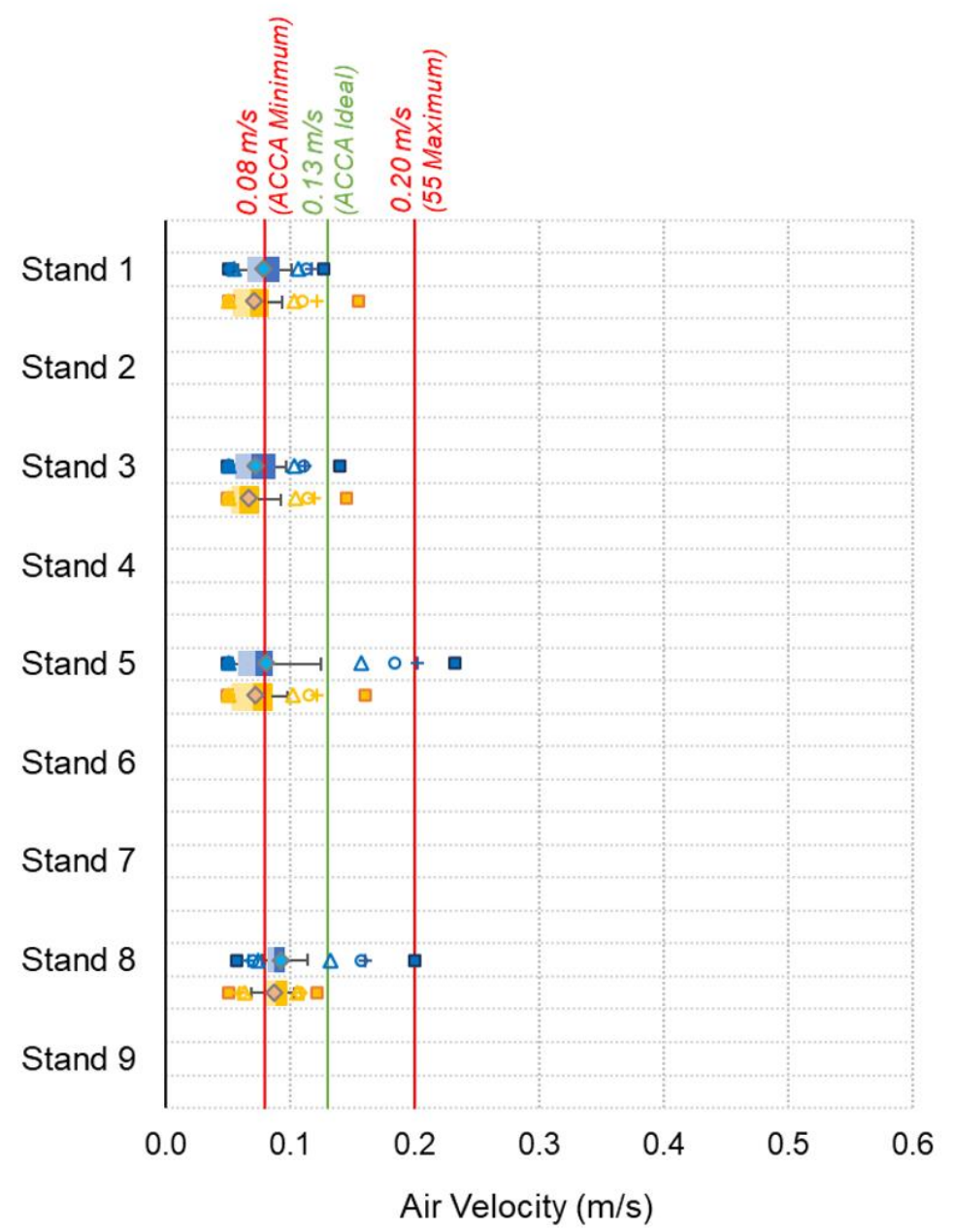

Transitional Season: HVAC OFF

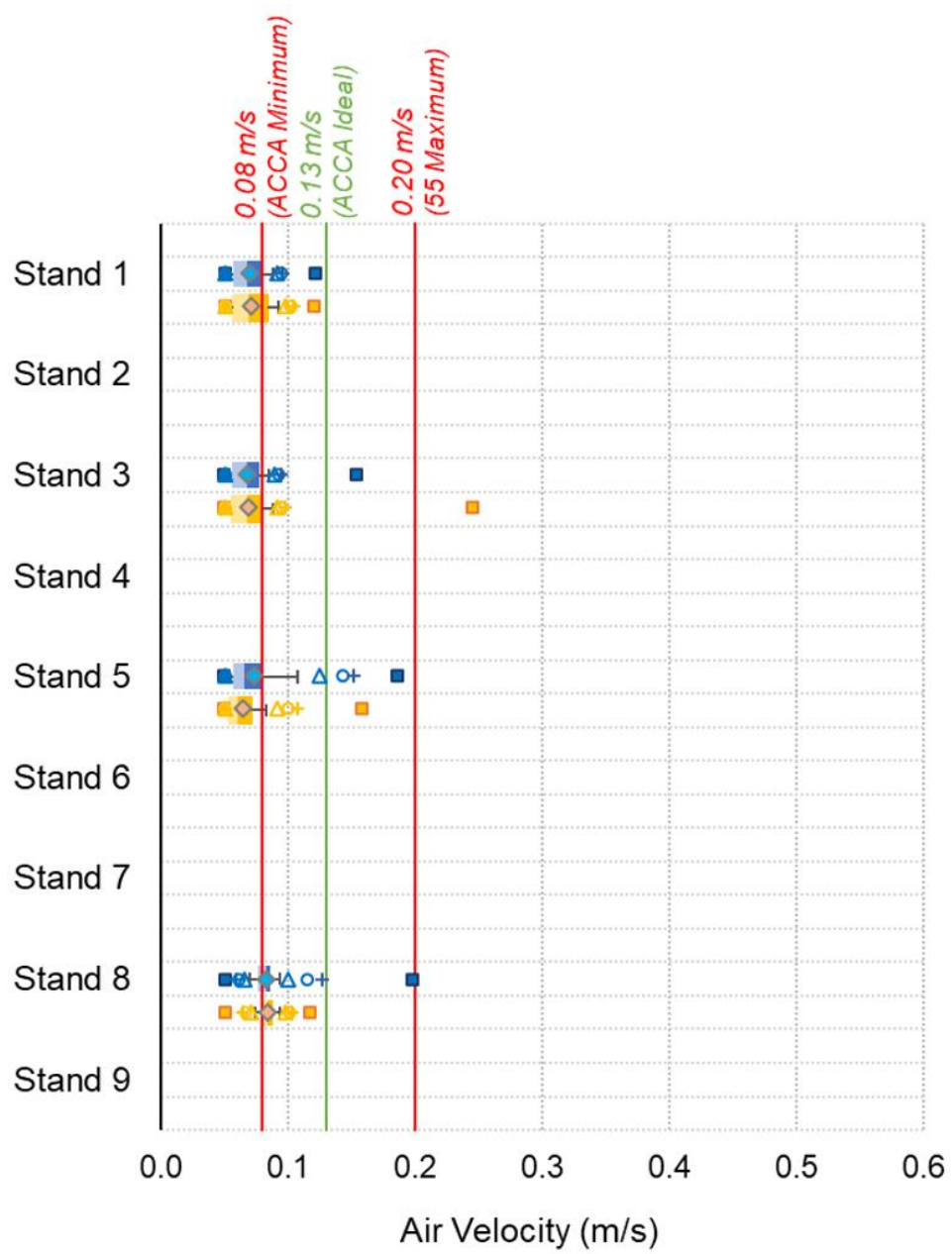

Figure 69: Graphical Summaries of the 5-Min Average Air Velocity When the System Was On Cycle (Left Figure) and Off Cycle (Right Figure) for the Transitional Season. 


\section{DISCUSSIONS}

This section presents discussions on several topics that appeared challenging or important to characterize residential air distribution system performance for thermal comfort.

Section 6.1 presents discussions on data time resolution for analysis depending on the purpose of the evaluation.

Section 6.2 presents discussions on suitable thermal comfort metrics to evaluate the residential system's fundamental ability to produce and deliver a certain temperature to multiple occupied spaces as installed in the house.

Section 6.3 presents discussions on a graphical index to characterize and benchmark continuously-measured long-term thermal comfort data.

Section 6.4 presents discussions on data decomposition to accurately quantify and report the extent of thermal comfort performance of the tested residential HVAC systems under different outdoor climate conditions.

Section 6.5 presents some efforts to develop advanced visualizations of the thermal comfort data using animation techniques.

Section 6.6 presents the results of benchmarking efforts between the four field studies selected for benchmarking and the data collected from NZERTF.

\subsection{DATA TIME RESOLUTION FOR ANALYSIS}

Different time resolutions were used for different types of data analysis to ensure the selected time resolution can provide sufficient granularity of data depending on the purpose of the evaluation. To evaluate temporal uniformity, the cyclic and drift temperature variations with time were calculated using the 1-min temperature data, which was the shortest time interval to catch cyclic changes in the room temperatures. To evaluate spatial uniformity based on the room-to-thermostat and the room-to-room temperature differences, this study selected the 5min average data based on its good degree of granularity, while the reduced data volume is easier to manage.

For example, Figure 70 compares the BR3 air temperature data at sub-hourly time resolutions (i.e., 1-min and 5-min averages) versus hourly averages for January 2017. The 5-min average temperatures were capable of catching drift temperature variations of the 1-min temperatures within $0.1^{\circ} \mathrm{C}$, which allowed to inspect dynamics in the continuously-measured temperature data. However, the hourly average temperature data were found to be too coarse to accurately detect the momentary fluctuations observed with the 1-min or 5-min average data, as highlighted using blue circles in the zoomed-in figure.

As a result, the 5-min average data were mainly used in the analysis, including a statistical characterization and an advanced characterization of the continuously-measured long-term data related to the outdoor climate. However, the hourly average data were used in a graphical analysis using the time-of-day colored map and the psychrometric chart since they visibly provide a good degree of granularity while providing easier data management. 


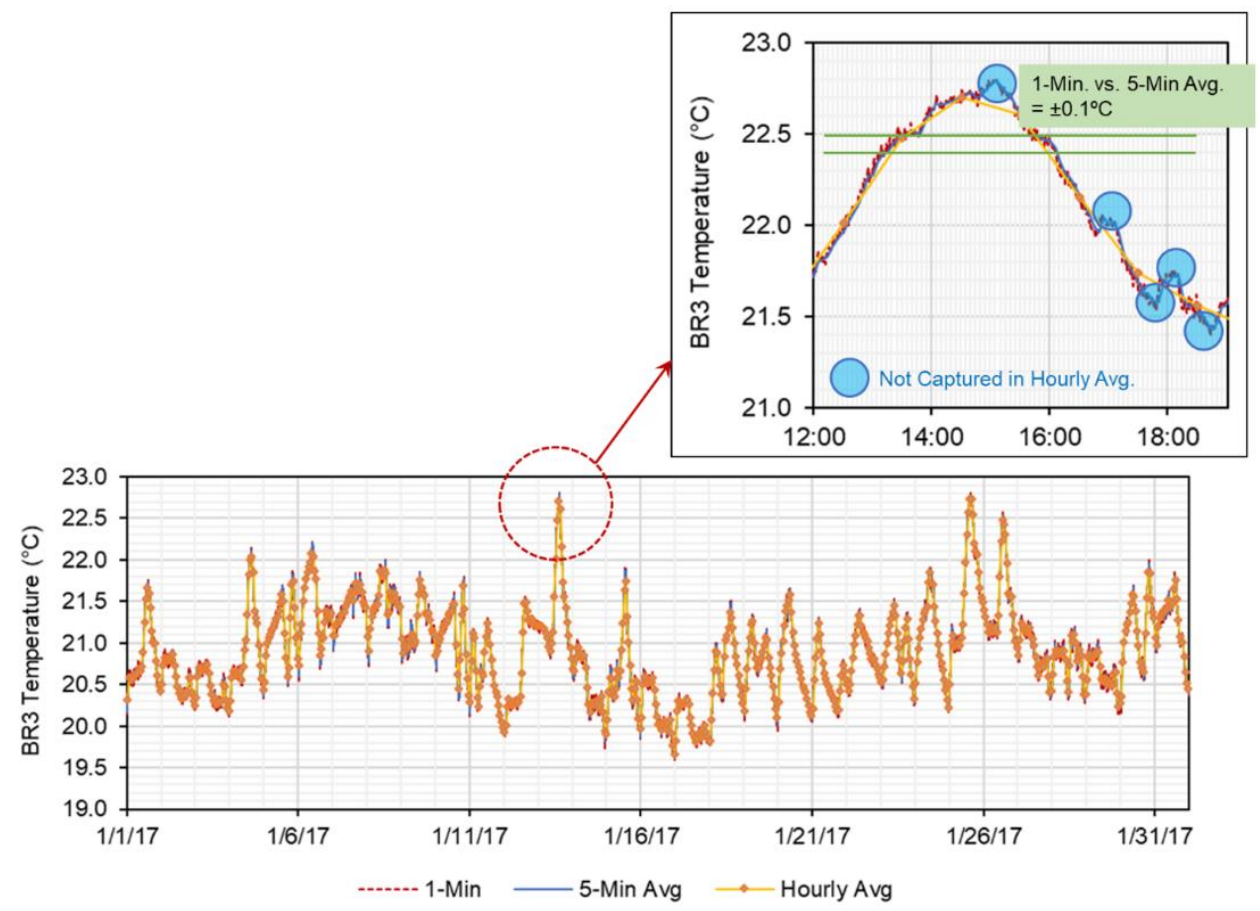

Figure 70: Comparison of the BR3 Temperatures with Different Time Resolutions, Including 1Min, 5-Min Average, and Hourly Average (January 1 to 31, 2017). 


\subsection{THERMAL COMFORT METRICS}

This study used room air temperature as the primary index for a thermal uniformity analysis in terms of providing uniform space temperatures across the house since this study primarily focuses on the residential system's fundamental ability to produce and deliver a certain temperature to multiple occupied spaces as installed in the house. This approach is also deemed reasonable based on the fact that most residential HVAC systems are single-zone systems that are configured to control the thermal conditions of the house solely based on air temperature at the thermostat. The use of PMV/PPD based on the analytical method as defined in Section 5.3.2 of the ASHRAE Standard 55-2017 with assumed personal variables may not provide useful insights unless the HVAC system installed in the house was configured to control the thermal conditions of the house/rooms to maintain neutral comfort conditions (i.e., \pm 0.5 PMV criteria).

As a supplemental metric, the measured thermal environmental factors were also plotted onto a psychrometric chart with a superimposed PMV-based comfort zone as defined in Section 5.3.1 of the ASHRAE Standard 55-2017. The use of the psychrometric chart provides a graphically rich description of the continuously-measured thermal comfort performance data that integrates the four environmental variables (i.e., air temperature, humidity, mean radiant temperature, and air speed ${ }^{53}$, as demonstrated by Kim and Haberl (2014). A direct comparison of the measurements against the ASHRAE 55 comfort zones does not deem reasonable in this study unless the comfort zone is adjusted to achieve a neutral PMV (i.e., 0 PMV) at the chosen heating and cooling setpoint temperatures. However, with the adjusted comfort zone ${ }^{54}$, a comparison of the measurements against the ASHRAE 55 comfort zones might provide useful insights in terms of evaluating discomfort due to strong external or internal radiation sources if they existed.

\subsubsection{GLOBE TEMPERATURE}

The globe temperatures were measured in the five rooms (i.e., LR, KIT, MBR, BR2, and BR3), which was used to calculate operative temperatures along with the shielded air temperatures. The globe temperature itself is also regarded as an approximation of the operative temperature in most indoor situations, which is derived from air temperature, mean radiant temperature, and air speed (ASHRAE 2017). Although this study primarily used air temperatures to evaluate the impacts of different residential systems on whole-house thermal comfort, the analysis of globe temperatures can provide insights on whether there are significant radiation sources in the measurement spaces.

Therefore, this study calculated the globe-to-air temperature difference (i.e., $\triangle \mathrm{T}\left({ }^{\circ} \mathrm{C}\right)=\mathrm{Tg}$ $\mathrm{Ta}$ ) using the 5-min average temperature data collected from the five primary rooms (i.e., $L R$, KIT, MBR, BR2, and BR3). Figures 71 to 73 graphically present the results using the graphical index proposed to display long-term thermal comfort data based on a statistical analysis (Figure 13): cooling season in Figure 71, heating season in Figure 72, and transitional season

\footnotetext{
${ }^{53}$ For the five rooms (i.e., LR, KIT, MBR, BR2, and BR3) where globe temperature (Tg) was measured along with air temperature $(\mathrm{Ta})$, the operative temperature was calculated and used in this analysis per ASHRAE Standard 552017. However, for other rooms where globe temperature was not measured, the air temperature was directly used instead of operative temperature.

54 For example, the use of higher clothing levels (i.e., 1.33 clo for the heating and 0.75 clo for the cooling) will yield 0 PMV at the chosen heating and cooling setpoint temperatures in this study.
} 
in Figure 73. Data were color-coded by system types (i.e., blue for CDHP and orange for SDHV).

In general, the globe-to-air temperature differences were within $\pm 0.5^{\circ} \mathrm{C}$, which was more than $97 \%$ of the period based on $\pm 1.5 \%$ extreme variations except for the kitchen. This indicates there were no significant radiation sources in these rooms especially at the location of the whole-house measurement stands in the center of the room. However, the kitchen, which is the room with the largest heat gains from various kitchen appliances, had higher globe-to-air temperature differences with larger temporal variations, which were affected by the schedule of the simulated kitchen appliances as well as the proximity of the measurement stand to the kitchen appliances (e.g., toaster oven). After the kitchen measurement stand was moved from the edge of the kitchen island to the center of the island on July 14, 2019, lower globe-to-air temperature differences were observed in the kitchen, as shown in Figure 74. 

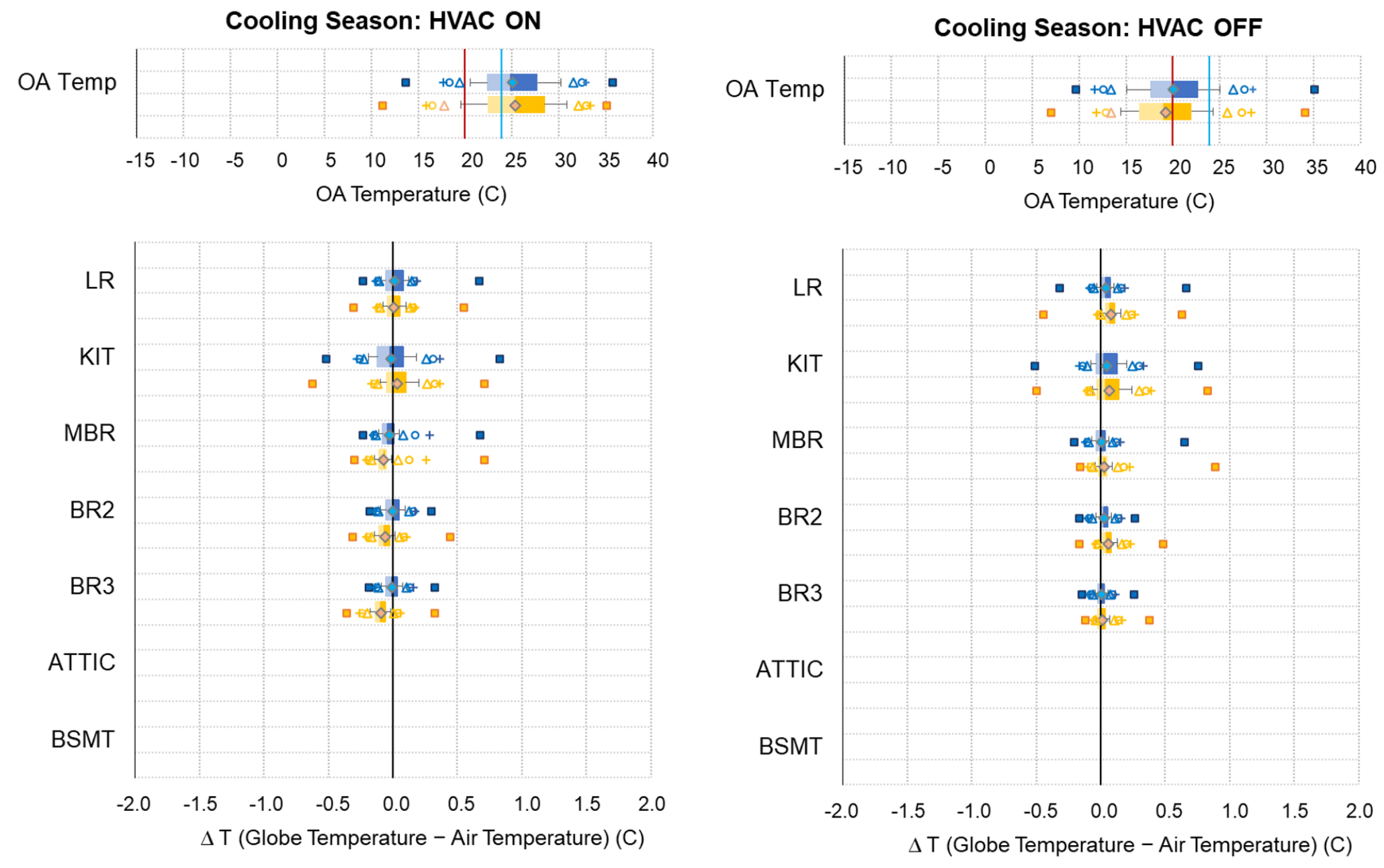

Figure 71: Graphical Summaries of the 5-Min Average Globe-To-Air Temperature Differences When the System Was On Cycle (Left Figure) and Off Cycle (Right Figure) for the Cooling Season. 

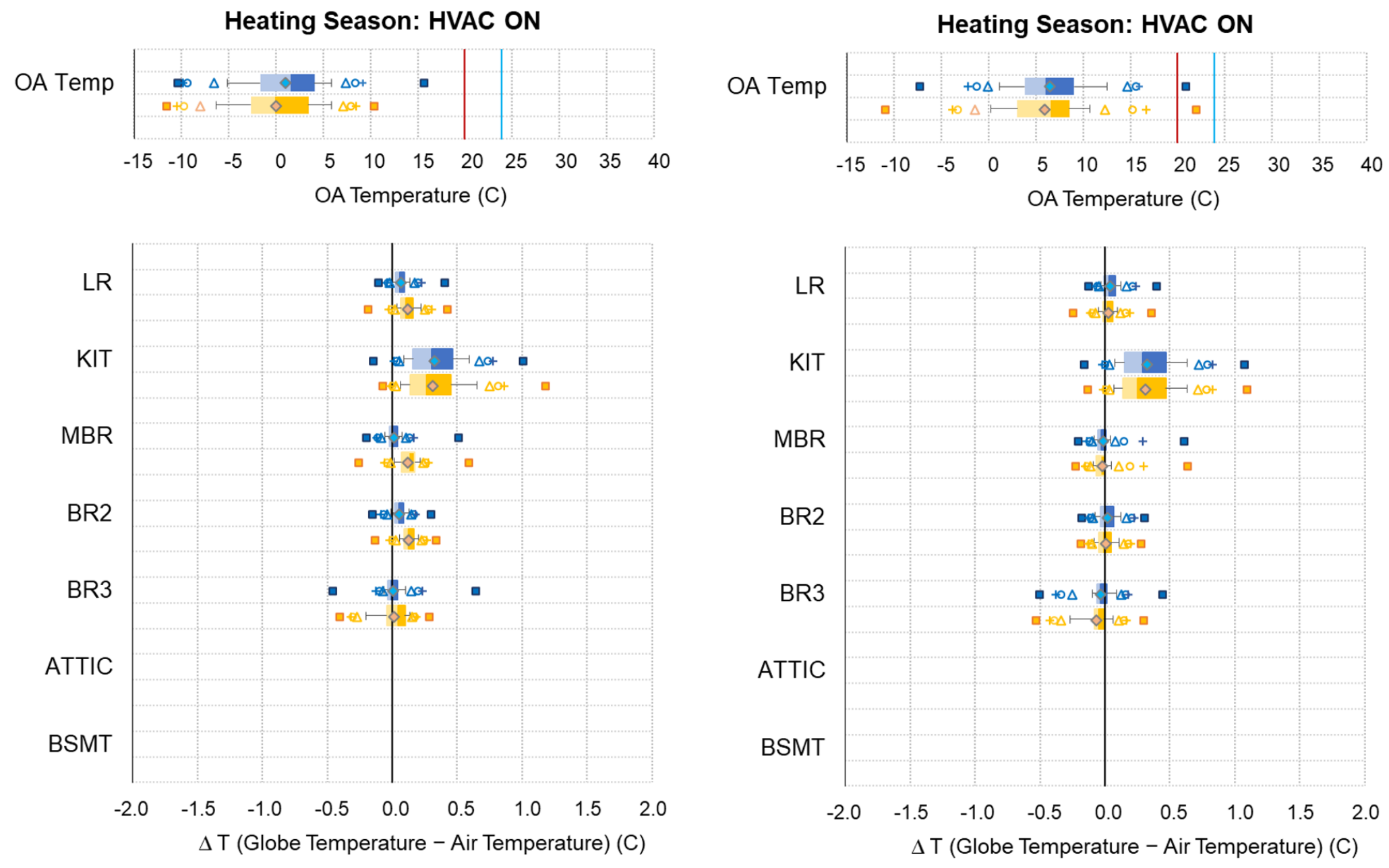

Figure 72: Graphical Summaries of the 5-Min Average Globe-To-Air Temperature Differences When the System Was On Cycle (Left Figure) and Off Cycle (Right Figure) for the Heating Season. 

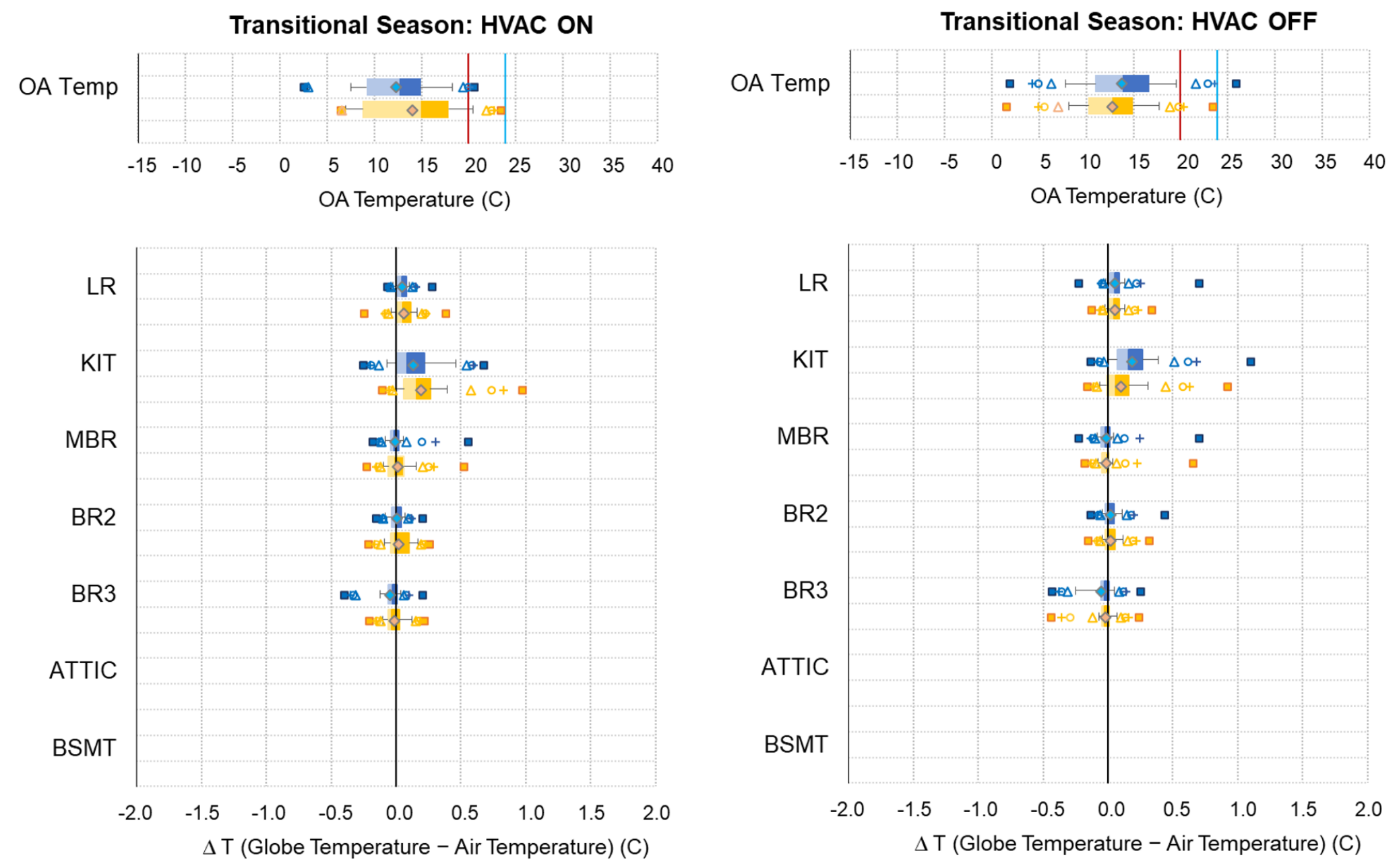

Figure 73: Graphical Summaries of the 5-Min Average Globe-To-Air Temperature Differences When the System Was On Cycle (Left Figure) and Off Cycle (Right Figure) for the Transitional Season. 
Cooling Season: HVAC ON

(Before July 14)

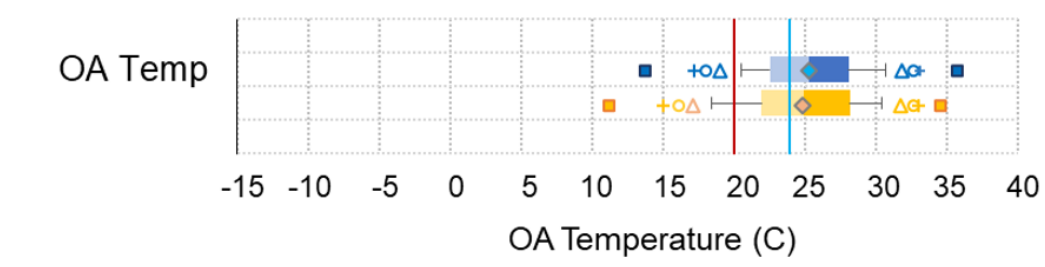

Cooling Season: HVAC ON

(After July 14)

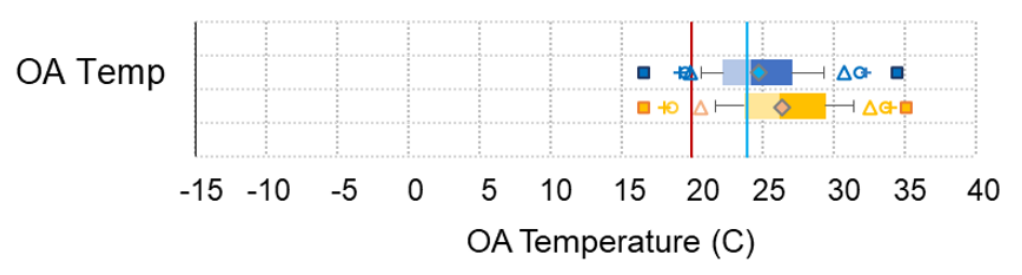

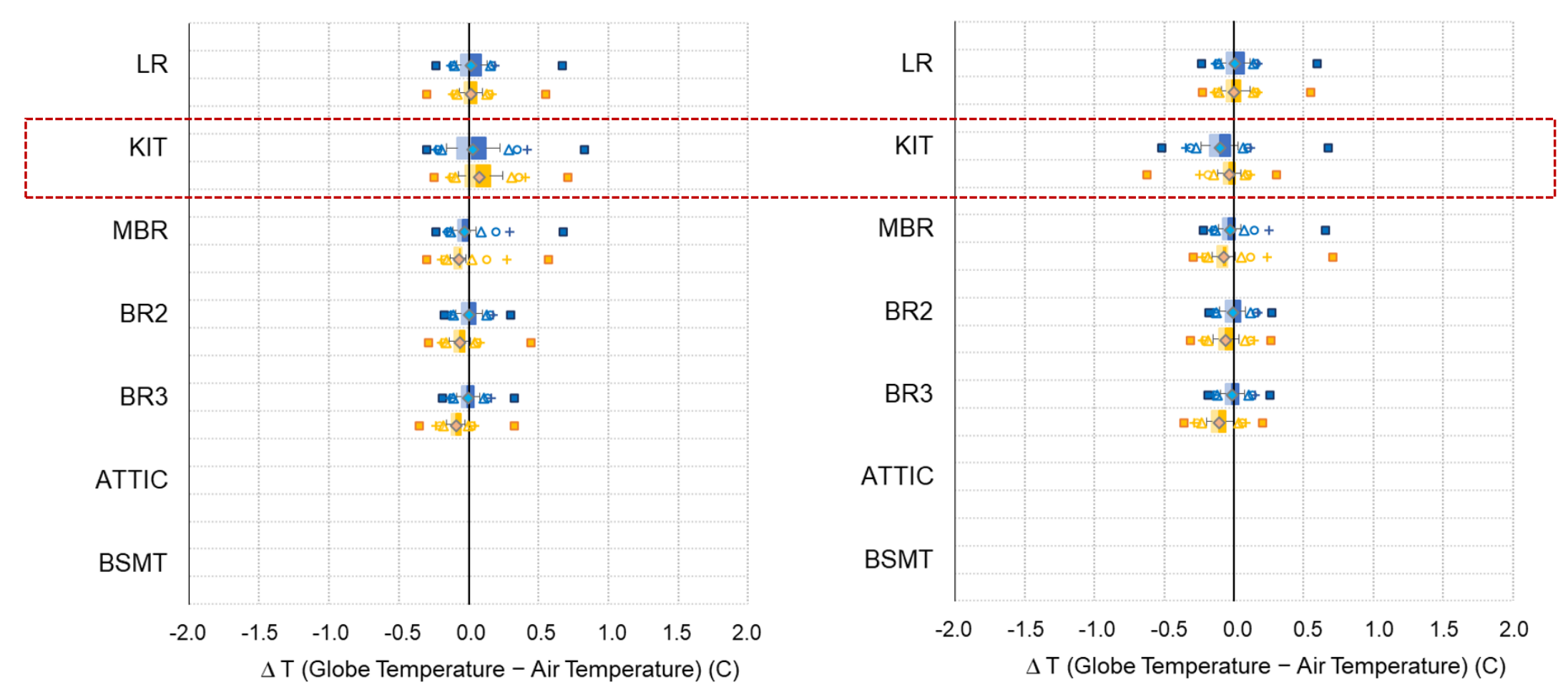

Figure 74: Graphical Summaries of the 5-Min Average Globe-To-Air Temperature Differences When the System Was On Cycle for the Cooling Season Before July 14 (Left Figure) and After July 14 (Right Figure). 


\subsection{GRAPHICAL INDEX FOR LONG-TERM THERMAL COMFORT DATA}

Since the current thermal comfort standards do not provide guidelines about how to graphically characterize and benchmark the results of continuously-measured long-term performance data, this study used a statistical analysis to describe the time-varying distribution of data, which allows an easy comparison between different distributions. Multiple percentile ranks were selected to characterize extreme variations based on $\pm 1.5 \%$, $\pm 2.5 \%, \pm 5 \%$, and $\pm 10 \%$ deviation.

For example, the $1.5^{\text {th }}$ and $98.5^{\text {th }}$ percentiles were chosen to characterize data based on $\pm 1.5 \%$ deviation, which corresponds to $3 \%$ of the period in total. In the same way, the $2.5^{\text {th }}$ and $97.5^{\text {th }}$ percentiles were chosen based on $\pm 2.5 \%$ deviation (i.e., $5 \%$ of the period in total), the $5^{\text {th }}$ and $95^{\text {th }}$ percentiles were chosen based on $\pm 5 \%$ deviation (i.e., $10 \%$ of the period in total), and the $10^{\text {th }}$ and $90^{\text {th }}$ percentiles were chosen based on $\pm 10 \%$ deviation (i.e., $20 \%$ of the period in total). The $3 \%$ and $5 \%$ deviations are the recommended criteria for acceptable deviations to evaluate long term performance of buildings provided in the Annex $G$ of the European standard, DIN EN 15251 (CEN 2007). As a result, the traditional box-and-whisker plot was modified to display the $10^{\text {th }}$ percentile for the lower whisker and the $90^{\text {th }}$ percentile for the upper whisker in addition to $1.5^{\text {th }}, 2.5^{\text {th }}, 5^{\text {th }}, 25^{\text {th }}, 50^{\text {th }}, 75^{\text {th }}, 95^{\text {th }}, 97.5^{\text {th }}$, and $98.5^{\text {th }}$ percentiles as well as minimum, mean, and maximum values, as shown in Figure 75.

To demonstrate the usefulness of the proposed graphical index for long-term thermal comfort data, Figure 76 compared its application against the use of traditional box-andwhisker plot to display the living room temperatures that were binned into $5^{\circ} \mathrm{C}\left(9^{\circ} \mathrm{F}\right)$ bins of outdoor temperatures, when the CDHP was on cycle (upper figures) versus off cycle (lower figures). As a result, the use of the proposed graphical index was found to be more informative by displaying additional percentiles based on $\pm 1.5 \%, \pm 2.5 \%, \pm 5 \%$, and $\pm 10 \%$ deviation.

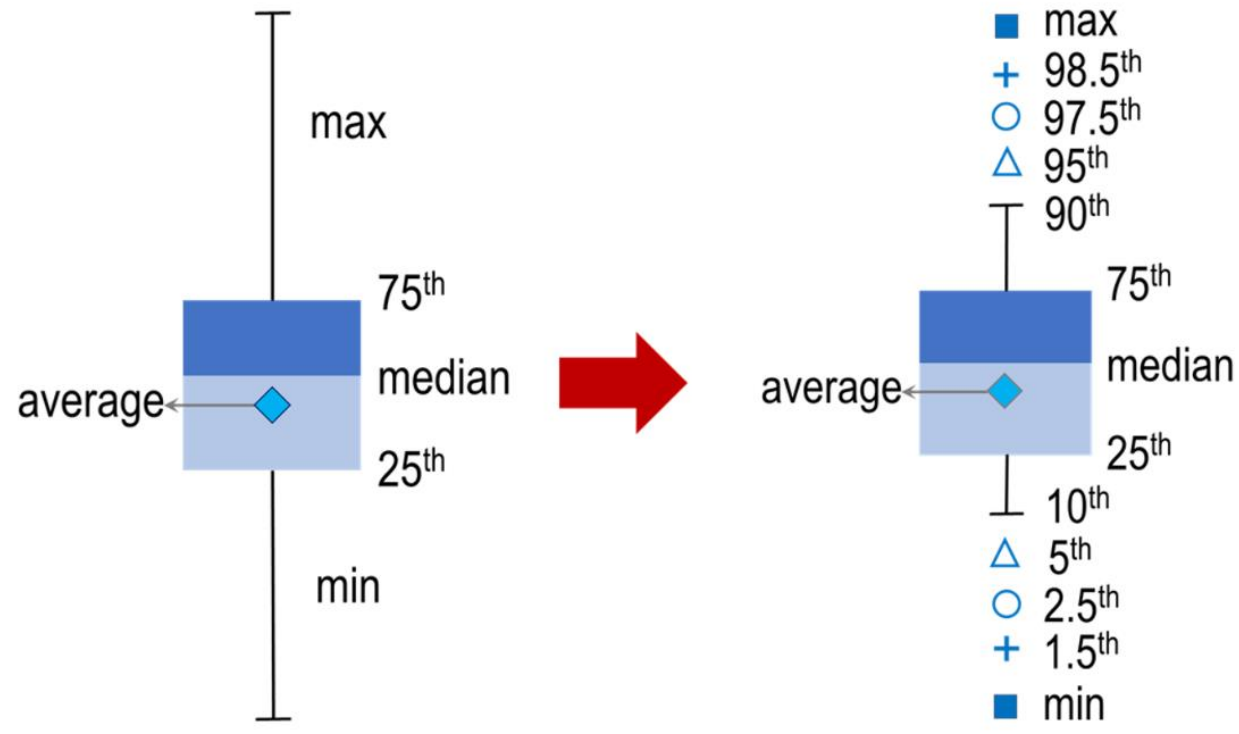

Figure 75: Traditional Box-and-Whisker Plot (Left Figure) versus the Proposed Graphical Index (Right Figure) to Display Continuously-Measured Thermal Performance Data. 

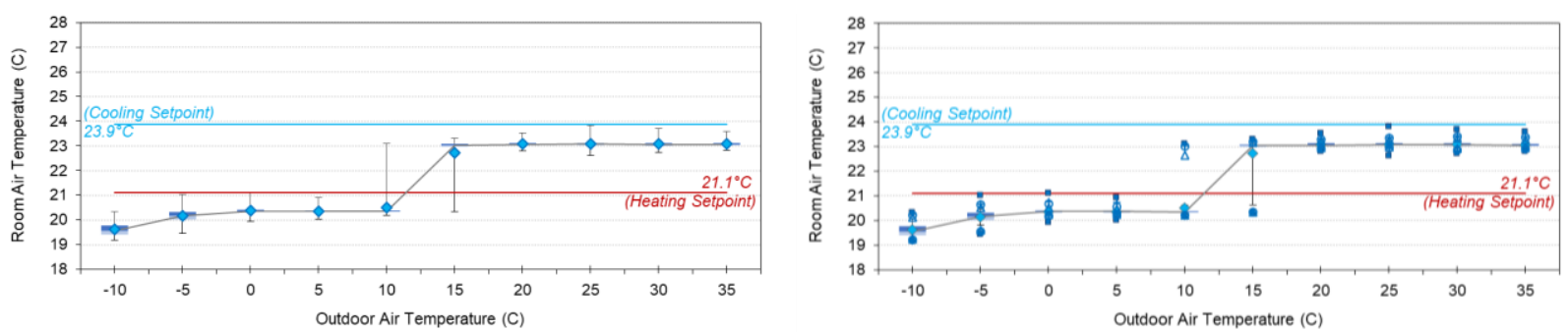

(a) LR CDHP On
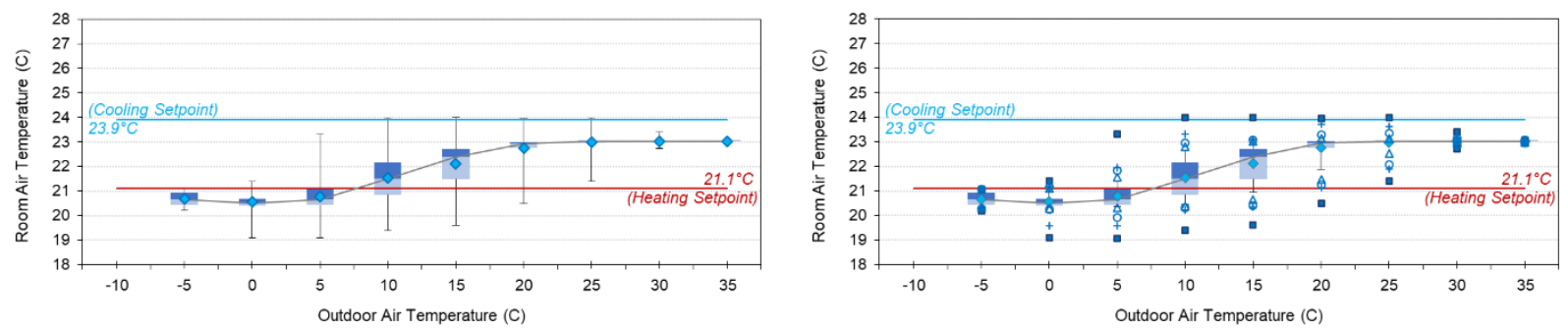

(b) LR CDHP Off

Figure 76: Comparison of an Application of the Traditional Box-and-Whisker Plot (Left Figures) versus the Proposed Graphical Index (Right Figures) to Display the Binned LR Temperatures against Outdoor Temperatures. 


\subsection{LONG-TERM THERMAL COMFORT DATA DECOMPOSITION}

Since the current thermal comfort standards do not provide guidelines about how to analyze the continuously-measured long-term thermal comfort data to accurately quantify and report the extent of thermal comfort performance of the tested residential HVAC systems under different outdoor climate conditions, this study divided the one-year thermal comfort data into the subgroups as follows:

- By system type and on/off cycle:

- CDHP on cycle

- CDHP off cycle

- SDHV on cycle

- SDHV off cycle

- By seasonal operation mode and actual response under given weather conditions:

- Cooling season

- Heating season

- Transitional season

As a result, this study found decomposing data by the system being on or off could provide useful insights on how the tested systems responded to different thermal needs, although the HVAC systems should provide thermal comfort regardless of the system's on and off cycles. For example, when the combined data, including both on and off cycles, were characterized using the binned box-and-whisker plots of living room temperatures that were binned into $5^{\circ} \mathrm{C}\left(9^{\circ} \mathrm{F}\right)$ bins of outdoor temperatures, as shown in Figure 77 for the CDHP, the observed IQR for outdoor temperature bins at $10^{\circ} \mathrm{C}$ and $15^{\circ} \mathrm{C}$ was less explainable. However, when the data were separated by the CDHP's on and off cycle, as shown in Figure 78, the observed large IQR occurred when the system was off cycle due to favorable weather conditions (i.e., cool OA temperature during the cooling mode; warm OA temperature during the heating mode).

This study further classified the data subdivided by system type and on/off cycle into the three seasons (i.e., cooling season, heating season, and transitional season) based on coincident daily average OA temperature to reflect the system's actual response under given weather conditions as well as the system's seasonal operation mode (i.e., heating mode or cooling mode $)^{55}$, as shown in Figure 79. In this classification, if the tested HPs were operated in the heating mode between November 16, 2016 and April 4, 2017, the days when the daily average $\mathrm{OA}$ temperature was below $11.2^{\circ} \mathrm{C}\left(52.2^{\circ} \mathrm{F}\right)$ were considered the heating season, while the days when the daily average $\mathrm{OA}$ temperature was above $11.2^{\circ} \mathrm{C}\left(52.2^{\circ} \mathrm{F}\right)$ were considered the transitional season. $11.2^{\circ} \mathrm{C}\left(52.2^{\circ} \mathrm{F}\right)$ was the daily average $\mathrm{OA}$ temperature below which the tested HPs were actively running to provide heating based on the HP electricity use regression model (i.e., five-parameter (5-P) change-point linear model), as shown in Figure 80.

If the tested HPs were operated in the cooling mode between September 1, 2016 and November 15, 2016 and between April 5, 2017 to August 31, 2017, the days when the daily average $\mathrm{OA}$ temperature was above $15.5^{\circ} \mathrm{C}\left(60.0^{\circ} \mathrm{F}\right)$ were considered the cooling season, while the days when the daily average $\mathrm{OA}$ temperature was below $15.5^{\circ} \mathrm{C}\left(60.0^{\circ} \mathrm{F}\right)$ were

\footnotetext{
55 The two heat pumps were operated in the heating mode between November 16, 2016 and April 4, 2017, while
} they were in the cooling mode for any other analysis period. 
considered the transitional season. $15.5^{\circ} \mathrm{C}\left(60.0^{\circ} \mathrm{F}\right)$ was the daily average $\mathrm{OA}$ temperature above which the tested heat pumps were actively running to provide cooling based on the same HP electricity use regression model.

The use of the proposed classification allowed to separately analyze the period when the HP systems did not necessarily provide cooling or heating while maintaining room temperatures below cooling setpoint temperature during the cooling mode; or above heating setpoint temperature during the heating mode due to favorable weather conditions, which was defined as the transitional season in this study. During the transitional season, the systems were mostly off, which confirms the proposed data decomposition to separate transitional days from active cooling/heating days using coincident daily OA temperature was performed as intended.

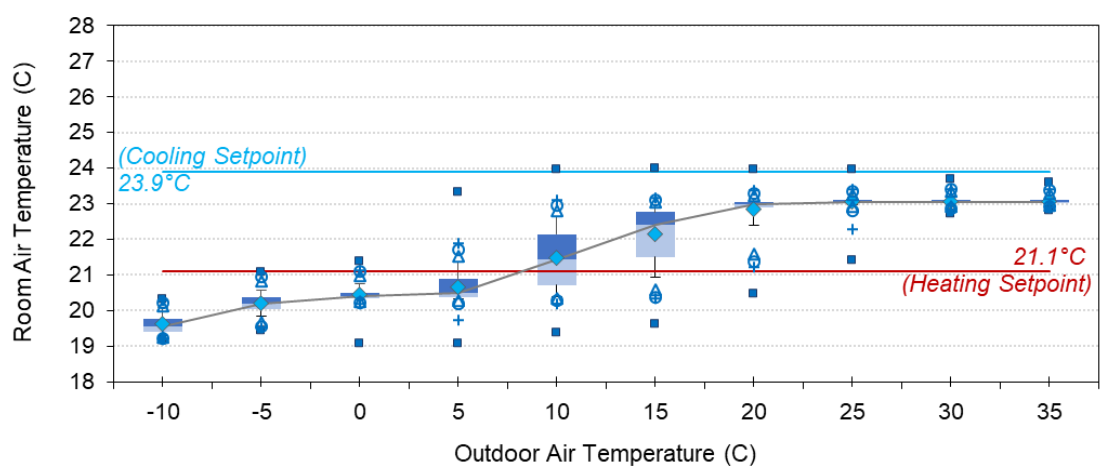

Figure 77: Binned LR Temperatures against Outdoor Temperatures for the CDHP Combined Data, Including Both On and Off Cycles.
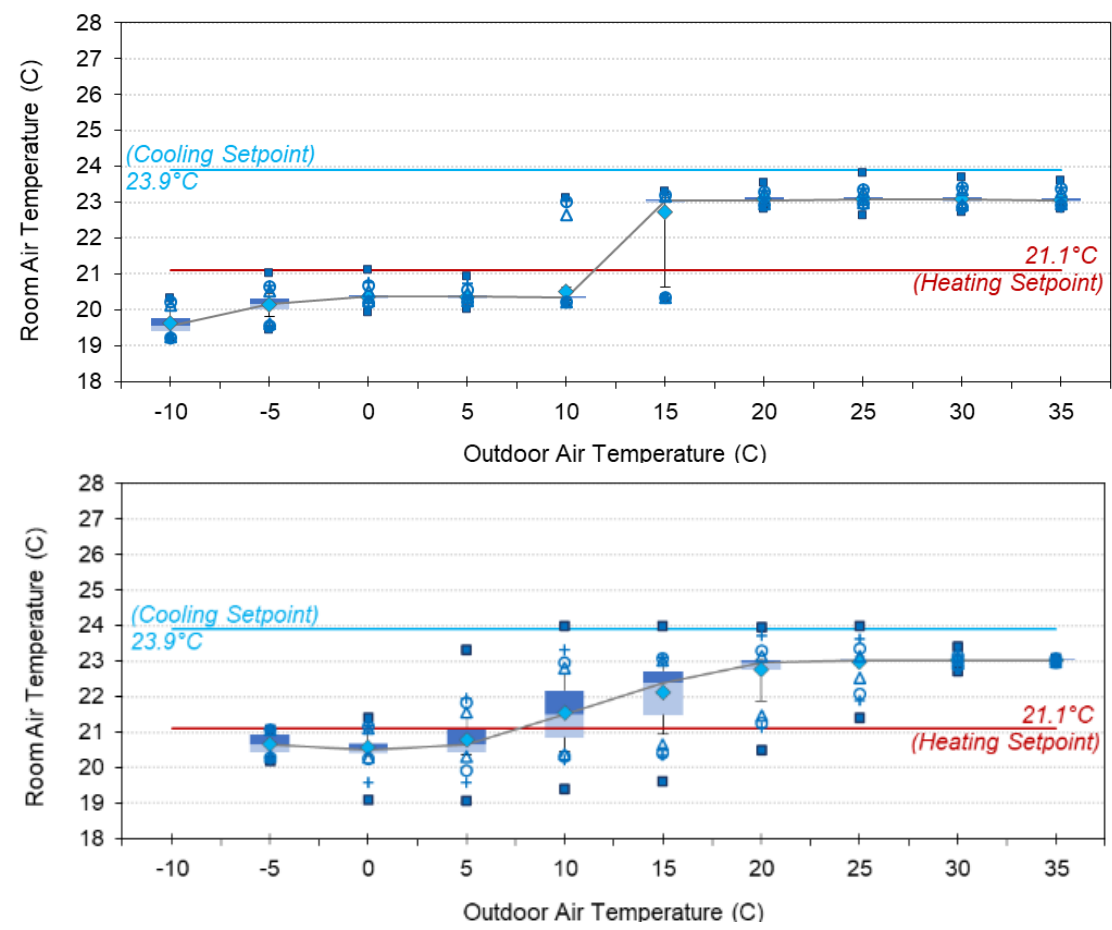

(a) LR CDHP On

(b) LR CDHP Off

Figure 78: Binned LR Temperatures against Outdoor Temperatures, Separately for (a) CDHP On Cycle and (b) CDHP Off Cycle. 


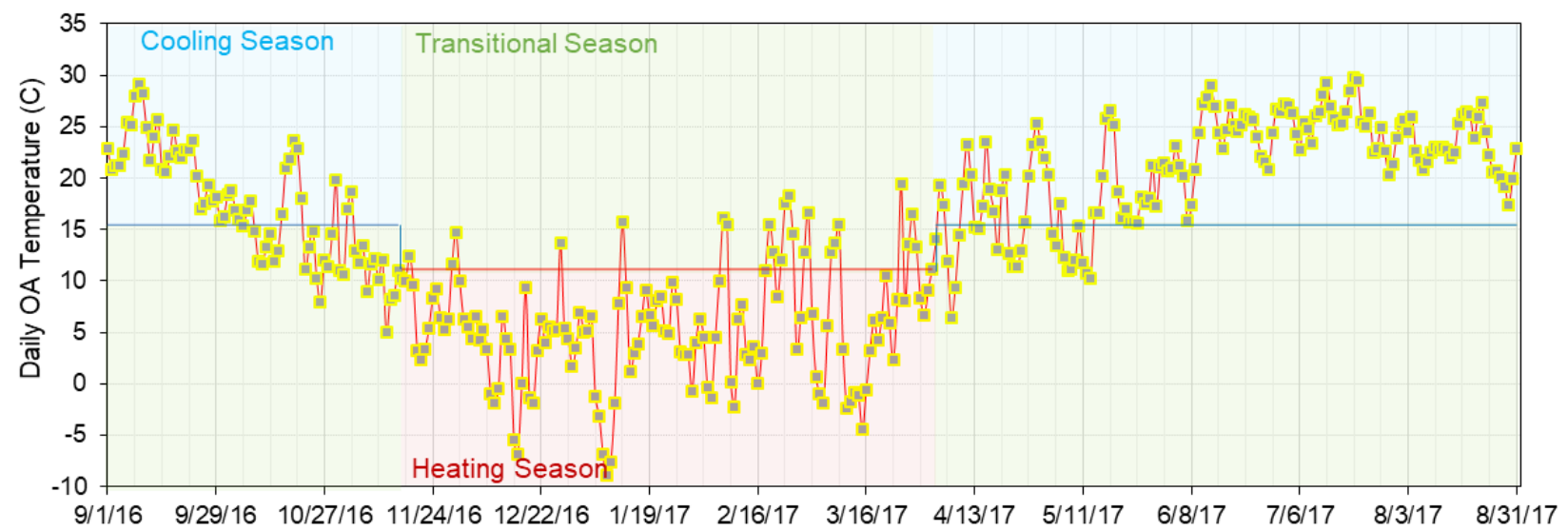

Figure 79: Classification of the Heating, Transitional, and Cooling Seasons Based on Daily Average Outdoor Air Temperature.

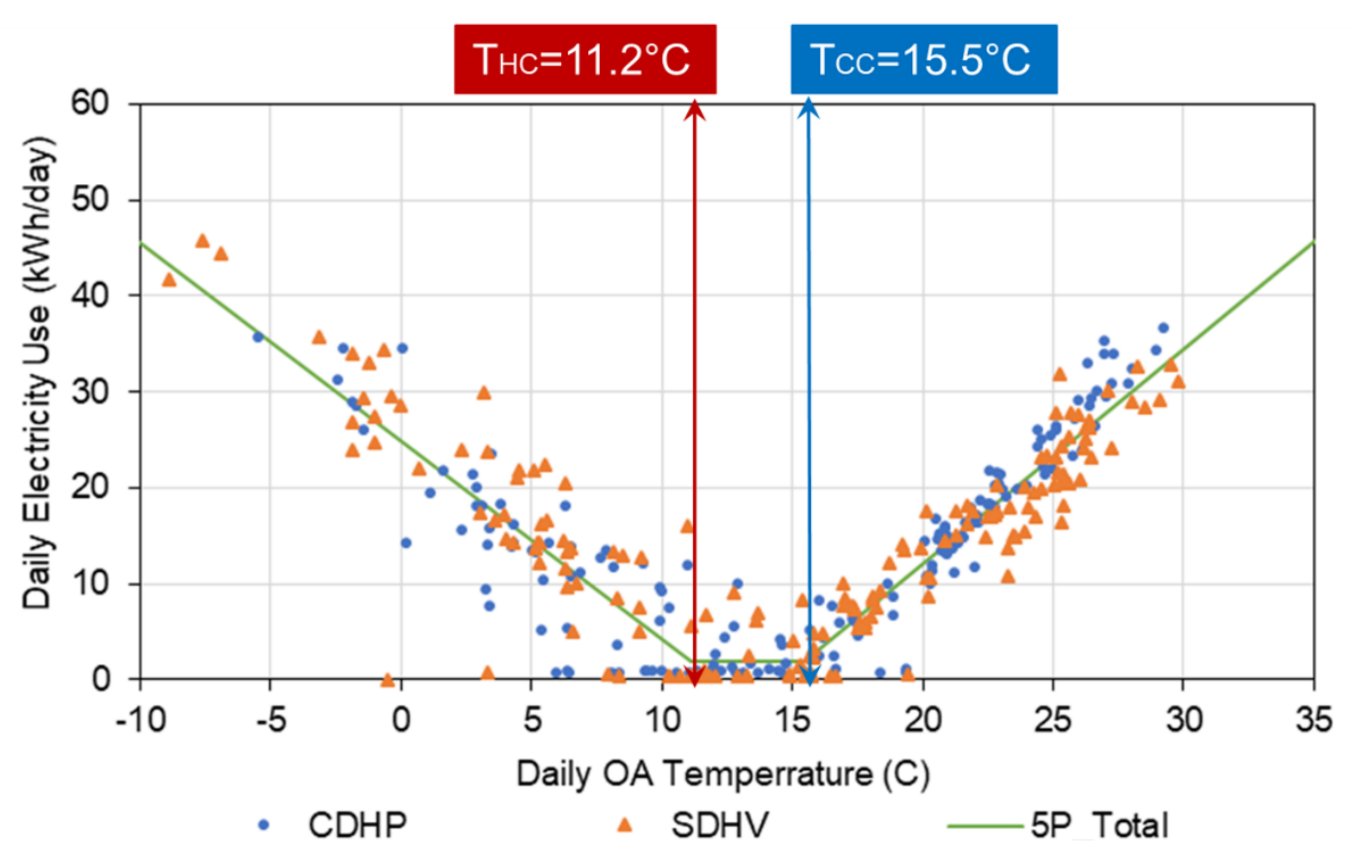

Figure 80: Daily HP Electricity Use Against the Daily Outdoor Air Temperature with a FiveParameter (5-P) Change-Point Linear Model, Including the Heating Change-Point Temperature $\left(T_{H C}\right)$ and the Cooling Change-Point Temperature ( $\left.T_{C C}\right)$. 


\subsection{TREND ANIMATION FOR GRANULAR ANALYSIS}

To quickly characterize granular thermal comfort data, this study displayed the hourly average thermal comfort data on the psychrometric chart with a super-imposed ASHRAE Standard 55-2017 comfort zone, as discussed in Section 4.8. Although the use of a psychrometric chart allows one to quickly view how the rooms were conditioned when different systems were in operation, it did not allow the viewer to track trends in the data over time. Therefore, this study developed advanced visualizations of the thermal comfort data collected at NZERTF using animation techniques, which helps to understand and quantify the trends and variations in the data for the following four analyses:

- Whole-house thermal comfort analysis;

- BR3 grid analysis;

- Entry hallway analysis; and

- Psychrometric analysis.

Figures 81 to 84 present screen captures of each visualization as examples. Appendix I presents the detailed steps on temperature data visualizing and animation using MATLAB 2017b. Appendix J presents the directories of example trend animation files, which accompany this report.

The animated whole-house thermal comfort analysis visualized the room temperature data by mapping the temperatures collected from 21 locations of the house on the floor plans of a building using a color-coded temperature scale. Information on the type of system (i.e., either CDHP or SDHV) in operation and the system on/off cycle were also animated using a timeseries plot. Two different visualizations were explored with different data time resolution:

- 5-min average data for 1 day animation (total 35 seconds with 8 frames per second $(f p s)) ;$ and

- Hourly average data for 1 month animation (total 90 seconds with $8 \mathrm{fps}$ ).

The animated BR3 thermal comfort analysis visualized the stand temperature data based on a $3 \times 3 \times 3$ grid of measurement system (i.e., three different heights at nine locations of the room) by mapping the temperatures on the three vertical measurement planes (i.e., side view) and the three horizontal measurement planes (i.e., plan view) of the grid using a colorcoded temperature scale. Like whole-house thermal comfort analysis, information on the type of system (i.e., either CDHP or SDHV) in operation and the system on/off cycle were also animated using a time-series plot. One visualization was explored:

- 5-min average data for 1 day animation (total 35 seconds with 8 fps).

The animated entry hallway (EH) temperature analysis visualized the 5-height EH temperature data by mapping the temperatures on the vertical measurement plane using a color-coded temperature scale. Like other animations, information on the type of system (i.e., either CDHP or SDHV) in operation and the system on/off cycle were also animated using a time-series plot. Two different visualizations were explored with different data time resolution:

- 5-min average data for 1 day animation (total 35 seconds with 8 fps); and

- Hourly average data for 1 month animation (total 90 seconds with $8 \mathrm{fps}$ ).

The animated psychrometric analysis visualized the room thermal comfort data by plotting the hourly average operative temperatures and humidity of the room on the psychrometric chart with a super-imposed ASHRAE Standard 55-2017 comfort zone. In this proposed 
visualization, the thermal comfort data of the LR where the thermostat is located are always presented as a reference (upper animations). In addition, the concurrent outdoor weather data are also included in the left animations, while the right animations include only the room thermal comfort data using zoomed-in plots. One visualization was explored:

- Hourly average data for 1 month animation (total 120 seconds with 6 fps).

As a result, the animated analysis by mapping temperatures on the floor plans or measurement planes for the first three analyses (i.e., whole-house thermal comfort analysis; BR3 grid analysis; and entry hallway analysis) was helpful to quickly relate the measurements with the geometry, orientation or space function over a course of day or month. This was also useful to identify any anomalies of the data (e.g., problematic locations of the house) at a single glance. The fourth animation using the psychrometric analysis shows the sequence of data points, which makes the trends in the data discernible.

The proposed visualization is also expected to benefit from interactivity that allows the user to manipulate the displayed variables as well as a period, which could not be demonstrated in this study. It should be noted that the proposed graphic form is one of the ways of visualizing the voluminous data efficiently in a condensed form to maximize the information contained in the data in addition to the statistical and advanced characterization of the results as discussed in Sections 4.4 and 4.5 . 


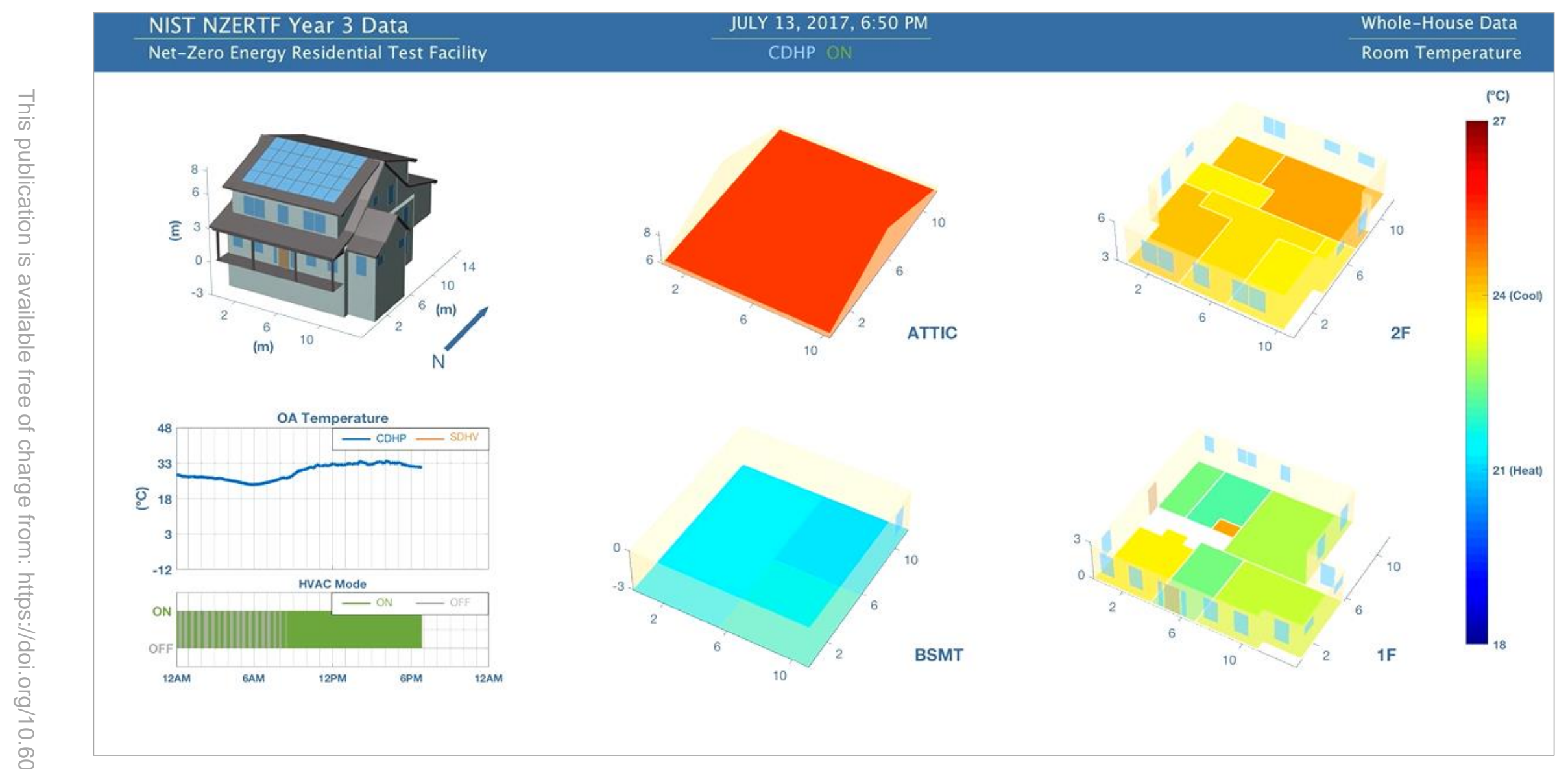

Figure 81: Animated Whole-House 5-Min Average Temperature Data Analysis Mapped on the NZERTF Floor Plans. 


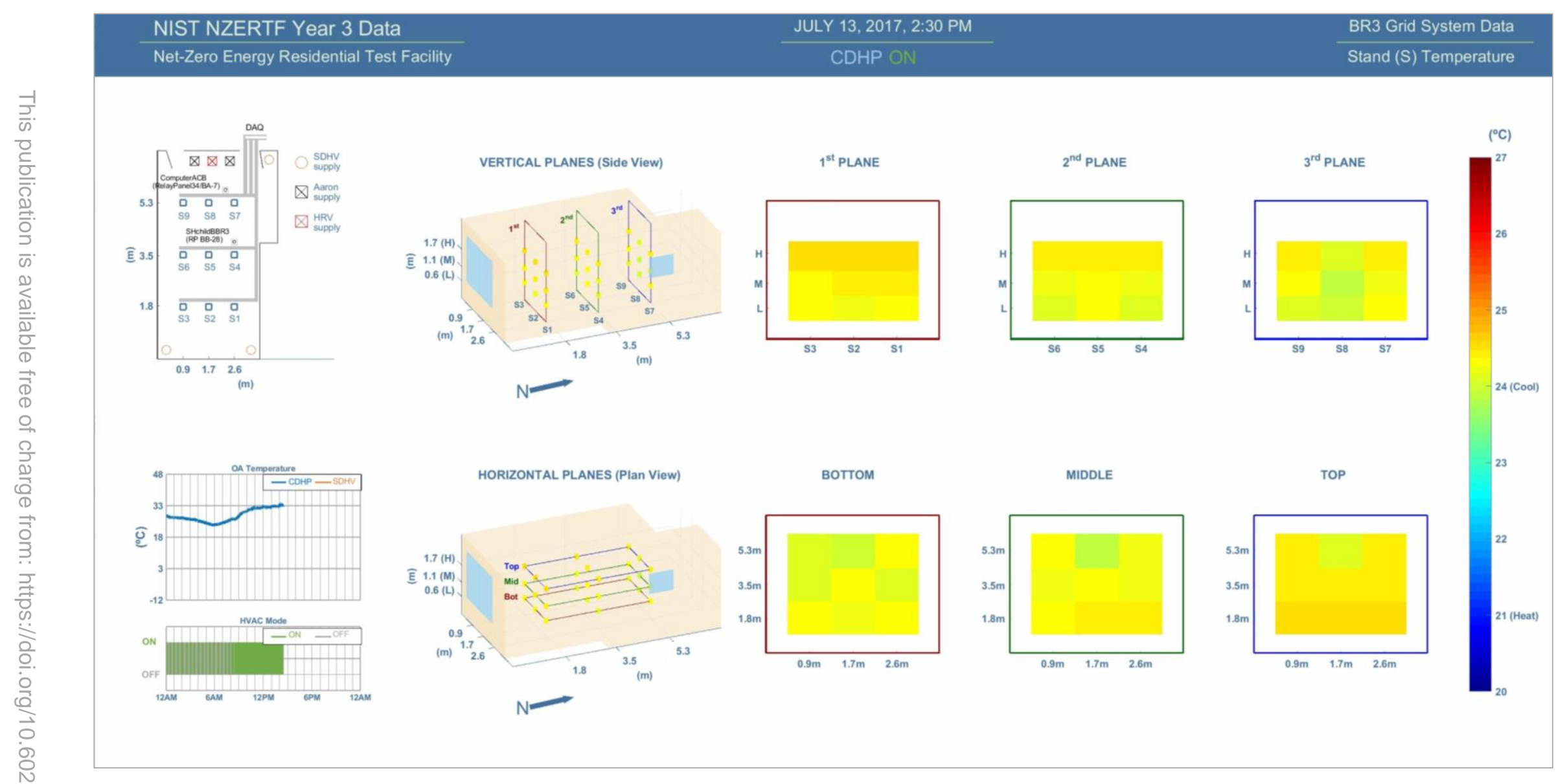

Figure 82: Animated 5-Min Average BR3 Temperature Data Analysis Mapped on the Vertical (Upper) and Horizontal (Lower) Measurement Planes. 


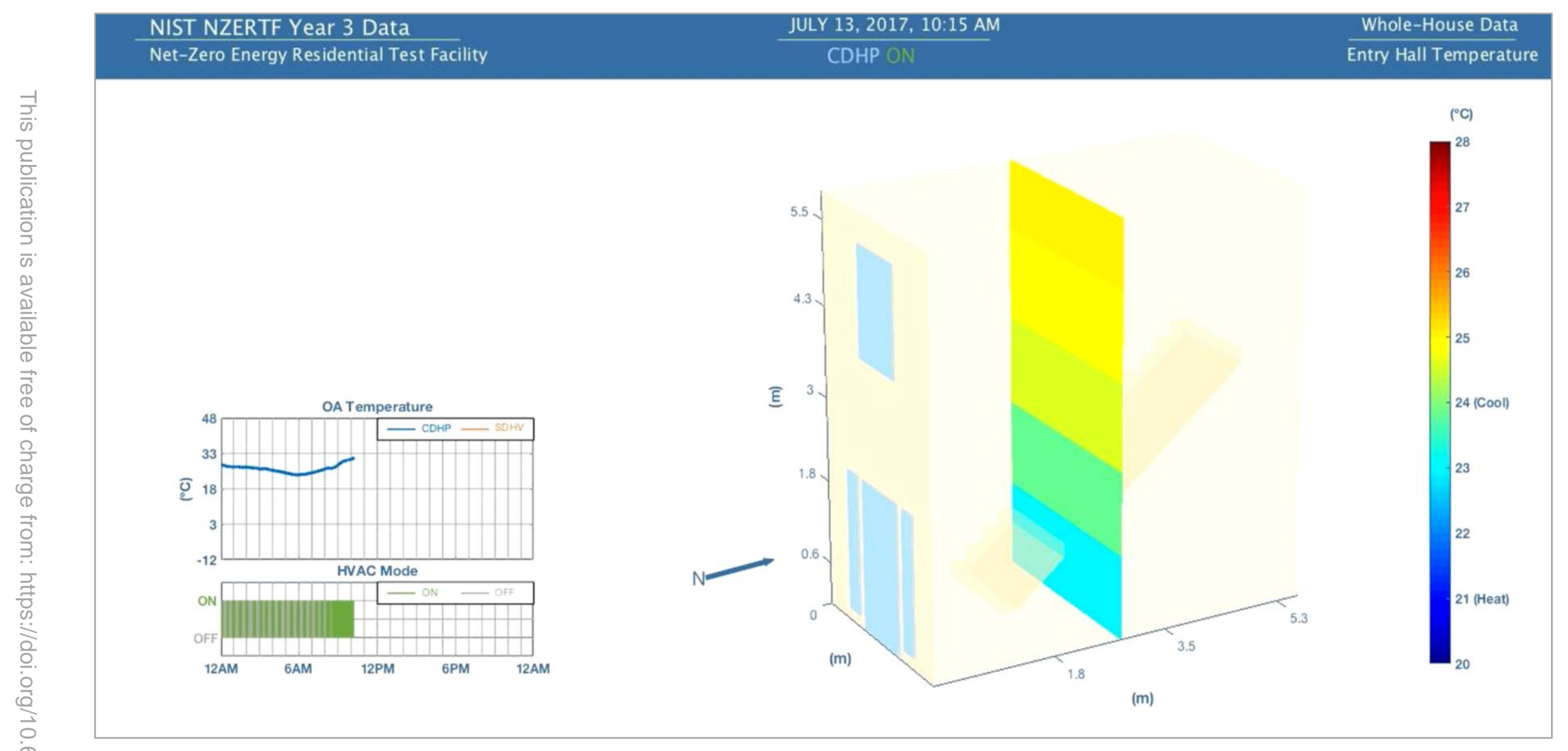

Figure 83: Animated 5-Min Average Entry Hallway Temperature Data Analysis Mapped on the Vertical Measurement Plane. 


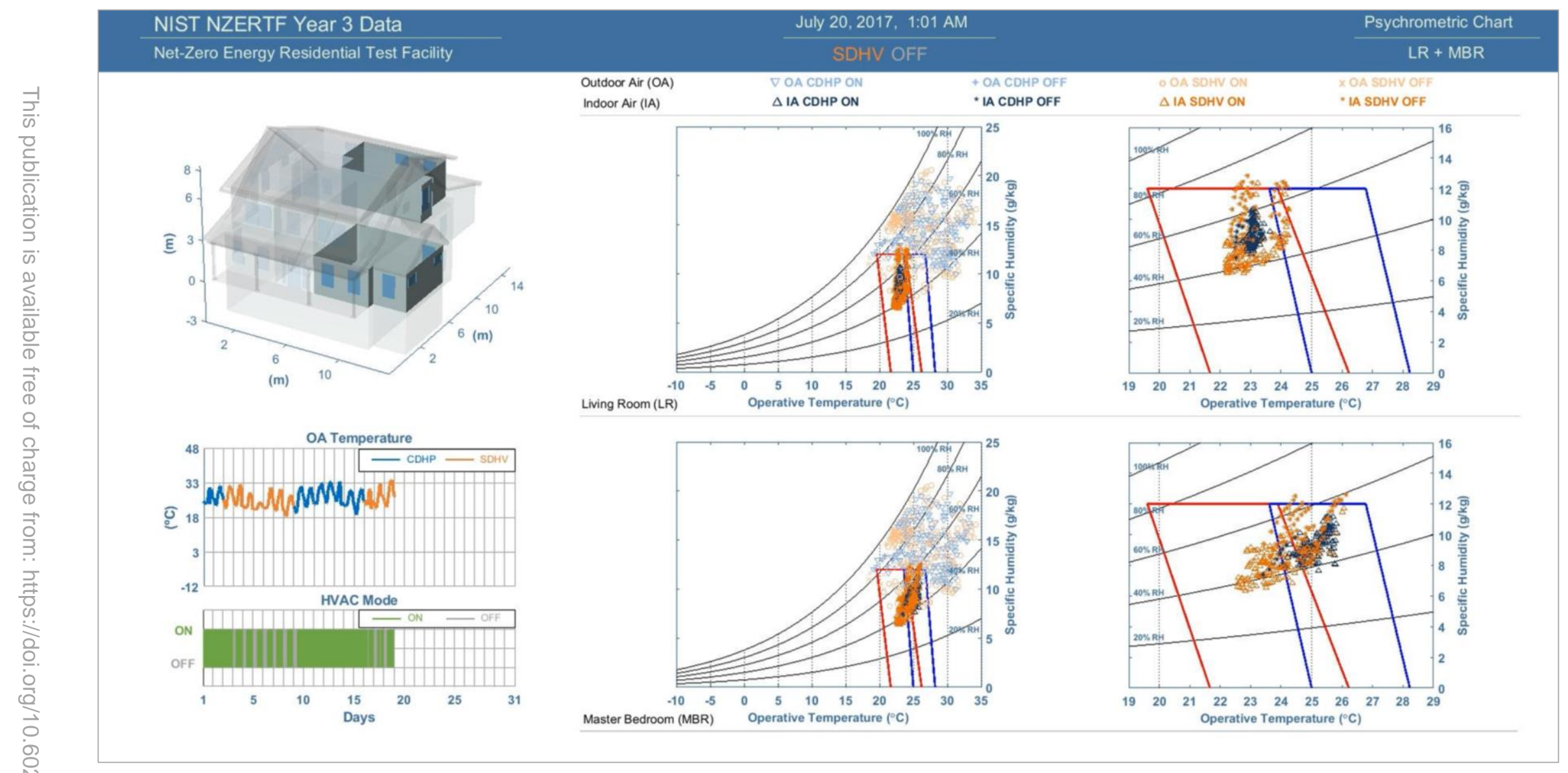

Figure 84: Animated Psychrometric Analysis Using Hourly Average Thermal Comfort Data of Living Room (Upper) and Bedroom 2 (Lower) Plotted on the Psychrometric Chart with a Super-Imposed ASHRAE Standard 55-2017 Comfort Zone. 


\subsection{BENCHMARKING}

To gain more general insights on the thermal comfort performance of residential air distribution systems, this study compared the results from the NZERTF with the four field studies $^{56}$ selected for benchmarking: Baskin and Vineyard (2003), Poerschke et al. (2016), Poerschke (2017) and Martin et al. (2018). It should be noted that there are some differences between the four field studies selected for benchmarking and the NZERTF in terms of the test house characteristics and climates that might affect the measured thermal comfort performance, including:

- Baskin and Vineyard (2003): One 1-story unoccupied detached house in Lenoir City, TN;

- Poerschke et al. (2016): Four 3-story occupied townhomes in Denver, CO;

- Poerschke (2017): One 2-story detached unoccupied house in Pittsburgh, PA; and

- Martin et al. (2018): One 1-story manufactured house in Cocoa, FL with simulated occupancy.

In terms of a data analysis period, three studies except Martin et al. (2018) were based on a series of short-term field tests between 1 and 9 days. Baskin and Vineyard (2003) and Poerschke et al. (2016) provide the results only for the cooling season with a focus on a system performance comparison between CDHP and SDHV. However, the other two studies by Poerschke (2017) and Martin et al. (2018) provide the results for both the cooling season and the heating season with a focus on the SDHV performance.

\subsubsection{SPATIAL THERMAL UNIFORMITY}

Table 17 compares the average room-to-room temperature differences measured in the NZERTF and the two field studies by Baskin and Vineyard (2003) and Poerschke et al. (2016) for the cooling season. Table 18 compares the percentage of failures in room-to-room temperature difference per ACCA Manual RS maximum benchmarks (i.e., $3.33^{\circ} \mathrm{C}$ for cooling). In terms of the percentage of failures, only one study by Poerschke et al. (2016) provided the results.

The average room-to-room temperature differences of the NZERTF were $2.1^{\circ} \mathrm{C}$ with the $\mathrm{CDHP}$ in operation and $1.3^{\circ} \mathrm{C}$ with the SDHV in operation, which were lower or similar to those of other test houses for the respective systems. It is also noteworthy that in all three studies, the SDHV provided more uniform temperatures throughout the house with lower room-to-room temperature difference that was also lower than the ACCA Manual RS average benchmarks (i.e., $1.67^{\circ} \mathrm{C}$ for cooling).

However, despite comparable average room-to-room temperature differences between the NZERTF and the test houses by Poerschke et al. (2016), the NZERTF maintained much lower percentages of failures: $1 \%$ with the CDHP and $0 \%$ with the SDHV. Meanwhile, the test houses by Poerschke et al. (2016) had $10.5 \%$ and $0.5 \%$ percentages of failures with the CDHP and SDHV, respectively.

\footnotetext{
${ }^{56}$ Detailed reviews of each study are provided in Section 2.1, including Table 1 summarizing details on the test house and data.
} 
Table 19 compares the percentage of failures in room-to-thermostat temperature difference per ACCA Manual RS benchmarks (i.e., $1.67^{\circ} \mathrm{C}$ for cooling) measured in the NZERTF and two field studies by Poerschke (2017) and Martin et al. (2018). Both benchmarks present only the SDHV performance, and for Poerschke (2017), the percentages of failures for three different fan modes were averaged in this table.

In the LR on the first floor, the NZERTF had a higher percentage of failures for the cooling season: $8 \%$ in the NZERTF due to the room temperature colder than the setpoint temperature (i.e., $\triangle \mathrm{T}$ below $-1.67^{\circ} \mathrm{C}$ ). On the other hand, the test house by Poerschke (2017) had a $0 \%$ failure rate in the LR on the first floor of the house, while the 1-story test house by Martin et al. (2018) had failure rates from $0 \%$ to $2 \%$ in the three bedrooms. In the bedrooms on the second floor, the NZERTF had $2 \%$ to $3 \%$ failure rates for the cooling season, which were comparable between rooms. However, the failure rates varied in the second-floor bedrooms of the test house by Poerschke (2017), which were from $0 \%$ to $32 \%$ due to insufficient (i.e., below-design) cooling airflow and solar heat gains. The observed overheating issue was improved with the high-speed fan mode ${ }^{57}$.

For the heating season, both houses had $0 \%$ failure rates in the LR on the first floor. However, the bedrooms on the second floor had failure rates from $9 \%$ to $14 \%$ in the NZERTF and from $3 \%$ to $29 \%$ in the house by Poerschke (2017) except for the MBR. The MBR in the house by Poerschke (2017) had a 100\% failure rate because of insufficient airflow, which was about $64 \%$ of its design heating air flow, while other rooms had above-design heating airflows. The observed incidences of failures in both studies were due to overheating (i.e., $\Delta T$ above $1.1^{\circ} \mathrm{C}$ ) on sunny days or natural stratification of warm air.

Table 20 compares the average vertical temperature differences measured in the NZERTF and the field study by Baskin and Vineyard (2003) for the cooling season. On average, both houses had much lower vertical temperature differences for both the standing and the seated occupants compared to the ASHRAE Standard 55 limits (i.e., $3^{\circ} \mathrm{C}$ for $1.1 \mathrm{~m}$ head level and $4^{\circ} \mathrm{C}$ for $1.7 \mathrm{~m}$ head level), indicating well-mixed air distributions. Between the houses, the NZERTF had lower or similar vertical temperature differences.

Table 17: A Comparison of the Average Room-to-Room Temperature Differences Between Studies for the Cooling Season.

\begin{tabular}{c|c|ccc|ccc}
\hline & NZERTF & \multicolumn{3}{|c|}{ Baskin and Vineyard (2003) } & \multicolumn{3}{c}{ Poerschke et al. (2016) } \\
& $\begin{array}{c}\Delta \mathbf{T}\left({ }^{\circ} \mathrm{C}\right) \\
\text { at 1.4m }\end{array}$ & $\begin{array}{c}\Delta \mathrm{T}\left({ }^{\circ} \mathrm{C}\right) \\
\text { at } 1.1 \mathrm{~m}\end{array}$ & $\begin{array}{c}\Delta \mathrm{T}\left({ }^{\circ} \mathrm{C}\right) \\
\text { at1 } 1.7 \mathrm{~m}\end{array}$ & AVG. & $\begin{array}{c}\Delta \mathrm{T}\left({ }^{\circ} \mathrm{C}\right) \\
\text { in House } \\
\text { Type 1 }\end{array}$ & $\begin{array}{c}\Delta \mathrm{T}\left({ }^{\circ} \mathrm{C}\right) \\
\text { in House } \\
\text { Type 2 }\end{array}$ & AVG. \\
\hline CDHP & $\mathbf{2 . 1}$ & 2.3 & 2.4 & $\mathbf{2 . 4}$ & 1.4 & 2.7 & $\mathbf{2 . 1}$ \\
SDHV & $\mathbf{1 . 3}$ & 1.8 & 1.8 & $\mathbf{1 . 8}$ & 1.3 & 1.2 & $\mathbf{1 . 3}$ \\
\hline
\end{tabular}

57 The failure rates were $13 \%$ with the low speed fan mode, $18 \%$ with the medium speed fan mode, and $3 \%$ with the high speed fan mode in BR3; and $40 \%$ with the low speed fan mode, $37 \%$ with the medium speed fan mode, and $18 \%$ with the high speed fan mode. 
Table 18: A Comparison of the Percentage of Failures in Room-to-Room Temperature Differences Per ACCA Manual RS Between Studies for the Cooling Season.

\begin{tabular}{c|c|ccc|ccc}
\hline & NZERTF & \multicolumn{3}{|c|}{ Baskin and Vineyard (2003) } & \multicolumn{3}{c}{ Poerschke et al. (2016) } \\
& $\begin{array}{c}\Delta \mathbf{T}\left({ }^{\circ} \mathrm{C}\right) \\
\text { at 1.4m }\end{array}$ & $\begin{array}{c}\Delta \mathrm{T}\left({ }^{\circ} \mathrm{C}\right) \\
\text { at } 1.1 \mathrm{~m}\end{array}$ & $\begin{array}{c}\Delta \mathrm{T}\left({ }^{\circ} \mathrm{C}\right) \\
\text { at } 1.7 \mathrm{~m}\end{array}$ & AVG. & $\begin{array}{c}\Delta \mathrm{T}\left({ }^{\circ} \mathrm{C}\right) \\
\text { in House } \\
\text { Type 1 }\end{array}$ & $\begin{array}{c}\Delta \mathrm{T}\left({ }^{\circ} \mathrm{C}\right) \\
\text { in House } \\
\text { Type 2 }\end{array}$ & AVG. \\
\hline CDHP & $\mathbf{1 . 0 \%}$ & - & - & - & $0.0 \%$ & $21.0 \%$ & $\mathbf{1 0 . 5 \%}$ \\
SDHV & $\mathbf{0 . 0 \%}$ & - & - & - & $1.0 \%$ & $0.0 \%$ & $\mathbf{0 . 5} \%$ \\
\hline
\end{tabular}

Table 19: A Comparison of the Percentage of Failures in Room-to-Thermostat Temperature Differences Per ACCA Manual RS Between Studies for the SDHV.

\begin{tabular}{|c|c|c|c|c|c|c|c|c|c|c|c|c|}
\hline & \multicolumn{4}{|c|}{ NZERTF } & \multicolumn{5}{|c|}{ Poerschke (2017) } & \multicolumn{3}{|c|}{ Martin et al. (2018) } \\
\hline & LR & MBR & BR2 & BR3 & LR & MBR & BR2 & BR3 & BR4 & MBR & SE BR & NE BR \\
\hline \multicolumn{13}{|c|}{ Cooling Season } \\
\hline$>1.70$ & $0 \%$ & $2.2 \%$ & $0.9 \%$ & $0.2 \%$ & - & - & - & - & - & - & - & - \\
\hline$<-1.7 C$ & $8.2 \%$ & $1.1 \%$ & $1.0 \%$ & $1.7 \%$ & - & - & - & - & - & - & - & - \\
\hline Total & $8.2 \%$ & $3.3 \%$ & $1.9 \%$ & $1.9 \%$ & $0 \%$ & $0 \%$ & $0 \%$ & $11.3 \%$ & $31.7 \%$ & $0 \%$ & $0.4 \%$ & $2.0 \%$ \\
\hline \multicolumn{13}{|c|}{ Heating Season } \\
\hline$>1.1 \mathrm{C}$ & $0.3 \%$ & $8.9 \%$ & $14.2 \%$ & $10.9 \%$ & - & - & - & - & - & - & - & - \\
\hline$<-1.10$ & $0 \%$ & $0 \%$ & $0 \%$ & $0.1 \%$ & - & - & - & - & - & - & - & - \\
\hline Total & $0.3 \%$ & $8.9 \%$ & $14.2 \%$ & $11.0 \%$ & $0 \%$ & $100 \%$ & $3.3 \%$ & $10.0 \%$ & $28.7 \%$ & - & - & - \\
\hline
\end{tabular}

Table 20: A Comparison of the Average Vertical Temperature Differences Between Studies for the Cooling Season.

\begin{tabular}{c|cc|cc}
\hline & \multicolumn{2}{|c|}{ NZERTF } & \multicolumn{2}{c}{ Baskin and Vineyard (2003) } \\
& $\Delta$ Tstanding $\left({ }^{\circ} \mathrm{C}\right)$ & $\Delta \mathrm{T}$ seated $\left({ }^{\circ} \mathrm{C}\right)$ & $\Delta \mathrm{T}$ standing $\left({ }^{\circ} \mathrm{C}\right)$ & $\Delta \mathrm{T}$ seated $\left({ }^{\circ} \mathrm{C}\right)$ \\
\hline CDHP & 0.2 & 0.1 & 0.5 & 0.1 \\
SDHV & 0.1 & 0.0 & 0.4 & 0.2 \\
\hline
\end{tabular}




\subsubsection{TEMPORAL THERMAL UNIFORMITY}

Table 21 compares the percentage of failures in cyclic and drift temperature variations per ASHARE Standard 55-2017 measured in the NZERTF and the field study by Poerschke (2017) for the following time periods:

- $0.25 \mathrm{~h}$ ( 15 minutes);

- $0.50 \mathrm{~h}$ (30 minutes);

- $1 \mathrm{~h}$ (60 minutes);

- $2 \mathrm{~h}$ (120 minutes); and

- $4 h$ (240 minutes).

Poerschke (2017) presents only the SDHV performance, and the percentages of failures only with the high-speed fan mode were included in this table because no failures were reported with the other fan modes. The NZERTF reported no incidences or very small percentages of failures of less than $1 \%$ for both the cooling and heating seasons. The test house by Poerschke (2017) also reported $0 \%$ failure rates for the cooling season. However, for the heating season, the reported failures varied from $4 \%$ to $15 \%$ in bedrooms 2 and 3 due to condenser coil defrost cycles only when the fan ran at its high-speed mode.

Table 21: A Comparison of the Percentage of Failures in Cyclic and Drift Temperature Variations Per ASHRAE Standard 55-2017 Between Studies for the SDHV.

\begin{tabular}{|c|c|c|c|c|c|c|c|c|c|}
\hline & \multicolumn{4}{|c|}{ NZERTF } & \multicolumn{5}{|c|}{ Poerschke (2017) } \\
\hline & LR & MBR & BR2 & BR3 & LR & MBR & BR2 & BR3 & BR4 \\
\hline \multicolumn{10}{|c|}{ Cooling Season } \\
\hline $0.25 h$ & $0 \%$ & $0.5 \%$ & $0 \%$ & $0 \%$ & $0 \%$ & $0 \%$ & $0 \%$ & $0 \%$ & $0 \%$ \\
\hline $0.5 \mathrm{~h}$ & $0 \%$ & $0.6 \%$ & $0 \%$ & $0 \%$ & $0 \%$ & $0 \%$ & $0 \%$ & $0 \%$ & $0 \%$ \\
\hline $1 \mathrm{~h}$ & $0 \%$ & $0.2 \%$ & $0 \%$ & $0 \%$ & $0 \%$ & $0 \%$ & $0 \%$ & $0 \%$ & $0 \%$ \\
\hline $2 \mathrm{~h}$ & $0 \%$ & $0.1 \%$ & $0 \%$ & $0 \%$ & $0 \%$ & $0 \%$ & $0 \%$ & $0 \%$ & $0 \%$ \\
\hline $4 \mathrm{~h}$ & $0 \%$ & $0 \%$ & $0 \%$ & $0 \%$ & $0 \%$ & $0 \%$ & $0 \%$ & $0 \%$ & $0 \%$ \\
\hline \multicolumn{10}{|c|}{ Heating Season } \\
\hline $0.25 \mathrm{~h}$ & $0 \%$ & $0.7 \%$ & $0 \%$ & $0 \%$ & $0 \%$ & $0 \%$ & $7.0 \%$ & $8.0 \%$ & $1.0 \%$ \\
\hline $0.5 \mathrm{~h}$ & $0 \%$ & $0.9 \%$ & $0 \%$ & $0 \%$ & $0 \%$ & $0 \%$ & $4.0 \%$ & $7.0 \%$ & $0 \%$ \\
\hline $1 \mathrm{~h}$ & $0 \%$ & $0.1 \%$ & $0 \%$ & $0 \%$ & $0 \%$ & $0 \%$ & $4.0 \%$ & $6.0 \%$ & $0 \%$ \\
\hline $2 \mathrm{~h}$ & $0 \%$ & $0.1 \%$ & $0 \%$ & $0 \%$ & $0 \%$ & $0 \%$ & $10.0 \%$ & $10.0 \%$ & $0 \%$ \\
\hline $4 \mathrm{~h}$ & $0 \%$ & $0 \%$ & $0 \%$ & $0 \%$ & $0 \%$ & $0 \%$ & $15.0 \%$ & $13.0 \%$ & $0 \%$ \\
\hline
\end{tabular}




\subsubsection{GRAPHICAL COMPARISON}

Figure 85 presents a graphical comparison of the room-to-room temperature differences measured in the NZERTF and the 36 high-performance occupied houses in a hot and humid climate as reported by Poerschke and Beach (2016). For comparison, the NZERTF results were presented by system types (i.e., blue for CDHP and orange for SDHV) only for the cooling mode. The black solid line represents the benchmarks by Poerschke and Beach (2016) based on the data collected during September and October in a hot and humid climate, which can be considered as the cooling season. The relevant ACCA Manual RS benchmarks for cooling (i.e., $1.67^{\circ} \mathrm{C}\left(3^{\circ} \mathrm{F}\right)$ average and $3.33^{\circ} \mathrm{C}\left(6^{\circ} \mathrm{F}\right)$ maximum) are also presented for comparison.

As a result, the SDHV showed better room-to-room temperature uniformity than the benchmarks by Poerschke and Beach (2016) based on the cumulative data above the $40^{\text {th }}$ percentile. Both the SDHV and the benchmarks had the $50^{\text {th }}$ room-to-room temperature differences lower than the ACCA average benchmarks. However, the CDHP had larger roomto-room temperature uniformity than the benchmarks except for the upper $10 \%$ of data. The $50^{\text {th }}$ room-to-room temperature difference of the CDHP also exceeded the ACCA average benchmarks. Against the ACCA maximum benchmarks, the CDHP had a better temperature uniformity compared to the benchmarks by Poerschke and Beach (2016) with a lower percentage of the period exceeding the ACCA maximum benchmarks.

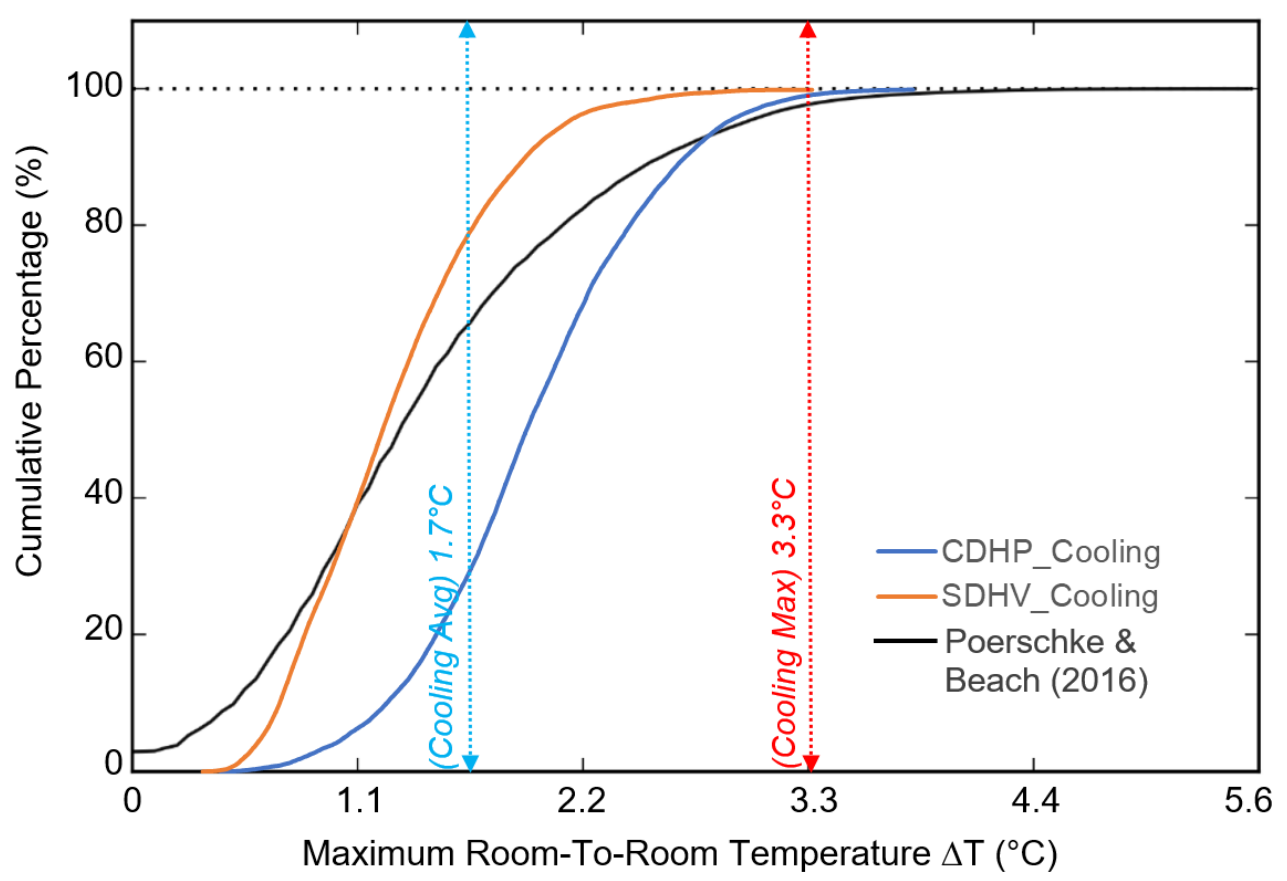

Figure 85: A Graphical Comparison of the Room-To-Room Temperature Differences Measured in the NZERTF versus the 36 High-Performance Occupied Houses in a Hot-Humid Climate Reported by Poerschke and Beach (2016). 


\section{SUMMARY}

This section provides a summary of this report and discusses the recommendations for future research, which will contribute to improved design, operation, and measurements of residential air distribution systems for energy efficiency and thermal comfort. The summary of key findings from the research is provided below.

\subsection{SUMMARY OF LITERATURE REVIEW}

\section{Key findings from a literature review are:}

- Previous field studies

Previous studies on the thermal comfort performance of residential HVAC systems as installed within a house were primarily performed or commissioned by national laboratories through the U.S. Department of Energy (DOE) Building America Program. Several studies have focused on the whole-house thermal comfort performance of forced-air heating and cooling systems that have conventional or unconventional air distribution systems, including a SDHV system, which was thoroughly reviewed in this report.

In brief, this review revealed a need for more field studies based on long-term measurements in the same test house with simulated/controlled occupancy and internal loads in order to develop an improved understanding of the impact of residential forced-air heating and cooling systems with a focus on different air distribution systems on thermal comfort at the whole-house level. This review also found there is a need to explore and develop more standardized data intervals, metrics, and advanced analytical methods to accurately quantify and report the extent of whole-house thermal comfort (e.g., in terms of thermal uniformity, local discomfort, cyclic discomfort, and latent performance), which will allow a comparison of the results between different field tests in the context of benchmarks.

- Thermal comfort performance measurement protocols and benchmarks

The review of the two thermal comfort performance measurement protocols and benchmarks revealed that the two documents (i.e., ASHRAE Standard 55 and ACCA Manual RS) agree with each other in terms of primary comfort parameters, although they were developed for quite different purposes. The ASHRAE Standard 55 aims to define the conditions that will produce acceptable thermal environmental conditions for a majority of the occupants within the space. On the other hand, the ACCA Manual RS focuses on the HVAC system's ability to produce and deliver comfort to multiple occupied spaces as installed in the house, which is primarily based on a temperature deviation from the thermostat setpoint (i.e., room-to-thermostat temperature difference) in any conditioned room of a house and the resultant room-to-room (or floor-to-floor) temperature differences.

The ACCA Manual RS's primary focus on air temperature provides reasonable benchmarks for the studies aiming to assess and compare the installed HVAC system's fundamental ability to maintain a certain and uniform temperature throughout the house since most residential HVAC systems are single-zone systems that are configured to control the thermal conditions of the house solely based on air temperature at the thermostat. However, the provided ACCA Manual RS benchmarks 
developed in 1997 are based on relatively old HVAC systems and houses built 20 years ago, which may not be applicable for today's low-load houses.

\subsection{SUMMARY OF WHOLE-HOUSE THERMAL COMFORT ANALYSIS}

Key findings from an analysis of the room-to-thermostat temperature difference are:

- Cooling season

The first-floor room-to-thermostat temperature differences $\left(\triangle \mathrm{T}\left({ }^{\circ} \mathrm{C}\right)=\right.$ Troom - Tsetpoint $)$ were mostly on the low side (i.e., $\triangle \mathrm{T}$ below $0^{\circ} \mathrm{C}$ ) with an average temperature difference of $-0.9^{\circ} \mathrm{C}(\mathrm{CDHP})$ and $-1.1^{\circ} \mathrm{C}(\mathrm{SDHV})$ in the living room where the thermostat was located. There were no occasions when the room-to-thermostat temperature difference unfavorably exceeded the ACCA cooling benchmarks (i.e., $\triangle T$ above $1.67^{\circ} \mathrm{C}$ ). However, the SDHV had higher non-compliance percentages of the first-floor rooms on the low side (i.e., $\Delta \mathrm{T}$ below $-1.67^{\circ} \mathrm{C}$ ). The kitchen had the highest percentages of low-side deviation (i.e., 5.3\% with the CDHP and 13.5\% with the SDHV) due to the evaporative cooling effect from the two humidifiers that were operated to emulate latent heat generation and located near the measurement stand in the kitchen.

For the rooms on the second floor, the non-compliance percentages were comparable between the two systems. However, the CDHP room-to-thermostat temperature differences tended to be on the high side (i.e., warmer room temperature) compared to the SDHV with an average temperature difference of $0.8^{\circ} \mathrm{C}$ $(\mathrm{CDHP})$ and $0.0^{\circ} \mathrm{C}(\mathrm{SDHV})$ in MBR. There were also occasions when the room-tothermostat temperature difference unfavorably exceeded the ACCA cooling benchmarks (i.e., $\triangle \mathrm{T}$ above $1.67^{\circ} \mathrm{C}$ ) in the second-floor bedrooms. The maximum deviation occurred in MBR: $4.2 \%$ (CDHP) and 2.2\% (SDHV), which was affected by heat gains from the simulated internal loads (i.e., occupancy and plug loads).

\section{- Heating season}

Like the cooling season, the first-floor room-to-thermostat temperature differences tended to be on the low side (i.e., $\Delta \mathrm{T}$ below $0^{\circ} \mathrm{C}$ ) though to a lesser extent during the heating season with an average temperature difference of $-0.4^{\circ} \mathrm{C}(\mathrm{CDHP})$ and $-0.3^{\circ} \mathrm{C}$ (SDHV) in the living room. When the CDHP was in operation, there were more occasions when the room-to-thermostat temperature difference unfavorably exceeded the ACCA heating benchmarks (i.e., $\Delta \mathrm{T}$ below $-1.11^{\circ} \mathrm{C}$ ) in both the first-floor and second-floor rooms. These deviations occurred over two days when the CDHP's electric resistance backup heater stayed off although the LR temperature was below the heating setpoint temperature. Similar to the cooling season results, the kitchen had high non-compliance percentages on the low side: $22.1 \%$ with the CDHP and $21.0 \%$ with the SDHV.

Unlike the cooling season results, the compliance percentage of the second-floor rooms were lower than the compliance percentages of the first-floor rooms along with higher non-compliance percentages on the high side (i.e., $\Delta T$ higher than $1.11^{\circ} \mathrm{C}$ ). The greater high-side non-compliance percentages of the second-floor bedrooms can be explained by natural stratification of warm air in addition to favorable weather conditions. 
- Transitional season

Although relatively high percentages of both low-side and high-side deviations were observed, the systems were mostly off cycle during the transitional season, which means the observed deviations did not occur due to the system's undesirable overcooling or overheating. Accordingly, the noted room-to-thermostat deviations against the ACCA benchmarks during the transitional season should not be used to evaluate the installed system's ability to produce and deliver a certain temperature to multiple occupied spaces as installed in the house.

Key findings from an analysis of the room-to-room temperature difference are:

- Cooling season

The SDHV maintained much smaller room-to-room temperature differences than the $\mathrm{CDHP}$ with an average room-to-room temperature difference of $1.3^{\circ} \mathrm{C}$, which was lower than the ACCA average benchmarks for cooling (i.e., $1.67^{\circ} \mathrm{C}$ ). However, the CDHP's average room-to-room temperature difference was $2.0^{\circ} \mathrm{C}$, which exceeded the ACCA average benchmarks. There were also occasions when the room-to-room temperature difference exceeded the ACCA maximum benchmarks for cooling (i.e., $3.33^{\circ} \mathrm{C}$ ), which was about $1.0 \%$ of the period when the CDHP was in operation. This deviation mostly occurred when the MBR's room-to-thermostat temperature difference exceeded the ACCA cooling benchmarks, which was affected by possible heat gains from the radiator in the MBR emulating sensible heat gains from an iron.

- Heating season

Unlike the cooling season results, the CDHP maintained a smaller room-to-room temperature difference than the SDHV with an average room-to-room temperature difference of $1.0^{\circ} \mathrm{C}$, which was lower than the ACCA average benchmarks for heating (i.e., $1.11^{\circ} \mathrm{C}$ ). However, the $\mathrm{SDHV}$ 's average room-to-room temperature difference was $1.3^{\circ} \mathrm{C}$, which exceeded the ACCA average benchmarks. Compared to cooling, there were more occasions when the room-to-room temperature difference exceeded the ACCA maximum benchmarks for heating (i.e., $2.22^{\circ} \mathrm{C}$ ), which was about $1.8 \%$ (CDHP) and $4.6 \%$ (SDHV), which mainly occurred due to the nighttime low-side deviation of the room-to-thermostat temperature difference in the kitchen.

\section{- Transitional season}

The room-to-room temperature differences were below the ACCA average cooling limit for about 73.8\% (CDHP) and 82.1\% (SDHV) of the period without any frequency exceeding the ACCA maximum cooling benchmarks. This means the natural stratification of warm air in this two-story house during the system off cycle still provided acceptable spatial thermal uniformity.

Key findings from an analysis of the cyclic discomfort are:

- In general, the percentage of failures was negligible, which was less than $0.1 \%$ of the period except for the kitchen and the MBR. No obvious difference was observed between the systems and between the system's seasonal operation modes. The kitchen and the MBR still had quite low percentages of failures below $1 \%$ of the period, and higher failure rates were observed for the shorter time periods such as $0.25 \mathrm{~h}$ and $0.5 \mathrm{~h}$ period, which occurred at a specific time of the day when the radiators near the measurement stands in each room was turned on to emulate one of the kitchen appliances (i.e., toaster oven) and an iron, respectively. 
Key findings from the statistical characterization of the long-term thermal comfort data are:

- Cooling season

On average, there was no noticeable difference in the first-floor room temperatures between the two systems. However, the CDHP maintained better temporal variations with noticeably smaller IOR compared to the SDHV, which was outstanding in the LR where the thermostat is located. In the rooms on the second floor, there was a noticeable difference in the measured room temperatures between the two systems. The temperatures in the second-floor bedrooms were colder and nearer to the cooling setpoint temperature when the SDHV was operated, which was affected by favorable attic temperature due to the location of the SDHV supply ductwork within the attic. This resulted in smaller room-to-room temperature differences when the $\mathrm{SDHV}$ was in operation during the cooling season.

\section{- Heating season}

Except for the LR when the CDHP was on cycle, the observed temporal variations between the two systems were comparable in the first-floor rooms. The LR had tightlycontrolled space conditions with a very small IQR when the CDHP was on cycle. However, in the second-floor rooms, there was a noticeable difference in the measured room temperatures between the two systems, but the trend was opposite to the cooling season. The temperatures in the second-floor bedrooms were now warmer when the SDHV was in operation. This was affected by favorable attic temperature, which resulted in higher room-to-room temperature differences when the SDHV was in operation during the heating season.

\section{- Transitional season}

In general, the room temperatures were between the heating setpoint and the cooling setpoint temperatures for both systems with wider temporal variations. Unlike other seasons, there was not a noticeable difference in the measured room temperatures between the two systems on average, but the observed temporal variations were wider with the CDHP because of the high-side and low-side deviations of the CDHP that mostly occurred over the four specific days that were relatively warmer in the heating mode or cooler in the cooling mode.

Key findings from the advanced characterization of the long-term thermal comfort data related to the outdoor climate are:

\section{- Rooms on the first floor}

The LR temperature where the thermostat was located was consistently lower than the setpoint temperature regardless of outdoor air temperature, which needs a further investigation considering the proximity of the thermostat to the LR measurement stand. The CDHP controlled LR temperatures much tighter than the SDHV regardless of outdoor air temperature. This also needs a further investigation considering the comparable throttling range between the two systems: $\pm 0.1^{\circ} \mathrm{C}(\mathrm{CDHP})$ and $\pm 0.14^{\circ} \mathrm{C}$ (SDHV).

The first-floor rooms appeared to have lower room temperatures with higher variation at the very low OA temperatures only when the CDHP was operated, which indicates the CDHP's smaller heating capacity $(7.8 \mathrm{~kW})$ could not meet the heating setpoint temperatures at these low OA temperatures. On the other hand, at the high OA 
temperatures, the SDHV appeared to have slightly higher room temperatures with more frequency exceeding the cooling setpoint temperature compared to the CDHP.

\section{- Rooms on the second floor}

Unlike the first-floor rooms, there was an obvious difference in the maintained room temperatures between the two systems under the same OA temperatures. The SDHV maintained the rooms warmer at the low OA temperatures but cooler at the high OA temperatures than the conditions maintained with the CDHP, which was affected by favorable attic temperatures due to the SDHV supply ductwork within the attic. When the SDHV was operated, the room temperatures during the SDHV off cycle tended to be cooler at the low OA temperatures but warmer at the high OA temperatures than the room temperatures during the SDHV on cycle. This is contrary to the expectation and might indicate the reduced heat transfer from the attic that had favorable conditions to the rooms when the SDHV was off cycle.

\section{- Attic and basement}

The SDHV maintained the attic warmer at the low OA temperatures but cooler at the high OA temperatures than the conditions maintained with the CDHP, which was caused by the SDHV supply ductwork within the attic. Although this difference was not directly caused by the tested air distribution system itself but rather affected by the different locations of the two systems' supply ductwork, their different locations in the house represent real-world applications.

The basement temperatures did not show a relationship with outdoor temperatures and had similar room temperatures across the year, which was colder than other rooms in the house. The SDHV maintained the basement warmer at the low OA temperatures but cooler at the high OA temperatures than the conditions maintained with the CDHP, which agrees with the observations made for the attic though to a much lesser extent. The SDHV supply ductwork for the first floor is located in the basement.

\section{- Comparison between rooms}

The rooms on each floor had similar indoor-outdoor temperature relationship to some extent regardless of the type of HP system in operation except for the kitchen. The kitchen had decreasing room temperatures with increasing OA temperatures when the CDHP was in operation during the cooling season. This is the opposite of the trends observed in other primary rooms and indicates a possible overcooling issue in the kitchen at the higher OA temperatures with the CDHP, which needs a further investigation.

When comparing the three bedrooms on the second floor, the BR3 and BR2 temperatures were consistently the lowest and the highest, respectively, when the CDHP was in operation, which might be affected by the presence of simulated occupancy/plug loads and solar heat gains. However, when the SDHV was in operation, there was no obvious difference in the room temperatures of the three bedrooms, which might be affected by unexpected interaction between the attic and the second-floor bedrooms.

Key findings from the time-of-day characterization of the long-term thermal comfort data are: 
- The use of the proposed time-of-day characterization was useful in tracking how the rooms were conditioned over the course of a day and a year separately for CDHP versus SDHV based on data with an hourly temporal resolution. Different temporal patterns were observed, which was affected by the schedule of internal loads simulated in each room as well as external conditions such as solar heat gains. For example, the LR temperature was always lower during the nighttime before the sun rises, which was affected by no presence of the simulated occupancy/plug loads in the LR at night. However, the opposite pattern (i.e., lower MBR temperatures during the daytime due to no presence of the simulated occupancy) was observed in the MBR.

- The use of the proposed time-of-day colored map also allowed the identification of non-compliant periods based on the ACCA Manual RS benchmarks and the resulting thermal discomfort. For example, the observed temporal patterns of the room-toroom temperature difference resembled those of the kitchen during the heating mode but those of the MBR during the cooling mode, of which localized impacts of the simulated occupancy and appliances were the reasons of the observed noncompliance.

Key findings from an analysis of the latent performance are:

- Statistical characterization of relative humidity (RH)

When the systems cycled on, the room $\mathrm{RH}$ levels during the cooling season were well within the optimum $\mathrm{RH}$ range between $30 \%$ and $60 \%$ for most of the measurement period with a deviation of less than $3 \%$ of the period except for the kitchen. During the heating season, the on-cycle room $\mathrm{RH}$ levels were below the lower limit of the optimum $\mathrm{RH}$ range (i.e., below $30 \% \mathrm{RH}$ ) for most of the measurement period except for the kitchen. When the systems cycled off, the room RH levels tended to be higher than those during the system on cycle with higher interquartile ranges regardless of the system type and season. However, attic and basement that did not directly get the $\mathrm{OA}$ ventilation from the HRV maintained similar room $\mathrm{RH}$ levels regardless of the system on and off cycle.

- Advanced characterization of absolute humidity related to outdoor humidity All primary rooms appeared to have an association between the outdoor and indoor absolute humidity levels to some extent regardless of the type of HP system in operation. At the high outdoor dew point temperatures, the SDHV appeared to maintain the primary rooms drier under the same outdoor dew point temperatures when the systems cycled on, which was more obvious at the outdoor dew point temperature bins between $10^{\circ} \mathrm{C}$ and $20^{\circ} \mathrm{C}$. This means the SDHV dehumidification performance was better than the CDHP when considering the same HRV schedule during the analysis period. However, when the systems cycled off, the SDHV had higher humidity ratios than those of the CDHP at the higher outdoor dew point temperatures with a number of incidences exceeding $0.012 \mathrm{~kg} / \mathrm{kg}$ especially when the SDHV cycled off.

In addition, the attic humidity ratio showed an obvious difference between the two systems at both low and high outdoor dew point temperatures. When the CDHP was in operation, the measured humidity ratios were consistently higher than the ratios when the SDHV was in operation. Since the attic did not get the OA ventilation directly from the HRV, the observed higher absolute humidity levels with the CDHP were likely 
to be introduced from the outside when the negative attic pressure with respect to the outside might pull humid outdoor air, which needs a further investigation.

Key findings from an analysis of the graphical analysis using the psychrometric chart are:

- The house's heating and cooling setpoint temperatures were at the low side of each ASHRAE 55 comfort zone (i.e., a red parallelogram for 1.0 clo representing winter clothing level; a blue parallelogram for 0.5 clo representing summer clothing level), respectively, which was also recognized in the ACCA Manual RS. As a result, a direct comparison of the measurements against the ASHRAE 55 comfort zones does not deem reasonable in this study unless the comfort zone is adjusted to achieve a neutral PMV (i.e., 0 PMV) at the chosen heating and cooling setpoint temperatures.

- In the LR, when the CDHP was operated, the thermal environments were conditioned differently for the system on cycle versus off cycle. However, no distinct differences were observed in the measured thermal environments between the SDHV on cycle versus off cycle. The observed mixed data points with the SDHV may represent the graphical signatures of the thermal comfort performance of the variable-speed compressor. In the MBR, there was no longer a clear distinction between the CHDP on cycle versus off cycle with a number of overlaps between the two conditions. 


\subsection{SUMMARY OF BR3 GRID ANALYSIS}

Key findings from an analysis of the BR3 horizontal and vertical thermal stratification are:

- Cooling season before August 10, 2017

No significant amounts of horizontal and vertical stratification were observed for both systems, and the vertical temperature differences way below the ASHRAE Standard 55 limits (i.e., $3^{\circ} \mathrm{C}$ for $1.1 \mathrm{~m}$ head level and $4^{\circ} \mathrm{C}$ for $1.7 \mathrm{~m}$ head level). In terms of horizontal stratification, the SDHV maintained smaller stand-to-stand temperature differences at $1.7 \mathrm{~m}: 0.35^{\circ} \mathrm{C}$ on average (CDHP) and $0.15^{\circ} \mathrm{C}$ on average (SDHV). The larger stand-tostand temperature difference observed with the CDHP was caused by the stand 8 near the two CDHP supply air outlets. In terms of vertical stratification, the two systems exhibited comparable vertical temperature differences, although the CDHP tended to have slightly larger $\Delta \mathrm{T}$ standing at some measurement locations. The three stands near the supply air outlets (i.e., stands 1, 3, and 8) exhibited unique profiles.

- Cooling season after August 10, 2017

The stand-to-stand temperature differences were larger when the sensor stands were spread out to be closer to the walls or windows, which was affected by a few stands that showed changed profiles as they moved to the outside of occupied zones. For example, when the CDHP was on cycle, the stand 1 moved to the southeast corner of the BR3 and the stand 2 moved near to the large south-facing window exhibited a strong vertical stratification, which contributed to larger stand-to-stand temperature differences. When the SDHV was on cycle, the stand 3 moved to right below one of the SDHV supply air outlets had consistently lower temperatures at all three heights, which caused larger stand-to-stand temperature differences when the SDHV was on cycle. However, the stand 3 itself maintained a well-mixed air distribution.

- Heating season

Unlike the cooling season, the on-cycle profile with the SDHV exhibited vertical stratification, while the CDHP had a similar on-cycle profile as the cooling season except for the stand 8. However, the reported vertical temperature differences were still way below the ASHRAE Standard 55 limits. The on-cycle vertical stratification with the SDHV was consistently observed across the nine stands with IORs larger than the $\mathrm{CDHP}$, which indicates insufficient air circulation. The observed lower temperature gradient with the CDHP regardless of the season might be affected by the two perimeter floor supplies in the BR3, although an attempt was made to make them inactive by closing both their in-duct mechanical dampers and the face dampers of their in-room supply registers.

In terms of horizontal stratification, the on-cycle stand-to-stand temperature differences with the CDHP were comparable to those of the cooling season when excluding the stand 8 that had a distinct profile during the cooling season. However, the SDHV had higher on-cycle stand-to-stand temperature differences compared to the cooling season, which was affected by the stand 1 that had a dissimilar profile of which average temperature at $1.1 \mathrm{~m}$ was lower than those of other stands by about $0.3^{\circ} \mathrm{C}$.

\section{- Transitional season}


Not surprisingly, both horizontal and vertical stratification during the transitional season were comparable to other seasons or better without any significant amounts of stratification. Like other seasons, the stand 1 did not follow the typical vertical temperature gradient related to the room height, of which temperature at $1.7 \mathrm{~m}$ was lower than the temperature at $1.1 \mathrm{~m}$.

Key findings from an analysis of the BR3 air velocity distribution are:

- Cooling season before August 10, 2017

Except for the stand 8 during the CDHP on cycle, the air velocities were generally lower than the ideal air velocity (i.e., $0.13 \mathrm{~m} / \mathrm{s}$ ) of the ACCA Manual RS for most of the measurement period. The stand 8 also had occasions exceeding the maximum air velocity limit of the ASHRAE Standard 55 (i.e., $0.20 \mathrm{~m} / \mathrm{s}$ ), which was more than $10 \%$ of the period, which indicates possible local discomfort due to drafts around the stand 8. At the locations of the stands 1 and 3 near the SDHV supply air outlets, the SDHV had fewer occasions when the measured air velocities were below the ACCA minimum air velocity (i.e., $0.08 \mathrm{~m} / \mathrm{s}$ ) compared to the CDHP. In the center of the room at the location of the stand 5 , the CDHP tended to have higher air velocities.

- Cooling season after August 10, 2017

When the sensor stands were spread out to be closer to the walls or windows, the stand 3 moved to right below one of the SDHV supply air outlets had extremely increased air velocities. The occasions exceeding the maximum air velocity limit of the ASHRAE Standard 55 at the stand 3 was more than $90 \%$ of the period. On the other hand, the stand 8 moved nearer to the wall had decreased air velocities since the air injected from the CDHP supply air outlets located on the upper wall did not directly reach the stand at the height of $1.1 \mathrm{~m}$.

\section{- Heating season}

Compared to the cooling season before August 10, 2017, both systems maintained lower air velocities during the heating season, which resulted in more incidences when the air velocities were lower than the ACCA minimum air velocity (i.e., $0.08 \mathrm{~m} / \mathrm{s}$ ). Unlike the cooling season, the SDHV had lower or similar air velocities at the locations of the stands 1 and 3 compared to the CDHP, although the two stands were located near the SDHV supply air outlets. The stand 8 located near the CDHP supply air outlets also had similar air velocities as the SDHV, of which trend differed from the cooling season. This means both systems with variable-speed indoor blowers delivered lower supply airflow rates in this low-load house during the heating season, which resulted in poorer air mixing compared to the cooling season.

\section{- Transitional season}

The two systems maintained comparable air velocities during the transitional season. Not surprisingly, the off-cycle air velocities except for several outliers were very similar to those of the cooling season before August 10 and the heating season. 


\subsection{SUMMARY OF DISCUSSIONS}

Key findings from the discussions are:

- Data time resolution for analysis

The 5-min average temperature data were capable of catching drift temperature variations of the 1 -min temperatures reasonably within $0.1^{\circ} \mathrm{C}$, which allowed to inspect dynamics in the continuously-measured temperature data. However, the hourly average temperature data were found to be too coarse to accurately detect the momentary fluctuations observed with the 1-min or 5-min average data.

\section{- Thermal comfort metrics}

This study used room air temperature as the primary index for a thermal uniformity analysis in terms of providing uniform space temperatures across the house since this study primarily focuses on the residential system's fundamental ability to produce and deliver a certain temperature to multiple occupied spaces as installed in the house. This approach is also deemed reasonable based on the fact that most residential HVAC systems are single-zone systems that are configured to control the thermal conditions of the house solely based on air temperature at the thermostat. A direct comparison of the measurements against the ASHRAE 55 comfort zones does not deem reasonable in this study unless the comfort zone is adjusted to achieve a neutral PMV (i.e., 0 PMV) at the chosen heating and cooling setpoint temperatures.

\section{- Graphical index for long-term thermal comfort data}

Since the current thermal comfort standards do not provide guidelines about how to graphically characterize and benchmark the results of continuously-measured longterm performance data, this study used a statistical analysis to describe the timevarying distribution of data, which allows easy comparison between different distributions. Multiple percentile ranks were selected to characterize extreme variations based on $\pm 1.5 \%, \pm 2.5 \%, \pm 5 \%$, and $\pm 10 \%$ deviation, including the recommended criteria for acceptable deviations (i.e., $3 \%$ and $5 \%$ ) provided in the Annex G of the European standard, DIN EN 15251.

\section{- Long-term thermal comfort data decomposition}

This study divided the one-year thermal comfort data into the subgroups by system type and on/off cycle as well as by season (i.e., cooling season, heating season, and transitional season) to reflect the system's actual response under given weather conditions. As a result, this study found decomposing data by the system being on or off could provide useful insights on how the tested systems responded to different thermal needs. The seasonal classification was also helpful to separately analyze the period when the HP systems did not necessarily provide cooling or heating while maintaining room temperatures below cooling setpoint temperature during the cooling mode; or above heating setpoint temperature during the heating mode due to favorable weather conditions, which was defined as the transitional season in this study.

- Trend animation for granular analysis

This study developed advanced visualizations of the thermal comfort data collected at NZERTF using animation techniques, which helps to understand and quantify the trends and variations in the data. As a result, the animated analysis by mapping 
temperatures on the floor plans or measurement planes was helpful to quickly relate the measurements with the geometry, orientation or space function over a course of day or month. This was also useful to identify any anomalies of the data (e.g., problematic locations of the house) at a single glance.

\section{- Benchmarking}

To gain more general insights on the thermal comfort performance of residential air distribution systems, this study compared the results from the NZERTF with the four field studies selected for benchmarking. The average room-to-room temperature differences of the NZERTF were $2.1^{\circ} \mathrm{C}$ with the CDHP in operation and $1.3^{\circ} \mathrm{C}$ with the SDHV in operation, which were lower or similar to those of other test houses for the respective systems by Baskin and Vineyard (2003) and Poerschke et al. (2016). It is also noteworthy that in all three studies, the SDHV provided more uniform temperatures throughout the house with lower room-to-room temperature difference that was also lower than the ACCA Manual RS average benchmarks (i.e., $1.67^{\circ} \mathrm{C}$ for cooling).

The LR of the NZERTF had a higher percentage of failures in room-to-thermostat temperature difference per ACCA Manual RS benchmarks (i.e., $1.67^{\circ} \mathrm{C}$ for cooling) for the cooling season when the SDHV was in operation: $8 \%$ in the NZERTF due to the LR temperature colder than the setpoint temperature (i.e., $\Delta T$ below $-1.67^{\circ} \mathrm{C}$ ). On the other hand, the test house by Poerschke (2017) had a $0 \%$ failure rate in the LR on the first floor of the house, while the 1-story test house by Martin et al. (2018) had failure rates from $0 \%$ to $2 \%$ in the three bedrooms. For the heating season, both houses had $0 \%$ failure rates in the LR on the first floor. However, the bedrooms on the second floor had failure rates from $9 \%$ to $14 \%$ in the NZERTF and from $3 \%$ to $29 \%$ in the house by Poerschke (2017) except for the MBR. The MBR in the house by Poerschke (2017) had a $100 \%$ failure rate because of insufficient airflow.

In a graphical comparison of the room-to-room temperature differences measured in the NZERTF and the 36 high-performance occupied houses in a hot and humid climate as reported by Poerschke and Beach (2016), the SDHV showed better roomto-room temperature uniformity than the benchmarks by Poerschke and Beach (2016) based on the cumulative data above the $40^{\text {th }}$ percentile for the cooling season. Both the SDHV and the benchmarks had the $50^{\text {th }}$ room-to-room temperature differences lower than the ACCA average benchmarks. However, the CDHP had larger room-toroom temperature uniformity than the benchmarks except for the upper $10 \%$ of data. The $50^{\text {th }}$ room-to-room temperature difference of the CDHP also exceeded the ACCA average benchmarks. 


\subsection{RECOMMENDATIONS}

This section provides recommendations for future research based on findings from this research.

- The continuous measurements of high-frequency IEO data are challenging and need continuous efforts in terms of data collection, processing/cleaning, and inspection. There is a need for effective methods to translate the large volume of high-frequency IEQ data into useful information.

- Room air temperature is recommended as the primary index for a residential thermal uniformity analysis in terms of the house/HVAC system's fundamental ability to provide and deliver uniform space temperatures across the house as installed. For example, this study calculated and compared temperature deviation from the thermostat setpoint (i.e., room-to-thermostat temperature difference) in any conditioned room of a house and the resultant room-to-room (or floor-to-floor) temperature differences against the ACCA Manual RS benchmarks. However, the provided ACCA Manual RS benchmarks developed in 1997 are based on relatively old HVAC systems and houses built 20 years ago, which may not be applicable for today's low-load houses. Therefore, there is also a need to reexamine the ACCA Manual RS benchmarks based on more data.

- Different time resolutions are recommended to be used for different types of data analysis to ensure the selected time resolution can provide sufficient granularity of data depending on the purpose of the evaluation. For example, this study primarily used the 5-min average data in the analysis, while the hourly average data were used in a graphical analysis since they visibly provide a good degree of granularity while providing easier data management. In addition, the cyclic and drift temperature variations were calculated using the 1-min temperature data, which was the shortest time interval to catch cyclic changes in the room temperatures.

- To fully understand the continuously-measured long-term thermal comfort data, it is recommended to perform a statistical characterization of the one-year granular thermal comfort data not only for the primary rooms but also for the rooms such as attic and basement that are thermally important due to possible heat transfer from/to the primary rooms. In addition, the use of the proposed graphical index was found to be more informative by displaying additional percentiles based on $\pm 1.5 \%, \pm 2.5 \%$, $\pm 5 \%$, and $\pm 10 \%$ deviation, including the recommended criteria for acceptable deviations (i.e., 3\% and 5\%) provided in the Annex $\mathrm{G}$ of the European standard, DIN EN 15251.

- The current thermal comfort standards do not provide guidelines about how to analyze the continuously-measured long-term thermal comfort data to accurately quantify and report the extent of thermal comfort performance of the tested residential HVAC systems under different outdoor climate conditions. However, proper data decomposition is necessary and essential to extract meaningful information from large datasets. For example, this study divided the one-year thermal comfort data into the subgroups by system type and on/off cycle as well as by season (i.e., cooling season, heating season, and transitional season) based on coincident 
daily average OA temperature to reflect the system's actual response under given weather conditions

- The proposed advanced visualization of the thermal comfort data using animation techniques is expected to benefit from interactivity that allows the user to manipulate the displayed variables as well as a period, which could not be demonstrated in this study. It should be noted that the proposed graphic form is one of the ways of visualizing the voluminous data efficiently in a condensed form to maximize the information contained in the data in addition to the statistical and advanced characterization of the results. 


\section{REFERENCES}

Abushakra, B., J. Haberl, D. Claridge, and A. Sreshthaputra. 2001. Compilation of diversity factors and schedules for energy and cooling load calculations. Final report on ASHRAE Research Project 1092-RP. Atlanta, GA: American Society of Heating, Refrigerating and Air-Conditioning Engineers, Inc.

ACCA. 1997. ACCA Manual RS - Comfort, Air Quality, and Efficiency by Design. Arlington, VA: Air Conditioning Contractors of America, Inc.

ASHRAE. 2004a. ANSI/ASHRAE Standard 55-2004, Thermal Environmental Conditions for Human Occupancy. Atlanta, GA: American Society of Heating, Refrigerating and AirConditioning Engineers, Inc.

ASHRAE. 2004b. ANSI/ASHRAE Standard 152-2004, Method of Test for Determining the Design and Seasonal Efficiencies of Residential Thermal Distribution Systems. Atlanta, GA: American Society of Heating, Refrigerating and Air-Conditioning Engineers, Inc.

ASHRAE. 2010. ANSI/ASHRAE Standard 55-2010, Thermal Environmental Conditions for Human Occupancy. Atlanta, GA: American Society of Heating, Refrigerating and AirConditioning Engineers, Inc.

ASHRAE. 2013a. ANSI/ASHRAE Standard 55-2013, Thermal Environmental Conditions for Human Occupancy. Atlanta, GA: American Society of Heating, Refrigerating and AirConditioning Engineers, Inc.

ASHRAE. 2013b. ANSI/ASHRAE Standard 113-2013, Method of Testing for Room Air Diffusion. Atlanta, GA: American Society of Heating, Refrigerating and AirConditioning Engineers, Inc.

ASHRAE. 2014. ANSI/ASHRAE Standard 152-2014, Method of Test for Determining the Design and Seasonal Efficiencies of Residential Thermal Distribution Systems. Atlanta, GA: American Society of Heating, Refrigerating and Air-Conditioning Engineers, Inc.

ASHRAE. 2016. ANSI/ASHRAE Standard 62.1-2016, Ventilation for Acceptable Indoor Air Quality. Atlanta, GA: American Society of Heating, Refrigerating and Air-Conditioning Engineers, Inc.

ASHRAE. 2017. ANSI/ASHRAE Standard 55-2017, Thermal Environmental Conditions for Human Occupancy. Atlanta, GA: American Society of Heating, Refrigerating and AirConditioning Engineers, Inc.

Baskin, E. and E. Vineyard. 2003. Thermal comfort assessment of conventional and highvelocity distribution systems for cooling season. ASHRAE Transactions 109(1):513522.

CEN. 2007. EN 15251:2007, Indoor Environmental Input Parameters for Design and Assessment of Energy Performance of Buildings Addressing Indoor Air Quality, Thermal Environment, Lighting and Acoustics. Brussels, Belgium: European Committee for Standardization.

Davis, M., W. Healy, M. Boyd, L. Ng, V. Payne, H. Skye, and T. Ullah. 2014. Monitoring techniques for the Net-Zero Energy Residential Test Facility. NIST Technical Note 1854. Gaithersburg, MD: National Institute of Standards and Technology.

Derby, M. and R. Pasch. 2017. Effects of low humidity on health, comfort and IEQ, ASHRAE Journal 59(9):45-51.

Fanney A.H., V. Payne, T. Ullah, L. Ng, M. Boyd, F. Omar, M. Davis, H. Skye, B. Dougherty, B. Polidoro, W. Healy, J. Kneifel, and B. Pettit. 2015. Net-zero and beyond! Design and 
performance of NIST's net-zero energy residential test facility. Energy and Buildings 101(0):95-109.

Francisco, P.W., J. Siegel, L. Palmiter, and B. Davis. 2006. Measuring residential duct efficiency with the short-term coheat test methodology. Energy and Buildings 38:1076-1083.

Guyton, M.L. 1993. Measured performance of relocated air distribution systems in an existing residential building. ASHRAE Transactions 99(2):429-439.

Jump, D.A., I.S. Walker, and M.P. Modera. 1996. Field measurements of Efficiency and Duct Retrofit Effectiveness in Residential Forced Air Distribution Systems. Proceedings of the 1996 ACEEE Summer Study on Energy Efficiency in Buildings, Pacific Grove, CA: 1-147-1-155.

Kim, H. and J. Haberl. 2014. Exploring methods to analyze and display continuouslymeasured time-series IEQ performance data. Proceedings of the $13^{\text {th }}$ International Conference on Indoor Air Quality and Climate-Indoor Air 2014, Hong Kong: Vol.V, pp. 181-188.

Kneifel, J. D. 2012. Annual whole building energy simulation of the NIST Net-Zero Energy Residential Test Facility. NIST Technical Note-1767. Gaithersburg, MD: National Institute of Standards and Technology.

Martin, E., C. Withers, J. Mcllvaine, D. Chasar, and D. Beal. Evaluating moisture control of variable-capacity heat pumps in mechanically ventilated, low-load homes in climate Zone 2A. U.S. DOE Building America Report DOE-EE 1702. Cocoa, FL: Florida Solar Energy Center (FSEC).

Modera M. 1993. Characterizing the performance of residential air distribution systems. Energy and Buildings 20(1):65-75.

NOAA. 2019. Data Tools: Local Climatological Data (LCD). Washington, DC: National Oceanic and Atmospheric Administration. Retrieved July 26, 2019, from http://www.ncdc.noaa.gov/qclcd/QCLCD?prior=N

NIST. 2019. The Future of Home Energy Data. Gaithersburg, MD: National Institute of Standards and Technology. Retrieved July 26, 2019, from https://pages.nist.gov/netzero/index.html

Omar, F. and S. T. Bushby. 2013. Simulating occupancy in the NIST Net-Zero Energy Residential Test Facility. NIST Technical Note-1817. Gaithersburg, MD: National Institute of Standards and Technology.

Pettit, B., C. Gates, A. H. Fanney and W.M. Healy. 2014. Design challenges of the NIST NetZero Energy Residential Test Facility. NIST Technical Note-1847.Gaithersburg, MD: National Institute of Standards and Technology.

Poerschke, A. and R. Beach. 2016. Comfort in High-Performance Homes in a Hot-Humid Climate. U.S. DOE Building America Subcontract Report DOE/GO-102016-4762. Pittsburgh, PA: Integrated Building and Construction Solutions (IBACOS).

Poerschke, A. and A. Rudd. 2016. Performance analysis of a modular small-diameter air distribution system. U.S. DOE Building America Subcontract Report DOE/GO-1020164751. Pittsburgh, PA: Integrated Building and Construction Solutions (IBACOS).

Poerschke, A., R. Beach, and T. Beggs. 2016. Comparative cooling season performance of air distribution systems in multistory townhomes. U.S. DOE Building America Subcontract Report DOE/GO-102016-4803. Pittsburgh, PA: Integrated Building and Construction Solutions (IBACOS). 
Poerschke, A. 2017. Measured performance of a varied air flow small-diameter duct system. U.S. DOE Building America Subcontract Report DOE/GO-102017-4664. Pittsburgh, PA: Integrated Building and Construction Solutions (IBACOS).

Siegel, Jeff, B. Davis, P. Francisco and L. Palmiter. 1997. Measured heating system efficiency Retrofits in Eight Manufactured (HUD-Code) Homes. Electric Power Research Institute Report TR-107737.

Stecher, D., K. Allison, and D. Prahl. 2012. Long-Term Results from Evaluation of Advanced New Construction Packages in Test Homes: Martha's Vineyard, Massachusetts. U.S. DOE Building America Subcontract Report DOE/GO-102012-3494. Pittsburgh, PA: Integrated Building and Construction Solutions (IBACOS).

Stephens, B., J.A. Siegel, and A. Novoselac. 2011. Operational characteristics of residential and light-commercial air-conditioning systems in a hot and humid climate zone. Building and Environment 46:1972-1983.

Sterling, E., A. Arundel, T. and Sterling. 1985. Criteria for human exposure to humidity in occupied buildings, ASHRAE Transactions 91(1B):611-622.

Rittelmann, W. 2006. A Systemic Short-Term Field Test for Residential HVAC Thermal Comfort Performance. Proceedings of the 2006 ACEEE Summer Study on Energy Efficiency in Buildings, Pacific Grove, CA:1-260-1-271.

Rittelmann, W. 2008. Thermal Comfort Performance: Field Investigation of a Residential Forced-Air Heating and Cooling System with High Sidewall Supply Air Outlets. Proceedings of the Building Enclosure Science and Technology Conference, Minneapolis, MN:E11-6.

Vineyard, E., R.L. Linkous, and E. Baskin. 2003. Measured performance of conventional and high-velocity distribution systems in attic and space locations. ASHRAE Transactions 109(2):45-51.

Werling, E. 2015. Building America research-to-market plan. U.S. DOE Building America Report DOE-EE 1285. Washington, DC: U.S. DOE. 


\section{APPENDIX A: DAYS TO EXCLUDE}

Appendix A provides a list of the 42 days that were excluded from the analysis with the reasons for exclusion.

- The following 20 days were excluded due to long-term IAQ testing at NZERTF.

- October 27, 2016 through November 15, 2016

- The following 8 days were excluded due to the switch between the two heat pumps occurred during the day rather than at midnight.

- September 23, 2016

- October 4, 2016

- January 4, 2017

- January 24, 2017

- February 13, 2017

- March 2, 2017

- March 14, 2017

- March 15, 2017

- The following 6 days were excluded due to operational anomalies of the SDHV HP system such as firmware issues.

- March 13, 2017

- March 16, 2017 through March 20, 2017

- The following 4 days were excluded due to some activities at NZERTF such as troubleshooting of sensors and systems or short-term sampling of the IAQ.

- February 23, 2017

- March 9, 2017

- March 23, 2017

- July 26, 2017

- The following 2 days were excluded due to cleaning activities by contractor service at NZERTF.

- January 19, 2017

- August 10, 2017

- The following 1 day were excluded due to the switch from heating to cooling. - April 5, 2017

- The following 1 day were excluded due to missing data caused by OFPM power outage.

- September 24, 2016 


\section{APPENDIX B: WHOLE-HOUSE TEMPERATURE DATA CORRECTION}

Appendix B presents graphical summaries of the recorded (i.e., before correction) and the corrected 1-min whole-house temperature data collected from September 2016 to August 2017 by following the thermocouple correction procedures provided by NIST for the following data channels:

- 24 room air temperatures (Appendix B-1);

- 5 room globe temperatures (Appendix B-2); and

- 1 outdoor air temperature (Appendix B-3).

Standard time-series plots present the recorded temperatures (i.e., before correction) and the corrected temperatures using the primary $Y$-axis on the left with the differences between the two temperatures using the secondary $Y$-axis on the right. In addition, the heating and cooling setpoint temperatures are presented as a reference for the primary rooms (i.e., LR, $\mathrm{KIT}, \mathrm{MBR}, \mathrm{BR} 2$, and BR3). 


\section{APPENDIX B-1: 1-MIN AIR TEMPERATURES BY ROOM ROOMS ON THE FIRST FLOOR}

- LR: Living Room
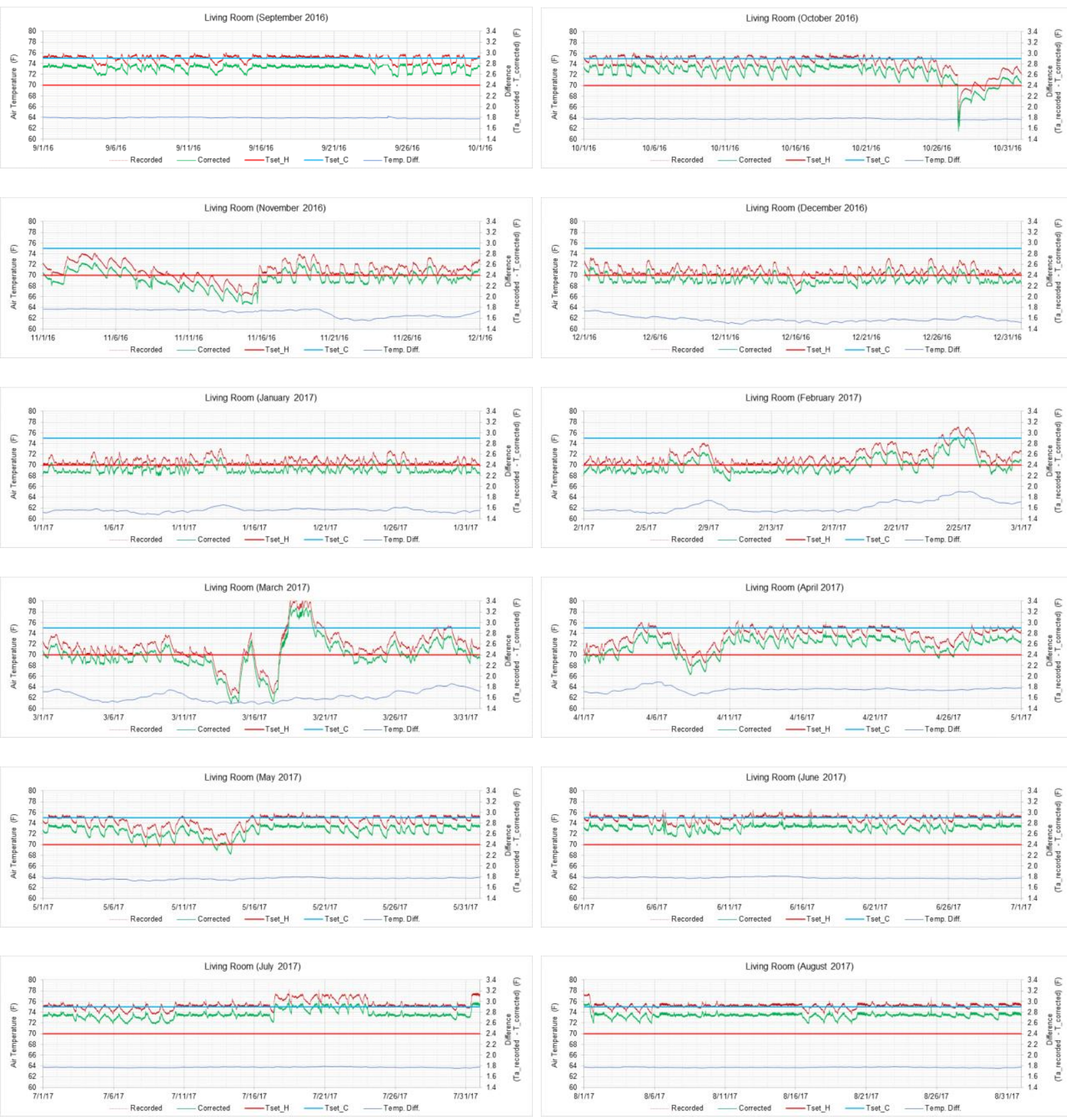

Figure B-1: Recorded and Corrected 1-Min LR Temperature. 
- KIT: Kitchen
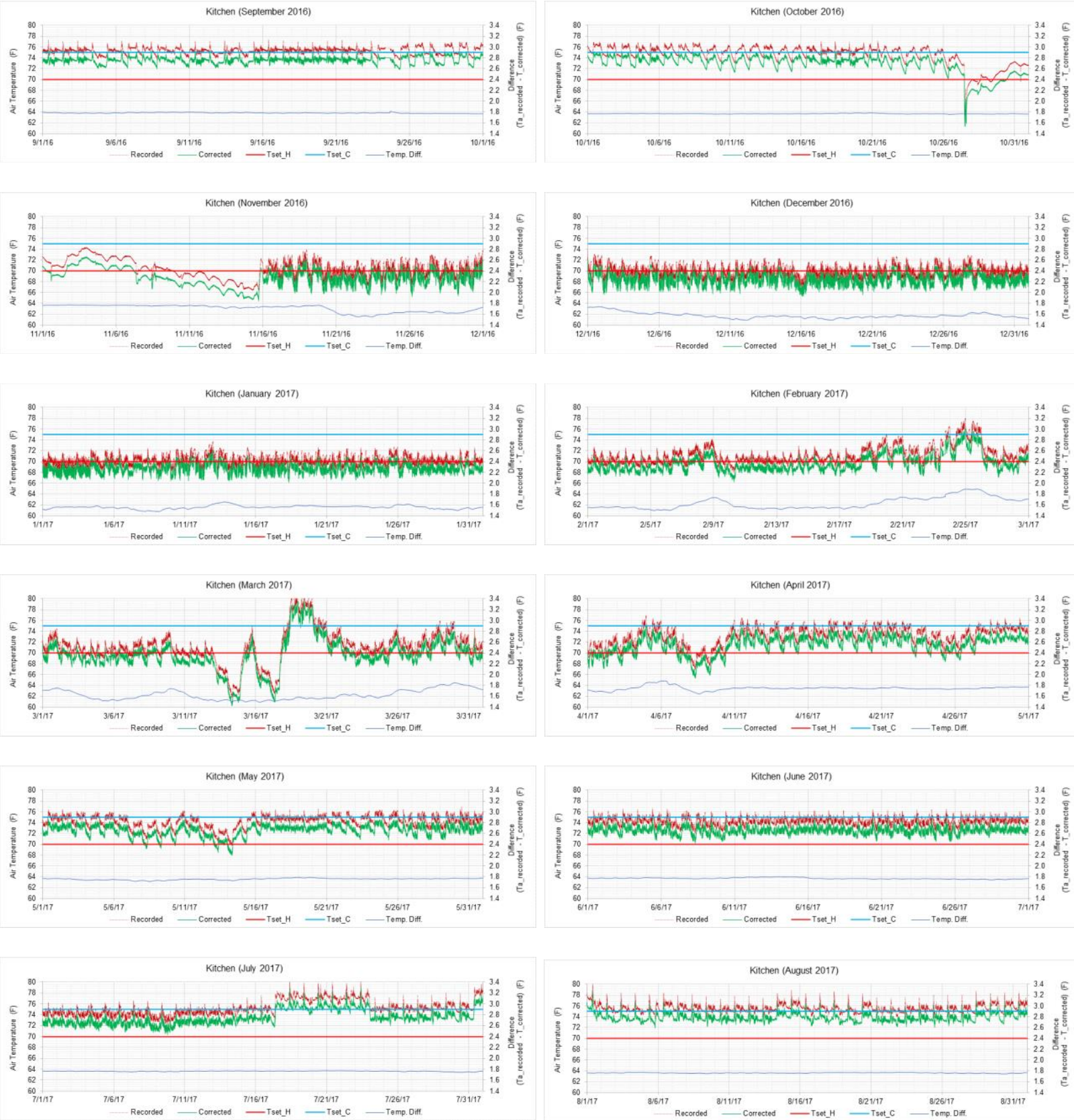

Figure B-2: Recorded and Corrected 1-Min KIT Temperature. 
- DR: Dining Room
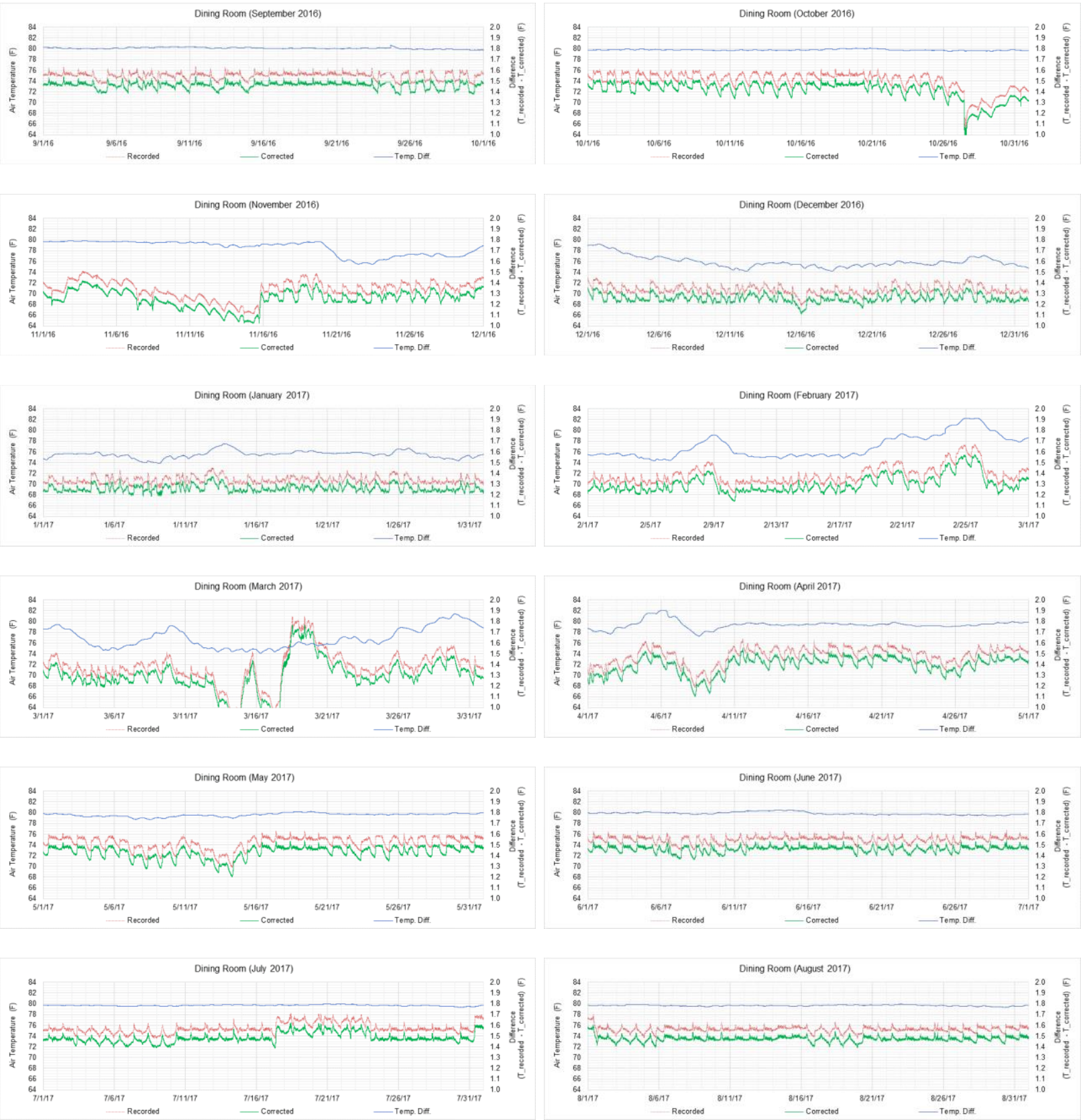

Figure B-3: Recorded and Corrected 1-Min DR Temperature. 


\section{- BR4: Bedroom 4}
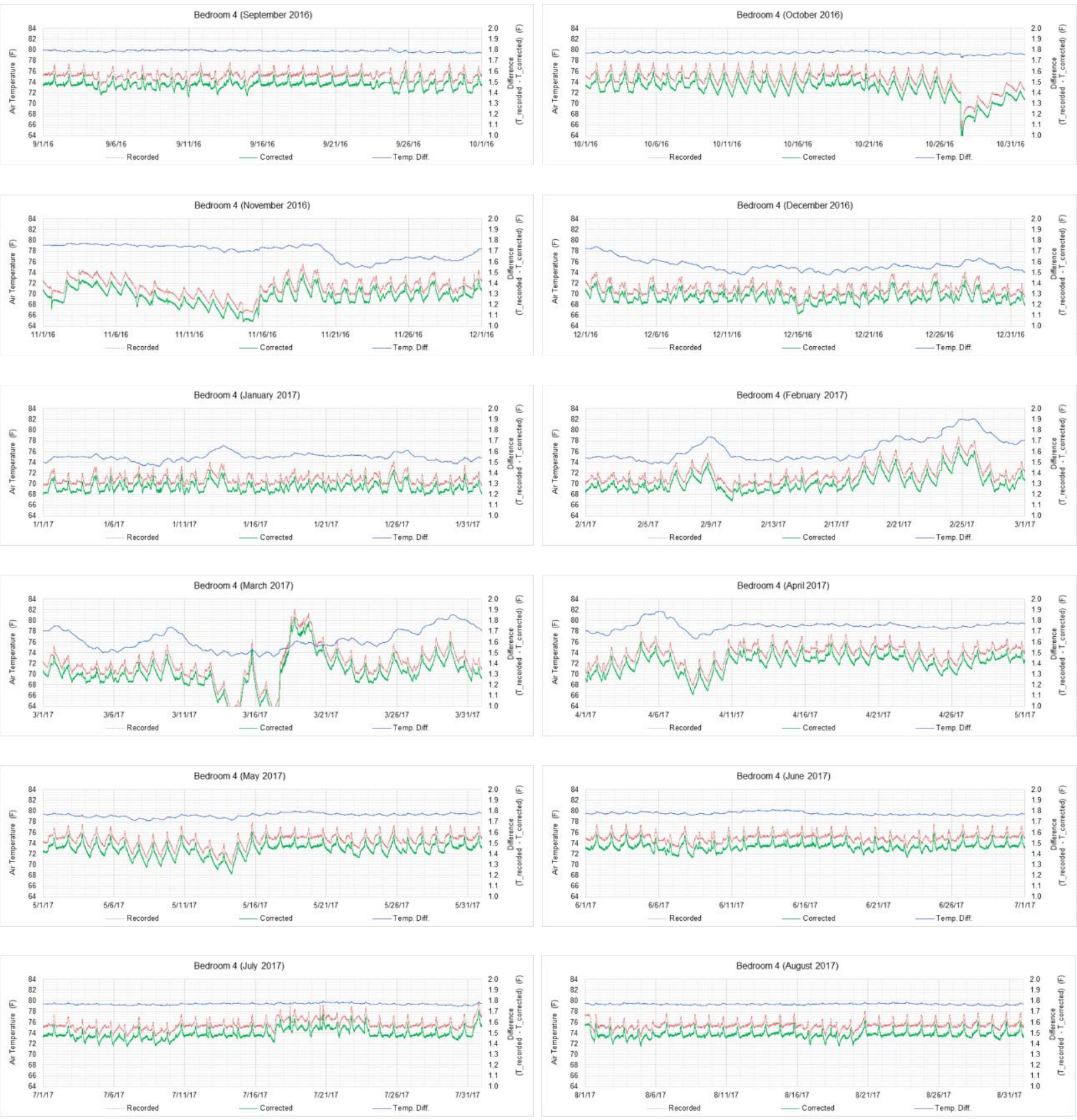

Figure B-4: Recorded and Corrected 1-Min BR4 Temperature. 


\section{- BA1: Bathroom 1}
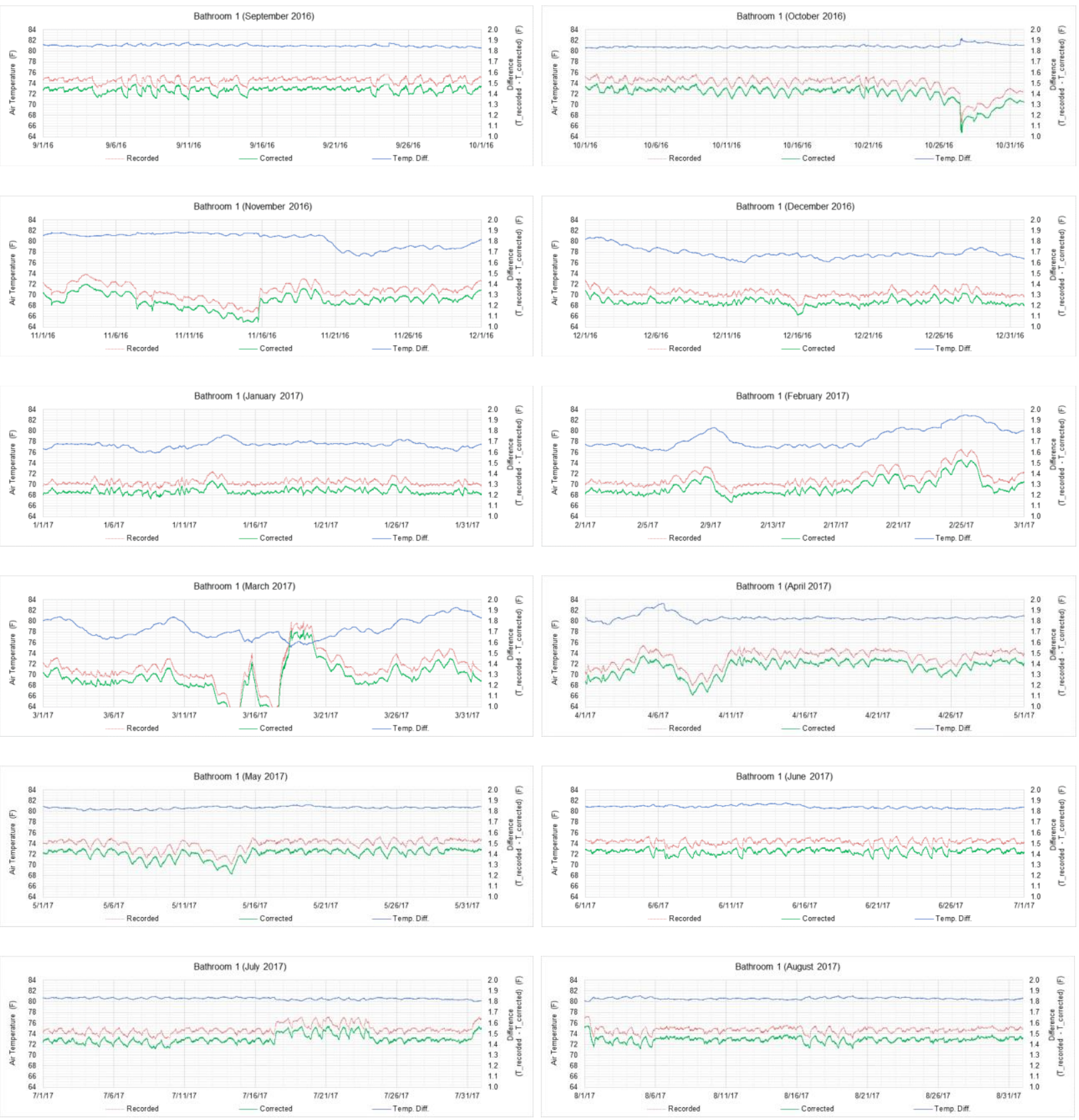

Figure B-5: Recorded and Corrected 1-Min BA1 Temperature. 
- WD: Washer and Dryer
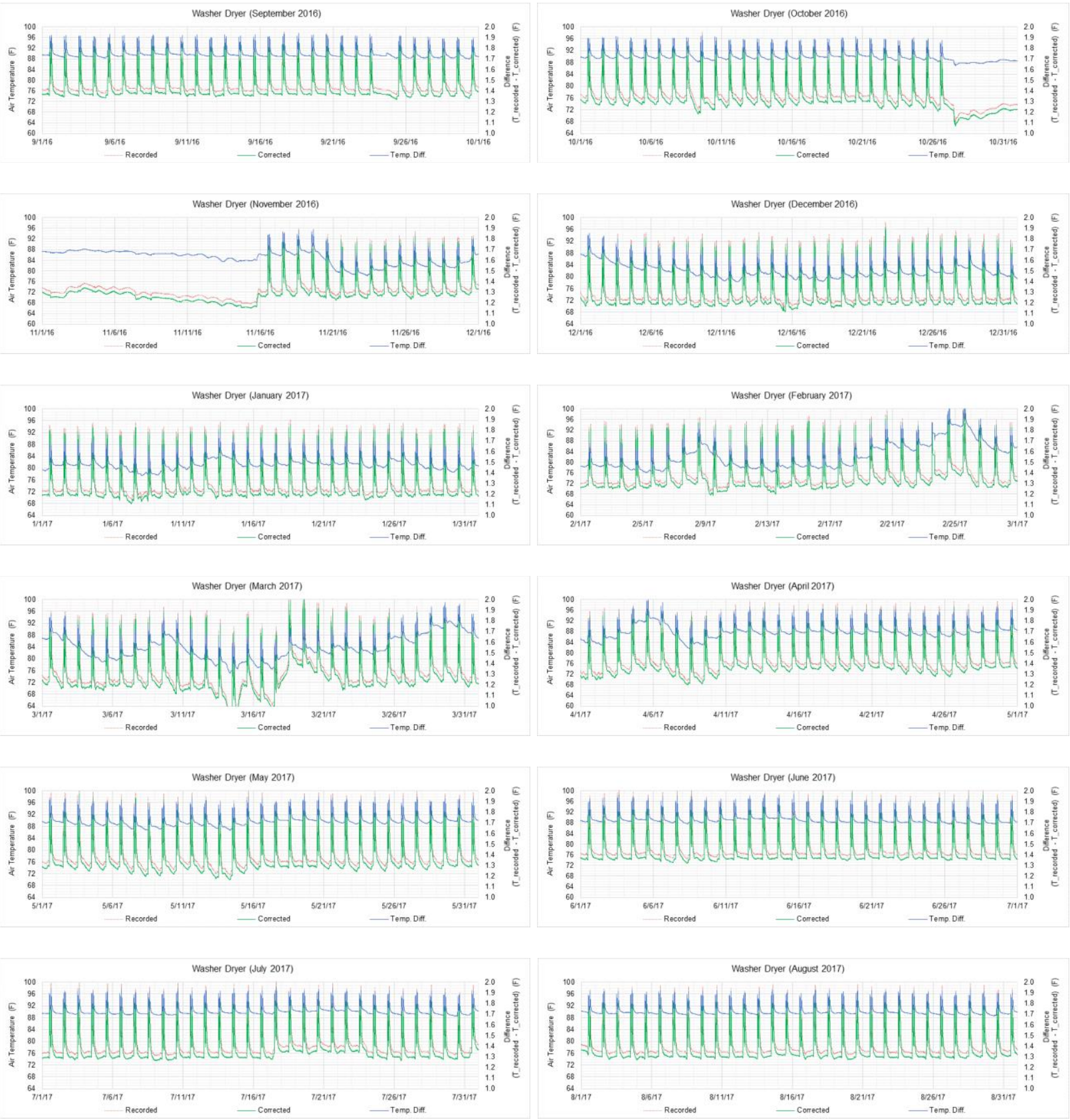

Figure B-6: Recorded and Corrected 1-Min WD Temperature. 


\section{ROOMS ON THE SECOND FLOOR}

- MBR: Master Bedroom
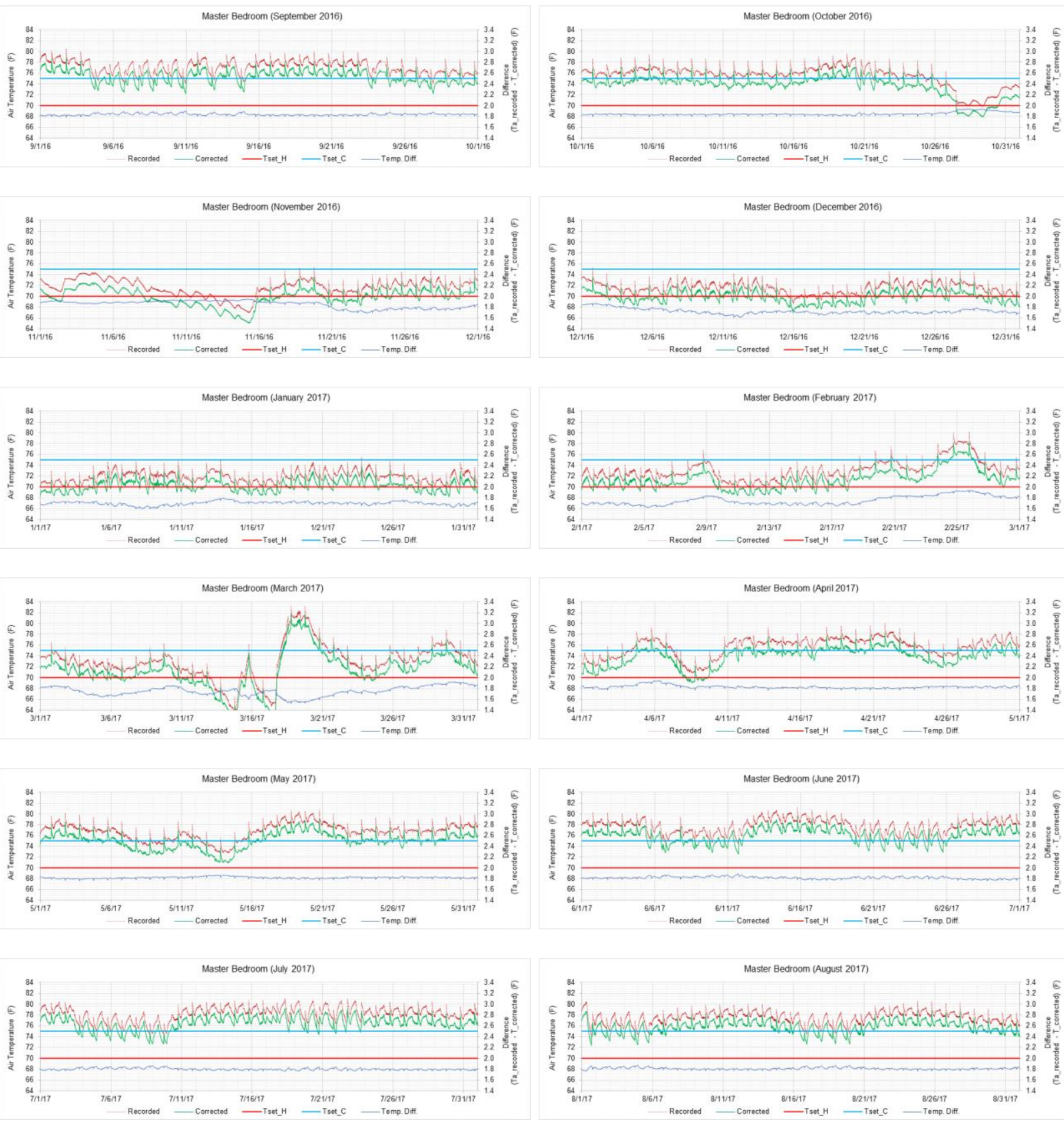

Figure B-7: Recorded and Corrected 1-Min MBR Temperature. 


\section{- BR2: Bedroom 2}
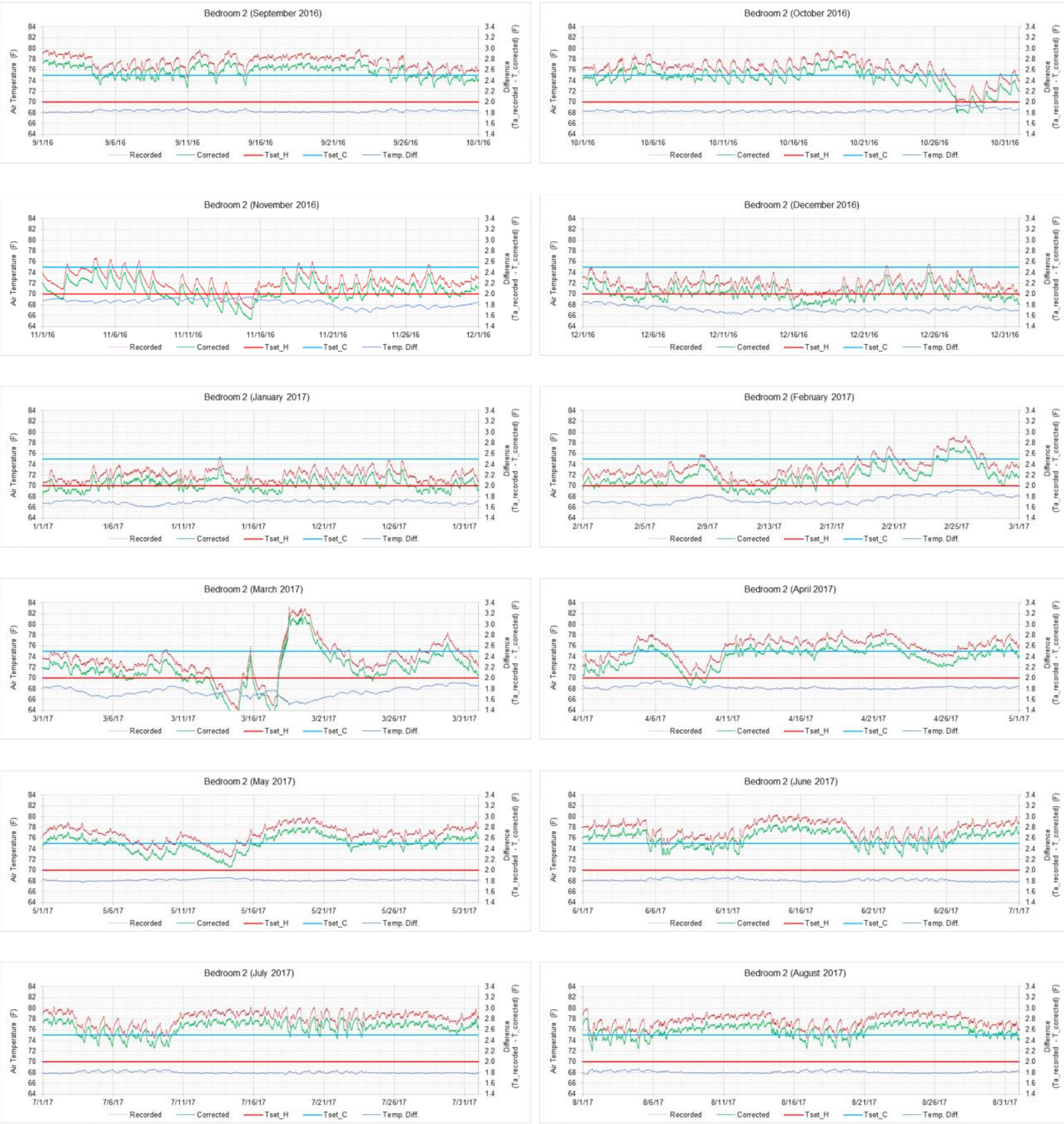

Figure B-8: Recorded and Corrected 1-Min BR2 Temperature. 
- BR3: Bedroom 3
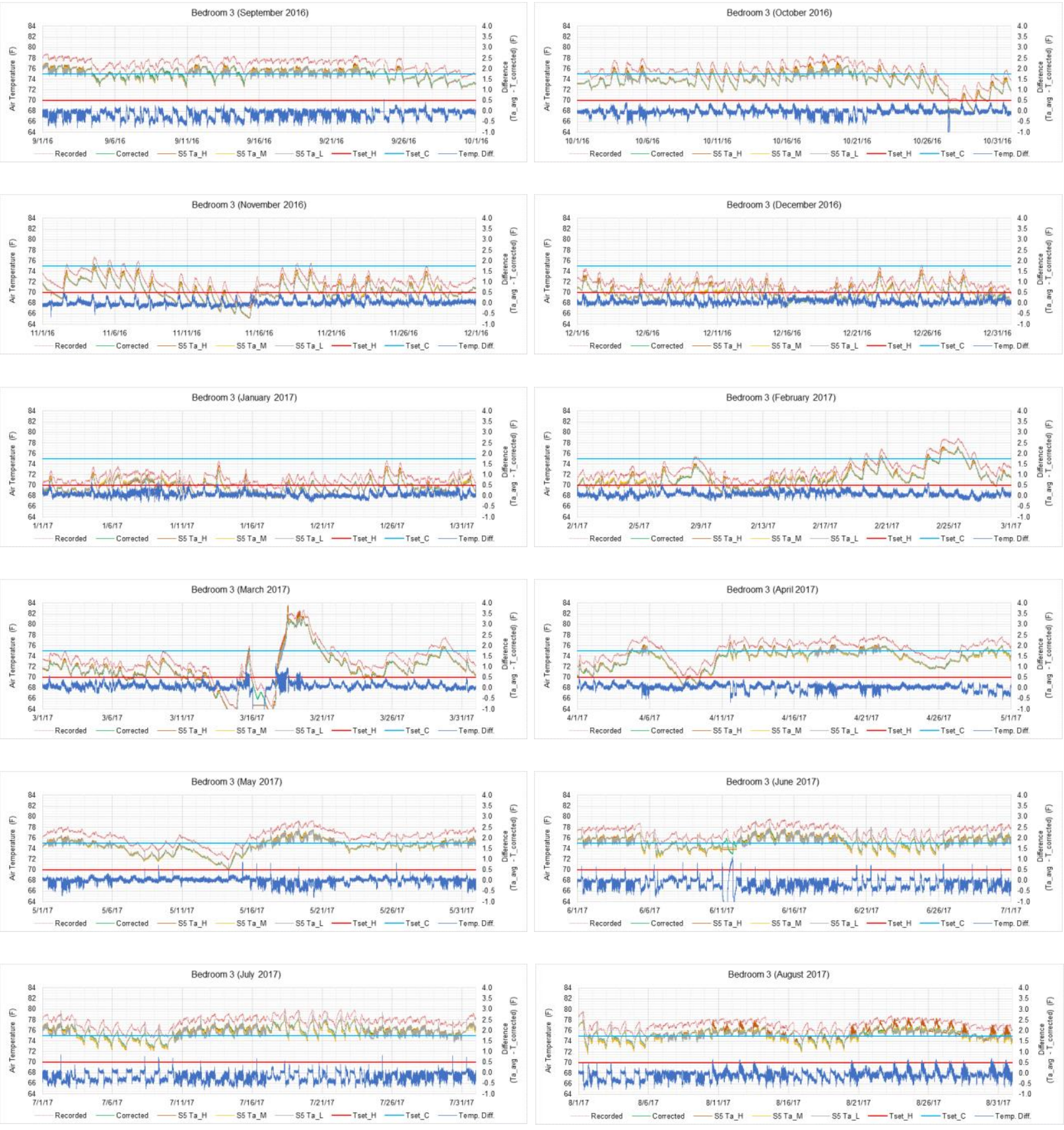

Figure B-9: Recorded and Corrected 1-Min BR3 Temperature. 
- MBA: Master Bathroom
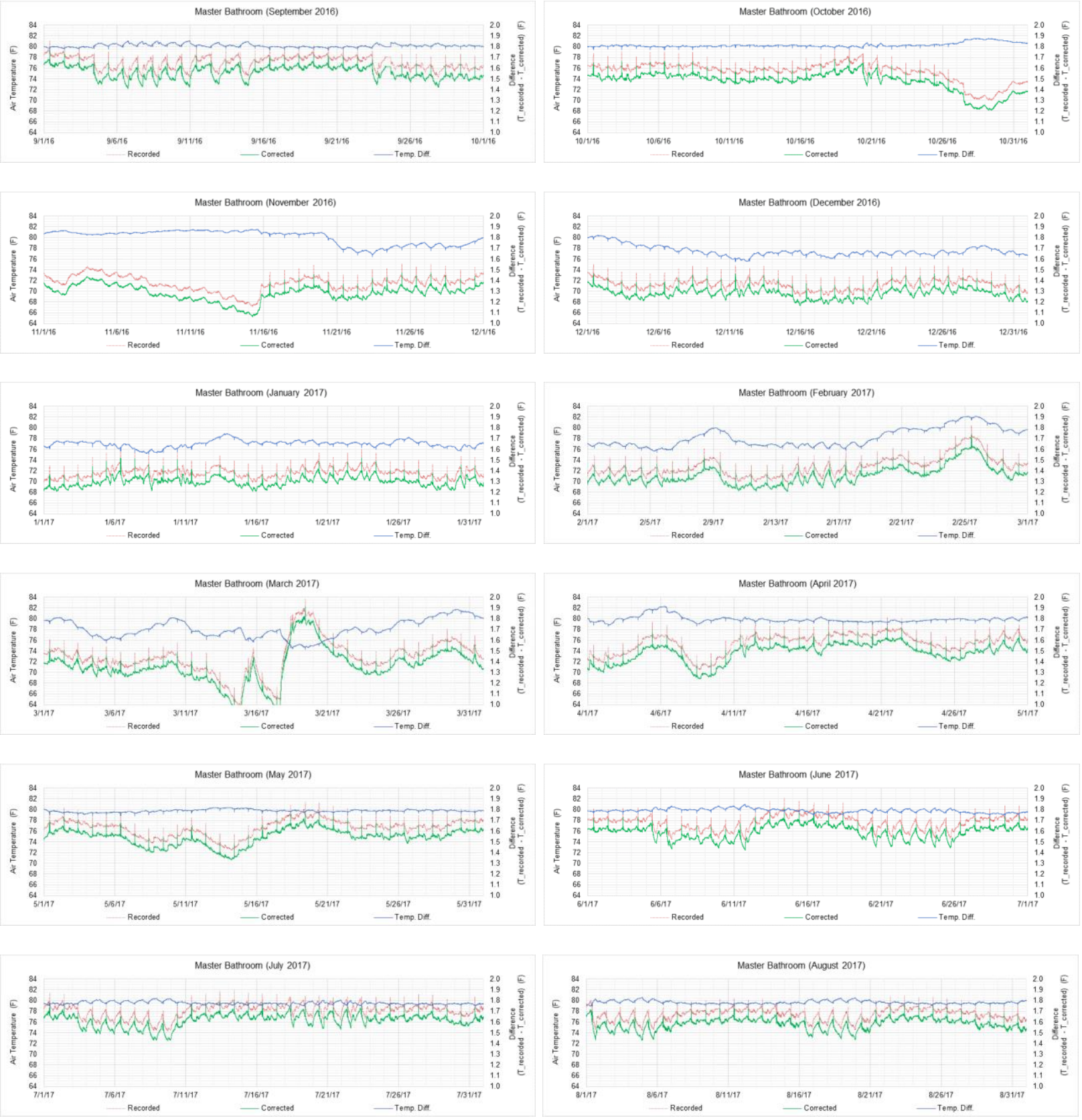

Figure B-10: Recorded and Corrected 1-Min MBA Temperature. 
- BA2: Bathroom 2
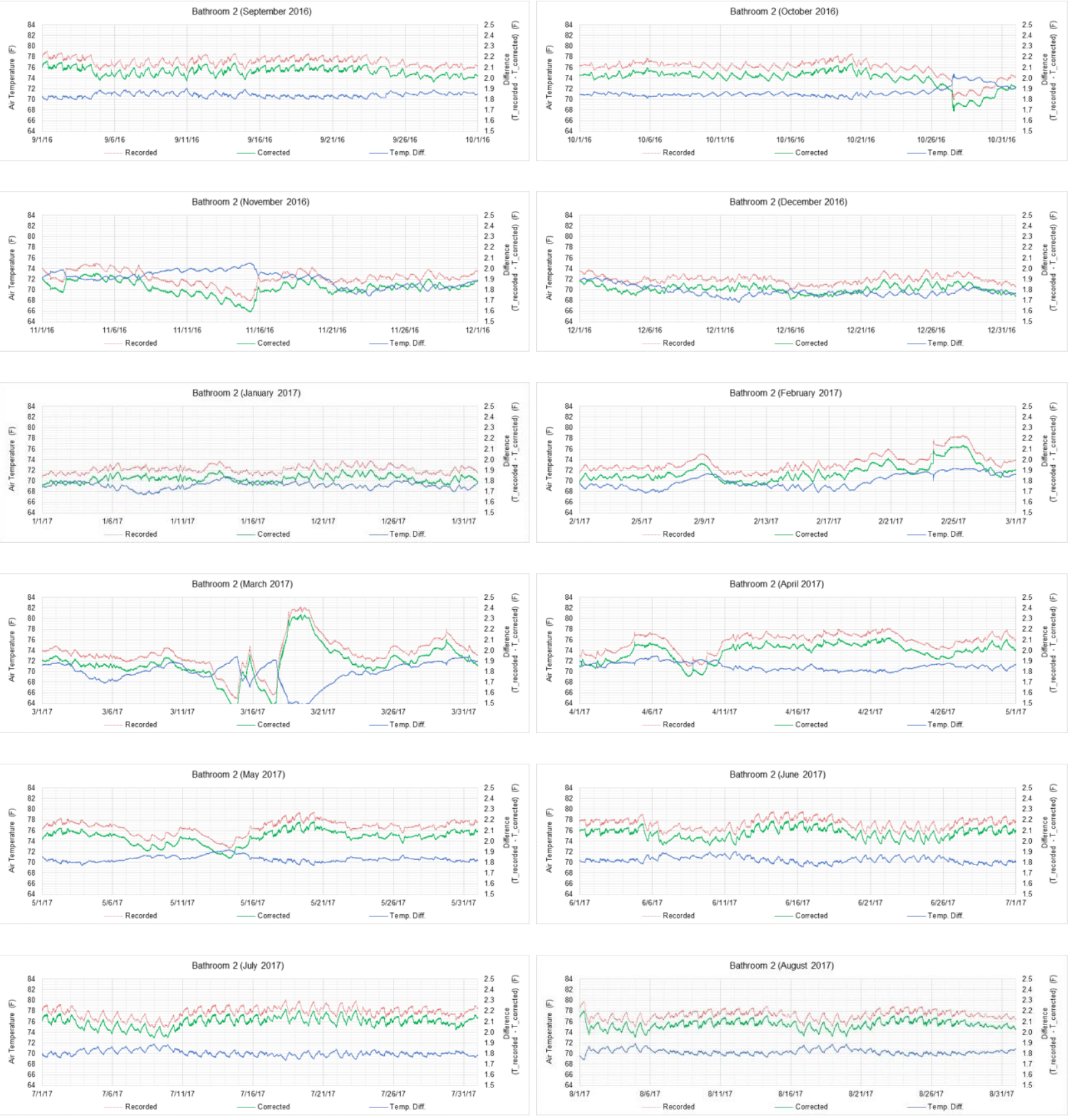

Figure B-11: Recorded and Corrected 1-Min BA2 Temperature. 


\section{ATTIC}

- A_NW: Attic-Northwest
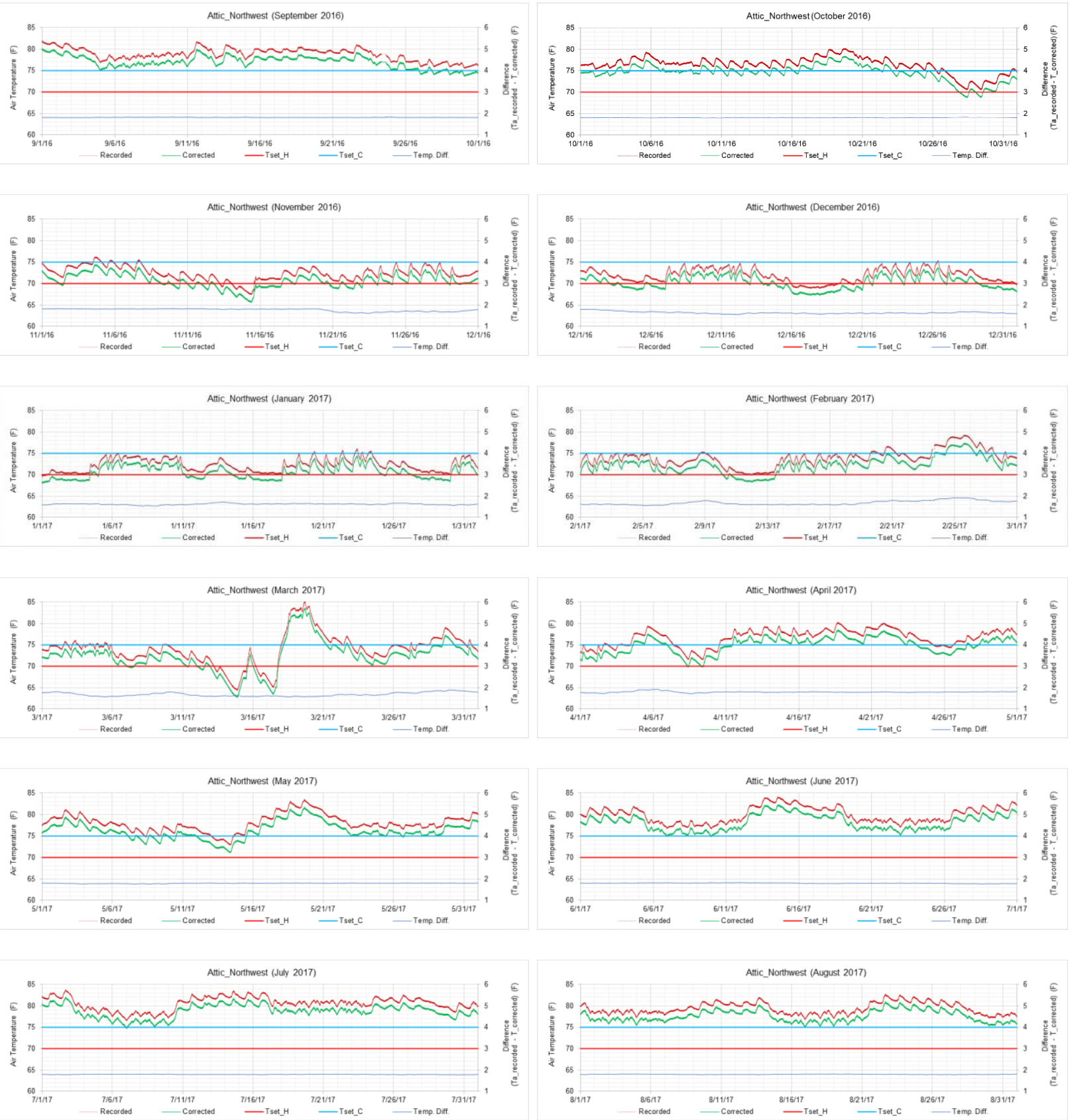

Figure B-12: Recorded and Corrected 1-Min Attic Northwest Temperature. 


\section{- A_NE: Attic-Northeast}
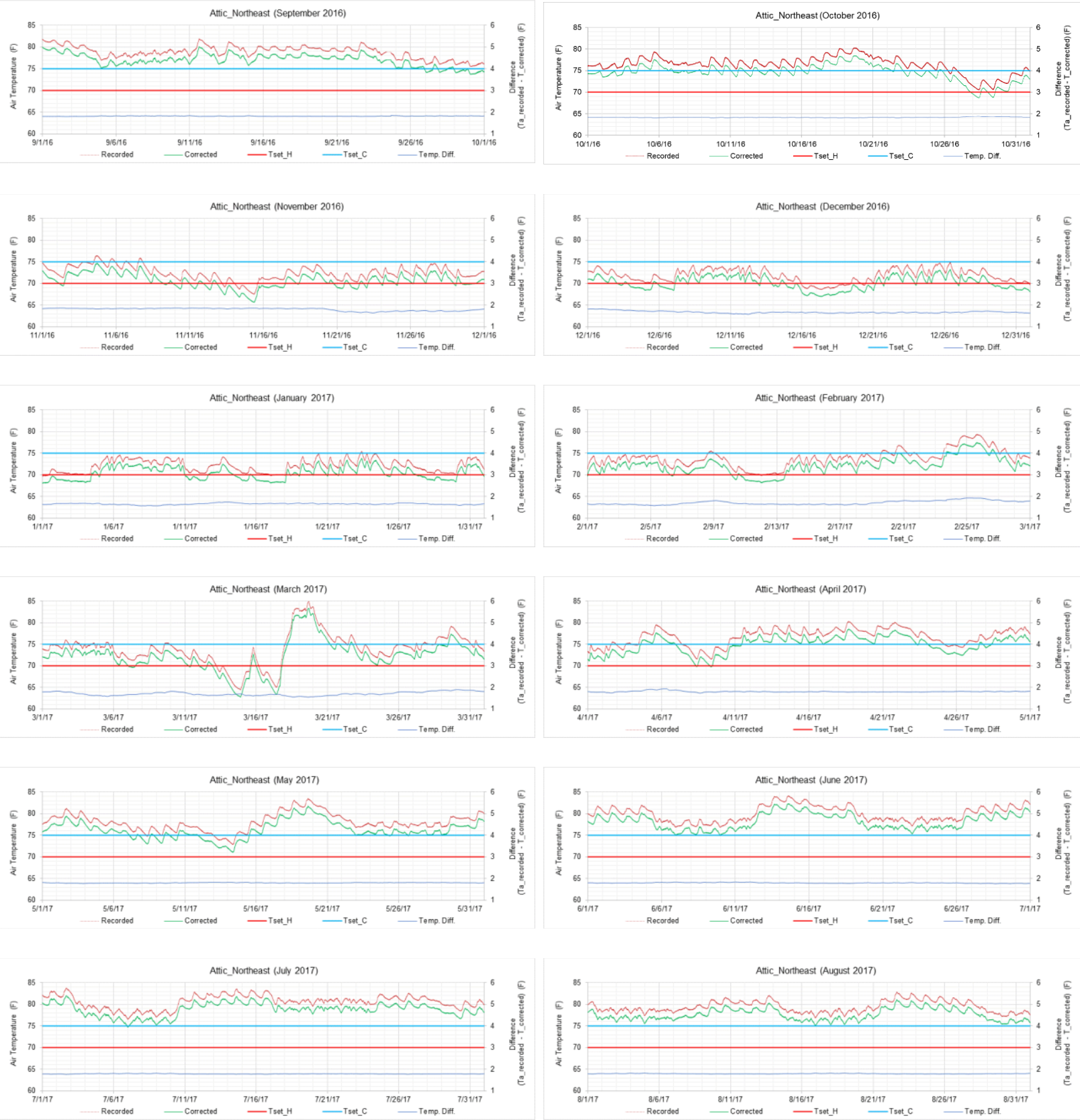

Figure B-13: Recorded and Corrected 1-Min Attic Northeast Temperature. 
- A_SE: Attic - Southeast
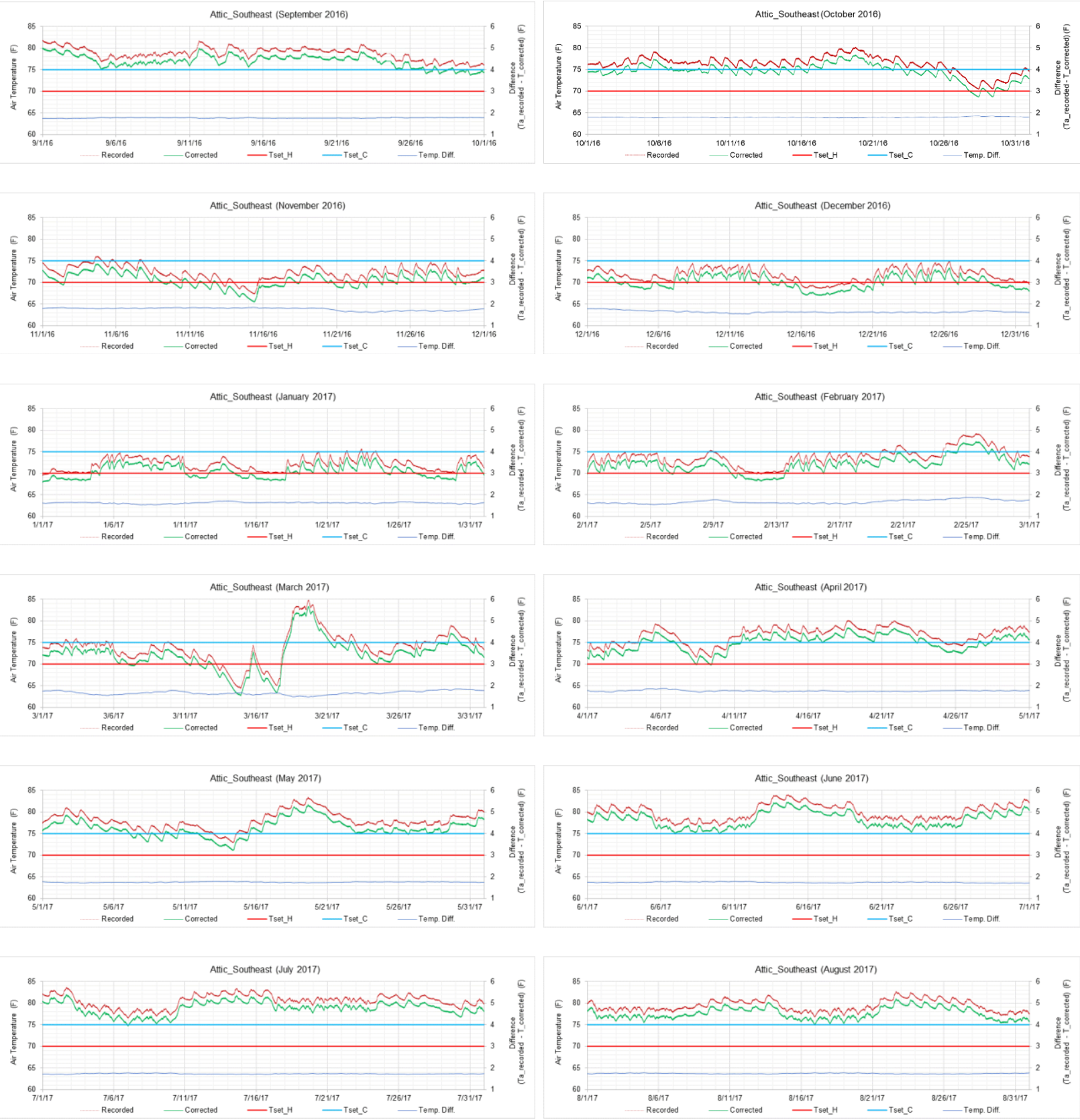

Figure B-14: Recorded and Corrected 1-Min Attic Southeast Temperature. 
- A_SW: Attic-Southwest
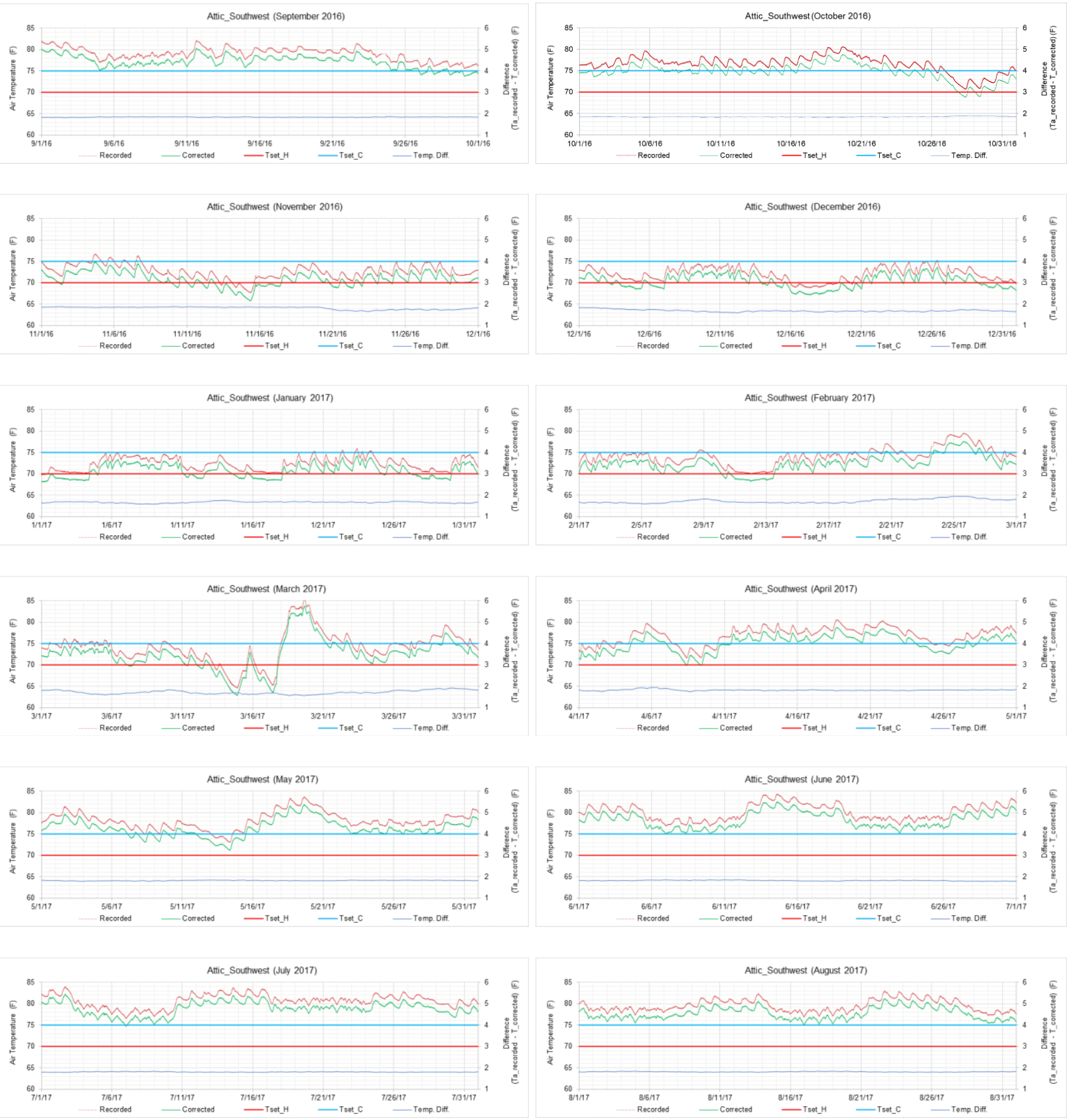

Figure B-15: Recorded and Corrected 1-Min Attic Southwest Temperature. 


\section{BASEMENT}

- B_NW: Basement - Northwest
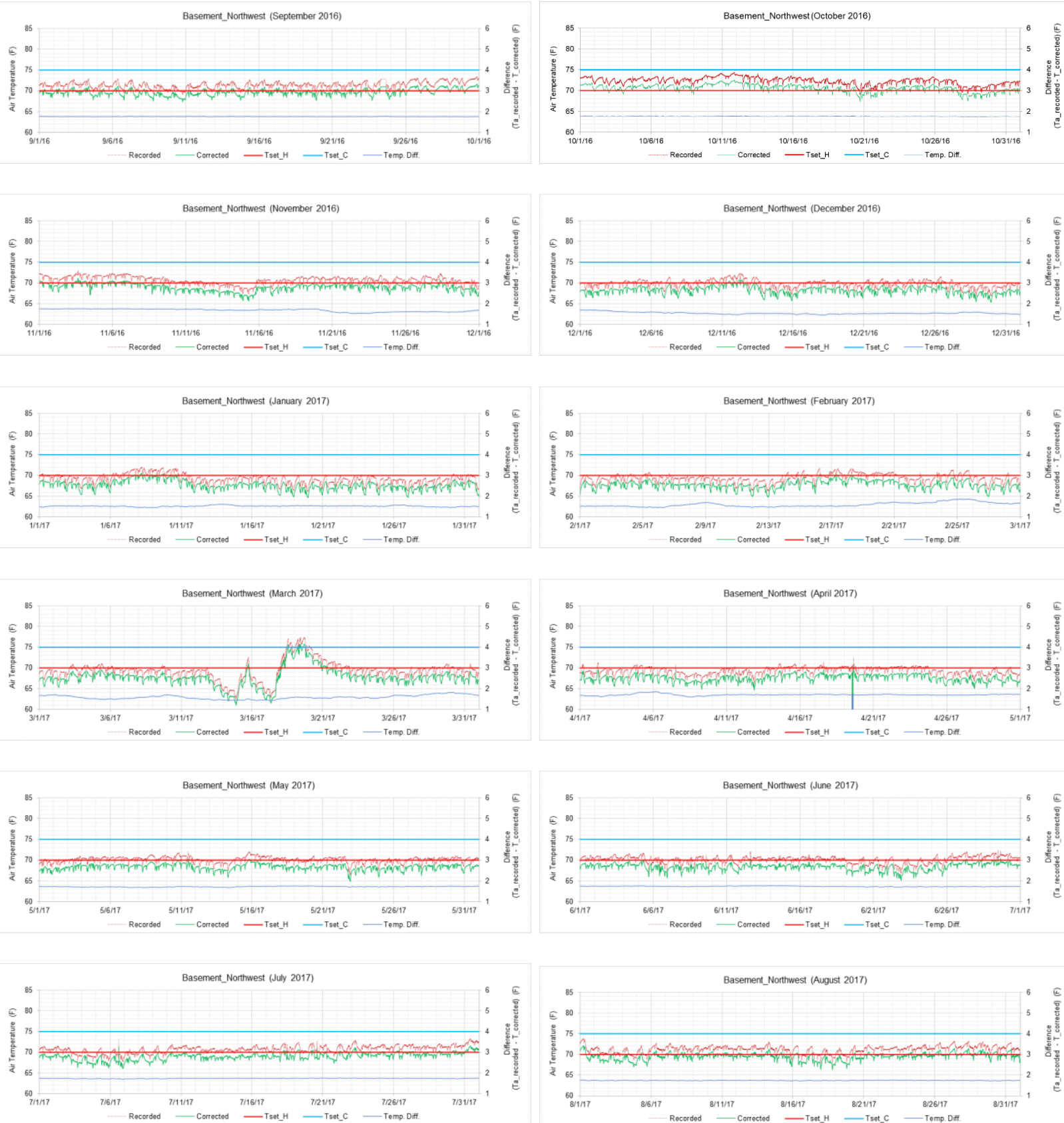

Figure B-16: Recorded and Corrected 1-Min BSMT Northwest Temperature. 
- B_NE: Basement - Northeast
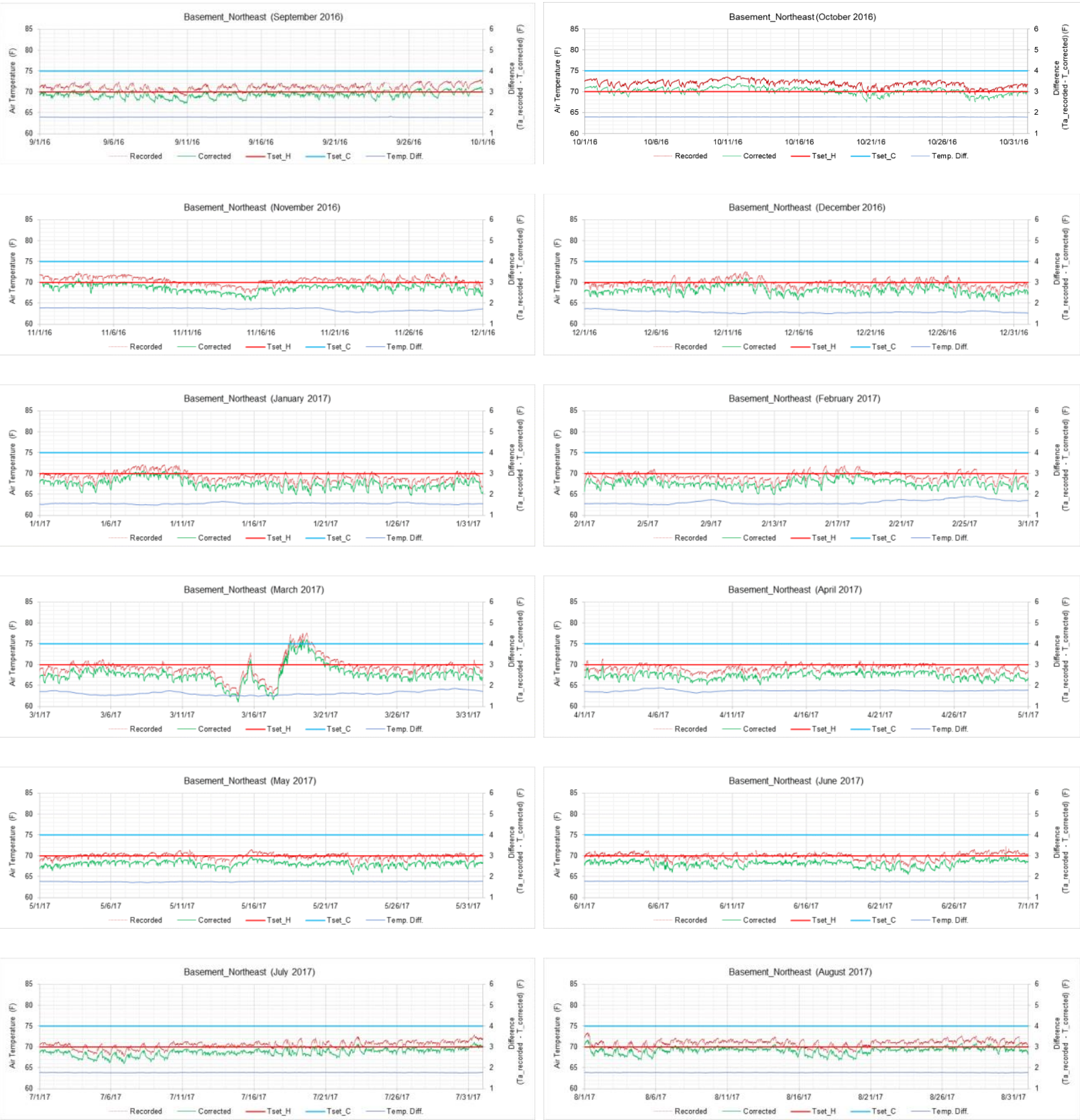

Figure B-17: Recorded and Corrected 1-Min BSMT Northeast Temperature. 
- B_SE: Basement - Southeast
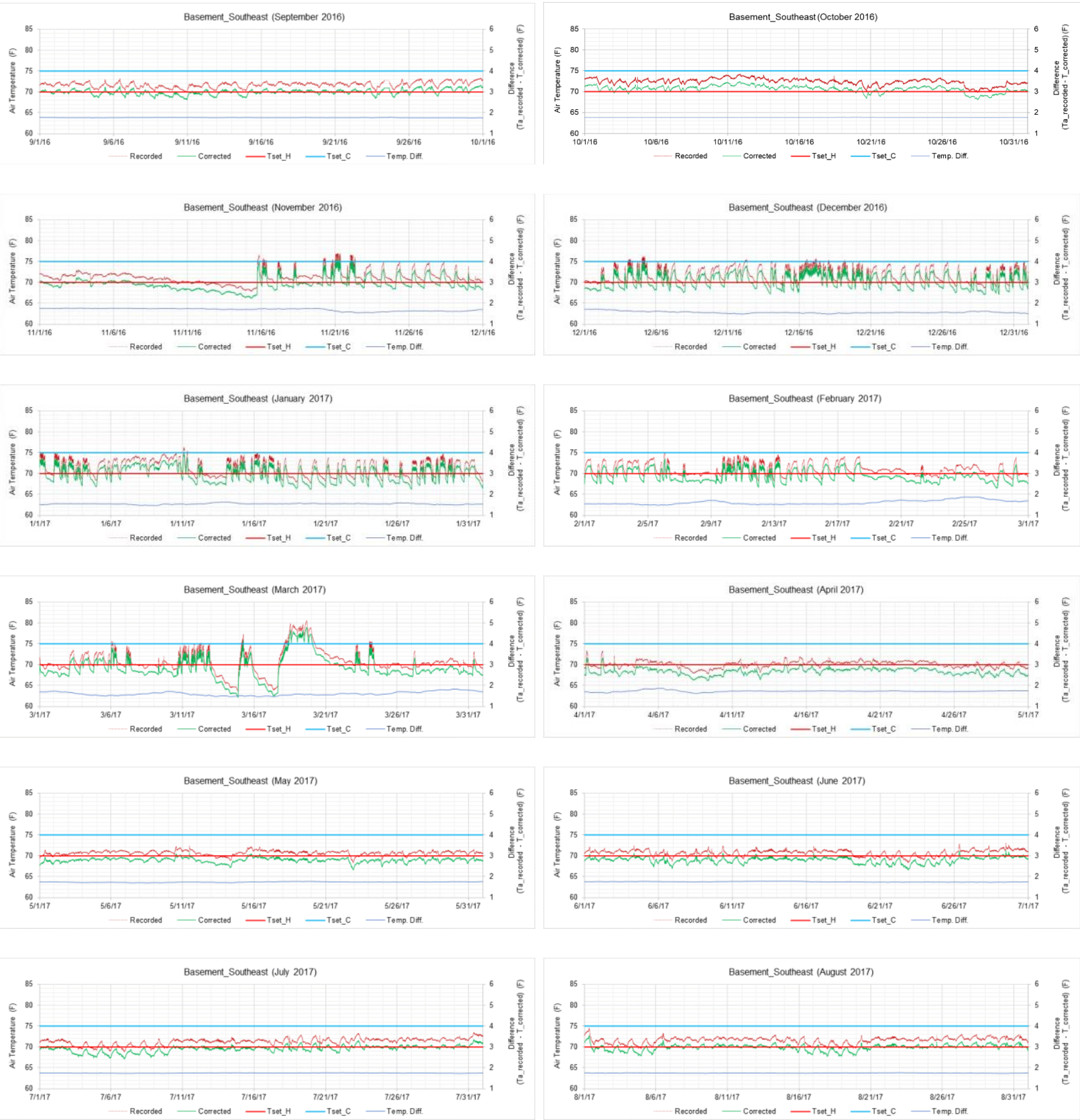

Figure B-18: Recorded and Corrected 1-Min BSMT Southeast Temperature. 
- B_SW: Basement - Southwest
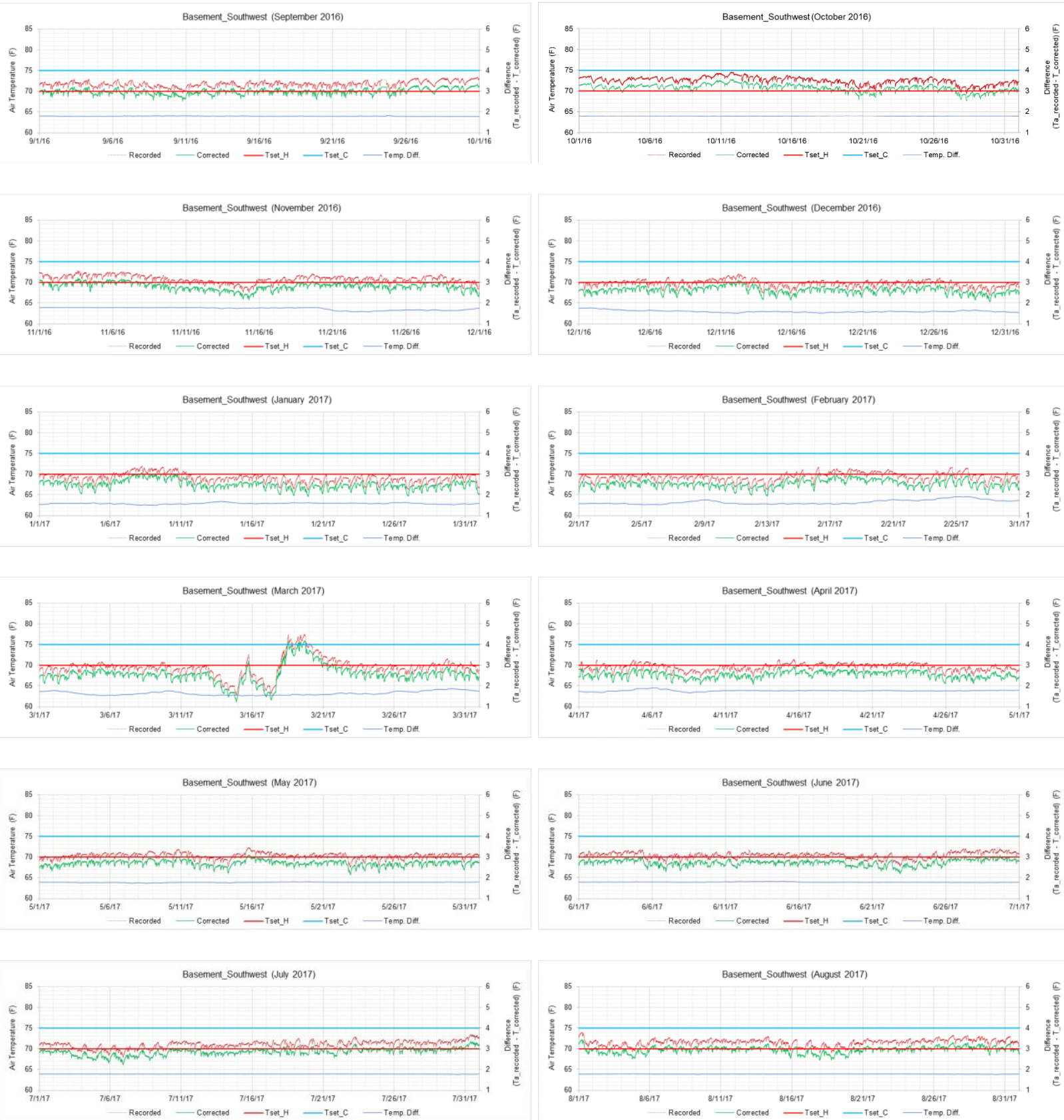

Figure B-19: Recorded and Corrected 1-Min BSMT Southwest Temperature. 


\section{ENTRY HALLWAY (EH)}

- HLowest: EH Lowest at 0.6m (24 in.)
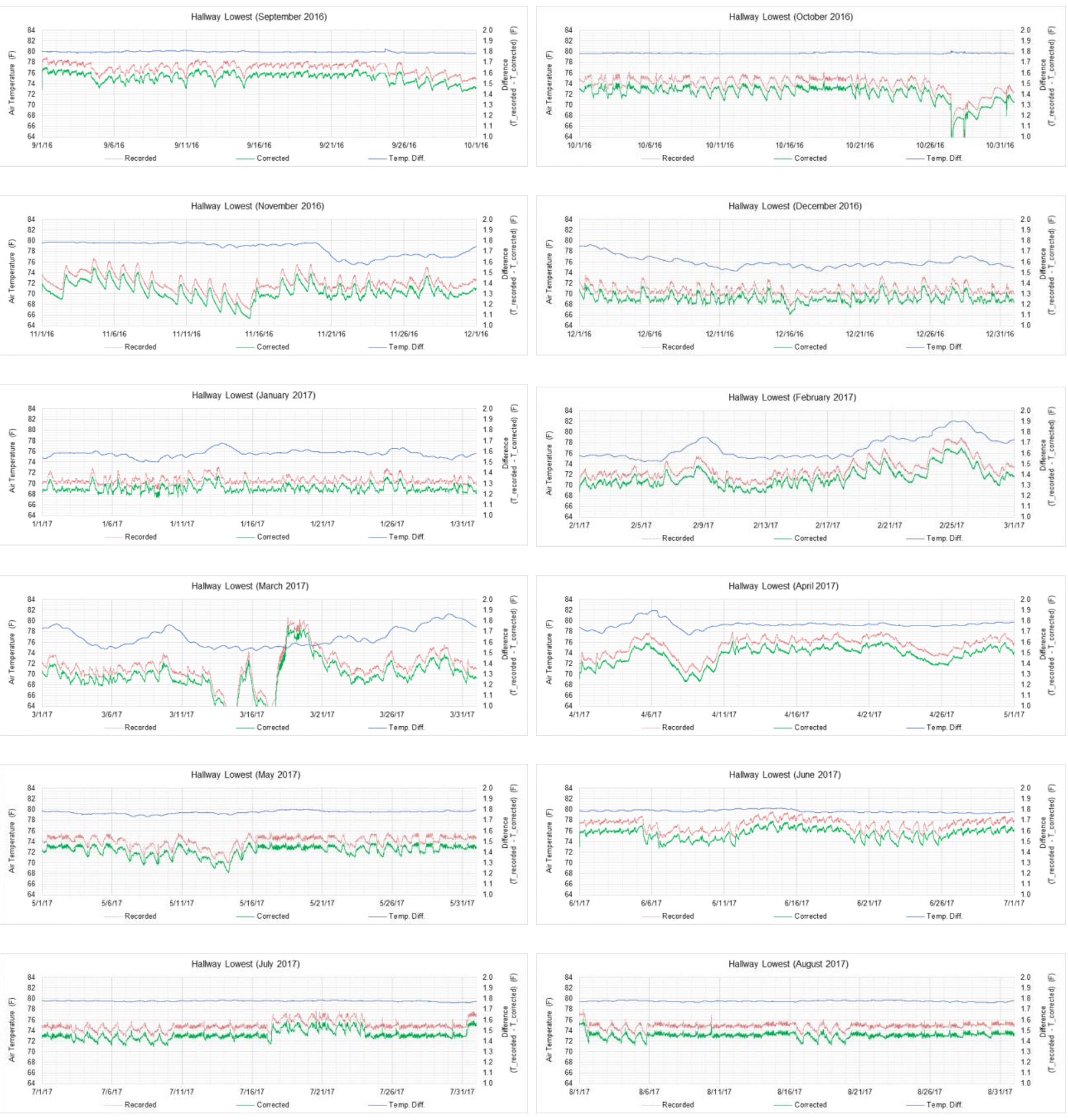

Figure B-20: Recorded and Corrected 1-Min EH Lowest Temperature. 
- HLowerMid: EH Lower Middle at 1.8m (71 in.)
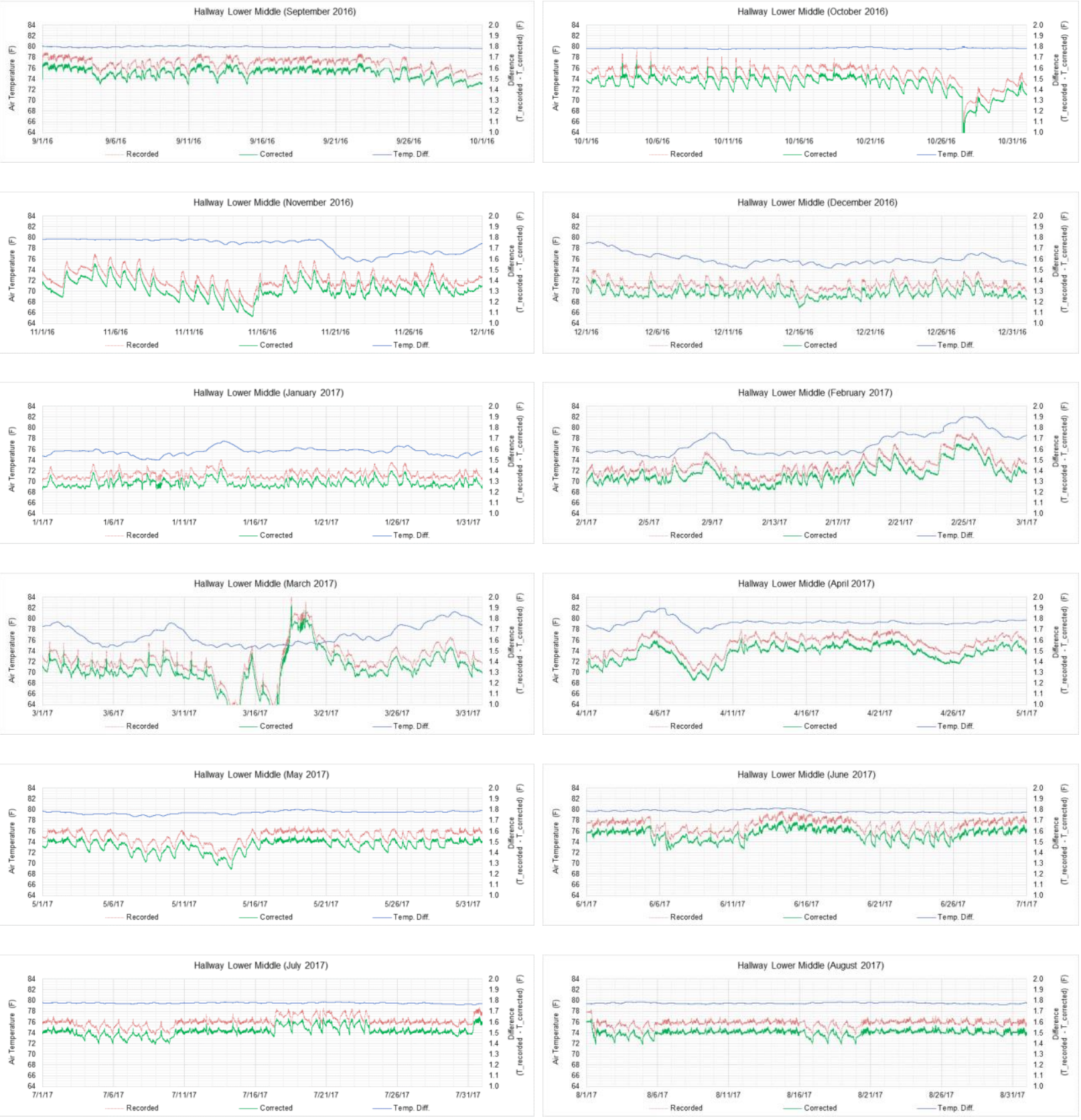

Figure B-21: Recorded and Corrected 1-Min EH Lower Middle Temperature. 
- HMiddle: EH Middle at 3.0 m (118 in.)
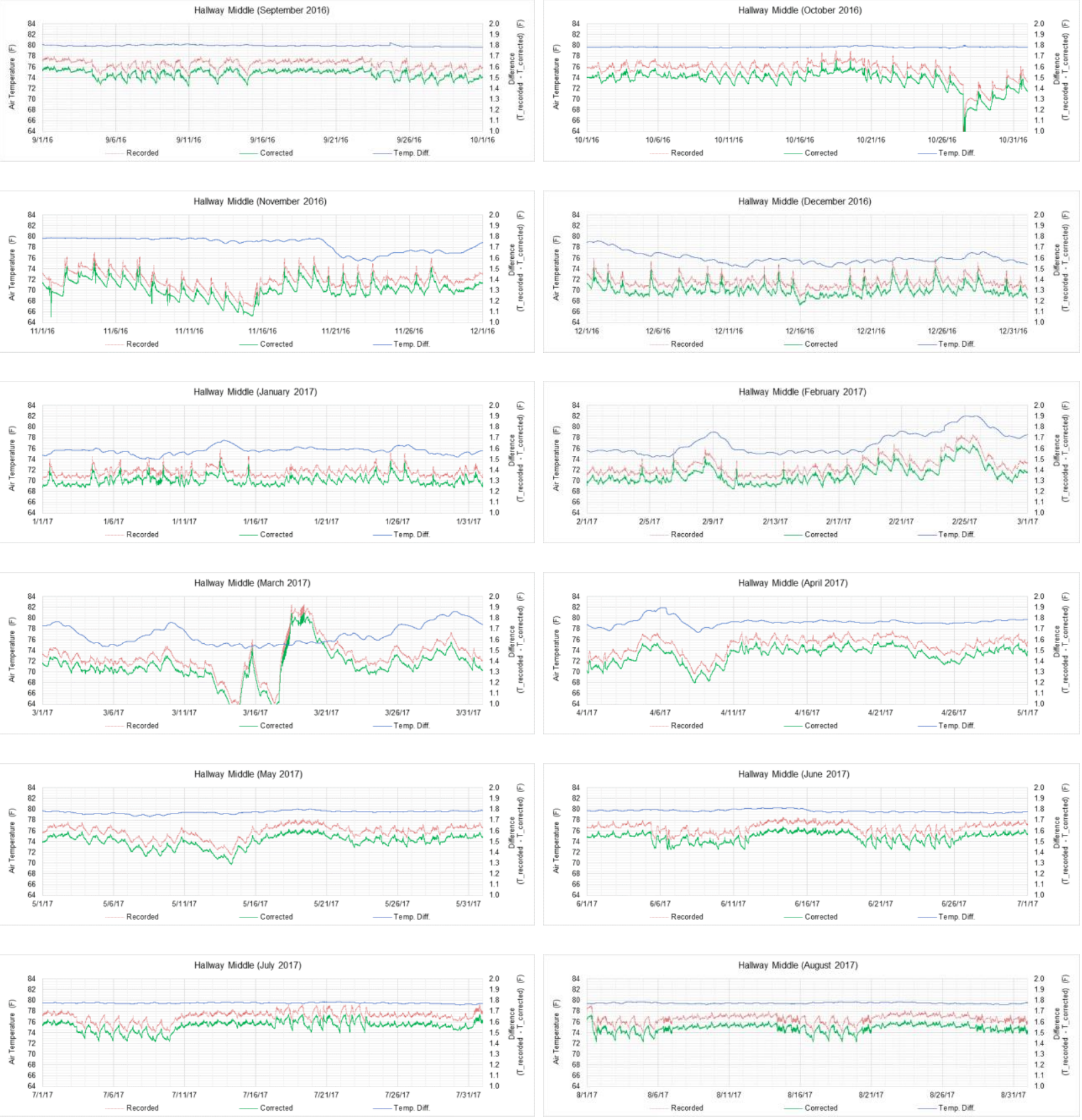

Figure B-22: Recorded and Corrected 1-Min EH Middle Temperature. 
- HUpperMid: EH Upper Middle at 4.3 m (169 in.)
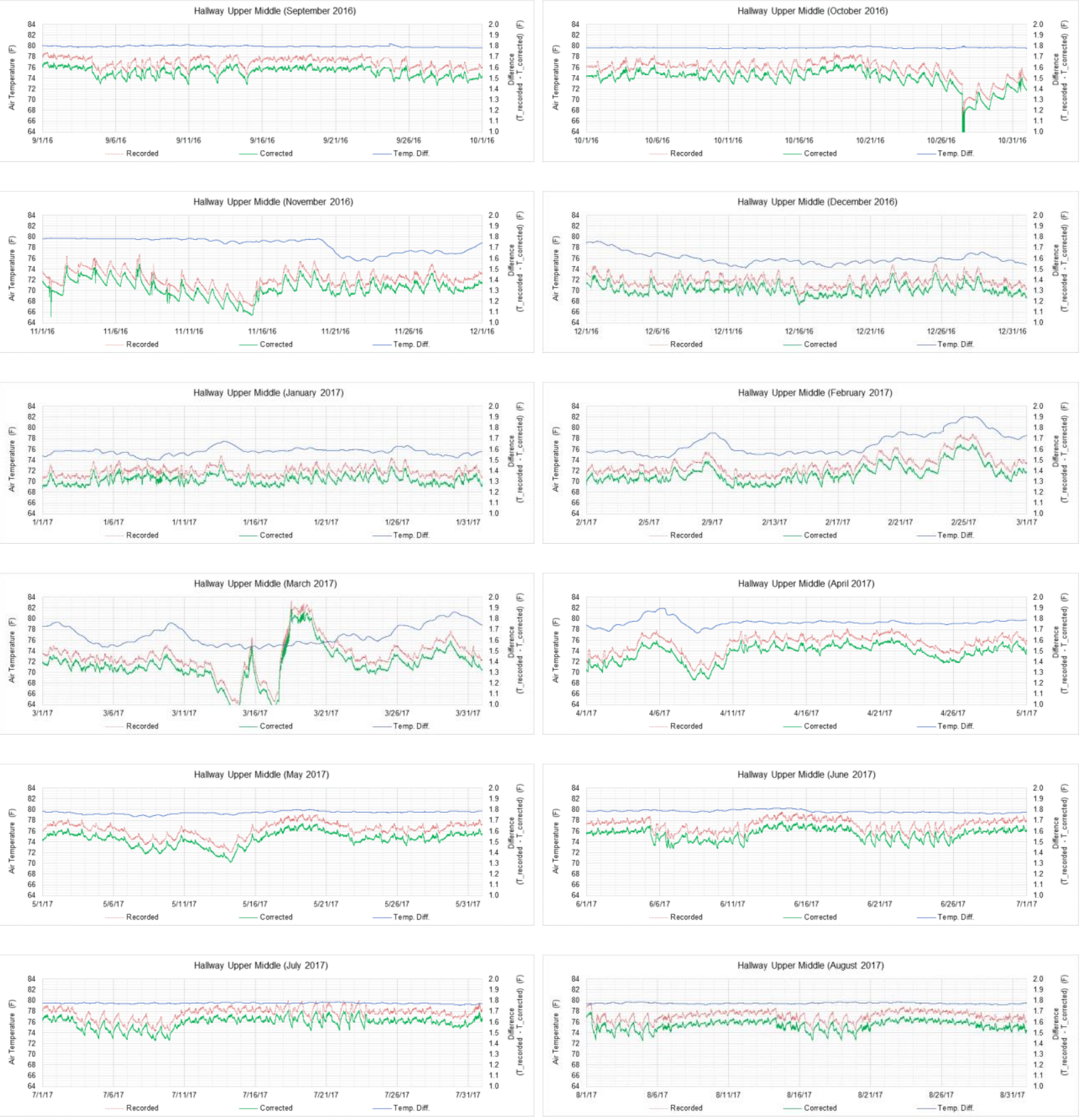

Figure B-23: Recorded and Corrected 1-Min EH Upper Middle Temperature. 
- HUpper: EH Upper at 5.5 m (217 in.)
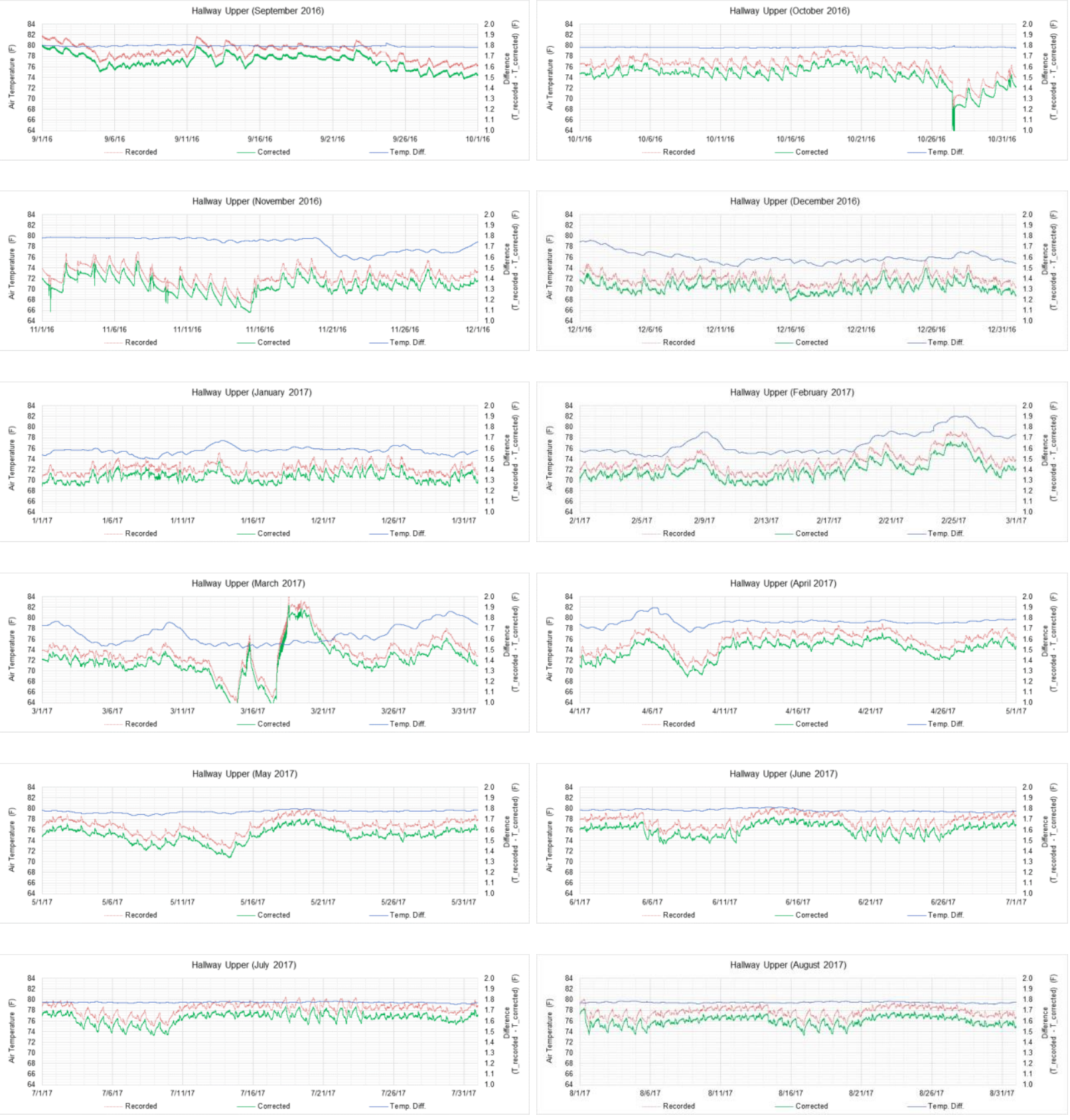

Figure B-24: Recorded and Corrected 1-Min EH Upper Temperature. 


\section{APPENDIX B-2: 1-MIN GLOBE TEMPERATURES BY ROOM ROOMS ON THE FIRST FLOOR}

- LR: Living Room
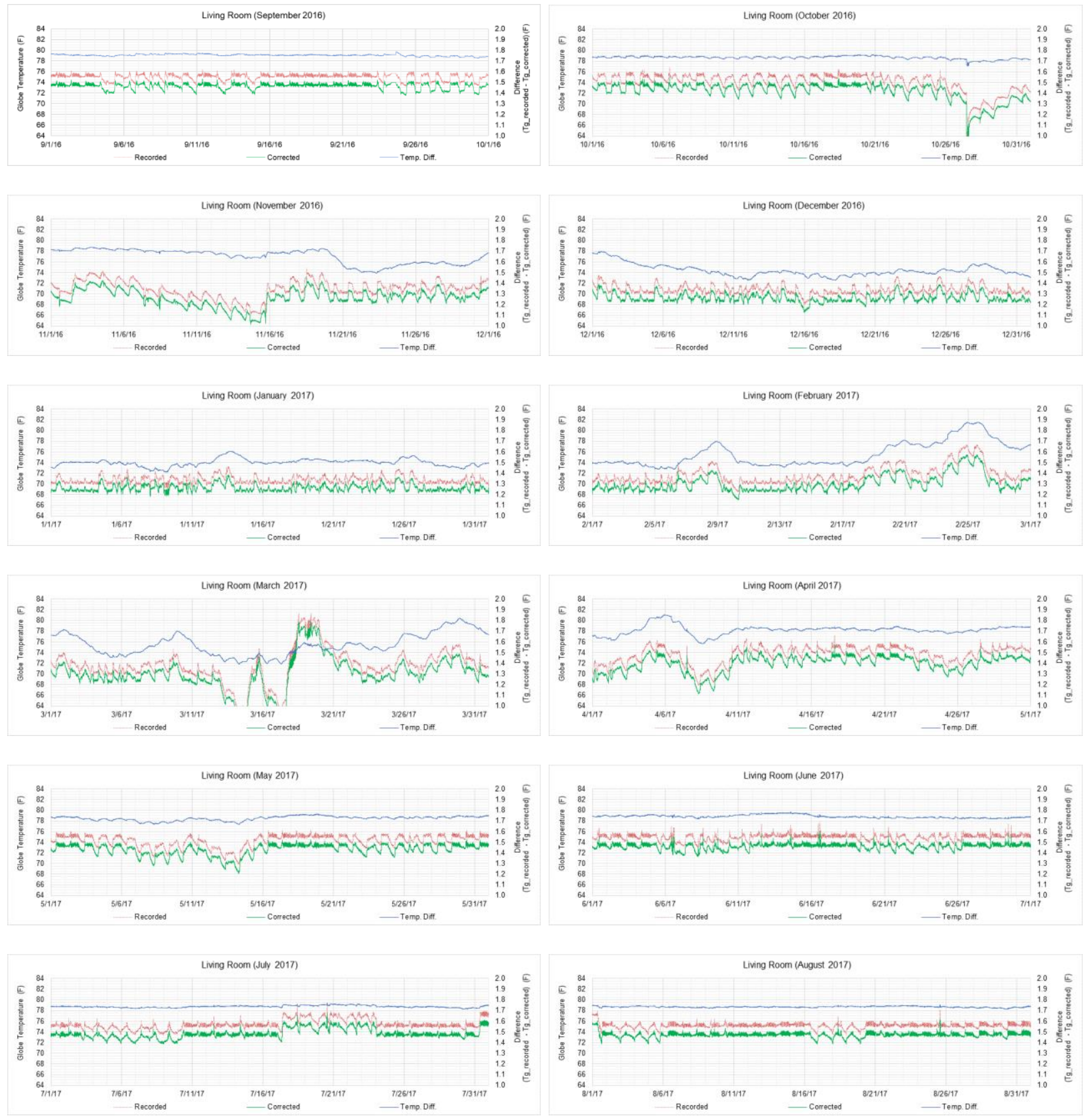

Figure B-25: Recorded and Corrected 1-Min LR Globe Temperature. 
- KIT: Kitchen
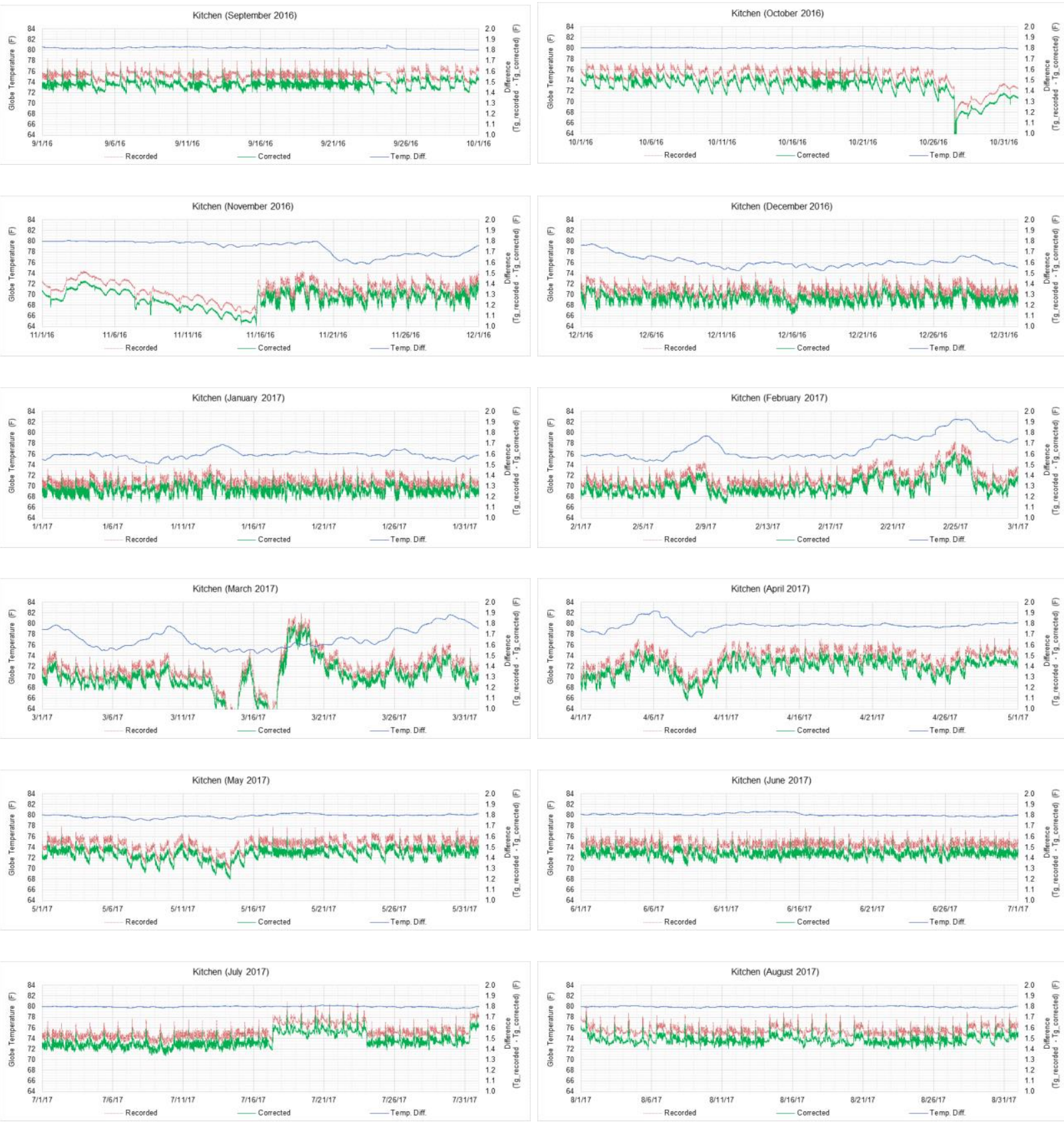

Figure B-26: Recorded and Corrected 1-Min KIT Globe Temperature. 


\section{ROOMS ON THE SECOND FLOOR}

- MBR: Master Bedroom

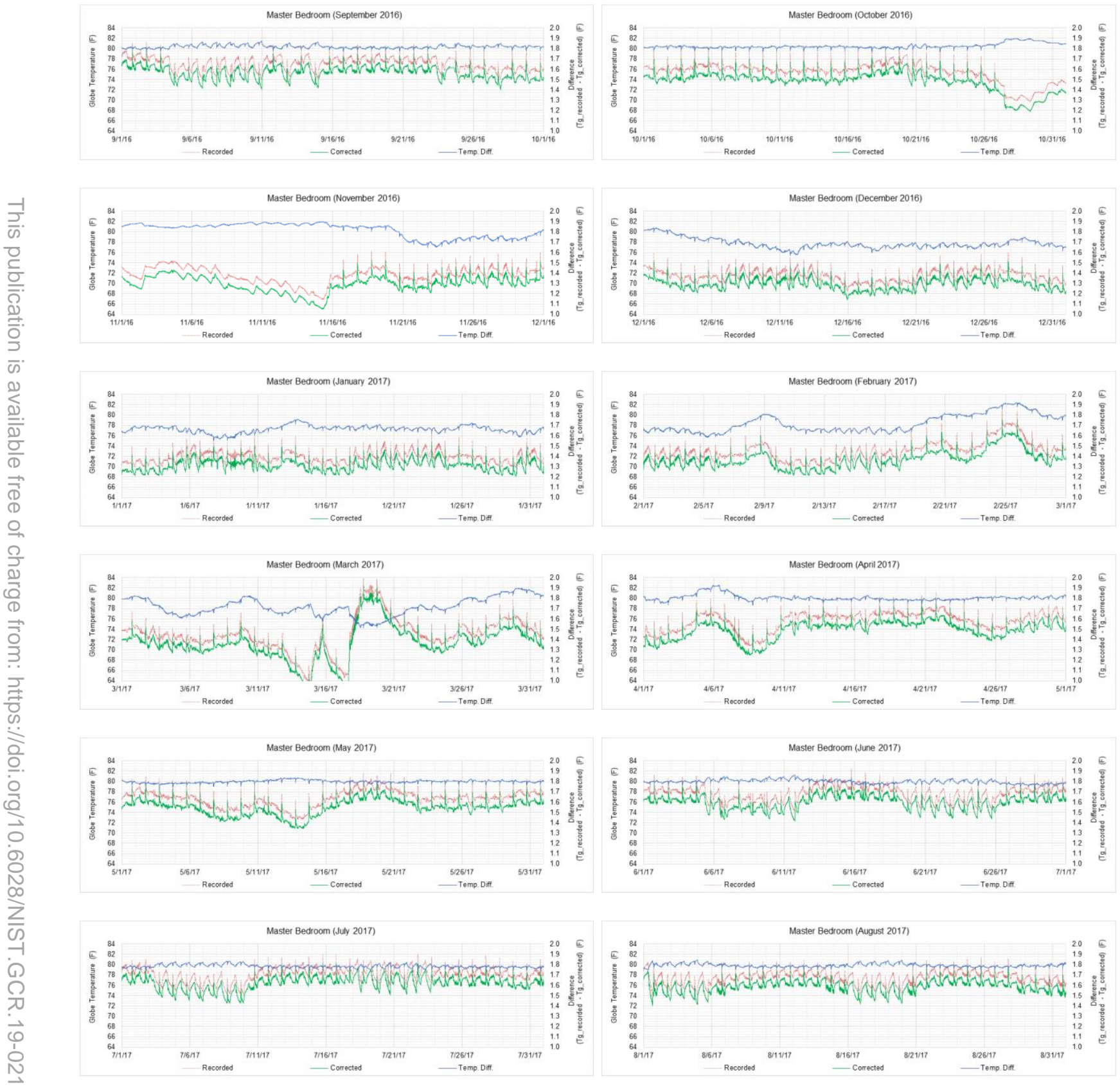

Figure B-27: Recorded and Corrected 1-Min MBR Globe Temperature. 


\section{- BR2: Bedroom 2}
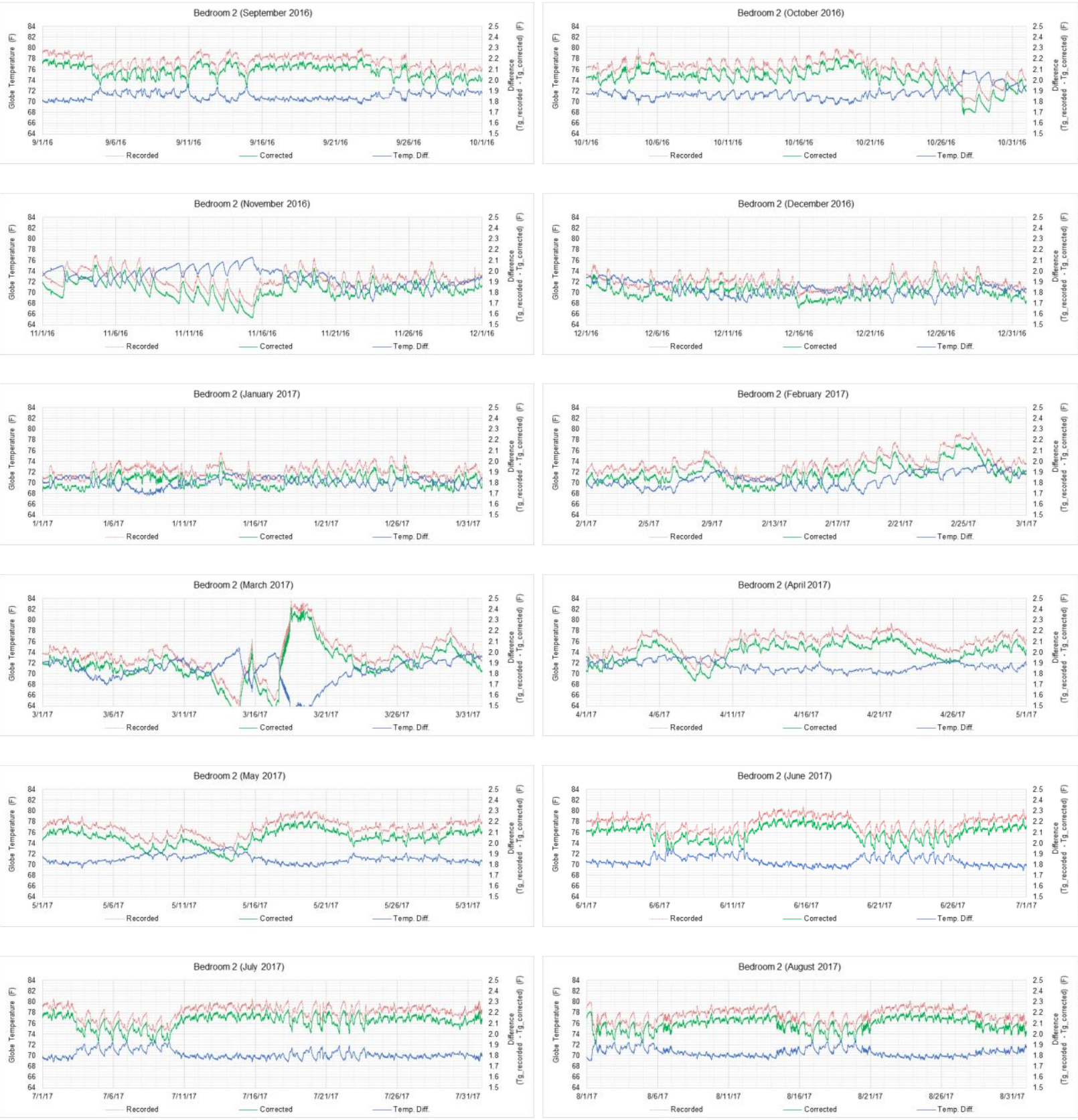

Figure B-28: Recorded and Corrected 1-Min BR2 Globe Temperature. 


\section{- BR3: Bedroom 3}
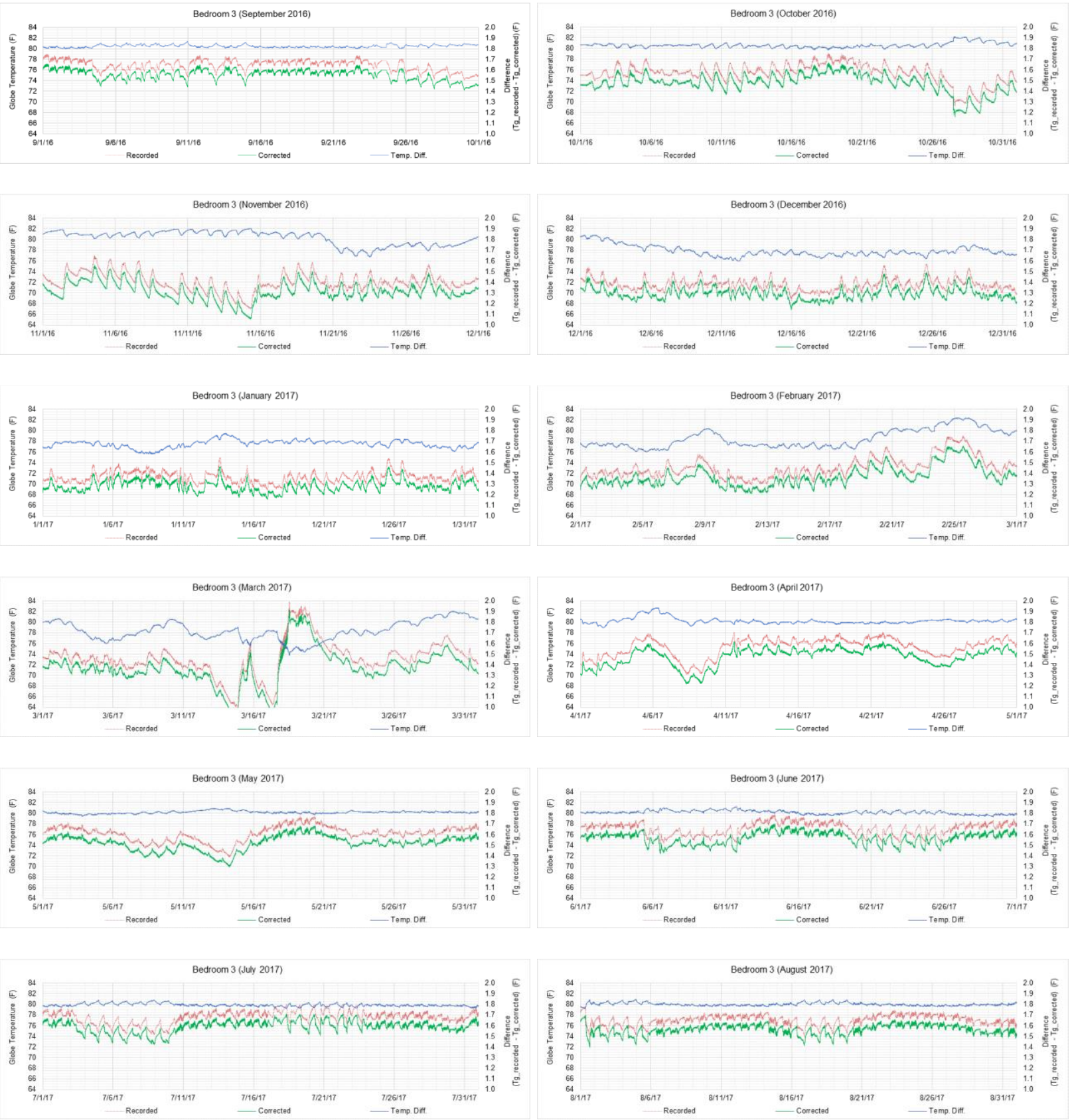

Figure B-29: Recorded and Corrected 1-Min BR3 Globe Temperature. 

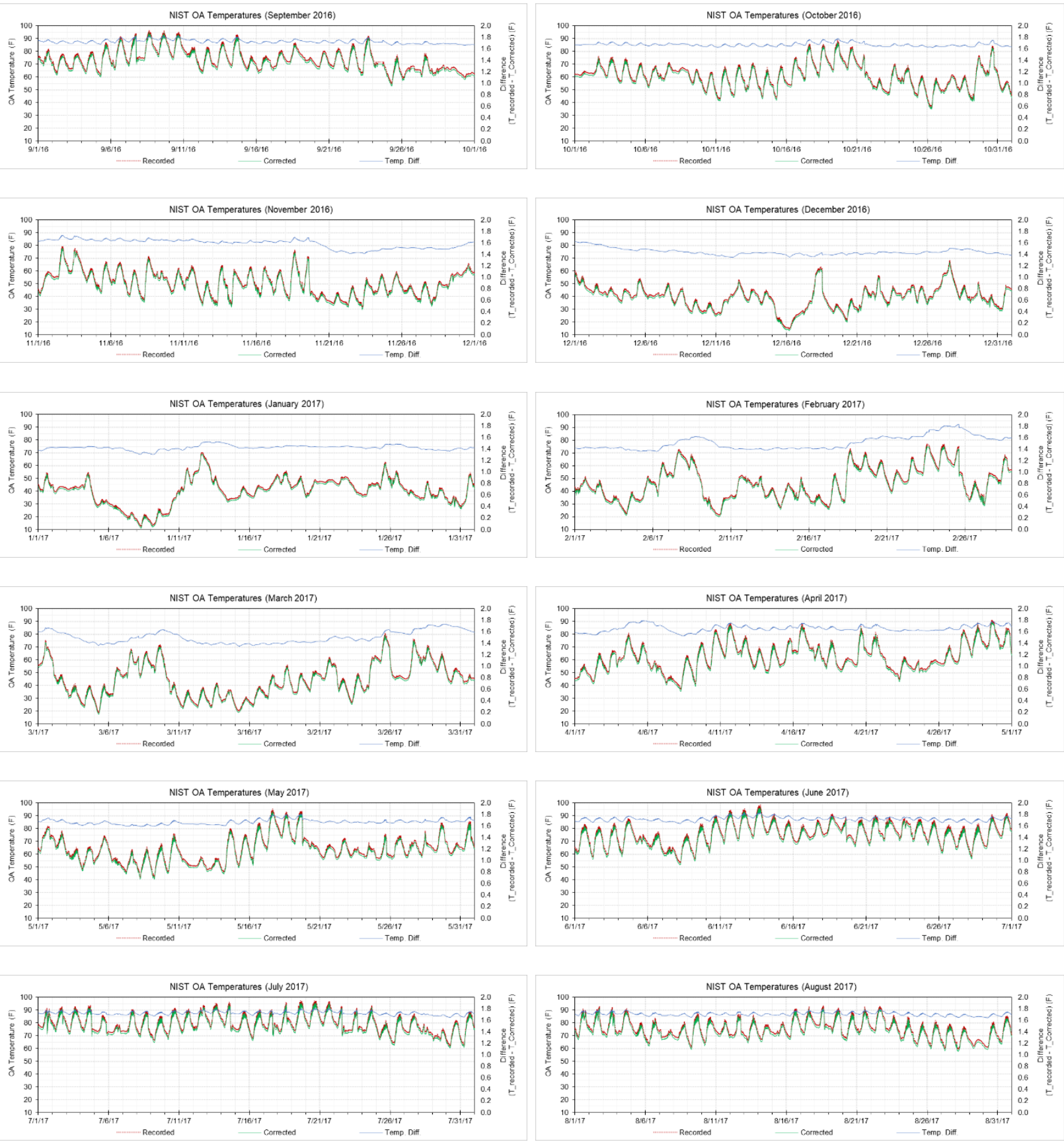

Figure B-30: Recorded and Corrected 1-Min Outdoor Air (OA) Temperature. 


\section{APPENDIX C: Data Quality Issues}

Appendix $C$ describes the data quality issues observed with:

- Heat pump electricity use data collected from in-house DAS (Figure C-1); and

- Outdoor air and dew point temperatures collected from the east side of the house near the heat pump outdoor unit (Figures C-2 to C-4).

Figure C-1 presents a comparison of hourly electricity use of CDHP outdoor unit and SDHV indoor unit between two different data files: Data File 1 collected from in-house DAS (i.e., indexing systems) and Data File 2 collected from a different data logger dedicated to each heat pump (i.e., processed text files). As a result, this study found:

- For the CDHP outdoor unit, the hourly electricity use data collected from Data File 2 were about 1.6 times higher than the data collected from Data File 1, which was pretty consistent.

- For the CDHP indoor unit, a discrepancy was observed in the collected hourly electricity use data between the two data files. However, the observed discrepancy was not consistent.

- For the SDHV indoor unit, the hourly electricity use data collected from Data File 2 were about 0.6 times to the data collected from Data File 1 when the hourly electricity use of the SDHV indoor unit was below $100 \mathrm{~W}$. At a higher power use, the observed trend was rather inconsistent.

After consultation with the NIST NZERTF team, this study decided to use the heat pump electricity use data collected from Data File 2 of which power metering systems were verified against hand-held power meters more recently.

Figure C-2 presents the observed data reliability issue with the outdoor air and dew point temperatures collected from the east side of the house near the heat pump outdoor unit by plotting the temperature differences between the temperatures logged at every 00 second timestamps and the temperature logged at every 30 second of the same minute. This comparison was initially performed to examine the discrepancy observed between the outdoor air temperature measured on the roof of the house and the outdoor air temperature measured on the east side of the house, as shown in Figure $\mathrm{C}-3^{58}$. As a result, the study found:

- For outdoor air temperature, the observed temperature difference (i.e., delta T) was up to $\pm 2^{\circ} \mathrm{F}$, which was consistent throughout the year and the time of day.

- For dew point temperature, the observed temperature difference (i.e., delta T) was up to $\pm 4^{\circ} \mathrm{F}$, which was higher during daytime when the unit was actively running.

After consultation with the NIST NZERTF team, this study decided to use the outdoor air temperature data collected from the roof of the house, which reasonable agreed with the outdoor air temperature collected from the NOAA weather station at Washington/Dulles International Airport (IAD), VA as shown in Figure C-4, along with the outdoor humidity data collected from the same NOAA weather station at IAD.

\footnotetext{
58 The maximum temperature difference between the outdoor temperature measured on the roof (i.e., Tdb_Roof, a gray line in Figure $\mathrm{C}-3$ ) and the outdoor temperature measured on the east side of the house (Tdb_HP (East), a purple line in Figure $\mathrm{C}-3$ ) was about $27.1^{\circ} \mathrm{F}$.
} 

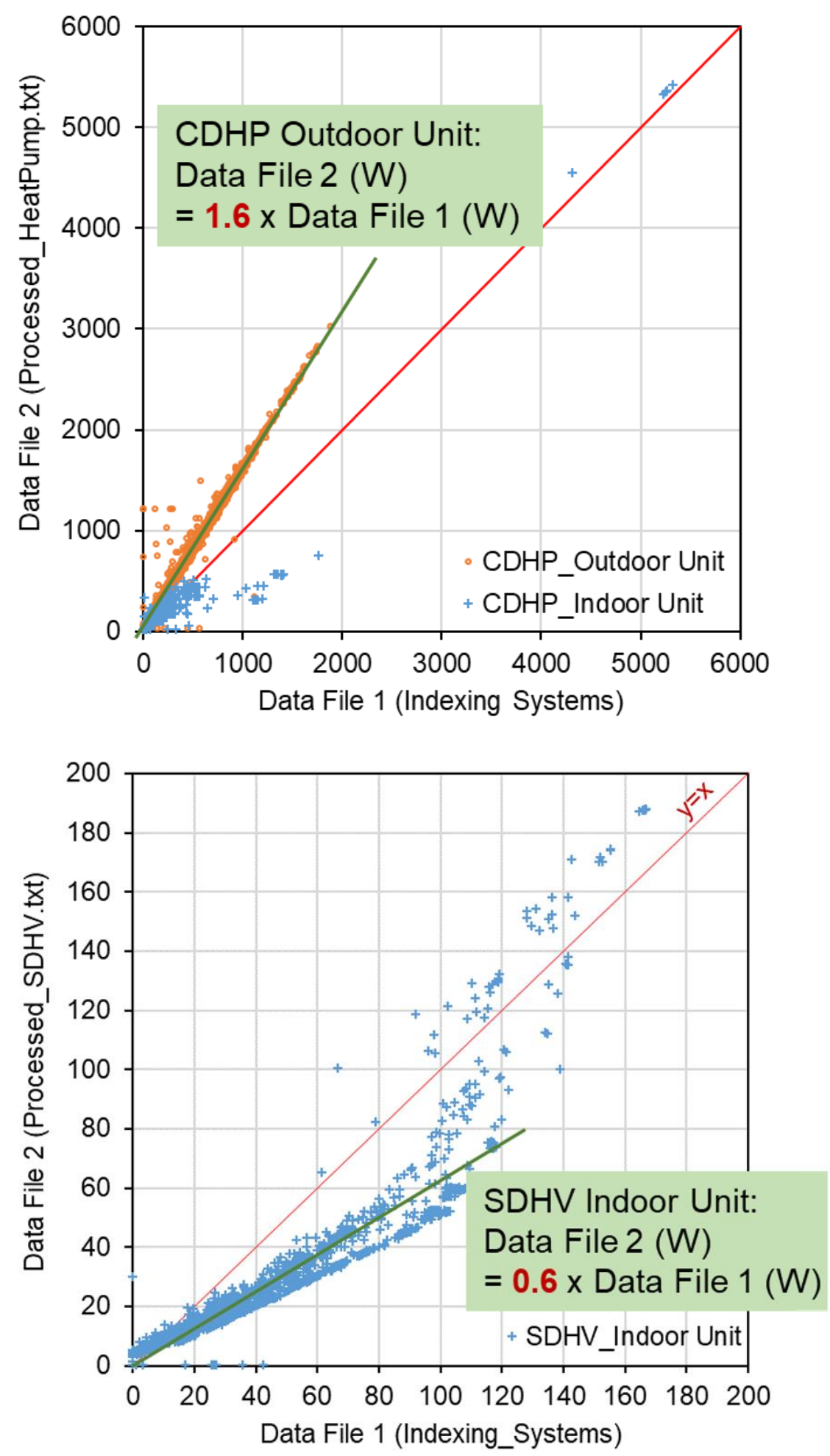

Figure C-1: Comparison of Hourly Electricity Use of CDHP Outdoor and Indoor Unit (Upper Figure) and SDHV Indoor Unit (Lower Figure) between Different Data Files. 

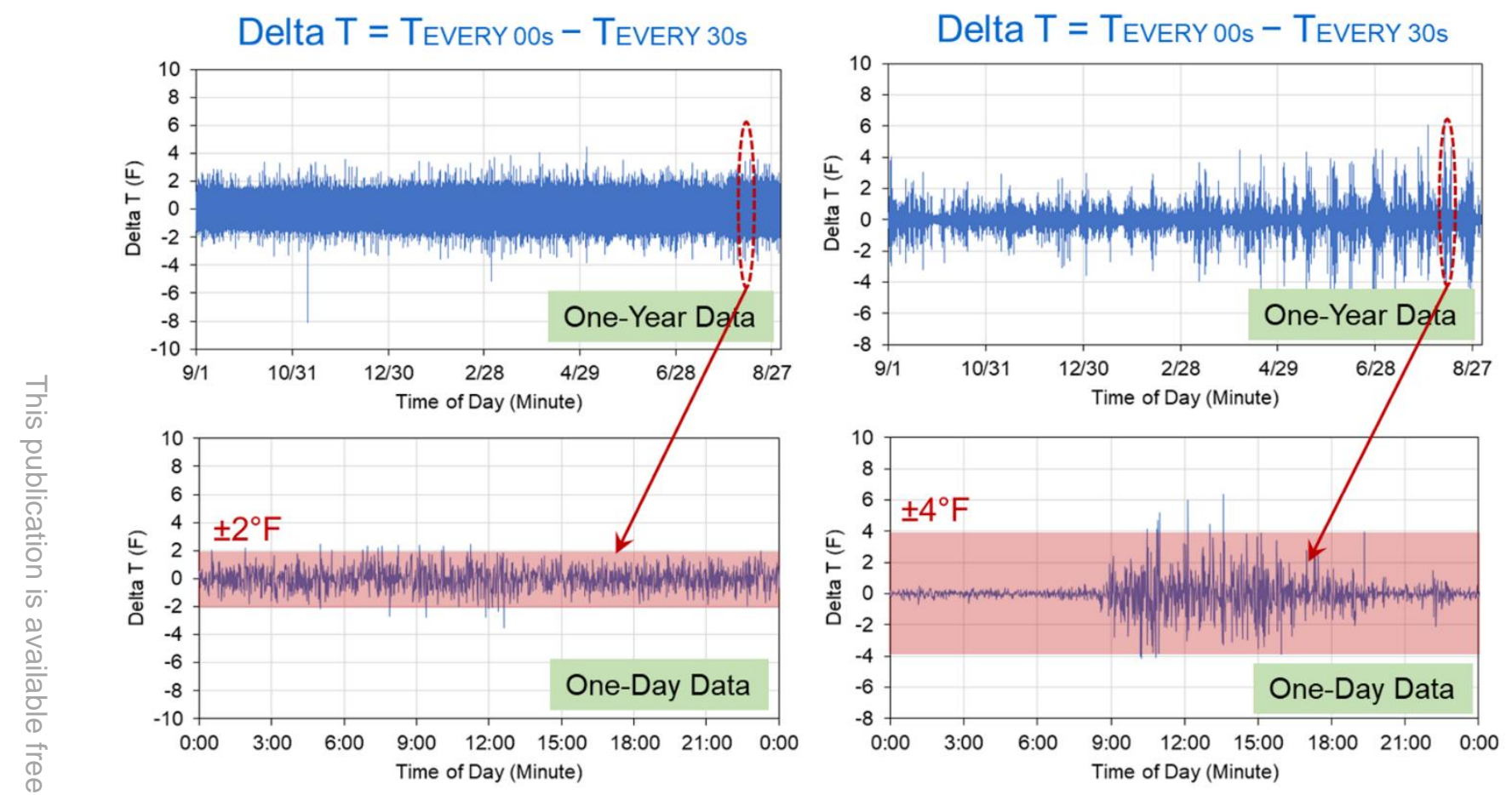

Figure C-2: Temperature Differences between the Temperatures Logged at Every 00 Second Timestamps and the Temperature Logged at Every 30 Second of the Same Minute for the Outdoor Air Temperature (Left Figures) and Dew Point Temperature (Right Figures) Collected from the East Side of the House near the Heat Pump Outdoor Unit.

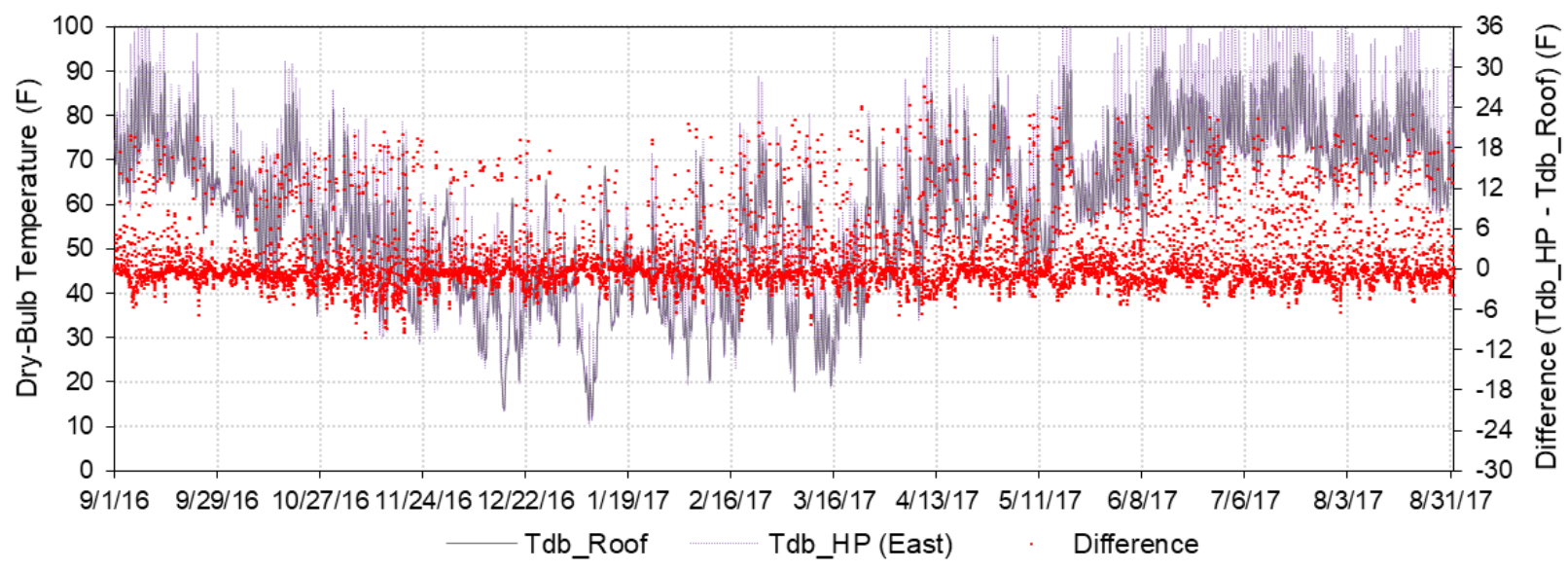

Figure C-3: Comparison of Outdoor Air Temperature Collected from the Roof of the House (Tdb_Roof) versus from the East Side of the House near the Heat Pump Outdoor Unit (Tdb_HP (East)). 


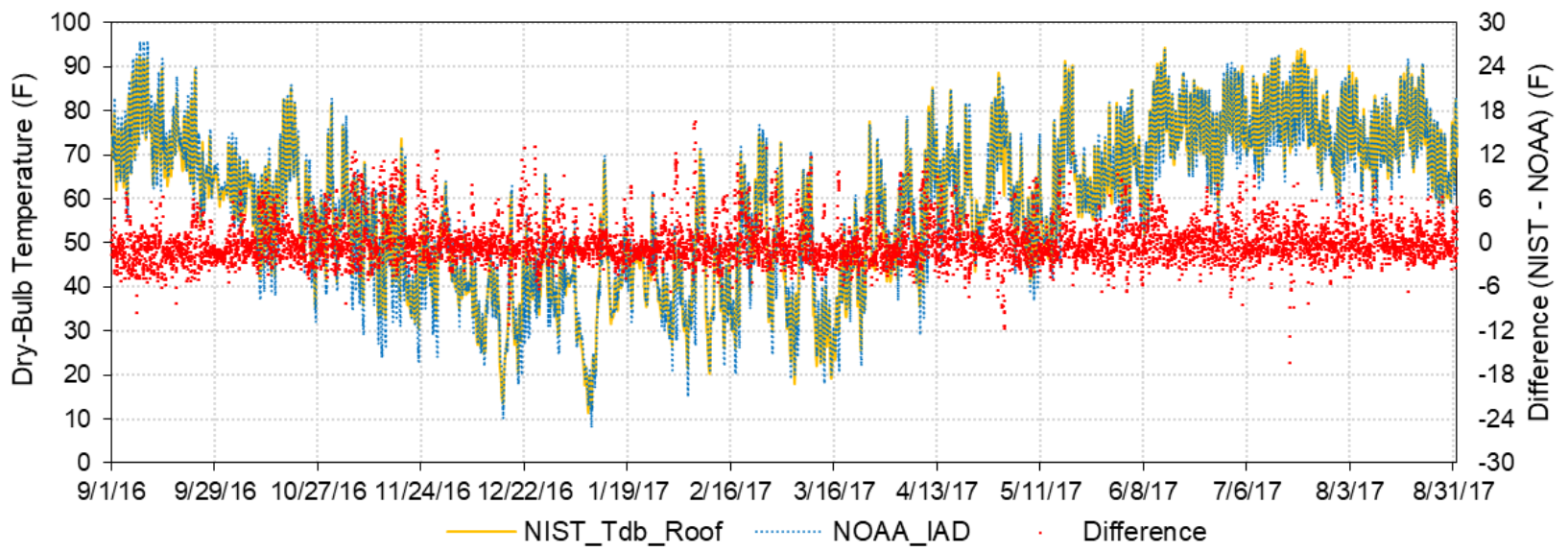

Figure C-4: Comparison of Outdoor Air Temperature Collected from the Roof of the House (NIST_Tdb_Roof) versus from the NOAA Weather Station at Washington/Dulles International Airport (NOAA_IAD), VA. 

Rooms)

Appendix D presents the binned room air temperatures against outdoor temperatures for the following rooms as supplementary materials to Section 4.5.1:

- Dining room (DR) (Figure D-1);

- Bedroom 4 (BR4) (Figure D-2);

- Washer and dryer (WD) (Figure D-3)

- Master bathroom (MBA) (Figure D-4);

- Bathroom 1 (BA1) (Figure D-5); and

- Bathroom 2 (BA2) (Figure D-6).

The DR and the BR4 had very similar trends to that of the LR, although the BR4 had a slightly higher temporal variation. Not surprisingly, the WD room experienced very high temperature extremes, which was affected by the operation schedule of the washer and dryer. As a result, different minimum and maximum scale values (from $18^{\circ} \mathrm{C}$ to $38^{\circ} \mathrm{C}$ ) were used for the vertical axis (i.e., y axis) in Figure D-3.

The MBA had a very similar trend to that of the MBR but with a higher temporal variation. The BA1 had a trend resembling the kitchen to some extent with a tighter temporal variation. It should be noted that the interesting counter-intuitive trend observed in the kitchen (i.e., decreasing temperature with increasing OA temperature with the CDHP during the cooling season) was also observed in the BA1. Lastly, the BA2 had a trend similar to the BR2 but with warmer room temperatures at the low $O A$ temperatures and cooler room temperatures at the high OA temperatures. 


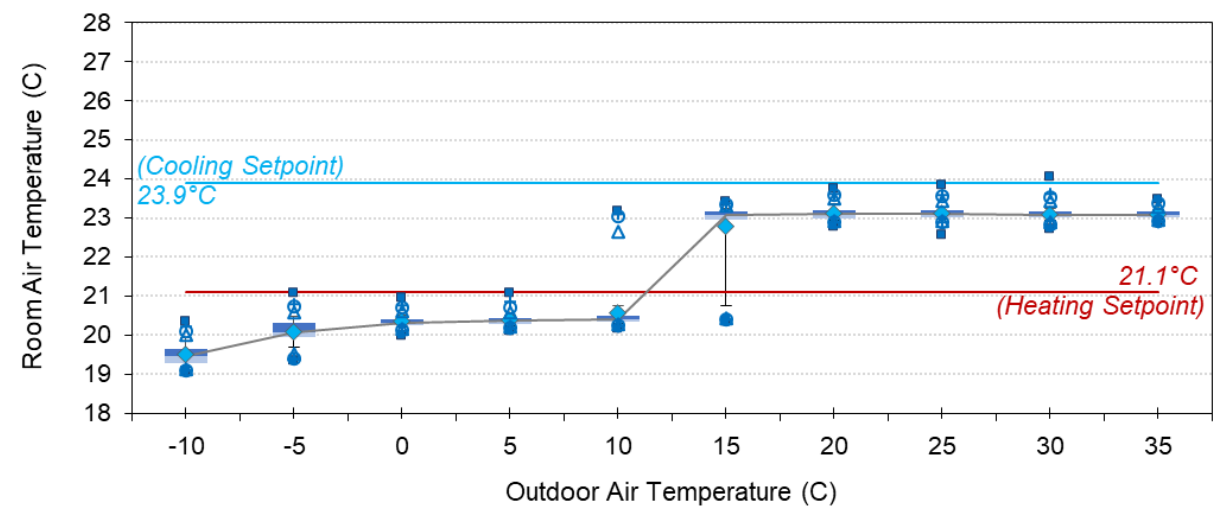

(a) CDHP ON

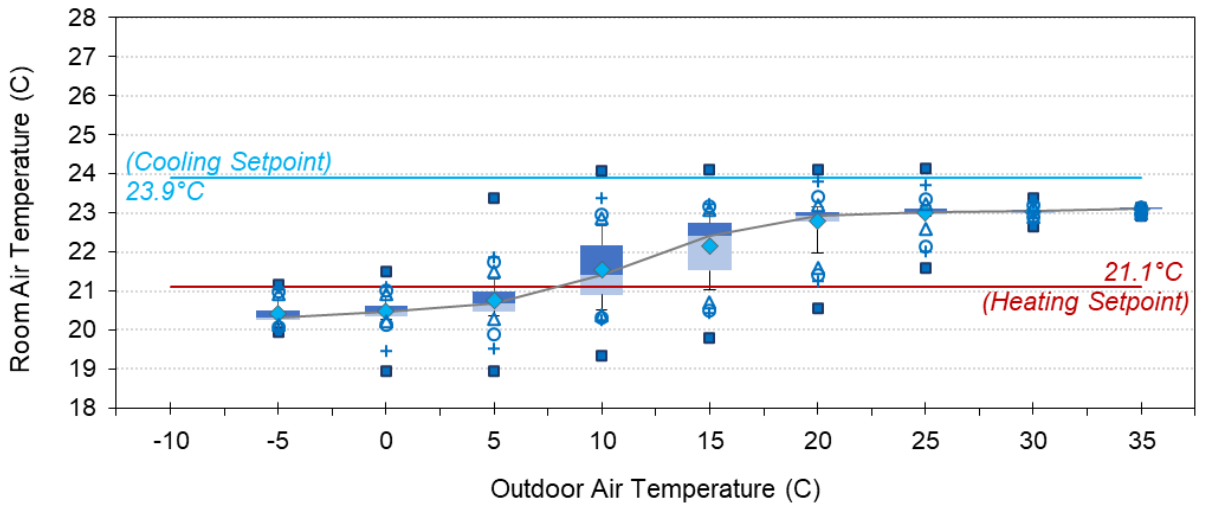

(b) CDHP OFF

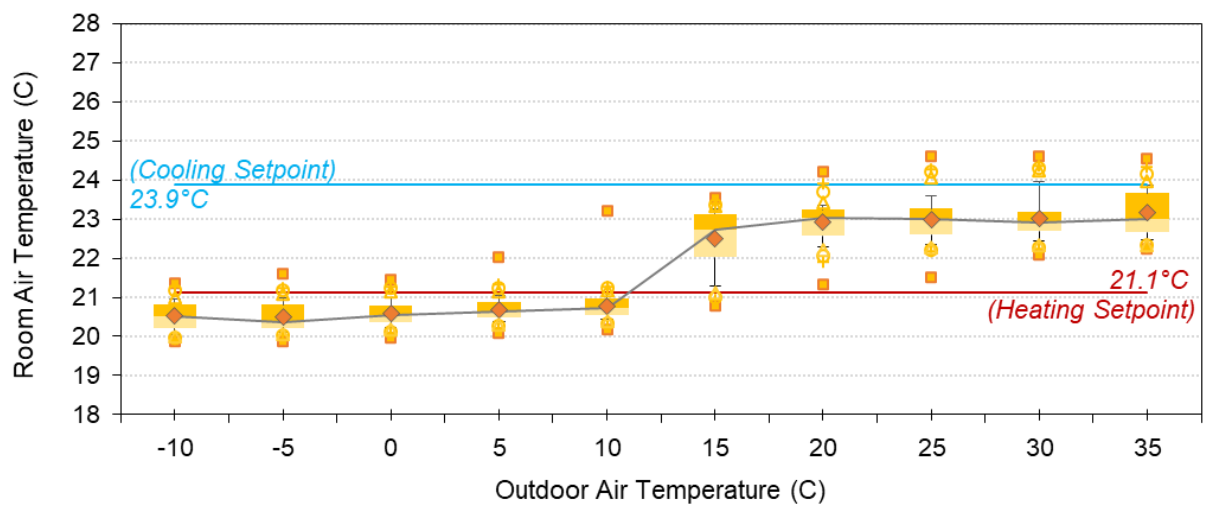

(c) SDHV ON

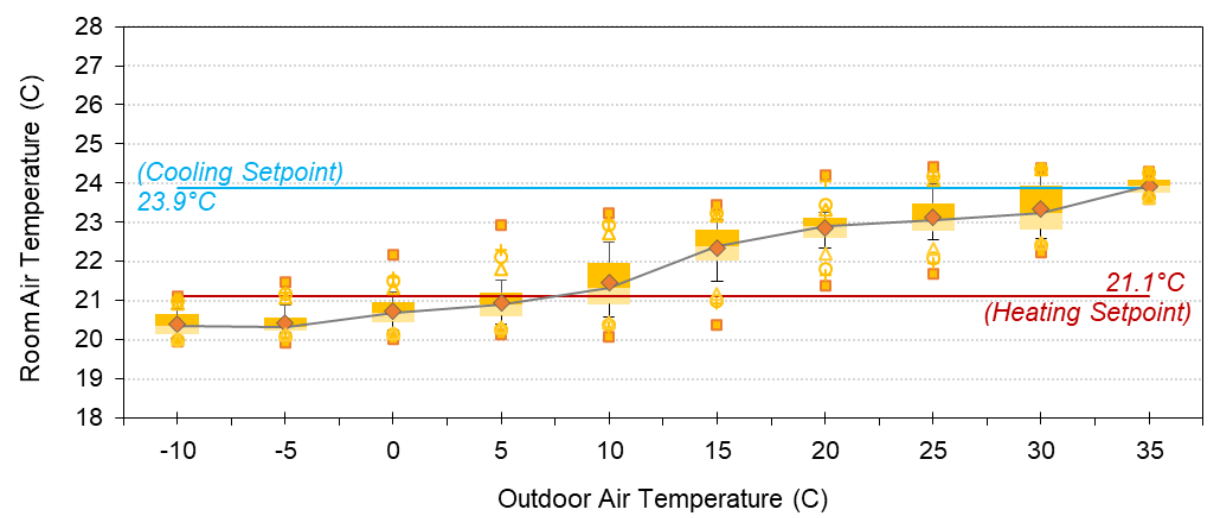

(d) SDHV OFF

Figure D-1: Binned DR Room Air Temperatures Against Outdoor Temperatures. 


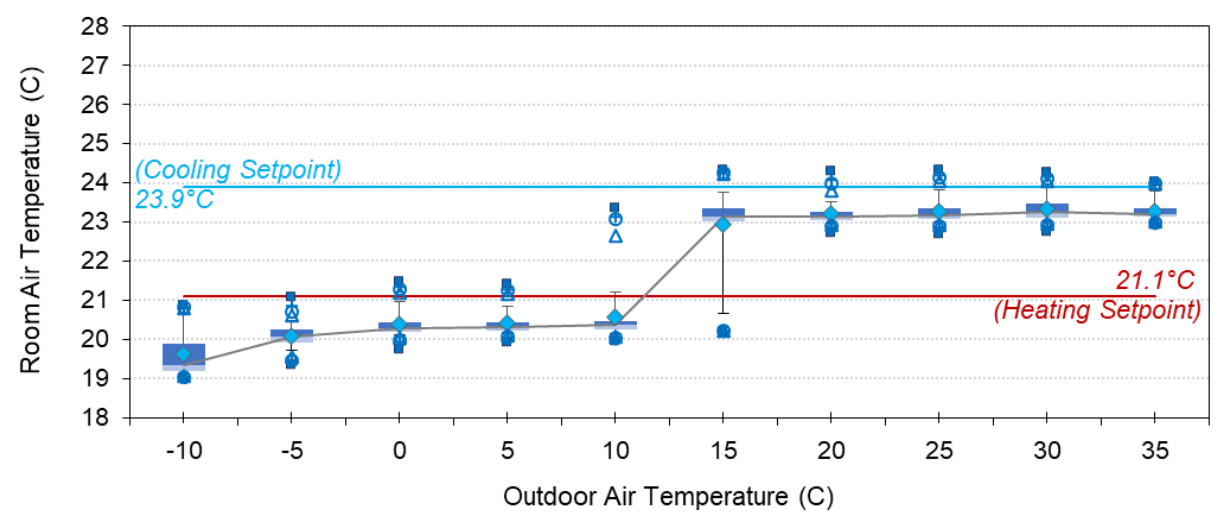

(a) CDHP ON

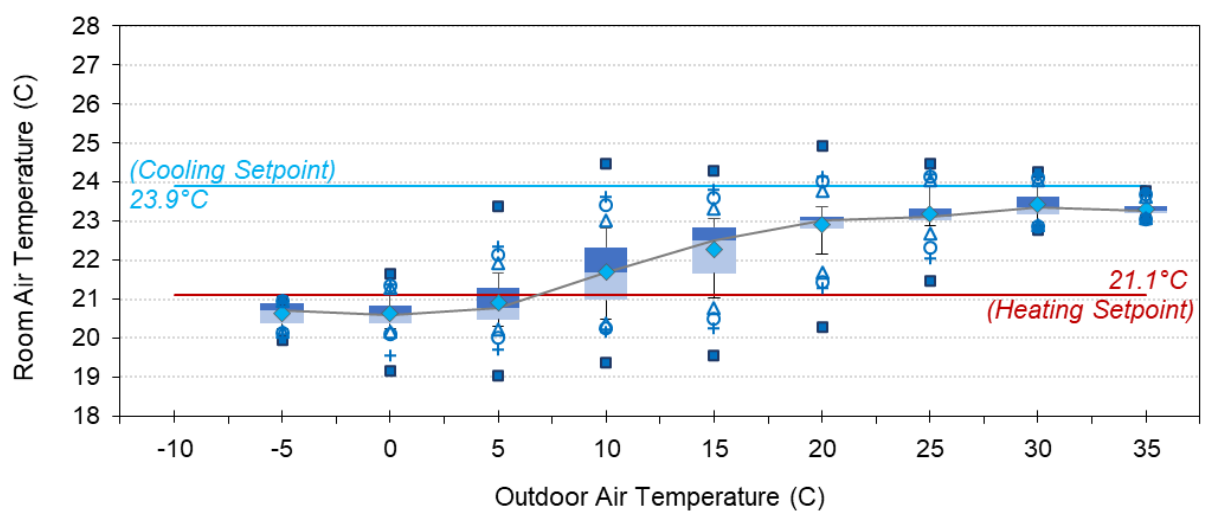

(b) CDHP OFF

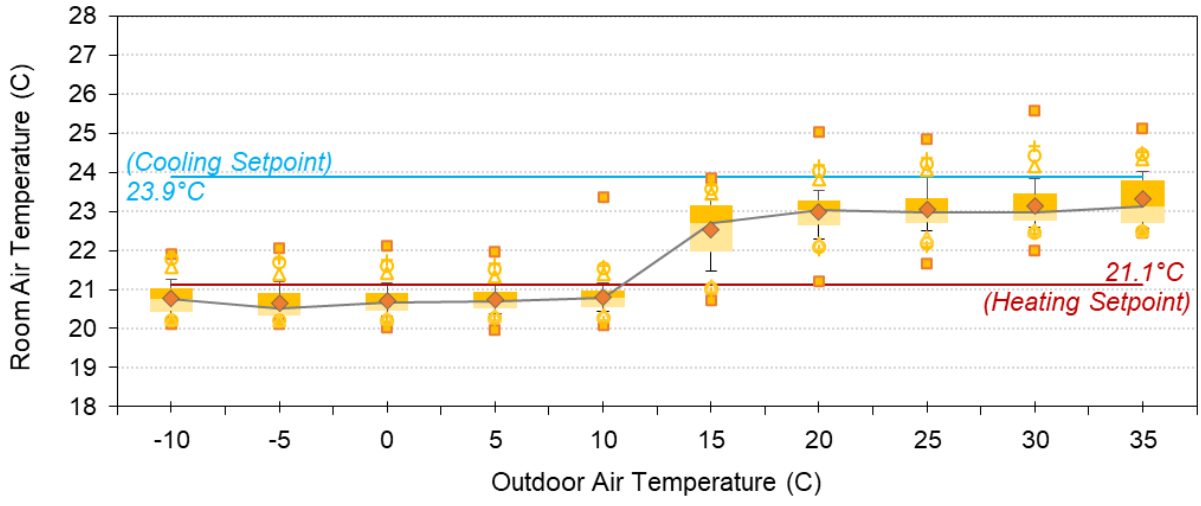

(c) SDHV ON

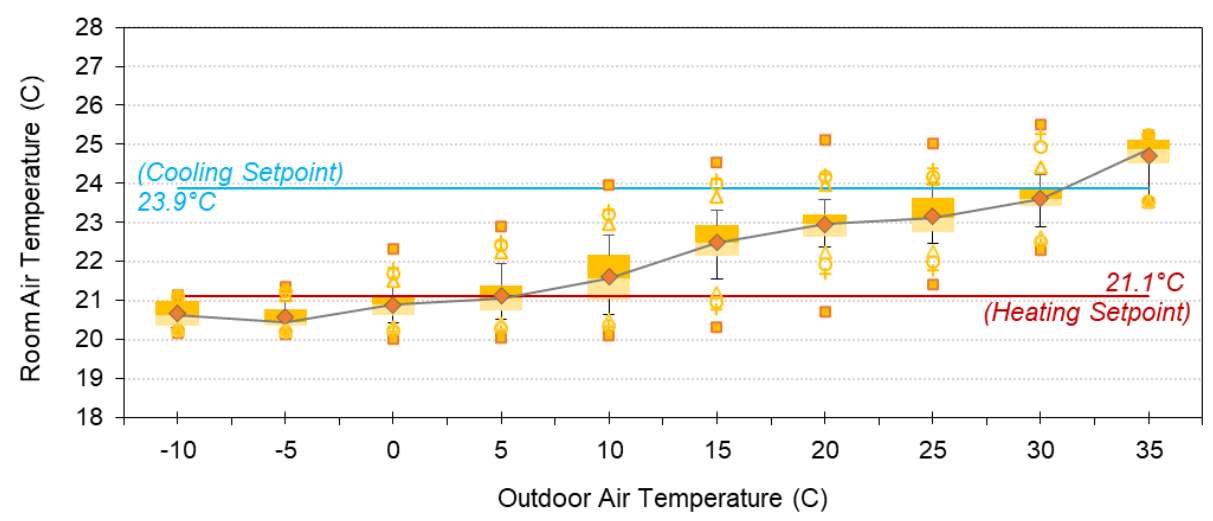

(d) SDHV OFF

Figure D-2: Binned BR4 Room Air Temperatures Against Outdoor Temperatures. 


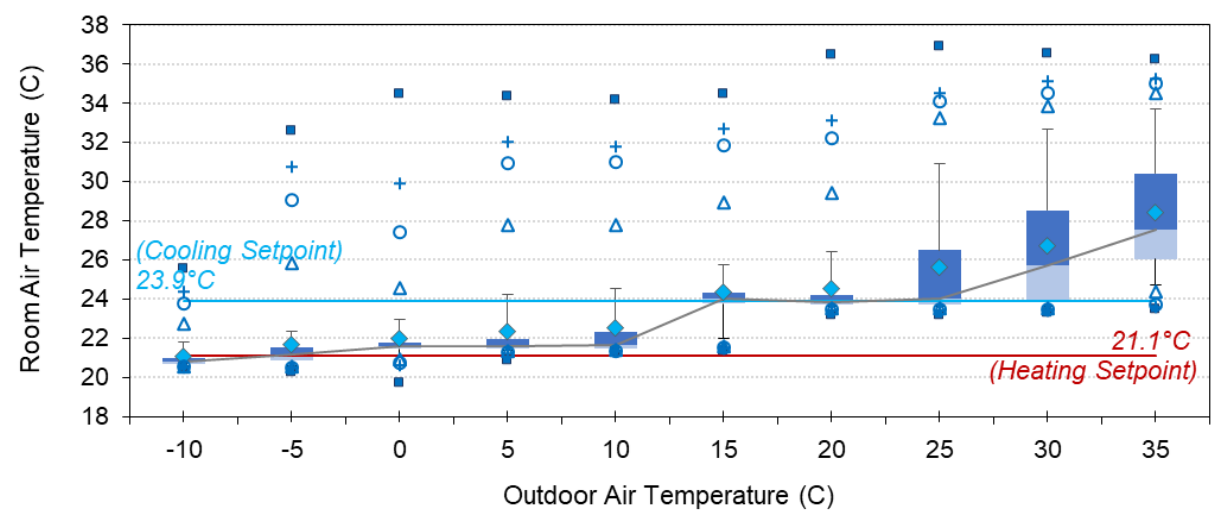

(a) CDHP ON

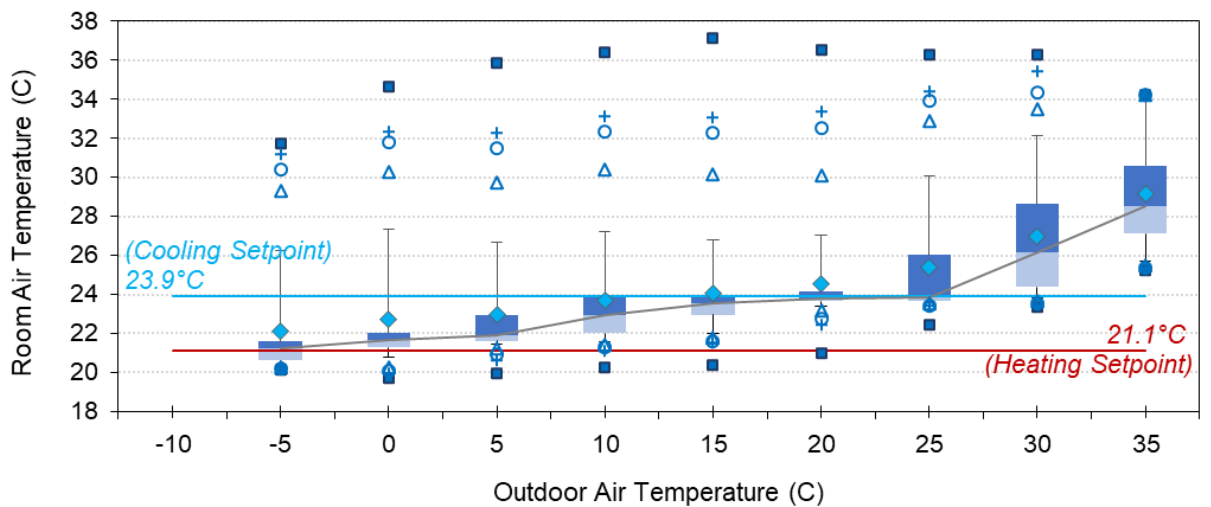

(b) CDHP OFF

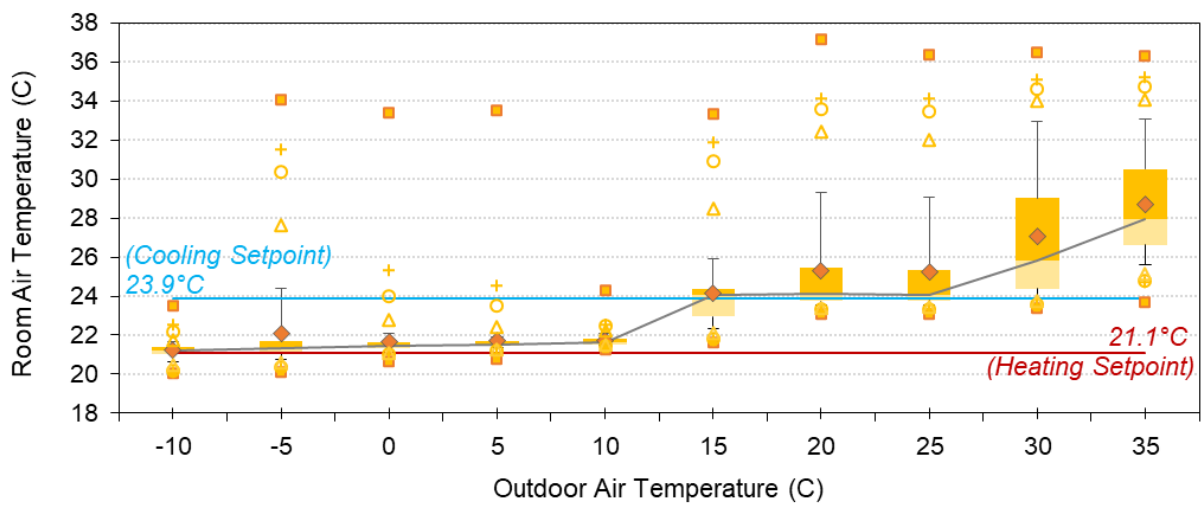

(c) SDHV ON

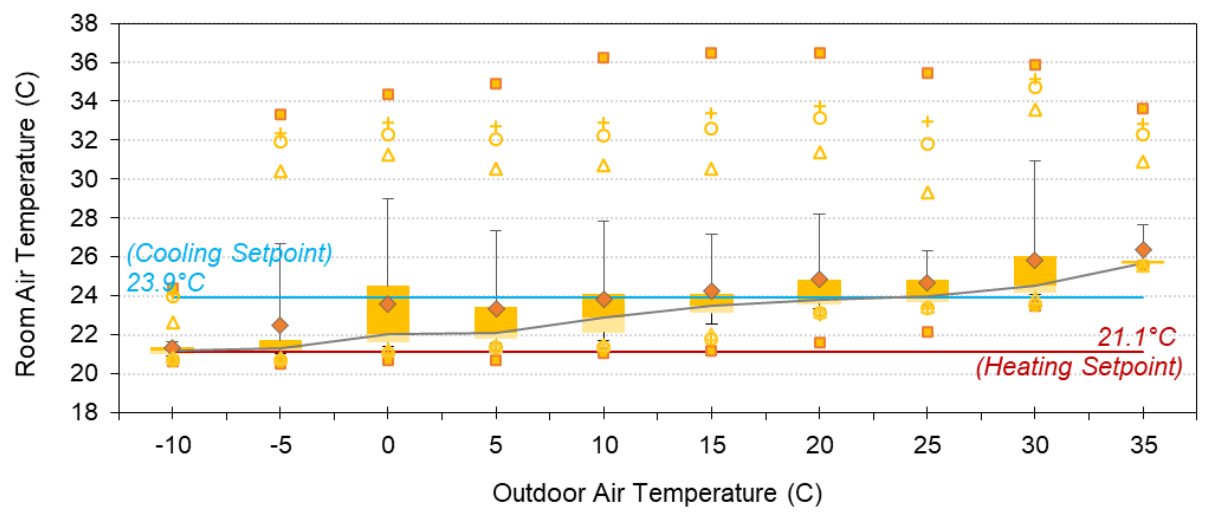

(d) SDHV OFF

Figure D-3: Binned WD Room Air Temperatures Against Outdoor Temperatures. 


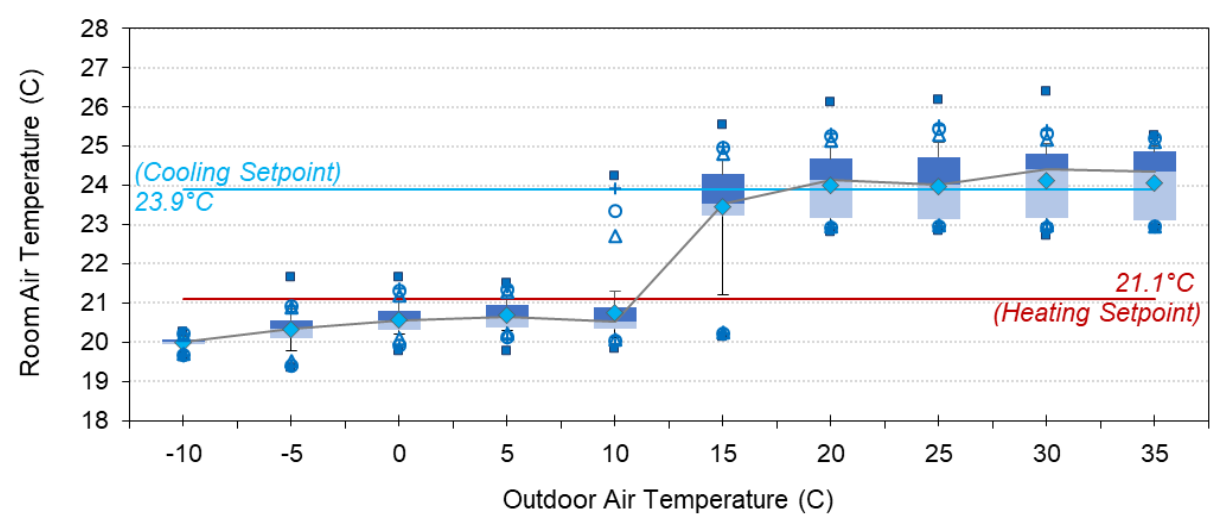

(a) CDHP ON

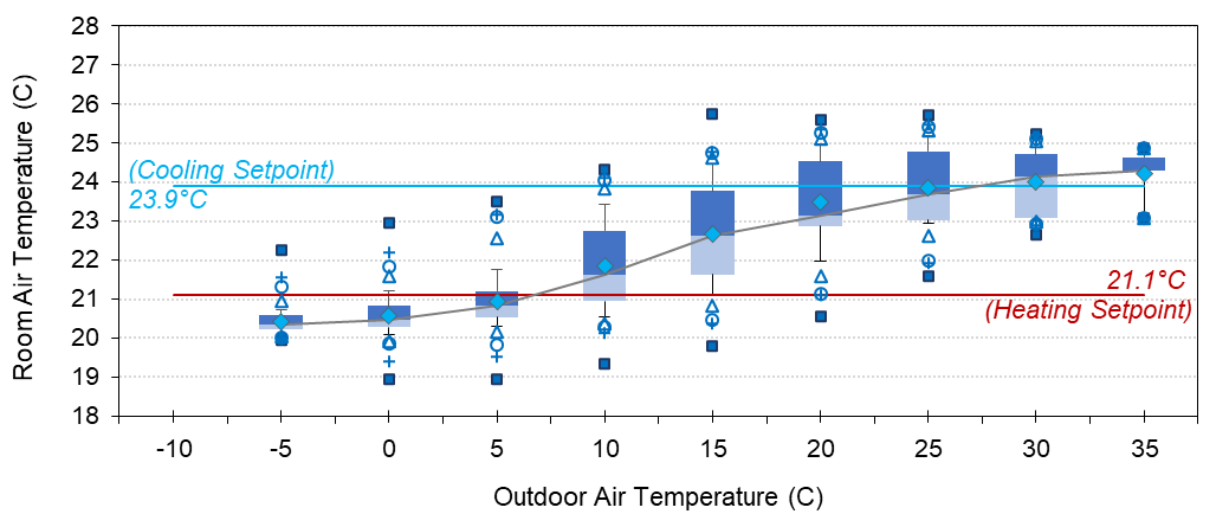

(b) CDHP OFF

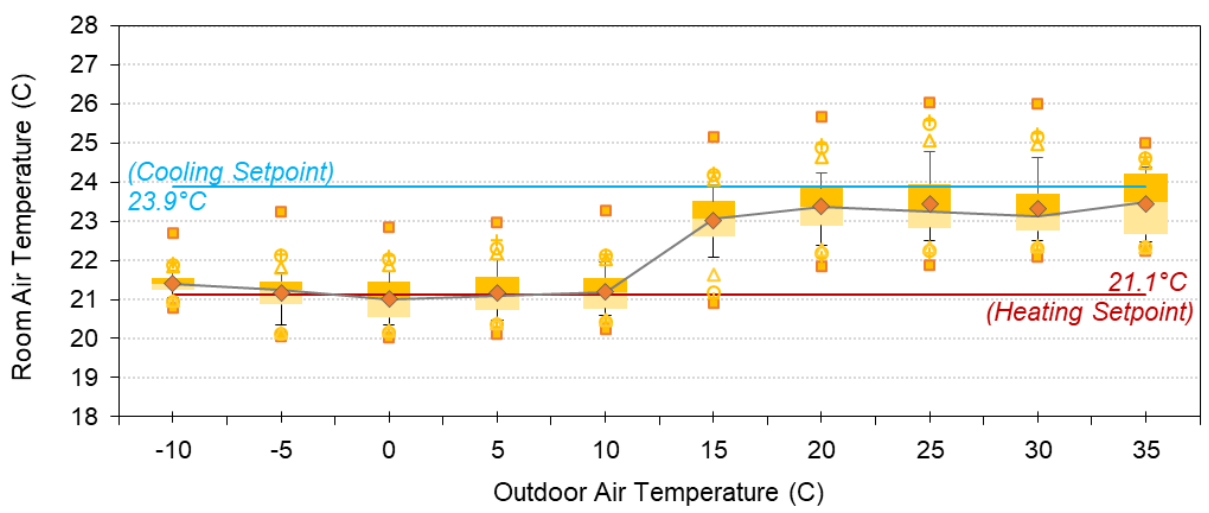

(c) SDHV ON

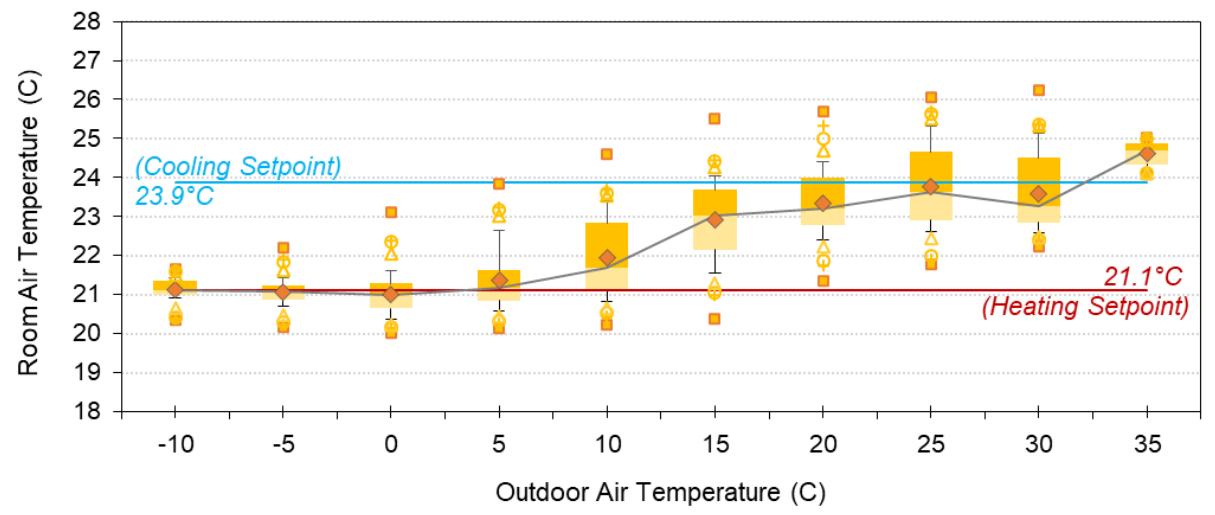

(d) SDHV OFF

Figure D-4: Binned MBA Room Air Temperatures Against Outdoor Temperatures. 


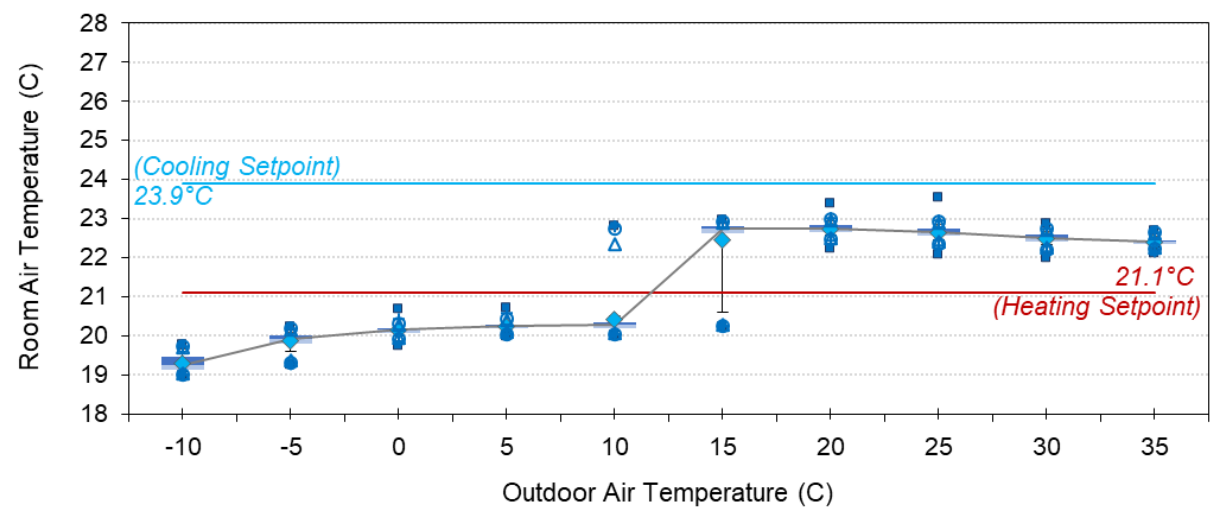

(a) CDHP ON

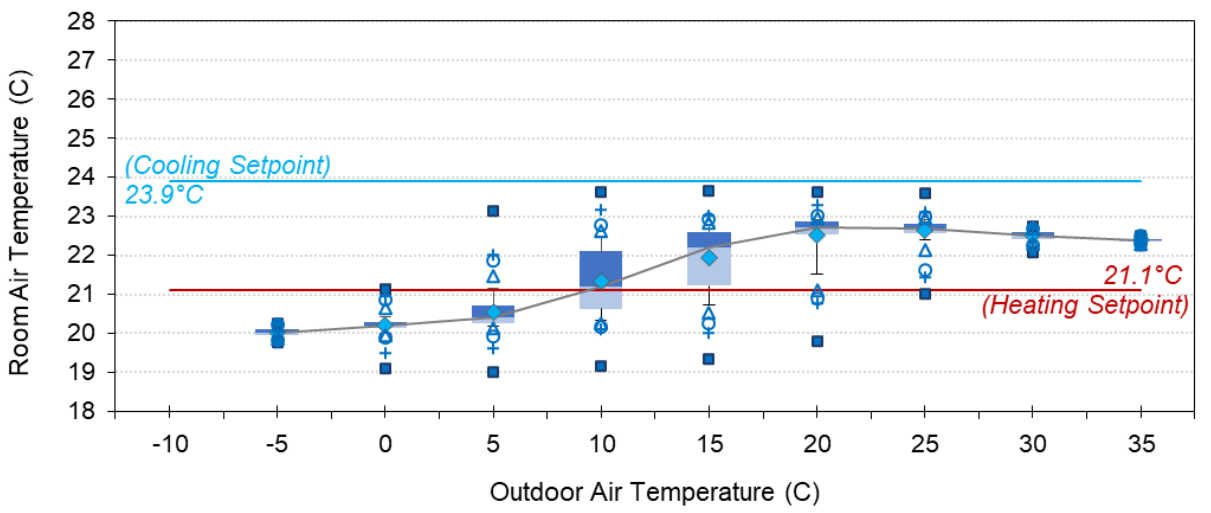

(b) CDHP OFF

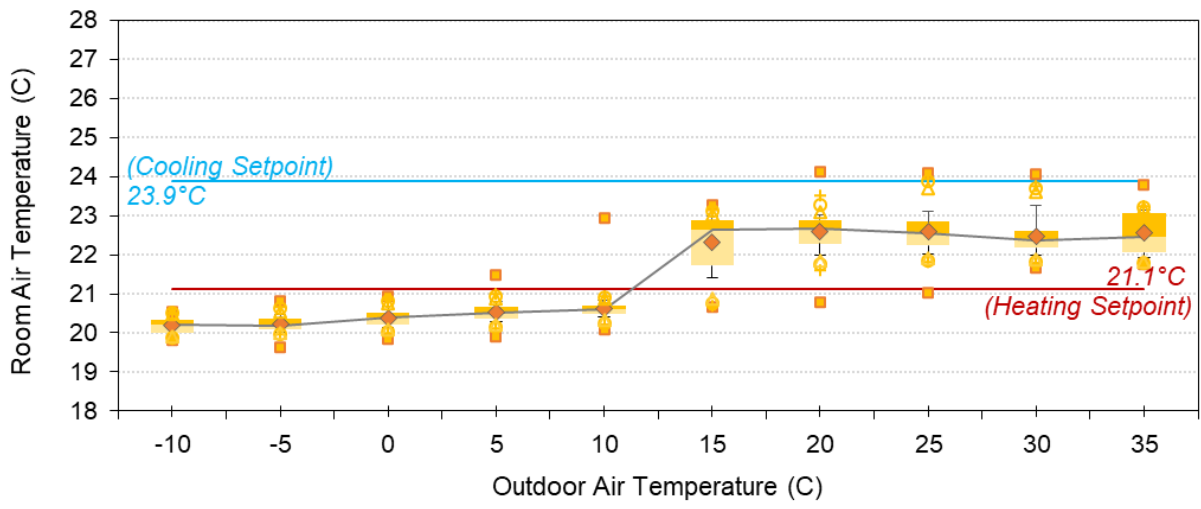

(c) SDHV ON

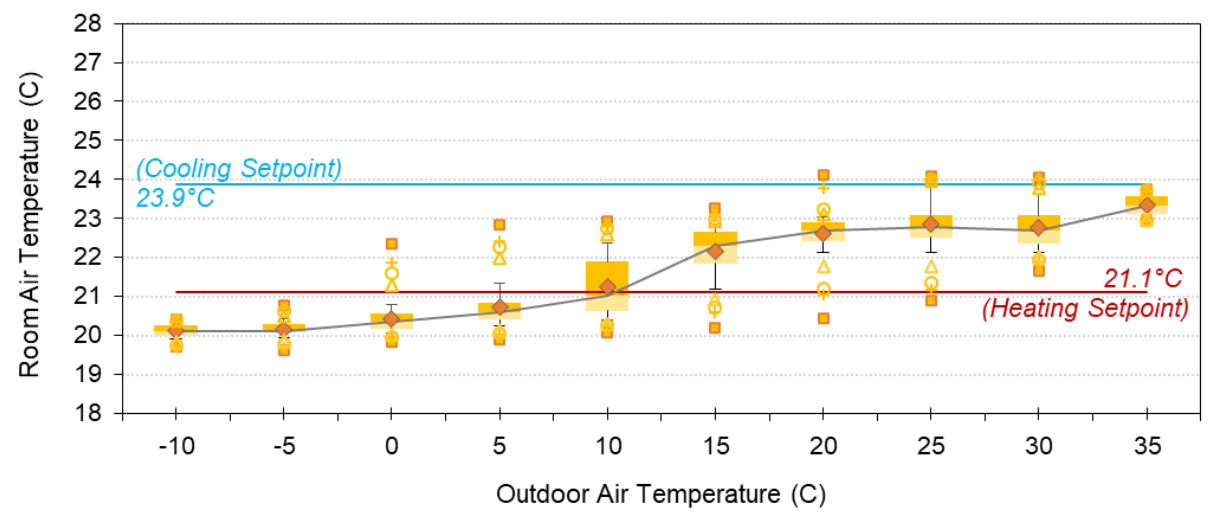

(d) SDHV OFF

Figure D-5: Binned BA1 Room Air Temperatures Against Outdoor Temperatures. 


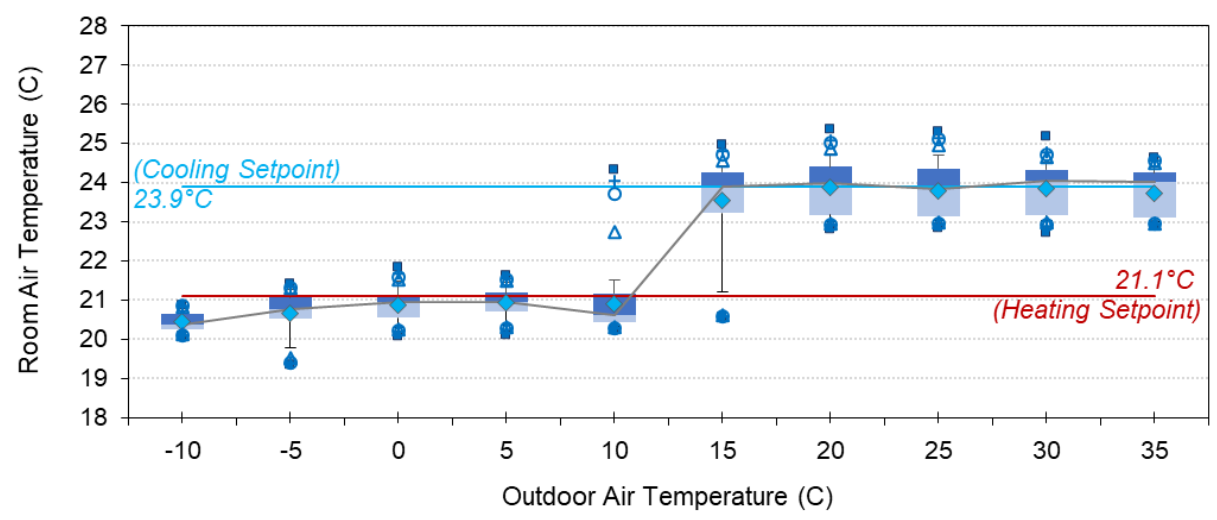

(a) CDHP ON

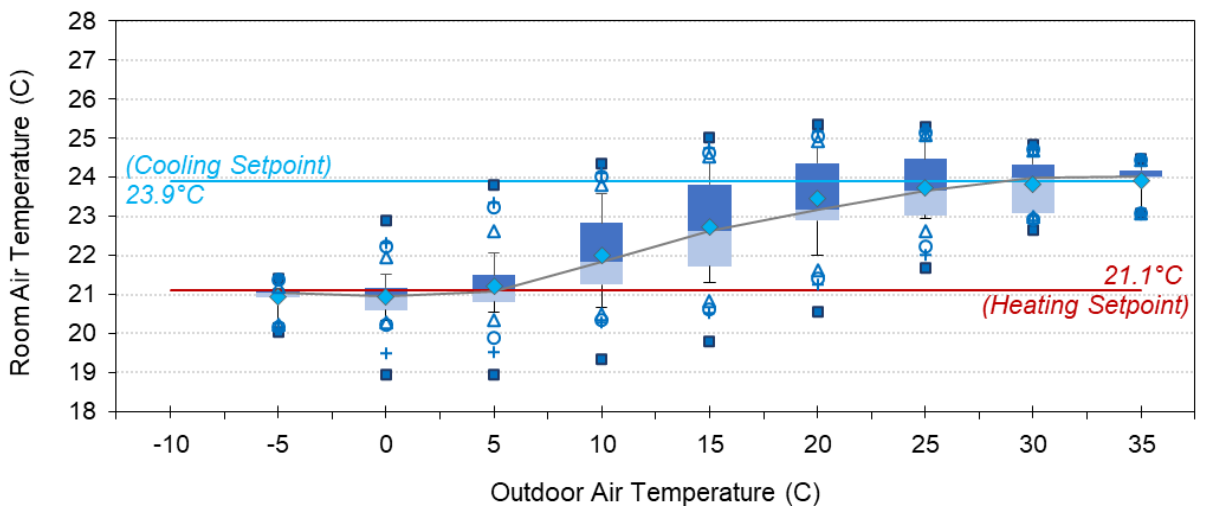

(b) CDHP OFF

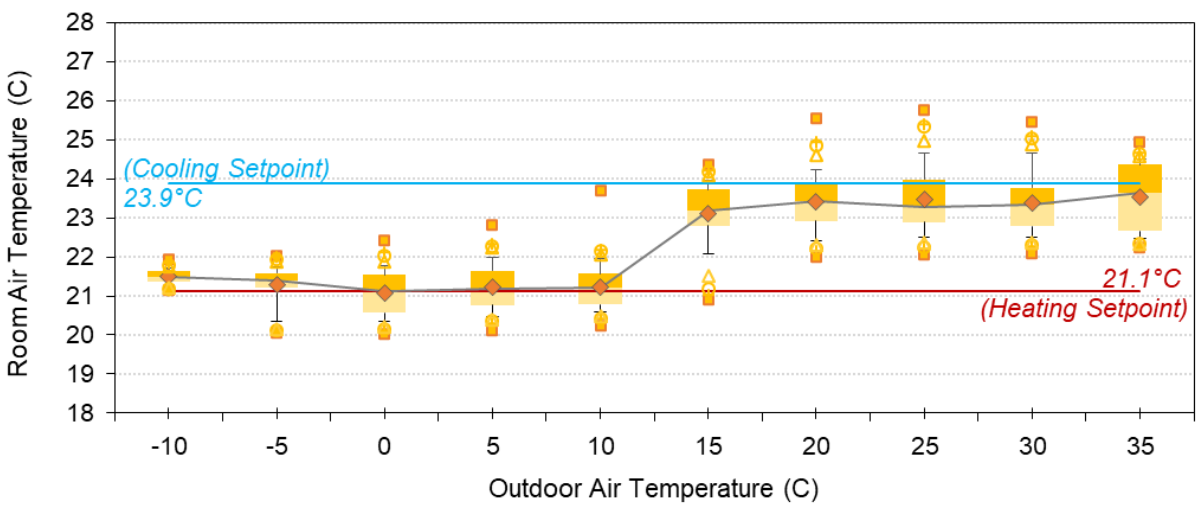

(c) SDHV ON

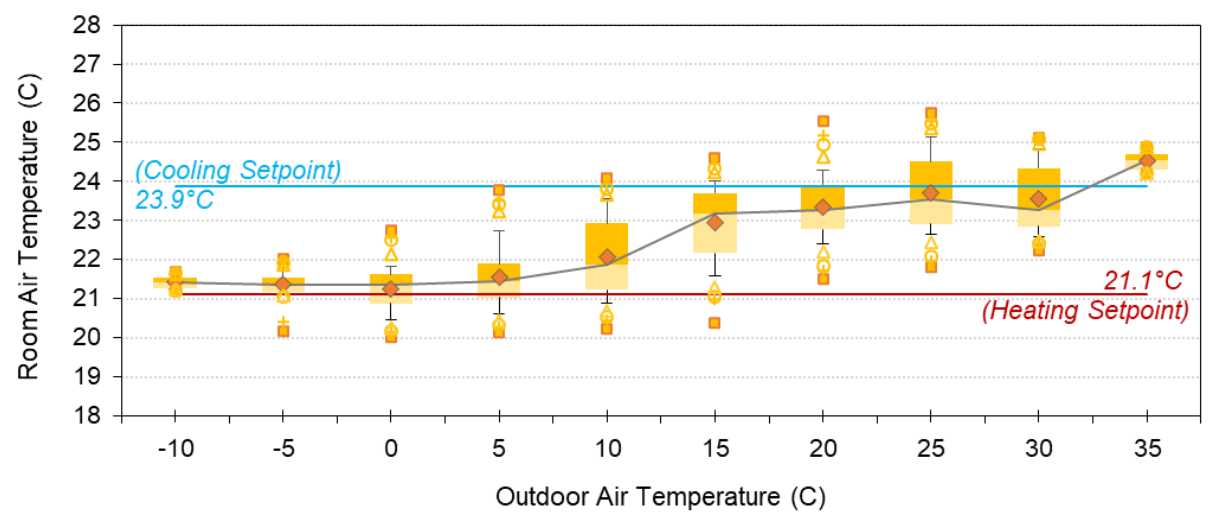

(d) SDHV OFF

Figure D-6: Binned BA2 Room Air Temperatures Against Outdoor Temperatures. 
Appendix E presents graphical summaries of the hourly room temperature profiles by different system types and on/off cycle (i.e., CDHP on, CDHP off, SDHV on, and SDHV off) and seasons (i.e., cooling season, heating season, and transitional season), including the $10^{\text {th }}$, $25^{\text {th }}, 50^{\text {th }}, 75^{\text {th }}$, and $90^{\text {th }}$ percentiles as well as minimum, mean, and maximum values, for the following rooms as supplementary materials to Section 4.6.1:

- Kitchen (KIT) (Figures E-1 to E-3);

- Bedroom 2 (BR2) (Figures E-4 to E-6); and

- Bedroom 3 (BR3) (Figures E-7 to E-9).

The temperature profiles of each room followed its own expected pattern of temperature drifts with small spikes when considering the schedule of internal loads simulated in each room. Among the three rooms, the localized impacts of the simulated internal loads in each room on room temperature was the highest in KIT but still less than $1^{\circ} \mathrm{C}$. The BR2 and the BR3 had very similar profiles to those of the MBR. 

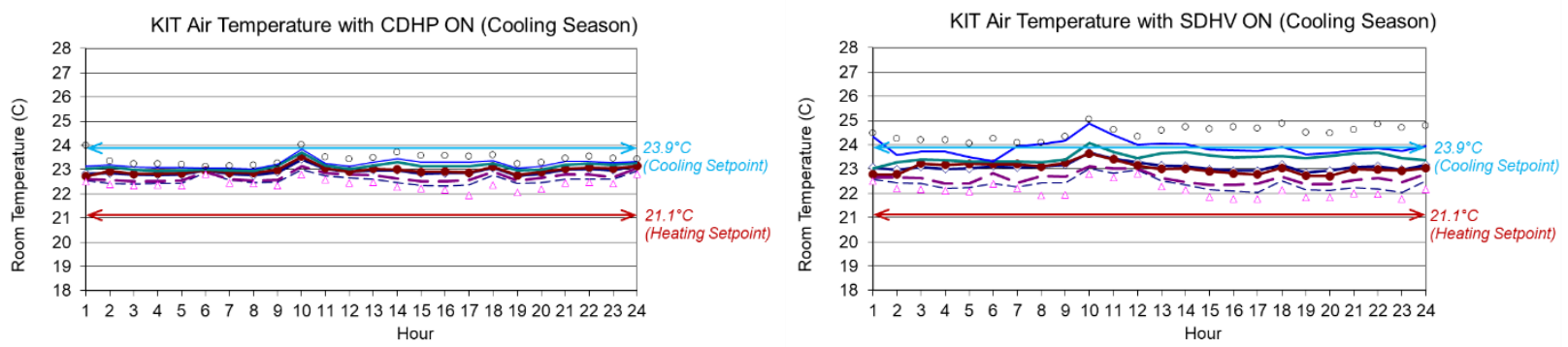

(a) CDHP On vs. SDHV On
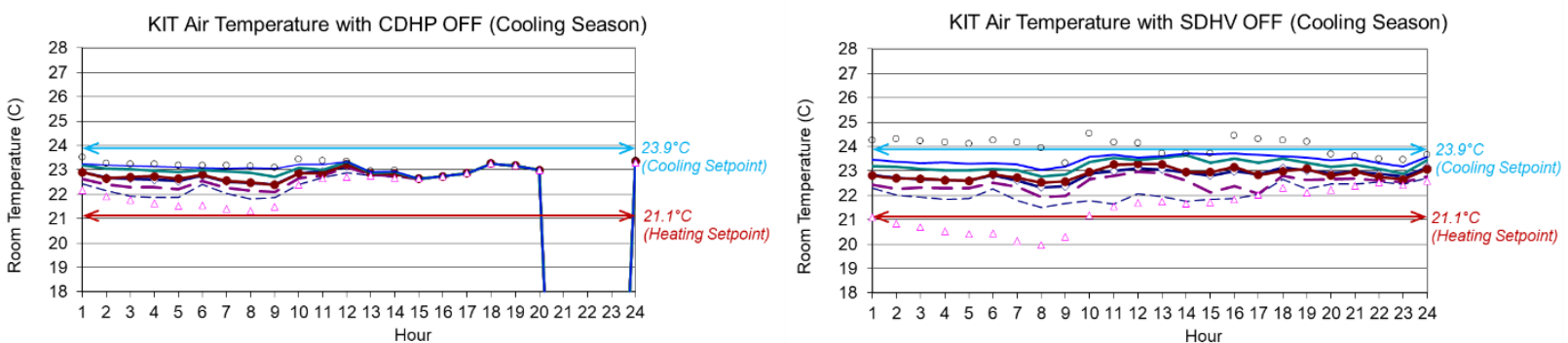

(b) CDHP Off vs. SDHV Off

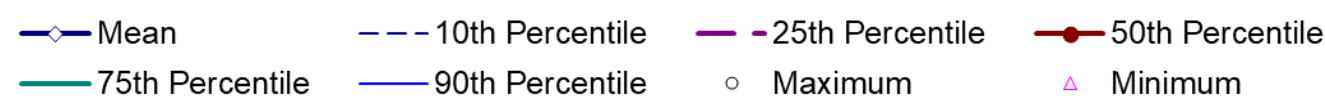

Figure E-1: Hourly KIT Temperature Profiles by Different System Types and On/Off Cycle during the Cooling Season.
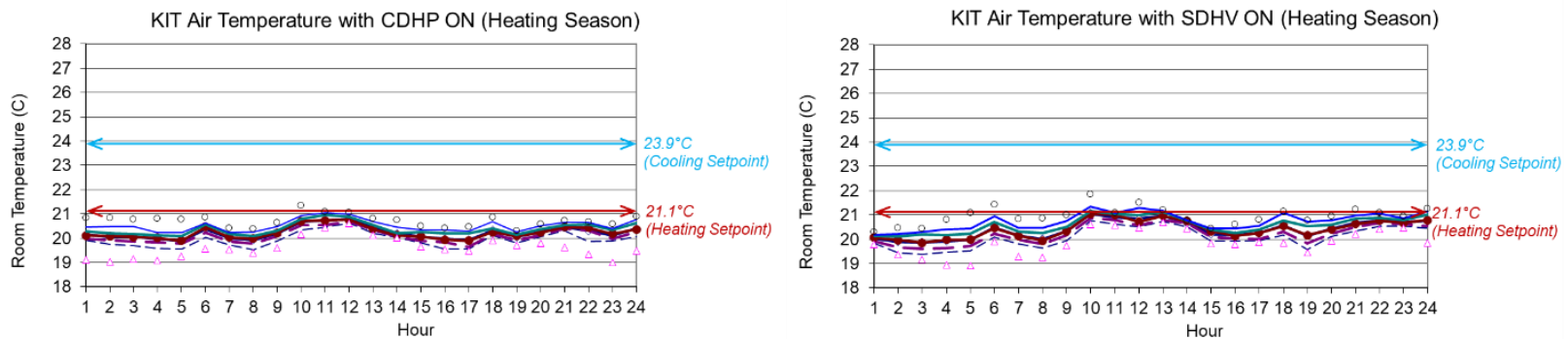

(a) CDHP On vs. SDHV On
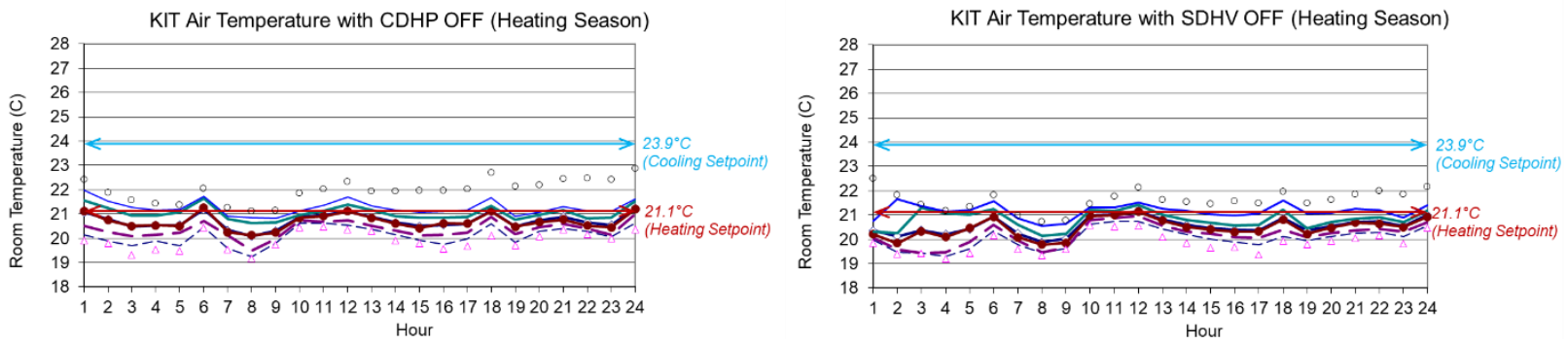

(b) CDHP Off vs. SDHV Off

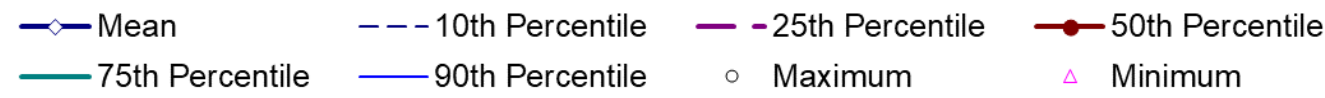

Figure E-2: Hourly KIT Temperature Profiles by Different System Types and On/Off Cycle during the Heating Season. 

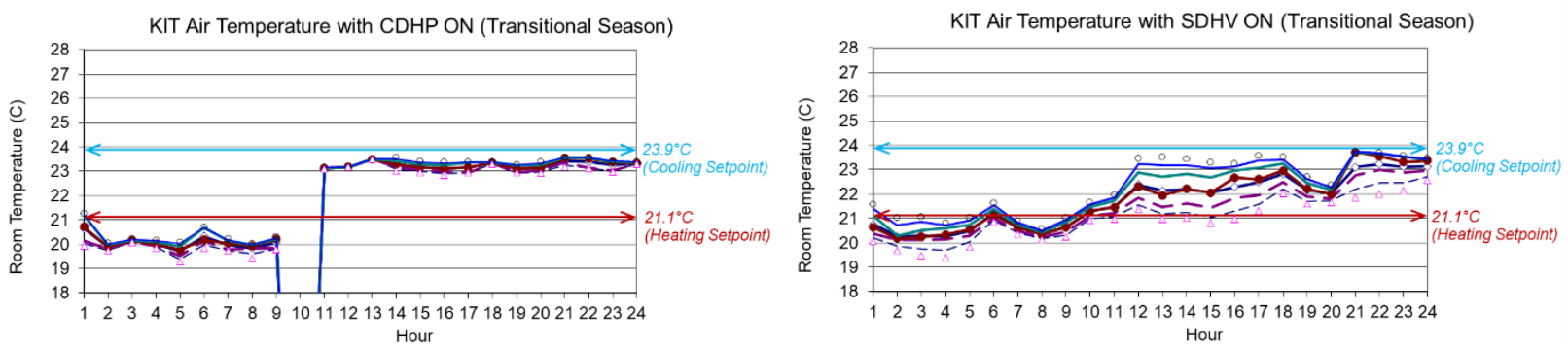

(a) CDHP On vs. SDHV On
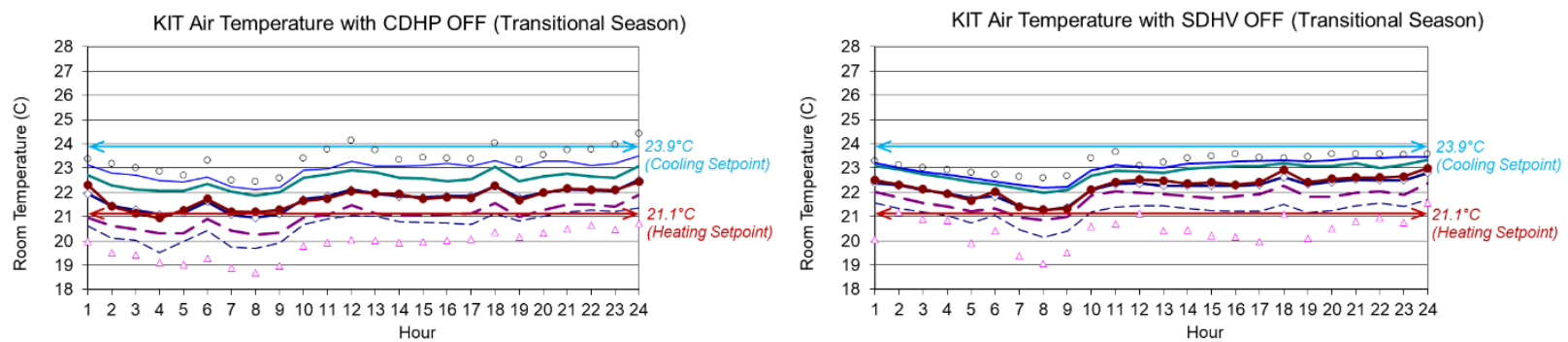

(b) CDHP Off vs. SDHV Off

\begin{tabular}{|c|c|c|}
\hline $\begin{array}{l}\text { Mean } \\
75 \text { th Percentile }\end{array}$ & $\begin{array}{l}---10 \text { th Percentile } \\
-90 \text { th Percentile }\end{array}$ & $\begin{array}{c}-\quad-25 \text { th Percentile } \\
\circ \quad \text { Maximum }\end{array}$ \\
\hline
\end{tabular}

Figure E-3: Hourly KIT Temperature Profiles by Different System Types and On/Off Cycle during the Transitional Season. 

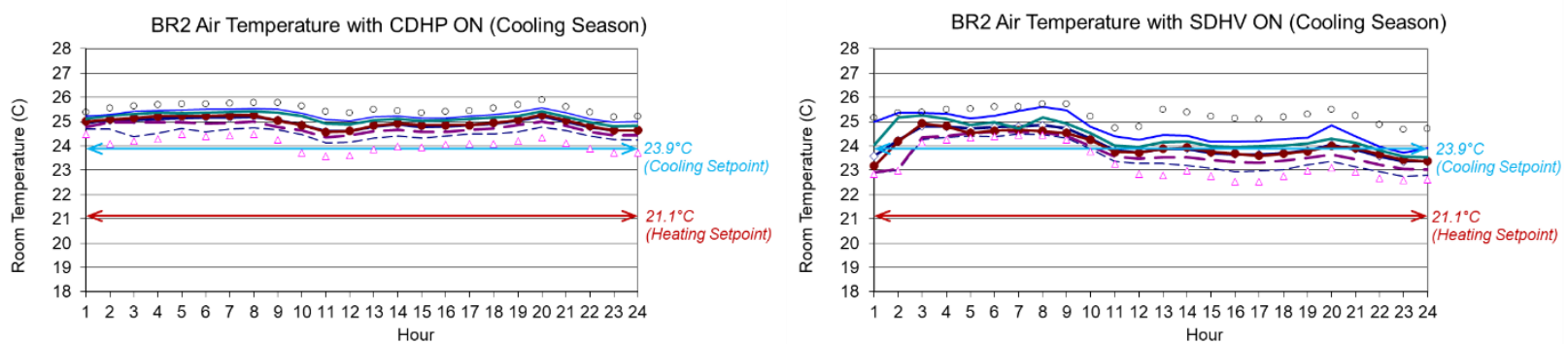

(a) CDHP On vs. SDHV On
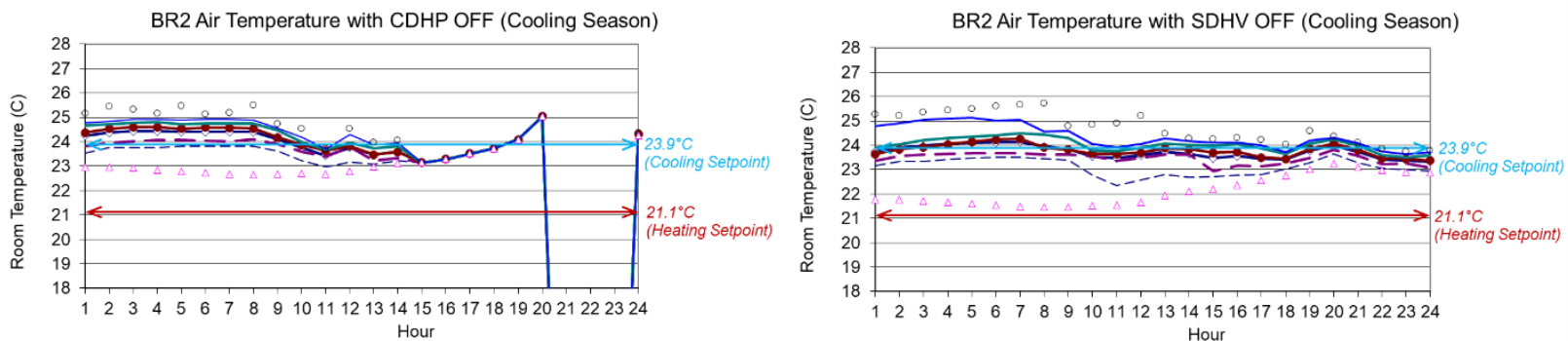

(b) CDHP Off vs. SDHV Off

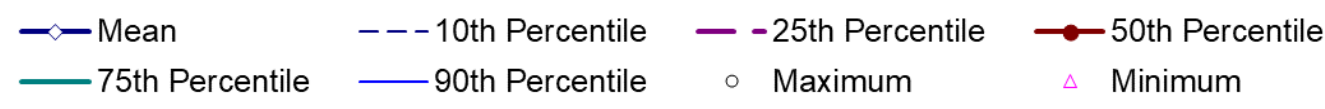

Figure E-4: Hourly BR2 Temperature Profiles by Different System Types and On/Off Cycle during the Cooling Season.
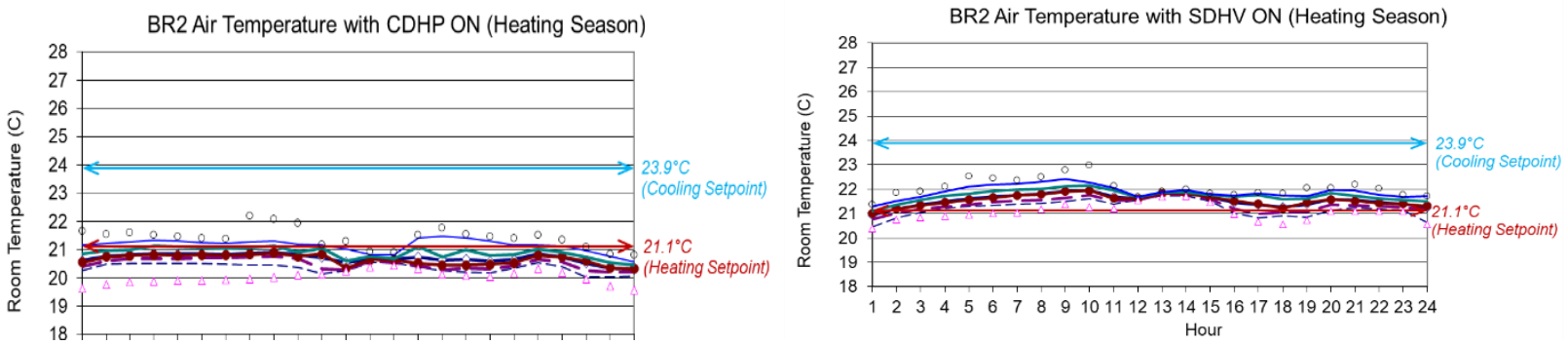

(a) CDHP On vs. SDHV On
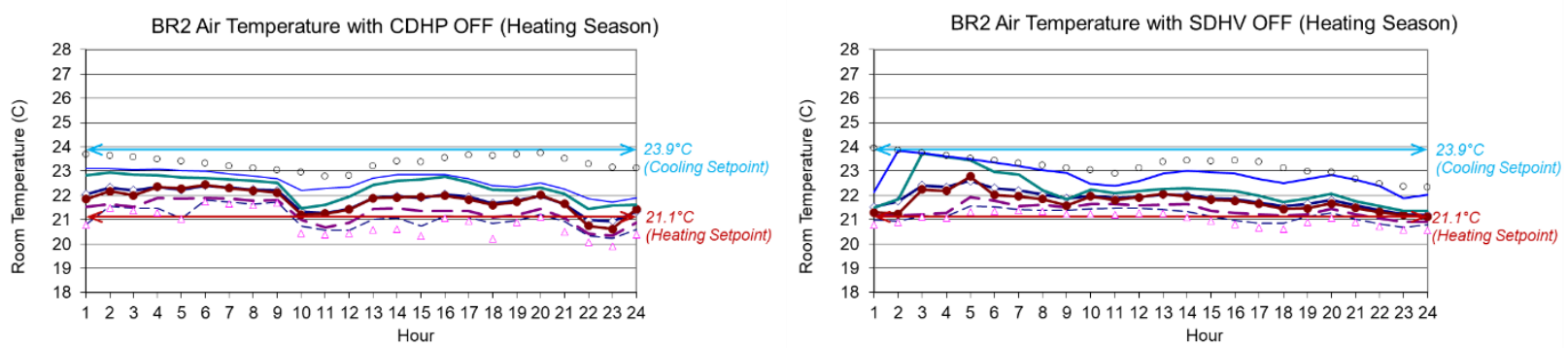

(b) CDHP Off vs. SDHV Off

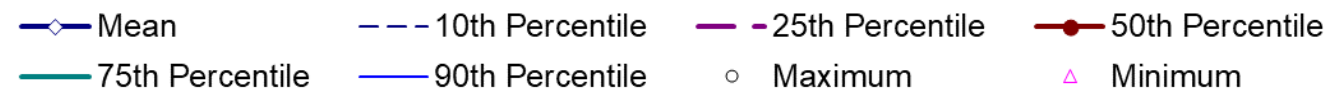

Figure E-5: Hourly BR2 Temperature Profiles by Different System Types and On/Off Cycle during the Heating Season. 

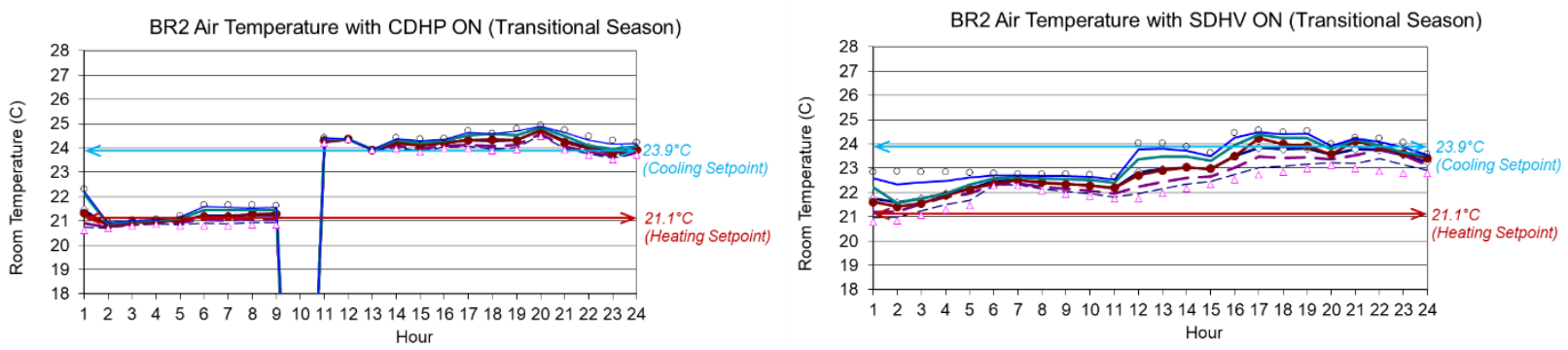

(a) CDHP On vs. SDHV On
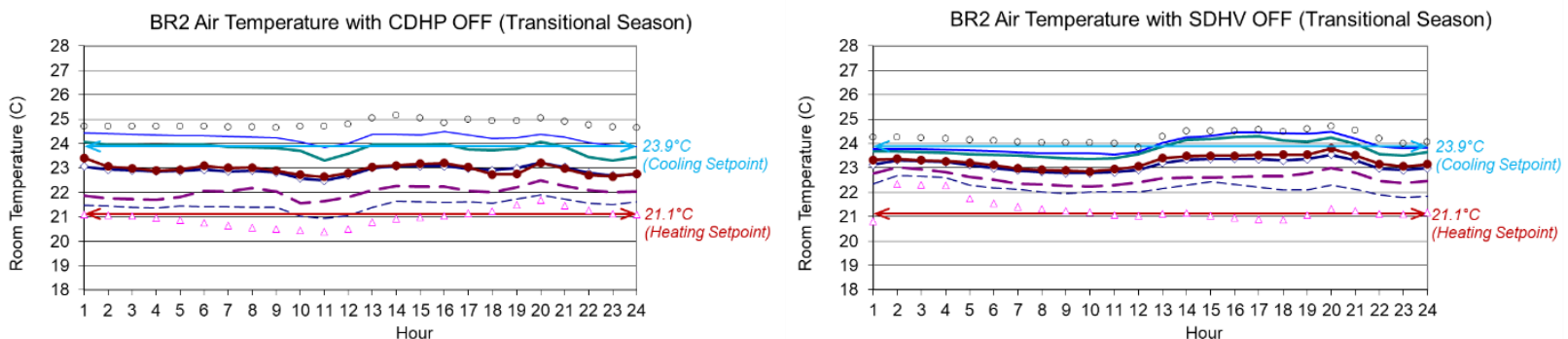

(b) CDHP Off vs. SDHV Off

\begin{tabular}{|c|c|c|c|}
\hline$\longrightarrow$ - Mean & ---10 th Percentile & - - 25th Percentile & $\multimap$ 50th $P$ \\
\hline -75th Percentile & — 90th Percentile & $\circ$ Maximum & $\triangle$ Minimum \\
\hline
\end{tabular}

Figure E-6: Hourly BR2 Temperature Profiles by Different System Types and On/Off Cycle during the Transitional Season. 

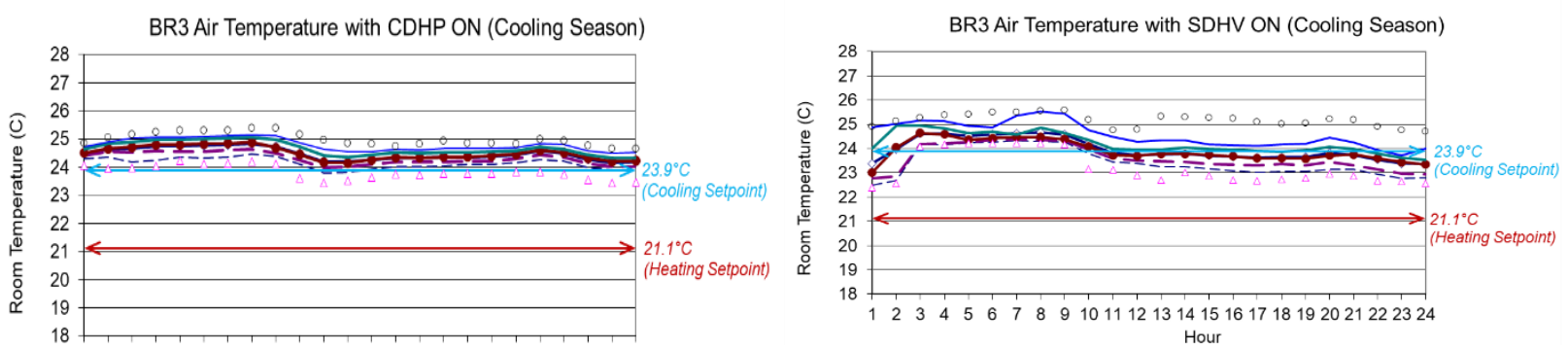

(a) CDHP On vs. SDHV On
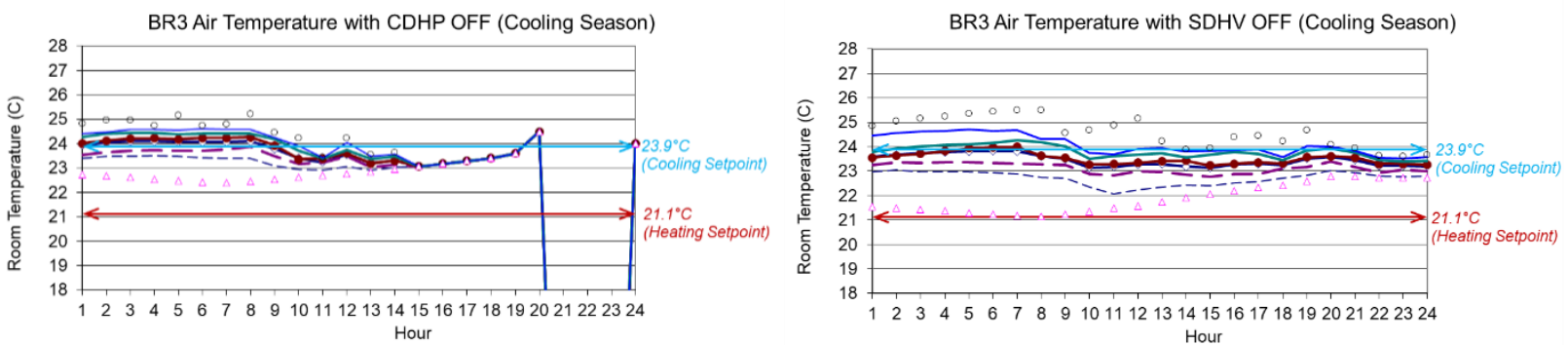

(b) CDHP Off vs. SDHV Off

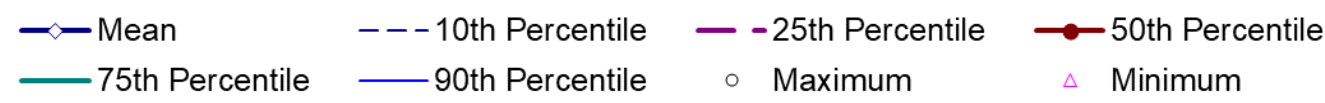

Figure E-7: Hourly BR3 Temperature Profiles by Different System Types and On/Off Cycle during the Cooling Season.
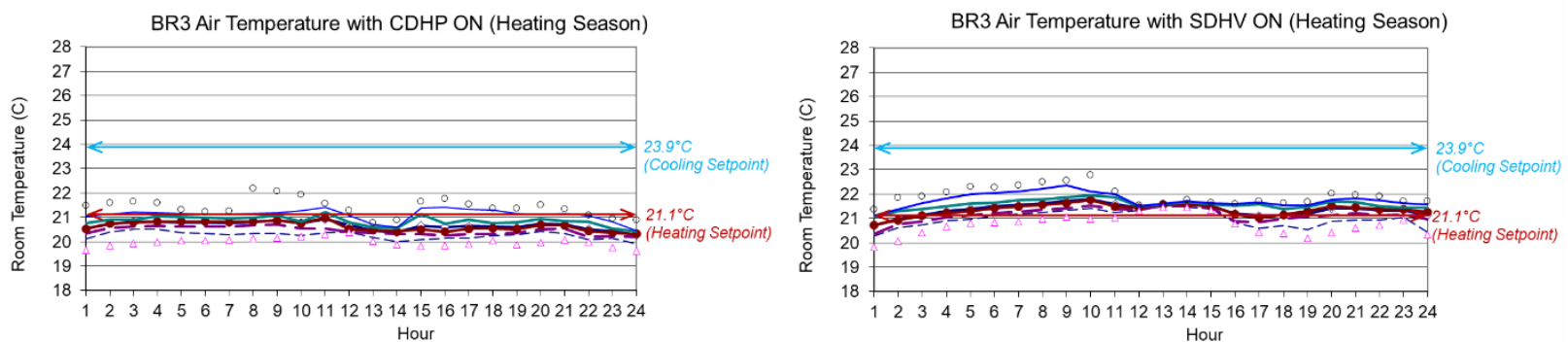

(a) CDHP On vs. SDHV On
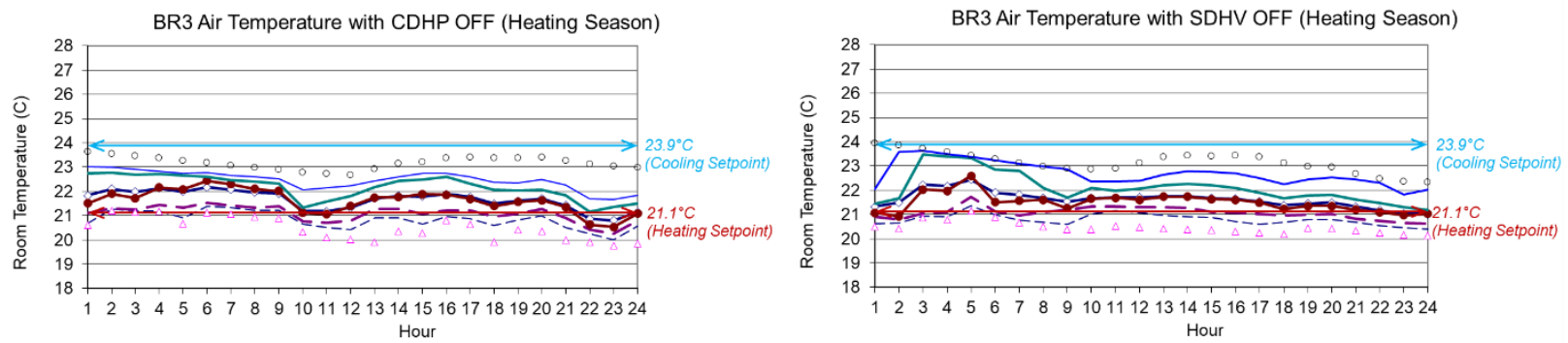

(b) CDHP Off vs. SDHV Off

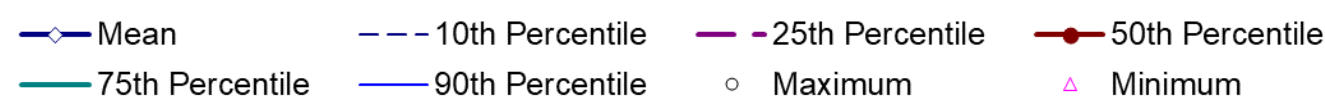

Figure E-8: Hourly BR3 Temperature Profiles by Different System Types and On/Off Cycle during the Heating Season. 

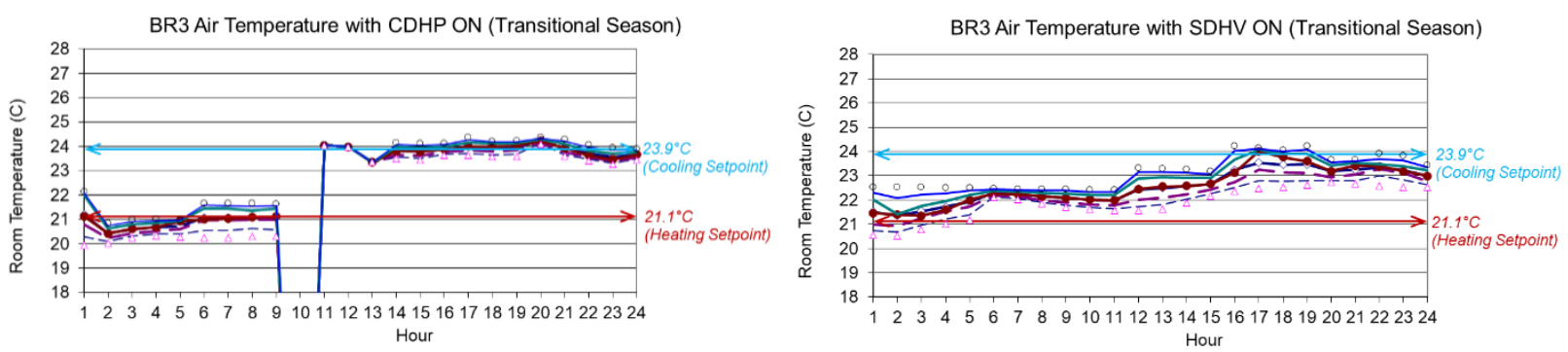

(a) CDHP On vs. SDHV On
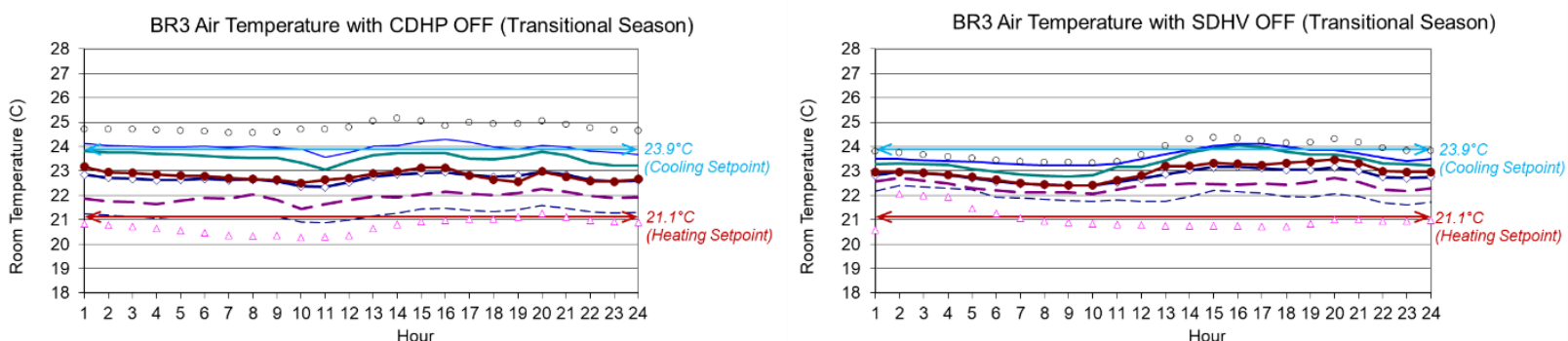

(b) CDHP Off vs. SDHV Off
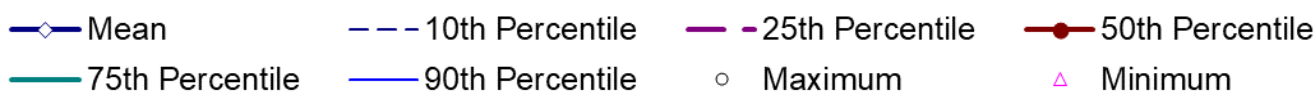

Figure E-9: Hourly BR3 Temperature Profiles by Different System Types and On/Off Cycle during the Transitional Season. 
Appendix F presents time-of-day colored maps applied to the hourly average room temperatures over the entire measurement period for the following rooms as supplementary materials to Section 4.6.2:

- Kitchen (KIT) (Figure F-1);

- Bedroom 2 (BR2) (Figure F-2); and

- Bedroom 3 (BR3) (Figure F-3).

Each room had different temporal patterns, which was mostly affected by the schedule of internal loads simulated in each room of this low-load house. The kitchen began to have a different pattern after July 14, 2017, when the kitchen measurement stand was moved from the edge of the kitchen island facing the two humidifiers to the center of the island.

The BR2 and the BR3 had very similar profiles to those of the MBR with fewer non-compliance incidences for the cooling season. The BR3's fewer non-compliance incidences might be affected by no presence of simulated occupancy/plug loads in the BR3 during the analysis period. 


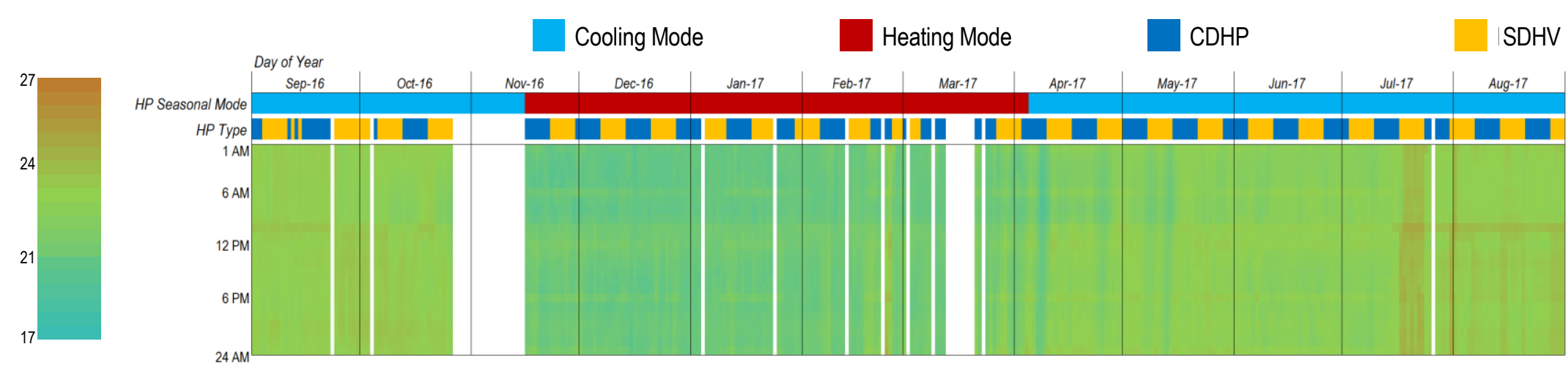

(a) Hourly Average Room Temperatures

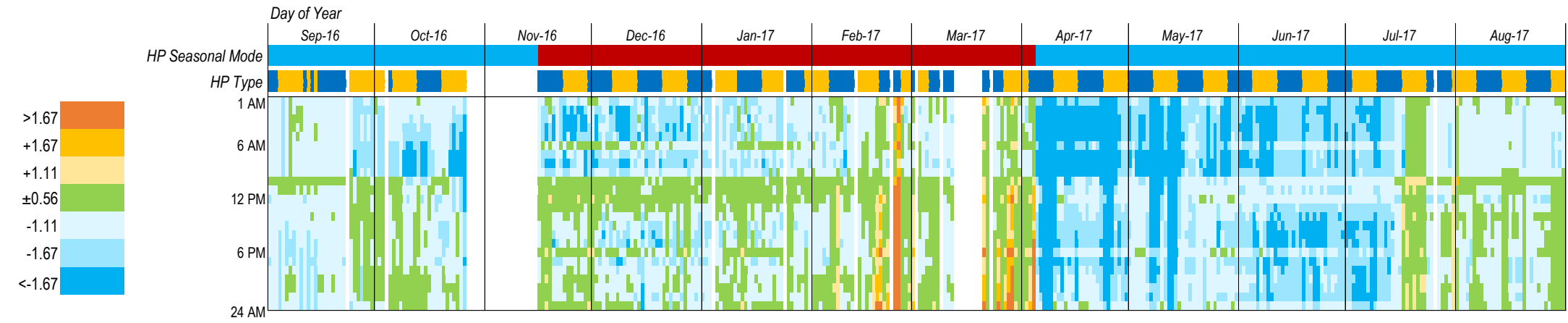

(b) Hourly Average Room-To-Thermostat Temperature Difference

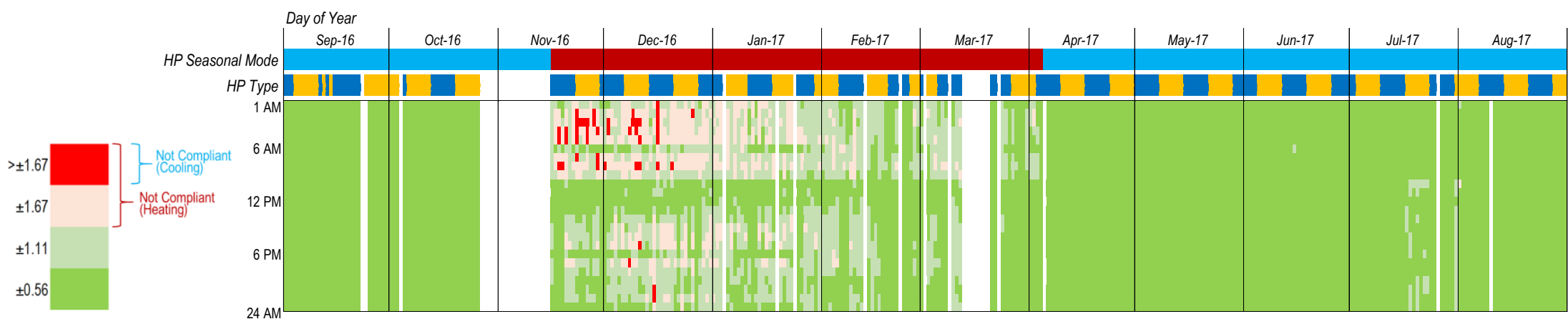

(c) ACCA Compliance Based on Hourly Average Room-To-Thermostat Temperature Difference Figure F-1: Time-of-Day Colored Map of KIT Temperature. 


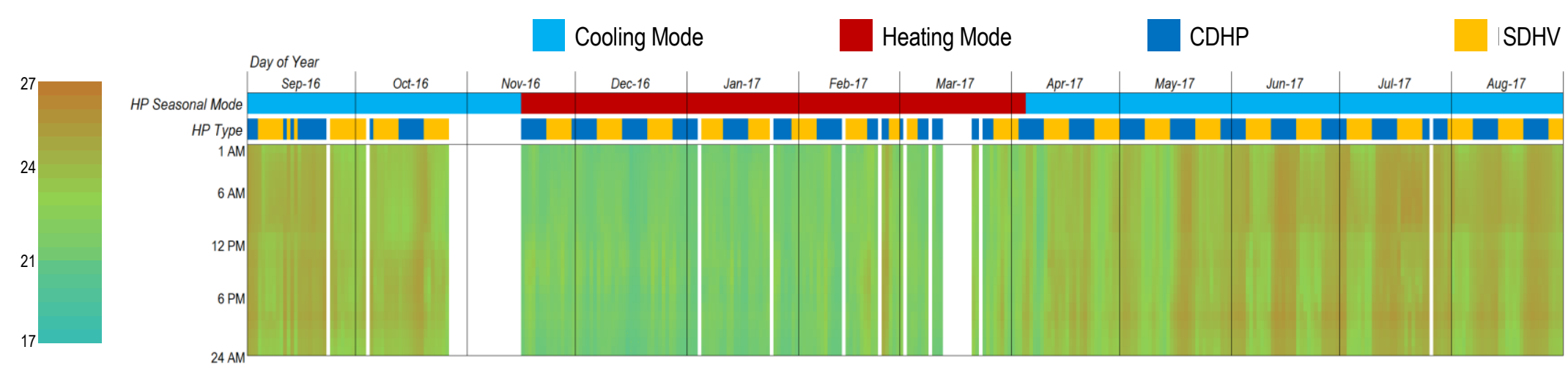

(a) Hourly Average Room Temperatures

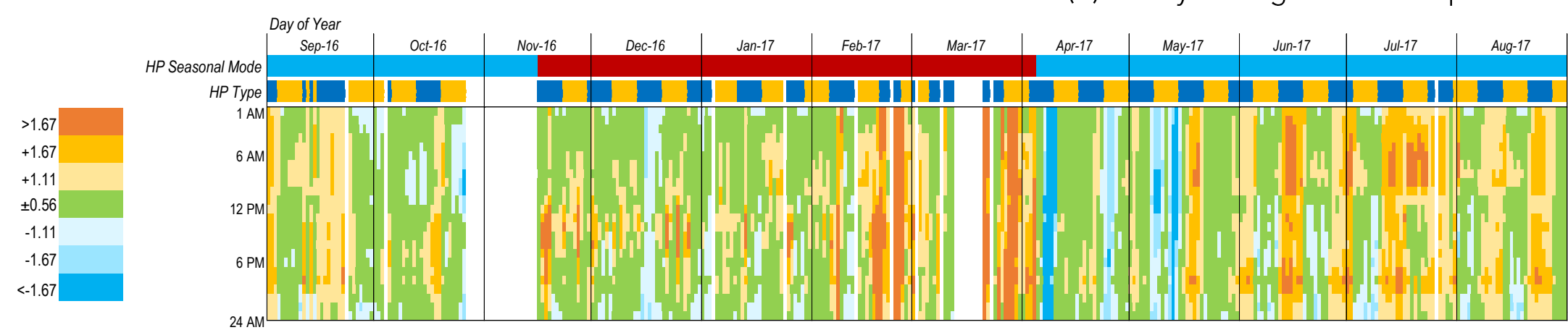

(b) Hourly Average Room-To-Thermostat Temperature Difference

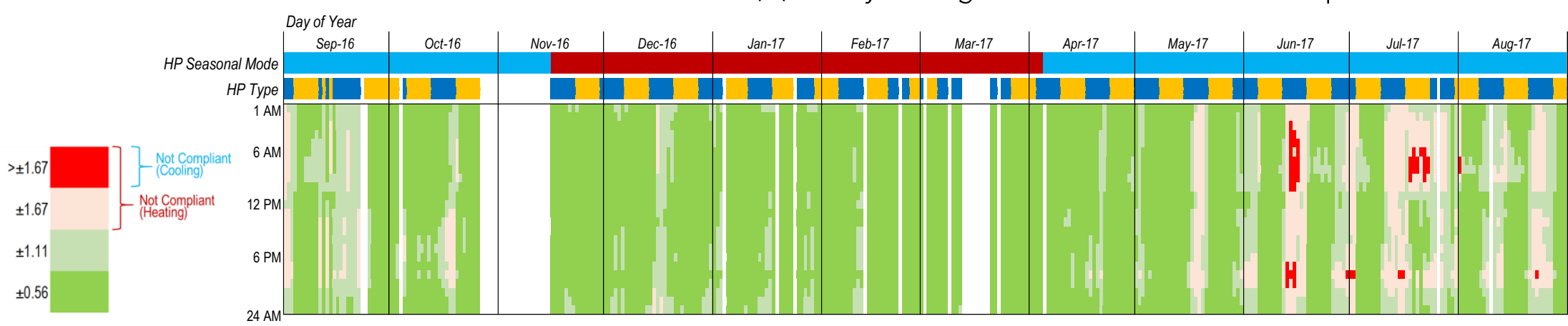

(c) ACCA Compliance Based on Hourly Average Room-To-Thermostat Temperature Difference

Figure F-2: Time-of-Day Colored Map of BR2 Temperature. 


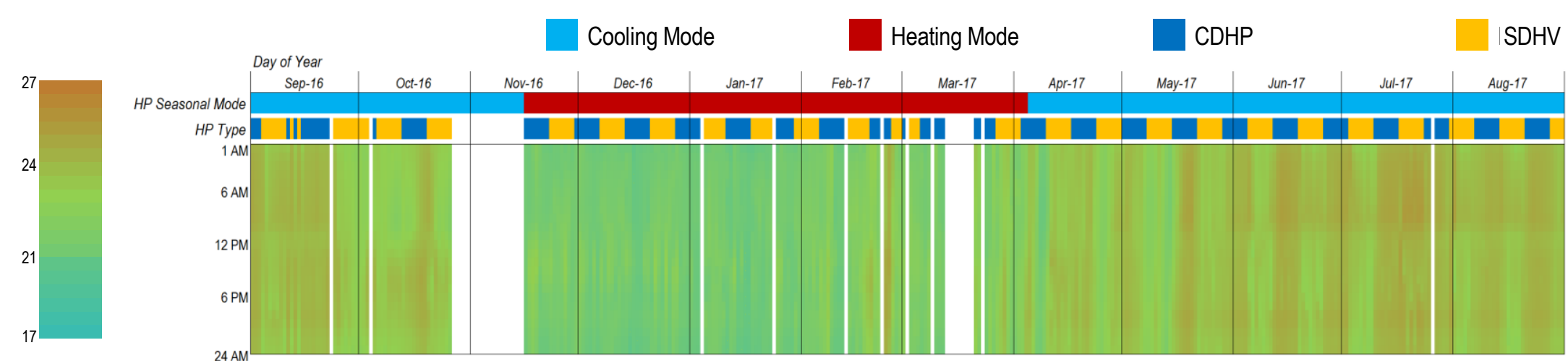

(a) Hourly Average Room Temperatures

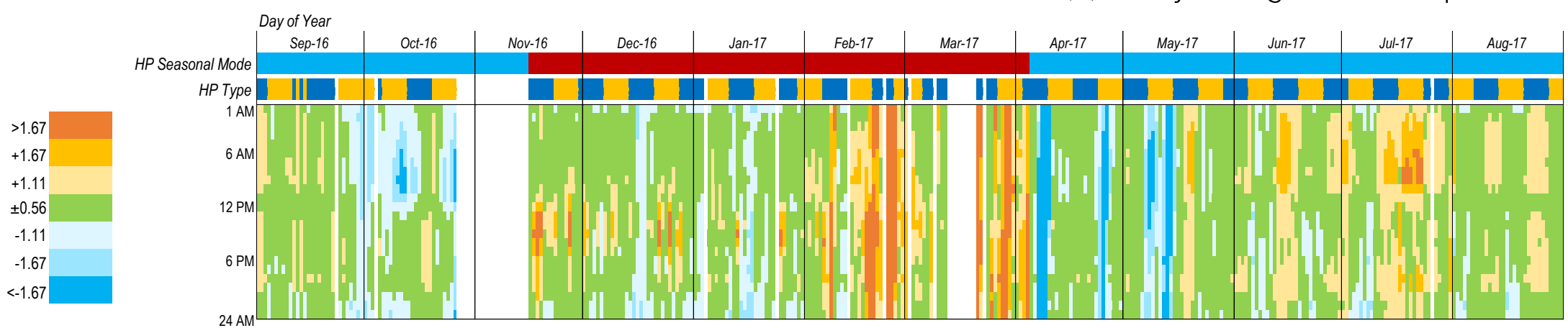

(b) Hourly Average Room-To-Thermostat Temperature Difference

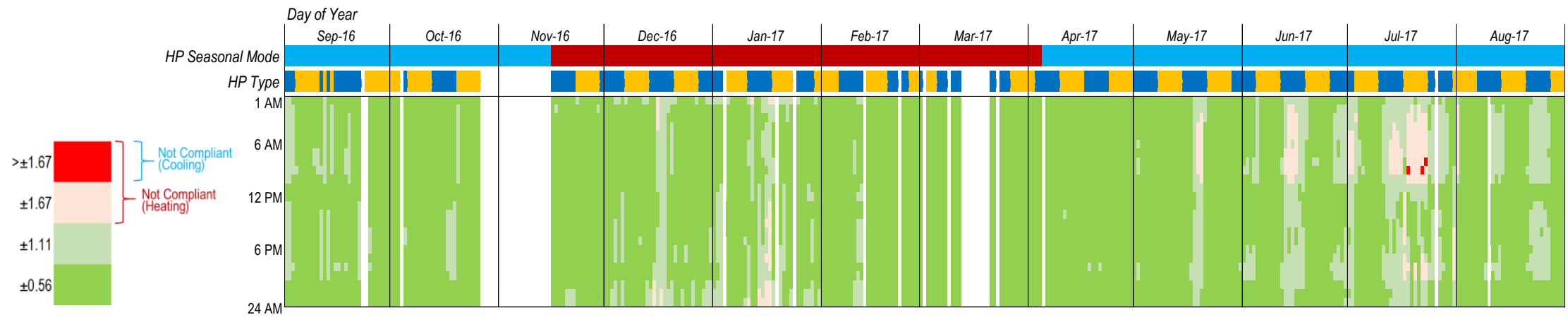

(c) ACCA Compliance Based on Hourly Average Room-To-Thermostat Temperature Difference Figure F-3: Time-of-Day Colored Map of BR3 Temperature. 
APPENDIX G: Graphical Analysis Using the Psychrometric Chart (KIT, BR2, BR3, Attic, BSMT, and MBA)

Appendix G presents a graphical analysis of the hourly average thermal comfort data using the psychrometric chart with a super-imposed ASHRAE Standard 55-2017 comfort zone for the following rooms as supplementary materials to Section 4.8:

- Kitchen (KIT) (Figure G-1);

- Bedroom 2 (BR2) (Figure G-2);

- Bedroom 3 (BR3) (Figure G-3);

- Attic (Figure G-4);

- Basement (BSMT) (Figure G-5); and

- Master bathroom (MBA) (Figure G-6).

The hourly average operative temperature was calculated in accordance with Normative Appendix A of the ASHRAE Standard 55-2017 and used in the analysis of the three primary rooms (i.e., KIT, BR2, and BR3). For other three rooms (i.e., Attic, BSMT, and MBA), only two variables (i.e., $\mathrm{Ta}$ and $\mathrm{RH}$ ) were monitored, so room air temperature was directly used instead of operative temperature. 

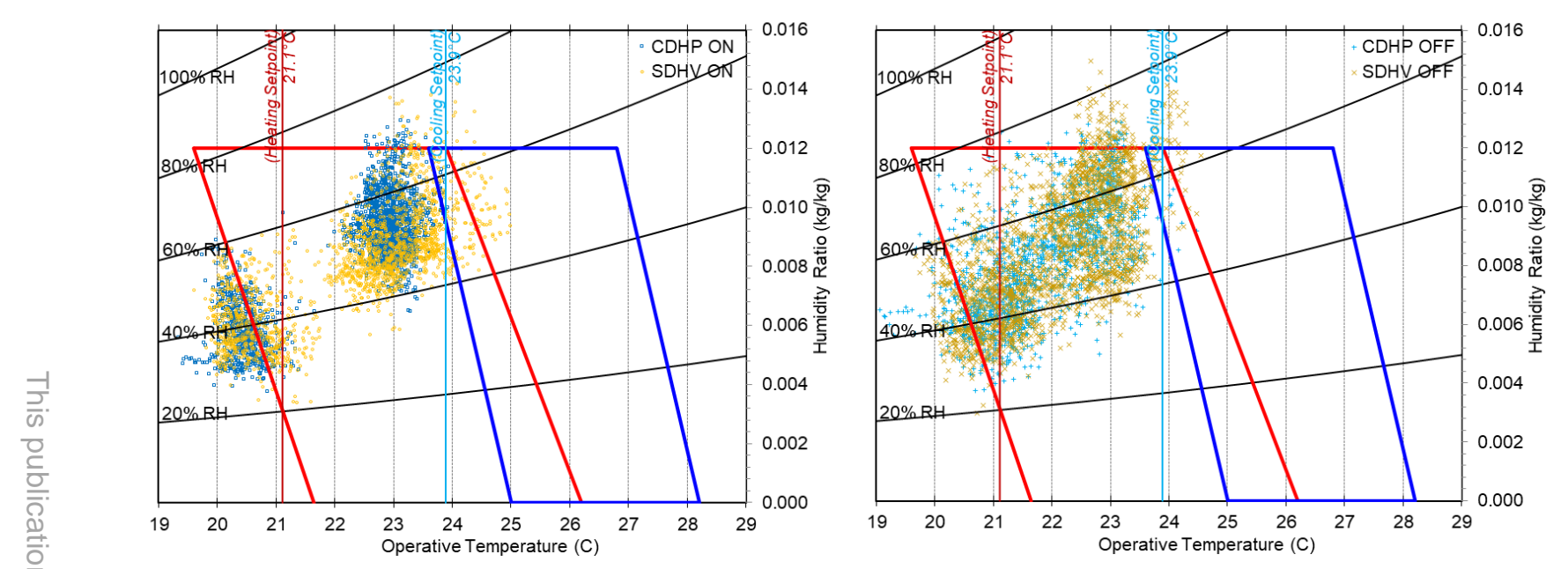

(a) HP On vs. Off
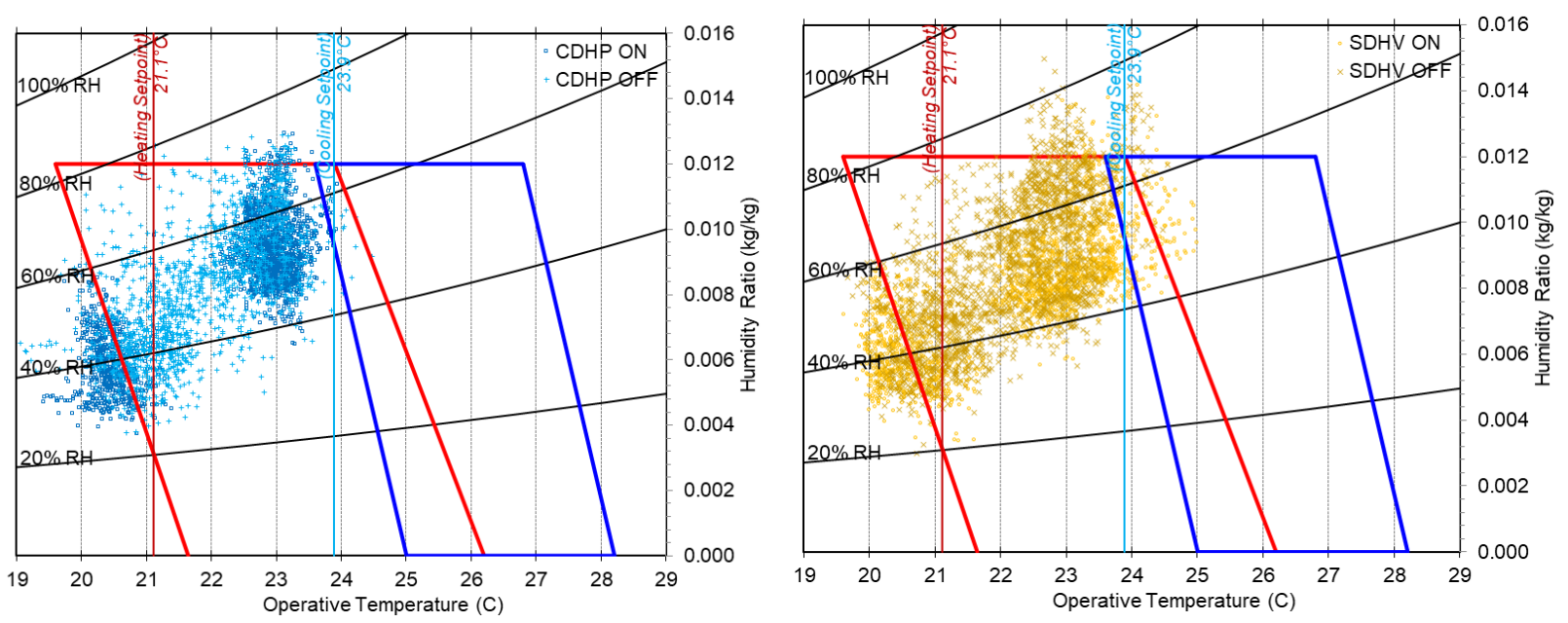

(b) CDHP vs. SDHV

Figure G-1: Hourly KIT Operative Temperature and Humidity Data Plotted on the ASHRAE 552017 Comfort Zones. 

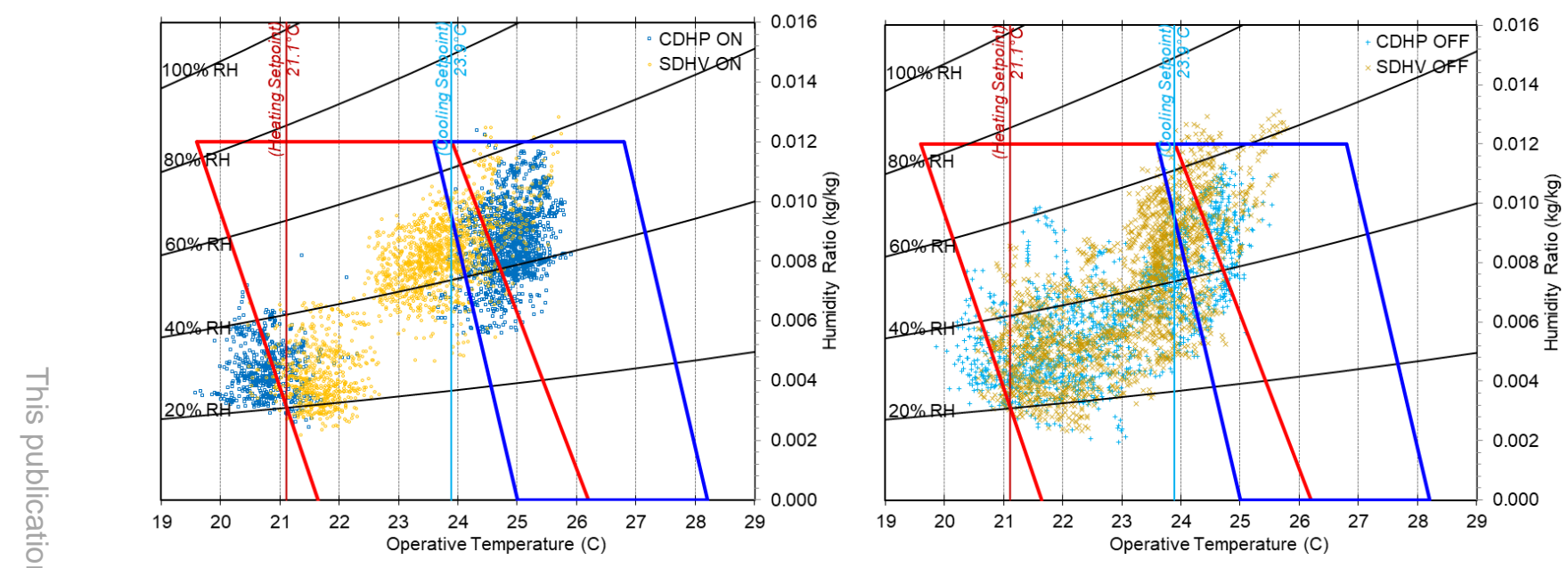

(a) HP On vs. Off
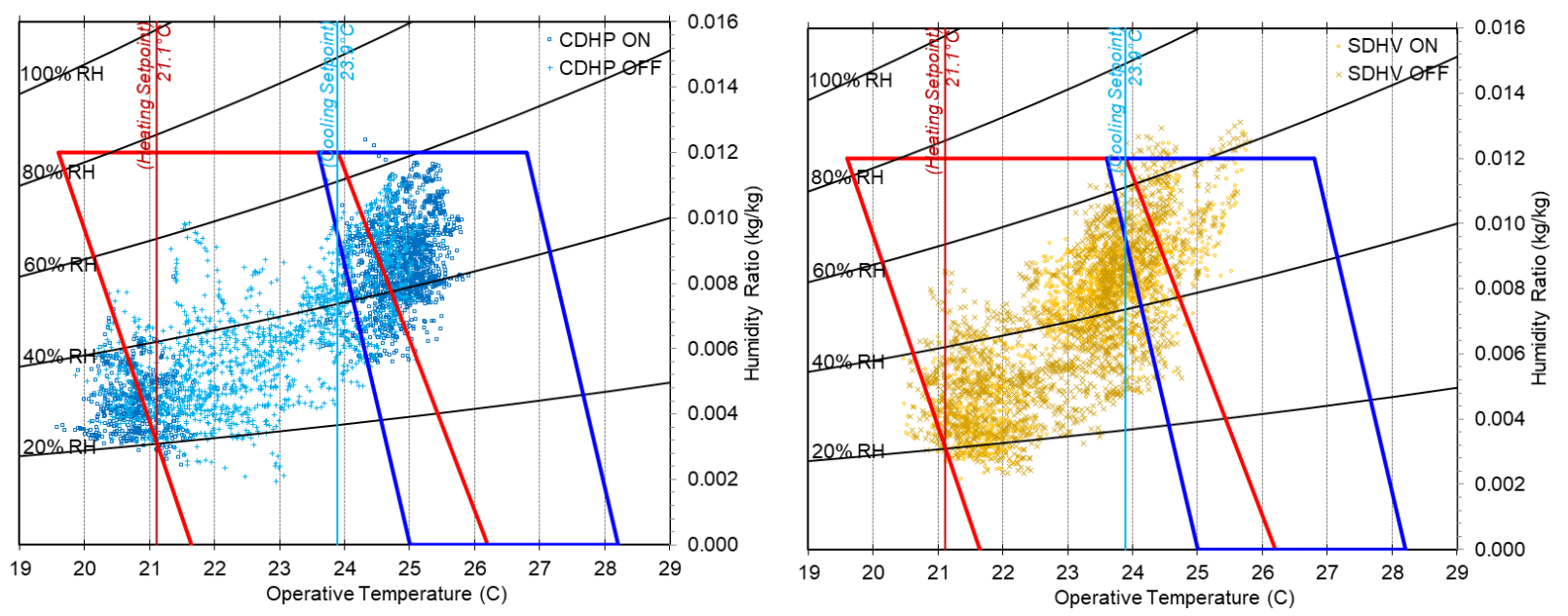

(b) CDHP vs. SDHV

Figure G-2: Hourly BR2 Operative Temperature and Humidity Data Plotted on the ASHRAE 55-2017 Comfort Zones. 

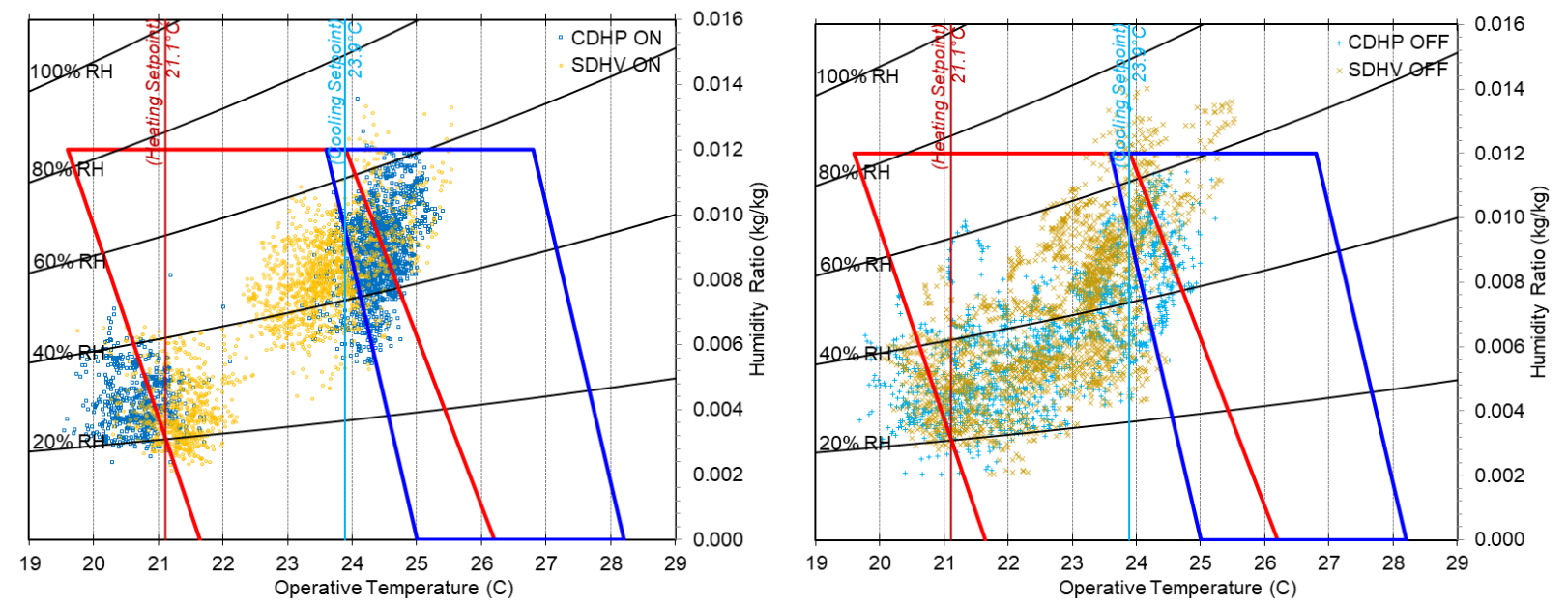

(a) HP On vs. Off
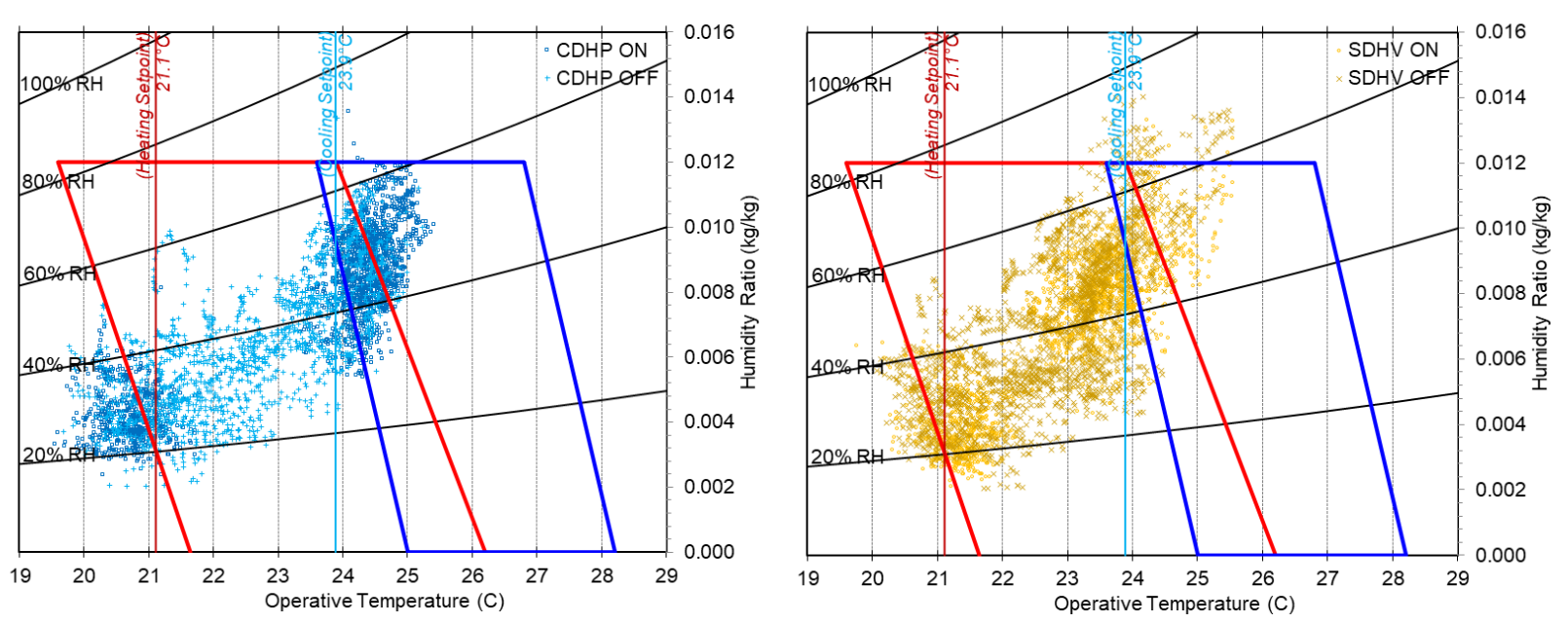

(b) CDHP vs. SDHV

Figure G-3: Hourly BR3 Operative Temperature and Humidity Data Plotted on the ASHRAE 55-2017 Comfort Zones. 

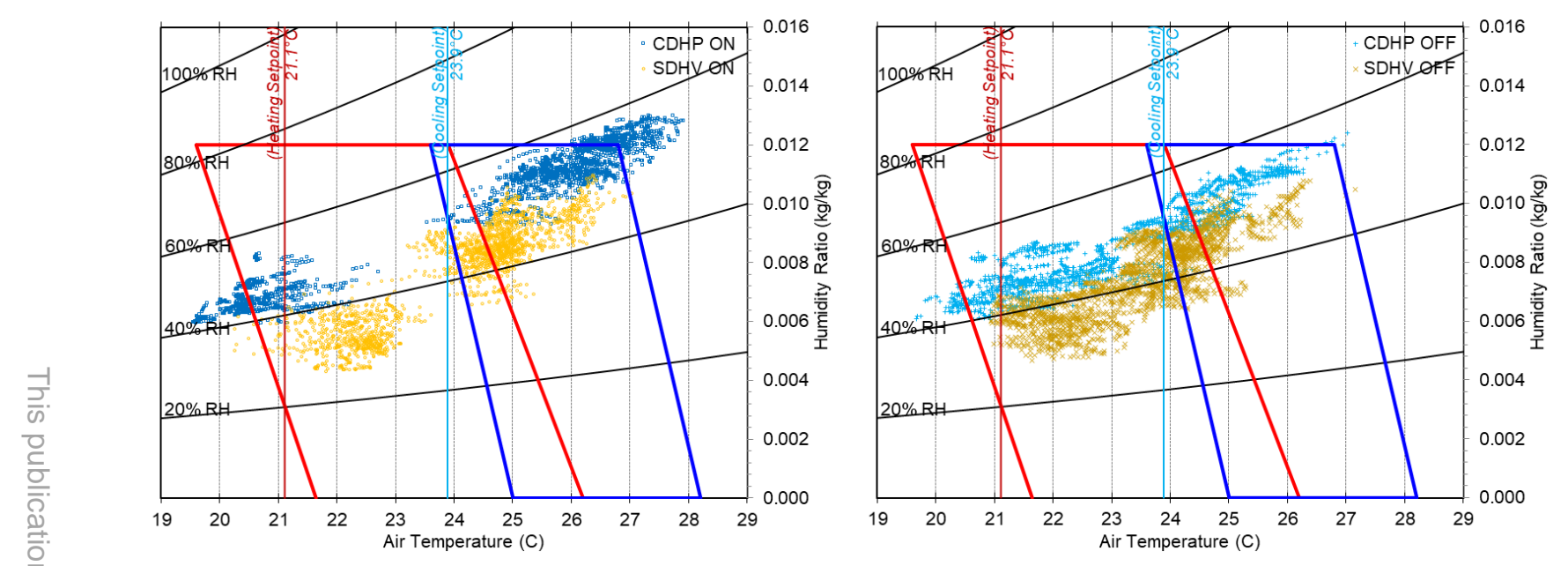

(a) HP On vs. Off
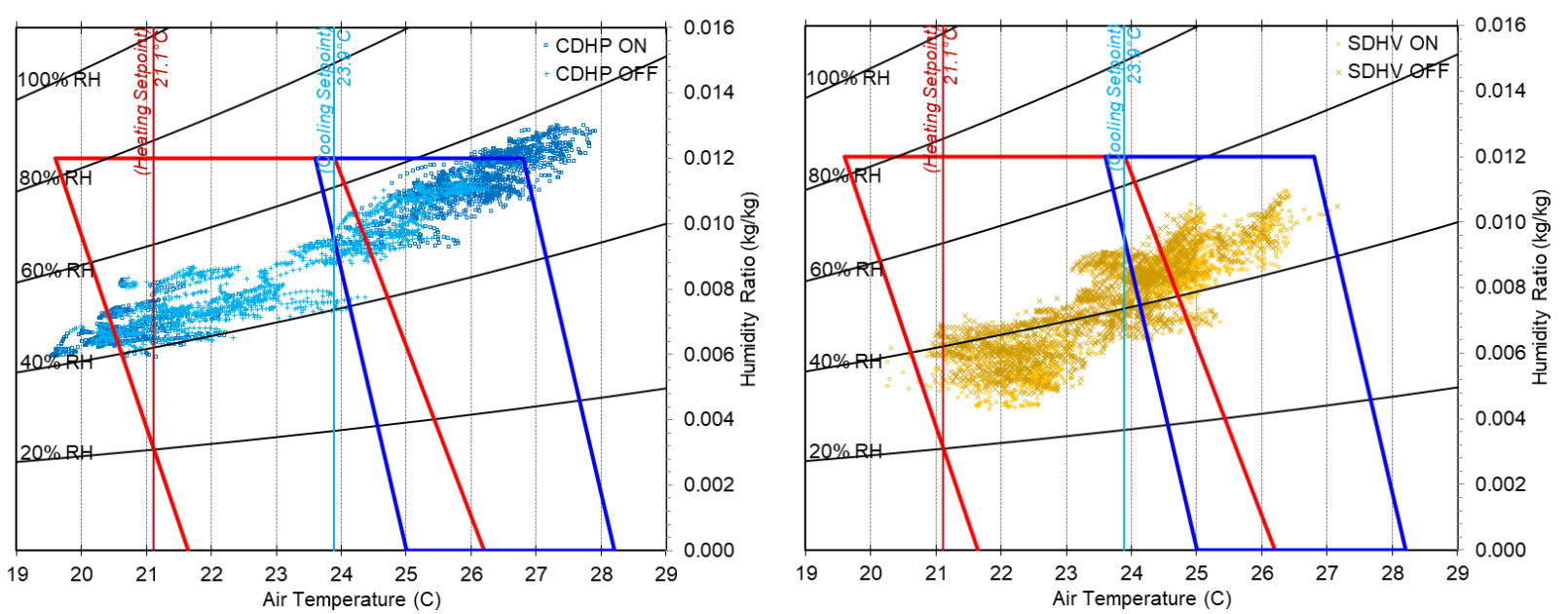

(b) CDHP vs. SDHV

Figure G-4: Hourly Attic Air Temperature and Humidity Data Plotted on the ASHRAE 55-2017 Comfort Zones. 

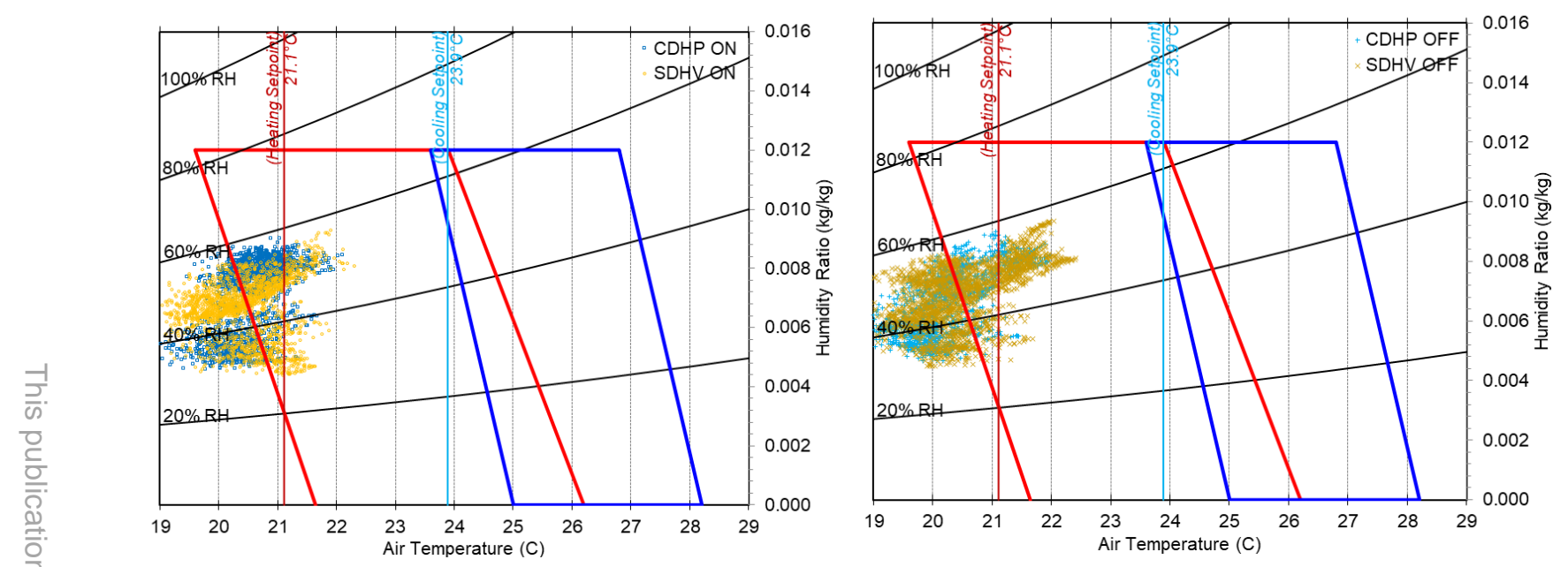

(a) HP On vs. Off
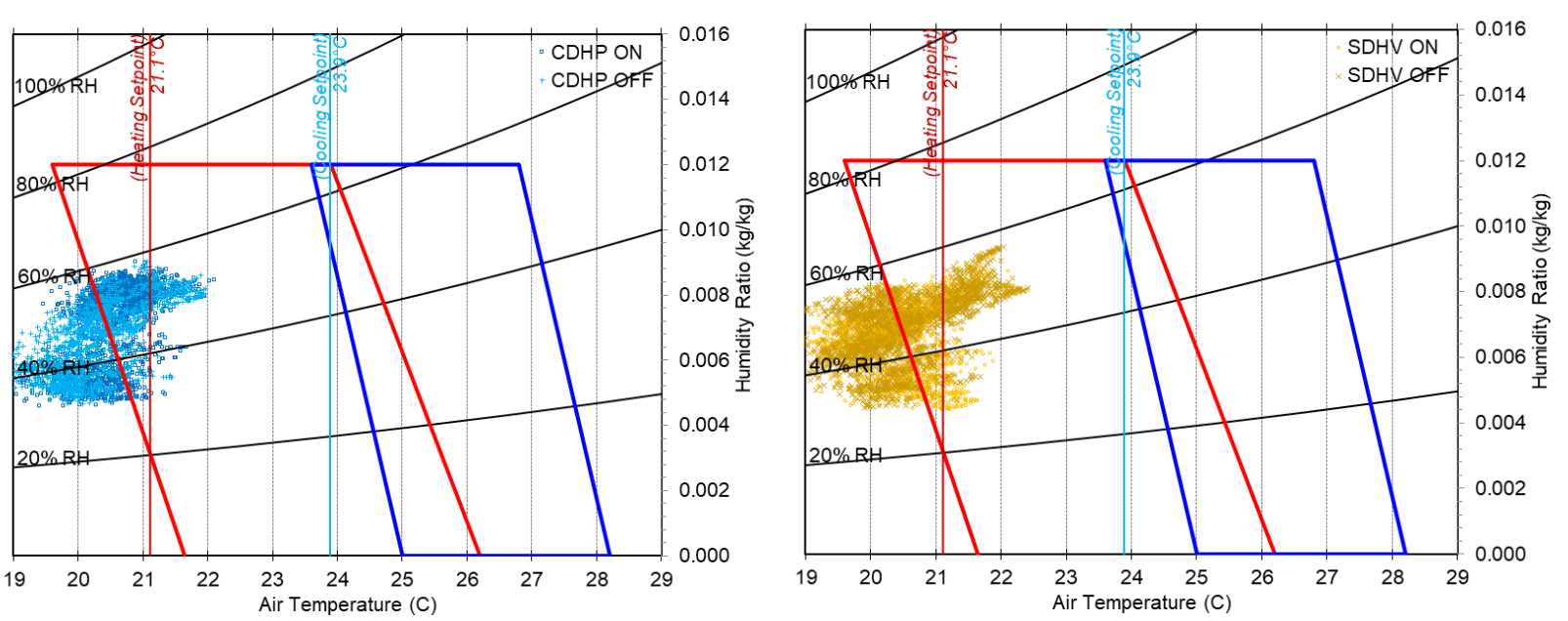

(b) CDHP vs. SDHV

Figure G-5: Hourly BSMT Air Temperature and Humidity Data Plotted on the ASHRAE 552017 Comfort Zones. 


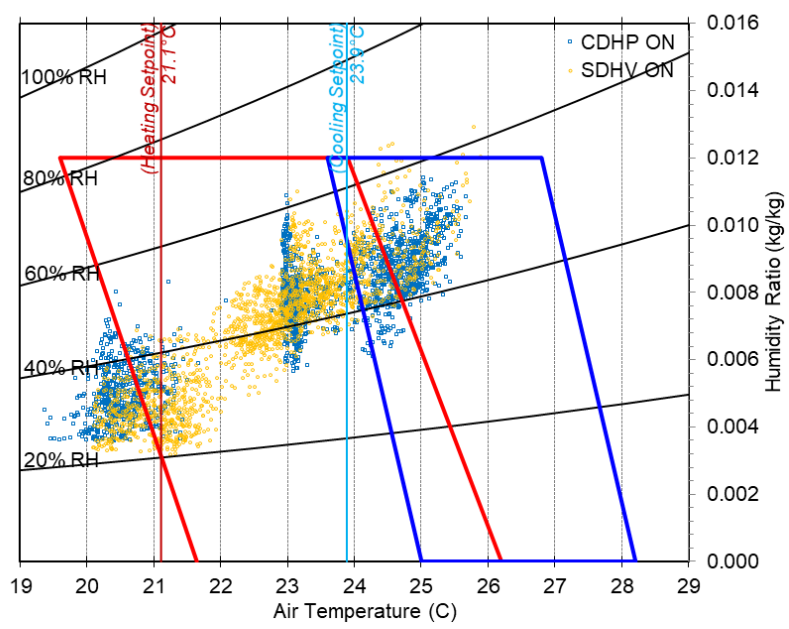

(a) HP On vs. Off

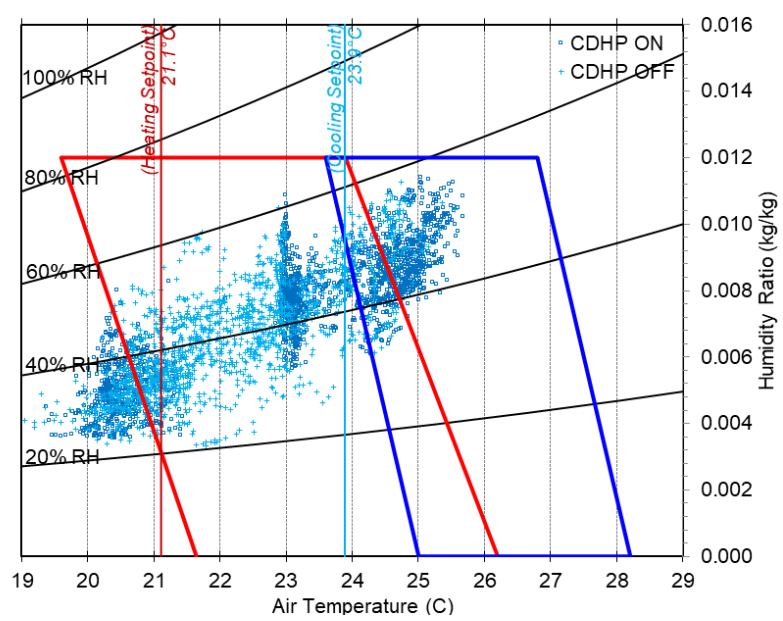

(b) CDHP vs. SDHV
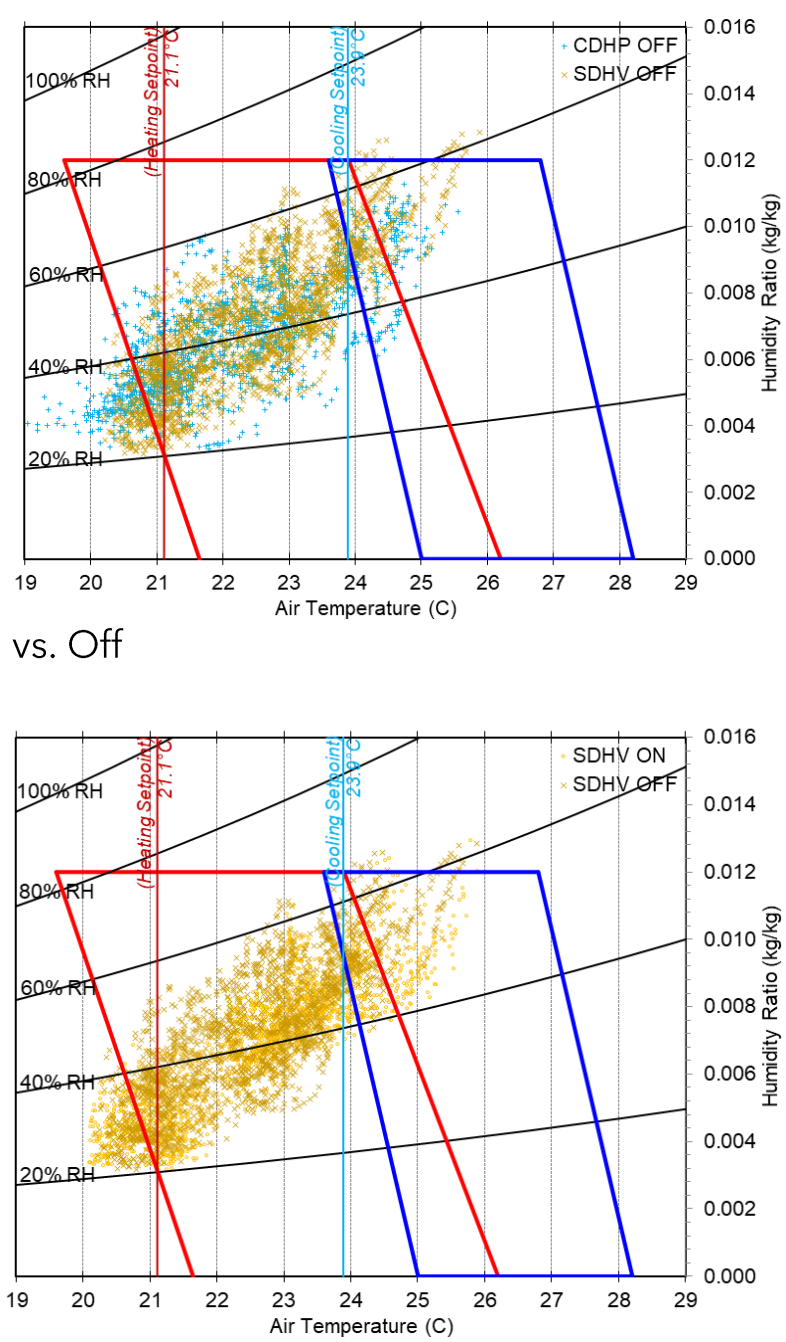
0.012

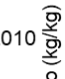
008 $06 \frac{\text { 흘 }}{\frac{7}{5}}$

04 .002 02$$
\text { . }
$$

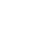

Figure G-6: Hourly MBA Air Temperature and Humidity Data Plotted on the ASHRAE 55-2017 Comfort Zones. 


\section{APPENDIX H: Statistical Characterization of the BR3 Grid Measurements}

Appendix $\mathrm{H}$ presents statistical characterization of measurements by individual stands at each measurement height using the 5-min average temperature and $\mathrm{RH}$ data as supplementary materials to Section 5.1. The results are color-coded by system types (i.e., blue for CDHP and orange for SDHV) and presented by season:

- Air temperature at $1.7 \mathrm{~m}$ (Figure $\mathrm{H}-1$ ), air temperature at $1.1 \mathrm{~m}$ (Figure $\mathrm{H}-2$ ), air temperature at $0.6 \mathrm{~m}$ (Figure $\mathrm{H}-3$ ), globe temperature at $1.1 \mathrm{~m}$ (Figure $\mathrm{H}-4$ ), and $\mathrm{RH}$ at $1.1 \mathrm{~m}$ (Figure $\mathrm{H}-5$ ) during the cooling season before August 10, 2017;

- Air temperature at $1.7 \mathrm{~m}$ (Figure $\mathrm{H}-6$ ), air temperature at $1.1 \mathrm{~m}$ (Figure $\mathrm{H}-7$ ), air temperature at $0.6 \mathrm{~m}$ (Figure $\mathrm{H}-8$ ), globe temperature at $1.1 \mathrm{~m}$ (Figure $\mathrm{H}-9$ ), and $\mathrm{RH}$ at $1.1 \mathrm{~m}$ (Figure $\mathrm{H}-10$ ) during the cooling season after August 10, 2017;

- Air temperature at $1.7 \mathrm{~m}$ (Figure $\mathrm{H}-11)$, air temperature at $1.1 \mathrm{~m}$ (Figure $\mathrm{H}-12)$, air temperature at $0.6 \mathrm{~m}$ (Figure $\mathrm{H}-13$ ), globe temperature at $1.1 \mathrm{~m}$ (Figure $\mathrm{H}-14$ ), and $\mathrm{RH}$ at $1.1 \mathrm{~m}$ (Figure $\mathrm{H}-15$ ) during the heating season; and

- Air temperature at 1.7m (Figure H-16), air temperature at $1.1 \mathrm{~m}$ (Figure $\mathrm{H}-17$ ), air temperature at $0.6 \mathrm{~m}$ (Figure $\mathrm{H}-18$ ), globe temperature at $1.1 \mathrm{~m}$ (Figure $\mathrm{H}-19$ ), and $\mathrm{RH}$ at $1.1 \mathrm{~m}$ (Figure $\mathrm{H}-20$ ) during the transitional season. 
Cooling Season (Before August 10): HVAC ON
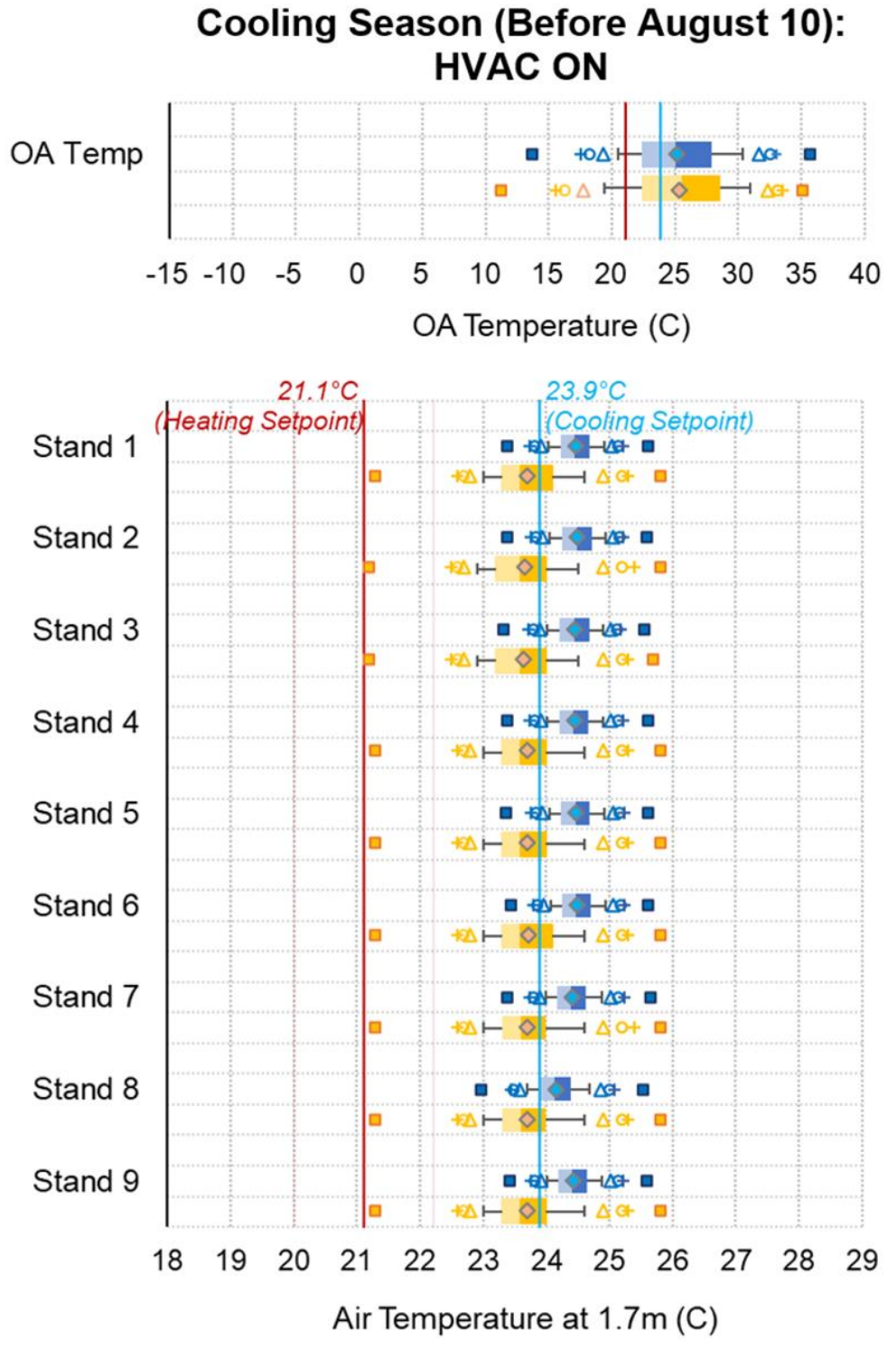

Cooling Season (Before August 10): HVAC OFF
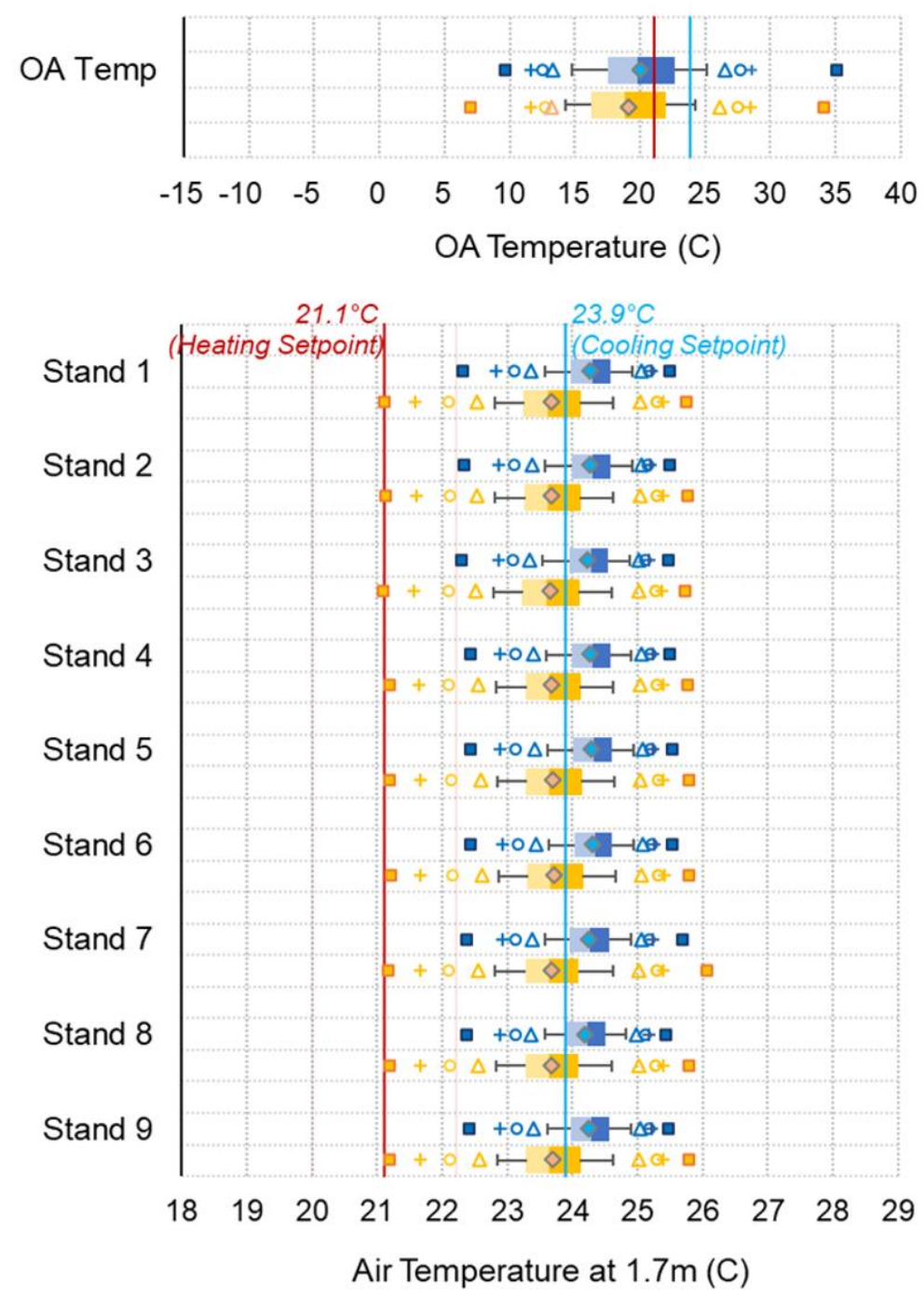

Figure H-1: Graphical Summaries of the 5-Min Average BR3 Stand Temperatures at 1.7 m When the System Was On Cycle (Left

Figure) and Off Cycle (Right Figure) for the Cooling Season Before August 10, 2019. 


\section{Cooling Season (Before August 10):} HVAC ON
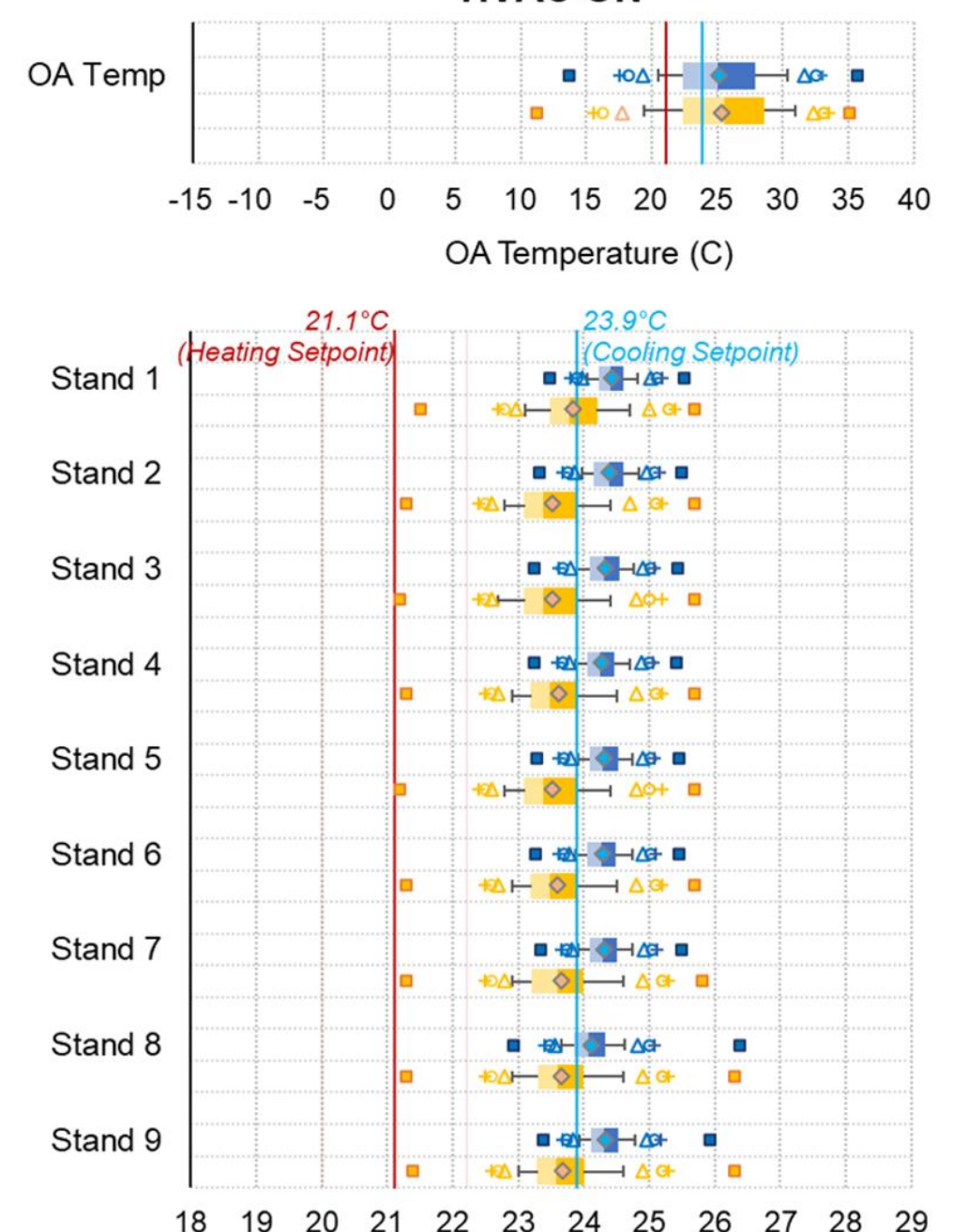

Air Temperature at $1.1 \mathrm{~m}(\mathrm{C})$
Cooling Season (Before August 10): HVAC OFF
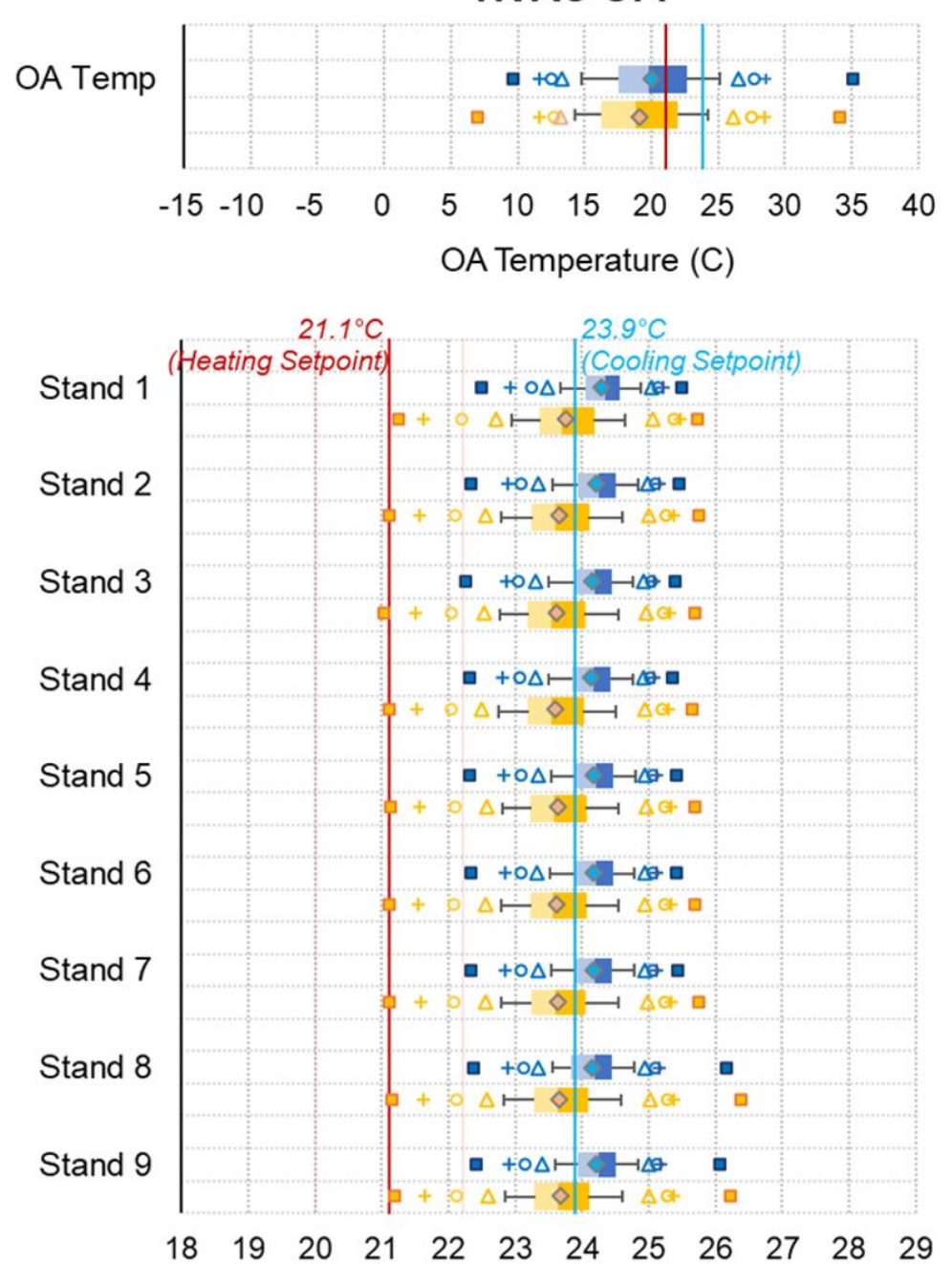

Air Temperature at $1.1 \mathrm{~m}(\mathrm{C})$

Figure H-2: Graphical Summaries of the 5-Min Average BR3 Stand Temperatures at 1.1 m When the System Was On Cycle (Left Figure) and Off Cycle (Right Figure) for the Cooling Season Before August 10, 2019. 
Cooling Season (Before August 10): HVAC ON
Cooling Season (Before August 10): HVAC OFF
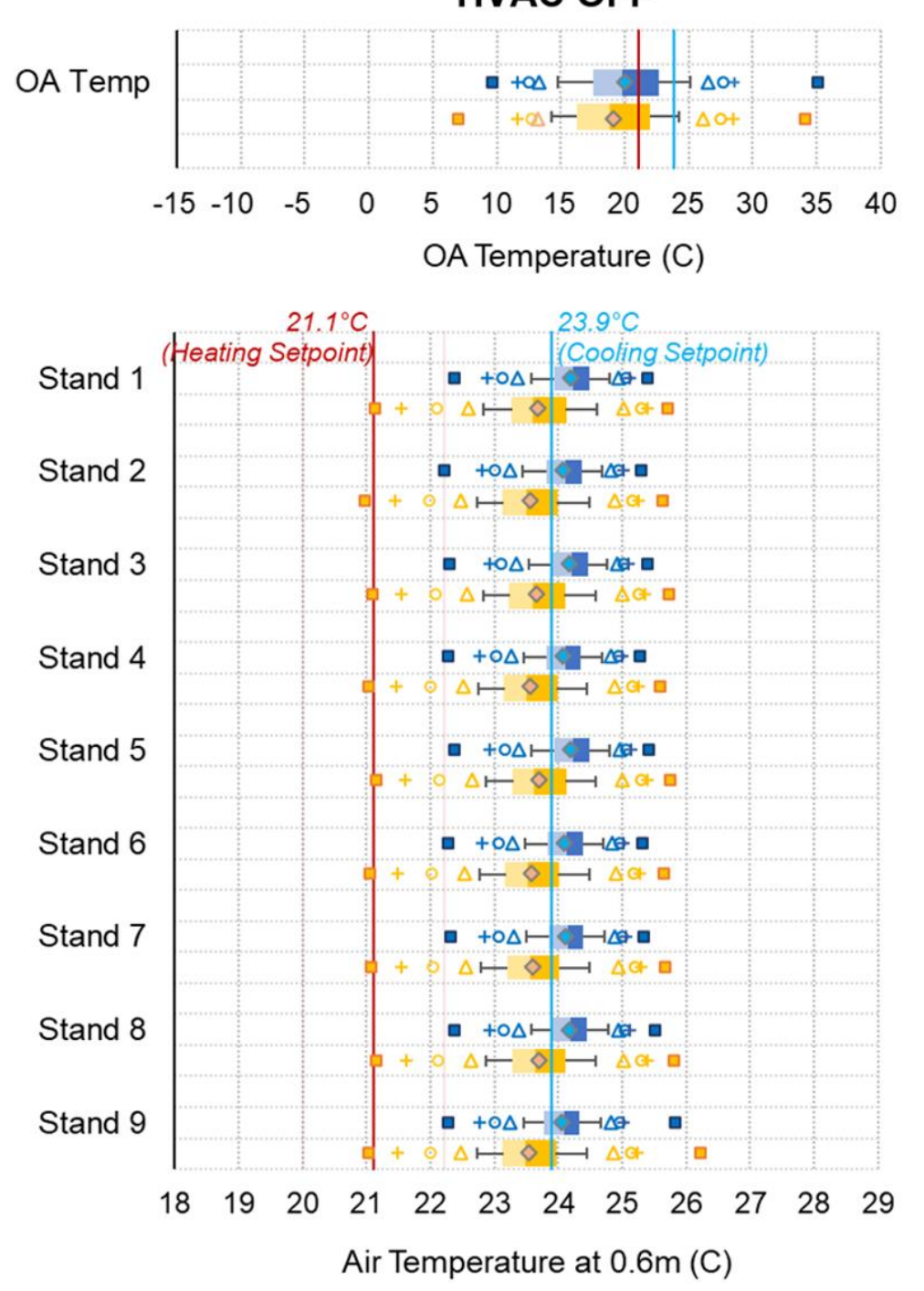

Figure H-3: Graphical Summaries of the 5-Min Average BR3 Stand Temperatures at $0.6 \mathrm{~m}$ When the System Was On Cycle (Left Figure) and Off Cycle (Right Figure) for the Cooling Season Before August 10, 2019. 
Cooling Season (Before August 10): HVAC ON
Cooling Season (Before August 10): HVAC OFF
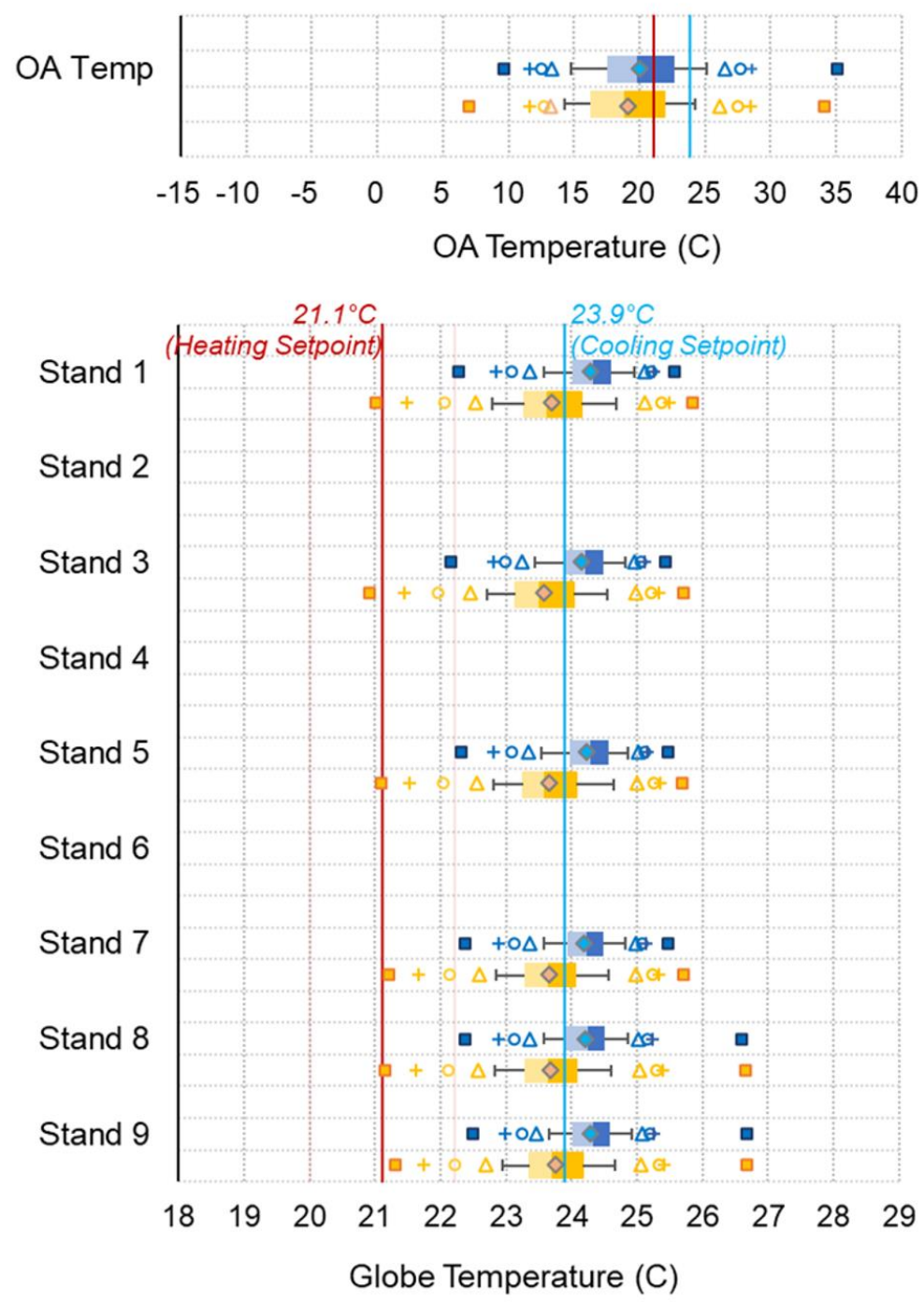

Figure H-4: Graphical Summaries of the 5-Min Average BR3 Stand Globe Temperatures at $1.1 \mathrm{~m}$ When the System Was On Cycle (Left Figure) and Off Cycle (Right Figure) for the Cooling Season Before August 10, 2019. 
Cooling Season (Before August 10): HVAC ON
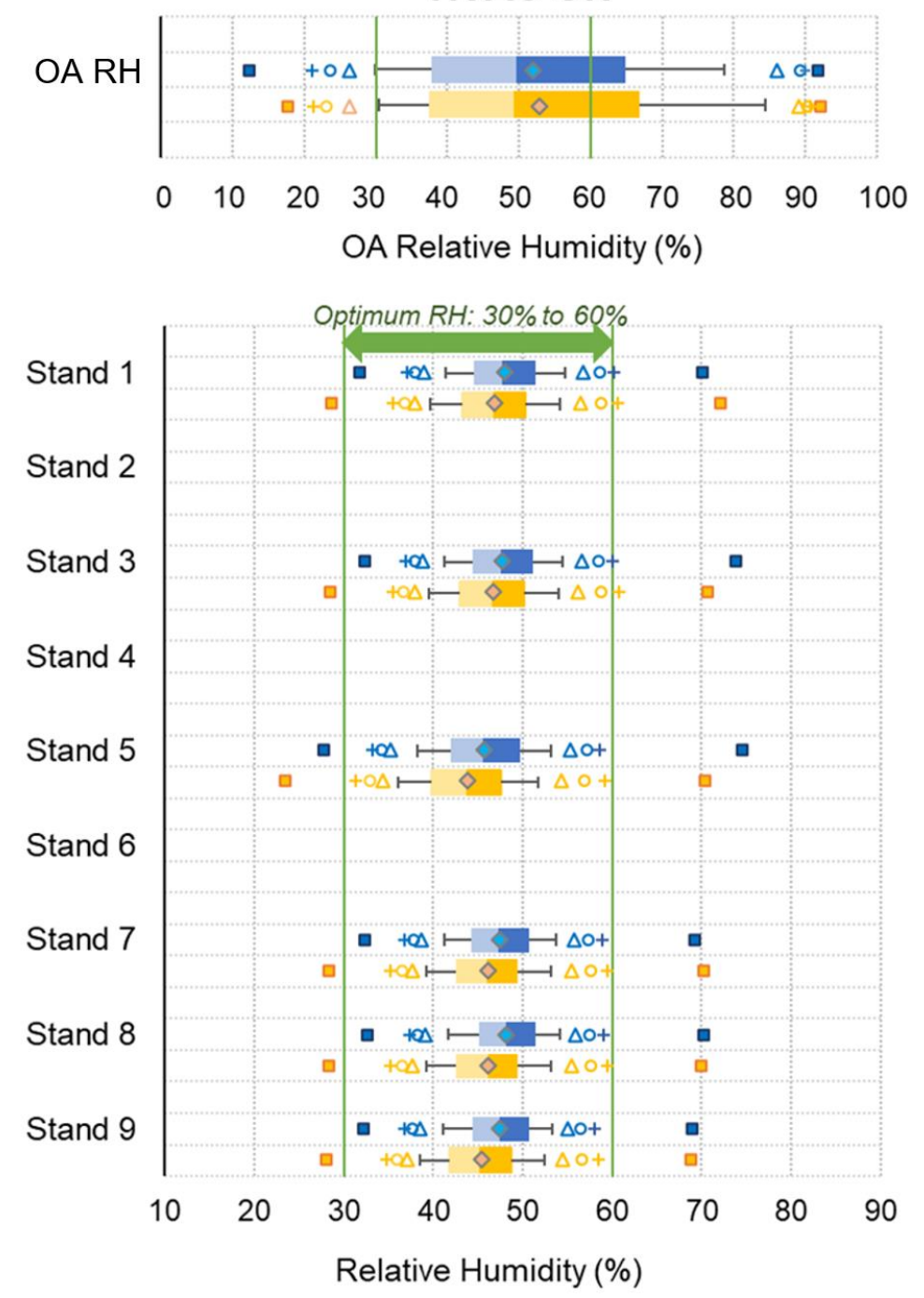

Cooling Season (Before August 10): HVAC OFF
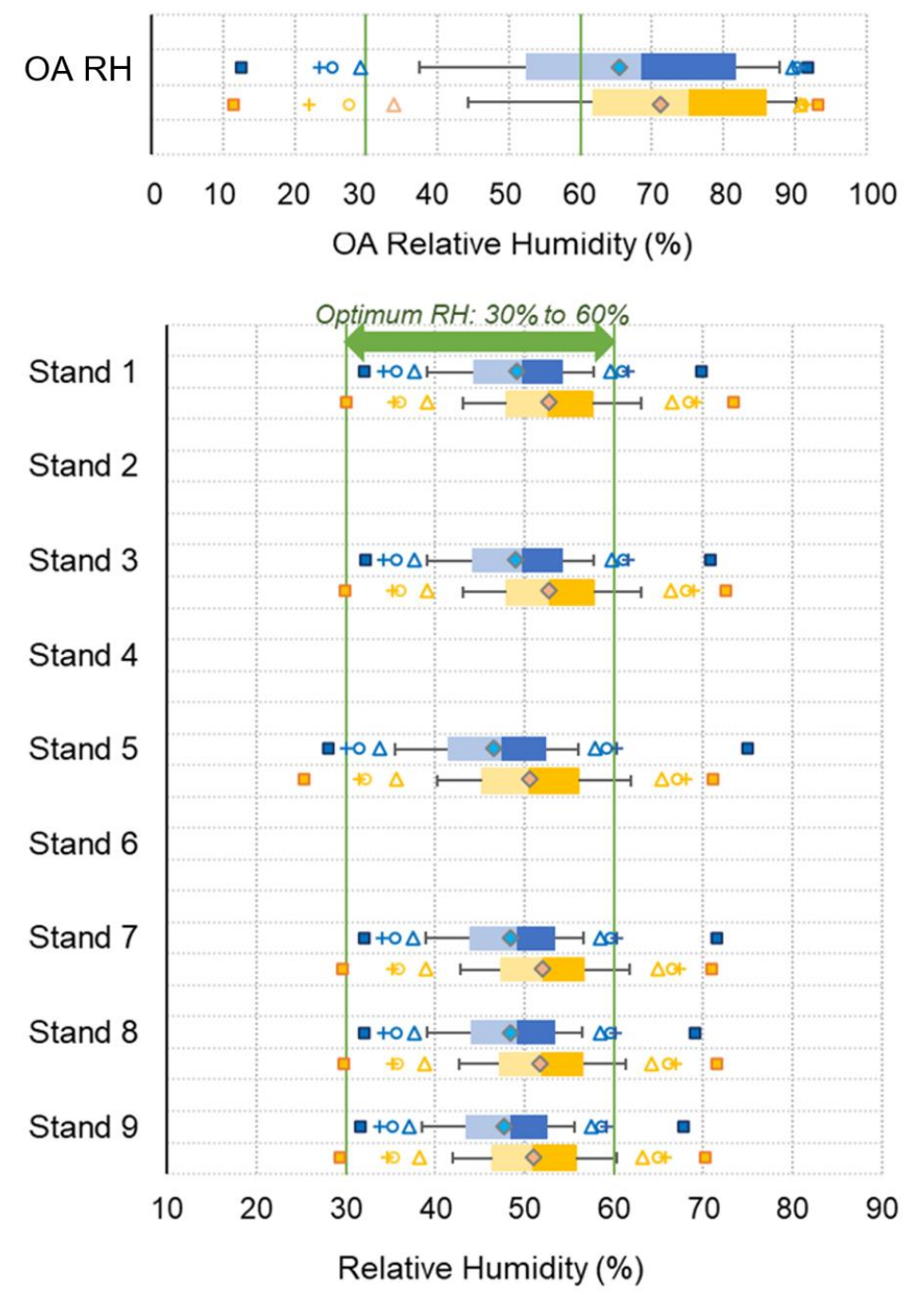

Figure H-5: Graphical Summaries of the 5-Min Average BR3 Stand RH at $1.1 \mathrm{~m}$ When the System Was On Cycle (Left Figure) and Off Cycle (Right Figure) for the Cooling Season Before August 10, 2019. 


\section{Cooling Season (After August 10):} HVAC ON
Cooling Season (After August 10): HVAC OFF
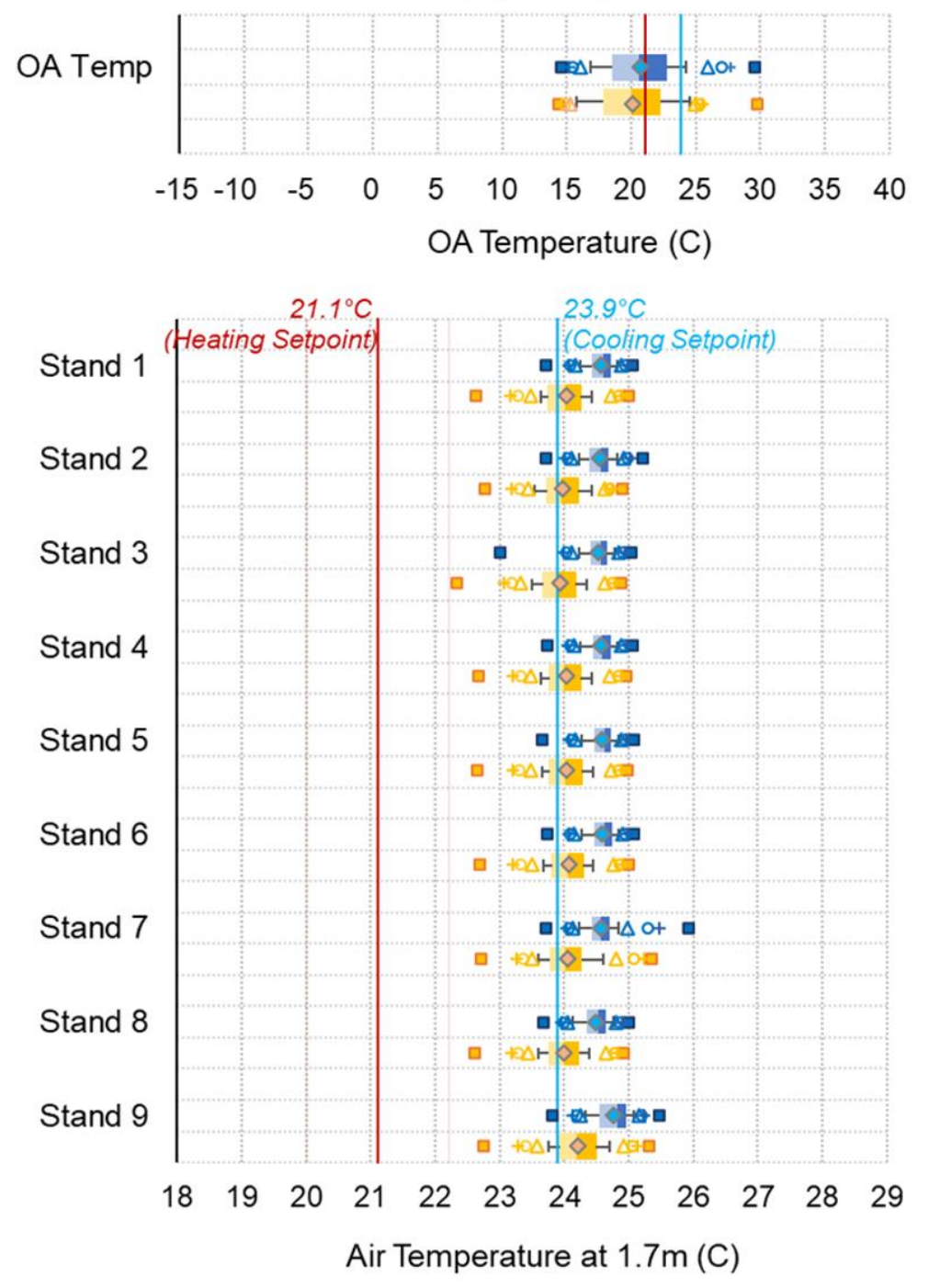

Figure H-6: Graphical Summaries of the 5-Min Average BR3 Stand Temperatures at 1.7 m When the System Was On Cycle (Left Figure) and Off Cycle (Right Figure) for the Cooling Season After August 10, 2019. 
Cooling Season (After August 10): HVAC ON
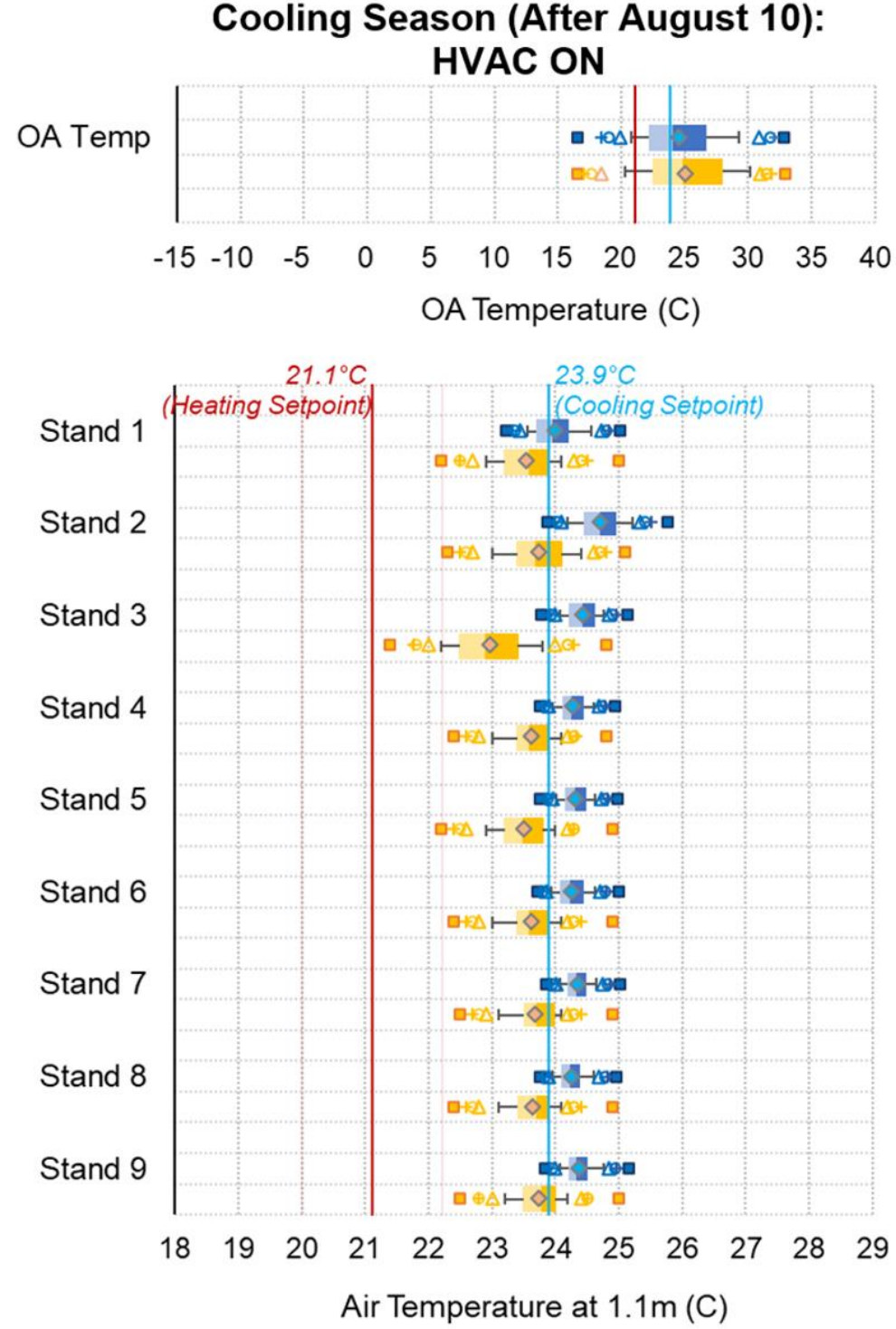

Cooling Season (After August 10):

HVAC OFF
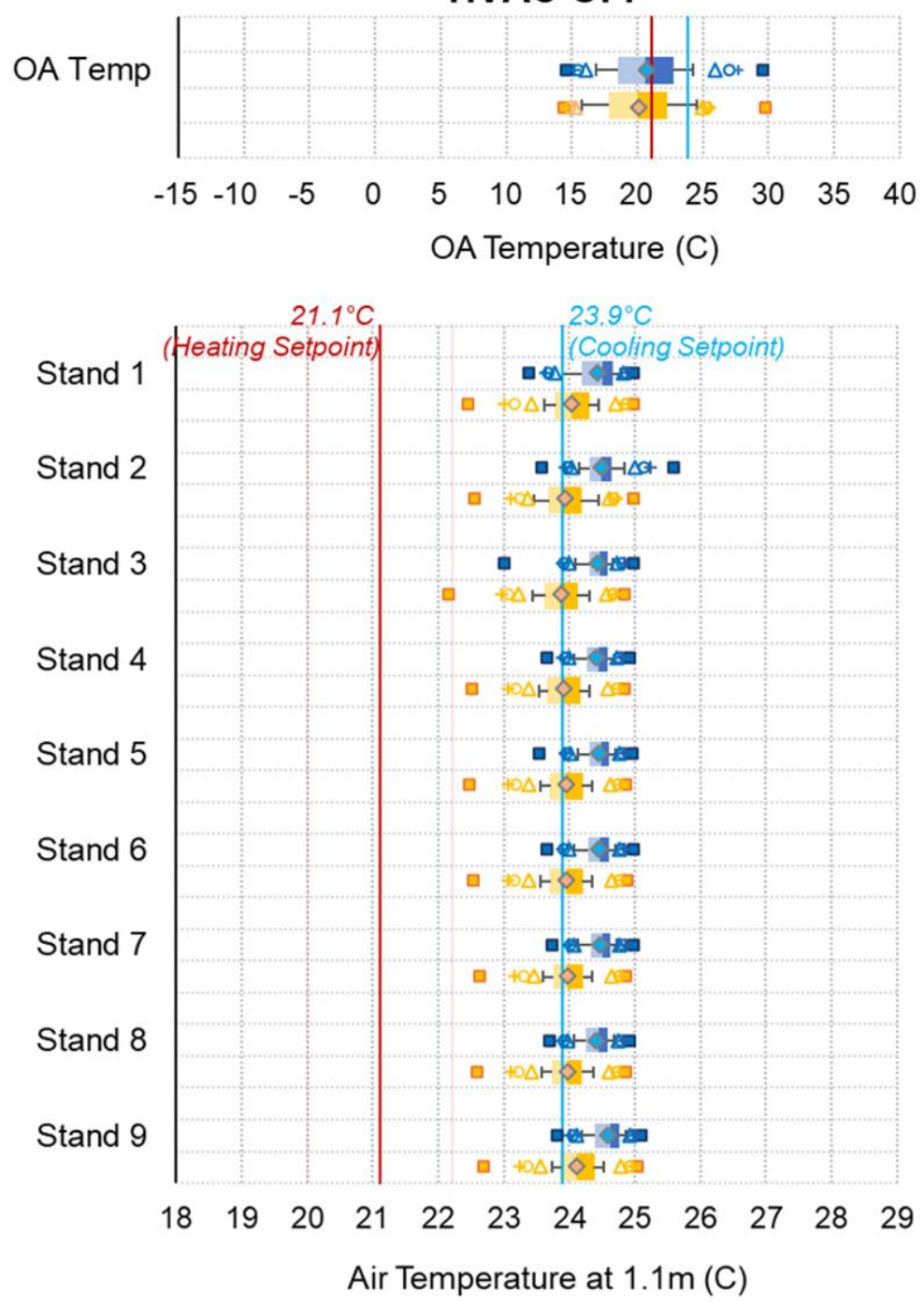

Figure H-7: Graphical Summaries of the 5-Min Average BR3 Stand Temperatures at $1.1 \mathrm{~m}$ When the System Was On Cycle (Left

Figure) and Off Cycle (Right Figure) for the Cooling Season After August 10, 2019. 
Cooling Season (After August 10): HVAC ON

\section{Cooling Season (After August 10):} HVAC OFF
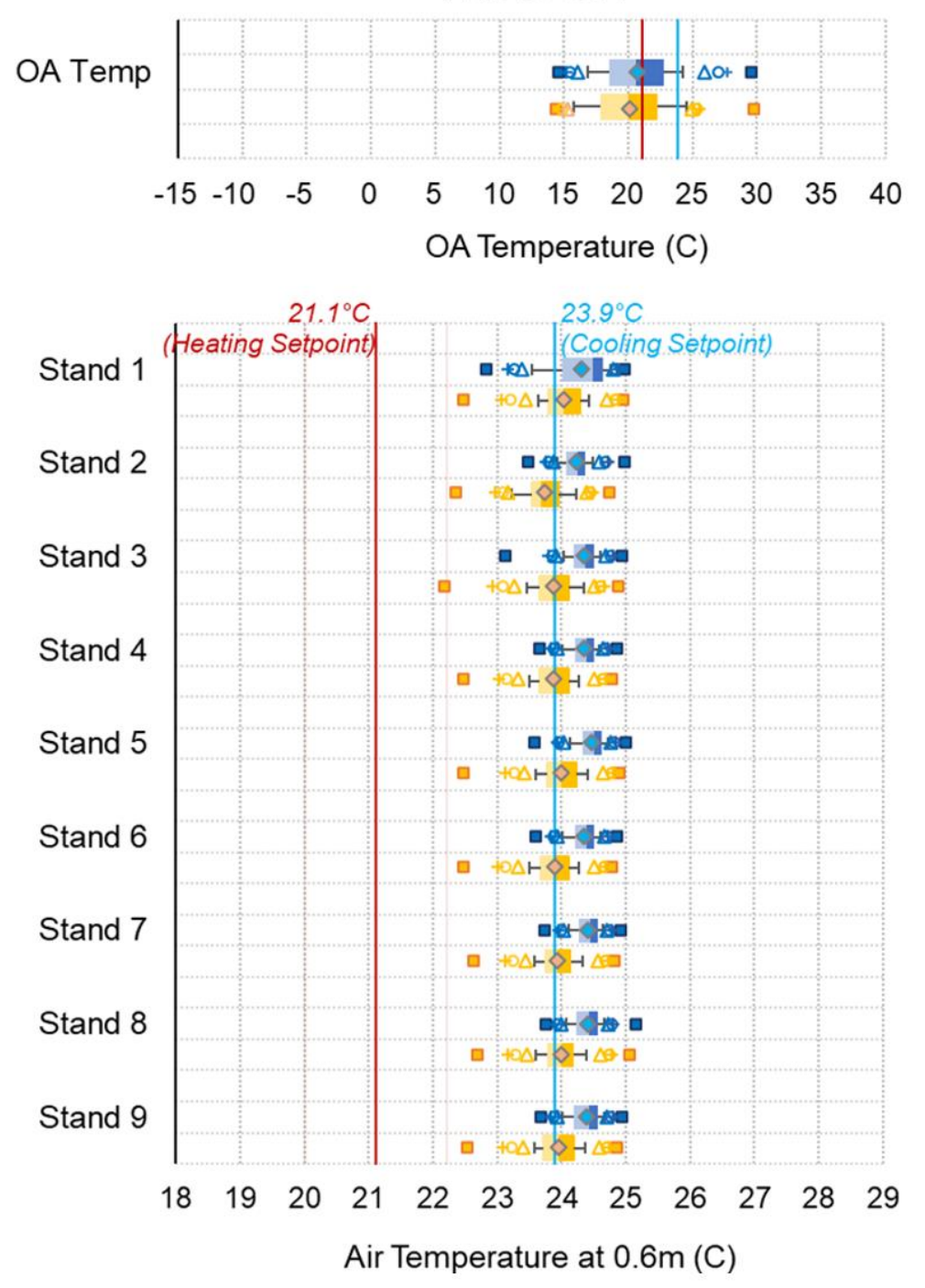

Figure H-8: Graphical Summaries of the 5-Min Average BR3 Stand Temperatures at 0.6 m When the System Was On Cycle (Left Figure) and Off Cycle (Right Figure) for the Cooling Season After August 10, 2019. 
Cooling Season (After August 10): HVAC ON
Cooling Season (After August 10): HVAC OFF
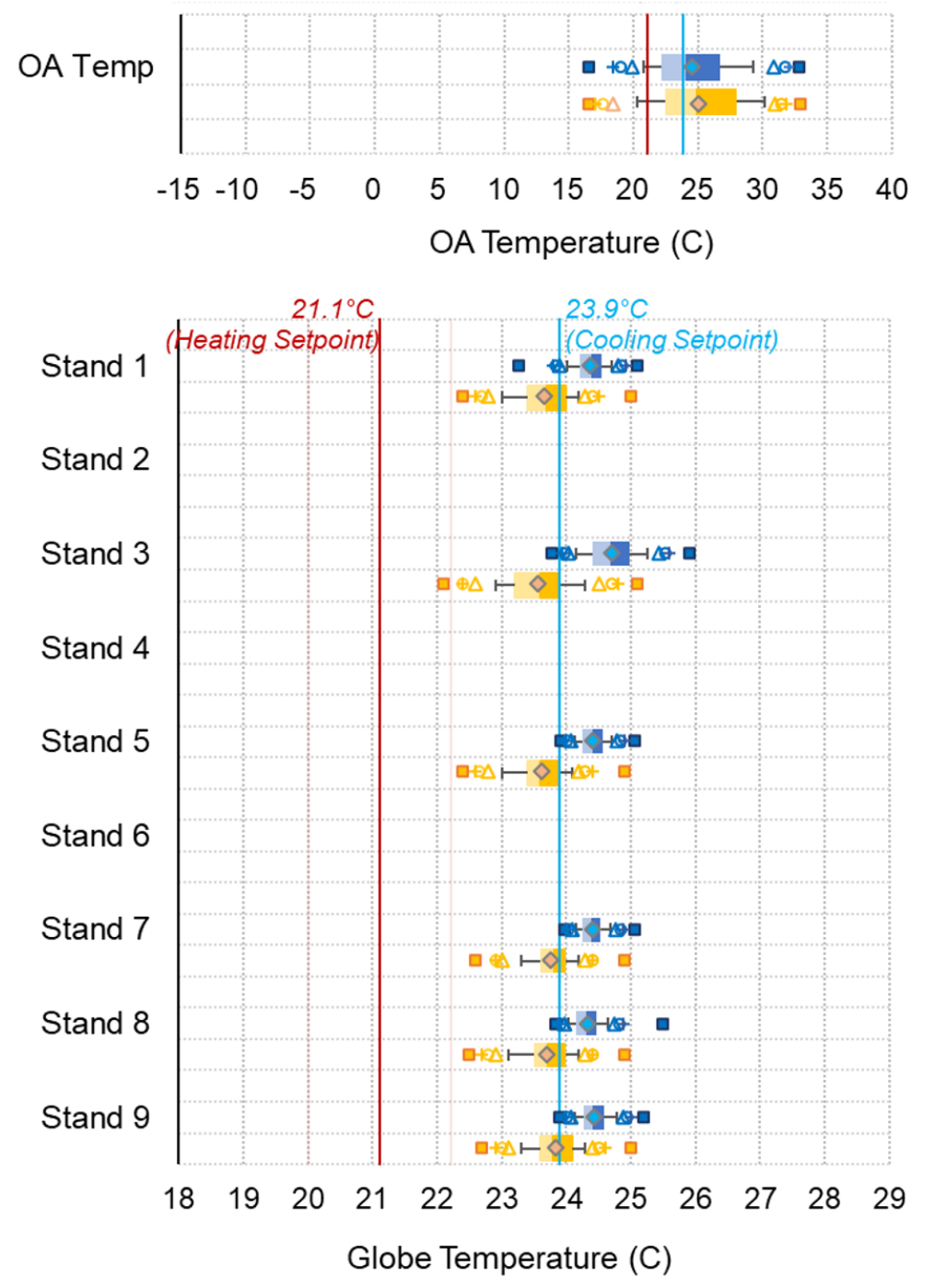
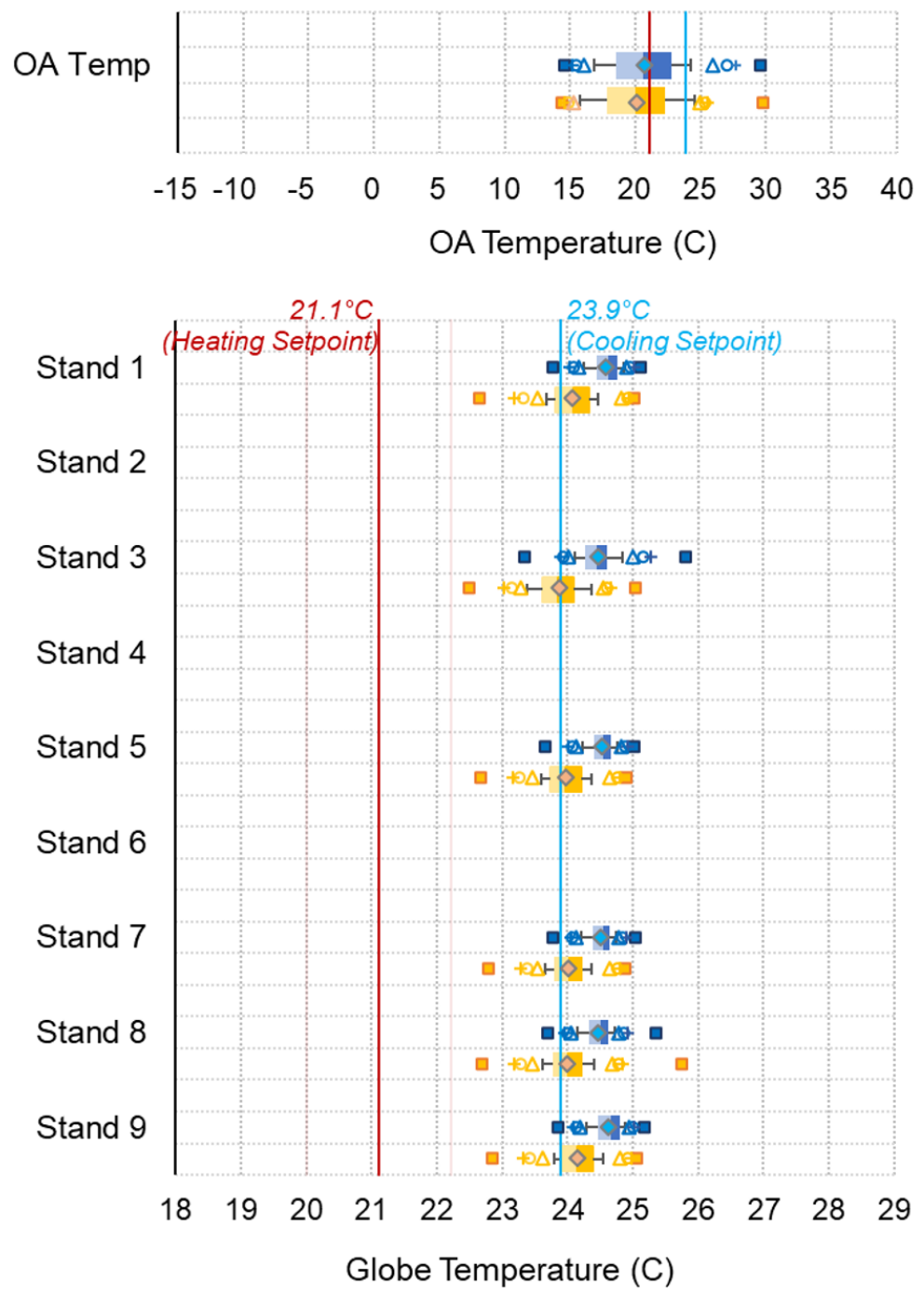

Figure H-9: Graphical Summaries of the 5-Min Average BR3 Stand Globe Temperatures at $1.1 \mathrm{~m}$ When the System Was On Cycle (Left Figure) and Off Cycle (Right Figure) for the Cooling Season After August 10, 2019. 
Cooling Season (After August 10): HVAC ON
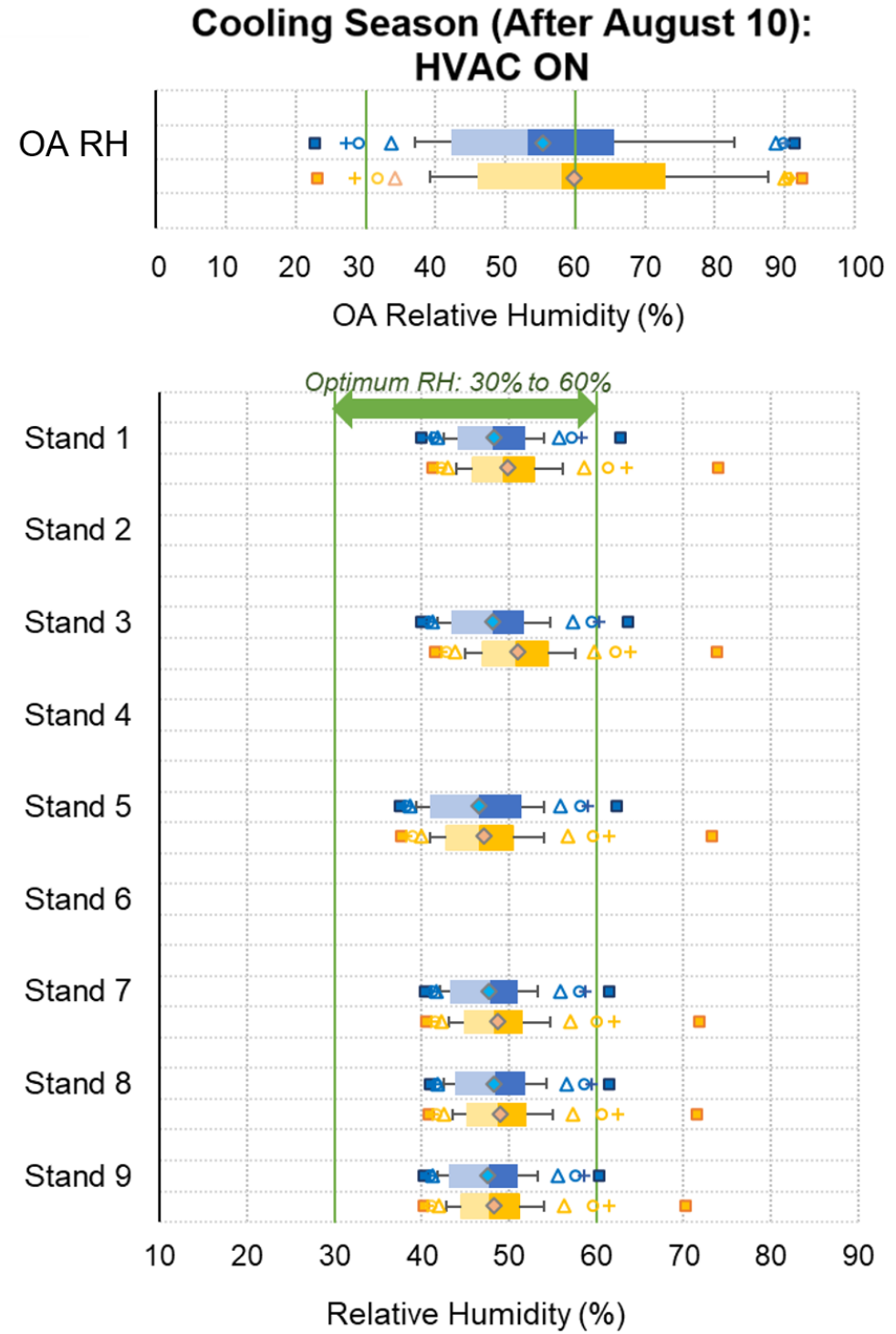

Cooling Season (After August 10): HVAC OFF
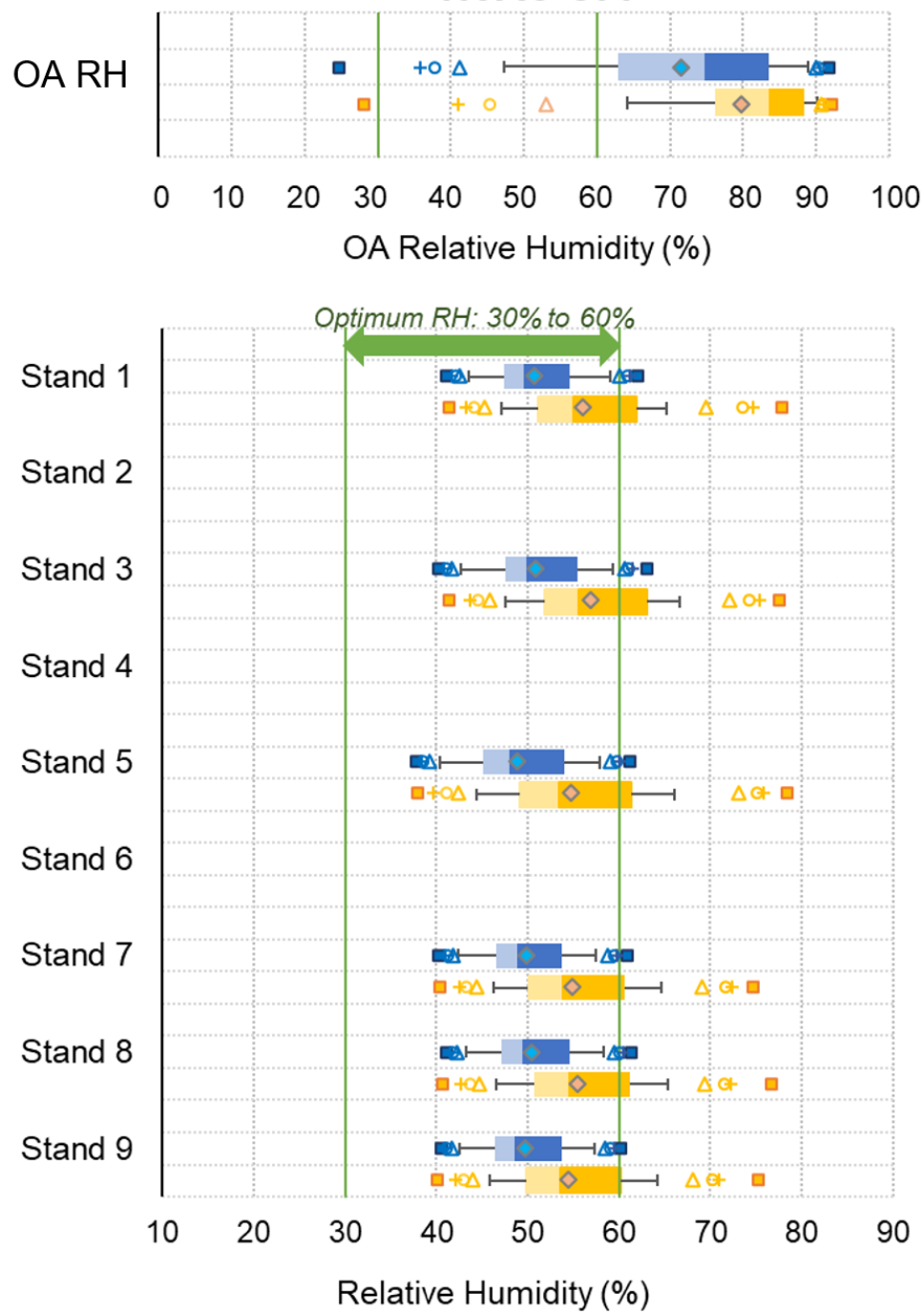

Figure H-10: Graphical Summaries of the 5-Min Average BR3 Stand RH at $1.1 \mathrm{~m}$ When the System Was On Cycle (Left Figure) and Off Cycle (Right Figure) for the Cooling Season After August 10, 2019. 


\section{Heating Season: HVAC ON}
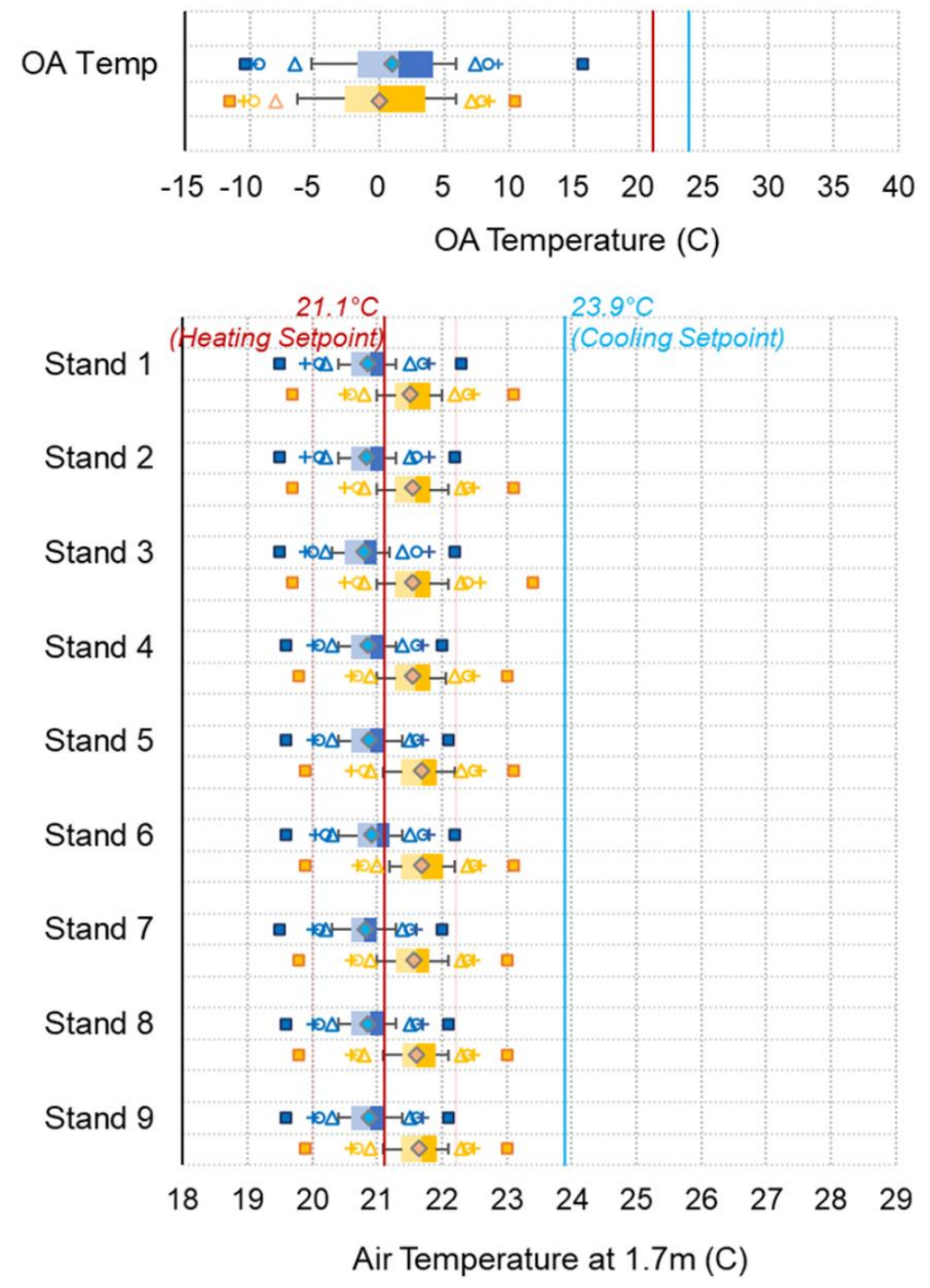

Heating Season: HVAC OFF
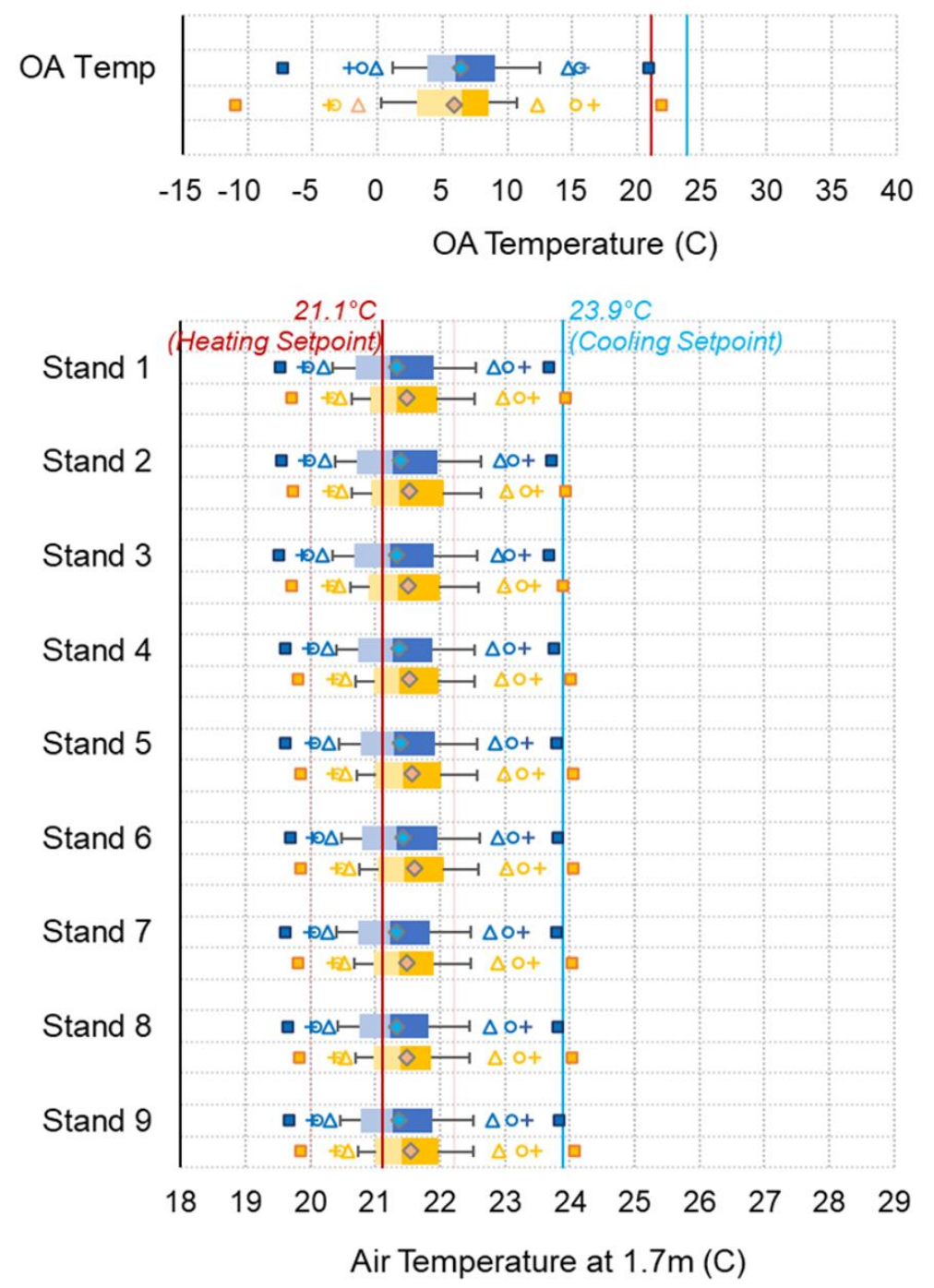

Figure H-11: Graphical Summaries of the 5-Min Average BR3 Stand Temperatures at 1.7 m When the System Was On Cycle (Left Figure) and Off Cycle (Right Figure) for the Heating Season. 
Heating Season: HVAC ON
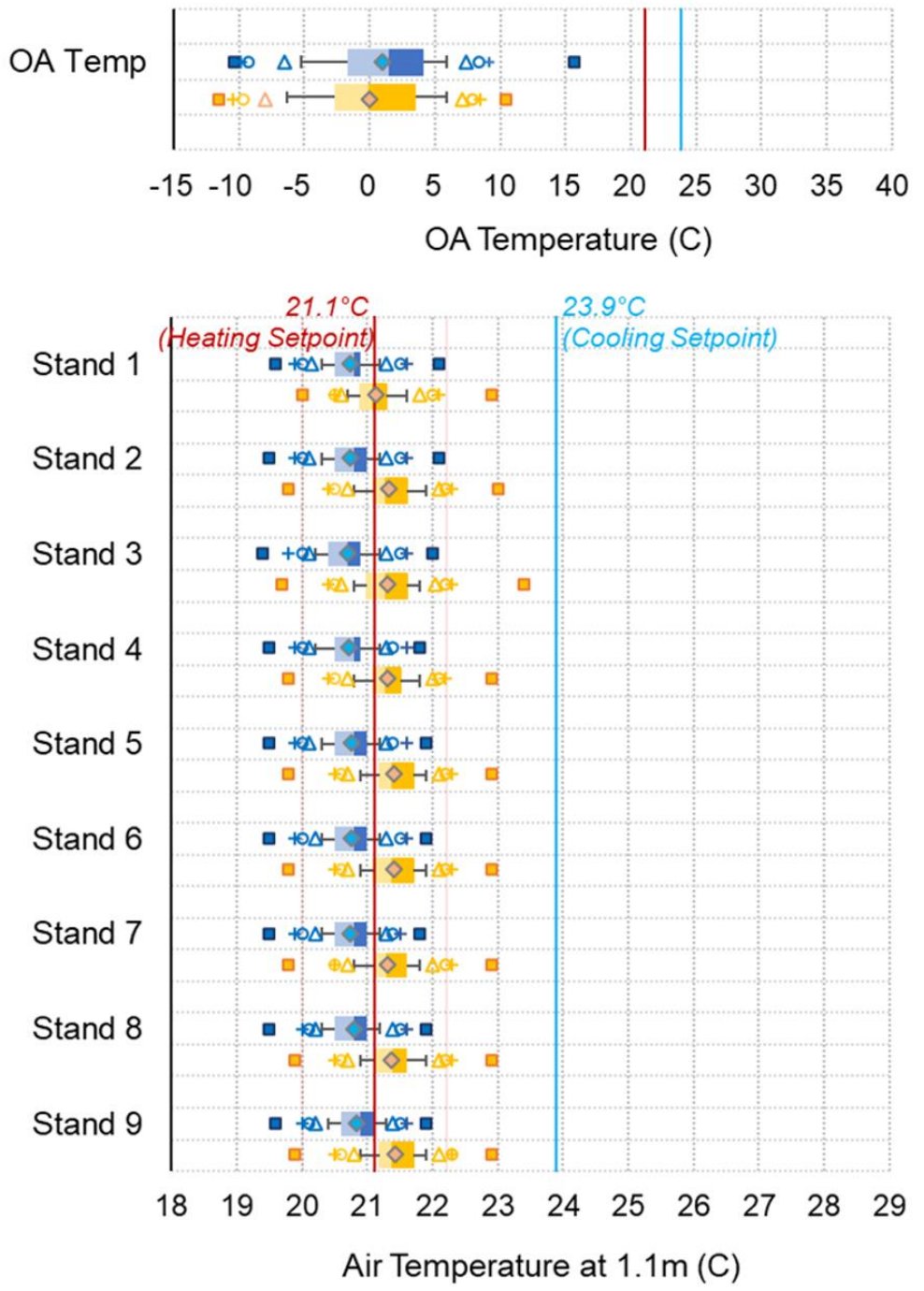

\section{Heating Season: HVAC OFF}
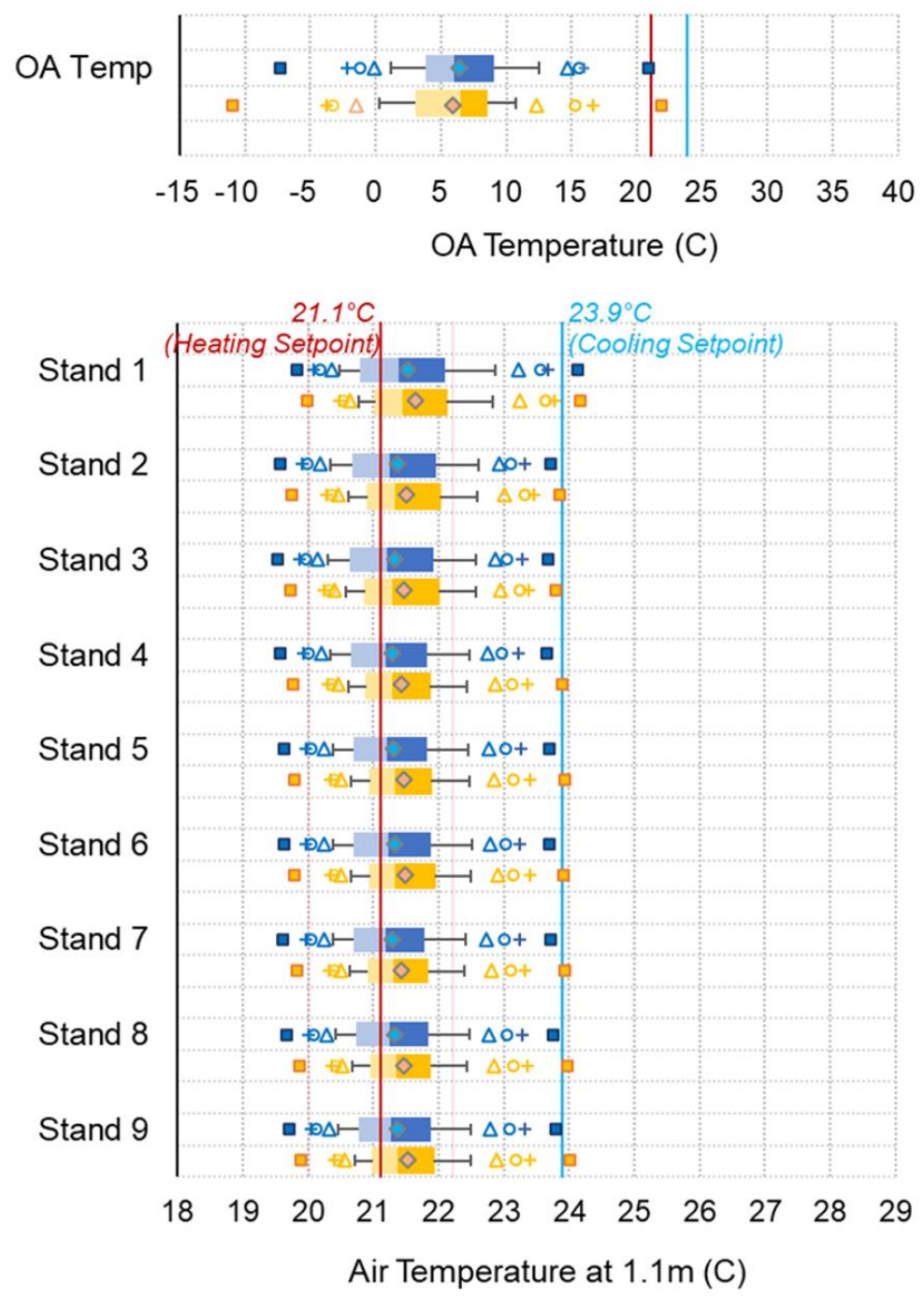

Figure H-12: Graphical Summaries of the 5-Min Average BR3 Stand Temperatures at $1.1 \mathrm{~m}$ When the System Was On Cycle (Left Figure) and Off Cycle (Right Figure) for the Heating Season. 


\section{Heating Season: HVAC ON}

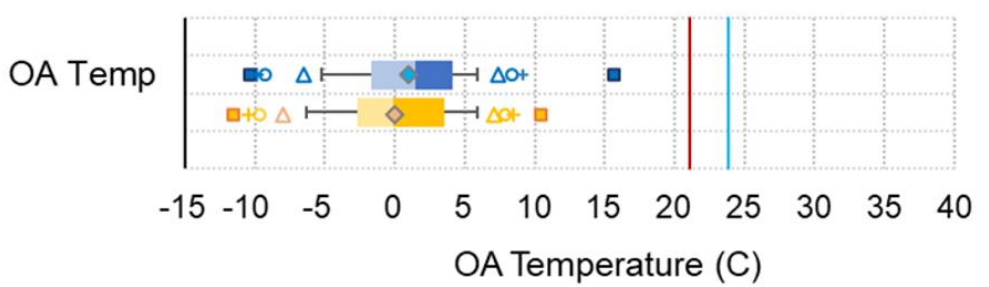

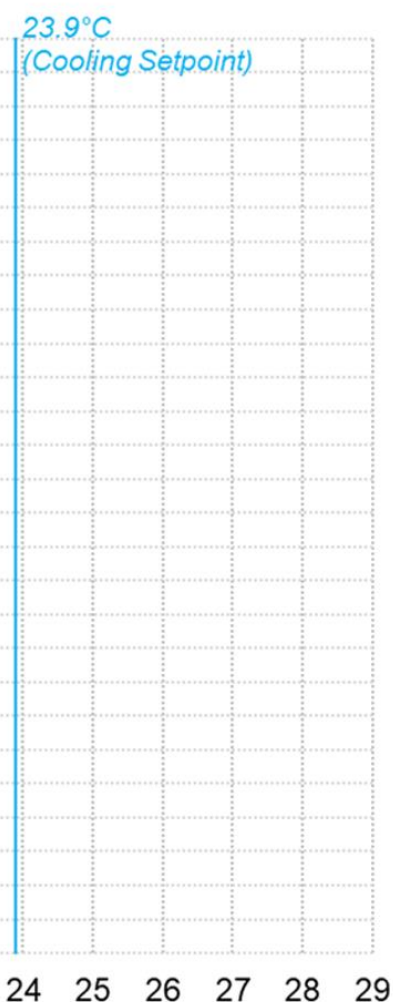

$\begin{array}{llllllllllll}18 & 19 & 20 & 21 & 22 & 23 & 24 & 25 & 26 & 27 & 28 & 29\end{array}$

Air Temperature at $0.6 \mathrm{~m}(\mathrm{C})$

\section{Heating Season: HVAC OFF}
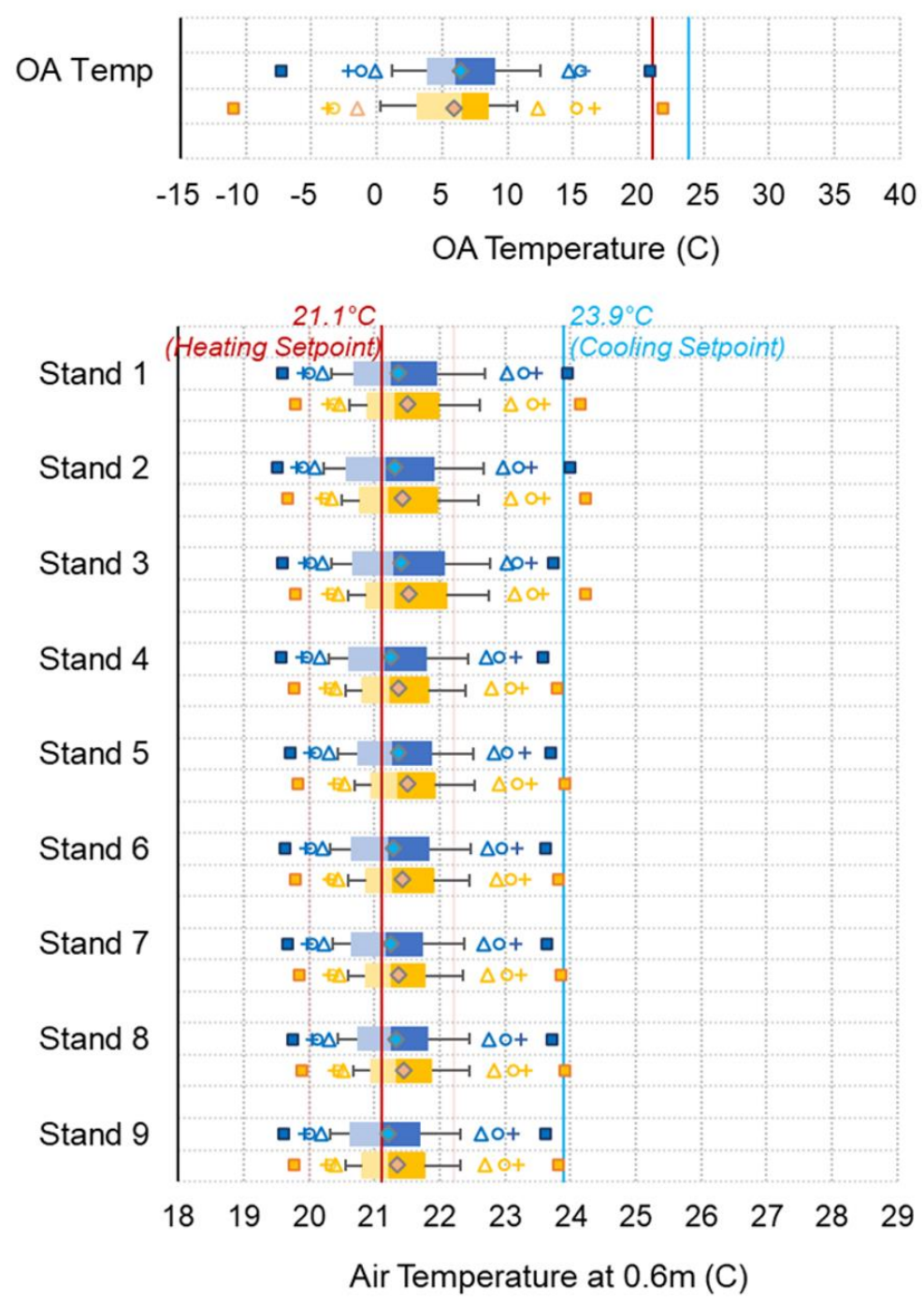

Figure H-13: Graphical Summaries of the 5-Min Average BR3 Stand Temperatures at $0.6 \mathrm{~m}$ When the System Was On Cycle (Left Figure) and Off Cycle (Right Figure) for the Heating Season. 
Heating Season: HVAC ON
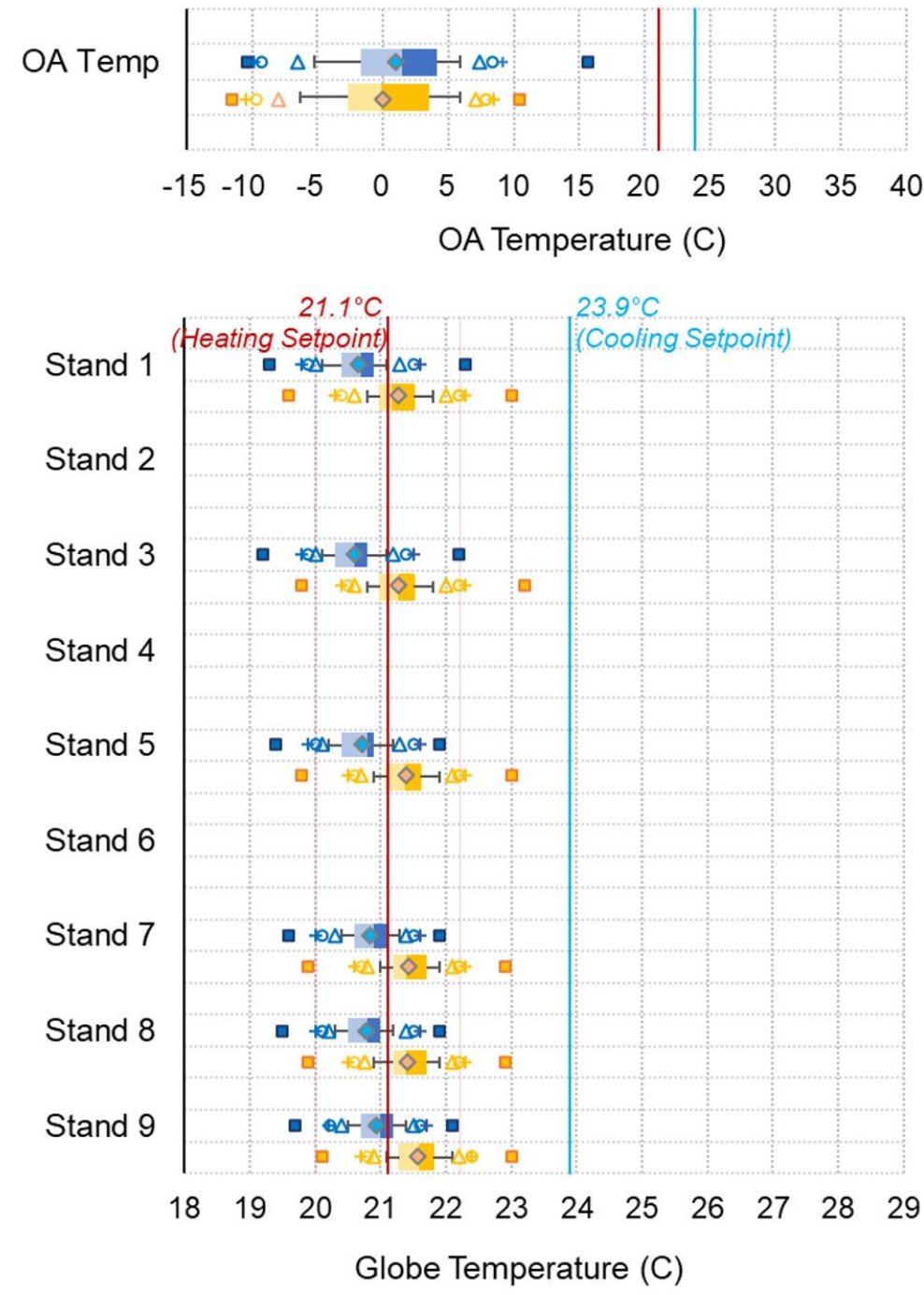

Heating Season: HVAC OFF
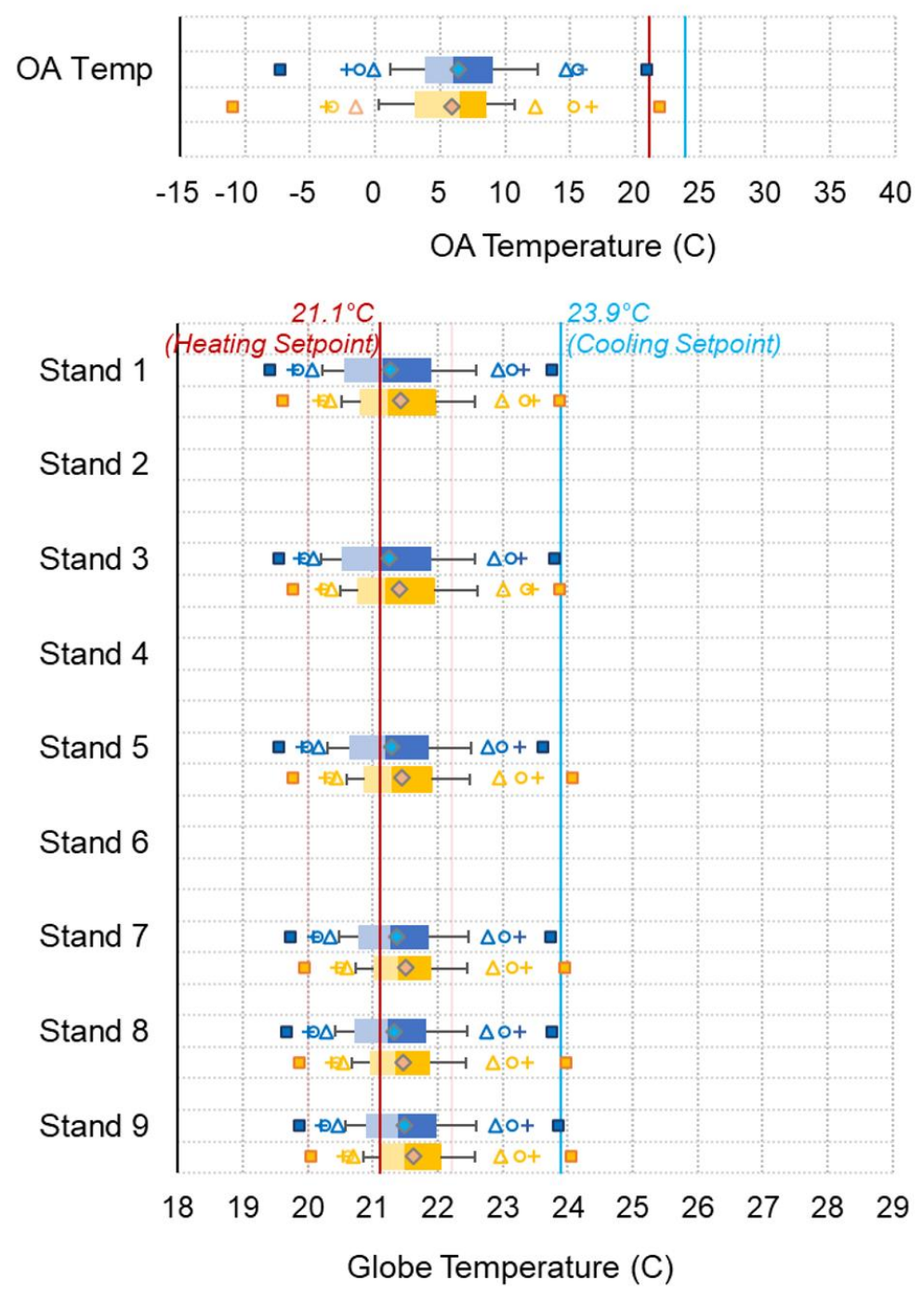

Figure H-14: Graphical Summaries of the 5-Min Average BR3 Stand Globe Temperatures at $1.1 \mathrm{~m}$ When the System Was On Cycle (Left Figure) and Off Cycle (Right Figure) for the Heating Season. 


\section{Heating Season: HVAC ON}

OA RH

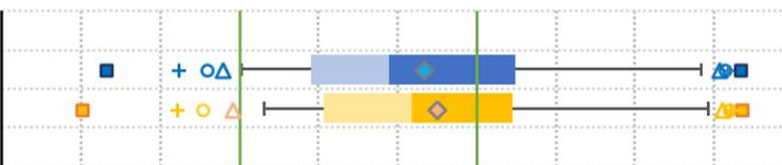

$\begin{array}{lllllllllll}0 & 10 & 20 & 30 & 40 & 50 & 60 & 70 & 80 & 90 & 100\end{array}$

OA Relative Humidity (\%)

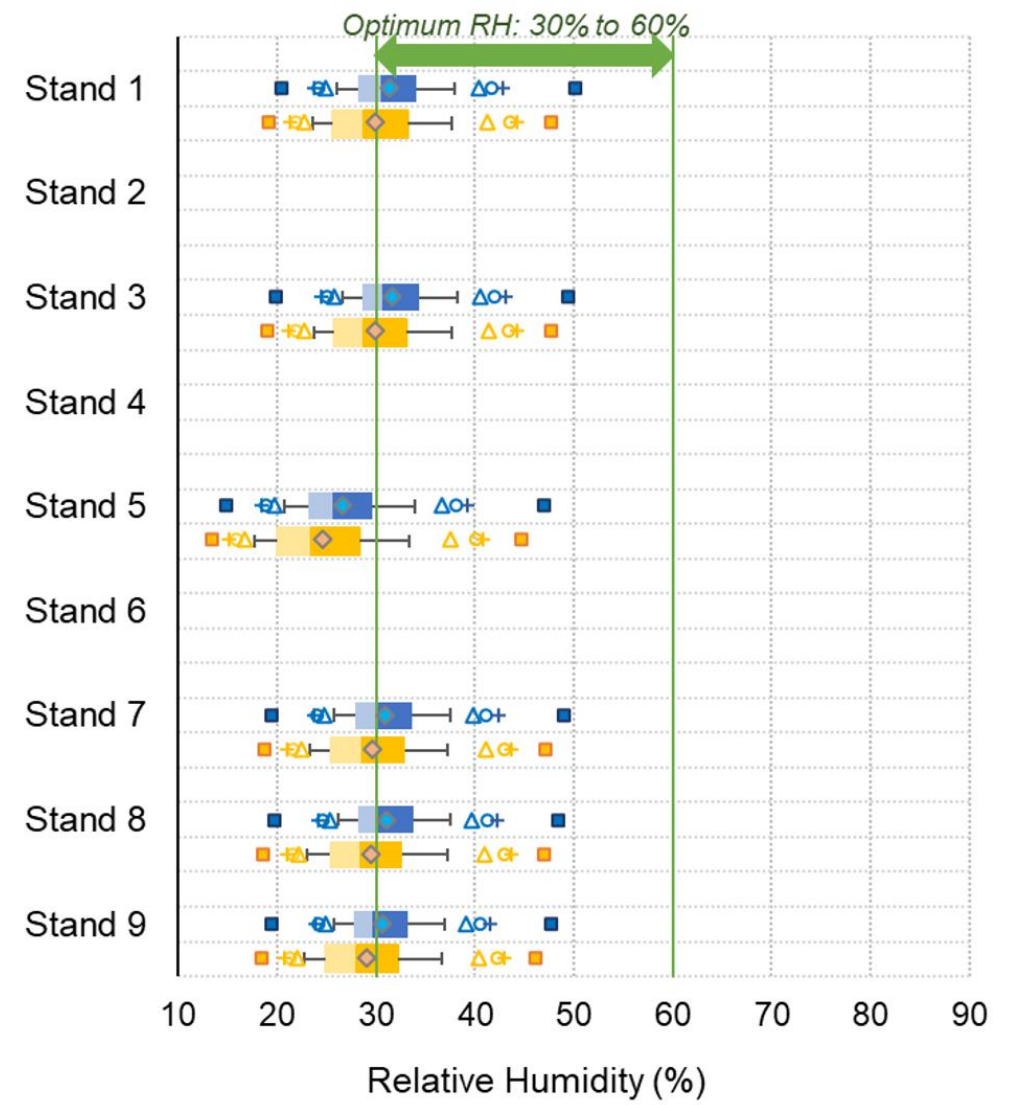

Heating Season: HVAC OFF
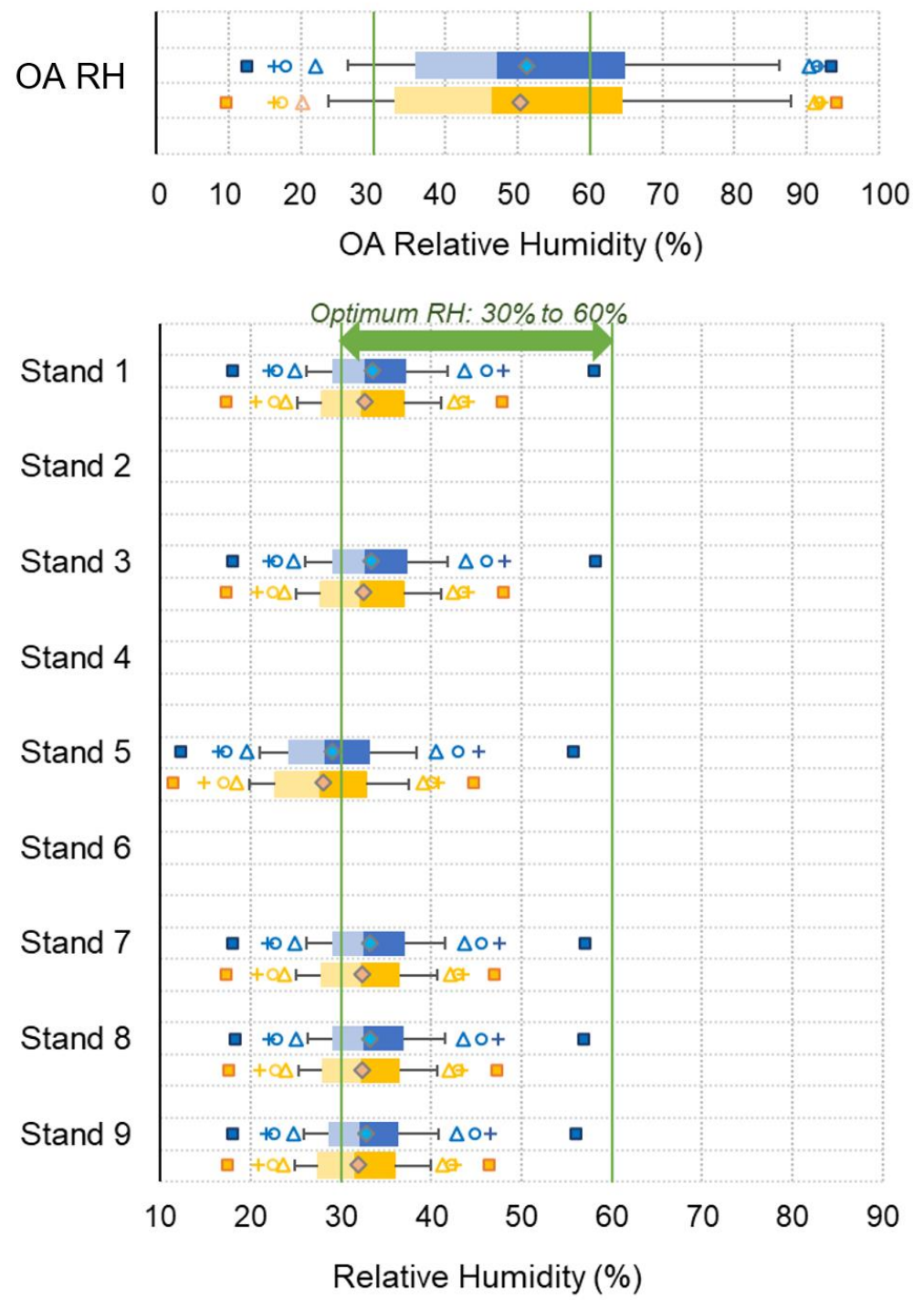

Figure H-15: Graphical Summaries of the 5-Min Average BR3 Stand RH at $1.1 \mathrm{~m}$ When the System Was On Cycle (Left Figure) and Off Cycle (Right Figure) for the Heating Season. 


\section{Transitional Season: HVAC ON}
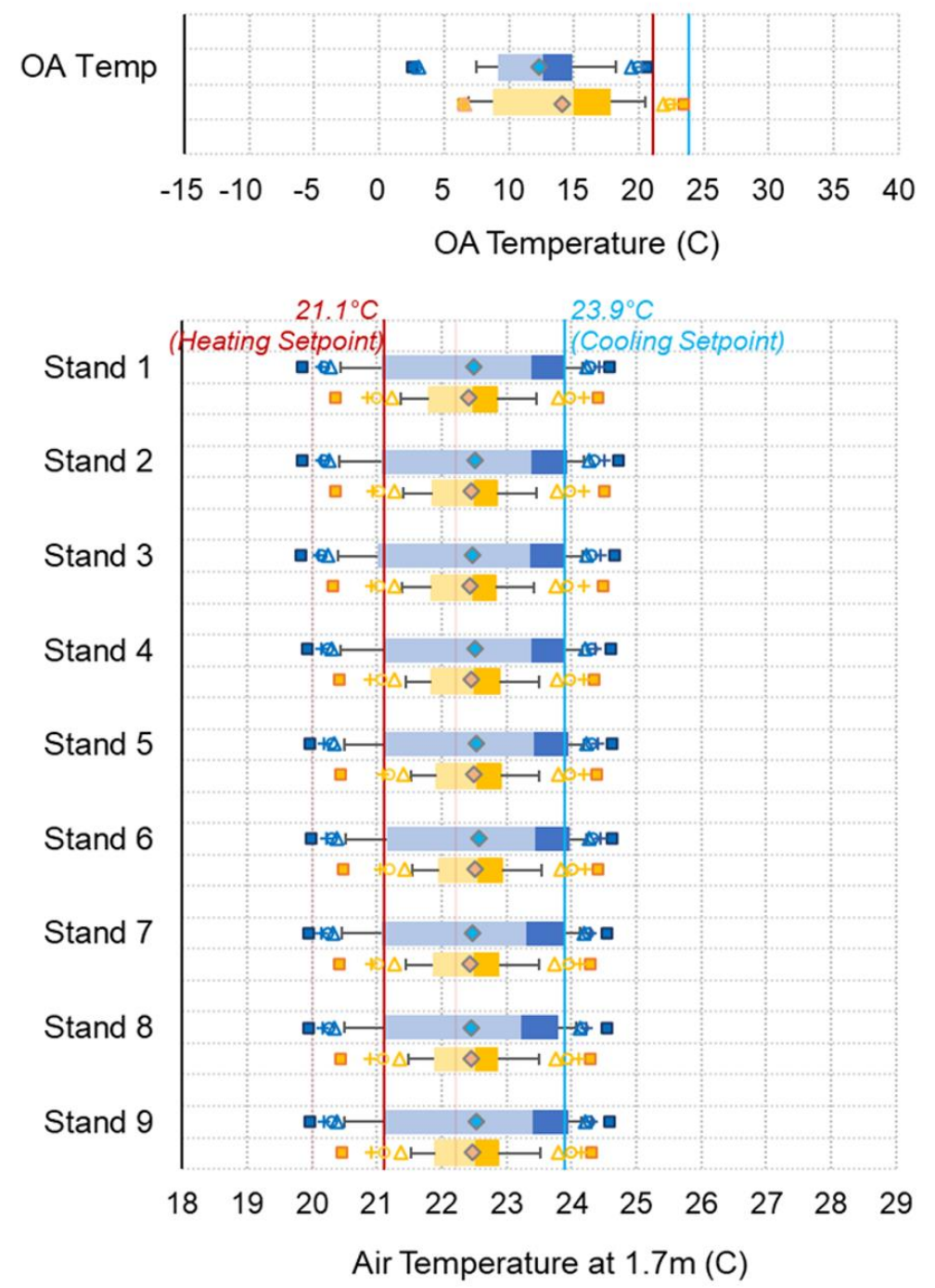

Transitional Season: HVAC OFF
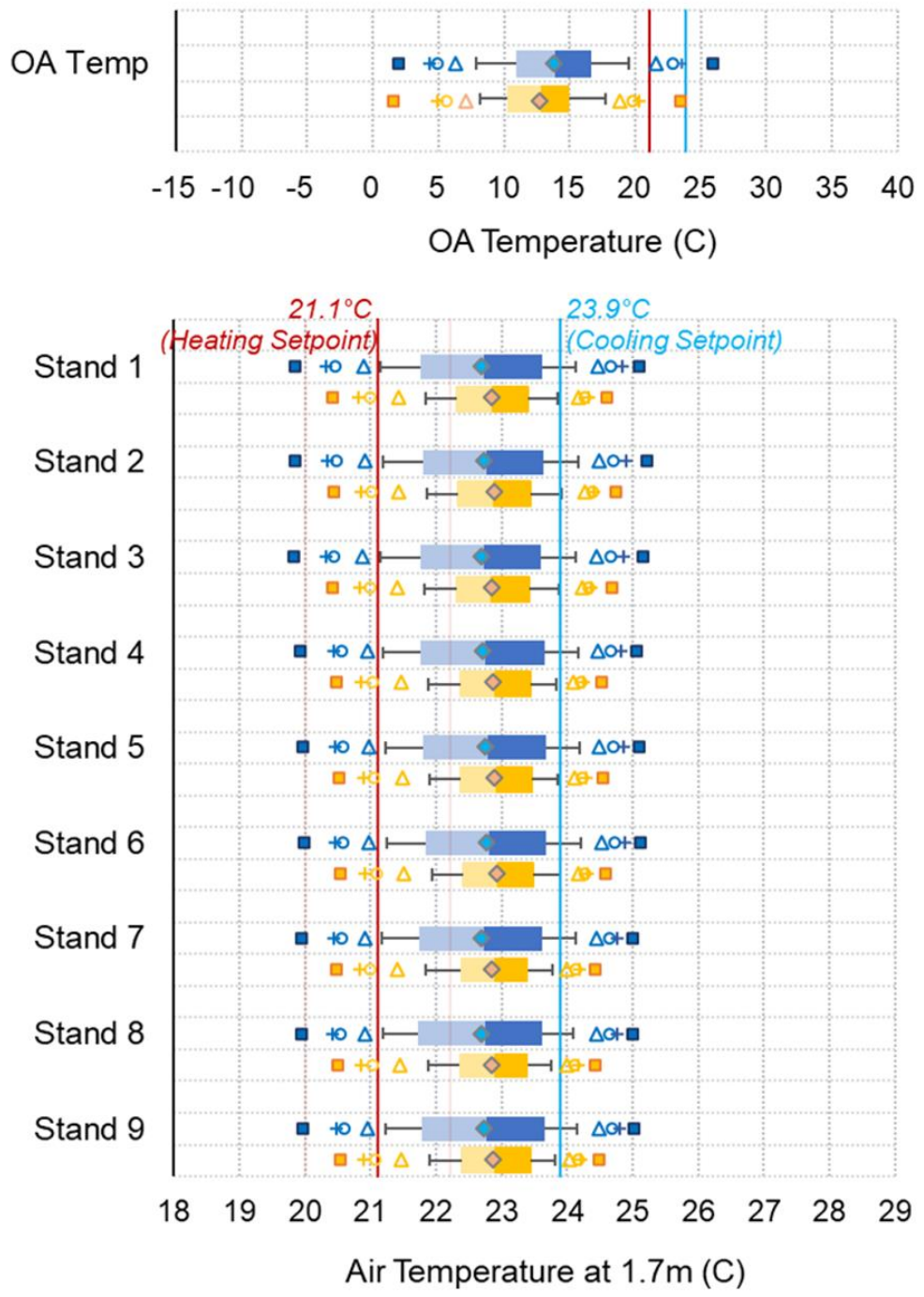

Figure H-16: Graphical Summaries of the 5-Min Average BR3 Stand Temperatures at 1.7 m When the System Was On Cycle (Left

Figure) and Off Cycle (Right Figure) for the Transitional Season. 
Transitional Season: HVAC ON
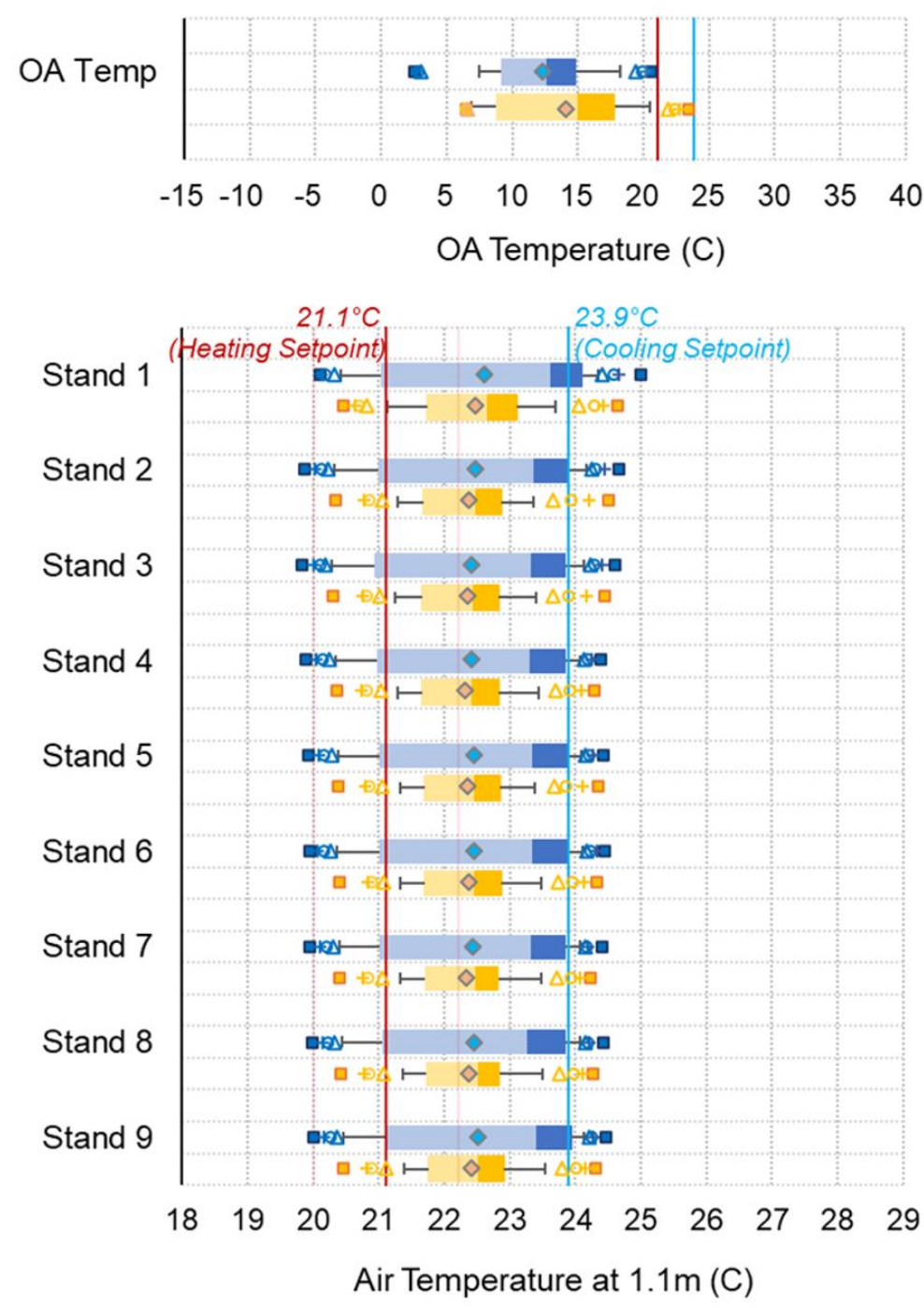

Transitional Season: HVAC OFF
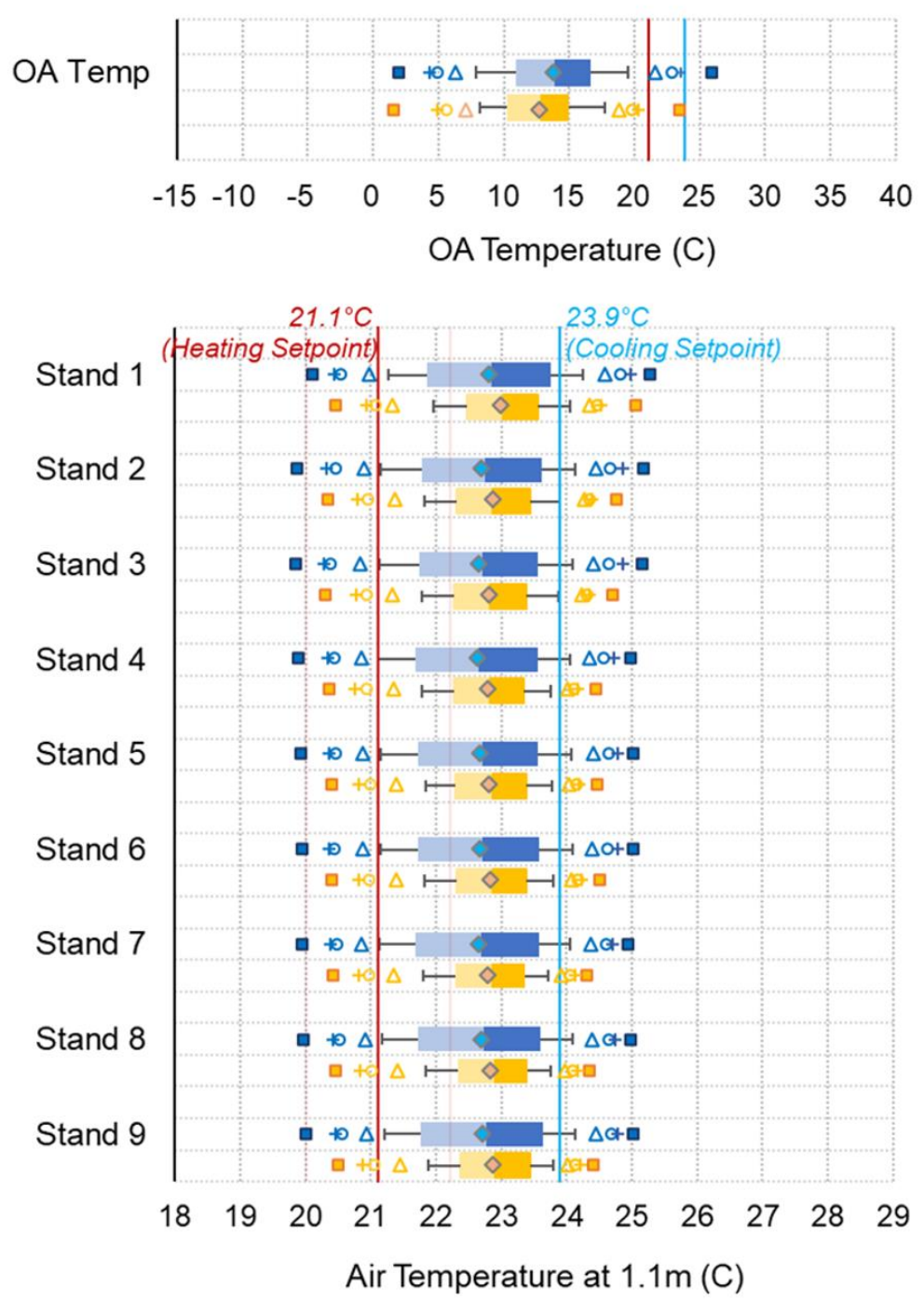

Figure H-17: Graphical Summaries of the 5-Min Average BR3 Stand Temperatures at 1.1 m When the System Was On Cycle (Left Figure) and Off Cycle (Right Figure) for the Transitional Season. 
Transitional Season: HVAC ON
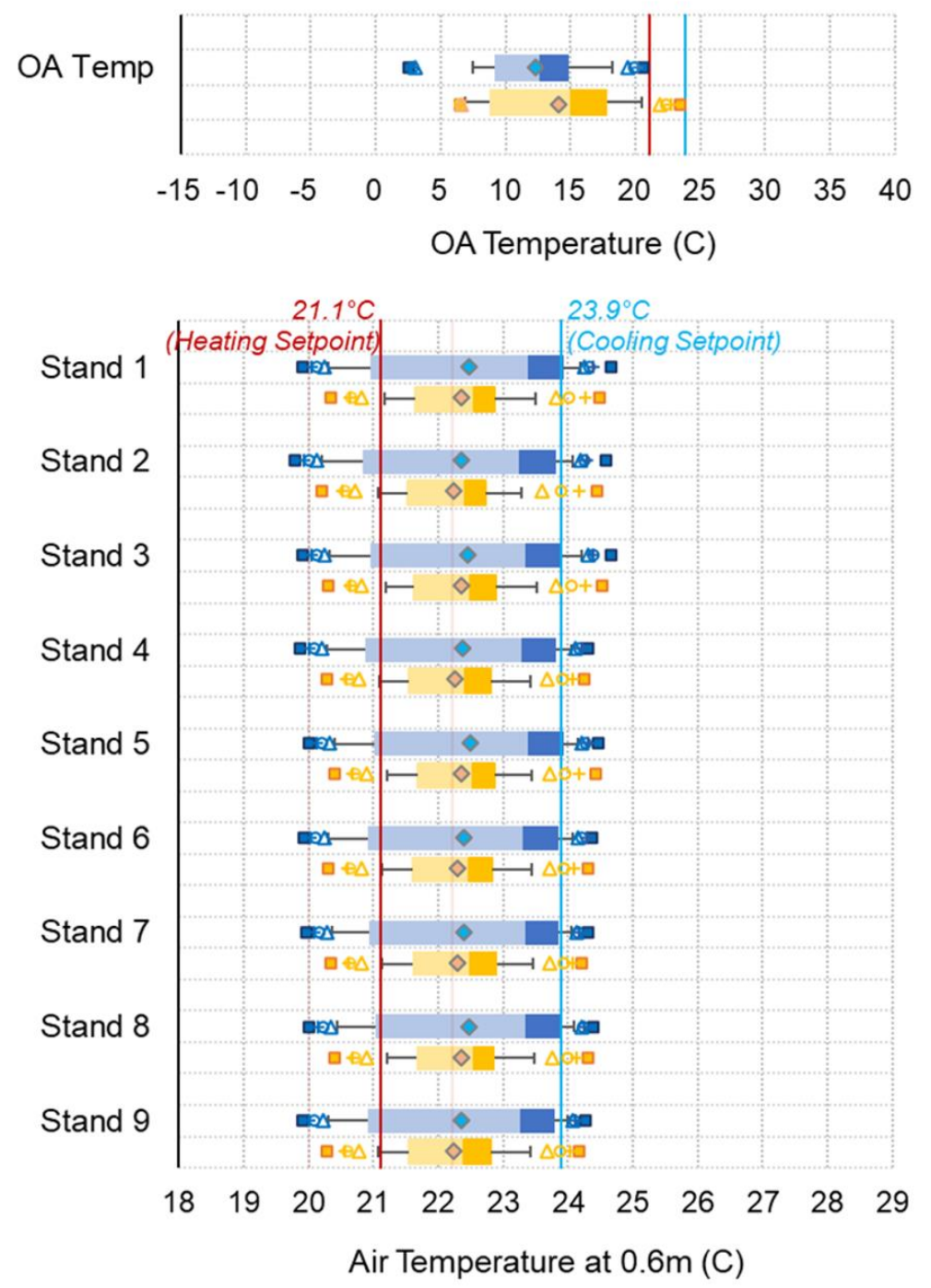

Transitional Season: HVAC OFF
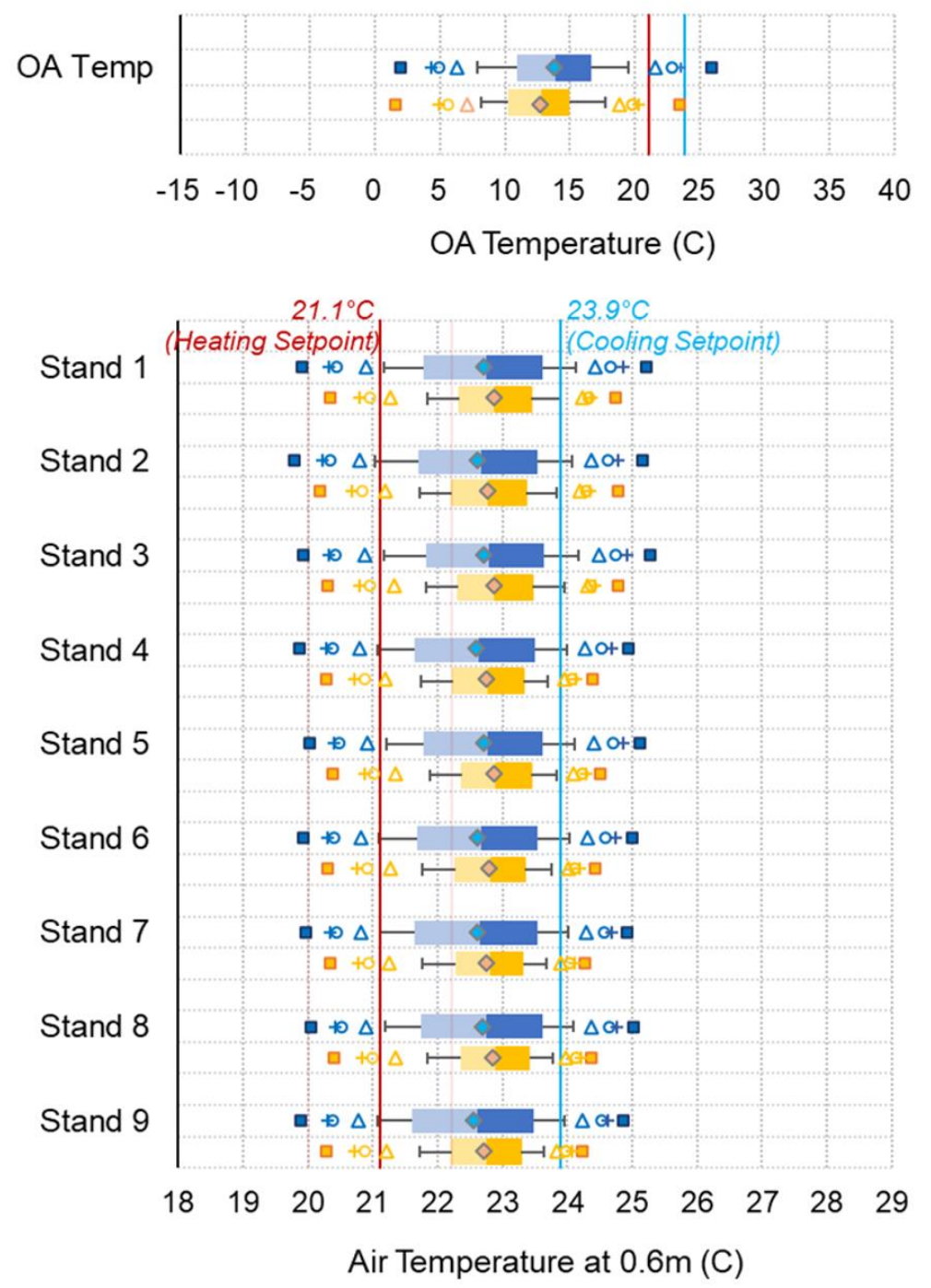

Figure H-18: Graphical Summaries of the 5-Min Average BR3 Stand Temperatures at 0.6 m When the System Was On Cycle (Left Figure) and Off Cycle (Right Figure) for the Transitional Season. 
Transitional Season: HVAC ON
Transitional Season: HVAC OFF
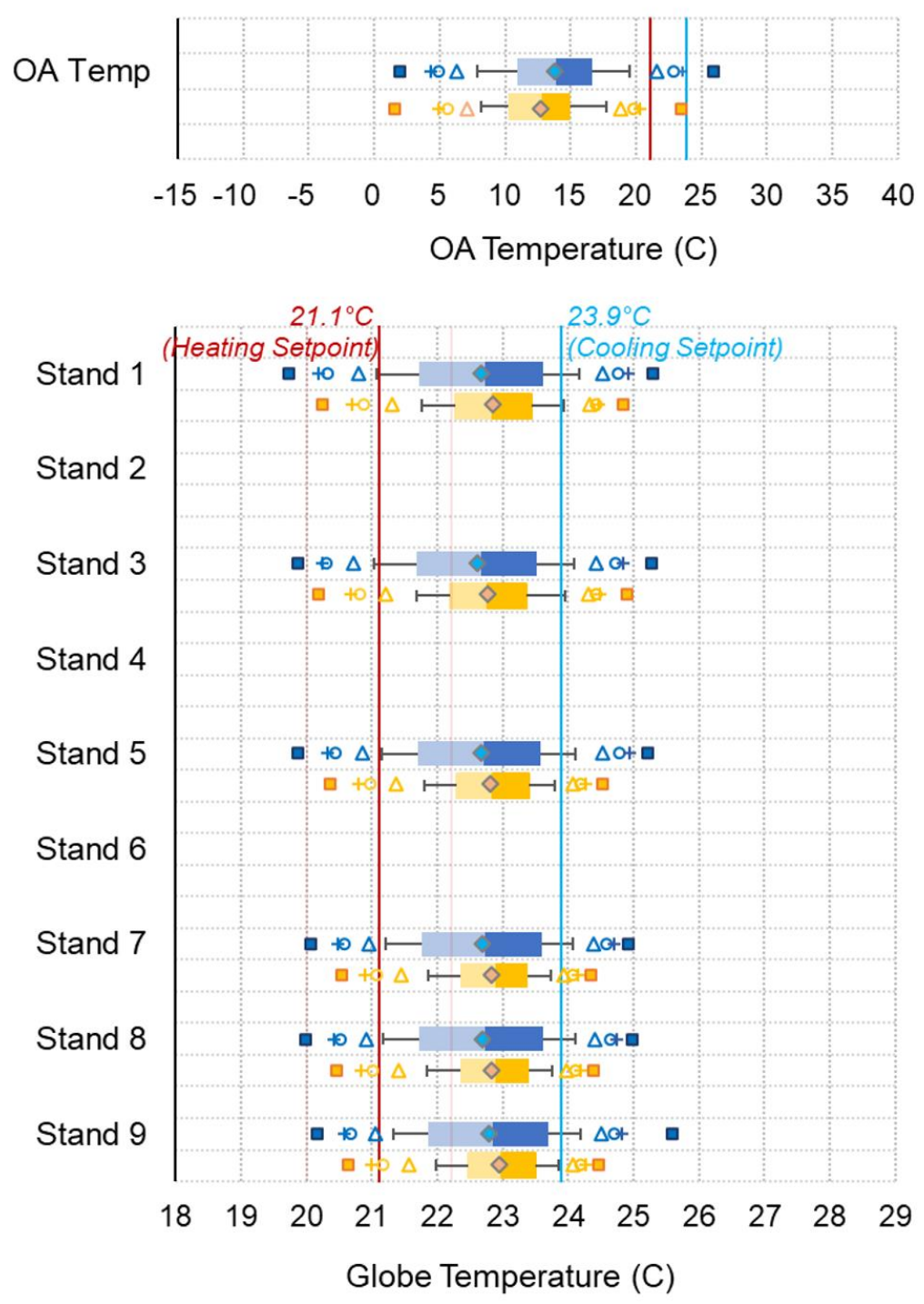

Figure H-19: Graphical Summaries of the 5-Min Average BR3 Stand Globe Temperatures at $1.1 \mathrm{~m}$ When the System Was On Cycle (Left Figure) and Off Cycle (Right Figure) for the Transitional Season. 
Transitional Season: HVAC ON
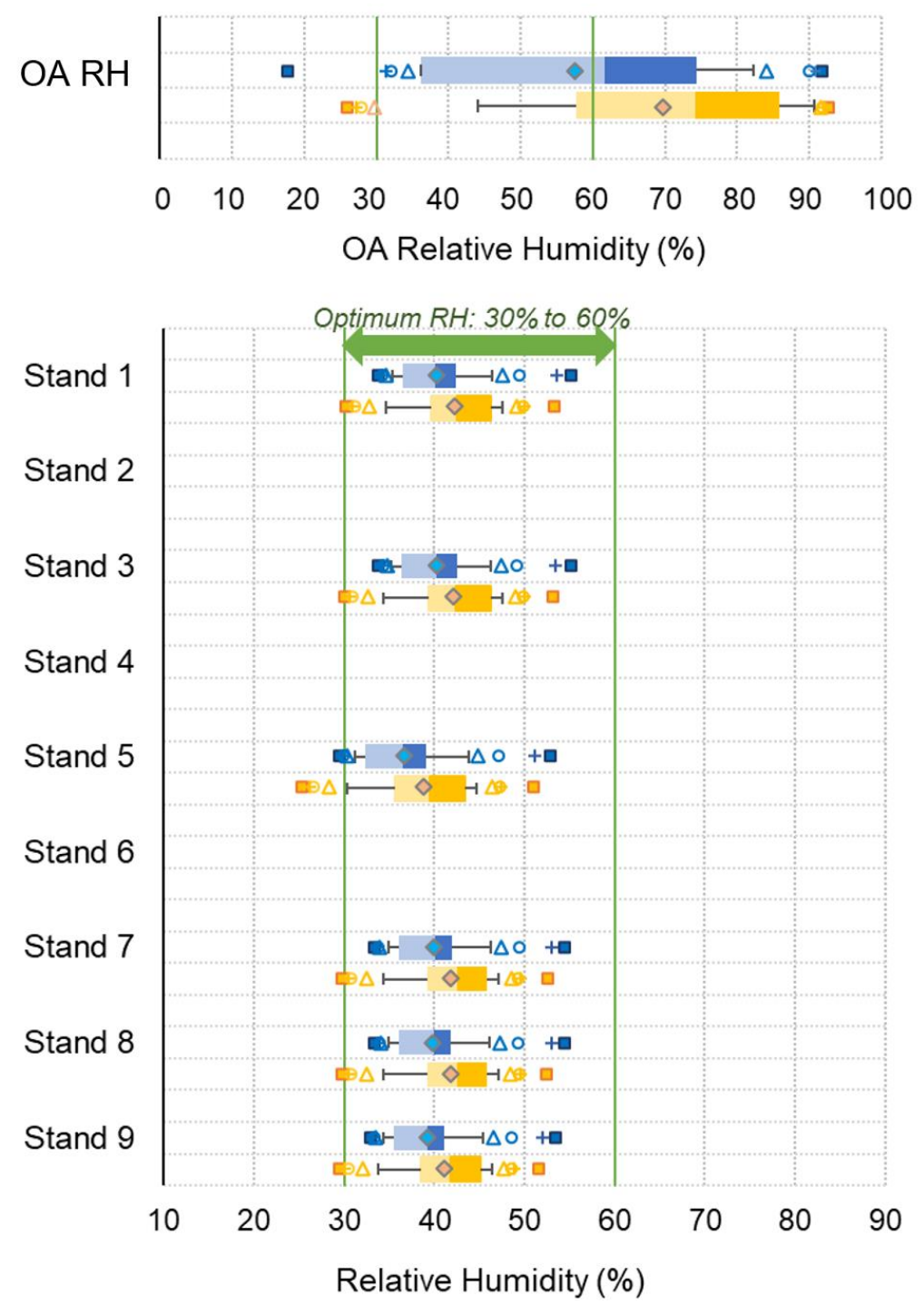

Transitional Season: HVAC OFF
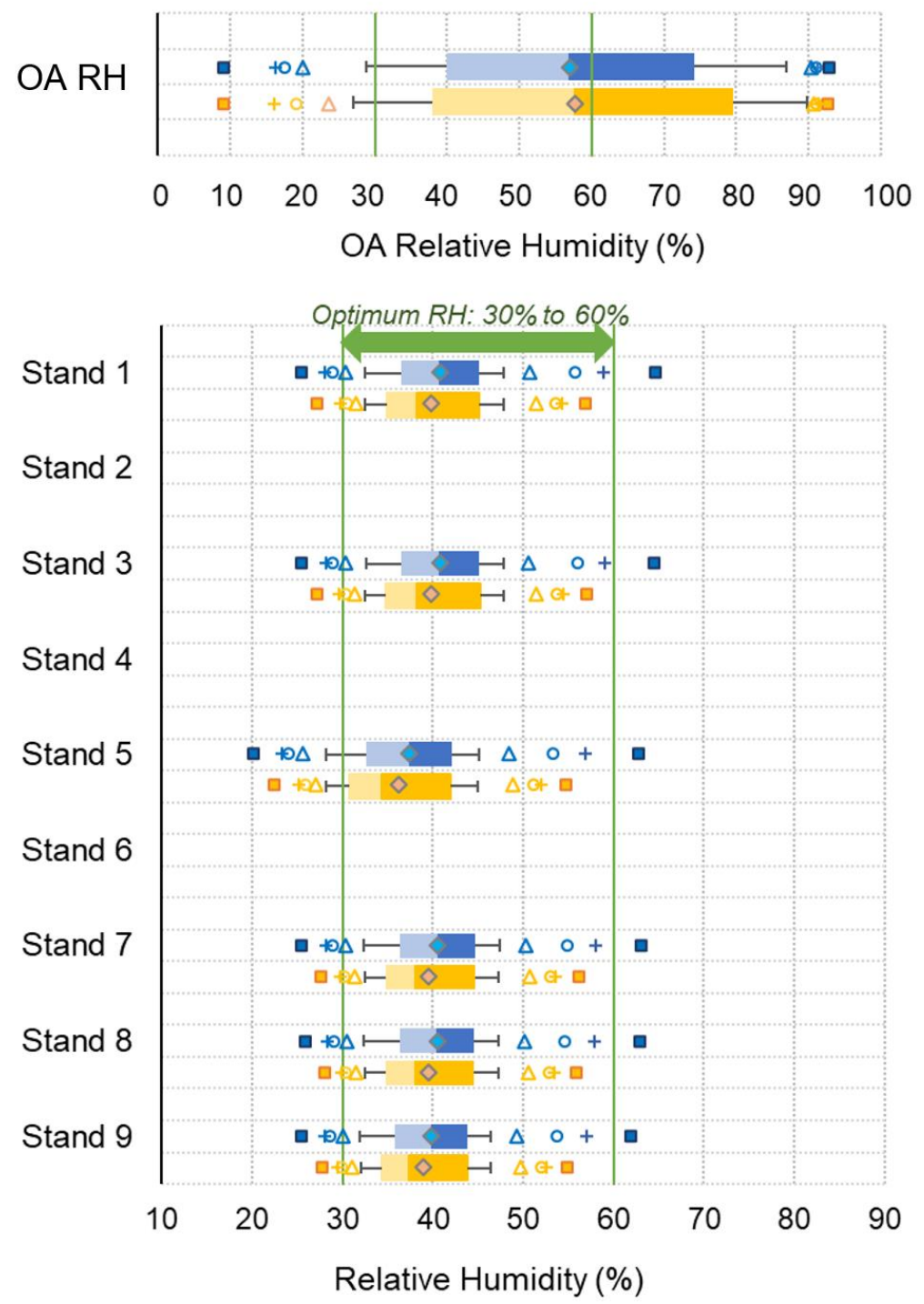

Figure H-20: Graphical Summaries of the 5-Min Average BR3 Stand RH at $1.1 \mathrm{~m}$ When the System Was On Cycle (Left Figure) and Off Cycle (Right Figure) for the Transitional Season. 
APPENDIX I: Temperature Data Visualization/Animation using MATLAB 2017b

Appendix I presents the detailed steps on temperature data visualizing and animation using MATLAB 2017b for the following four analyses:

- Whole-house thermal comfort analysis (Appendix I-1);

- BR3 grid analysis (Appendix I-2);

- Entry hallway analysis (Appendix I-3); and

- Psychrometric analysis (Appendix I-4). 


\section{APPENDIX I-1: WHOLE-HOUSE THERMAL COMFORT ANALYSIS}

The steps to animate the temperature data for the whole-house thermal comfort analysis include:

- Step 1: Import house geometry from Sketchup (.skp) into MATLAB.

- To make the visualization/animation more informative and graphically appealing, the 3D model of the house was imported from Sketchup (.skp) into MATLAB so that it was easier to show the physical layout of the house. Figure I-1 demonstrates the house model imported into MATLAB from the Sketchup model.

- Importing the 3D model from Sketchup into MATLAB is not simple and often requires a third- party software. Although there are several methods to perform this task, this work proposes a method that is widely used in the computational engineering community with the aid of AUTOCAD and FEKO. Figure I-2 presents a flowchart showing the steps to import the 3D model from Sketchup into MATLAB.

- The mesh of each part of the house was acquired individually so that it was easier to access each of them and assigned color code as show in Figure I-1.
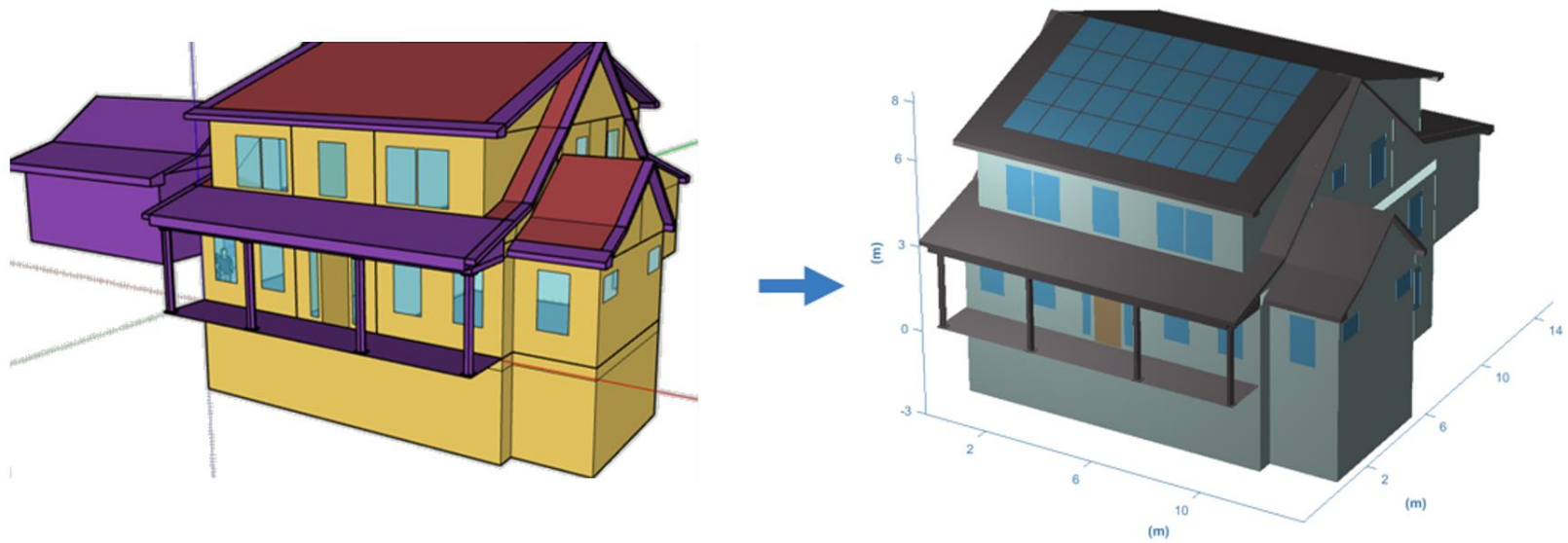

Figure I-1: NZERTF 3D Model Imported from Sketchup into MATLAB.

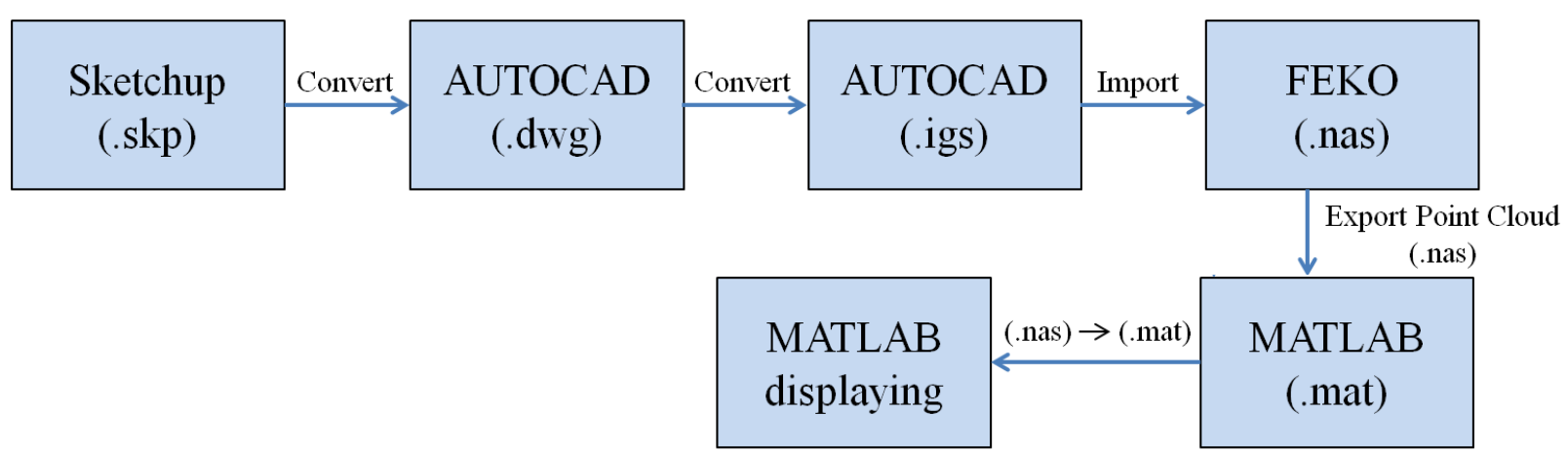

Figure I-2: Flowchart Showing Steps to Import 3D Model from Sketchup to MATLAB. 
- Step 2: Specify the necessary data files.

- The 1-min, 5-min average, and hourly average data processed per Section 3.2.2 were used in this step. These data were saved in an identical format using MS excel.

- Step 3: Convert data from MS excel files into formats that are smaller in size and can be easily accessed by MATLAB.

- The data specified in Step 2 were processed in MATLAB to reduce processing time to open the MS excel files when the MATLAB program is running.

- The MATLAB scripts were developed to read the temperature for 1-min, 5-min average, and hourly average data and to save the temperature data into the format that can be accessed by MATLAB.

- Step 4: Load the MATLAB formatted temperature data into MATLAB workspace.

- Before visualizing the temperature data in Step 5, the MATLAB formatted data for each room of the house were loaded into MATLAB workspace.

- Step 5: Visualize the temperature data.

- The MATLAB scripts were developed to display the temperature data from the MATLAB formatted data files. The MATLAB scripts consist of the following four sections: animation period, geometry mesh, temperature data loading, and animation.

- The animation period section defines the date for a one-day animation or the month for a one-month animation so that the program will animate the temperature data of the defined date/month.

- The geometry mesh section creates the panels and plots the physical layout of the house to prepare for the animation as shown in Figure l-3.

- The temperature data loading section loads the necessary temperature data corresponding to each level/room of the house from the MATLAB formatted data files.

- The animation section performs the animation of temperature for each level of the house (i.e., $1^{\text {st }}$ floor $(1 \mathrm{~F}), 2^{\text {nd }}$ floor $(2 \mathrm{~F})$, attic, and basement). This section also displays corresponding outdoor temperature and HVAC System/Mode in operation. The speed of animation in the outputted video depends on the frames per second (fps) values. The fps value used in this analysis was 8 but can be changed according to the user's preference. 


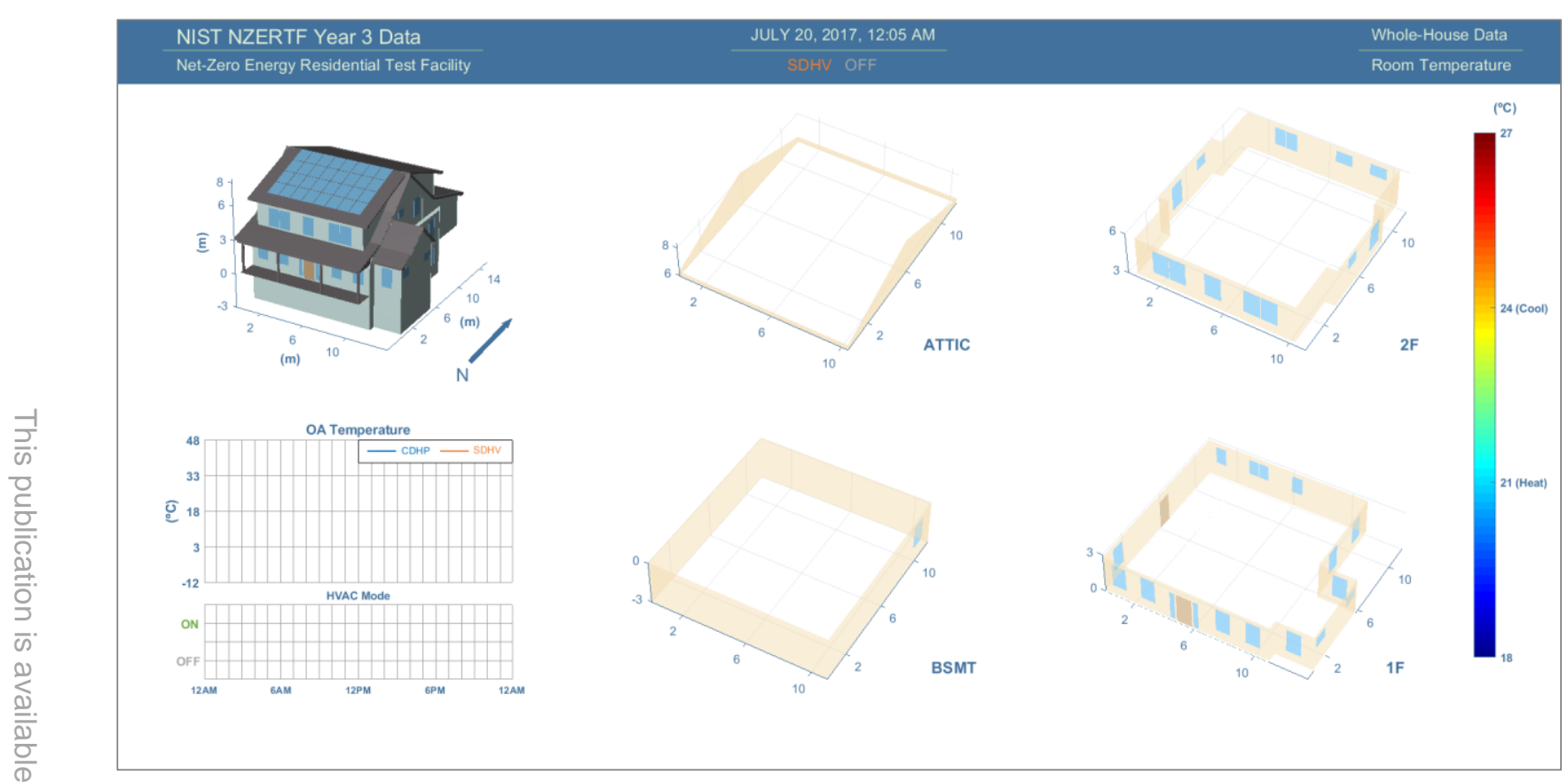

Figure I-3: Panels Created for the Animation of the Whole-House Thermal Comfort Analysis. 


\section{APPENDIX I-2: BR3 GRID ANALYSIS}

The procedures of animating the temperature data in the BR 3 were similar to those in the whole-house thermal comfort analysis in Appendix I-1 except for the fact that the data were based on a $3 \times 3 \times 3$ grid of measurement system. As a result, the temperature data were displayed on the three vertical measurement planes (i.e., side view) and the three horizontal measurement planes (i.e., plan view) of the grid for a better understanding and analysis of the data.

The steps to animate the temperature data for the BR3 grid analysis include:

- Step 1: Import BR3 geometry from Sketchup (.skp) into MATLAB.

- Since the mesh of the house geometry was already obtained, the mesh of the BR3 geometry was reused in this step. Figure I-4 shows the geometry of the BR3 and its windows plotted in MATLAB.

- $\quad$ Step 2: Specify the necessary data files.

- The 1-min, 5-min average, and hourly average data processed per Section 3.2.2 were used in this step. These data were saved in an identical format using MS excel.

- Step 3: Convert data from MS excel files into formats that are smaller in size and can be easily accessed by MATLAB.

- The data specified in Step 2 were processed in MATLAB to reduce processing time to open the MS excel files when the MATLAB program is running.

- The MATLAB scripts were developed to read the BR3 temperature for 1-min, 5min average, and hourly average data and to save the temperature data into the format that can be accessed by MATLAB.

- $\quad$ Step 4: Load the MATLAB formatted temperature data into MATLAB workspace.

- Before visualizing the temperature data in Step 5, the MATLAB formatted BR3 temperature data were loaded into MATLAB workspace.

- Step 5: Visualize the temperature data.

- The MATLAB scripts were developed to display the temperature data from the MATLAB formatted data files. The MATLAB scripts consist of the following four sections: animation period, geometry mesh, temperature data loading, and animation.

- The animation period section defines the date for a one-day animation or the month for a one-month animation so that the program will animate the temperature data of the defined date/month.

- The geometry mesh section creates the panels and plots the physical layout of the BR3 to prepare for the animation as shown in Figure I-5.

- The temperature data loading section loads the necessary temperature data corresponding to each temperature of the BR3 from the MATLAB formatted data files.

- The animation section performs the animation of the BR3 temperature on the three vertical measurement planes (i.e., side view) and the three horizontal measurement planes (i.e., plan view) of the grid. This section also displays 
corresponding outdoor temperature and HVAC System/Mode in operation. The speed of animation in the outputted video depends on the fps values. The fps value used in this analysis was 8 but can be changed according to the user's preference.

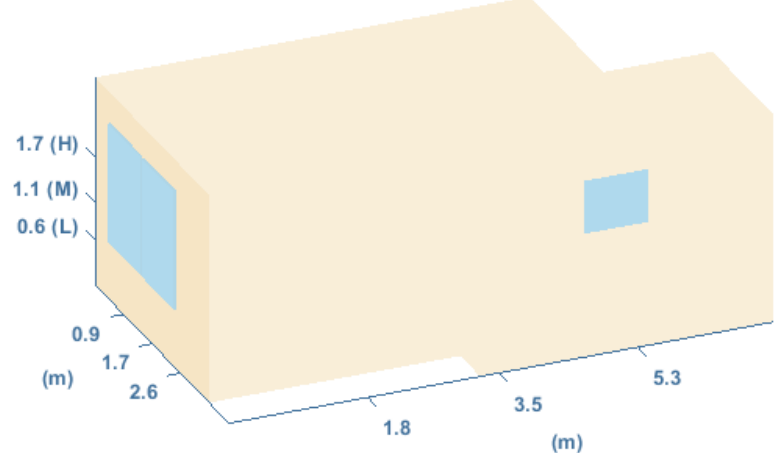

Figure I-4: BR3 Geometry with Windows in MATLAB.

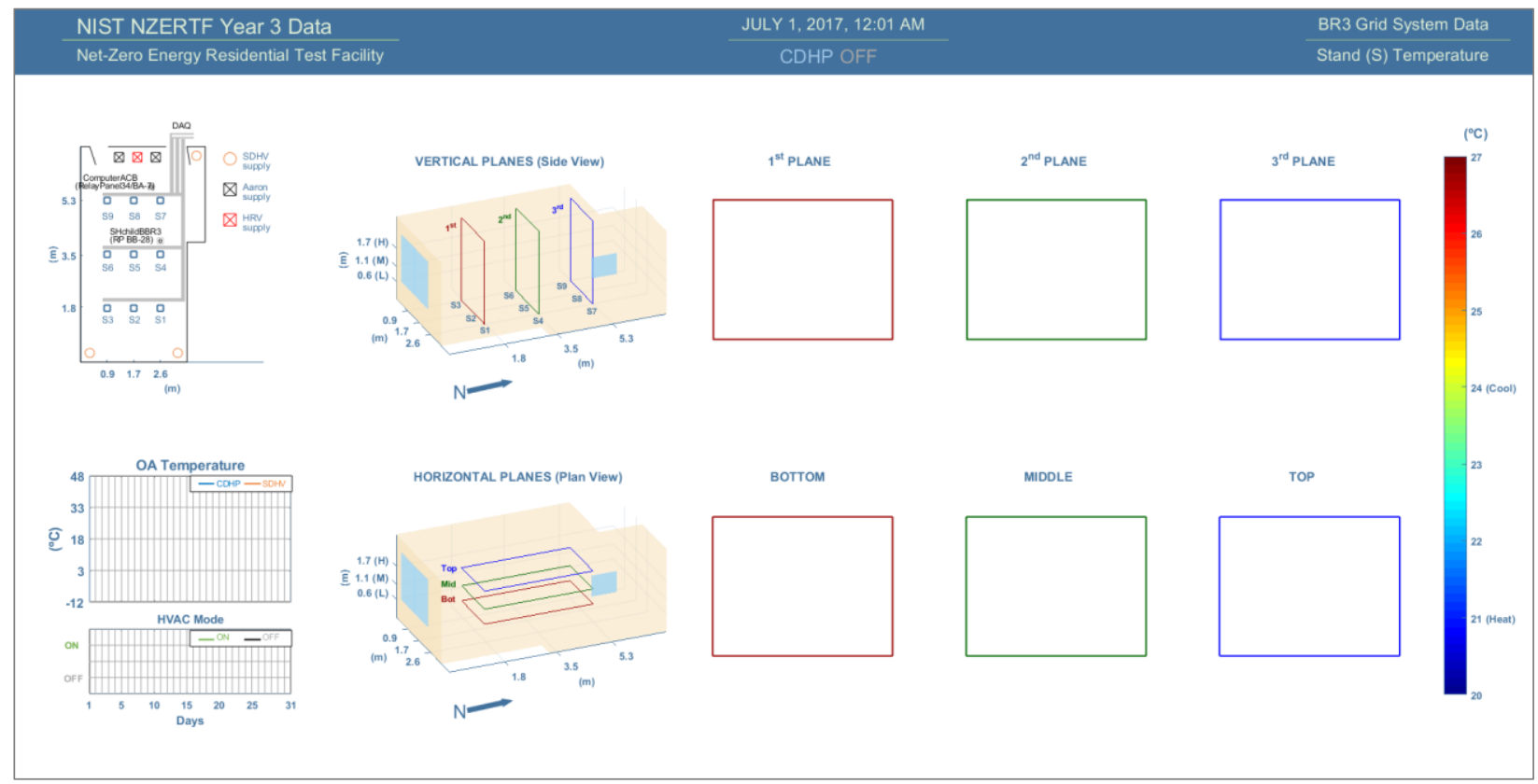

Figure I-5: Panels Created for the Animation of the BR3 Grid Analysis. 


\section{APPENDIX I-3: ENTRY HALLWAY ANALYSIS}

The procedures of animating the temperature data in entry hallway $(\mathrm{EH})$ were similar to those in the whole-house thermal comfort analysis in Appendix l-1. The steps to animate the temperature data for the $\mathrm{EH}$ analysis include:

- Step 1: Import EH geometry from Sketchup (.skp) into MATLAB.

- Since the mesh of the house geometry was already obtained, the mesh of the EH geometry was reused in this step. Figure I-6 shows the geometry of the EH plotted in MATLAB.

- Step 2: Specify the necessary data files.

- The 1-min, 5-min average, and hourly average EH temperature data processed per Section 3.2.2 were used in this step. These data were saved in an identical format using MS excel.

- Step 3: Convert data from MS excel files into formats that are smaller in size and can be easily accessed by MATLAB.

- The data specified in Step 2 were processed in MATLAB to reduce processing time to open the MS excel files when the MATLAB program is running.

- The MATLAB scripts were developed to read the EH temperature for 1-min, 5-min average, and hourly average data and to save the temperature data into the format that can be accessed by MATLAB.

- $\quad$ Step 4: Load the MATLAB formatted temperature data into MATLAB workspace.

- Before visualizing the temperature data in Step 5, the MATLAB formatted EH temperature data were loaded into MATLAB workspace.

- Step 5: Visualize the temperature data.

- The MATLAB scripts were developed to display the temperature data from the MATLAB formatted data files. The MATLAB scripts consist of the following four sections: animation period, geometry mesh, temperature data loading, and animation.

- The animation period section defines the date for a one-day animation or the month for a one-month animation so that the program will animate the temperature data of the defined date/month.

- The geometry mesh section creates the panels and plots the physical layout of the EH to prepare for the animation as shown in Figure I-7.

- The temperature data loading section loads the necessary temperature data corresponding to each temperature of the EH from the MATLAB formatted data files.

- The animation section performs the animation of the $\mathrm{EH}$ temperature on one vertical measurement plane. This section also displays corresponding outdoor temperature and HVAC System/Mode in operation. The speed of animation in the outputted video depends on the fps values. The fps value used in this analysis was 8 but can be changed according to the user's preference. 


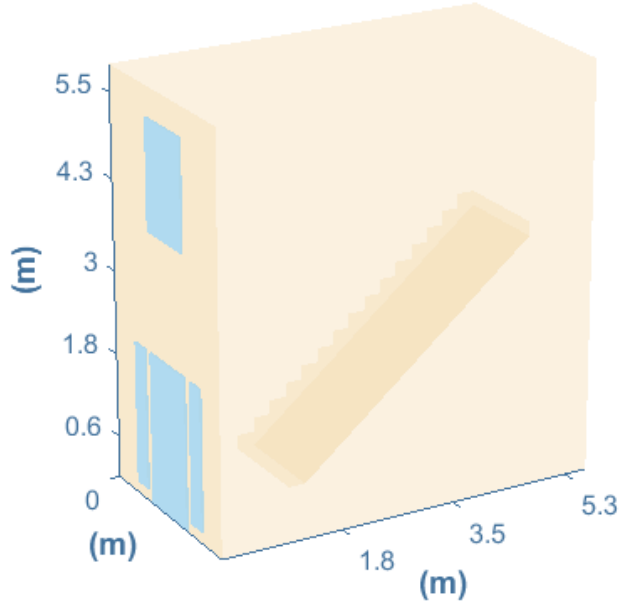

Figure I-6: Entry Hallway Geometry with Windows in MATLAB.

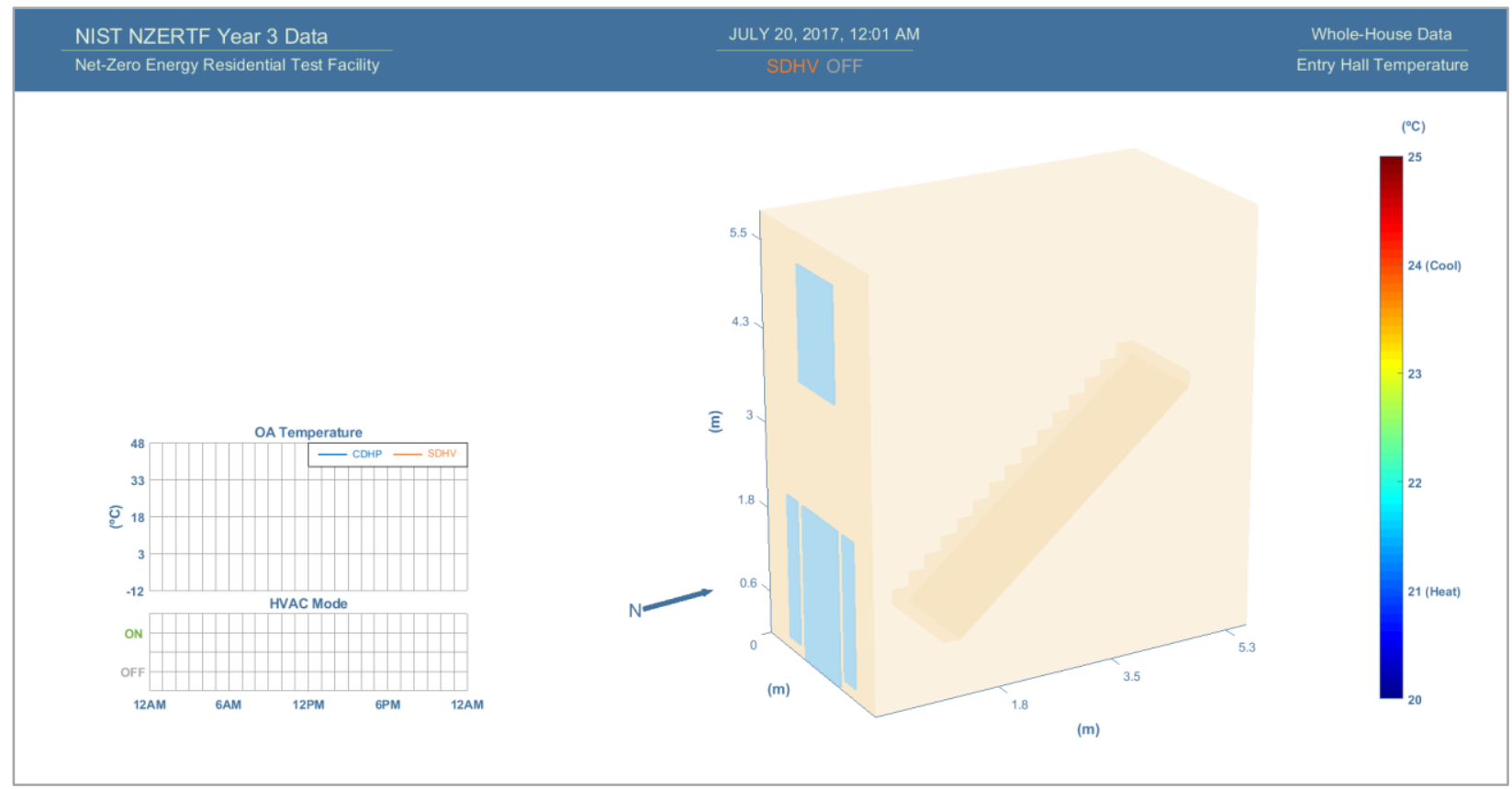

Figure 1-7: Panels Created for the Animation of the Entry Hallway Analysis. 


\section{APPENDIX I-4: PSYCHROMETRIC ANALYSIS}

The steps to animate the temperature data on the psychrometric chart include:

- Step 1: Specify the necessary data files.

- The hourly average room temperature data processed per Section 3.2.2 were used in this step. These data were saved in an identical format using MS excel.

- Step 2: Convert data from MS excel files into formats that are smaller in size and can be easily accessed by MATLAB.

- The data specified in Step 1 were processed in MATLAB to reduce processing time to open the MS excel files when the MATLAB program is running.

- The MATLAB scripts were developed to read the hourly average room temperature data and to save them into the format that can be accessed by MATLAB.

- $\quad$ Step 3: Load the MATLAB formatted temperature data into MATLAB workspace.

- Before visualizing the temperature data in Step 4, the MATLAB formatted room temperature data were loaded into MATLAB workspace.

- Step 4: Visualize the temperature data.

- The MATLAB scripts were developed to display the temperature data on the psychrometric chart from the MATLAB formatted data files. The MATLAB scripts consist of the following four sections: animation period, geometry mesh, temperature data loading, and animation.

- The animation period section defines the month for a one-month animation so that the program will animate the temperature data of the defined month.

- The geometry mesh section creates the panels of the psychrometric charts to prepare for the animation as shown in Figure I-8.

- The temperature data loading section loads the necessary temperature data on the psychrometric charts from the MATLAB formatted data files.

- The animation section performs the animation of the room temperature data on the psychrometric charts. This section also displays corresponding outdoor temperature and HVAC System/Mode in operation. The speed of animation in the outputted video depends on the fps values. The fps value used in this analysis was 6 but can be changed according to the user's preference. 


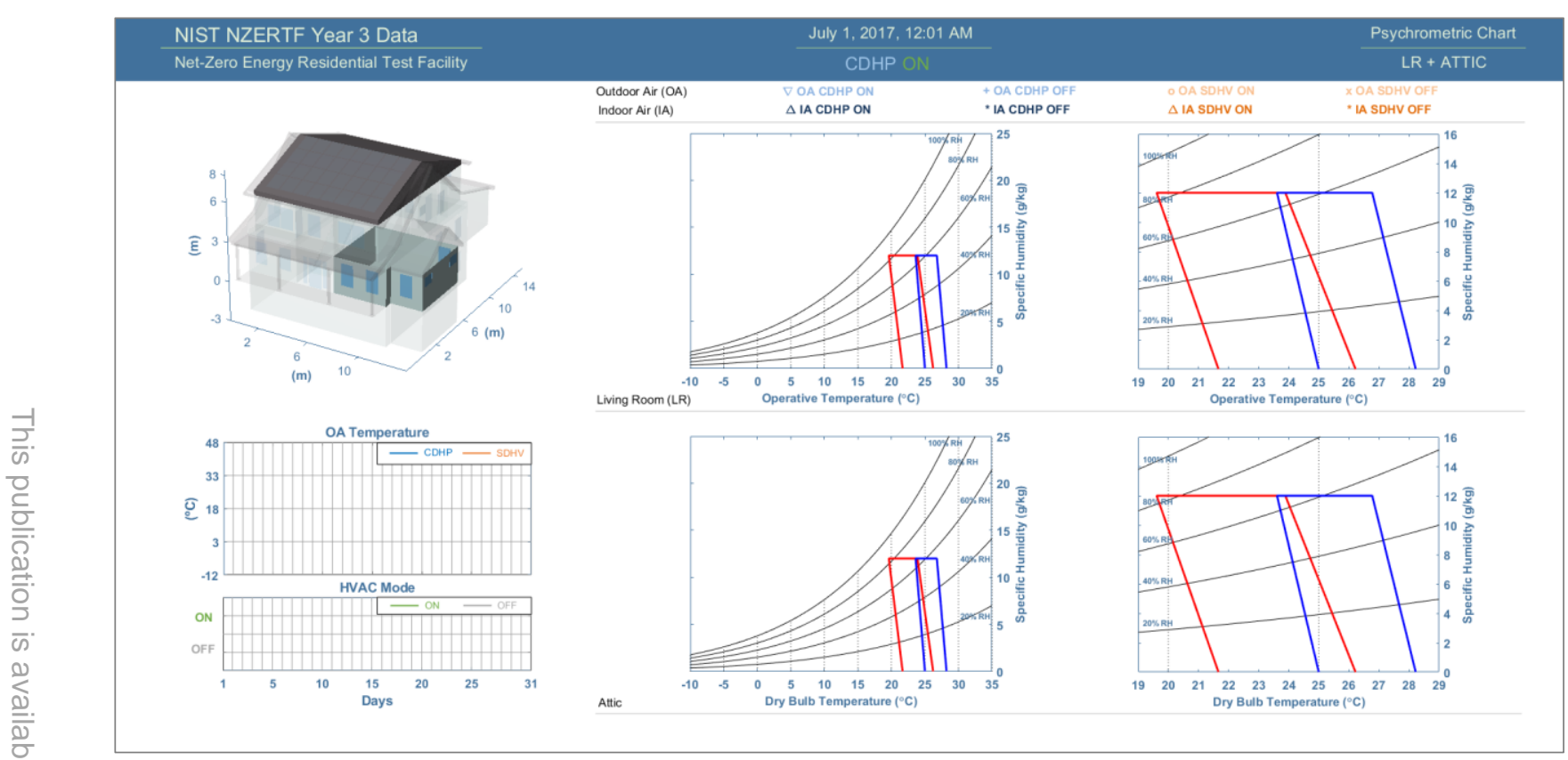

Figure I-8: Panels Created for the Animation of the Psychrometric Analysis. 


\section{APPENDIX J: Directories of Trend Animation Files Attached}

Appendix K presents the directories of example trend animation files, which accompany this report. Table J-1 shows the organization of the files.

Table J-1: Directory of the Example Trend Animation Video Files.

\begin{tabular}{|c|c|c|}
\hline \multirow[t]{2}{*}{ Data Files } & \multicolumn{2}{|c|}{ Example trend animation video files directory } \\
\hline & \multirow{9}{*}{ 1. Whole House } & Animation files for whole-house thermal comfort analysis \\
\hline & & OneDay_Animation \\
\hline & & WH_5min_Jan_8_2017.avi \\
\hline & & WH_5min_Jan_13_2017.avi \\
\hline & & WH_5min_July_13_2017.avi \\
\hline & & WH_5min_July_20_2017.avi \\
\hline & & OneMonth_Animation \\
\hline & & WH_hourly_Jan_2017.avi \\
\hline & & WH_hourly_July_2017.avi \\
\hline & \multirow[t]{6}{*}{ 2. BR3 Grid } & Animation files for BR3 grid analysis \\
\hline & & OneDay_Animation \\
\hline & & BR3_5min_Jan_8_2017.avi \\
\hline & & BR3_5min_Jan_13_2017.avi \\
\hline & & BR3_5min_July_13_2017.avi \\
\hline & & BR3_5min_July_20_2017.avi \\
\hline & \multirow[t]{9}{*}{ 3. Entry Hall } & Animation files for entry hall analysis \\
\hline & & OneDay_Animation \\
\hline & & EH_5min_Jan_8_2017.avi \\
\hline & & EH_5min_Jan_13_2017.avi \\
\hline & & EH_5min_July_13_2017.avi \\
\hline & & EH_5min_July_20_2017.avi \\
\hline & & OneMonth_Animation \\
\hline & & EH_hourly_Jan_2017.avi \\
\hline & & EH_hourly_July_2017.avi \\
\hline & \multirow[t]{15}{*}{ 4. Psychrometric } & Animation files for psychrometric analysis \\
\hline & & LV_AT_hourly_Jan_2017.avi \\
\hline & & LV_AT_hourly_July_2017.avi \\
\hline & & LV_BR2_hourly_Jan_2017.avi \\
\hline & & LV_BR2_hourly_July_2017.avi \\
\hline & & LV_BR3_hourly_Jan_2017.avi \\
\hline & & LV_BR3_hourly_July_2017.avi \\
\hline & & LV_BSMT_hourly_Jan_2017.avi \\
\hline & & LV_BSMT_hourly_July_2017.avi \\
\hline & & LV_KIT_hourly_Jan_2017.avi \\
\hline & & LV_KIT_hourly_July_2017.avi \\
\hline & & LV_MBA_hourly_Jan_2017.avi \\
\hline & & LV_MBA_hourly_July_2017.avi \\
\hline & & LV_MBR_hourly_Jan_2017.avi \\
\hline & & LV_MBR_hourly_July_2017.avi \\
\hline
\end{tabular}

